\title{
ENVIRONMENTAL MANAGEMENT IN DEVON AND CORNWALL'S SMALL AND MEDIUM-SIZED ENTERPRISE SECTOR
}

\author{
Hutchinson, Michael Andrew
}

http://hdl.handle.net/10026.1/2575

http://dx.doi.org/10.24382/3264

University of Plymouth

All content in PEARL is protected by copyright law. Author manuscripts are made available in accordance with publisher policies. Please cite only the published version using the details provided on the item record or document. In the absence of an open licence (e.g. Creative Commons), permissions for further reuse of content should be sought from the publisher or author. 
ENVIRONMENTAL MANAGEMENT IN DEVON AND CORNWALL'S

SMALL AND MEDIUM-SIZED ENTERPRISE SECTOR

By

Michael Andrew Hutchinson

M.A. (Hons)

A thesis submitted to the University of Plymouth

in partial fulfilment for the degree of:

\section{DOCTOR OF PHILOSOPHY}

Department of Social Science

Plymouth Business School

December 1994 


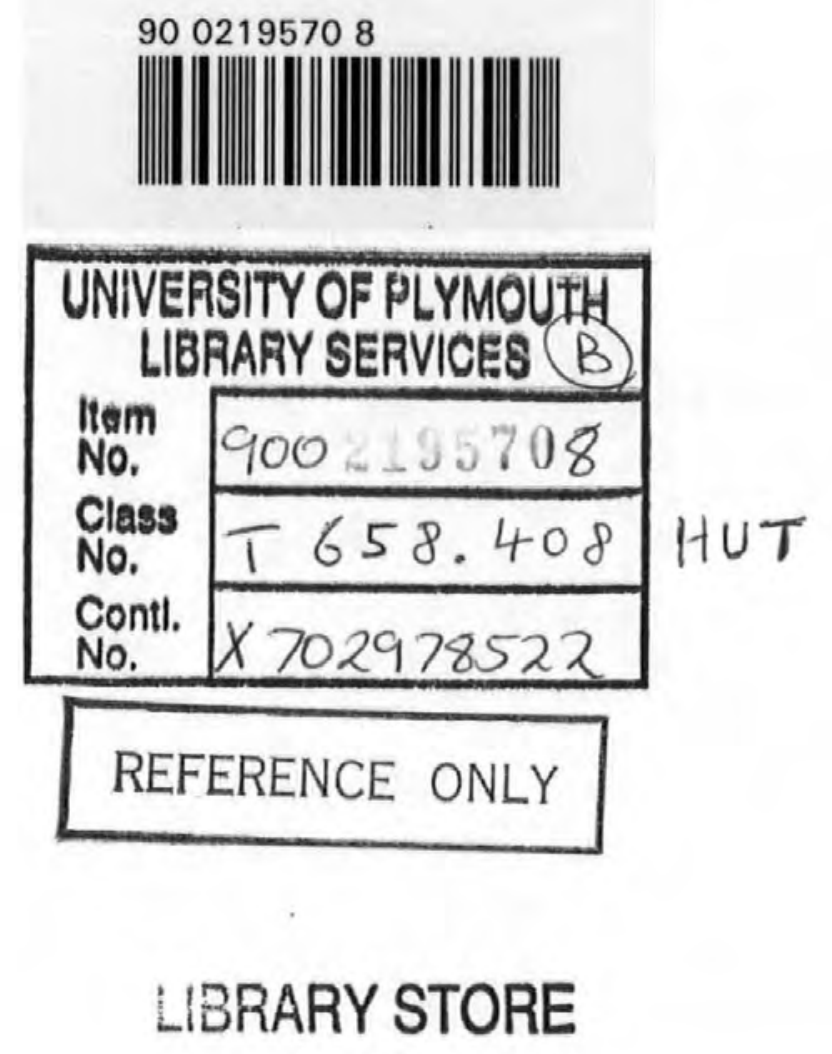




\section{CONTENTS}

List of Tables

List of Figures

Acknowledgements iii

Abstract

\section{CHAPTER}

1. INTRODUCTION 1

1.1. Introduction

1.2. Background

1.3. Research Plan

2. THE ROOTS OF ECOLOGICAL THOUGHT

2.1. Literature Progression

2.2. Pre -1900

2.3. $1900-1980$

3. THE BUSINESS ENVIRONMENT PERSPECTIVE

3.1. Environmental Management

3.2. Strategic Management

3.3. Strategic Management in the Small and Medium Sized Enterprise Sector (SME)

3.4. Environmental Management within the SME Sector

3.5. Sustainable Development - Alternative Models

4. RESEARCH AIMS AND METHODOLOGY

4.1. Research Aims

4.2. Research Hypotheses

4.3. Research Ideology

4.4. Methodology

5. RESULTS - MAIL SURVEY 1

5.1. Sample Characteristics and Hypotheses

5.2. Environmental Perceptions and Attitudes

5.3. Environmental Awareness

5.4. Environmental Management Practices 
6.1. Sample Characteristics and Objectives

6.2. Environmental Incentives

6.3. Environmental Initiatives

6.4. Problems and Solutions

7. RESULTS - MAIL SURVEY 2

7.1. Sample Characteristics and Hypotheses

7.2. Strategic Environmental Response

7.3. Further Proposals

8. TOWARDS A SUSTAINABLE DEVELOPMENT STRATEGY FOR THE SME SECTOR

8.1. Introduction

8.2. Review of Empirical and Qualitative Results

8.2.1. Mail Survey 1

8.2.2. In-depth Interviews

8.2.3. Mail Survey 2

8.3. Towards a Sustainable Development Strategy

8.4. Socially and Environmentally Accountable Development Strategies - A Series of Case Studies

8.4.1. LETSystems

8.4.2. Credit Unions

8.4.3. Permacultural Community Design

8.4.4. Urban Re-generation

8.4.5 Rural and Urban Re-generation

8.4.6 Economic Re-generation

8.5. Conclusions

9. BIOREGIONAL RE-GENERATION STRATEGIES - A MODEL FOR SME SUSTAINABILITY

9.1. Model Ideology and Assumptions

9.2. Bioregional Re-generation Model

10. CONCLUSIONS AND RECOMMENDATIONS 
Page

BIBLIOGRAHPHY

275

APPENDICES

Appendix 1 - Statistical Oütput: Máil Sürvèy 1!

A1

Appendix 2--In-depth Interview Transcripts

A109

Appendix 3 - Mail Süryey 2: Statistical Output and BS 7750:

A118

Appendix 4 - Mail Surveys

A206 


\section{Tables}

Page

3.1 - Environmental Pressures Understanding the Key Issues 44

3.2 - Environmental Audits: The Key Issues 45

3.3 - Types of Management Theory 47

3.4 - The Value Chain 55

3.5 - Opportunities and Threats of Environmental Management 56

4.1 - Economic Fabric of the South West Sample 88

5.1 - Industrial Classification $\quad 104$

5.2 - Business Types 105

5.3 - Number of Employees 106

5.4 - Percentage Importance of Environmental Issues 109

5.5 - Specific Environmental Issues: A Factor Analysis 111

5.6 - Importance of Environmental Issues: Company Response By $\begin{array}{ll}\text { Industrial Sector } & 115\end{array}$

5.7 - Univariate F. Tests 116

5.8 - Importance of Environmental Issues: Significant Differences Between $\begin{array}{ll}\text { Exporters and Non-Exporters } & 118\end{array}$

5.9 - Importance of Environmental Issues: $\begin{array}{ll}\text { Significant Differences Between Large and Small SMEs } & 120\end{array}$

5.10 - Percentage Awareness of Environmental Legislation and Regulation 122

5.11 - Chi-Square: Awareness of Legislation and Regulation By Company Type 125

5.12 - Chi-Square: Awareness of Legislation and Regulation By Company Size 127

5.13 - Chi-Square: Awareness of Legislation and Regulation By Sector 128

5.14 - Environmental Practices 130

5.15 - Environmental Management By Industrial Sectors 135

5.16 - Environmental Management By Company Size 136

5.17 - Environmental Management By Company Type 137

6.1 - In-Depth Interview: Environmental Initiatives 150

7.1 - Industrial Classification and Response Rates 160

7.2 - Business Types 165

7.3 - Number of Employees 166

7.4 - Company Age 168

7.5 - Why Companies Do Not Have Environmental Policies 172

7.6 - Chi-Square: Implementation of BS 7750; By Exporting and Strategy 181

7.7 - Why Companies Are Not Able to Implement BS $7750 \quad 182$

7.8 - Environmental Support Provision 186 


\section{Figures}

Page

1.1 - Research Plan 5

2.1 - Literature Progression 10

3.1 - Environmental Management Systems: BS $7750 \quad 50$

3.2 - Support Organisations for Small Firms in the UK 61

4.1 - Research Flow $\quad 82$

5.1 - Reduced Response Rates 104

5.2 - Percentage Number of Exporters and Non-Exporters 107

5.3 - Percentage Importance of Environmental Issues 108

7.1 - Reduced Response Rates 161

7.2 - Percentage Number of Exporters and Non-Exporters 164

7.3 - Percentage Number of Companies Who Have Implemented BS $7750 \quad 180$

9.1 - Bioregional Re-generation Model 247

9.2 - Bioregional Re-generation Model: The Spatial Dimension 250 


\section{Acknowledgements}

I am indebted to a whole host of people for their advice, encouragement and support over the past three years, unfortunately I am not able to name everybody here. I think in particular of a number of individuals working tirelessly for environmental concerns throughout the UK who have offered advice and guidance in the preparation of this thesis.

Firstly I would like to thank my main supervisor Dr. Ian Chaston for his professional guidance. I would also like to thank Frances Hutchinson for her knowledgeable advice, comment and support throughout and Keith Hutchinson for editorial comment and encouragement. I also thank Dr. John Eales, Terry Mangles and Vince Hooper for their invaluable statistical guidance and Dr. John Furse, my second supervisor, for inspiration against the odds.

I am further indebted Adrian Watts, Peter Seldon and Jackie Young of the Groundwork Trust, Plymouth Chamber of Commerce, Chris Trevan from Cornwall County Council, Ian Hutchcroft from Devon County Council, Dr. Tony Curtis for the most obscure references ever published, Dr. George Chryssides from the University of Wolverhampton, and to the administration and technical departments of the Business School for their continuous support. Thanks are also due to my research colleagues for continued irrelevance without whose humorous relief I would surely have finished well ahead of schedule. I also thank all of my other friends for their consistent and active sensationalism in times of editing malaise.

Finally I give thanks to my Lord Jesus Christ for the power to love and the discipline to work when my batteries ran down. 


\author{
Enterprise Sector - By Michael Andrew Hutchinson
}

\begin{abstract}
The challenge of sustainable development has become one of the most important strategic, economic and social concerns facing global society today. Although literature on environmental management theory and sustainable development philosophy has increased apace throughout the 1980s and 1990s, very few of these writings have documented the case of the small and medium-sized enterprise (SME).

The objectives of this research are: i) to determine the level of awareness and perception of environmental issues within the SME sector and to assess prevailing attitudes of owner/managers to the importance they attach to managing this aspect of their business operations; ii) to gain an understanding of the scale and nature of response to environmental issues across a broad section of SMEs; iii) to utilise the knowledge gained about awareness, attitude and organisational response to assess the relevance of the environmental management systems so far developed to and to link this to achieving sustainable development; iv) to draw upon the expertise of owner/managers and appropriate institutions to validate and, if appropriate, further refine the new and/or revised systems as necessary; v) to assess the possibilities for sustainable development within the SME sector.

The first phase of the research involves a mail survey which identifies: what the SME sector is doing to improve its environmental performance; what the general attitudes to organisational change are: and levels of awareness of various environmental issues. Phase two of the research considers in more depth the issue of practical response to environmental issues through a series of in-depth interviews concentrating particularly on reasons why companies do not have detailed strategic management plans to deal with the environment. Phase two tests the results from the in-depth interviews on a larger sample frame providing the empirical foundations for testing existing models of environmental management. Phase three of the research analyses the need for an alternative strategy for the SME sector to manage environmental concerns. Material for a new model is obtained from case study material of best practice, alternative literature and primary source information.
\end{abstract}

Results show that existing models are inappropriate for the majority of SMEs and that environmental practices are limited within the sector. Awareness of environmental issues and attitudes towards change are more positive from larger secondary sector companies. To this end the research proposes an alternative Bioregional Regeneration Model which could be tested and applied to induce local community regeneration and the development of a sustainable community based SME sector. 


\section{CHAPTER 1}

\section{INTRODUCTION}




\subsection{Introduction}

The initial research aims were to clarify what the SME sector in the UK is doing in terms of environmental management and critically assess the need for change in: management practices; socio-economic structures; and personal attitudes to attain sustainable development.

Literature on environmental management has continued to expand throughout the 1990s. However, research on sustainable development in the UK Small and Medium Sized Enterprise Sector, (SME) has been limited (Welford and Gouldson, 1993; Hendry, 1993). This is due in part to the diverse nature of the SME sector. Environmental management systems (EMS) are generic in nature and hence incompatible with the diverse nature of the SME sector. As management systems are per se inappropriate to small owner managed companies the requirements of the SME sector have largely been ignored in research on environmental management. Equally, the predominance of prescriptive literature based around (EMS) BS 7750 and the European Union (EU) Environmental Management and Auditing Scheme (EMAS) has proved inappropriate to SMEs. Micro-SMEs (0-9 employees) have a priori particularly low levels of strategic orientation (Gibb, 1983; Perry, 1986 et al) limiting the effective application of prescriptive solutions based on strategic systems.

\section{$\underline{1.2}$ Background}

Undertaken by Plymouth Business School between 1991 and 1994 in the UK, the research collates selected results from two mail surveys and case study material to argue for the development of a regional re-generation model for the SME sector. Each survey was limited in its spatial distribution, in order to increase the response rate. Typically surveys of this sort have incurred a very low response rate when covering a large area (Erdos, 1970). Devon and Cornwall was chosen as the sample 
area and the research was limited to SMEs because the area is predominantly SME based (Gripaios, 1989, 1990, 1991).

With a research area as interdisciplinary as this it is necessary to clarify terminology. The definitions of Small and Medium Sized Enterprises (SMEs) often vary from author to author (Buckley, 1993). In this case the definition will be taken from the EU Observatory for SMEs (EC Observatory, 1993). Any company with under 500 employees will be deemed an SME. Other definitions include further economic criteria like turnover and ownership. However due to the sensitivity of obtaining this empirical information at the data collection stage, with the potential subsequent reduction in response rates from questionnaires, it was decided employ the EU definition.

The terms ecology and environment have recently been used interchangeably within the management field. This has lead to confusion and a degree of misunderstanding. Ecology is the study of the relationships between living organisms and their environment (Collins English Dictionary, CED). The environment is the external surroundings. In relation to ecology, environment is the external surroundings in which a plant or animal, lives which tends to influence its development and behaviour (CED). The difference lies in the relationship. Ecology is an interdependent concept where humans and nature co-exist. The environment, however, pertains to a situation where there is a split between the observer and the observed. Nature and humankind are, therefore, conceptually separate. It should also be stressed that the Environmental Management and Auditing Scheme (EMAS) is also referred to as the Eco-Audit Scheme on occasions. This is because the title was changed through the regulation validation process. 
Management (with regard to environmental considerations) is a controlling concept that requires a dominant decision maker or makers. Therefore it fits well with the term environment. External control of nature becomes environmental management. The term environmental is at times used in the more traditional industrial sense to mean a businesses external (or internal) environment. When this usage is employed it is made clear in the text which application is being used.

Green is defined as a set of ideas based upon ecological thought (Cooper T, 1990). There is, however, a distinction to be made within this term as there are varying levels of green. The two terms usually used are light and dark green. These terms have developed from an original distinction drawn by Arne Naess between shallow environmentalism (light green) and deep ecology (dark green), (Naess, 1973). This distinction is discussed by Mellor:

Shallow environmentalism is a human-orientated concern with immediate environmental issues, such as pollution or resource depletion, which aims to reconstruct the relationship between human society and nature in a way that would ensure human survival. Against this Naess sees deep ecology as a nature-orientated desire to adjust human life in such a way that its destructive impact on the planet ceases. Deep ecology celebrates the complexity and diversity of the natural world for its own sake, not as something useful or even necessary for humanity (Mellor, 1992 pp.83-84)

Sustainable development was defined as "meeting the needs of the present generation without compromising the ability of future generations to meet their own needs" (World Commission on Environment and Development, 1987). The term sustainable development is frequently used to refer to financial or economically sustainable development. Within the context of this research, however, sustainable development will relate to environmental sustainability unless stated otherwise. 


\section{Figure 1.1}

\section{RESEARCH PLAN}

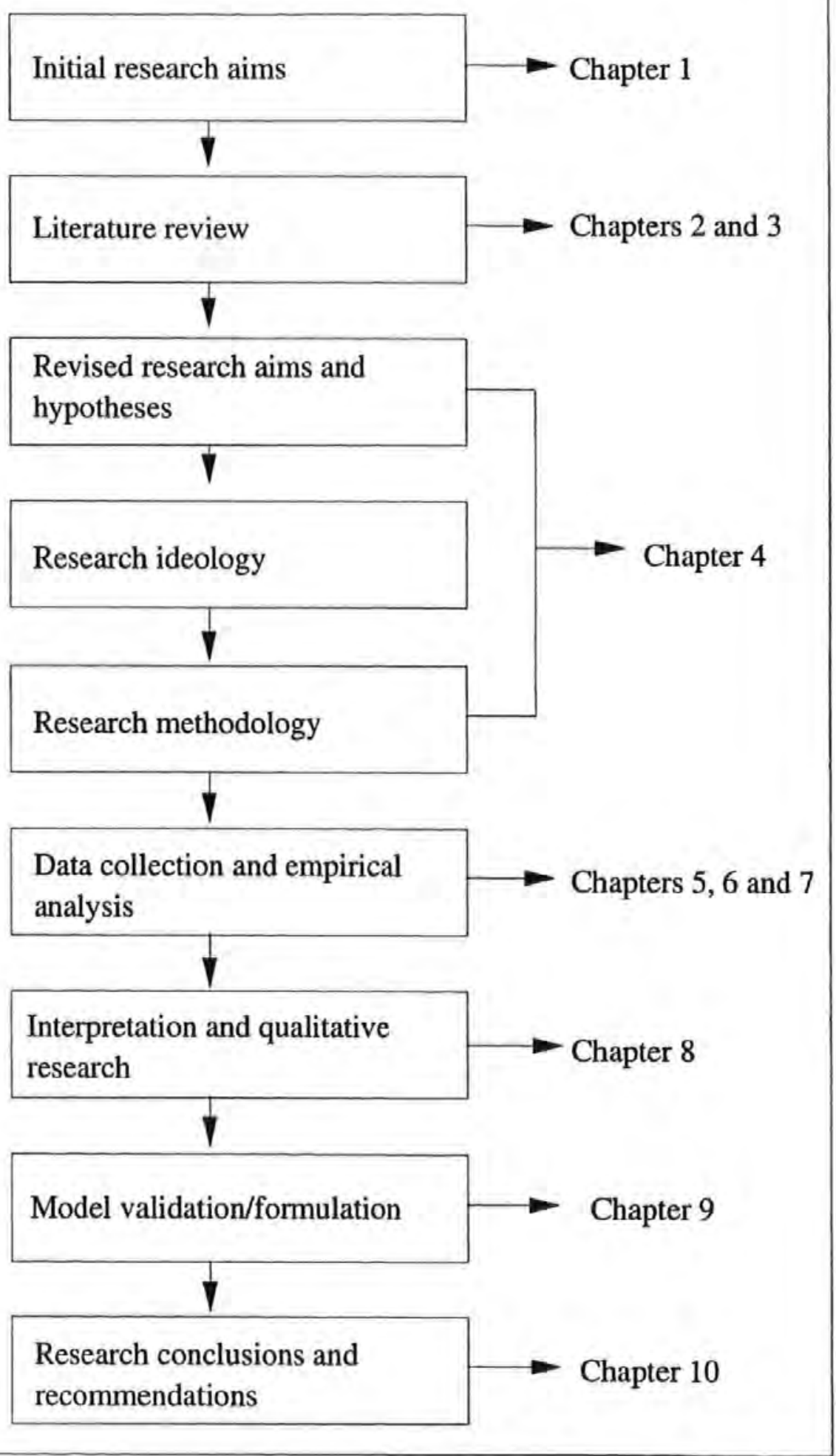




\subsection{Research Plan (see Figure 1.1.)}

Chapter 1 introduces the research area, delineates the research aims and clarifies the general research design (Figure 1.1). Chapter 2 covers the evolution of environmental philosophy pre-1980, establishing an understanding of the roots of contemporary environmental thought. Chapter 3 covers all of the relevant literature post-1980. The distinction in history was made due to the marked increase in environmental management literature in the 1980s. Chapter 3 considers both economic and environmental management literature accumulating in a section on alternative holistic solutions to the problem of sustainable development. Chapters 2 and 3 enable the initial research aims outlined in the introduction to be revised and expanded. Chapter 4 delineates the revised research aims and the subsequent hypotheses. It also outlines the research ideology and covers the methodology used to test these hypotheses.

Chapter 5 presents the results of the first mail survey and issues of environmental perceptions, awareness and practice are explored. First, the chapter looks at attitudes towards environmental issues and compares the differences between industrial sectors, size and type of company in response. Second, it clarifies levels of awareness of environmental regulation and compares industrial sector, company size and type response. Third, levels of operational and strategic environmental management are observed. Variance of response is tested between industrial sectors and company types.

Chapter 6 clarifies some of the issues arising from the first mail survey and explores new questions of environmental perception through the concept of action learning (Morgan, 1993). Action learning is a practical research technique which allows the interviewer to loosely structure the interview whilst concurrently extracting primary source information from the interviewee. This chapter explains company response, 
attitudes, awareness and policy in the first survey. It also gauges opinion on the prescribed environmental management systems solutions and their alternatives.

Chapter 7 develops the questions and ideas from the in-depth interviews, empirically testing their validity with a larger sample size. This is achieved through the distribution of a second mail survey which covers the applicability of strategic environmental management theory to the SME sector. Chapter 7 also covers issues of present and future support for the SME sector. Chapter 8 summarises the empirical findings of the research and considers the requirements for alternatives to present theory on the strength of the research findings. Case study material is presented in Chapter 8 as one variable of the alternative model which is presented in Chapter 9. The model devised also includes inputs from the literature as well as alternative primary source information. Chapter 10 concludes the research by delineating future research. 


\section{CHAPTER 2}

THE ROOTS OF ECOLOGICAL THOUGHT 


\subsection{Literature Progression}

The purpose of Chapters 2 and 3 are to trace the roots of environmental management and the greening of business literature. The review is chronological in form and is drawn from a number of diverse subject areas. Two main strands of literature emerge (Figure 2.1). First, ecologically based writings which include business or industry as just one variable. Second, business literature which includes ecological or environmental issues as just one external variable in the business environment.

These two paths do, however, subdivide again: ecological literature emerges from at least as far back as the deep green thought of the 17th century socio-religious sect the Diggers and their political wing, the Levellers. The more light green ecological literature which is concerned with resource depletion, pollution and industrial expansion is epitomised by Schumacher (1973). Business literature on the environment also falls into two subsections. First a section of the literature is concerned with awareness of the ecological problem. A second body of work embraces human superiority and natural domination over nature (Bacon, 1561-1626; O'Riordan, 1977). Subsections are not, however, mutually exclusive. Many concepts are equally acceptable in all subsections of literature. This is inevitable when dealing with such a cross-disciplinary subject area as the environment. Basic management theory and characteristics of the Small and Medium-Sized Enterprise (SME) will also be considered to place the research into context.

The final group forms a category of its own, being neither purely ecological nor business oriented but both. This literature, forming the final section of Chapter 3 , relates to alternative, holistic solutions. The majority of literature reviewed post-1989 (the year Margaret Thatcher influenced business thought through her Royal Society speech) in the U.K. fits in to this category. 


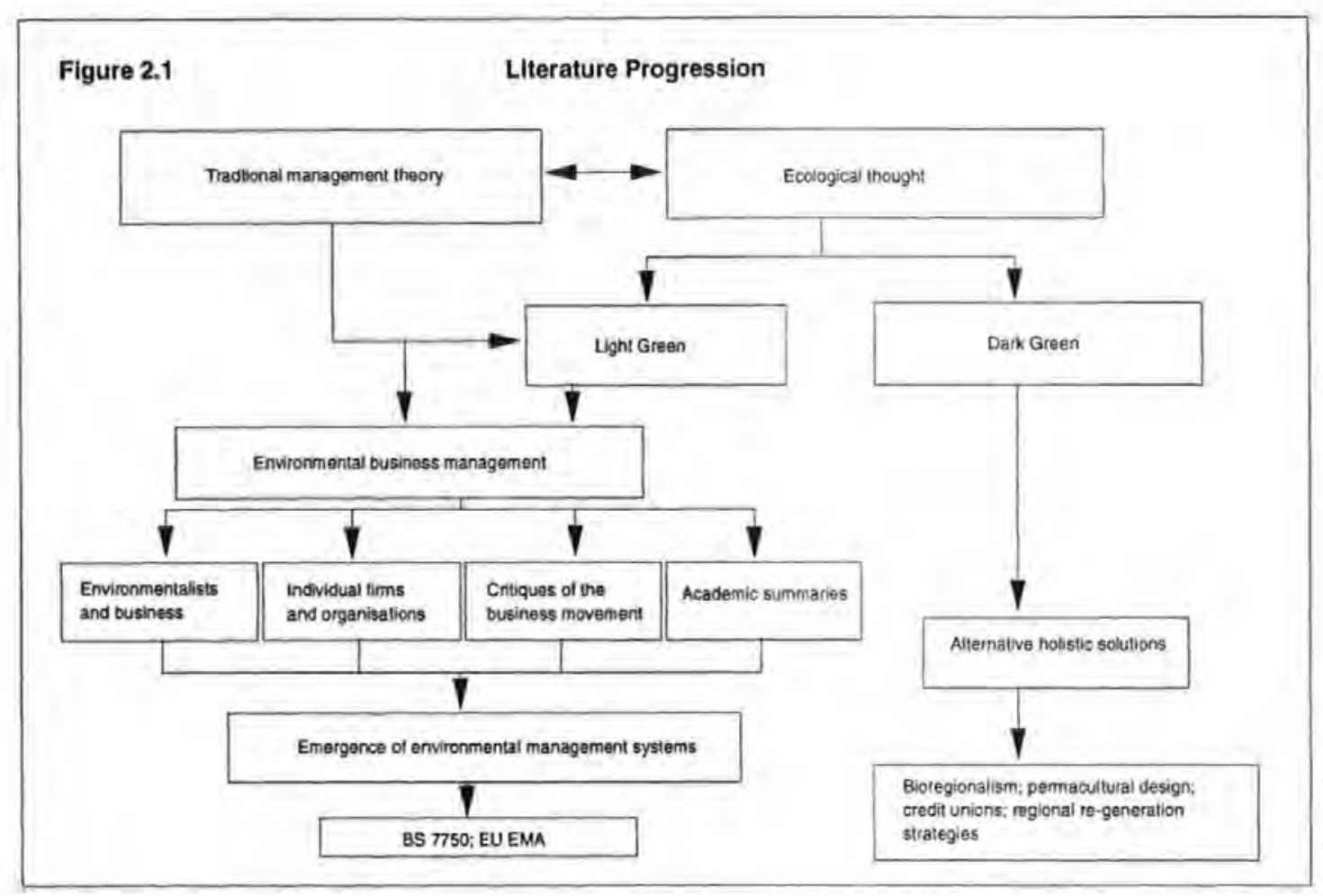

According to Roberts (1992), however, this too can be subdivided further into four categories with distinctions being made between: a) work undertaken by environmentalists and business (Winter, 1988; Elkington, Knight and Hailes, 1991); b) individual firms and business organisations (World Industry Conference on Environmental Management, WICEM, 1984; Confederation of British Industry, CBI, 1989); c) critiques of the green business movement (Dauncey, 1988; Irvine, 1989), and d) academic summaries of business environment studies (Cope and James, 1990). Much of this work is in its embryonic stage with little or no work challenging the legitimacy of the connection between business operations and environmental repercussions, with the exception of Nordhaus (1990a and 1990b), More cooperatively and holistically oriented alternative approaches to sustainable development are also reviewed. 


\subsection{Pre-1900}

There has always been a relationship between humankind and the environment, but it is the nature of the relationship that is pertinent. The Bible, with its ambiguity of teaching concerning people's role on earth is the earliest text relevant to this review. Depending on interpretation, the Old Testament offered humankind dominion over or domination of nature. This is central to the contemporary business/environment debate in relation to a business's freedom to use (or dominate) nature in its own way (Cooper T. 1990).

Hippocrates in the 5th Century $\mathrm{BC}$, arguably began the environmental determinism debate. He suggested that a deterministic and causal relationship existed between nature and man (Glacken 1967). This philosophical line of thought became preeminent in the nineteenth century (Carl Ritter amongst others developed it further) and is still cited today. Environmental determinism is central to the understanding of contemporary environmental business issues as it creates a split between man and nature thus requiring a need for some kind of causal and deterministic relationship. Without this split it could be argued that most of our environmental problems today would not exist. However, this would have to be at the expense of modern industrial development. The Aboriginal society is an example of how people can live in harmony with the environment without forging a split between the two.

Other writers have traced contemporary philosophy, action and thought back to the twelfth and thirteenth centuries to Aristotelian philosophy and Judaeo-Christian theology. White (1967), Lovejoy (1974) and Mills (1982), for example, discuss how certain theological issues in history have influenced humankind's actions. There are two opposing arguments here, one suggesting theological teaching and Christianity in particular, have given people a "free-holding reign" over their environment and the second saying Christian teaching preaches stewardship over nature. Dominion not 
Domination. This basic disagreement is at the heart of the environmental debate and has particular significance to business (Cooper T. 1990). The argument is that, attitudes towards environmental issues are determined by perceptions of the human relationship with the environment. One can relate this to the famous Margaret Thatcher speech at the Conservative Party Conference in 1988 when she talked about nobody having a free holding reign on the planet. This in turn was the catalyst for the Pearce Report (1989), the government's ensuing document "This Common Inheritance" and the Environmental Protection Act of 1990, which has had a significant impact on large U.K. businesses with respect to their environmental policies.

There is little doubt that the application of new techniques in science and technology are at the root of most global environmental problems. White (1967) suggests that science actually developed in the eighth and twelfth centuries, far earlier than is customarily accepted and believes that it was only when this science was married with technology that the scientific revolution of the sixteenth and seventeenth centuries was allowed to take place with its consequential implications for the environment.

However, it is also important to highlight the main point of the pre-scientific era discussed at length by Pepper (1984). In that period humankind lived as part of the universe and did not seek to dominate it. Medieval cosmology is very much holistic in nature putting what we now call the 'environment' on a pedestal. It was more of a modern day humanistic, qualitative approach as reflected in the thoughts of the 17 th Century Diggers and Levellers and the present day "Deep Greens" (Devall and Sessions, 1985; Naess, 1973, 1990).

According to Pepper (1984) a change occurred in 1543. Following on from the work of Copernicus, the scientific revolution lasted until 1687 and the era of Issac Newton's Mathematical Principles of Natural Philosophy. Up to this point humankind may 
have had the will to dominate but did not have the capabilities. Writings were mostly subjective analyses of philosophical bias which could easily be (and regularly were) challenged:

\author{
In 1553, Copernicus suggested a simple \\ revision to the cosmography whereby the \\ position of the sun and the moon were \\ reversed, but the implications of this \\ were so enormous that it needed 150 years \\ to construct the new cosmography that \\ was required. (Pepper, 1984, p47).
}

A framework for understanding the emerging dichotomy of thought between philosophical ecological writing and business ecology literature, (possibly stemming from this point in history), could be O'Riordan's (1977) dualistic separation of environmentalists into 'Ecocentrics' and 'Technocentrics'. He distinguishes between technologically optimistic environmentalists, technocentrics, who believe that technology will always provide solutions to environmental problems, and ecocentrics who mix ecology with the non-scientific philosophy of Romanticism. An example often cited by technocentrics, is how the depletion of natural reserves of nitrate in Chile was combated by the development of substitute synthetic nitrate. Ecocentrics believe that one cannot blame the progressive degradation of the biosphere on technical failings in the implementation of our socio-economic policies. They believe it is the policies themselves that are at the root of the problem. They also question the acceptance and normality of the existing paradigms of science and economics, blaming this dogma for the present global economic problems and ecological crises (Goldsmith 1992). 
O'Riordan (1977) and Pepper (1984) discuss the genesis of what they believe this separation to be. The revision suggested by Copernicus is seen as the root of the technocentrics movement as it questioned the existing cosmology and eventually lead to the blossoming of what we now call the root of classical science. According to Pepper (1984, p46), these principles are sometimes known as the Newtonian Paradigm.

Key pieces of work in the evolution of technocentric thought include Johannes Kepler (1571-1630), the development of mathematical reasoning, by Galileo Galilei (1564 1642) and Rene Descartes' (1596-1650) radical geometric observations of matter being no more than extension in space. Descartes also introduced the dualistic concept in modern thought between mind and matter (which has become known as Cartesian Dualism). This proved to be fundamental in environmental thought progressions as it forged a split between man and nature. Nature was regarded as being composed of objects metaphysically separated from man. Man was of primary importance and objectively based. Nature and the mind were of secondary importance, being subjectively based and consequentially analysed. Although this 'split' was created in theory it was accepted that the action of either man or nature, mind or matter would have a significant impact on each other, they were not mutually exclusive. This is in essence an extension of the conceptual analysis of environmental determinism raised by Hippocrates.

Following Descartes, Francis Bacon (1561-1626) asserted that science was equitable with human progress and that scientific knowledge meant power over nature. Bacon used deductive reasoning to argue his case whereas Descartes was inductive in his approach. Schumacher (1973) suggested this approach, not only to scientific thought but to all forms of analysis, leads to knowledge becoming divorced from values. 
With the progression of science, the concept of objectivity (first suggested by Galileo), flourished. This was to become the central focus of the technocentrics in the environmental movement. Only if something could be proved objectively and scientifically could it be accepted as reasonable (a point later to be made by Schumacher, 1973). Yet it is interesting to note that as Prior (1954) says of Bacon in Bacon's Man of Science scientists were in Bacon's view "democratic, compassionate, humble, radical, socially aware, philanthropic, honest, unselfish, serene, noble, dedicated, priestly, good, cosmopolitan and apolitical". There is, however, one notable exception to this list of epithets: objective. In fact the majority of the list are subjective in nature. If this was deliberate or not is unclear but what is clear is that science has hardly been objective in history and continues to this day to be highly selective (Kuhn, 1970; Polanyi, 1978). Otherwise it is difficult to explain the fact that both Technocentrics and Ecocentrics, to use O'Riordan's neologisms, both "use science and scientific method to investigate nature but they come to very different conclusions about it" (Pepper 1984, p116). This refers to the technocentrics use of science in the Baconian creed to dominate and control nature and in the ecocentric language from their systems perspectives. According to Merchant (1980), the JudeoChristian God-given right of domination of nature was embodied in modern science superseding the previous organic view of nature that restrained exploitation (Mellor, 1992). One of the first exponents of the change was Bacon.

Bramwell (1989), in her recent work Ecology in the 20th Century, traces the origins of the Ecology movement back to the 1880's and Ernst Haeckel (1834-1919) and his Generelle Morphologie (1866). Haeckel highlights one of the problems of using O'Riordan's framework as he was an holistic scientist. Bramwell talks of Haeckel coining the phrase "Oekologie", meaning "the science of relations between organisms and their environment". The word ecology comes from the Greek words, Oikos and Logos meaning, broadly speaking, looking after the home (Oikos). Bramwell suggests that it is only when this holistic scientific method is coupled with the new "energy 
economics" of the early 1970's that ecology gained the strength of an independent discipline. Under O'Riordan's framework we have been able to see some of the main points that lead to the development of the scientific side of the environmental debate. O'Riordan's framework provides a basis for further analysis of the beginnings of ecocentric thought.

Before considering ecocentricism it is interesting to note that neither Pepper or Bramwell in their respective analyses of the environmental movement mention Adam Smith. Adam Smith's 'invisible hand' lead to the development of what we know today as rational economic man, or Homo Economicus. This abstract animal underwrites the major concepts of neo-classical economics (marginal utility and price theory) and has been a fundamental in the evolution of our present economic system. It has been argued that it is the preponderance of Homo Economicus that has designed an economic system bereft of morality and social justice (Daly and Cobb, 1989). Smith also said, however, that "the land constitutes by far the greatest, the most important, and the most durable part of the wealth of every extensive country" (Smith, 1776). His influence on the environmental sphere is so fundamental it is curious he is not mentioned in this context. Historians of economic thought have, however, been equally selective in their reviews of leading thinkers. As Daly (1973, pp12-13) has shown, 19th Century economists like J.S. Mill provided early warnings of the unsustainability of unbridled industrialism.

A number of writers have turned to the middle/late period of the Romantic movement after the Enlightenment to explain the present day philosophies of the Ecocentric environmentalists. Russell (1946) describes the Romantic oriented man in at least two ways. Firstly he is imaginative, passionate and unoppressed in nature and consequently: 
is violent and anti-social, an anarchic rebel

or a conquering tyrant.

(Russell 1946, p656)

Quite how the two depictions correlate is open for debate, but it suggests that the basis of the Ecocentric argument (if we are to take O'Riordan's premise) is at least in one sense, anarchic in nature. This fits in well with geo-anarchists like Kropotkin (18421921), one of the most influential philosophers of the time, whose arguments are still cited today (Naess, 1990) by radical elements of the environmental movement (Kropotkin, 1955).

Lovejoy (1974) takes a less aggressive stance, talking more of the uniqueness and diversity of the Romantics. He takes the analogy of a chain. If one link breaks all is disconnected like a series circuit in physics. This and his connections with medieval cosmology make Lovejoy's arguments fit in well with O'Riordan's ecocentric man. The Romantic period is thus the re-launch of ancient ideals of morality and idiography which are still the fundamental nucleus of deep green thought today.

Pepper, too, makes these links:

\author{
Romanticism was and is the antithesis of \\ everything scientific, logical behaviour, order, \\ authority. Indeed it has been regarded as a \\ sweeping revolt against rationalism and the \\ Enlightenment. \\ (Pepper 1984, p77)
}

He also suggests that this free will of spirit was annexed to more securely scientifically based work by Darwin and Malthus, providing the scientific support for some modern ecocentrics. Ironically, the eco-fascists have also adopted both Malthusian and Darwinian philosophy as heavyweight support for their beliefs that the 
growth of global population is the central problem and that there are only so many resources to go around (developed later by Hardin, 1974).

With Malthus's quantifiable results and Darwin's revolutionary text The Origin of Species (1859), the ecocentric school was provided with a systems view of nature, inextricably linking humankind with nature. However, Darwin's work also essentially pitted man against nature, introducing the concept of survival of the fittest which inevitably means there must be a loser. Both Darwin and Malthus were extremely influential 19th century figures whose work made a lasting impression on the environmental debate. The work of Darwin in particular made the final link in the full circle back to Hippocrates in the 5th century BC and the concept of Environmental Determinism.

So, using O'Riordan's framework one could suggest that the more technical, practical and light green business side literature of the late 20th century is mainly technocentric in origin and that the deeper green more structurally philosophical literature of this period is ecocentric.

\section{$\underline{2.3 .1900-1980}$}

The relationship between science, technological development and environmental imbalance has already been made (Merchant, 1980 et al) and many see the industrial revolution as the beginning of its manifestation (Schumacher, 1973; Porritt, 1984; Mellor, 1992). It is from this point that the literature becomes far more specific in nature. Gradually environmental literature began to separate out into specific subject areas, such as economics, philosophy, sociology and business management. They are all important to the development of environmental business literature, in differing degrees. 
Much of the early worker, producer and consumer, co-operative writings are directly relevant to the environmental debate in an historical perspective (Webb, in Coates ed. 1976; Huddleston, 1937; Bonner, 1961; Bradley and Gelb, 1983; Stephen, 1984; Bayley and Parnell (eds) 1987; Bartlett, 1992 et al). The impact of the co-operative movement on the U.K. economy, however, has been limited to date. Beatrice Webb, at the turn of the century, suggested that it would be difficult for "islands of socialism to survive in a sea of capitalism" (in Coates 1976). This has been proved correct, in that worker and producer co-operatives are acceptable mainly as a means to reduce the unemployment figures. "The development of co-ops and the introduction of various training schemes are no substitute for the creation of decent, permanent jobs in Britain" (emphasis added, GMBATU 1986). This line of thought has reduced the impact of the co-operative movement in the U.K. but does not render it insignificant. The co-operative certainly has a significant role in the localised development concepts of bioregionalism and permacultural design. Two concepts of regional economic development that will be considered in detail later.

Jevons (1905), Gray (1914) and Hotelling (1931) examined the concept of exhaustibility of resources in economic terms and Pigou (1932) discussed quality of life, post industrial revolution. However, it was Galbraith (1958) who provided an early critique of the morality of development in terms of the human environment. He crystallised the dichotomy that had previously existed, but had not really been articulated, between the rich and poor societies. There is little doubt that this text had a significant influence on the direction of literal work to follow. It debatably challenges Silent Spring (Carson, 1962) as the base text of contemporary environmental literature.

The influence of Silent Spring is unparalleled in the history of environmental business literature. It popularised the environmental cause for the first time with its discussion of the effects of DDT (the chemical fertiliser) on the human food chain. It resurrected 
the smouldering embers of the holistic, scientific debate but was far more influential than previous attempts to do this because of the nature of the content. This was a contentious public issue and therefore received far more publicity than much of the abstract theoretical work that had preceded it. Silent Spring contains a rigorous theoretical analysis. One can make a comparison here with the boom of green consumerism in the late 1980's and general interest in environmental issues after the high publicity of the effects of industry on the ozone layer, the Greenhouse effect, and the destruction of the tropical rainforests in the 1980s. High media profile based primarily on self-interest leads to a significant increase in the interest of the general public towards environmental concerns.

Pepper (1984) locates four periods in history when the environmental debate in general has been high on the public agenda: the 1890s, 1920s the late 1950s/early 1960s and each decade after the mid 1970s. These were all times following periods of sustained economic growth. They were consequently (according to Pepper) "well off" reactions to the existing materialist values. The question of the ability of the individual and indeed businesses to be environmentally friendly because of the implied 'cost of green', began to be discussed rather later (Elkington and Burke, 1989).

Between Carson and the next bench mark of the Limits to Growth, (The Club of Rome, 1972), there were a number of notable texts written, all with different contents and levels of significance. Boulding (1966) began to address the concept of environmental cost and laid the foundations for the search for alternative indicators to Gross National Product (GNP) and the accounting for the environment debate of the late 20th century (Anderson 1991). Mately (1966) made a connection between Marxism and the geographical environment which influenced work later done by Fry (1975) and Burgess (1978) on Marxism and the environment. Also Mishan (1969) addressed the concept of the cost and benefits of economic growth following on from Boulding (1966). 
Perhaps the most well known work of this intermediate period was The Population Bomb, Ehrlich (1968). This text popularised further the ecological cause, appealing not only to the moral green converts of the 1960s but also to the right wing global conservatives and neo-Malthusians. Like Hardin (1974), Ehrlich suggested a global population problem was not just a third world problem but a Western one as well. Population growth would place intolerable strains on the Western environment and the developing world threatening the standard of living of the west. His basic message was that too many people were chasing too little food and there was a need for a drastic reduction in the human population worldwide. If nothing else this book highlighted the concept of finite resources.

With work by Commoner (1967) addressing the idea of free use of the environment, the late 1960s and early 1970s provided a strong platform to lead in to the extremely important year of 1972. Earlier it was suggested that there are two paths of literature leading to the understanding of environmental business, one of them being business orientated. The majority of work reviewed so far has been ecologically based, but 1972 saw the publishing of an influential text that included a significant input from the business fraternity. It was commissioned by The Club of Rome, a select group of concerned individuals whose only common interest was in the environment. The group of scientists, academics, businessmen, economists, humanists and international civil servants came from an initial meeting in the Accademia dei Lincei in Rome in 1968 to form the Club of Rome. The Club commissioned the Massachusetts Institute of Technology (MIT) in 1970, to produce a report on The Predicament of Mankind. Their initial response was ambitious, but they did signal the first serious concerns of international business regarding their role in the environmental equation.

The work MIT came up with was Limits to Growth (1972) a neo-Malthusian observation of the exponential growth of mankind and its activities. Pepper suggested 
in his 1984 work that Malthus gave the ecocentrics part of their scientific credibility. However the work of certain neo-Malthusians worried about the total carrying capacity of the globe comes very close to what some have called eco-fascism. This is not to suggest that the Club of Rome were eco-fascists, although one of their primary conclusions in the early 1970 s was that technical solutions delay rather than extinguish the possibility of environmental disaster.

The Club of Rome asked MIT to run computer projections of future ecological developments in five areas: human population; agricultural production; natural resources; industrial production; and pollution. The rather apocalyptic conclusions acted as a catalyst for the emerging green movement and sounded a firm warning to industrialists (the majority of them being at this stage unaware of the environmental tide) about the practical aspects of environmental management.

Business environmental awareness evolved rapidly, particularly among the larger global companies with the resources to invest in $R \& D$ to extrapolate future gains and understand the concept of efficiency and the consequential cost savings. This is due in part to the influence of the landmark article which set the environmental debate firmly in the public domain. A Blueprint For Survival [Goldsmith (ed). 1972] by the editorial board of The Ecologist, largely ignored by the business community, presented an ecocentric, global survival kit. Developed in part from Goldsmith's earlier work (Goldsmith, 1971) and other influential contributors of the time (Jarret and Mishan, 1969; Graham F. 1970), 'Blueprint' included a radical revision of the economic order of the western world. The philosophy of the work was not in keeping with contemporary industrial practice. It entailed a wholesale revision of the relationship between business and the environment, providing an early prescriptive solution based on the causes of environmental impacts rather than consideration of means to alleviate the symptoms. 
Up to this point industry had regarded the environment as a free resource. The Blueprint For Survival challenged this and consequentially challenged and threw down the gauntlet to the business sector. The repercussions of this were immense and have culminated in the new economic movement of today (Ekins and Carcasson, 1982; Ekins, 1986 and 1992: Daly and Cobb, 1989; Anderson, 1991; Lang and Hines et al). The 'Blueprint' looks in part at the concept of GNP (quoting from Boulding, 1971), demonstrating that the use of the environment is not reflected as a cost to business, while the levels of fines for pollution of externalities and policing of them remain inadequate. It also considers how increased consumption of raw materials and levels of pollution are reflected as additional to GNP. If someone is injured in a road accident, or taken to hospital with asthmatic breathing problems due to the combination of low climatic pressure and vehicle emissions, the costs of care will add to the nation's National Product through the present national accounting procedures. According to the Blueprint for Survival "GNP...provides the most misleading indication of our well-being" (Goldsmith ed. 1972). The 'Blueprint' considers all aspects of environmental degeneration, including the correlation between environmental degradation and social disorder. The work takes the neo-Malthusian stance that further increases in population can only exacerbate social pressures and put further strains on potential economic growth. These ideas are covered extensively by Ehrlich (1968 and 1971).

In 1973 E.F.Schumacher produced Small is Beautiful. Although he is often misinterpreted as proposing 'small' to the exclusion of all, the influence of this text on contemporary environmental thought is immeasurable. Schumacher did not see small scale industrial development as a panacea:

There is no single answer. For his different purposes man needs many different structures, both small ones and large ones, some exclusive, 
some comprehensive.

(Schumacher 1973, p57).

Schumacher's work may have been so widely acknowledged because of its more positive approach to the environmental problems of the times. It is certainly not in the 'doom and gloom' category and does not challenge the concept of business per se since it offers solutions and not just criticisms, it was, therefore, more immediate and acceptable than much of the previous influential work [Goldsmith (ed.) 1972].

Schumacher furthered the economic angle of the environmental debate as he discussed economics "As if People Mattered", (the sub-title to Small is Beautiful). This ethical dimension, so evidently vacant within neo-classical economics, has become one of the central variables of the new economic movement of today. Schumacher avoids alienation of subjects and highlights their interrelationship. However he finds Christianity (or at least the institutionalisation of the religion) unsatisfactory for his analysis of economic utopia, and turns to Buddhist economics to fill the gaps. He concludes that what has been missing from the Western social and economic system and has consequently lead to (amongst other things) environmental disequilibrium, is the presence of moral values. Schumacher argues that large businesses and their android treatment of employees lend support to this advocacy of the decentralisation of economic power. This, he argues, would not only give the land back to the tiller but also return economic power and self determination to the citizen.

One of the first distinctions Schumacher makes is that in Buddhist societies work and leisure are inter-linked, making the holistic experience a social experience. Over-use of environmental resources, therefore, jeopardise the existence of leisure. Hence, over-consumption of natural resources is seen as barbaric. In the west increased consumption is regarded as synonymous with an increased standard of living, a totally opposite view that obviously has immense consequences for the environment. Our 
present system of economics measures values in purely monetary terms. Because of this, according to Schumacher, one "Measures the immeasurable" (Schumacher, 1973, p42) with reference to the environment. There are plenty of contradictory arguments about standards of living and economies of scale that could justify large scale economic organisation. What Schumacher argues, however, is that this way of life will inevitably be self-defeating. A comparison with Marxist doctrine could be made in relation to the self-destructing nature of capitalism.

Parson's (1977), Bramwell (1989), Schmidt (1971) and numerous other writers on Marx and ecology or the environment (Mately, 1966; Fry, 1975; Burgess, 1978; Marx and Engles, 1984) make the rather obvious links between capitalist over production and the consequences on the environment, whilst not really offering too many well formulated alternatives. It does seem that the link between Marxism and the environmental debate is a little tenuous, an attempt to fit unrelated bits of reference together. However the business practices and the consequential environmental disasters of the former Soviet Union cannot be taken as examples of how Marxism regards the environment. Nicaragua, in the mid 1980s would be a far more accurate case study to take, bereft of any totalitarian order. It is also important to point out that with the apparent decline in the popularity of Marxism and the planned economy, the freer market is not exactly providing environmental protection either. Elements of the planned economy may yet still be required to fill the ethical gap in the free market system. Indeed there is an ironic contradiction in the arguments of orthodox economic theory with respect to the environment. On the one hand the suggestion is that the price mechanism can regulate for social concerns and the environment and on the other there is a requirement for intervention to protect the environment in the form of taxation and subsidy. Theory and reality seem to be at odds on this issue (Mulberg, 1993; Hutton, 1994). 
1972 certainly proved to be an extremely important year in environmental terms not only with the publication of Blueprint for Survival and Limits to Growth, but also with the first United Nations (U.N.) conference on the environment in Stockholm. Daly (1973) edited a collection of mostly philosophical work that includes essays from many of the most influential ecologists of the time. The theme is that economic growth for the sake of economic growth is destructive and unsustainable. Subject matter ranges from physics to theology showing the boundary crossing nature of the environment as an academic subject. The book's main emphasis is, however, on political economy. Work includes, Schumacher, Cloud, Ehrlich, Boulding, Lewis and Hardin. Hardin's (1974) contribution on the "Tragedy of the Commons" has had a particularly lasting influence as he attempts to explain the problems of cumulative irresponsibility on common land. He suggests, through an agricultural analogy, that a farmer may increase his individual utility by adding one further animal to his herd. He will not necessarily pay the full price of the strain increased grazing would impose on the land. This is because everybody shares in the reduced fertility of the common land. If all farmers increase their herds by the same amount, increasing diminishing returns from the land sets in, so removing the source of sustaining wealth for all (also see Ecologist Vol. 22 No4, 1992).

This 'Tragedy' has become central to a section of the green movement's philosophy as it explains very simply the risk of over using the earth's finite resource stores. In fact Hardin (1974) also indirectly showed how the issue of the environment so easily crosses the political divides, with his 'Lifeboat Ethic' concept. This has been adopted by many right wing ecologists and politicians as an argument against offering aid to starving nations, as there are only a limited amount of resources and food to go around. Such neo-Malthusian arguments, distract from the real issues of overexploitation by western industry (Goldsmith, 1992 et al). 
1974 in fact not only saw Hardin's work published, but also the first Conference on Environmental Management Systems (EMS) held by the International Chamber of Commerce (ICC). This was a positive response from, what Roome (1992) would later call, the 'Leading Edge' companies, to the demands of the increasingly influential, environmental movement and the U.N. Stockholm conference. It also proved to be an important watershed with business beginning to realise the threat of the environment as an issue and the possibility of competitive advantage to be gained from it. However it was on the whole the larger companies who could afford to plan proactively.

As the 1970s toppled into recession, business interest rather tailed off but academic work continued with political explanations, theories on the recession and links to the environment. After all it has been argued that oil (a limited natural resource) was central to the recessional decline of the 1970s (Callenbach, 1978). Literature on the crisis of capitalism and possible alternatives began to emerge once again (Stretton, 1978). The re-emergence of Marxist literature was also prominent, as it always has been in times of capitalist recession (Burgess, 1978).

In 1979, Lovelock developed the concept of the earth as a self regulatory mechanism in the form of the Gaia hypothesis. This hypothesis has become central to many New Age ecologists' work as it personifies the earth as a goddess (Gaia) and explains how the earth could require the eradication of the human species to guarantee its continued existence. Most ecologists have been influenced by this work, from Porritt (1984) to Goldsmith (1992).

With Willy Brandt's report to the U.N. NorthlSouth Divide (Brandt, 1980) on the dichotomy of lifestyles and environments, and population problems, the West came to regard global population issues as not just somebody else's problem, taking a neoMalthusians stance. Preservation of the environment in the south was as much a 
northern problem as it was for the indigenous populations. The early 1980s generated, in the main, pessimistic ecological literature. It was educative and informative, but lacked direct solutions, preferring to dwell on description of the symptoms of pending ecological disaster and socio-political explanations for these states of affairs (Schnaibergs, 1980; Bookchin, 1980). On the positive side, the literature was educative and diffused information regarding the 'impending ecological crisis'. Works by McRobie (1981) and Goldsmith and Hildyard (1986) are amongst the more positive texts of the early to mid-1980s suggesting clear human response to the, "Case of the environmental impasse" (Allissa, 1991). It is to this response that we now turn with a review of relevant management texts with relation to the environment. 


\title{
CHAPTER 3
}

\section{THE BUSINESS-ENVIRONMENT}

\author{
PERSPECTIVE
}




\subsection{Environmental Management}

Although contributions on the business environment side have been minimal until the 1980s, environmental management is an age old phenomena. Early Nomads and Settlers understood the concept of over-exploitation of the land, the basis of environmental management. The concept appears in the context of business terminology in Beale (1980), setting out the principles of business environmental management, on strategic and operational levels. As Beale aptly comments:

\footnotetext{
Environmental management does not mean, management of the environment. It does mean management of activities within environmentally tolerable limits.
}

(Beale, 1980)

Beale explains why global industry responded so slowly to the U.N. call in 1972 and to the obvious signs from nature:

$$
\begin{aligned}
& \text { There is almost a complete lack of organised } \\
& \text { material related to the definition and } \\
& \text { practicabilities of fashioning a coherent } \\
& \text { environmental decision making framework. }
\end{aligned}
$$

(Beale, 1980)

To a certain extent this is still the case today, although since Beale (1980) and Winter (1988), in particular, this situation is changing, with the gaps being slowly filled. According to Beale (1980) four pressurising forces, Technical, Legislative, Consumer and 
Administrative structures have their impact upon business. Subsequently business literature has become interested in the environment as an issue.

The early and mid-1980s may not have seen too much environmentally concerned literature written that was directly applicable to businesses, but it did see the beginnings of recognition of the environment by the CBI. Also, in the USA the 1980s saw a huge increase in environmental legislation following the establishment of their Environmental Protection Agency (EPA) in the 1970s. This forced business to assess its environmental performance and to change certain environmental practices or face gaol sentences or fines. Managing directors are now directly responsible for their businesses environmental performance and gaol sentences of up to five years have been served.

In the U.K. regulation of business was limited to the Control of Pollution Act (1974) until the present day Environmental Protection Act (EPA, 1990). Neither of the acts has been rigorously enforced. Endorsements by influential figures like Margaret Thatcher in the late 1980's had a profound effect in increasing awareness in industry and so providing the framework for the more applied literature that followed. Porritt (1984) and Seymour (1987) certainly had their influences on the political and consequently business agenda. In Britain, however, there was one piece of literature and one political event in the $1980 \mathrm{~s}$ that finally encouraged writers from academia and business to write specifically about U.K. business and the environment. First, Elkington and Hailes (1987) informed the public on environmentally destructive and friendly products in the U.K. Second the success of the Green Party in the 1988 European elections (where they won $15 \%$ of the vote) had significant implications. There were a number of political reasons for this success, which has proved not to be a permanent electoral swing. However, it made politicians of all persuasions realise that environmental issues were now major issues politically and that policy statements and new legislative promises were now required. 
The effect on business was remarkable. From this point on we saw a huge increase in the amount of literature that was written directly addressing the practical problems that faced business and the solutions that they could employ. From business advice guides (Bic, 1991; Ralston/Church, 1991; Davis, J. 1991) to specific environmental management systems (Winter, 1988; Roome, 1992; Rickmann, 1992; Welford and Gouldson, 1993) the literature rapidly attempted to satisfy both consumer and producer.

Although the work of Elkington and Hailes (1988) had an indirect influence on businesses, making them more aware of the green consumer, the text was not written specifically for business application. This may have been a superb piece of marketing in itself, since Elkington followed it up with a book co-written by Burke (1989). Aimed at business people who were already committed in some way to the future importance the environment would play in business, this was a 'solid text book', full of concepts and philosophies that are the foundations of environmental philosophy in business:

\author{
Most excellent companies now include \\ environmental quality objectives among \\ their core values.
}

(Elkington, 1989, p16)

Elkington was influenced by a number of contemporary texts. The Winter Model (1988) is based on the Integrated System of Environmentalist Business Management, forming a practical guide to businesses management of the environment. It is not really an EMS, in fact it is more operational than strategic in nature. However, it does pose strategic questions, e.g. why is environmental management necessary? The Winter Model itself is more of a check-list than a model, developed in a live trading company. It covers all the 
main aspects of management, (corporate objectives, worker motivation and training, materials management, production technology, waste disposal, building, international relations etc) and is geared to a planned and gradual implementation process in companies It is better than most of the 'Guides' although suffering somewhat from vagueness, the "useful addresses" section is particularly useful.

Emerging alongside the business guides of the 1980 s came the development of what is now being called 'new economics' (Daly and Cobb, 1989; Anderson, 1991; Hines and Lang, 1993 et al). Although much of the content of this school is not new the critique gained in strength as it supported the environmental movement of the 1980s. The distinction between new economics and the more traditional environmental economics seems to stem from the requirement within new economics to develop an alternative measurement for the environment other than one based on financial yardsticks.

On the one hand, Mulberg suggests, the price mechanism is viewed as the ideal regulator within the capitalist system and on the other taxation and subsidies are required to "protect" the environment. With this intervention comes an attached recognition that the capitalist economy is not an untouchable. This therefore requires subjective intervention. As soon as this decision has been made the artificial bubble of objectivity attached to the market has been burst. Vested interests become the motivating factor. Hence the Austrian New Right (a school of economics from the turn of the century) argues that the only truly efficient way of preserving the environment is through allowing prices to regulate ecological considerations (Mulberg, 1994).

At the moment the environment can only be valued purely in financial terms. There is no intrinsic value attached to the environment. In orthodox economic terms Pareto optimality (as part of Welfare economirs, Curwen 1990) is the only measure of efficiency 
and this is one of allocative efficiency. Society is seen to improve if personal utility can increase for one person without reducing the utility function of another. The problem is the measurement is necessarily financial. It cannot take account of costs or benefits outside this. This leads to a number of logistical problems. For example, the measurement of environmental impact through the Cost Benefit Analysis (CBA) technique is flawed. CBA attaches financial value to parts of ecology that are not tradeable commodities. Clean sea water would be an example. The attachment of financial value creates a tradeable commodity. If one is to accept the predominance of the price mechanism, therefore, all ecological goods should be tradeable.

The literature relating to valuing the environment is extensive (Maler, 1974; OECD, 1975; Pearce, Markandya and Barbier, 1989; Pearce, 1991b; Barde and Pearce (eds) 1991; Markandya and Richardson, 1992 et al). Most of it has taken the view that the ecology can be valued in financial terms. Indeed it has been argued that any ecological decision implies a monetary evaluation (Barde et al 1991), that ecology can be valued through CBA. For example, in considering the environmental impact of noise pollution and attempting to place a value on it one could draw a measurement based on the market prices for noise absorbing windows. As in all economic theory, ability to buy is not taken into account. Alternative techniques such as contingent valuation, hedonic pricing and the travel cost method have also been used for valuation purposes. The contingent valuation technique creates an artificial market for the non-tradeables like clean air and tries to decipher the total economic value of these non-tradeables. Hedonic pricing is an attempt to judge how much value we place on the environment through an analysis of the property market and the condition of the environment around the houses bought (Pearce et al, 1989). Alternatives to these monetary valuations of the ecology are presently being developed. The supposition that neo-classical economics and subsequent economic rationalism is objective, is however under question. Planning decisions that take account 
of ecological concerns are necessarily subjective. Taxation or subsidy are two examples. An alternative theory that considers a truer representation of reality by including ecological considerations will be more objective. It is certainly feasible to consider a regional economic system that accounts for ecological considerations without placing monetary evaluations on it (Hines and Lang, 1993). Such a system is, however, still in the process of development.

Other important economic revisions include the questioning of the measurement of GNP. Environmental economists and accountants backing this challenge, Anderson (1991), Pearce (1989 and 1991), Gray (1990) and Kestigan (1991), have recently had very influential pieces of literature published. The challenge is seen as the development of alternative economic indicators that more accurately express the wealth of a nation. These four in particular have considered the concept of GNP and its fallibility with Anderson in particular developing alternative indicators based upon quantifiable social and environmental impacts (Anderson, 1991).

Dauncey (1988), Pearce (1989), Cairncross (1991) and Jacobs (1991) have all looked closely at the fundamental nature of the economic problem offering a range of economic solutions. Issues such as 'The Polluter Pays', 'Tradeable Permits' and the price mechanism as an indicator are all high on the agenda. They certainly do not all come to the same conclusions. Pearce in particular alienates himself from some sections of the green movement, with his pro-price mechanism stance, seeing the price mechanism as an adequate control for environmental resource scarcity. Opposing this, Cairncross (1991) says:

To rely solely on the market, however ingeniously

harnessed to clean the environment, is as naive as relying solely on government intervention 
However, all demonstrate how a changing economic climate could effect the business community. Most of the environmental economists already mentioned see consumption as the root cause of impending environmental disarray. Galbraith (1958) suggested that western culture accords consumption great social value. This view is supported by Daly and Cobb who argue that the attempt to turn a naturally subjective discipline of economics into an objective science has lead to a number of questionable concepts, not least the predominance of rational economic man or Homo Economicus (Daly and Cobb, 1989). Daly and Cobb argue that although the theory of marginal utility is sound, there is an unwarranted bias towards the consumption element. Neo-classical theory states that the action of giving can increase an individual's utility function but this benevolence variable is limited in that a third party cannot derive utility from another's altrusim. However, perhaps more fundamental is the recognition that although the social welfare function can collate group utility, the theory requires that utility is derived from the transaction. There is no provision for altruistic behaviour for its own sake, as there needs to be a 'gain' in the individual/community utility function. They argue this is unrepresentative of reality and has lead to a number of misguided policy directions. Alongside this is the challenge to price theory. Neo-classical theory states that Homo Economicus has an insatiable desire for commodities. The reasoning is that once rational economic man has satisfied his want for a good he will move on to another good, ad nauseam. Daly and Cobb argue, that this is not always the case in reality and conclude that rather than being objective Homo Economicus is in fact subjective and biased towards self-interest. Lee, Tarpy and Webley conclude along similar lines:

The axiom of greed must be rejected because real people, unlike Homo Economicus, are not insatiable

(Lee, Tarpy and Webley, 1987, p111) 
The argument is developed further by Daly and Cobb. They argue that the following statement made by Robert Samuelson (a neo-classical economist) proves the fallacy of the objective claim of neo-classical economics. "Efforts to help small businesses as a class are no more virtuous than aiding large business as a class" (Samuelson, 1982 in Daly and Cobb p90). They argue that the decision to make no moral distinction in the market is a value judgement in itself and therefore firmly establishes the theory as subjective, self-interested economics.

If, therefore, neo-classical economics is subjective and biased towards self interest and reality does not match this picture, a false abstraction of reality is personified in Homo Economicus. This, Daly and Cobb argue, has lead to misplaced economic practice and the development of an economic system that is unlikely to become sustainable if left to its own devices. This conclusion suggests the need for a revision of economic thought if accurate practical application of theory is to be extrapolated and if sustainable development is to be achieved. These considerations have lead to the new economics characterised by a literal conceptualisation of reality and including more community, social and ethical considerations than traditional orthodox economic theory. New economics exists to counter the perceived incongruency of present economic theory which holds (as Norman Lamont, Chancellor of the Exchequer, 1992 argued) that consumption brought Britain into the current recession and consumption will get it out. New economics is developing an economic theory that places importance on sustainability rather than 'end of pipe' economic tinkering (Anderson, 1991; Jacobs, 1991 et al). Characteristic of the new economic theories is community or collective interest. This requires responsibility for an altered course of action from industry.

However, most of the economic guidance accepted to date has been from the more moderate environmental economists like David Pearce who reinterates Hotelling's 
premise that the business community may have its hands tied to radical clean up if the economic system decides that price cannot control finite resources and the environment around us. J.M. Keynes also suggested that important economic problems should not be overestimated to such an extent that matters of higher and more permanent significance are sacrificed to its supposed necessities. Hence, using the philosophical concepts of some of the more moderate environmental economists like David Pearce, writers like Elkington (1989, 1991), Ralston and Church (1991) and Davis J. (1991) began to write more specialised literature. Their aim was to make the often complex concepts of the intricacies of green issues, accessible to businessmen. These green business texts of the late 1980s/early 1990s are mostly philosophical and strategic in approach. The importance of green as a strategic issue became the target, with additional "steps to excellence" sections included at the end.

The "ten steps" in The Green Capitalists is arguably the most relevant to a business. It does not try to be a panacea or to over-simplify the 'steps to excellence' as, e.g. Ralston and Church (1991) with their ten steps to a Greener office. All these texts are very short on practical green policies. Although all have sections on legislation and its potential effect on businesses, this is usually based on UK and EC directives on pollution emissions. These are less and less relevant as the UK industrial sector becomes increasingly retail and service based. Davis J. (1991), in Greening Business, goes one step further by only discussing legislation on a theoretical level, with few concrete facts beyond how legislation will be an important variable. Environmental law is one of the most rapidly changing legal areas of the present day (Ball and Bell, 1991; Hughes, 1991; Garbutt, 1992; Journal of Environmental Law) but is not dealt with in Greening Business in any depth. Greening Business, perhaps the most Ecocentric 'guide' of them all, is certainly a text for the firmly committed. Similar to Elkington's The Green Capitalists 
(1989) it is more interested in the need for a change in values within business and the need for businesses to realise the "New Rules" (p163) of the business world.

Although a pro-active stance can be relevant, Davis preaches a little too much, alienating his readers. What Davis does manage well, however, is to offer suggestions for product formulation and diversification. These are not exhaustive, but offer positive catalyst ideas, suggesting businesses in ironing and creches at places of work to name but two examples. His section on the psychology of business and his analysis of Maslow's Hierarchies of Human Needs model, is also particularly perceptive.

In the same year a more user friendly guide was published by Elkington in collaboration with Knight and Hailes (1991). As its sub title suggests, "How to take up - and profit from - The Environmental Challenge" stresses the potential for profit that could be created from a sound environmental policy. Knight and Hailes (1991) set out what they feel are the most important issues for business, in a very accessible format. The key issues emphasised are: Legislation; Investments; Marketing; R\&D; The Workplace; Personnel and Corporate strategy. Offering summaries, case studies for examples, check points and most importantly, useful addresses, it provided the type of information required by the business community. It is, however far from conclusive in its subject matter (especially with its lack of small firm analysis) but provided a useful starting point for businesses interested in the area of environmental business strategy.

The appearance towards the end of the 1980s of these 'greening' business texts, marked an important watershed in environmental literature, creating what one could call, strategic environmental management literature for business. Environmental Management Systems (EMS) have been around for years, in one form or another. Pollution control, for example, has been an area of public corcern since the industrial revolution, leading to the 
Clean Air Acts of 1956 and 1968, and the Control of Pollution Act in 1974. Much of the work done in the 1970s and early 1980s was either UN commissioned or produced by organisations like the International Chamber of Commerce (ICC). The Business of Environmental Management (1986) or the British Institute of Management (BIM) Managing the Environment. With a few exceptions, (the BIM report for one) this kind of literature was concerned with managing the environment on a global scale, with industry as but one variable. The individual business manager requires more focused information.

Indeed, much literature on the environment has direct relevance to business, but only deeply committed business people have the time to read it . For the majority, the issue of the environment is only one more external factor to be taken into account when planning business strategy. In marketing terms it is a PEST(E) (ie. an external strategic issue).

It is this approach to the environment issue that has been seen as the root cause of the problem. As the next piece of work suggests, the answer lies in pro-active value change. Adams, Hamil and Carruthers (1991) highlight the various unscrupulous environmental companies in the U.K. The authors have subsequently established their own magazine, The New Consumer. It is in fact this type of literature that alienates business further from the environmental debate as it becomes more and more of a 'pest'. This is of course exactly what it is designed to do: namely to replace the inadequate legislation by raising public awareness and so forcing changes in company policy. There is evidence to show this kind of literature and campaigns like the Friends of the Earth 'Green Con Award' have had an effect on companies like ICI, who have radically revised their U.K. environmental policy well ahead of current legislative requirements.

With the establishment of The Department of the Environment (DoE) the U.K. Government showed the first signs of serious interest in British environmental heritage. 
Mrs Thatcher's Royal Society speech in 1989 raised the profile of the DoE which became the lynch pin of the 1990 Environmental White Paper, This Common Inheritance.

However, by far the most important service the DTI and DoE provide is as information and contact diffusion agencies. For example the DTI produces Environmental Contacts A Guide For Business, quarterly, produced in conjunction with the DoE. However, because of the nature of the Conservative government's philosophies on private enterprise, the majority of publications simply provide information contacts and broad philosophical sermons like:

\author{
Pressure for environmental improvement is now \\ a strategic issue for business, whether it comes \\ from rising consumer demand for environmentally \\ improved goods and services, tighter \\ environmental regulation, or both. It demands \\ a positive, properly planned business response \\ aimed at meeting requirements while maintaining \\ competitiveness.
}

(DTI, 1991, p19).

These are very good to arouse interest in business but not very practical in advice. The Enterprise Initiative established by the DTI provided the above quotation plus numerous consultancy agencies and contact addresses. The Conservative government of the 1980s and early 1990s clearly felt the private sector was in the best position to deal with these issues. This general policy also boosted the argument that there was and still is, money to be made from the environmental sector. How much the Government should employ the 
'carrot-stick' philosophy to businesses through legislation and subsidies for BATNEEC for example, is another issue. BATNEEC stands for Best Available Technology Not Entailing Excessive Costs and is part of the Governments Integrated Pollution Control. Although we have not seen much evidence of practical support for BATNEEC in the U.K. so far and even the pro-environmental literature coming from government sources has been more re-active than pro-active in its advice to U.K. businesses (Gray R. 1990). Governmental literature has presented general platitudes and slogans suggesting that the environment means business. In practice, however, environmental business incentives have been few.

'The Environment Means Business' is, in fact, the Confederation of British Industries (CBI) environmental slogan under which it has provided newsletters and contacts for businesses on environmental issues. The CBI has also been heavily involved in promoting NAGEL (National Advisory Group on Eco-Labeling) an organisation which has been working on the EC Eco-Label launched in the Autumn of 1992. The scheme covers a limited range of products and operates on a voluntary basis.

More practical advice and suggestions have come from vested interest organisations. For example, the Environmental Data Services company (ENDS, 1992) Business in the Environment (Bie) is part of Business in the Community (Bic), an organisation run by businesses for business. Bie produced a D-I-Y Review for companies in 1991 called Your Business and the Environment. This was intended to provide the basis for a company to review its environmental position, with sections on all the environmental issues that may be of importance to companies. Although predictably generalised it is practical in approach and highlights the following "Key Issues"; 
1. Atmospheric emissions

2. Water use and discharge

3. Solid waste

4. Energy

5. The natural environment

6. Corporate and market pressures

7. Human health

8. Accidents and emergencies

(see Table 3.1; Bie 1991 p Annex v).

The text details the detrimental effects on the environment and on human health of specific business practices, and presents a range of alternative strategies. This guide is probably the most user friendly piece of literature reviewed here. It is not so much an environmental management strategy or system as an educational guide, discussing possible areas of concern and once again providing further information addresses. Perhaps its most useful sections are the legislative sections, although in such a dynamic field these tend to become rapidly antiquated. 


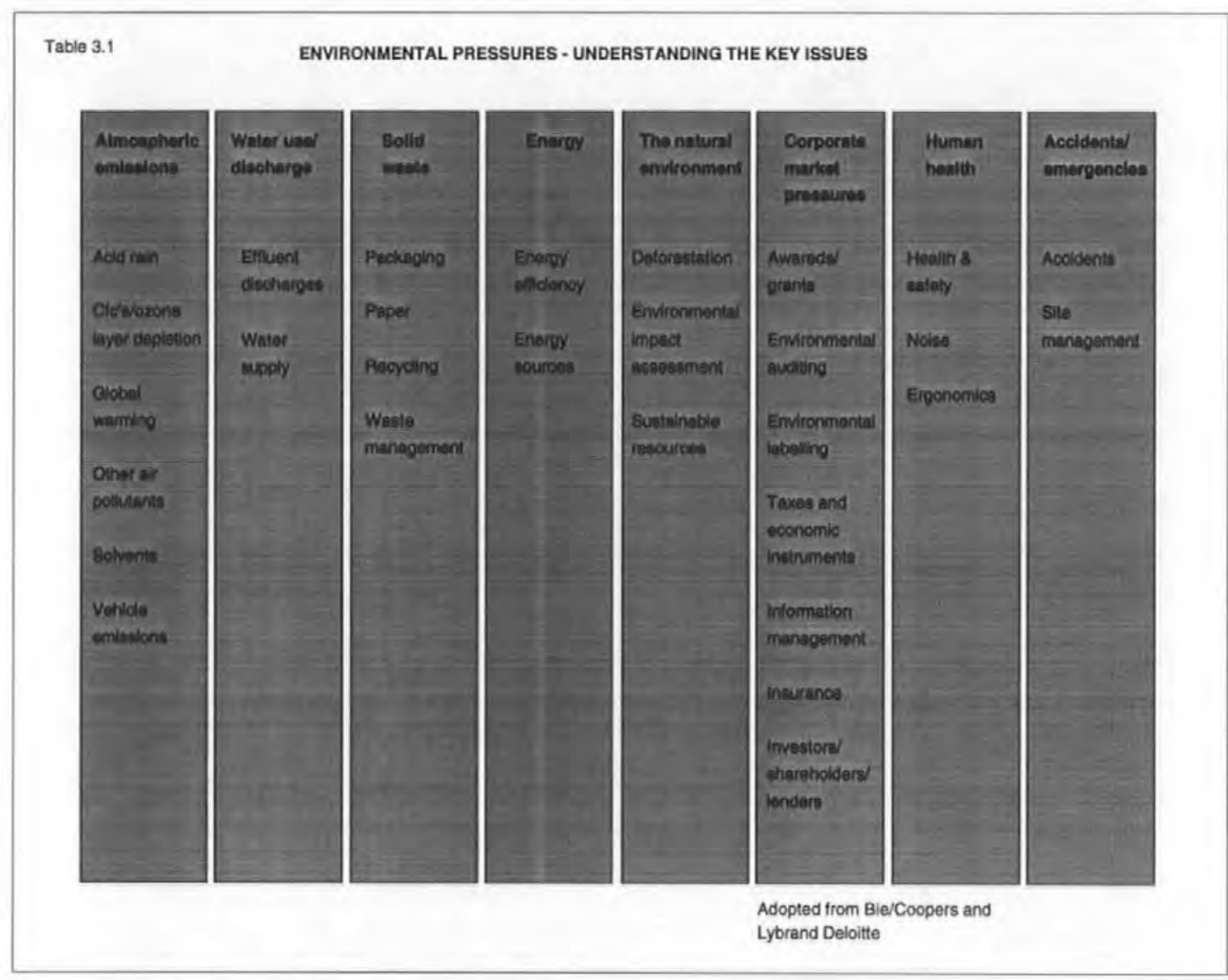

With relation to the environmental auditing process, Hastam (1991) produced a relatively detailed guide filling the gap in the literature noted by Hemming (1992).

The environmental audit can be defined as:

The evaluation of a site, plant, or production and processing system in relation to the laws regulations, policies and good practices that directly or indirectly affect the environment (Ed. Cockburn, 1990, p52). 
Hastam (1991), (see Table 3.2), gave four main reasons why companies should undertake an environmental audit: they are legal; economic; professional and ethical. Hastam also pointed out that the control of risk is an aim of all well managed organisations. Risks must be identified before they can be controlled and monitored. The Hastam guide is similar in aim to the Bie guide, although it surpasses it easily in content. A 'useful addresses' might have been useful, however.

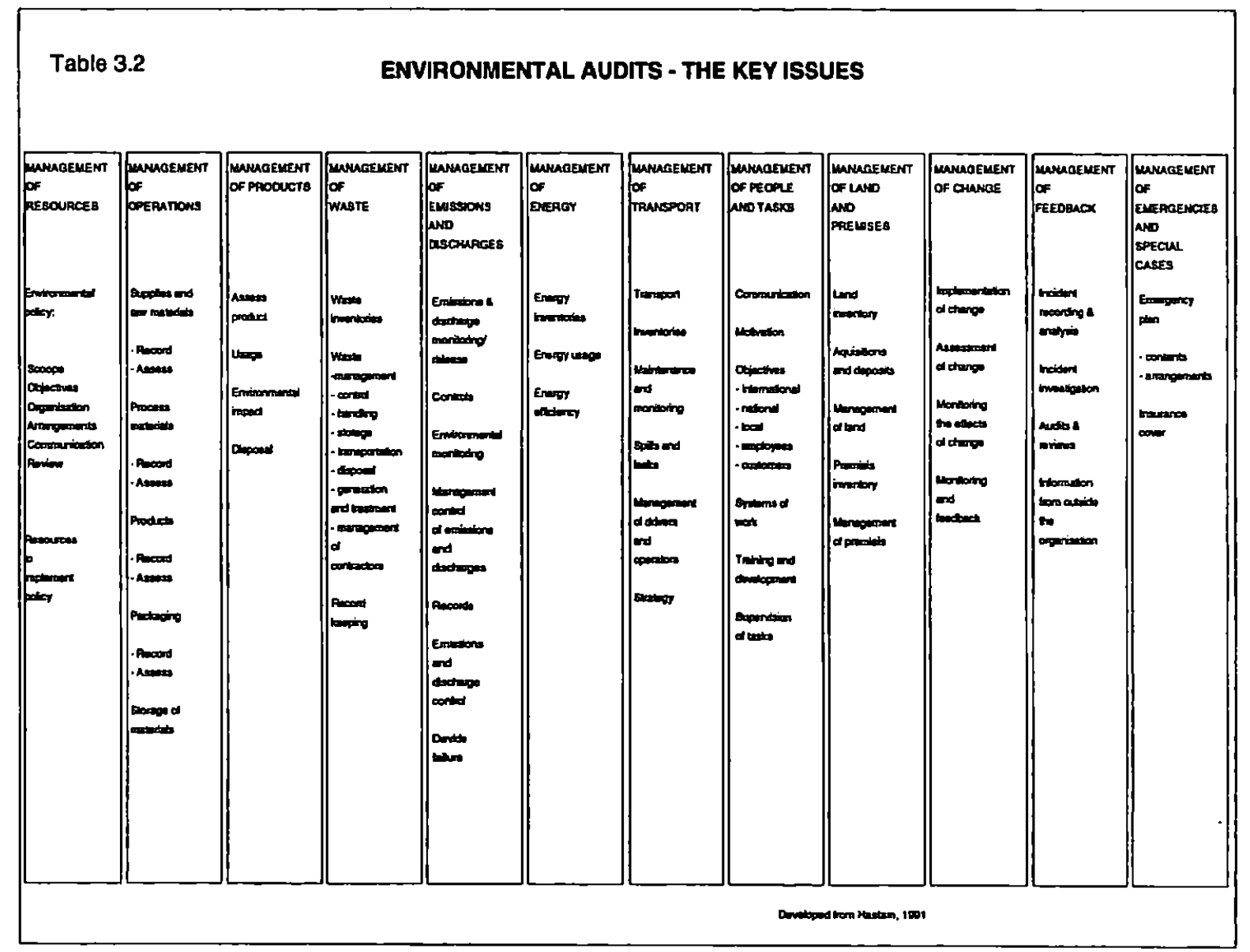

Unlike Cockburn (1990) whose audit is very much operational, Hastam (1991) considers both strategic and operational issues under the umbrella of the environmental audit and not management systems. There has always been specialised literature available on the intricacies of specific environmental issues, pollution abatement, and energy conservation 
and other environmental issues. Hence an all encompassing book on environmental business would be an impractical proposition.

\title{
3.2 Strategic Management
}

Since the late 1980 s work on strategic environmental management has increased considerably. One definition of business strategy (as opposed to environmental strategy) is:

\author{
A stream of decisions that a) guides the \\ organisations ongoing alignment with its \\ environment and b) shapes internal policies \\ and procedures.
}

(Fannin and Rodrigues, 1986)

Before considering the concept and development of pro-active strategy formulation in the literature it is necessary to put strategic management into context. There are numerous definitions of management (Kast and Rosenzweig, 1974). The following definition; however, seems to encapsulate most of the criteria: namely management is; "the process of planning, organising, directing and controlling the activities of employees in combination with other organisational resources to accomplish stated organisational goals" (Steers, Ungson and Mowday, 1985).

Thurley and Wirdenius (1989), identify two basic paradigms of management theory: first the crucial objectives, techniques, systems and framework theories; second the more prescriptive approach to management solutions. They go on to further subdivide these two paradigms into five main areas of management theory (see Table 3.3). 
Table 3.3

Types of Management Theory

\begin{tabular}{|c|c|c|c|}
\hline TYPE & $\begin{array}{l}\text { ISSUES } \\
\text { DISCUSSED }\end{array}$ & EXAMPLES & COMMENT \\
\hline $\begin{array}{l}\text { A) Individual } \\
\text { manager behavior } \\
\text { (How to behave as } \\
\text { a manager) }\end{array}$ & $\begin{array}{l}\text { 1. Great men } \\
\text { biographies } \\
\text { 2. Empirical role } \\
\text { studies } \\
\text { 3. Behavioral science } \\
\text { prescriptions }\end{array}$ & $\begin{array}{l}\text { Sloan, lacocca } \\
\text { Carlson, Stweart \& Styles } \\
\text { Mintzberg, Marples } \\
\text { McGregor, Blanchard } \\
\text { Herzberg }\end{array}$ & $\begin{array}{l}\text { Role models } \\
\text { as prescriptions } \\
\text { Analysis of complexity } \\
\text { of roles played } \\
\text { Organisational peopie } \\
\text { theories }\end{array}$ \\
\hline $\begin{array}{l}\text { B) Manager } \\
\text { subordinate } \\
\text { relations } \\
\text { (How to lead and } \\
\text { integrate peopta } \\
\text { in systems) }\end{array}$ & $\begin{array}{l}\text { 4. Leadershlp } \\
\text { - traits } \\
\text { - philosophies } \\
\text { - styles } \\
\text { - power } \\
\text { - behaviour } \\
\text { - work tasks }\end{array}$ & $\begin{array}{l}\text { Bingham, McGregor } \\
\text { Blake, Bakke, Macoby } \\
\text { Likert, Dalton } \\
\text { Certwright, Whyte } \\
\text { Sayles, Cartson } \\
\text { Thurtey-Wirdenius } \\
\text { Fiedler-Yelton }\end{array}$ & $\begin{array}{l}\text { Covers different } \\
\text { aspects of } \\
\text { leadership } \\
\text { and integration }\end{array}$ \\
\hline $\begin{array}{l}\text { C) Organisattonal } \\
\text { Systems Design } \\
\text { (Factors in } \\
\text { planning system) }\end{array}$ & $\begin{array}{l}\text { 5. Functions } \\
\text { 6. National culture } \\
\text { 7. Environmental } \\
\text { uncertanty }\end{array}$ & $\begin{array}{l}\text { Fayol, Drucker } \\
\text { England, Hotstede } \\
\text { Bums-Stalker } \\
\text { Woodward } \\
\text { Lawrence-Lorsch }\end{array}$ & $\begin{array}{l}\text { Factors which make } \\
\text { management } \\
\text { different in } \\
\text { different } \\
\text { organisations }\end{array}$ \\
\hline $\begin{array}{l}\text { D) Management } \\
\text { process } \\
\text { (what management } \\
\text { has to do) }\end{array}$ & $\begin{array}{l}\text { 8. Decision making } \\
\text { - Retional } \\
\text { - Satisficing } \\
\text { 9. Techniques }\end{array}$ & $\begin{array}{l}\text { Schumpter, Mintzberg } \\
\text { Simon } \\
\text { Cyert-March } \\
\text { Drucker } \\
\text { Kepner-Tregoe }\end{array}$ & $\begin{array}{l}\text { Activities and } \\
\text { processes } \\
\text { required }\end{array}$ \\
\hline $\begin{array}{l}\text { E) Planning for } \\
\text { Change } \\
\text { (How managers } \\
\text { should plan and } \\
\text { organise change } \\
\text { programmes) }\end{array}$ & $\begin{array}{l}\text { 10. Strategic } \\
\text { management } \\
\text { 11. Organisational } \\
\text { culture } \\
\text { development } \\
\text { 12. Change } \\
\text { management }\end{array}$ & $\begin{array}{l}\text { Ansoff, Porter } \\
\text { Schein, Bennls } \\
\text { Tichy, Beckard } \\
\text { Argyris, Thackway }\end{array}$ & $\begin{array}{l}\text { Critical aspects to } \\
\text { watch in } \\
\text { change situations }\end{array}$ \\
\hline
\end{tabular}

Adopted with changes from Thurley and Wirdenius 
The first two subsections, 'Individual manager behaviour' and 'Manager subordinate relations' relate to early prescriptive internal and behavioural theories. Section $\mathrm{C}$ relates to Organisational Systems design literature which is cross tabular in analysis and more concerned with the external business environment than Sections A and B. Section D relates to Management Process which could be seen as operational management, and the nucleus for Environmental Management concern. These are the day to day activities and processes required to run a business. The concept of the Environmental Management System (EMS) (see Rickmann 1992) would fit between this section and Thurley and Wirdenius' final section E, Planning for Change. This effectively relates to strategic management and could well be the area of management theory most relevant to the greening of U.K. business. For these reasons Sections D and E are most relevant to this review as they encompass most of the relevant literature for this work.

Strategic management divides the environment in which businesses operate into two, the external and internal environments (Porter 1985). For this reason it is suggested that the formulation of a strategy is:

\section{Concerned with matching the capabilities}

of an organisation with its environment

(Johnson and Scholes, 1989)

There are numerous other definitions of strategic management, (Mintzberg, 1973; David, 1989; Higgins, 1991) which highlight stages of strategic management development from strategy formulation through implementation and evaluation. All have the common principle of pro-active response, stressing the need for an effective strategic plan to 
develop successful operational management while releasing any latent potential for growth.

There are five fundamental stages of strategy development a company must go through to be engaged in strategic management (Jauch and Glueck, 1988) it must develop a Mission Statement: set its objectives; undertake an external environmental analysis; undertake an internal environmental analysis; and implement a relevant strategic programme suitable to the company. This process should then be revised and fed back to constantly update procedures. Not only is the written commitment essential but this statement of values must be diffused effectively to the workforce.

The concept of the Mission Statement is fundamental to the EMS models created so far, (see BS 7750, Figure 3.1). The BS 7750 is principally strategic in nature, and has been heralded as the panacea for businesses environmental concerns (see Appendix 4). A written commitment to the environment is absolutely central to the success of the process (Welford, 1992). The standard has a dual function, first to provide assurance for the company of appropriate control measures to achieve its defined environmental standards and to provide a mechanism to publicly demonstrate this compliance. The standard follows a positive feedback loop control system. Development of an environmental policy is based on a thorough environmental emissions and impact review of the companies operations allowing objectives to be set. A cycle of monitoring audits and reviews then allows performance to be checked and policy to be continually reassessed (BS 7750, HMSO, 1992). Prepared under the direction of the Environment and Pollution Standards Committee in response to increasing environmental concems and piloted in 1992, BS 7750 has now become established (alongside the EU Environmental Management and Auditing scheme, EMAS) as an accepted measure of environmental quality (Pearce H. 1993). 


\section{Figure 3.1 ENVIRONMENTAL MANAGEMENT SYSTEM BS 7750}

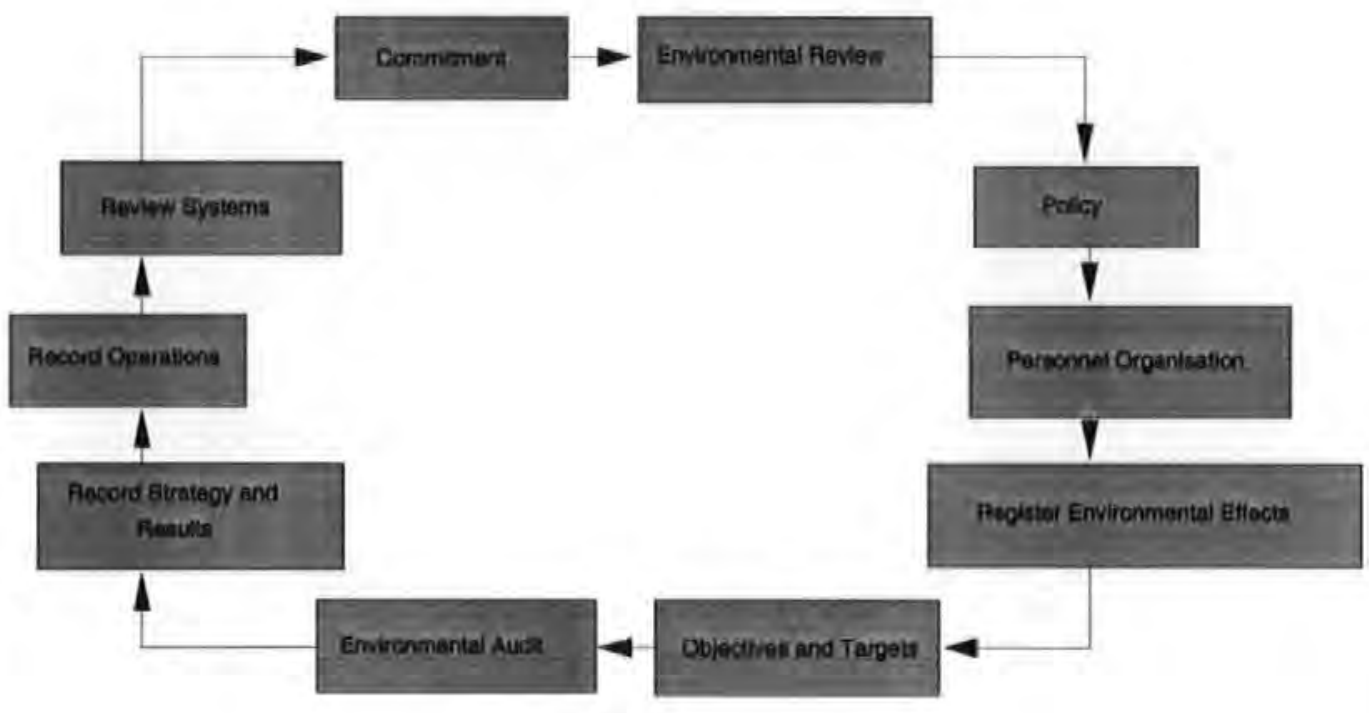

BS 7750 includes a processes of reviewing and auditing two procedures that are inherent but separate parts of the system. "Audits assess both the effectiveness of the environmental management system and the achievement of the environmental objectives. Reviews check the continuing relevance of the environmental policy, update the evaluation of environmental effects and check the efficacy of audits and follow up actions" (HMSO, 1992). The BS 7750 was designed to compliment the quality standard BS 5750 (and the international standard, ISO 9000) with which it shares common management system principles. 
BS 7750 considers the internal environment in the main, the external business environment however is considered by a number of authors, Bourgeois, et al (1980); Jauch and Glueck, (1988); Johnson and Scholes (1989). Porter $(1980,1985)$ considers the following factors as the four original external factors:

\section{Political \\ 2. Economic \\ 3. Social \\ 4. Technical}

'Ecological' has recently been added to this list (Johnson and Scholes, 1989) creating the acronym STEEP. This is a significant addition as it shows that even traditional management theory feels that the green 'threat' merits serious attention. Johnson and Scholes (1989); Jauch and Glueck (1988) and Bedeian (1990), consider the analysis of the business environment. Johnson and Scholes (1989), suggest a five stage process model to understand a firm's strategic position as a business. This includes: the auditing of environmental influences; an assessment of the nature of the environment; identification of key environmental forces through structural analysis; identification of competitive position and the identification of key opportunities and threats. The fourth stage of this model is explained by Porter $(1980,1985)$. Porter considers in detail the concept of competitive rivalry within industrial sectors. Porter's Five Forces suggests that the threat of new entrants, the threat of substitutes, supplier bargaining power and buyer bargaining power all create competitive rivalry. It has been suggested on a number of occasions in the past by prominent figureheads of environmental causes, (Prince Charles for the Bie, 1990; Rt Hon. Michael Heseltine, DTI 1990 as well as academics like Hunt and Auster 1990 et al) that becoming more environmentally friendly as a business 
will increase competitive advantage. It is for this reason a firm must consider where the environment fits in to the business environment.

However, Nielson (1988) argues that firms can be more efficient by adopting a sustained co-operative strategy between organisations rather than relying on the external market mechanism for efficiency. Dundas and Richardson et al (1980) proved internal coordination and co-operative strategies within can be more efficient than the more traditional competitive management practices. Nielson (1988) cites the Japanese as examples of a successful trading nation that is developing national co-operation strategies for its small business sector to allow them to become internationally competitive.

This view is supported by Jarillo (1988) amongst others and has lead to the development of the co-operation critique of the competitive advantage paradigm. This has been enhanced by work on network developments that require a form of co-operation to take place (Jarillo and Ricart, 1987; Jarillo, 1988; Hakansson and Johanson, 1988). Johannisson in particular has made the case for localised development in the form of cooperative networking (Johannisson, 1983). He has argued for the requirement of a strong local community and a well structured business climate. This would include a local authority that is supportive to local needs in its distribution of resources. Although this particular point may be more relevant to northern European countries than the U.K. at present, the concept of regional self-reliance is undoubtedly theoretically ubiquitous.

This approach is supported by a Danish model for SME co-operative networking. Networking is defined loosely as having four linear dimensions:

1. Joint solutions and common problems 
2. Development and exploitation of mutually complementary strengths

3. Developing the quality of subcontracting links

4. Individual access to end markets.

(Jakobsen and Mertinussen, 1991)

Here they suggest that the regional co-operative networking model established in 1989 has had encouraging results. In particular they suggest that the model has increased the competitiveness of a significant number of SMEs. The reasons given in this case (and in a number of other cases) is that co-operation reduces the transaction costs in the traditional contractual relationships.

Although trust is an important aspect of the networking principle it is suggested that this does not necessarily mean that the network will collapse. Jarillo (1988) says that if long term relationships are established trust develops. This would seem to be rather obvious and the question remains limited to the short-term time period. His suggestion is that one can try to modify the game through a number of variables which include, co-operation, reward, opportunistic gain and punishment. However there would seem to be a place for collective, co-operative SMEs in this system. Indeed, they could as a short term measure be based on traditional concepts of competitive advantage through co-operative networking (Jarillo, 1988).

Johannisson suggests that the challenge for the SME sector is to create a climate that simultaneously supports individualism and collectivism, anarchy and order. He sees the necessity to move from functional specialisation to an area of specialisation where SMEs co-operate to survive. This point is strengthened by empirical research from Sweden that suggests that many local communities do not either want or need to grow. Therefore the criterion applied to business theory is quite different from that in larger urban areas 
(Johannisson, 1978, 1983). With Galtung et al (1980) arguing that the 'arena perspective' where SMEs co-operate for mutual benefit, generates self-reliance, self-respect and a prosperous local economy not reliant on one or two large industries, evidence suggests that SMEs have a central role to play in North European community development. Johannisson in particular sees collective networking as a central aspect of developmental economics and the role of the SME as pivotal to this theory (Johannisson, 1983).

Linking this work with earlier work from Jarillo (1988) one could therefore suggest that what is required is a revision of 'the game' in the form of a new approach to socioeconomic decision making to enable SMEs to trade locally in co-operative formats that include certain aspects of networking.

Porter (1985) considered the internal environment. His 'Value Chain' considers the role a company's resources play within this environment. This includes human resources as well as inputs. The model links human resource use to the support activities required to lubricate the corporate machine, for example to computers and building infrastructure. The central idea of the model is to allow a measurement of the margin of profitability. Will the added value of the outputs exceed that of the inputs? McKinsey 7's in Peters and Waterman (1982), compliments Porter's work. The emphasis of the Value Chain is on the component parts of the business as a single entity. The human resource element is seen as a catalyst for activity to make the Value Chain work. McKinsey's 7's framework looks more closely at this particular element. People within the organisation, for example, relate to the skills required, systems in place and style expected.

Smith (1992) adapted the Value Chain to explain the primary and support activities required to become a more environmentally friendly company (Table 3.4). This framework leads Smith to comment that too many businesses are concentrating on the 
marketing and service elements of the Value Chain, rather than on the more integral fundamental activities. He suggests that the changes that are occurring within industry are cosmetic rather than operational in nature. This belief is strongly supported by the bioregional movement considered later in this chapter.

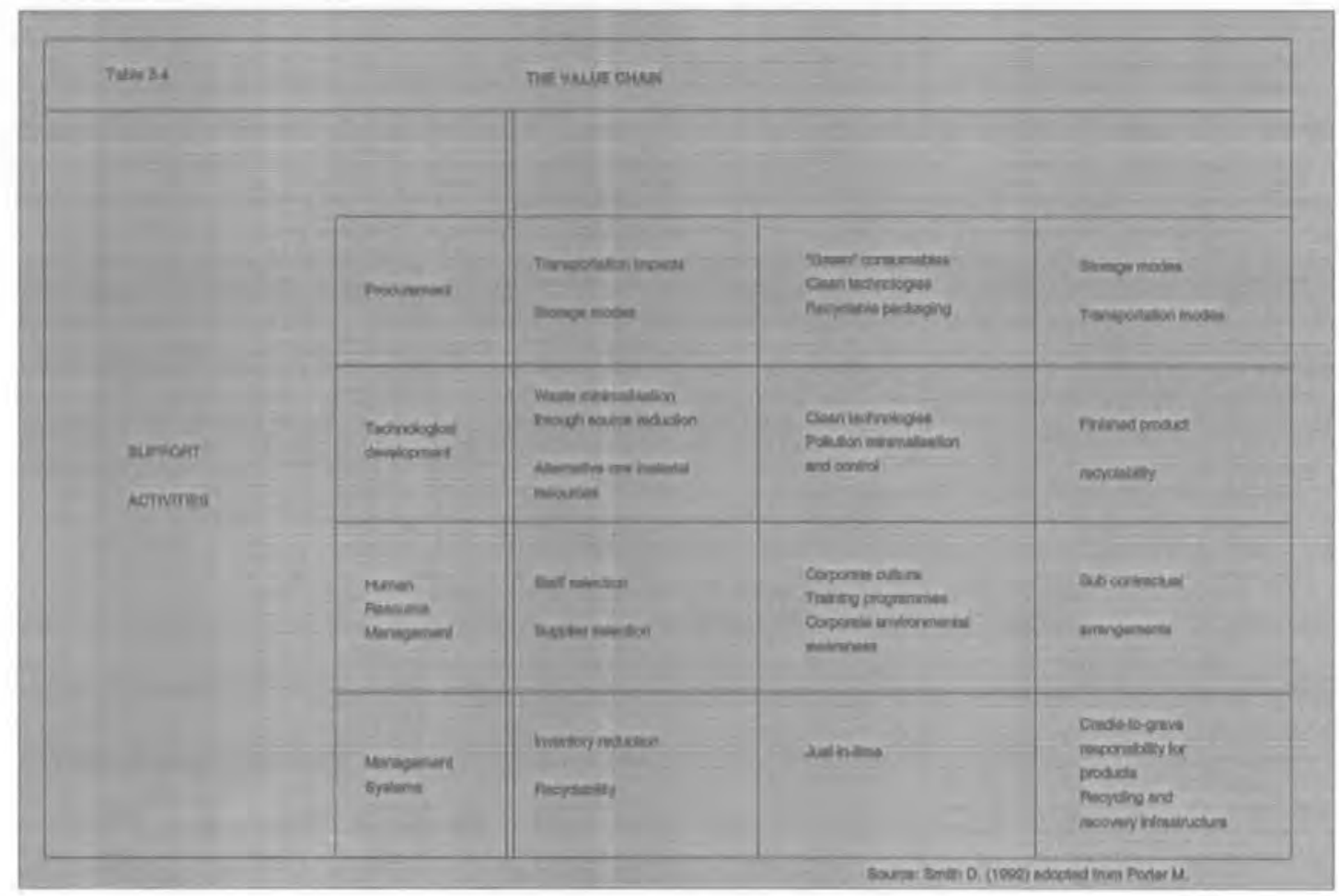

The criticism from Smith and the more radical bioregionalists (Bookchin, 1980; Kelly, 1984; Sale, 1985; Morehouse (ed), 1989) is that business is not best placed to regulate change as it will always put self-interest first and the environment second. The need is therefore for either more stringent legislation or a new system. The later option is favoured by the bioregional movement.

Meredith (1992) makes the environmental strategic link by suggesting that strategic management is essentially a balancing of these internal and external factors. The reference here is to the SWOT and PESTE (STEEP) analyses. SWOT relates to a 
company's internal business environment and stands for Strengths, Weaknesses, Opportunities and Threats. Meredith also suggests that social responsibilities and the environment have now come in high on a managers external agenda, although this is not supported by any empirical analysis. Shrivastava (1992) goes even further, arguing that there has to be a fundamental change in the definition of the business environment from its preoccupation with competition, ie. barriers to entry, economic power of buyers and suppliers and the economic exploitation of the resource base to gain competitive advantage, to a more ecological approach (in Smith, 1992). An alternative approach could be the more co-operation based approach touched on by Nielson (1988).

Table 3.5 - Opportunities and Threats of Environmental Management

\begin{tabular}{|l|l|}
\hline \multicolumn{1}{|c|}{ THREAT } & \multicolumn{1}{c|}{ OPPORTUNITY } \\
\hline Potential cost of a reactive approach & Potential benefits of a pro-active approach \\
\hline 1. Decreased market share & 1. Increased market share \\
\hline 2. Fall in corporate standing & 2. Climb into corporate standing \\
\hline 3. Increase in cost of manufacture & 3. Decrease in manufacturing costs \\
\hline 4. Increasing material costs & 4. Reduction in material costs \\
\hline 5. Increasing energy costs & 5. Reduction in energy costs \\
\hline 6. High level of pollution taxes & 6. Minimisation of pollution taxes \\
\hline 7. Large increase in disposal costs & 7. Decrease in disposal costs \\
\hline & 8. Opportunities for diversification and \\
& technology supplier, recycling and waste \\
\hline & $\begin{array}{l}\text { 9. Increased world competitiveness, } \\
\text { competitive advantage. }\end{array}$ \\
\hline
\end{tabular}

(Gacpar 1993) 
This also allows for more effective diffusion of information including environmental procedures, a central problem to many businesses interested in improving their environmental performance. Shrivastava (1992) goes further, saying that this is the only way to fully integrate Green issues into the strategic management process.

However, as mentioned above, the conclusions reached from the analysis of the external and internal environments are then focused by the S.W.O.T analysis Kotler (1984). Table 3.5 provides an example of how this concept can be expanded to encompass the management of environmental issues. Gacpar (1993) details the growing costs of a reactive approach to environmental management in contrast to the benefits of a pro-active approach.

From the S.W.O.T. analysis assumptions are made, strategic choices developed, objectives set and a strategy formulated. The strategy can then be implemented and with most management models, the results being fed back and revised over time. An example of a strategic policy suggested above is Ansoff's Options Matrix. This allows a company the flexibility to consider new markets, products and acquisitions. Essentially they are diversification strategies rather than retrenchment strategies (Ansoff, 1965).

The idea of focused strategies was developed by Porter $(1980,1985)$, with the evolution of his 3 Generic Strategies, which are:

1. Cost

2. Differentiation

3. Focus 
Cost leadership relates to a strategy of maintaining a low cost structure. Differentiation relates to a strategy of making a product stand out. Focus relates to operating in a subsector of the market, utilising either cost leadership or differentiation.

\subsection{Strategic Management in the SME Sector}

BS 7750, (see Figure 3.1), requires commitment to the environment as well as effective diffusive flows of the knowledge of this commitment within the business to the workforce. In this respect one could assume that the SME will be able to do this more effectively than its larger counterpart because of the autonomy of authority, minimal hierarchical layers of management and short communication channels. Indeed, SMEs can achieve success and compete with larger firms as their thin organisational structures allow a higher level of flexibility. Also endemic in their nature are the lower cost structures which can enable them to exploit the narrow niche markets that are uneconomic to larger companies.

Literature on the SME and environmental management or sustainable development has; however, been limited (Barrow and Burnett, 1990; ACBE 1992, 1993a, 1993b; Hendry, 1992; Leicestershire TEC, 1993; Patton et al 1994). The SME has not moved quickly to embrace the concept of environmental management, suggesting that there is a fault somewhere within the diffusive pathways between theory and practice. Research into attitudes and practices may reveal the reasons for the occurrence of this unexpected fault.

Employment of a certain level of strategic management in companies certainly allows for more efficient managing of the company, but the level of strategic management in SMEs is low, according to Sexton and Auken, (1982); Gibb (1983); Birley and Gibb, (1984); Mescon, (1984); Gibb and Davis (1990); Faulkner et al (1986) and Perry (1986). Indeed 
most of the writers from 1961-1982 summarised by Robinson et al (1984) are negative in their descriptions of the SME as far as strategic planning is concerned. They have focused heavily on the unstructured, irregular and incomprehensive nature of SME strategic management (Brytting, 1990). Buack and Mathys comment, however, that strategic planning can be improved in SMEs as a result of environmental considerations (Buack and Mathys, 1989). A section of the literature, however, does consider strategic management both appropriate to SMEs and conducive to small business growth (Wheelwright, 1971; Cooper A. 1979; Van Hoorn, 1979; Kotter, 1982; Churchill and Lewis, 1983; Graham, 1991).

Robinson's summary suggests, however, that most SMEs do not have strategic plans, and when they do occur they are fragmented and short term. However, Storey et al, (1987) point out that SMEs are fundamentally different from large companies, therefore comparison of performance and level of strategic planning cannot be verified. Dilts and Prough, (1989) agree with this analysis and concluded that smaller firms are not simply. smaller versions of large organisations.

Indeed Dilts and Prough as well as Rice (1983) go further, suggesting that many SMEs do in fact have strategic management plans but that they differ in nature to the prescriptively accepted large firm models. Their research highlights the strategic options available to different sizes of organisation. For example, a co-operation strategy may well be a more efficient strategy for a smaller business than a more competitive one. This is confirmed by Nielson (1988). Not only would a co-operative strategy reduce costs but it would also allow for easier diffusion of environmental information through the support organisations. The concepts of management development and management for change, however, are central to the business environment debate. The environment is, in strategic 
management terms, a Threat and an Opportunity to a firm and therefore needs to be taken account of and planned for.

One can conclude that although there is some disagreement about the levels of strategic management within the SME sector, the descriptive analyses of the characteristics of SMEs are fairly accepted. In general SMEs have limited market share and lack resources to do much about it (Sutton, 1984). However they succeed by following niche market strategies and by concentrating on their strength of being flexible (Macpherson, 1992). SMEs also concentrate on tasks rather than pro-active scientific planning. They could gain from educational training (Birley and Gibb, 1984) and Management Development, (Beckhard, 1985; Houghton, 1986; Alexander, 1987; Mumford, 1987; Wagel, 1987; Storey, 1989). This may be the area that management theory should be addressing in terms of the SME and EMS. If their strengths are in operational task management, education on critical incidence situation management could be more effective than strategic management implementation advice.

The characteristics of the SME have been considered in great depth in the literature, from the internal operations and strategies employed to the characteristics of the entrepreneur. However, most of the work has revolved around the latter as analysis seems to be seen as easier to collate (Perry 1986). In fact, as Dilts and Prough (1989) point out, most research has traditionally been focused on large firms anyway and small firm research has traditionally been neglected and fragmented. Ramstrom $(1975,1986)$, similarly suggests that small firm research is as fragmented as small firm theory. However, one area of relative expansive literature is that of Growth Models for SMEs. D'Amboise and Muldowney (1988), have a relatively well summarised table of the development of these models and their respective authors from 1972-1984. The most significant area of this 
work for this particular study is the heavy concentration on co-operation as an integral variable in the growth model.

Most of the literature on the development of the SME stresses the requirement for increased diffusion of information and technology (Sutton, 1984; Nielson, 1988). Cooperation generally leads to increased efficiency in a wide number of operational areas and Bamberger (1989) further suggests that the strategic decisions made by the firm are determined by the flow of information from the environment and the internal capacity of the company. Because of the lack of capital, resources and time an SME has at its disposal, the only way to keep up with these information flows is through some sort of co-operation. This explains why there are so many different sorts of small business support organisations (see Figure 3.2). The problem seems to be one of co-ordination and information diffusion since small businesses often do not realise help and advice is available. This is especially relevant in the environmental area, where co-operation can reduce the individual costs of operational implementation.

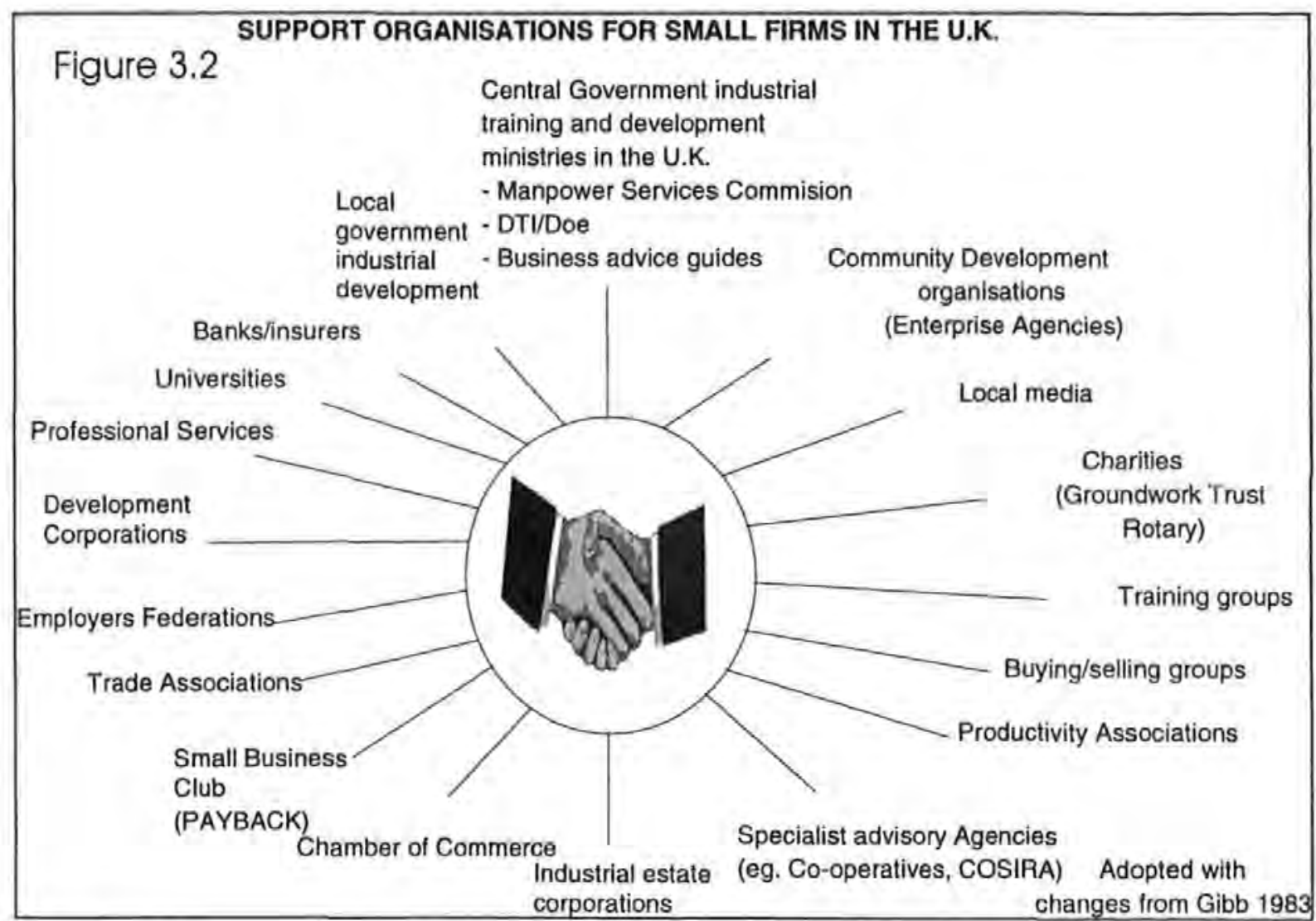


Indeed, many writers have already highlighted the fact that healthy co-operative systems are unlikely to develop without well established secondary support organisations (Vanck, 1970, 1975; Campbell, 1977; Horvat, 1980, 1982). Just as with the theories and models of small business research, the organisational structures available to support them are also fragmented and lacking in resources (Bennett and McCoshan, 1993). There may therefore be a definite requirement for the focusing and agglomeration of these organisations to clarify small business advice. This is the thinking behind the latest Government development of the One Stop Advice Shop Business Centres that were established in the spring of 1993. However with little increased funding because of the Governments belief in the lack of intervention in both private and public sectors, one cannot see them being any more successful than the Manpower Commission which they superseded.

Much of the work in the SME sector has focused on the personal characteristics of the entrepreneur (Perry, 1986). Bamberger (1983) looks in particular at the values of the entrepreneur and how they affect the decision making process and management process. This area has not received much attention in the literature because of the complexity of the research. Its importance is, however, significant particularly within the field of business and the environment.

Clearly management development, information diffusion, values and strategy formulation are linked. An entrepreneur begins trading with a set of values from his/her past: these values could lead directly to the development of a business strategy or be influenced on the way by some sort of information flow which will in turn affect the entrepreneur's strategy. Therefore, if a concept like environmental protection requires a change in an entrepreneur's values to become effective (this presupposes that individual regulation is the most effective catalyst for change) then relevant authorities need to increase the flows 
of information regarding various aspects of the environment and increase their effectiveness. Large amounts of information flowing in the wrong direction swiftly become redundant and ineffective.

One can now clearly see the scale of the problem for the SME sector in adopting an environmental management policy. The existing solutions proposed by the EC and British Standards require a high level of strategic planning to take place yet according to Collins (1990), most small businesses do not formulate plans and strategies. Hence according to Cranfield School of Management, only 10\% carry out environmental audits and these are only for energy and waste (Barrow and Burnett, 1990).

Many factors militate against the small firm: time: manpower; investment capital; information shortages and lack of strategic plans. In addition, the policing bodies responsible for new legislation lack the resources to prosecute on a large scale. As Dilts and Prough et al (1989) indicate in their diagnosis, research findings are not wholly transferable from large firms to small enterprises because of the differences in company fabrics. This is central to the problem raised earlier in this section about the formulation of a Mission Statement and the relevance of Management Systems to small businesses. If the hypothesis that SMEs are not simply smaller versions of larger corporations is valid, then it follows that systems or models developed for large scale organisations may not be applicable to smaller businesses. This may explain why SMEs response to green issues has been so low. If the management solutions are not applicable company inertia is likely to be high. This area requires clarification in order to assess the relevance of existing management tools in the environmental area. 


\subsection{Environmental Management within the SME Sector}

The literature review has, thus far, studied the emergence of ecological business literature and the strategic management process. This penultimate section looks rather more closely at the solutions offered by theory to the business environment problem. In particular it considers the Environmental Management Systems literature and possible applications to the small firm. This will be followed by a final section that reviews the more holistic bioregional literature.

The U.N. Stockholm conference in 1972 could be viewed as the platform of development for strategic environmental thought. The oil crisis of the early 1970s and the need for economic growth, however, had failed to secure much commitment from industry (Meredith, 1992). Prior to this, environmental management literature was specifically technical in nature, solving particular problems usually in the scientific domain. These writings have continued since Stockholm alongside the development of source writings, ie. the tackling of the cause of environmental problems and not just the symptoms. There seems to be a consensus of opinion that "Going Green requires a commitment, and then it requires a strategy" (Carson and Moulden, 1991). The technical writings and answers to specific problems are important but they fit into the equation rather later on, after there has been commitment by the firm to adopt an environmental philosophy. Ecocentricism precedes technocentricism. Vandermerwe and Oliff (1990), agree with this but add that there needs to be a genuine adjustment of strategy. This came in response to survey results where companies saw no point in going green unless the information was communicated heavily to stakeholders and customers.

Smith (1990) writes of the opportunities in periods of rapid cultural change for farsighted businesses to jump ahead of the competition and gain real competitive advantage. 
He advocates an early internal environmental SWOT analysis for companies and the implementation of an Environmental Management System. This view is echoed by most writers of environmental business management (Hunt and Auster, 1990; Porter, 1991; Stern, 1991; Kleiner et al 1991).

However, by $1990,60 \%$ of the firms surveyed in a CBI questionnaire (1990, survey of Green Businesses) had developed some kind of environmental policy, but only $40 \%$ had instituted a management system to put this policy in place. Significantly, these results reflect the Cranfield 1991 survey where $51 \%$ of the SMEs surveyed had some sort of measures to protect the environment. This is less than the CBI survey suggested, but to be expected within the SME sector, as it is generally the smaller companies who take the reactive approach to environmental issues (Meredith 1992, p229).

There is very little written on environmental management of any kind for SMEs. However it is suggested that:

Companies taking the reactive (passive) approach are typically the smaller and medium sized organisations.

(Meredith, 1992)

This view is supported by a survey done by the Cranfield School of Management in 1990 , where $30 \%$ of the 200 SMEs surveyed thought that green issues were unimportant in their business sector and $49 \%$ took almost no measures to protect the environment. The Cranfield survey is, however, only a survey with little or no analysis or discussion, it simply describes the findings. A further caveat is the extremely low response rate of the survey (below 10\%) making the findings questionable. This is a rather surprising lack of 
literature as the combination of damage done by a large number of small businesses on the environment is very significant. According to Winter (1988), environmental damage caused by small firms is likely to exceed that of larger companies in a cumulative form.

Marketeers like Davis J.J., suggest that, "A prerequisite to the development and marketing of true Green products is an appropriate corporate plan and outlook" (Davis J.J. 1991 p15). Hunt and Auster, add: "to avoid potentially debilitating problems, corporate managers must begin to consider environmental management a critical component for sustaining competitive advantage" (Hunt and Auster, 1990, p7). All emphasise the need for commitment as a prerequisite for environmental management.

However, between Winter (1988) and the development of EMS, literature did appear on environmental affairs and business strategy. Hooper and Rocca (1991), stressed the need for "guiding principles" in strategy and the linkage of environmental affairs with operations at all organisational levels. Apart from a philosophical digression highlighting the profit side of environmentalism, they generally take the acceptance of the need for an environmental strategy, for granted. Issues such as senior management participation are reiterated. Suggestions of how to promote good internal environmental practice are offered, but most significantly Hooper and Rocca, suggest that:

\section{Product design, manufacturing, transportation, customer use and ultimate disposal of a product should not merely reflect environmental considerations, but be driven by them} (Hooper and Rocca, 1991, p30) 
Smith (1992) explains why environmental issues should be on the strategic rather than just the short term operational agenda. He says that the fears of companies that legislation will make an unlevel playing field and lose U.K. companies the critical edge of competitiveness have to be put aside. Smith makes a distinction here between "Environmental improvements and standards of living and economic prosperity" (Smith, 1992, p1). He seems to be saying companies must change their ethical stance, a view held more commonly in the philosophical environmental literature than the business strategy literature of the late 1980s-early 1990s. In The Environment means Business (CBI, 1990) the more prominent message was:

With complete disregard for conventional wisdom, a few companies have demonstrated that the conjunction of environmental affairs and operations can produce real synergies.

(Hooper and Rocca, 1991, p28)

Smith makes a link between the traditional morally driven environmental attitudes of managers to the well established strategic agenda (Johnson and Scholes, 1989 and Porter et al, 1980) therefore suggesting the need to move away from the ad hoc environmental policies of the past and to develop a regulatory framework into which environmental issues could fit. This provides a cue for the development of EMS. He points to the need for the education of managers in the importance of including environmental issues on the strategic agenda, rather than merely educating them on the potential gains of this move.

Building on these works and that of Winter in the 1980s-early 1990s, writers and theorists have developed Environmental Management Systems defined by Rickmann as: 
... a strategy which firstly involves the formulation of a policy

statement setting out the organisations philosophy on the environment and the aims to be achieved. Secondly a detailed assessment of the environmental status and performance of the operation is then undertaken, key issues identified and targets set. The performance of the operation or unit is then regularly audited to measure progress toward the target set

(Rickmann, 1992, p15).

This is by no means an exclusive definition of an EMS. Many writers see them in different terms. For example although Welford agrees "there has to be commitment at all levels of the organisation" (Welford, 1992, p27), his criteria for an EMS is quite different, including environmental policy but concentrating on environmental committees and action teams. Welford also links EMS with Total Quality Management (TQM), the phenomena of the 1980s. "For many forward looking organisations environmental responsibility has become an aspect of the search for total quality and as such zerodefects also mean zero-negative impact on the environment" (ibid, p25). It should be noted, however, that this link was broken in a subsequent publication (Welford, 1995). For discussion on the British Quality Standard 5750 see Walsh, (1993).

Roome identifies five strategic options available to the firm in the discussion of Environmental Management Strategies:

\author{
1. Non Compliance \\ 2. Compliance
}


3. Compliance Plus

4. Commercial and Environmental Excellence

5. Leading Edge.

(Roome, 1992)

Evidently, although Rickmann sees Environmental Management Systems as the same as Environmental Management Strategies, a distinction does seem to be made by Roome. He identifies strategic options and then discusses integrated Environmental Management Systems in relation to a firm in the compliance plus category of the strategic options strategy.

Like Welford, Roome sees a link between TQM (or in this case the British Quality Standard BS 5750) and environmental management, but his criteria for an integrated EMS are quite different. Roome takes a fairly standard management strategy of mission statement to strategy and policy, through to performance measurement and review, and requires that each one of these stages be considered with respect to five aspects of:

1. Health and safety programme

2. Emergency planning programme

3. Compliance programme

4. Pollution reduction programme

5. Product stewardship programme

(Roome, 1992, p21)

There is little or no discussion about the content or definition of the above. The positioning of the product stewardship programme as last on the table seems misplaced. First place would appear a more appropriate positioning as the product begins the life 
cycle. However, Roome once again seems to agree with Welford when commenting on communication which seems to be the central point to Welford's EMS, or at least the diffusion of information and policy. He sees a need "to improve communication and participation through network and cluster organisations or quality circles" (Roome, 1992, p22). Roome also stresses that his compliance plus or excellent companies have their environmental policy and management run by senior management.

From the late 1980s onwards to the present day there has been a quite unparalleled increase in the volume of business environment literature. Most of it has been naturally geared towards the large corporate manager and strategic implications or towards the marketing advantage to be gained from being more environmentally friendly (O'Neill, 1990; Forrester, 1990; Bijapurkar, 1990; Newall, 1990; Simms, 1990; Bertsch and Williams, 1991; McKee, 1991; Stead, W. Stead, J. 1992; Smith D. (ed.) 1992; Foecke, et al, 1992; Bennett and Wilson, 1992; Jackson, 1993; Wiesmann, 1994; McCloskey and Maddock, 1994; Karls, 1994 et al). Concurrently there has also been a large increase in the number of academic and practical journals, including a few articles which suggest businesses have been getting too much praise for environmental innovativeness (Cairncross, 1992; Doyle, 1992). Literature has also included a large increase in the business ethics grouping, which have begun to incorporate environmental considerations as a major component (Donaldson 1989, 1992; Hoffman and Moore, 1990; Chryssides and Kaler, 1993 et al).

The banking and financial sectors are starting to put the environment on their agenda with pressure from central government to include the environment in their business loan criteria, following the practice in the USA (Thomas, 1993, Cowe, 1993). This trend is likely to continue as the Government has proposed that the banking and insurance sectors apply grass roots pressure on companies to clean up their act, under the new ACBE 
(Advisory Committee on Business and the Environment, 1990a and 1990b; Whitaker, 1993).

This is perhaps the most intriguing area of literature and has inspired work on the development of a new concept of an Environmental Credit Rating Agency (Tanega, 1992). Indeed ACBE proposals have also suggested the possibility of public companies being required to divulge more environmental information as possible new policy. All these factors will have a profound affect on the SME in the not too distant future.

However, a large proportion of the more recent writings seem irrelevant to the SME owner manager, for many of the reasons outlined above. Only Gruber and Brand (1991), Welford, (1992) and Kok, Welford, O'Laoire, (1993), Welford and Gouldson (1993) and Hendry (1993) have made any significant comment on the SME and environmental business practice. Gruber and Brand explore the possibilities for external consulting within SMEs with respect to energy usage. They argue that service charges could be calculated on a cost savings basis (Gruber and Brand, 1991). This idea is taken further by Hutchinson and Chaston to include all of a small company's operations (Hutchinson and Chaston 1993). Welford in particular has been instrumental in developing the regional orientation of management theory for the sustainability of the SME sector by advancing the concept of the Catchment Management System and by reviewing, on a regional level, possible developments of SME management skills. Welford and Gouldson also offer a model for SME environmental management based on flexible specialisation and quality (Welford and Gouldson, 1993). Regionalisation of industrial behaviour is not, however, new. Functional regionalism (where a state is responsible for regional demarcation) has formed the basis for economic geographical research for a number of years (Rees et al, 1981; Rokkan and Urwin, 1983; Knox, 1984; Massey, 1984; Nijkamp, Van Der Mark and Alsters, 1988). Concurrently, what is broadly known as the regional movement with 
feelings of collective identity which are not rooted in an officially defined region but emanate from a grass roots identity, has existed from the beginning of time, (Bennett $R$. 1985; Smith G. 1985 et al). The present day separation is perhaps seen within this typology. The functional regionalists correlate to the regional economists and industrialists. The regional movement could relate to the bioregionalists discussed later in this chapter. The northern Europeans Johannisson, Jarillo, Galtung et al also fit into the regionalist genre and provides a strong argument for the requirement of regional development based on co-operational strategies. Their arguments support the analysis that the differing economic and social conditions of small regional economies dictate the requirement for alternative economic and industrial management strategies be developed in order to understand and create the "arena perspective" where SMEs and communities alike prosper (Johannisson, 1978, 1983; Galtung et al (eds) 1980; Jarillo, 1988). Johannisson in particular links the success of the locally based SME economy to community welfare (Johannisson, 1983).

Most of the literature reviewed in the 1980s and 1990s has had an endemic bias towards. business. Indeed, the 1990 s has seen the publication of a whole host of environmental management material, mainly for large businesses. Few, however, consider the broader picture. This requires analysis of the inter-relationships of economics, politics and society. The place industrial development has within this more holistic picture is gradually emerging. The next section, therefore considers some of the more alternative approaches to industrial development into which secure the future of the SME sector within a framework of bioregional and permacultural thought. To date no work has specifically been documented within this area with regard to the SME per se. The nature of the systems described, however, are small scale and localised, offering the potential to locate the SME at the centre of bioregional and permacultural theories. 


\subsection{Sustainable Development - Alternative Models}

The majority of work discussed within this final section derives from the perception that existing economic and political systems have failed to provide the framework necessary for sustainable development. Most of the literature reviewed is an attempt to understand the underlying propensity of the industrial system to cause environmental damage. The philosophies discussed are holistic in their approach and require a lateral analysis of the environmental questions facing contemporary society. Although this research is limited geographically it is necessary to understand the broader external economic and industrial influences that exercise a determining influence on the future possibility of sustainable development within the locality.

The analyses within this section derive from the need to address sustainable development. The Brundtland Report concluded that because economics, politics and society were so inter-related there was a fundamental need to consider them so in research (World Commission for the Environment and Development, 1987). Whereas orthodox economics argues its neutrality, objectivity and separation from ethical subjective considerations (i.e. politics) the 'new economics' touched on earlier fully accepts this requirement. The new economic movement accepts the reality of economic policy and the need for definite value judgements attached to these theoretical applications. This holistic and practical approach to economics forms a part of the first alternative concept, bioregionalism.

Bioregionalism is necessarily holistic in nature, considering the whole picture of society, economics, management and politics. It proposes that an alternative way of life is required if sustainable development is to be achieved. Bioregionalism is an attempt to fit 
ourselves to a particular place and not to fit a place to our predetermined tastes (Sale, $\mathrm{K}$. in Dobson (ed), 1991).

It is only a matter of time before bioregionalism accumulates as many definitions as sustainability (around 73 to date) because of its endemically diverse content. Bioregionalism comes from "bio" as in life and "regio" as in regions or territories. It addresses the concept of life form equilibrium and asks questions about the integration of human affairs and nature. For further discussion on bioregionalism see Callenbach, (1975); Sale, (1985, 1991); LeGuin, (1986); Andruss and Plant, (1990); Plant (ed), (1991); Ponting, (1991); Dobson, (1991); Seymour, (1991); Mellor, (1992); Plant and Plant, (1993). However this rather alienates the human spirit from nature. It suggests a separation exists between humans and nature. Bioregionalism could perhaps be described more accurately as a regionally autonomous collective thought movement for sustainable lifestyles.

Bioregionalism is a reappraisal of place on the earth both in spatial and idealistic terms. It is about reinhabiting the local environment and learning to live there again, rather than converting Devon into the USA. Bioregionalism stands for collective living, regional identity and localised priority trading. It is a broad concept by necessity as it allows for a multitude of expressions. It challenges our existing priorities and asks questions about our self consciousness. The "bio" centralises ecological concerns and could succeed in challenging the dominant capitalist paradigm where state socialism failed. It has already been suggested that the green movement in politics (if taken in conjunction with socialism and feminism) will provide the new alternative to capitalism (Mellor, 1992). Placed within a bioregional framework these concepts begin to shape a credible alternative. Green business strategy, like green politics may have so far failed, because it 
has lacked a credible holistic strategy. Bioregionalism encompasses all that green politics and economics stands for within a well structured frame.

The economic mechanisms of bioregionalism can accommodate the type of principles outlined above, i.e. trading locally first, regionally second, nationally third and internationally as a final resort. This implies a form of 'new protectionism' of the kind outlined by Lang and Hines (1993). New Protectionism requires some traditional protectionist barriers (tariffs and quotas on a regional level). In the main, however, it concentrates on the need to re-educate the community on issues of sustainability, used here in the sense of economic and environmental sustainability. New protectionism emphasises the need for a more realistic appraisal of the 'cost' of goods and services. This includes the environmental and social costs. Lang and Hines argue that a locally oriented trading system would reduce unnecessary transport costs and provide many more jobs. This under utilisation of the human resource is seen as a critical aspect of the present economic system that does not take the loss of unemployed labour in to account when considering the cost of goods and services. This may sound simple or naive, but Lang and Hines argue that an on-going underlying theme to the change towards bioregionalism would be education. The concept of new protectionism argues that if the region or community can be educated about the economic benefits of trading locally, i.e. the fact that employment would be increased as the locality learnt to be self-sufficient they are more likely to want to buy locally. In the long term this would reduce the need for the more traditional economic barriers around the region.

Aberley suggests that a central element to bioregionalism is the development of regional maps to understand the locality within which the individual and industry operates (Aberley, 1993). This educative process of mapping a region's trade flows, cultural information points, physical geography and geology, political initiatives to promote 
sustainability enables the community to live 'in place' again and reduces dependence on external investment. The underlying argument is that it is both economically and ecologically beneficial for a region to be self-sufficient and self-reliant (Sale, 1985; Torry, 1988).

The practicalities of this vision could be realised by the application of a practical and philosophical theory permacultural design (Mollision, 1978). This holistic system of living, designs lifestyles and business practices with the maximum regard for ecological and sustainable considerations. Permaculture could be defined as the conscious design and maintenance of agriculturally productive ecosystems which have the diversity; stability and resilience of natural ecosystems (Mollison, 1993):

\author{
Permaculture (permanent agriculture or \\ permanent culture) is a successful approach \\ to designing sustainable environments. \\ It is based on the philosophy of \\ co-operating with nature and caring \\ for the earth and its people
}

(Permaculture Vol 1 No.3 p2)

Permaculture is a holistic, localised design system. It considers all aspects of life, the economy, the individual's place within the bioregion and attempts to provide a system. based on sustainable philosophies. It is essentially a design concept used to create sustainable human habitats (Mollision, 1993), be they in cities or in rural areas. When applied it empowers the individual to become more self-reliant and acts as a central part 
of the re-education process called for by so many of the bioregional writers to alter value perceptions in the wider community.

Consumption patterns, dictated by both the demand and supply side, will have to change according to Lang and Hines. This requires a certain level of re-evaluation by the individual. Jones has suggested that this 'inner journey' by each individual is central to sustainable development and would lead to an enlightened community. Further, according to Jones, only through individual self-appraisal on a spiritual level will sustainable change occur Jones (1993).

There is a growing consensus that these spiritual issues can not be ignored in the effort to understand the holistic picture of sustainable development (Carson 1962; Schumacher 1968, 1973; Capra 1983; Porritt 1984; Spretnak 1985; Bahro 1986; Dobson 1990; Mellor 1992). The spiritual dimension has effected most bioregional thought, raising philosophical questions along the lines of: 'what is the point of looking after the earth to preserve it for future generations if we are all eventually going to die?'; 'why pass anything on?' 'At the end of the road, when the earth finally explodes, the 'inheritance' vanishes and the last remaining people have no one to pass the inheritance to.' In the long term we are all dead, as Keynes so rightly remarked, conservation would therefore appear pointless. It is possible to argue, however, that life has intrinsic value and is therefore worth respecting. There are no definitive answers to these questions. All depends on the view of the individual.

One can clearly see from the above debate, the plurality and extent of the question of sustainable development. Motivations, and subsequent solutions, vary depending on the individual's perception of the problem. If the primary motivation is short-term profit maximisation and cost reduction the analysis and subsequent research will take one 
direction. Different requirements are necessary if it is deemed desirable to consider the long term implications and the cost to society of ecological destruction.

This research will take the view that the problem is the attainment of sustainable development, defined as development that meets the needs of the present generation without compromising the ability of future generations to meet their own needs (World Commission on Environment and Development, 1987). The cosmetic greenwashing of the SME sector is considered here neither useful nor desirable. Since the environmental summit in Rio De Janeiro in 1992 the U.K. government has been committed to sustainable development through the signing of the Action Plan for sustainable development Agenda 21. It therefore seems pertinent to accept this as the defining problem to be solved. This is an important distinction. A considerable proportion of the literature on the subject of environmental management has not necessarily been directed towards this particular aim. Bioregionalism and permacultural design are however, geared towards an holistic ecological appraisal of the system in an attempt to achieve sustainable development.

Both bioregionalism and permacultural design stem from the ecological or ecocentric thoughts discussed earlier. In one respect they provide the beginning of a re-evaluation of philosophical thought. In essence the ideas are not new. They are communal, socialistic, collective and ecological in essence. By socialistic, one means that the economic systems which would feature reduced economic conflict with the ownership of the means of production by the majority rather than the minority (Hutchinson F. 1994).

Theory has offered a solution to the issues and problems facing U.K. businesses. However, whether this theory is relevant to the SME sector still has to be verified. The literature suggests that SMEs may be endemically different from larger companies and 
that different strategies need to be employed to succeed in achieving sustainable development (localised networking, co-operational strategies for example).

As Ramstrom (1975, 1986), suggested, small firm research has a tendency to be fragmented and neglected. This emerges as the case in the SME literature on business and the environment. Research is required to establish awareness levels and operational behavioural patterns within the SME sector in order to lay the foundations for explaining why, if the solutions exist, they are not being used in the SME sector. Further, operational models designed to accommodate the needs and resources of the SME sector require development.

Although much work has been done within the field of Environmental Management and sustainable development, it seems that the balance between ecological idealism (as a prerequisite for motivation, commitment, strategic and operational management), practical frameworks and the Small and Medium Sized Enterprise, has still to be clarified.

The literature review has covered a number of diverse subject areas in order to understand all the implications of theory in the subject area of sustainable development and the SME. A gap in the literature has emerged, with little analysis of the implications of sustainable development to the SME sector. Further, analysis of the future role the SME has to play to achieve sustainable development is undeveloped. 


\title{
CHAPTER 4
}

\section{RESEARCH AIMS}

\author{
AND
}

METHODOLOGY 


\subsection{Research Aims and Questions}

The literature review covered the development of ecological literature from the roots of environmental determinism 5th century BC through to the debates on sustainability in the 1990s. It also considers the strategic management literature and other relevant management writings (supplying the chronological framework into which this work will fit).

The review then specifically considered the limited amount of work available on SMEs and environmental management. No work specifically related to Devon and Cornwall. It concluded with a resume of alternative models to sustainable development which included issues of co-operation, bioregionalism and permacultural design. In an early stage of development in the UK, both concepts of bioregionalism and permacultural design and their repercussions were viewed as significant to the SME and the question of sustainable development. An important distinction was made, however, between the writings, motivations and objectives of the bioregionalists and the management strategists. This was considered significant as the definition of the problem delineates the solution.

Having established the relevant literature, a research plan was devised to structure the research (see Figure 4.1). This chapter will explain this diagram by systematically considering each phase. The research plan explains the flow of the research, both diagramatically and textually. Its fundamental purpose is to display the research flow from beginning to end and to explain the background behind the research hypotheses. 


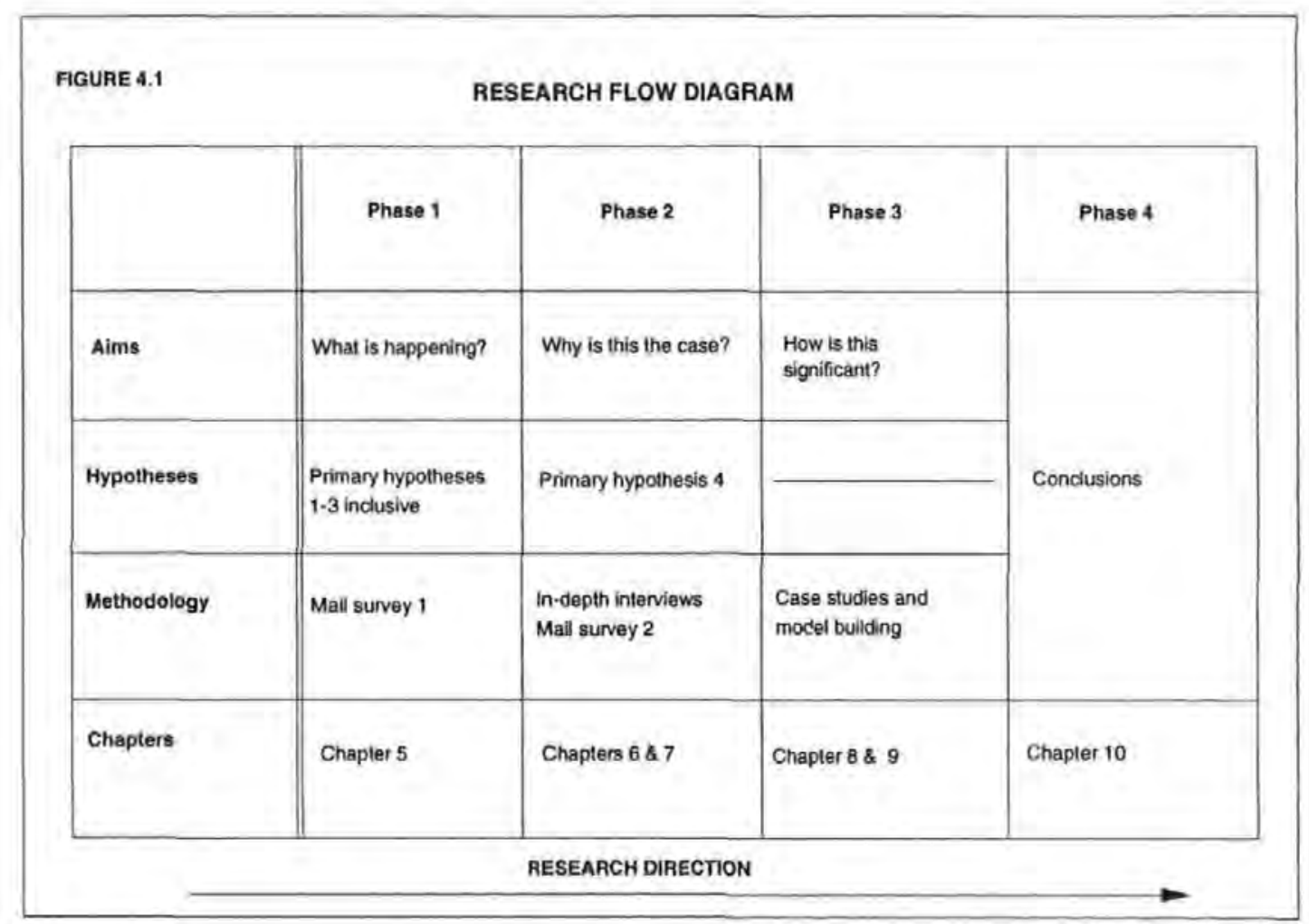

Clearly there was a gap in the literature generally with respect the SME and sustainable development. The initial research question was what part has the SME sector to play in the attainment of sustainable development? To answers this question it was necessary to research what SMEs were doing and were capable of doing to improve their environmental performance. Attitudes in particular decipher future possibilities for a change in management practices. The research literature has suggested that the pathways to sustainable development are twofold. On the one hand traditional industry considers the environmental management systems (EMS) as the best route. Alternatively or concurrently, more stringent legislation could be developed (although there are question marks over both of these concepts in the light of the Uruguay round of the GATT talks). Finally there are the broader bioregional visionaries who feel that the attainment of sustainable development requires a total change in the socio-economic structures. The question posed within this research is where does the SME fit? Are the management 
systems solutions devised primarily for the large company applicable to the SME? Is legislation going to make any difference and is it feasible within the present movement towards free unregulated trade? Or is there a requirement to consider alternative pathways? and if so is there a need to devise a new conceptualised model for the SME?

To answer these questions it was necessary to understand the present position and to analyse if there was a need for a revision of theory. The revised research aims, therefore, consider: the attitudes, awareness and practices of SMEs to environmental business practices and environmental issues in general; and if the existing solutions and support systems are adequate for the SME.

\section{Revised Research Aims}

1. To determine the level of awareness and perception of environmental issues within the SME sector and to assess prevailing attitudes of owner/managers to the importance they attach to managing this aspect of their business operations.

2. To gain an understanding of the scale and nature of response to environmental issues across a broad section of SMEs and to cross tabulate results.

3. To utilise the knowledge gained about awareness, attitude and organisational response to assess the relevance of the environmental management systems so far developed to and to link this to achieving sustainable development.

4. To draw upon the expertise of owner/managers and appropriate institutions to validate and if appropriate further refine new/and or revised systems as necessary. 
5. To assess the possibilities for sustainable development within the SME sector.

Having clarified the research aims it was now necessary to consider how best these questions could be researched. For this purpose it was decided to apply the empirical, quantitative, deductive hypotheses testing method to produce a foundation from which qualitative analysis and interpretation could then flow. The following primary, deductive null hypotheses were designed for this purpose.

\subsection{Research Hypotheses}

\section{Primary Null Research Hypotheses}

1. There are no significant differences within the SME sector with respect to attitudes towards environmental issues.

2. There are no significant differences within the SME sector with respect to awareness of relevant environmental issues.

3. There are no significant differences within the SME sector with respect to levels of environmental management.

4. There is no significant variation of response within the SME sector to why levels of strategic and operational environmental management are at such a level.

These primary null hypotheses were designed to establish the empirical foundations for the subsequent qualitative, inductive analysis and model building stages highlighted in the research plan. 
A pilot survey was undertaken through the Chamber of Commerce to ascertain if the above hypotheses were worthy of consideration and to develop the rudiments for the first mail survey. It was decided that the hypotheses were valid and worth researching and the first mail survey was constructed accordingly.

Before considering the methodological concepts in more detail the ideological foundations for the methodological routes chosen will be considered. This section provides the base by which the methodology chosen can be understood.

\subsection{Ideology}

To understand the relationship between data and theory one has to consider the philosophical aspects of research. These 'choices' determine the direction research takes and the methods used and are fundamental to the outcome of the work. Philosophers have argued for centuries about the nature and philosophy of research and a clear dichotomy of thought has developed since the Quantitative Revolution of the 1950s. Work by Comte A. (1853) lead the development of the research philosophy Positivism which challenged the previously subjective, inductive research technique which became known as Phenomenology, (Husserl, 1946).

One can see here a clear distinction in the philosophy of research. On the one hand there is the factual, deductive, objective, external reality of Positivism and the other is the subjective, inductive, socially constructed world of phenomenological research philosophy. The outcome of the research is obviously dependant on which philosophy is prevalent. Fortunately it is not necessary, within a large body of research, to have to use either philosophy exclusively. In fact many writers argue the benefits of combining the strengths of the two philosophies (Easterby-Smith, et al 1991). For example if one takes 
this work as an example, the large data collection process of the mail survey, lends itself well to the positivist school of thought. This requires large samples, value free observations based on facts, independent observations and the use of hypotheticodeductive methodology. Whereas the more qualitative techniques of the interview research format more accurately ally themselves with phenomenology. For example, focusing on exploratory research, meanings and social effects.

It is important to understand that the chosen philosophical base with which one approaches research determines the research methodology used. For example if one acts within a positivist framework, then one has to use quantitative research techniques to satisfy this research criteria. Whereas using a phenomenological philosophical framework one would have to use qualitative techniques like the semi-structured in-depth interview format.

Effectively positivism (and the related methodological techniques) excels in helping to explain what a situation is descriptively. Whereas phenomenology tries to understand and explain why there are different experiences. It does not search for external fundamental laws in an external objective reality. Although most positivists argue that this form of philosophical ideology is value free, one has to suggest that no research is totally value free. The choice of research in the first place requires some sort of subjective judgement. In this case, as explained earlier in the chapter, the definition of the perceived problem is undecided therefore the pathway of research is immediately unclear and open to value judgement.

So to conclude, one can see how Phase 1 (Figure 4.1) has been designed exclusively within a positivist philosophical framework. Phases 2 and 3 also have this dimension as well as an element of phenomenology philosophy (in the form of the in depth interviews). 
The deductive, factual, quantitative and objective mail survey is endemically positivist and the inductive, qualitative, subjective action learning, (Morgan 1993) of the in-depth interviews and case studies portray the requirements of phenomenological research philosophy. However, within the second mail survey there are open ended questions which ally themselves more accurately to phenomenology. This is because the survey is trying to decipher why a certain situation is the way it is. Therefore one can see that the two philosophies can be interconnected and work well in co-operation. Just as quantitative and qualitative research methodologies can also be interchanged effectively.

\subsection{Methodology}

\section{Data Collection and Analysis - Sampling}

\section{a) The Company Sample}

Table 4.1 below describes the economic characteristics of the South West (figures are not available for Devon and Cornwall alone). This explains the characteristics behind the company sample. It shows that although the South West has a higher percentage of people employed in the primary and tertiary sectors than the national average, the two sets of statistics are fairly close. Therefore (if one takes employment as a measure of size of industrial sector) national population inference would be valid. However, one can see that the figures for GDP at factor cost and per employee show a totally different picture of the size of industrial sectors. Therefore although the vast majority of people in the South West are employed in the service industry, the GDP (here calculated by the incomes method) shows the manufacturing sector to be the largest in these terms. This discrepancy is exacerbated when the figures are further modified to take into account the percentage number of employees in the sector. 
Table 4.1 - Economic Fabric of the South West Sample

\begin{tabular}{|c|c|c|c|c|c|c|}
\hline Sector & $\begin{array}{c}\text { \% No. of } \\
\text { Emplo- } \\
\text { yees }\end{array}$ & $\begin{array}{c}\text { \% No. of } \\
\text { Emplo- } \\
\text { yees }\end{array}$ & $\begin{array}{c}\text { GDP, } \\
\text { Factor } \\
\text { Cost }\end{array}$ & $\begin{array}{c}\text { GDP, } \\
\text { Factor } \\
\text { Cost }\end{array}$ & $\begin{array}{c}\text { GDP, } \\
\text { Per } \\
\text { Emplo- } \\
\text { yee }\end{array}$ & $\begin{array}{c}\text { Survey } \\
\text { Resp- } \\
\text { onse } \\
\text { Rate }\end{array}$ \\
\hline & S.W. & UK. & fm & $\%$ 's & $\%$ 's & \\
\hline Primary & 3.73 & 2.82 & N/A & N/A & N/A & 4 \\
\hline $\begin{array}{c}\text { Second- } \\
\text { ary }\end{array}$ & 18.79 & 21.17 & 9807 & 30 & 44 & 40 \\
\hline Tertiary & 77.48 & 76.01 & 14064 & 42 & 27 & 55.4 \\
\hline Totals & 100 & 100 & N/A & N/A & N/A & 100 \\
\hline
\end{tabular}

South West, UK Classification of Industrial Commodity Groups (1993).

One can see how a brief analysis of the sizes of industrial sectors is rather vague. The general conclusion is that the service sector is the largest in the South West as it has a similar GDP to the manufacturing sector but far more people employed in it. However, the sample does contain similar characteristics to the national average. The analysis of the size of sectors is required to analyse the response rate per sector. The universe was defined as Small and Medium Sized Enterprises. This was limited spatially to Devon and Cornwall. The population concerned in the winter of 1992 was 58,250 companies in Devon and Cornwall (14,500 Cornwall, 43,750 Devon). 


\section{The Random Non-Probability Sample}

Due to cost limitations, it was not possible to obtain a complete sampling frame (a complete list of the relevant population in Devon and Cornwall). Therefore, although the frame included the vast majority of companies in Devon and Cornwall one has to accept that the sample was a non-probability sample rather than the more accurate Probability Sample (Sandy, 1990). However, to reduce any further inaccuracies a random sampling technique was employed for all of the mail surveys. The first two surveys were taken from a list of 4040 companies in Devon and Cornwall and a random sample of 600 were taken for both.

The random sample was used to identify 600 SMEs in Devon and Cornwall. The data lists came from Enterprise Plymouth and the Cornwall Industrial Directory and the random sample was generated using the random sampling command in the statistical package SPSS PC and then translated into a word processing package for mail merging purposes.

Yates (1981) suggests five criteria on with which one can evaluate the sampling frame. They include five criteria;

1. Adequacy - The sample frame should cover the population to be surveyed and it should do this adequately related to the purpose of the survey

2. Completeness - The frame should include all those units of the population that should be included

3. Duplication - Each unit should appear once only, multiple entries can result in bias 
4. Accuracy - Many sampling lists contain non-existent units owing to the dynamic nature of these populations

5. Convenience - Accessibility of the list and suitability of its arrangement for the purpose of sampling.

Although the sampling frame used in this research does not totally satisfy all of the Yates criteria it comes close to most of them. The fact that a 'perfect' list was not convenient because of the price and the dynamic nature of the list (due to companies starting up and failing constantly especially in recessional times) vindicates the sampling frame used in this research.

\section{Simple Random Sample}

This technique was used to identify companies who would be willing to take part in the in-depth interview stage of the research. This was taken randomly from the respondents to the first survey and interviewees were asked if they would be willing to participate by telephone, as it was thought that it was harder to decline to offer over the phone. There were, however, some constraints to the sample, it was felt to get a balanced picture the simple random sample should be taken from each industrial sector group, rather than from the total sample. This procedure for the first set of in-depth interviews located 14 companies. This was felt to be a sufficient amount of companies for a semi-structured, qualitative, exploratory study.

This was also the technique employed in the model building stage (phase 3). Relevant organisations and individuals were contacted selectively to attain as much relevant information for the model as possible. 


\section{The Inclusive Sample}

The inclusive sample was used to identify the companies for the second mail survey. It was decided that because of the interactive effect and the reduction in response rates, that a new random sample would be taken from the original data base. Cross referencing between survey's would still be possible as a number of questions relating to company characteristics would be duplicated. This also has a dual purpose as it acts as a verification process.

\section{b) Data Analysis Techniques}

Since the Quantitative Revolution of the 1950s the dominant paradigm has been quantitative rather than qualitative research methods. This paradigm shift, however, has not removed the need to use qualitative methods in certain circumstances. The strength of the two methods in co-operation is much underrated, they are not mutually exclusive by any means. Indeed, as in this research, qualitative and quantitative methods can compliment each other rather effectively.

The data analysis was designed into four distinct phases. (Figure 4.1). Each phase was either complimentary or chronological to the previous stage. The initial phase included a mail survey to decipher what the current situation was in the SME sector regarding environmental performance and attitudes. This was a straight forward deductive; quantitative exercise designed to create the foundation of the work. It also briefly asked why this was the position. This was designed to be a link with the qualitative research of phase 2. 
Phase two was structured in the form of in-depth interviews. They were semi-structured as to reduce the subjectivity of the research, but were qualitative in nature allowing for the flexibility in response required to satisfy the aims. They were also inductive, meaning that the research exercise considered in field observations and retrogressed to theoretical patterns. The aim of phase two was to link the first and second surveys together by considering in more depth the question why SME behaviour towards the environment is the way it is. It also considered in an informal way how relevant the existing solutions were to the interviewees.

Phase 2 not only considered why environmental behaviour is the way it is in the SME sector but also how relevant the solutions offered were to the sector. It took the answers from the inductive, qualitative research and tested it on a deductive, quantitative level in the form of a mail survey. One can see here how the two types of research methodology can be complimentary.

Finally a series of case studies/in-depth interviews were undertaken in Phase 3 of the programme. These were again semi-structured to allow maximisation of information and inductive in nature. The reasoning here was to gain an understanding of the best practices and examples of innovative environmental practice in Devon and Cornwall with relation to the generalised model formulated from Phases 1 and 2 .

\section{Mail Survey}

The mail survey is a quantitative research technique that allows mass data generation over a large geographical area. Its highly structured and deductive format tests pre-determined hypotheses in the field. 
There are a number of problems attached to the mail survey: the response rate; the bias produced by the non-response; the availability of the population; the size of the subsequent standard error of the sample with relation to the population and therefore subsequent population inference and the design of the survey (readability, superficiality of closed questions and subjectivity of open ones). Each of these factors will be considered below. It remains, however, the most systematic way of generating large amounts of information from diverse sources. Mail surveys are also generally simple to use and analyse (assuming a strong design).

\section{i) Mail Survey Design}

The design of a questionnaire is of paramount importance to the success of the project. A poorly designed questionnaire will lead to numerous analytical problems. Tull and Hawkins (1990) provide excellent advice on this stage of the research considering aspects such as:

1. Initial considerations

2. Question content

3. Question phrasing

4. Types of response format

5. Question sequence

6. Questionnaire layout

7. Pre-test, revision and final version of the questionnaire.

The classic works of Oppenheim (1966) and Moser and Kalton (1971) also provide sound advice on the design stage even though they are rather dated. More practical advice is 
provided by Youngman (1984). There are of course many texts in this area all of which say pretty much the same thing.

\section{ii) Response rate}

This is probably the greatest problem attached to the mail survey and has lead to multifarious comment. Jobber and Horgan (1987) suggested that low response rates may be due to the limited interest of the respondent in the subject area. Erdos (1970) also recognised that this low response rate could destroy the randomness of the sample. Therefore one has to consider all possibilities to reduce the non response of the survey.

The issue of response rates is a highly debated area. It is generally accepted that one can statistically work with 30 cases. How representative they are of the population depends on the percentage this is of the sample. Although the Advertising Research Foundation recommend $80 \%$ or above as a minimum requirement, $50 \%$ response rate seems to be the minimum acceptable rate to allow for population inference, without some sort of nonresponse test being undertaken, (Erdos, 1970). This can be done through the analysis of first and second wave respondents. If the second wave respondents are similar in their responses to the first wave respondents one can assume that the non respondents would answer in a similar way to the respondents, (Erdos, 1970). There are of course limitations in this exercise and a second follow up survey of the non respondents, by mail of by telephone, would be a more accurate way of testing the non-respondents. Therefore the first and second wave respondent technique was used to test the non-respondents in Devon and Cornwall. Another similar survey was mailed in a new geographical location to further verify results. This procedure also allowed for comparative analysis. 
The main influences on the response rates are the nature of the subject, the educational level of the respondent and the size and length of the questionnaire. However, inducements to respond are also important factors. Response rates can be significantly increased with incentives to return, like money, gifts or reports related to the survey. In this case a report was used as an incentive to respond.

Although response rates are of course of great significance, Belson (1986) suggests that low response rates are not completely void. The suggestion is that one requires a high response rate to make accurate predictions of likely events in the future. Low response rates can provide useful information on general patterns.

In order to increase the response rate certain procedures were undertaken in accordance with the literature: an explanatory covering letter (Webb, 1992) was used to explain the importance of the research; a report of the research was offered; the covering letter also stressed the speed in which the survey could be completed; freepost envelopes were included with each survey, (Belson, 1986); the survey was printed and spaciously laid out in a vertical format, (Erdos, 1970); the research was given further credibility through the printing of the collaborating establishments (in this case the Chamber of Commerce and the Groundwork Trust) on the cover (Webb, 1992). A pilot survey was also undertaken, (Scott, 1961).

\section{Survey 1 (see Appendix 1)}

Questions 1-4 were objective factual questions designed to acquire back ground information on the companies to be studied. This was to allow for cross tabulation, comparisons of group means and various other multivariate analytical techniques to be used. Questions 5 and 6 clarified the perceptions of the companies and the individual 
respondents towards specific environmental issues. Question 7 addressed company awareness of environmental legislation and regulation. Questions 9-12 considered actual environmental practices within the SME sector. Questions 8 and 13 were concerned with the perceived solutions the SME sector has to the problems it faces.

Survey 1 was designed to satisfy research aims 1 and 2 . First, to determine the level of awareness and perception of environmental issues within the SME sector and to assess prevailing attitudes of owner/managers to the importance they attach to managing this aspect of their business operations. Questions 5 to 8 inclusive considered questions of attitude and awareness: questions $5 \mathrm{a}, 5 \mathrm{~b}$ and $6 \mathrm{a}-6 \mathrm{~m}$ relate to attitudes of importance of environmental issues; questions $7 \mathrm{a}$ to $7 \mathrm{~h}$ look at awareness of regulations; and questions $8 \mathrm{a}$ to $8 \mathrm{e}$ consider the most effective ways of improving environmental business practices.

Second, to gain an understanding of the scale and nature of response to environmental issues across a broad section of SMEs and to cross tabulate results: questions 9a to $9 \mathrm{j}$ consider operational company practices and questions 10 and 11 relates to strategic orientation. Questions 12 and 13 are not analysed within the main body of the text as they were designed to provide initial information for the subsequent in-depth interviews. Statistical analysis can however be seen in Appendix 1.

\section{Survey 2}

Survey 2 was designed to consider further the issue of why SMEs responded in the way they did to the first survey and the subsequent in-depth interviews. In particular it considered the issue of strategic environmental management in SMEs. Again linking to the third phase of the case study analysis, it also considered the issue of the proposed solutions offered and asked how relevant these were. 
Questions 1-5 dealt with objective, factual information about the company. This was necessary as it was decided to use a new random sample for the second survey to vary the input and increase the expected response rate. Questions 8-12 then considered the proposed solution for improved environmental business practices of SMEs. This section included for the first time some open ended questions. These were designed to extract unexpected response and new ideas. Questions 13 and 14 referred to the companies' external business environment. Finally, questions 15-19 dealt specifically with the business support organisation PAYBACK (which is run through the Groundwork Trust). Therefore effectively questions 8-19 further developed the what the solutions are to the problems raised in survey 1 and the In-depth interviews, with particular regard to the lack of strategic environmental management in SMEs.

Designed to satisfy research aims 2 and 3, survey 2 aimed to gain further understanding of the scale and nature of response to environmental issues with particular regard to strategic inclinations. The literature review suggested that strategic management can be low in SMEs, this is not, however, definitive. It was necessary, therefore, to understand the sample characteristics to deduce the optimum solution to the initial research question. Questions 6 to 12 related to issues of strategic environmental management. The requirement was for a fuller understanding of the motivations of SMEs with regard to environmental concerns. Questions 13 to 19 considered present and future environmental support initiatives and deduced perceptions from respondents. The second mail survey, therefore, helped to satisfy the third research aim to assess the relevance of the environmental management systems so far developed to and to link this knowledge to the issue of sustainable development. 


\section{In-Depth Interviews}

All interviews were based on a semi-structured format relying in the main upon open ended questions. They were all taped to allow for accurate transcriptions to be made at a later date. Interviews can be classified according to their degree of structuring. They are placed on a continuum between structured and unstructured, (Walker, 1985). There are however, certain caveats attached to this research process, in particular that of the interviewer bias. Issues such as voice inflection, lack of appropriate etiquette in a particular situation, induced answer suggestion and voluntary expression of the interviewer's opinion can all lead to biased analysis, (Easterby-Smith, et al 1991). There will always be a certain level of bias within this research technique and it is essential to understand the pitfalls and caveats in order to minimise their effects.

The in depth interview technique was used as the research was in an under researched area that required Action Learning from the interviewee. This qualitative research technique was specially designed by Morgan (1993) to allow a dualistic approach to research in an area that requires a level of problem solving or the unlocking of a new kind of initiative:

Action-learning approaches to research build on the idea that it is possible for the research process to have a dual objective in, a) trying to produce useful research knowledge while, b) using a process that can help the people involved in the research gain a better understanding of their situations

(Morgan, 1993 p296). 
The process allows the researcher to keep an open mind during the research and to become immersed in the issues. This facilitates the development of new knowledge rather than having pre-formulated ideas to test in a deductive way in the field. It is an inductive form of subjective research that has some structure in the form of question and answer analysis. For example three distinct forms of answers are suggested allowing the analysis of response to have a somewhat structured format.

Action-learning links theory with practice, developed through the work of [Dewey (1929, 1933); Lewin (1948, 1951); Argyris (1985); Trist (1976, 1982) and Trist and Murray (1990) all in Morgan (1993)]. They considered issues like Action-research and Actionscience. The research tries to get the situation to speak for itself. Hypotheses and value judgements are suspended to allow for new insights to emerge.

There are three 'classes' of data, Class one refers to the so called objective facts of the situation: Class two represent all social constructions of reality other than the above, eg. what people say about situations, what they say about other people and how they interpret what is happening. Class three represents the researcher's social constructions of reality, ie. the way the researcher reads the situation. Although the distinction between the three classes is somewhat arbitrary however, it does allow for a certain amount of structure within an endemically unstructured process. This makes the analysis of the responses a little easier to interpret.

The aim is to "provide a rich description of the situation [that has been] encountered together with an accurate record of thoughts and interpretations", (Morgan, 1993, p303). This allows one to trace one's own influence throughout the course of the whole intervention. 
Action learning improves understanding of each individual situation. This facilitates comparison elsewhere, for example spatially. The suggestion here is that one can gain an understanding of a particular situation in one area (academically or geographically) and then use this experience elsewhere. However it does not allow one to say because $\mathrm{A}$ equals $\mathrm{B}$ in one area that $\mathrm{C}$ will automatically equal $\mathrm{D}$ in another area. One can only make general observations about the new situation from the previously studied area.

The aim of the in-depth interview stage of the research was to clarify issues within the first survey and to link it to the second mail survey. It considered why respondents answered the way they did in the first survey. This was an exploratory question in the first survey that required further research. So, although data already existed on this area in the first survey, using the action learning technique questions were not specifically angled towards the responses of the first survey. The aim was to compare the responses in an in-depth interview situation with the responses of the company in the mail survey (to verify consistency) and with the average responses of all the other respondents in the first mail survey. The other general aim was to consider what companies felt were the solutions to the need to improve SMEs environmental performance, (or if there was a need to act in the first place).

\section{Case Studies}

The literature review and empirical analysis revealed that SMEs were not moving substantially towards sustainable development and that this situation was unlikely to change in the foreseeable future. There was, therefore, a requirement to consider alternative options and models. The case studies provided the practical observations for these alternatives. The case studies were semi-structured in nature and applied the action learning approach. The research aims were to gather relevant information from the field 
that could be used in the development and re-evaluation of the conceptual model. Therefore, rather than interviewing companies who would explain how they were reducing energy usage as far as possible and using more and more recycled paper as examples of best practice, it was decided to take a more holistic approach to the problem. This meant the consideration of the application of a number of concepts introduced in the literature review, including networking, co-operation, bioregionalism and permacultural design. The model is, therefore, designed from theory and primary source observation.

\section{Research Conclusions and Recommendations}

This provides the focus of the research where the answers to the original research questions are answered. The research recommendations suggest areas of research that require further analysis as they place this research into context and recommend future research study. 


\section{CHAPTER 5}

\section{RESULTS -}

MAIIL SURVEY 1 


\subsection{Sample Characteristics}

Three primary, null hypotheses are tested in this chapter. All concern the relationship between the SME and environmental concerns, and are as follows:

1. There are no significant differences in the attitudes of the SME sector towards environmental issues.

2. There are no significant differences in the awareness of SMEs to environmental issues.

3. There are no significant differences in the levels of environmental management within the SME sector.

To test these hypotheses a mail survey of 600 randomly selected companies was conducted. This was done through the random selection feature on SPSS PC+. The survey framework was developed from a pilot survey (Appendix 1). The response rate was $40.17 \%$ and a non-response error test was undertaken by comparing first and second wave respondents. Since no significant difference was found, it was concluded that population inference would be valid. Surveys were sent to named managers and a freepost envelope was included to increase the response rate. For full statistical analysis of the results within this chapter see Appendix 1.

Table 5.1 shows the industrial classifications used in the survey and the valid response rates from each sector. Any 'valid' percentage means that the missing variables are missing from the percentage. 
Table 5.1 - Industrial Classification

\begin{tabular}{||l||c||}
\hline \multicolumn{1}{|c||}{ INDUSTRIAL SECTOR } & \multicolumn{1}{|c||}{ VALID PERCENTAGES } \\
\hline \multicolumn{1}{|c||}{ PRIMARY } & \\
\hline \multicolumn{1}{|c||}{ Agriculture - Forestry and Fishing } & 3.3 \\
\hline SECONDARY & 0.9 \\
\hline Energy and Water Supplies & \\
\hline \multicolumn{1}{|c||}{ Mineral Extraction and Construction } & 1.3 \\
\hline Engineering and Vehicle manufacture & 9.2 \\
\hline Other manufacturing & 23 \\
\hline Construction & 6.7 \\
\hline \multicolumn{1}{|c||}{ TERTIARY } & \\
\hline Distribution and Retailing & 5.4 \\
\hline Transportation and Telecommunications & 2.1 \\
\hline Financial Services & 5.9 \\
\hline Other Services & 42.2 \\
\hline
\end{tabular}

Figure 5.1 displays the industrial response rates. These are taken from Table 5.1 to allow a more accurate comparative analysis to take place. The amalgamation of groups was not arbitrary, however, it was determined by the Standard Industrial Classification (SIC) breakdown.

Figure 5.1 - Reduced

Response Rates

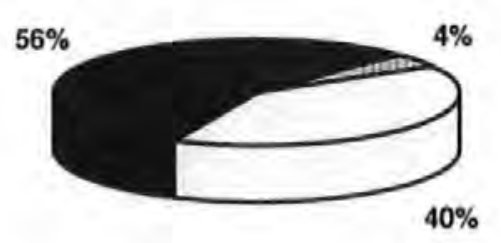


The response rate of the primary sector is significantly lower than the other two sectors. Therefore interpretation of these comparisons should be approached with a degree of caution. Although the most useful comparisons will be between the secondary and tertiary sectors, the primary sector will be included in some of the comparative analysis. If the response rates of the survey are compared with the economic fabric of the South West economy (Table 4.1) it is clear that the manufacturing sector has responded in larger numbers than would be expected. Although the majority sector is the tertiary sector (one would expect this as nearly two thirds of employment comes from this sector in the South West), the secondary sector accounts for a higher percentage than would be expected from the employment and GDP figures.

Having described the sectoral breakdown of the sample, Tables 5.2 and 5.3 display further sample characteristics.

Table 5.2 - Business Types

\begin{tabular}{|l|c|c|c|c|c|}
\hline Value label & Value & Frequency & Percentage & Valid \% & Cum. \% \\
\hline $\begin{array}{l}\text { Single Site } \\
\text { Business }\end{array}$ & 1 & 161 & 66.8 & 67.6 & 67.6 \\
\hline $\begin{array}{l}\text { Head- } \\
\text { quarters }\end{array}$ & 2 & 33 & 13.7 & 13.9 & 81.5 \\
\hline $\begin{array}{l}\text { Subsidiary/ } \\
\text { Branch of } \\
\text { National } \\
\text { Enterprise }\end{array}$ & 3 & 38 & 15.8 & 16 & 97.5 \\
\hline $\begin{array}{l}\text { Subsidiary/ } \\
\text { Branch of } \\
\text { Foreign } \\
\text { Enterprise }\end{array}$ & 4 & 6 & 2.5 & 2.5 & 100 \\
\hline
\end{tabular}


Table 5.2 shows that the majority $(67.6 \%)$ of respondents were single site businesses while $18.5 \%$ were subsidiaries of national or foreign enterprises. As the economy of the South West is predominantly driven by small, owner managed, single site businesses (Gripaios, 1989, 1990, 1991) this distribution is not unexpected.

Table 5.3 - Number of Employees

\begin{tabular}{|l|c|c|c|c|c|}
\hline Value Label & Value & Frequency & Percentage & Valid \% & Cum. \% \\
\hline Employees & & & & & \\
\hline $0-10$ & 1 & 133 & 55.2 & 55.6 & 55.6 \\
\hline $11-25$ & 2 & 48 & 19.9 & 20.1 & 75.7 \\
\hline $26-100$ & 3 & 42 & 17.4 & 17.6 & 93.3 \\
\hline $101-200$ & 4 & 8 & 3.3 & 3.3 & 96.7 \\
\hline $200+$ & 5 & 8 & 3.3 & 3.3 & 100 \\
\hline
\end{tabular}

Table 5.3 shows that the majority $(93.3 \%)$ of respondents had under 100 employees. Only 3.3\% had 101-200 or over 200 employees. Therefore any comparisons made or interpretations induced using the larger company data should be approached with caution. The value category is an SPSS assignment and the frequency is the frequency of response.

Having descriptively analysed the sample, this subsequent section considers the sample characteristics in more depth. It will consider the component parts of each significant sample characteristic and highlights any relevant deviations from the mean. The single site business category corresponded in nature to the sample average response, i.e. the nature (industrial sector, exporters or non-exporters, number of employees) of the single site businesses were similar to the overall sample. Being the largest respondent group, this distribution is to be expected. The headquarters units had, however, a greater proportion of tertiary respondents than the average $(66.7 \%$ compared with a sample average of $55.6 \%$ ). The national subsidiaries or branch plant respondents were skewed further towards the larger, secondary industrial sector companies and 50\% of the foreign 
subsidiary or branch plant respondents had over 200 employees. The sample average of companies with over 200 employees was $3.3 \%$. $100 \%$ of the subsidiaries of foreign enterprises were from the secondary sector. A caveat, however, is the relatively low level of response from this sector.

Figure 5.2 - Percentage Number of Exporters and Non-Exporters

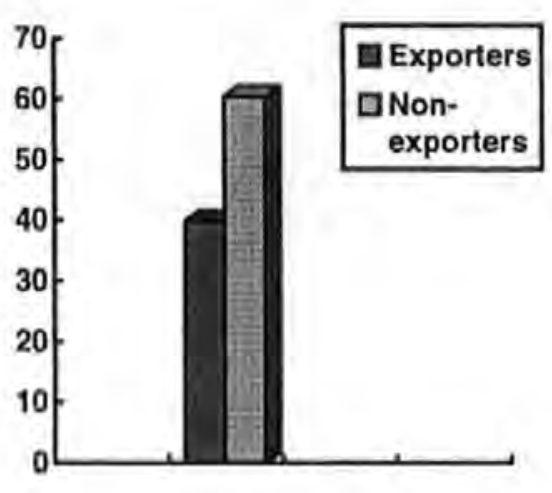

Of the companies with $0-10$ employees, $84.1 \%$ were single site businesses (the sample average was $67.6 \%$ ), there were no subsidiaries or branches of foreign enterprises and $65.4 \%$ were from the tertiary sector compared with a sample average of $55.6 \%$. In the category of $11-25$ employees, $6.3 \%$ were from the primary sector, which is a relatively large deviation from the sample average of $4.2 \%$. Of the respondent companies with 26100 employees, $33.3 \%$ were national subsidiaries or branch plants, compared with an average for the sample of $16 \%$. $59.5 \%$ were from the secondary sector. The general trend that the larger the company, in employee terms, the more likely it would be a subsidiary or a branch plant of a national or foreign enterprise, continued in the 101-200 and $200+$ categories. 
Figure 5.2 graphically displays the percentage response of exporters and non-exporters. Just over $60 \%$ of the companies who responded were non-exporters, which is to be expected with the predominance of small, owner managed firms in the sample area. None of the companies within the primary sector were foreign based companies, neither did they have above 100 employees. The secondary industrial sector category had a bias towards the larger nationally owned companies than the sample average and the tertiary sector respondents corresponded to the average sample response.

\subsection{Perceptions and Attitudes}

Primary Null Hypothesis 1 - There are no significant differences in the attitudes of the SME sector towards environmental issues.

The survey results are full of apparent contradictions suggesting that the SME sectors level of awareness of environmental issues is low and knowledge is confused.

Figure 5.3. - Percentage Importance of Environmental Issues

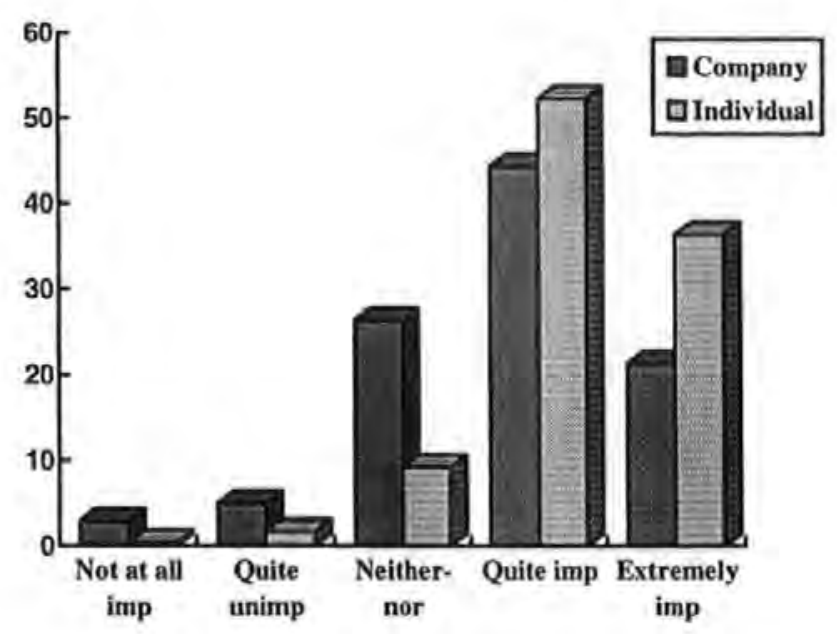


Table 5.4 - Percentage Importance of Environmental Issues

\begin{tabular}{|c|c|c|c|c|c|}
\hline \multirow{2}{*}{$\begin{array}{l}\text { Environm- } \\
\text { ental Issue }\end{array}$} & \multicolumn{5}{|c|}{ VALID PERCENTAGES } \\
\hline & $\begin{array}{l}\text { Not at all } \\
\text { important }\end{array}$ & $\begin{array}{c}\text { Quite } \\
\text { unimportant }\end{array}$ & $\begin{array}{l}\text { Neither imp } \\
\text { nor un-imp. }\end{array}$ & $\begin{array}{c}\text { Quite } \\
\text { important }\end{array}$ & $\begin{array}{l}\text { Extremely } \\
\text { important } \\
\end{array}$ \\
\hline Acid rain & 13.9 & 4.2 & 44.7 & 21.9 & 15.2 \\
\hline $\begin{array}{l}\text { CfCs } \\
\text { Ozone } \\
\text { depletion } \\
\end{array}$ & 11 & 5.1 & 38.1 & 24.6 & 21.2 \\
\hline $\begin{array}{l}\text { Global } \\
\text { warming }\end{array}$ & 11.9 & 3 & 40.9 & 23 & 21.3 \\
\hline $\begin{array}{l}\text { Water } \\
\text { pollution }\end{array}$ & 8.4 & 2.9 & 26.9 & 25.2 & 36.6 \\
\hline $\begin{array}{l}\text { Energy } \\
\text { usage }\end{array}$ & 5 & 1.7 & 15.9 & 42.3 & 35.1 \\
\hline $\begin{array}{l}\text { Effluent } \\
\text { waste } \\
\text { disposal } \\
\end{array}$ & 9.2 & 3.4 & 28.2 & 26.1 & 33.2 \\
\hline $\begin{array}{l}\text { Deforest- } \\
\text { ation }\end{array}$ & 13.1 & 2.5 & 39.4 & 22.5 & 22.5 \\
\hline $\begin{array}{l}\text { Noise } \\
\text { pollution }\end{array}$ & 5.5 & 2.1 & 30.3 & 36.6 & 25.6 \\
\hline $\begin{array}{l}\text { Vehicle } \\
\text { emissions }\end{array}$ & 10.1 & 2.5 & 33.3 & 32.9 & 21.1 \\
\hline $\begin{array}{l}\text { Solid waste } \\
\text { disposal }\end{array}$ & 10.1 & 1.3 & 28.2 & 32.4 & 28.2 \\
\hline $\begin{array}{l}\text { Resource } \\
\text { depletion }\end{array}$ & 8.9 & 4.2 & 33.5 & 29.7 & 23.7 \\
\hline $\begin{array}{l}\text { Employee } \\
\text { health and } \\
\text { safety }\end{array}$ & 2.1 & 0.4 & 4.6 & 27.2 & 65.7 \\
\hline $\begin{array}{l}\text { Financial } \\
\text { support for } \\
\text { environm- } \\
\text { ental groups }\end{array}$ & 12.2 & 8.4 & 47.7 & 21.9 & 9.7 \\
\hline
\end{tabular}


Respondents were asked how important environmental issues were to their business practices (Appendix 1). Answers ranged from extremely important to not at all important (Figure 5.3). Most respondents stated that environmental issues were important to their business practices. This was encouraging, at least on a subjective level, as it suggested a high level of interest in the environment as a business issue.

However when asked about specific environmental issues e.g. global warming and acid rain, answers converged more on the neither unimportant nor important point on the scale (Table 5.4). This suggests limited understanding of the particular environmental issues considered and appears to contradict the previous answers on the importance of environmental issues. After saying environmental issues in general are important to their business practices, respondents regard most specific issues as neither unimportant nor important to their business practices. It could be argued that an amalgamation of a number of less important specific issues creates one larger cause for concern. In this case it must be assumed that, to date, SMEs have placed little importance on understanding the issues themselves.

Energy usage was considered either quite important or extremely important to their business practices by $77.4 \%$ of companies and $62.2 \%$ felt noise pollution had the same levels of importance. Employee health and safety, energy efficiency, noise pollution and waste disposal ranked as the most important environmental issues.

The questions in this section were designed to fall into two broad groupings to aid further analysis. The issues in Table 5.5 can be seen as either 'micro' or 'macro' environmental issues. The micro issues relate to any localised environmental issue that has a tangible effect on the operations of a company: energy usage would be an example. The macro environmental group relates to more global problems that may well owe their existence to 
localised practices but are not felt directly by company operations. The intention was to see if there were any associations between groups. Although micro and macro issues are interdependent and interrelated, a distinction was made to clarify a point of general awareness.

Table 5.5 - Specific Environmental Issues - A Factor Analysis

\begin{tabular}{|l|c|c|c|}
\hline $\begin{array}{l}\text { Environmental } \\
\text { issue }\end{array}$ & Factor 1 & Factor 2 & Communalities \\
\hline Acid rain & $\mathbf{0 . 5 1}$ & $\mathbf{0 . 7 2}$ & 0.77 \\
\hline $\begin{array}{l}\text { CfC / Ozone layer } \\
\text { depletion }\end{array}$ & 0.43 & $\mathbf{0 . 7 5}$ & 0.75 \\
\hline Global warming & 0.48 & $\mathbf{0 . 7 3}$ & 0.76 \\
\hline Water pollution & $\mathbf{0 . 7 6}$ & 0.33 & 0.69 \\
\hline Energy usage waste & $\mathbf{0 . 7 9}$ & 0.14 & 0.64 \\
\hline $\begin{array}{l}\text { Effluent } \\
\text { disposal }\end{array}$ & $\mathbf{0 . 7 4}$ & 0.31 & 0.65 \\
\hline Deforestation & $\mathbf{0 . 6 1}$ & 0.59 & 0.74 \\
\hline Noise pollution & $\mathbf{0 . 8 1}$ & 0.09 & 0.66 \\
\hline Vehicle emissions & $\mathbf{0 . 7 4}$ & 0.35 & 0.66 \\
\hline $\begin{array}{l}\text { Solid waste } \\
\text { disposal }\end{array}$ & $\mathbf{0 . 7 9}$ & 0.2 & 0.66 \\
\hline Resource depletion & $\mathbf{0 . 6 1}$ & 0.45 & 0.59 \\
\hline $\begin{array}{l}\text { Employee health } \\
\text { and safety }\end{array}$ & -0.08 & 0.45 & 0.21 \\
\hline $\begin{array}{l}\text { Financial support } \\
\text { for environmental } \\
\text { groups }\end{array}$ & 0.31 & 0.65 & 0.51 \\
\hline
\end{tabular}

$\begin{array}{lll}\text { Eigenvalue } & 7.24 & 1.05 \\ \text { Percentage variance } & 55.7 \% & 8.1 \%\end{array}$

Factor 1 - $\quad$ Classified as Micro environmental issues

Factor 2 - $\quad$ Classified as Macro environmental issues 
It could be argued that while all environmental issues are localised in essence, some have global cumulative effects. Therefore a useful distinction could be made between those activities having a tangible effect on everyday business management and those with effects which are less immediate because of the scale of the impact e.g. global warming.

To research the possibility of a dichotomous grouping here, a confirmatory factor analysis was undertaken (see Table 5.5 and Appendix 1). Factor analysis groups variables, according to common factors (Child, 1990). In this case the variables were grouped together according to the scale of the environmental issue. The results confirm that most items load on two interpretable factors when using a conservative loading factor of 0.5 (Cureton et al, 1983). The significance of the factor model was tested by applying the Kaiser-Meyer-Olkin (KMO) measure of sampling adequacy as well as the Bartlett Test of Sphericity.

With both tests the factor's model was highly significant. The KMO was very close to the perfect figure of 1 at 9.1059 and the Bartlett test resulted in 2076 with a significance level of 0.00 , which is highly significant. Factor one interprets as the micro environmental issues and factor two as the macro environmental issues, with the only anomalies being deforestation and employee health and safety. Deforestation fell into both groups, whereas employee health and safety did not classify in either. Respondents felt that the more localised micro environmental issues were more important than the global, macro environmental issues.

Using the T. Test, (Appendix 1), further analysis of the company characteristics of each factor group showed that the larger SMEs considered micro environmental issues to be more important than the macro issues (e.g. acid rain and global warming). This suggests that the larger the company, the more educated and aware it is of relevant environmental 
issues. Smaller less informed companies generally quoted the more popular and higher media profile environmental issues as important, (e.g. deforestation and global warming), even though these had less immediate impact to their present circumstances.

Having constructed a descriptive picture of SME attitudes towards environmental issues, the sector was comparatively analysed. For this purpose a more detailed analysis of the relationship between business sectors, exporting and non-exporting companies and the different sizes of company was made in order to see if there were any significant differences between these groups in relation to the level of importance they placed on environmental issues. The multivariate analysis of variance test MANOVA was employed (full results can be seen in Appendix 1). MANOVA is a multivariate analysis of variance technique that allows for comparison of two (or more) sets of data. In the following hypotheses the data is said to be significant if the following criteria have been satisfied. First, that the multivariate test of significance Wilks Lambda has been minimised below 0.05 and second, that the following univariate $\mathrm{F}$ significance test was also below 0.05. (See Table 5.6 for an example of MANOVA). If these criteria are met then the null hypothesis can be rejected at the $5 \%$ significance level. Which means that the relationship could occur by chance 5 time out of 100 . A significance level of 0.00 means that one can say with $100 \%$ confidence that there is a relationship. In most cases it is acceptable to say with $95 \%$ confidence that the relationship has not occurred by chance. This research will predominantly use $5 \%$ as the critical statistical significance level (Tabachnick, 1989).

The industrial sectors analysed were reduced from ten specific sectors to three more general ones for comparative purposes. The number of responses for the smaller industrial sectors would have invalidated many of the statistical tests, so the results were 
amalgamated into primary, secondary and tertiary sectors (see Appendix 1 for univariate and multivariate analysis of all sectors of industrial activity).

In order to analyse the results effectively a number of secondary hypotheses were designed. By testing these secondary null hypotheses and accepting or rejecting them it would be possible to make a more accurate analysis of the primary, deductive hypothesis. In certain cases variation in response from different groups have not been included in the main body of the research but are available in the relevant appendices. For example, one set of secondary, null hypotheses may include cross sectoral analysis, the differences in response of exporters and non-exporters and respondent variation between company types, whereas another set of null hypotheses may not include analysis of exporters and non-exporters, but may include further discussion on large and small SMEs and the variation in response between those two groups. This is to reduce the amount of unnecessary repetition.

Secondary Null Hypotheses

1. There are no significant differences in the perceptions of environmental issues between industrial sectors.

2. There are no significant differences in the perceptions of environmental issues between exporters and non-exporters.

3. There are no significant differences in the perceptions of environmental issues between large and small SMEs. 
The reasoning behind this group of hypotheses was to decipher how important environmental issues were to the SME sector. This includes analysis of company size, type and sector differentials.

Secondary Null Hypotheses 1

There are no significant differences in the perceptions of environmental issues between industrial sectors.

As far as the importance of environmental issues were concerned, there were no significant differences (when answering on behalf of the company and as individuals) between industrial sectors regarding their perceptions of the importance of environmental issues (Table 5.6).

Table 5.6 - MANOVA importance of Environmental Issues - Company Response By Industrial Sector.

\begin{tabular}{|l|c|c|c|c|c|}
\hline Test name & Value & Approx. F & Hypoth. DF. & Error DF. & Sig. of F. \\
\hline Pillais & .01695 & 1.00020 & 4.00 & 468.00 & .407 \\
\hline Hotellings & 0.1713 & .99352 & 4.00 & 464.00 & .411 \\
\hline Wilks & $\mathbf{. 9 8 3 1 0}$ & $\mathbf{. 9 9 6 8 6}$ & $\mathbf{4 . 0 0}$ & $\mathbf{4 6 6 . 0 0}$ &. $\mathbf{4 0 9}$ \\
\hline
\end{tabular}

Table 5.6 tabulates the multivariate significance test in the full appendix form. Because it is only the Wilks Lambda statistic that is used to judge the significance of the multivariate model, future tables will include only the Wilks Lambda figure and univariate F. statistic, which is the statistic that indicates any significance differences in the comparative 
analysis. This reductive methodology will also be applied to any univariate tables within the main body of the text (Table 5.7).

To confirm that there is no significant difference between categories of industrial sector perceptions of the importance of environmental issues to their business practices, a further MANOVA test was run with respect to the specific environmental issues.

Table 5.7 - Univariate F. Tests

\begin{tabular}{|c|c|c|c|c|c|}
\hline Variable & Hypoth SS. & Error SS. & Hypoth MS. & Error MS. & Sig. of F. \\
\hline Q5A & 1.59214 & 209.175 & .79607 & .89391 & .412 \\
\hline Q5B & .66845 & 121.02776 & .33422 & .51721 & .525 \\
\hline
\end{tabular}

No significant differences between industrial sectors response to any of the issues were detected. This is a somewhat surprising statistic, as one would expect, the secondary sector to find water pollution more important to their business practices than the tertiary sector. The inference is, the SME sector has either little understanding or interest in the issues.

The null hypothesis that there are no significant differences between industrial sectors perceptions of the importance of environmental issues, is therefore accepted at the $5 \%$ significance level. 
Secondary Null Hypothesis 2

There are no significant differences in the perceptions of environmental issues between exporters and non-exporters

Using the MANOVA multivariate analysis of variance, Wilks Lambda was minimised below 0.05 (at the individual respondent level) suggesting that there was a significant difference in the attitudes of managing directors or owner managers in the exporting and non-exporting sectors. Exporters found environmental issues to be significantly more important than non-exporters.

However, similar to the previous hypothesis, there were no significant difference in response between exporters and non-exporters when answering on behalf of the company. This trend tends to suggest that respondents were more inhibited in their responses when answering on behalf of the company rather than as individuals.

Having established this fact however, MANOVA did show significant differences in certain perceptions between exporters and non-exporters on a company level. Although there had been no significant difference between exporters and non-exporters when asked generally about the importance of environmental issues to business practices, when asked more specific questions about individual environmental issues there were some significant differences (Table 5.8).

Exporters found global warming, water pollution and effluent waste disposal significantly more important to their business practices than non-exporters. Without further analysis of the specific companys' characteristics, however, one can not really comment on these results as their significance will lie in the nature of business practices. 
Table 5.8 - Importance of Environmental Issues for Exporters and Non-Exporters

\begin{tabular}{|l|c|}
\hline VARIABLE (Importance of) & SIGNIFICANCE OF F. \\
\hline Environmental issues to company & .352 \\
\hline Environmental issues to individual & .012 \\
\hline Acid rain & .355 \\
\hline CfC/Ozone layer depletion & .101 \\
\hline Global warming & .014 \\
\hline Water pollution & .002 \\
\hline Energy usage & .165 \\
\hline Effluent waste disposal & .047 \\
\hline Deforestation & .498 \\
\hline Noise pollution & .688 \\
\hline Vehicle emissions & .529 \\
\hline Solid waste disposal & .897 \\
\hline Resource depletion & .544 \\
\hline Employee health and safety & .502 \\
\hline $\begin{array}{l}\text { Financial support for environmental } \\
\text { groups }\end{array}$ & .584 \\
\hline
\end{tabular}

In general, however, exporters have greater empathy towards the environment than nonexporters. A likely explanation is the requirements to adhere to more stringent legislative and regulatory requirements in the exporting markets, with Germany and the USA being two of the major exporting locations of South West firms (see Appendix 1 for export market descriptive statistics). In both countries green issues have a higher profile than in the U.K.

The null hypothesis that there is no significant difference in their perceptions of the importance of environmental issues between exporters and non-exporters is, therefore, rejected at the $5 \%$ significance level. 
Secondary Null Hypothesis 3

There are no significant differences in the perceptions of environmental issues between large and small SMEs.

Following the trend set by the analysis of exporters and non-exporters, perceptions of the importance of environmental issues continues in this sub-section. Although there were no significant difference between the different sizes of company in their perceptions of importance's on a company level, there were significant differences in the perceptions of specific environmental issues. There was also a significant difference between respondents answering as individuals and those answering on behalf of the company. This strengthens the alternative hypothesis that there is a significant difference between large and small SME's perceptions of the importance of environmental issues.

Although it cannot be deduced from the data that there is a significant difference between companys perceptions on a general level according to size, there are significant differences of opinion with regard to specific environmental issues. With Wilks Lambda minimised below 0.05 at 0.001 one can prognosticate, with $95 \%$ confidence, that larger SMEs are more likely to find water pollution, energy usage, effluent waste disposal and solid waste disposal more important to their business practices than smaller companies (Table 5.9). This confirms the previous factor analysis that larger firms find the more localised, micro environmental issues to be of importance, forming a significant cross reference in the validation of the research findings. The conclusion, reached through inductive analysis of the data, suggests that the larger the company the more likely it will have a greater understanding of relevant environmental issues. 
Table 5.9 - Importance of Environmental Issues for Large and Small SMEs.

\begin{tabular}{|l|c|}
\hline \multicolumn{1}{|c|}{ VARIABLE } & SIGNIFICANCE OF F. \\
\hline Water pollution & .011 \\
\hline Energy usage & .010 \\
\hline Effluent waste disposal & .016 \\
\hline Solid waste disposal & .034 \\
\hline
\end{tabular}

Deriving from the fact that larger companies are far more likely to have the time and resources available to address their perceived, peripheral strategic issues like the environment. The results suggests that there is a statistical relationship between size of company and environmental awareness.

The null hypothesis is therefore rejected at the 5\% significance level and accept the alternative hypothesis, that there are significant differences between the size of the SME and the perceived importance of environmental issues.

With two out of the three secondary hypotheses rejected at the 5\% significance level, there is enough evidence to reject the primary, deductive hypothesis that there are no significant differences in the attitudes of the SME sector towards environmental issues. Clearly there are significant differences of opinion regarding attitudes towards environmental issues in a number of areas. There are also, however, a number of areas where significant differences do not exist. An example is that there is no significant difference in response between industrial sectors with regard to their attitudes towards environmental issues generally. 
Having considered the question of attitude towards environmental issues and gleaned a basic understanding of SME opinions of environmental issues, it was then necessary to analyse in more detail issues of environmental awareness.

\subsection{Environmental Awareness}

Primary Null Hypothesis 2 - There are no significant differences in the awareness of SMEs to environmental issues.

This hypothesis relates to questions $7 \mathrm{a}$ to question $7 \mathrm{~h}$ in mail survey one (Appendix 1) and considers matters of fact with particular reference to the awareness of SMEs to environmental legislation and regulations.

Before considering comparisons within the SME sector a few comments are necessary on a general level regarding the data generated. General awareness of environmental legislation and regulation is low in Devon and Cornwall's SME sector, (Table 5.10). $62.8 \%$ of respondents were unaware of the implications to their business practices of the 1990 Environmental Protection Act (EPA) and only 27.4\% of respondents were aware of the implications of BS 7750. This compares favourably, however, with the EC Eco-Audit Scheme (now EMA, the Environmental Management and Auditing Scheme) of which only $16 \%$ were aware. $21 \%$ were aware of the existence of the EC eco-label, although subsequent in-depth interviews showed this figure to be over inflated. Many respondents thought they knew what the eco-label was but were confusing it with many other environmental labels. Only $13 \%$ were aware of any EC directives on the environment. This lack of interest in EC policy making, suggests a reactive approach to the environment. 
Nearly a quarter of the respondents were not aware of the implications of the quality standard BS 5750. With $62.8 \%$ still unaware of the implications of the 1990 EPA, $68.8 \%$ unaware of the implications of the 1989 Water Act and 43.3\% unaware of the implications of the Control of Substances Hazardous to Health (COSHH) to their business practices, it must be concluded that levels of awareness of environmental legislation and regulation are low in the SME sector.

Table 5.10 - Percentage Awareness of Environmental Legislation and Regulation

\begin{tabular}{|l|c|c|c|}
\hline \multirow{2}{*}{ LEGISLATION/REGULATION } & \multicolumn{3}{|c|}{ PERCENTAGE AWARENESS } \\
\hline & Yes & Do Not Know & No \\
\hline EC Eco-labelling scheme & 20.9 & 46.9 & 32.2 \\
\hline EC Eco-Auditing scheme & 15.9 & 51.9 & 32.2 \\
\hline Forthcoming EC directives & 12.8 & 54.3 & 32.9 \\
\hline BS 5750 & 74.2 & 13.6 & 12.3 \\
\hline BS 7750 & 27.4 & 43.9 & 28.7 \\
\hline 1990 EPA & 37.2 & 38 & 24.8 \\
\hline Water Act 1989 & 31.2 & 42.7 & 26.1 \\
\hline C.O.S.H.H. 1988 & 56.6 & 27.2 & 16.2 \\
\hline
\end{tabular}

A laggard approach towards the environment is likely to encourage a reactive management culture. This is the antithesis of the proactive management structure required to establish environmental management systems solutions. 
A strong dichotomy of response is apparent: on the one hand companies feel that environmental issues are important to their business practices; on the other they are unaware of relevant legislation and regulations. A number of reasons could lie behind this ignorance. Faults in the diffusive information pathways from support organisations seem probable. There could also be time constraints on the company as well as limited financial resources available. Opinions were more positive on general attitudes towards the environment than on specific issues. It would appear that SMEs have not, in general, considered the relevance of the environment to their particular business. Alternatively they were only paying lip service to the environment as a topical issue.

A Chi-Square test was used to consider if there were any significant differences in the responses of the different business types, sizes of business and industrial sectors to the expected awareness of environmental legislation and regulation (Table 4.11). The ChiSquare distribution is one that consists of the sum of a series of independent squared standard normal random variables and is used when the data being analysed is nonparametric. To help with this analysis three secondary, deductive hypotheses were established.

Secondary Null Hypotheses:

1. There are no significant differences in awareness of environmental legislation and regulation between company types.

2. There are no significant differences in awareness of environmental legislation and regulation between large and small SMEs. 
3. There are no significant differences in awareness of environmental legislation and regulation between industrial sectors.

Secondary Null Hypothesis 1:

There are no significant differences in awareness of environmental legislation and regulation between company types.

Company types categorises businesses as single site units, headquarters units, subsidiary or branches of national enterprises or as subsidiaries or branches of a foreign enterprises.

Because of the relatively large number of variables, the number of cells with expected frequencies of more than 5 (a requirement for the test according to Sandy, 1990) did not achieve the required amount $(80 \%)$. It was therefore felt that collapsing the data into the following categories, would provide greater accuracy. This proved to be the case. Therefore all Chi Square tables printed in the main body of the research have fulfilled this requirement. Pearson's Chi statistic was also used on all occasions.

Hence the categories of $a$ subsidiary or branch of a national enterprise and a subsidiary or branch of a foreign enterprise were amalgamated having the common denominator of subsidiary. It was felt that, for the purpose of comparison, this classification was valid since the original classifications were arbitrary.

A highly significant grouping of data resulted. Significant differences of observed and expected data were found in each category. The higher the Chi statistic the more significant this is. A significant difference between business types in their expected and 
observed response to their awareness of the implications of the eco-label appeared. Observed frequencies of single site businesses knowing of the implications of the ecolabel are lower than would be expected and observed frequencies of subsidiaries or branches of national or foreign enterprises are higher than would be statistically expected. Effectively this means that the larger the business unit the more likely it will be aware of the implications of the regulation to its business practices.

Table 5.11 - Awareness of Regulation By Company Type

\begin{tabular}{|l|c|c|}
\hline \multicolumn{1}{|c|}{ VARIABLE } & PEARSON'S CHI & SIGNIFICANCE \\
\hline Eco-Labelling & 31.98445 & $\mathbf{0 0 0 0 0}$ \\
\hline EC Eco-Audit scheme & 24.54011 & .00006 \\
\hline Forthcoming directives & 12.90064 & $\mathbf{0 1 1 7 7}$ \\
\hline BS 5750 & 10.96817 & $\mathbf{0 2 6 9 2}$ \\
\hline BS 7750 & 19.37284 & $\mathbf{0 0 0 6 6}$ \\
\hline EPA & 20.63949 & $\mathbf{0 0 0 3 7}$ \\
\hline Water Act & 17.89926 & $\mathbf{0 0 1 2 9}$ \\
\hline C.O.S.H.H. & 22.31162 & $\mathbf{0 0 0 1 7}$ \\
\hline
\end{tabular}

The pattern is replicated with regard to the awareness of the eco-auditing scheme, with larger company units being more likely to be aware of the implications to their business practices than the smaller single site businesses or even headquarters units. This general pattern applies for all responses related here. The larger the business unit the more likely it will be aware of environmental legislation and regulations. 
Although most of the significance levels are valid at the $1 \%$ significance level one can not reject the hypothesis at this level. The more general hypothesis that there is no significant difference in awareness of environmental legislation and regulations between company types is therefore rejected at the $5 \%$ significance level. The reason for this is that one loses some significance by amalgamating significance levels and it would be safer to conclude at this lower level.

\section{Secondary Null Hypothesis 2}

There are no significant differences in the awareness of environmental legislation and regulation between large and small SMEs.

Once again the data set was reduced to allow for a more accurate comparison to take place. The categories were reduced from (0-10); (11-25); (26-100); (101-200) and (200+) to (0-25); (26-100) and (101+), (Table 4.12). The statistical trend was similar to the previous hypothesis, the larger the company the more likely it would be aware of environmental legislation and regulations.

Further analysis of the cell information showed that all of the questions followed this trend. Again because one is considering the amalgamation of significance levels one has to err on the side of caution and reject the null hypothesis at the confidence $95 \%$ level although many of the individual significance levels are significantly lower than this. 
Secondary Null Hypothesis 2

There are no significant differences in the levels of environmental management between large and small SMEs.

Using the same method as above, the multivariate test of significant variation was minimised below 0.05 at 0.00 . The univariate $F$ tests suggested that there was significant variation in response with the following issues: energy efficiency, waste management, environmental auditing, pollution control policy, environmental staff training and the implementation of environmental management systems (Table 5.16).

Table 5.16 - Environmental Management By Company Size

\begin{tabular}{|l|c|}
\hline \multicolumn{1}{|c|}{ VARIABLE } & SIGNIFICANCE OF F. \\
\hline Recycling policy & .406 \\
\hline Energy efficiency & .001 \\
\hline Waste management & .000 \\
\hline Checking suppliers policy & .360 \\
\hline Reduction of packaging & .163 \\
\hline Environmental audit & .000 \\
\hline Pollution control policy & .004 \\
\hline Environmental staff training policy & .006 \\
\hline Environmental transport policy & .456 \\
\hline Environmental management system & .000 \\
\hline
\end{tabular}


The explanation for this variance was also clear, after analysis of the cell information (Appendix 1). The larger the company (or more employees) the more likely it would either have considered or implemented the policies. The null hypothesis is therefore rejected at the $5 \%$ significance level and the alternative hypothesis that there are significant differences in the levels of environmental management between large and small SMEs is accepted.

Secondary Null Hypothesis 2

There are no significant differences in the level of environmental management between different company types.

Table 5.17 - Environmental Management By Company Type

\begin{tabular}{|l|c|}
\hline \multicolumn{1}{|c|}{ VARIABLE } & SIGNIFICANCE OF F \\
\hline Recycling policy & .159 \\
\hline Energy efficiency & .075 \\
\hline Waste management & .000 \\
\hline Checking suppliers policy & .026 \\
\hline Reduction of packaging & .136 \\
\hline Environmental audit & .000 \\
\hline Pollution control policy & .005 \\
\hline Environmental staff training policy & .001 \\
\hline Environmental transport policy & .323 \\
\hline Environmental management system & .002 \\
\hline
\end{tabular}


The multivariate test of significance, Wilks Lambda, was minimised below 0.05 which suggested that there was significant variation in the responses of different company types. For the areas of variation see Table 5.17. They appear as waste management, checking suppliers policy, environmental audit, pollution control policy, environmental staff training and the implementation of Environmental Management Systems.

By analysing the cell information and the mean responses one can explain the significance of the univariate $F$ tests. The picture for all of the tests is similar on each occasion: the larger the operation the more likely it is that they would have considered or implemented the environmental procedures.

The null hypothesis must therefore be rejected at the $5 \%$ significance level and the alternative hypothesis, that there are significant differences between company types and their level of environmental management must be accepted.

Each secondary null hypothesis has been rejected with $95 \%$ confidence. The primary null hypothesis is therefore rejected and the alternative hypothesis that there are significant differences in the levels of environmental management within the SME sector is accepted.

Evidently attitudes, awareness and levels of environmental management differ within the SME sector. This chapter has proved that the larger the company, especially in the secondary sector, the higher the likelihood it will take the environmental question seriously. This is, however, by necessity a relative comparison. If these levels of awareness, attitudes and practices of the larger SMEs are universally applied it is unclear whether sustainability would result. What is certain is that SMEs (in particular the smaller ones) are not sufficiently environmentally conscious to make substantial changes 
to their practices. Therefore the question has to be, why? Why are the smaller SMEs not changing their practices significantly? Further, why are the majority of SMEs not planning for the environment strategically? Until these fundamental questions are resolved and an appropriate framework for dealing with them constructed, SMEs will continue to be reactive in their approach to environmental issues. 


\section{CHAPTER 6}

\section{RESULTS -}

\section{THE IN-DEPTH INTERVIEWS}




\subsection{Objectives and Sample Characteristics}

Phase one of the empirical data collection involved establishing what the position was with regard to SMEs in Devon and Cornwall. It allowed for detailed analysis and comparison between industrial sectors and types of SMEs with regard to their environmental attitudes, procedures and practices. Phase two (see Figure 4.1.) of the empirical data collection aimed to clarify some of the questions raised in phase one and to introduce questions relating to the next major research question of why the attitudes and practices in phase one were the way they were. Chapter 6 satisfies the second research aim (Chapter 1) to gain an understanding of the scale and nature of response to environmental issues across a broad section of SMEs and to cross tabulate results.

This second phase took the form of in-depth interviews with 14 companies. The interviews were semi-structured to allow freedom to discuss ideas and for inductive, qualitative research techniques to be used. However, the loose questioning technique was sufficiently structured to constrain the interviewee to at least a certain area of discussion. This is an important consideration for discussion of an interdisciplinary subject (Walker, 1985).

It was anticipated that the in-depth interviews would also provide the basis for a second mail survey, which would test on a a larger sample the questions and issues highlighted by interviewees. Therefore phase 2 of the empirical data collection has a dual purpose, firstly to collect data from owner managers about green issues and to gauge the general feeling in the field, but it also acts as a bridge between research techniques. The questions posed and individual, company profiles can be found in Appendix 2. 
The companies were selected randomly from each industrial sector to give a balanced picture. Of the fourteen companies interviewed, six were from the secondary sector and eight were from the tertiary sector. Availability of company managers was the predominant determining factor in the selection of firms for interview. All were taken from a random sample of 10 companies from each industrial sector and there was no bias towards environmentally friendly companies. No specific hypotheses were built because this phase of the research was inductively based. The general objectives were threefold:

1. To clarify specific issues arising from the first mail survey, e.g. certain management practices and any ambiguous response.

2. To explain company response, attitude and awareness in the first mail survey.

3. To gauge opinion on the prescribed environmental management solutions and their alternatives.

The in-depth interviews consider the environmental initiatives and policies in place: how companies feel about the initiatives they have employed; and why environmental strategic. management in the SME sector is so low. The results from this inductive research were intended to clarify the structure for the second mail survey. This would consider the applicability of the proposed solutions offered to SMEs to reduce their adverse environmental impact, examine the cause of environmental degradation and review alternative solutions.

The in-depth interviews also aimed to elicit what SMEs would find useful as far as additional help was concerned, to reduce their adverse environmental impact. The 
applicability of BS 7750, the environmental standard, is considered in the light of interviewee response.

Questions were loosely designed to allow for the Action Learning techniques discussed in Chapter 4 to emerge. This meant that on most occasions discussions were broadened quite considerably, although the semi-structured format of the interview did allow for a certain amount of directional encouragement with respect to the discussions. Questions were designed to elicit information on the following subject areas:-

1. Company details and background information.

2. Environmental perceptions, initiatives and strategies.

3. Perceived problems with environmental management.

4. Helpful solutions.

5. General issues relating to the environmental attitudes and policies of the firms.

What follows is a summary of the discussions under the following headings: Incentives to. be environmentally friendly; Initiatives in place; and Perceived solutions. The three sections relate to the above questions in a general way and allow for a conglomeration of a number of the issues raised. Full transcripts can be viewed in Appendix 2.

\subsection{Incentives to be Environmentally Friendly}

In discussion it was suggested that analysis of solutions to environmental problems were hampered by inadequate delineation of the "problem". In theory and practice, green issues are so wide ranging in nature that the management structures of SMEs are simply. not adequate to deal with them holistically. Companies are confused about the range of issues and effective solutions. This confusion usually leads to a reluctance to act. Most 
(93\%) SMEs deal with environmental problems (if at all) by employing critical incident situation management. They wait for the issue to become a problem and then apply "common sense". This reactive approach is unlikely to achieve sustainable development: by definition it is not preventative in nature. The achievement of sustainable development may require more than just critical incidence situation management. It could require education about the concept of sustainability and a fuller understanding of the businesses, potential environmental impact.

This essentially educative process takes time and therefore money, both of which are not available to most SMEs within the present system. Even if the employment of environmental strategies within an SME did lead to cost savings, many SMEs (79\%) feel that the opportunity cost (or time spent) on the consideration of green issues and the subsequent implementation of these strategies, are too great. That time could have been spent selling more goods or building up more business.

A clear distinction appeared between the secondary and tertiary sectors in their motivational interest in the environment. The dominant motivation factor in the secondary sector was legislation, whereas the tertiary sector felt customer pressure to be more of a catalyst for change. However, one area both sectors seemed to agree on was the fact that environmental issues were becoming more and more of a competitive issue.

In general the secondary sector reacts primarily to legislation but there were other reasons for companies to have an interest in environmental issues. Secondary sector companies (as suppliers) found themselves under increasing pressure from larger buyers to improve their environmental performance. An integral part of an holistic environmental management strategy for a large company is to check their suppliers' environmental records. Therefore smaller companies are beginning to be affected by the self-regulatory 
mechanisms of the environmental management systems employed by larger companies. Pressure to comply to legislation was particularly high amongst those companies who exported to northern continental Europe. It was however suggested that accreditation to a standard like BS 7750 can be a purely cosmetic exercise undertaken for commercial reasons only. Indeed, $86 \%$ felt cynical in about the process of environmental management and the subsequent accreditation procedure.

A general feeling, in particular from the secondary sector, was that legislation was the dominant force of change (50\% felt legislation was the dominant catalyst for change). However, interviewees felt that legislative pressure (rather than self imposed regulation) encouraged companies to wait until they were forced to undertake changes and resulted in the implementation of no more than the minimum requirements. Roome has labelled these companies as compliance companies (Roome, 1992). It was generally felt that this system of 'worst legal practice' could never produce sustainability. A preferable strategy, could be to improve the educational provision and information diffusion to companies to persuade companies in the virtues of environmental improvement. The imposition of unwanted and incomprehensible requirements on companies was generally agreed to be severely limited in its effectiveness, by $93 \%$ of interviewees.

The use of economic instruments was regarded in a similar light. Although concepts like changing the direction of company taxation away from profits towards the use of environmental resources were seen as conceptually interesting by $43 \%$ of interviewees, change on this level was viewed with a certain amount of unease. Insurance and banking incentives to improve environmental performances were viewed with particular cynicism. The primary explanation for this was that financial matters could easily be personalised and biased as banks took environmental issues in to account with a limited empathy for the plight of specific trades. There was cynicism about the ability of external auditors to 
understand the intricacies of their specific trade areas and a general feeling than companies could be discriminated against due to inaccurate information. Development of the idea of barriers to environmentally unfriendly goods was viewed as restrictive. This was due to the fact that SMEs felt that they would find themselves being discriminated against as they could not afford to compete with the larger companies in terms of innovation.

In the course of the interviews, attempts were made to explore the implications of the limitations of GNP as an indicator of sustainable lifestyles. As with most discussions on the use of economic instruments to reduce environmental damage this concept was generally not understood. SMEs are conservative and wary of large scale change in any economic or political area, they consequentially feel that the optimum response to environmental pressures is self-regulation. Self-regulation would, however, require a much higher level of environmental awareness than that revealed by the first mail survey (Table 5.10) or indeed in the in-depth interviews.

$71 \%$ of interviewees felt that information diffusion to the SME sector regarding environmental issues was poor. This is theory consistent (Hendry, 1992) and emerged as one of the most important areas considered in this research. If the information required to. change attitudes and practices is not reaching the SME sector, progress will inevitably be slow. Additionally environmental dissemination flows may be regarded as irrelevant when issues are imperfectly understood. It would appear that applicable environmental information flows are essential for an SME to start to understand the benefits and potential of efficient environmental management. As and when these emerge, SMEs may achieve self-regulation and aim for best practice. 
Although it was accepted that increased information flows would help most SMEs with their decision making process with regard to environmental considerations, there was a certain level of unease regarding the use of information to aid compliance with legislation. Traditionally SMEs have viewed legislation as a priori restrictive to practices with regard to environmental considerations. This tends to occur where legislative policy formulation occurs with little consultation and when decisions are taken at a distance from the workplace. Decisions on business practices can be taken by legislators who are unaware of and unsympathetic to their own particular industrial practices. The general feeling emerged that legislative change may be impractical as the experience of the individual businesses are not sufficiently incorporated into the legislative process.

Interviewee response to the legislation/self-regulation debate was mixed. Some regarded legislation as essential. Others placed their faith in self-regulation and no clear conclusion can be drawn here. The argument for self-regulation had its critics. Selfregulation was seen by some as an escape clause allowing businesses to ignore the issues and their responsibilities and take no action. However, the market can exert a powerful influence on decision making. Where this occurs, self-regulation is infinitely preferable to imposed regulation which is reactive and often compromises the long term needs of the environment. There are a number of other problems attached to the legislation route, not least the issue of policing the legislation and enforcing penalties. This may be relatively straightforward where there is potential for a large environmental disaster and where large firms are involved. However, proof and prosecution on the SME scale is a totally different matter. It is therefore necessary to work out how SMEs can be persuaded of the merits of environmental best practice and supplied with the support framework and information to enable them to change their practices. 
In theory it is plausible that the SME sector could fully understand the benefits of clear environmental management, therefore allowing radical change, in the short term, however, this is unlikely. Legislative developments are therefore an essential means to keep environmental considerations on the agenda. In practice compliance with EU directives (in the secondary sector) has provided a firm foundation from which to build.

Of the $29 \%$ that were aware of the existing environmental legislation affecting their business, $75 \%$ felt that the legislation had been drawn up without due consultation with respective trade associations. This would seem to be a critical point with respect to SME environmental management. The high level of resentment towards external decision makers imposing regulations on a trade they were not perceived to understand could be counter productive. Equally the voluntary environmental management standards developed to be universally applicable were often perceived as irrelevant and in cases detrimental to business practices. A generic approach may have been mistakenly applied to the SME sector because of the diverse nature of firms. Building a model that is as applicable to a corner shop in Barnsley as a chemical manufacturer in Birmingham is impractical. Since trade associations are highly respected it was felt that sector specific environmental models disseminated through trade association journals would be more highly regarded than the more generic British standard. These sector specific models would, of course, include a large input from the relevant industry, making implementation financially viable and logistically feasible.

Further it was felt that the location of the SME itself was a significant factor with regard to incentives to be more environmentally friendly. Businesses located in a small villages find the views of the community to be extremely important. This aspect of the theory of bioregionalism indicates that, in practice, other values compete with profit maximisation to be taken into account by the SME (Morehouse, 1993; Conaty, 1993b). Since local 
residents value their environment highly a company small enough to have a real feel for the surroundings and residents feelings, gives the environment a higher priority. Larger companies with headquarters elsewhere can become detached from the locality in terms of policy formation. This would suggest that an integral part of a central business policy on the environment would encompass enhanced opportunity for small-scale operations and local trade.

\subsection{Initiatives in Place}

Results broadly confirmed the findings of the first mail survey (see Table 6.1.) with regard to the level and type of environmental initiatives in place. Recycling, energy efficiency, employee health and safety and waste management programmes were the most common initiatives. The tertiary sector (in particular the office based companies) considered recycling to be the most important environmental concern, being a high profile initiative that saved money and raised the consciousness of the workforce. In general the more manufacturing based companies considered recycling an extremely efficient process which could accrue a substantial cost saving.

It was suggested, however, that the unduly restrictive nature of the Duty of Care Regulation (Part Two of the 1990 EPA) could act as a disincentive to recycling. This is a reference to the fact that companies can no longer legally transport waste from their site to a recycling centre. There is a legal requirement for an independent company to undertake this task at a cost to the waste producer. Exasperation and negative feeling towards green issues has resulted especially where the initial reason for interest in the environment was personal conviction. Such legislation can be counterproductive. The very complexity of the subject area leads many companies to avoid legislative compliance. Indeed many companies feel that it is safer to avoid drawing attention to 
their operations in the first place by ignoring the issues completely. Small companies also find legislative legal advice is far too costly.

Table 6.1 - In-depth Interview: Environmental Initiatives

\begin{tabular}{|l|c|}
\hline \multicolumn{1}{|c|}{ INITIATIVE } & VALID PERCENTAGE \\
\hline Recycling & 50 \\
\hline Energy efficiency policy & 35.7 \\
\hline Waste management programme & 42.8 \\
\hline Checking suppliers policies & 7.1 \\
\hline Packaging policy & 14.2 \\
\hline Environmental audit & 7.1 \\
\hline Pollution control policy & 14.2 \\
\hline Staff training policy & 7.1 \\
\hline Transport policy & 28.5 \\
\hline Environmental management system & 7.1 \\
\hline
\end{tabular}

Energy efficiency is seen as a potential cost saver and has been implemented by $36 \%$ of the interviewees. Many energy efficiency initiatives in place, however, are limited to simple procedures like switching off the lights. Few interviewees had considered more in-depth issues like insulation and energy supplies. The initiatives in place were more simple operational initiatives that required little time and financial investment. This is unlikely to change without strategic plans in place to allow for a more holistic understanding of green issues. Waste and emission control was seen as an more of an important issue for the secondary sector companies interviewed than the tertiary sector 
companies. However, tertiary sector companies that dealt with large amounts of packaging also suggested that waste disposal was an important issue.

Generally, the results mirrored the mail survey. Most environmental initiatives arose from the need for legislative compliance in the secondary sector and from the customer image impact in the tertiary sector. Environmental issues on the whole were considered a low priority business issue, initiatives usually taking the form of ad hoc, critical incidence situation management.

Certain companies with an integral interest in the environment tended to have a more holistic approach to the environment. Some consultancies, for example, were interested in BS 7750 accreditation for commercial reasons and were therefore more likely to have considered the environment as a business opportunity. Similarly companies dealing with highly toxic substances were traditionally concerned to present an environmentally friendly image. They were therefore likely to have more environmental initiatives in place than companies who considered their environmental impact to be minimal.

In general, the inclination to plan strategically to incorporate green considerations into business practices, was low. Only 7\% had an EMS in place. This confirmed the findings of the first mail survey. Indeed the inclination to formulate strategic plans at all was often non-existent. Interviewees were already over worked and disinclined to spend valuable time and money producing written policy statements and strategic plans. The Devon and Cornwall Training and Enterprise Council (TEC) has highlighted this as a crucial area of concern. They consider the increase in the level of strategic management in the SME sector as an essential requirement if the high level of business failures are to be reduced, especially just after start up (a survey by Storey, 1987, found that nearly $40 \%$ of SMEs failed in the first three years). This is not an encouraging sign since trading ethically to 
take account for the environment requires forward planning and proactive management. Once mechanisms are in place for this to be achieved (i.e. willingness to spend time on strategic planning) environmental strategic planning becomes feasible. If, however, these structures are not in place the likelihood of persuading SMEs to take account of environmental considerations is lower.

The implementation of BS 7750 (or any other environmental standard) was generally regarded as a waste of time and money. It was considered a purely cosmetic exercise (as was the implementation of the quality standard BS 5750), one which would only be considered under extreme legislative or consumer pressure. $100 \%$ of interviewees from the tertiary sector felt that the standard was totally inappropriate in nature and could not be implemented even if they wanted to. They felt that management systems were only appropriate to large manufacturing companies and were therefore not relevant to their modest business practices.

\subsection{Perceived Solutions}

The above discussion has explored the critical response of the interviewees. In general, feelings were negative about environmental issues. The most commonly cited responses for lack of interest in any environmental activity requiring more than critical incidence situation management were: time constraints; financial constraints; the nature of the management systems solutions (both due to the generic nature of the standard and the fact that they are systems based); lack of relevant information; lack of subsidy support to implement any changes; lack of relevance of environmental issues to their business practices in the first place. 
In this light interviewees were asked to discuss possible solutions. Suggestions varied in nature depending on the type of business and the interests of the interviewee. Those with strong personal commitments to green issues were more inclined to have considered alternatives and to have an opinion. However, $50 \%$ felt that any consideration of alternative strategies to make their business more environmentally friendly were a waste of time since they did not regard their business activities as environmentally damaging.

More positively, a common request was for an increase in the amount of high quality information and professionally produced reports being made available for senior management consultation. Such information presently reaching SMEs is neither of good quality nor from unbiased sources. Many interviewees had come to adopt cynical and sceptical attitudes to green issues for this very reason. They considered the maintenance of a decent environment and the maintenance of a certain quality of life achievable only with community or tax-payer support for educational initiatives. Further it was considered that government support was essential to implement improved performance. If forced to change and pay for the changes firms would invariably go out of business. This type of comment was more frequent among companies who considered their activities to have some effect on the environment and were engaged in environmentally deleterious activities. They were the companies that were conscious that public demand for environmentally sounder practices would have to be met by increased prices or public funding. The concept of a One Stop Advice Shop was welcomed as a positive initiative. $29 \%$ of interviewees felt that they were unsure about where to go for confidential and independent advice on environmental issues. Trade journals were cited as a regular source of reference and it was suggested that a One Stop Advice Shop could disseminate information to trade associations as well as provide an information shop for individual businesses. There were some reservations however, since neither the TECs nor the Chambers of Commerce were perceived to have the necessary expertise required. 
A One Stop Advice Shop on the environment could increase independent advice to the SME sector, increasing individual commitment towards green issues and inducing a more proactive form of self-regulation. There is a danger, however, that this being a voluntary process SMEs might actively decide to abstain from any involvement with environmental improvement unless further supporting initiatives were in place e.g. public and business educational and consciousness-raising schemes.

Training courses and half day seminars were suggested in particular by the larger manufacturing SMEs. Here again the larger manufacturing companies were more positive in their suggestions. SMEs with a high environmental impact and SMEs with the lowest environmental impact appear to have the least to offer on a constructive level. Heavily polluting SMEs are conscious that their activities could lead to a sharp increase in their costs and are therefore seeking to avoid the issues. Similarly, SMEs with the least environmental impact have few practical suggestions and they feel excluded from the debate due to their lack of environmental impact. The majority in the secondary sector do however have plenty of suggestions.

The general feeling was that interest in environmental protection would only be generated if innovations were shown to be profitable. Definitions of 'profit' were not discussed. At this stage of our economic evolution profit undoubtedly refers to financial gain. However, in an alternative society profit might be perceived to include increases in the quality of life through the sustenance of a clean environment. In this event environmentally sound practices could be deemed advantageous. Further a revision of our societal and economic value structures could induce the change of attitudes within the SME sector required to allow for self-regulation of environmental performance. 
Efficient environmental business means good business, by reducing waste and energy usage (amongst other measures) companies can save considerable amounts in financial terms. As yet any further steps towards environmental protection e.g. the potential reduction in the trade of unnecessary (and therefore environmentally unfriendly) goods are considered unnecessary and undesirable.

Other useful suggestions made to reduce the environmental impacts of SMEs included a free or highly subsidised consultancy and newsletters from trade specific angles regarding economically viable environmental improvements. The establishment of an environmental forum for debate and dissemination of information was considered appropriate: as a co-operative venture, an environmental forum could spread the cost of consultancy. These ideas are not particularly new. The concept of co-operation to reduce the financial strain on SMEs has been suggested by Welford and Gouldson (1993). Concurrently the suggestions of local newsletters and subsidised consultancies already exist and are operating on a small scale. The Groundwork Trust, for example, offers these services in certain areas within the U.K (the South West and the North East). The inference is that the information required to reduce environmental impacts of business practices is available but is not reaching local businesses.

$50 \%$ of interviewees felt that legislation was in theory the best way to get results as it would level the playing field. Further discussion usually elicited that some were reluctant to see environmental legislation which might be restrictive to their business practice. On the whole self-regulation was the preferred solution with subsidised support for change and increased availability of information. This view typified the response of companies that had little or no environmental policies or practices in place. Companies with relatively well developed environmental policies, however, felt that a levelling of the playing field was theoretically sound and feasible in practice. These firms (usually larger 
manufacturing companies) also felt that further more rigorous legislation is required. This would be in the interest of the large proactive company on a competitive level as they are already strategically planning for the environment and often have the required management structures in place to deal with any change in legislation quickly. It could also force their smaller competitors out of business.

In conclusion, the most striking observation from this series of in-depth interviews is the minimal management understanding of and response to environmental issues. Although larger manufacturing companies had a better understanding of relevant issues, the vast majority of SMEs has little or no understanding of green issues. 


\section{CHAPTER 7}

\section{RESULTS -}

\section{MAIL SURVEY 2}




\subsection{Hypotheses and Sample Characteristics}

The purpose of this mail survey was to further develop phase 2 of the research (Figure 4.1). It was designed to clarify some of the issues emerging from the in-depth interview stage (in particular attitudes towards BS 7750) and to consider the applicability of various environmental support initiatives. Company views on various educational support initiatives were also to be analysed which would provide a more complete picture of future SME behaviour. This analysis of attitudes to future support initiatives provides an indication of likely SME environmental management levels in the future.

The survey questioned why the level of strategic environmental management was so low in the first survey and in-depth interviews. Although operational environmental initiatives often improve a company's environmental performance, an holistic environmental management plan that takes account of the environment in every aspect of company operations would be a more preferable strategy. The reasons for this apparent lack of progress on this level were therefore pinpointed for further analysis.

The in-depth interviews had suggested a number of reasons why companies were not either able or prepared to take full account for the environment. Time, finance and the nature of the regulations (amongst others) were suggested in the interviews as important reasons for not having a strategic approach to environmental management in their business practices. This survey clarifies many of these responses through the analysis of a larger sample frame.

The survey sample was changed to clarify some critical results from the first survey (e.g. level of strategic environmental management) and to increase the potential response rate. 
It is generally accepted that reduced response rates occur from a previously used sample population (Erdos, 1970 et al).

In accordance with the general research aim to consider the reasons for the levels of environmental management in the SME sector, the following primary null hypotheses were formulated.

\subsection{Strategic Environmental Management Response}

Primary Null Hypotheses:

4. There is no significant variation in response within the SME sector to indicate why the level of strategic environmental management is so low.

5. There are no significant differences in attitudes within the SME sector towards environmental support initiatives.

To test these hypotheses a mail survey of 600 randomly selected companies was conducted. The selection procedure followed the random generation feature on SPSS PC+. The response rate was $30 \%$. A non-response bias test was undertaken by drawing a comparison between first and second wave respondents as in the first mail survey. No significant difference was found and it was therefore concluded that population inference would be valid. All survey's were sent to named owner managers or managing directors. Full statistical analysis of the results to this survey can be found in Appendix 3. 
Table 7.1. shows the industrial classifications used in the survey and the valid response rates from each sector. The classification used here is the same as in the first survey to allow for cross tabulation.

Table 7.1. Industrial Classification and Response Rates

\begin{tabular}{|l|c|}
\hline \multicolumn{1}{|c|}{ INDUSTRIAL SECTOR } & VALID PERCENTAGES \\
\hline PRIMARY & $\mathbf{5 . 6}$ \\
\hline Agriculture - Forestry and Fishing & 3.9 \\
\hline Energy and Water Supplies & 1.7 \\
\hline SECONDARY & 47.2 \\
\hline Mineral Extraction and Construction & 0.6 \\
\hline Engineering and Vehicle manufacture & 10.1 \\
\hline Other manufacturing & 25.8 \\
\hline Construction & 10.7 \\
\hline & 47.2 \\
\hline TERTIARY & 9.6 \\
\hline Distribution and Retailing & 1.7 \\
\hline Transportation and Telecommunications & 3.9 \\
\hline Financial Services & 32.0 \\
\hline Other Services & \\
\hline
\end{tabular}

Table 7.1. and Figure 7.1. both indicate a relatively low response rate from the primary sector. It must be emphasised that this is due in part to the limitations of the data base. Many agricultural businesses were not included on the data base as their details were not available. This could have been rectified if an alternative data base had been used, however, due to financial constraints, the research was limited to the use of the data base 
from Devon and Cornwall Manufacturing Directories. Although a slight bias can be detected in the sample, it is evident from Table 4.2. that the response rates per sector correlate closely to the regional and national sector sizes (SIC, 1993).

Figure 7.1. Reduced Response Rates

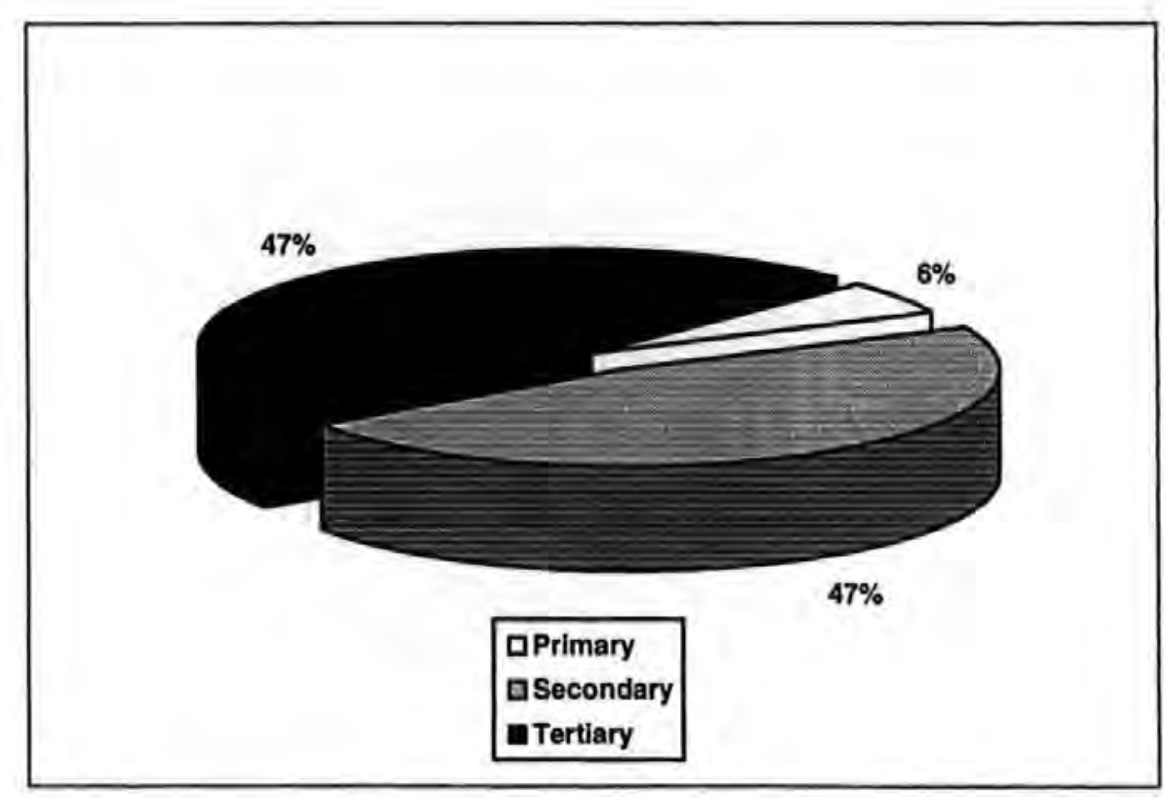

There is an important caveat here: the primary sector has few employees but provides an extremely important provision in economic terms for the society. Commonly accepted statistical indicators (e.g. employee numbers or market share) can lead to highly misleading contrasts. Without a primary sector there can be neither secondary nor tertiary sectors, indeed no economic activity at all. Hence resource depletion and environmental pollution, which initially threatens the primary sector in the short term, provides a long term threat to the economy as a whole. Significantly since only approximately $2 \%$ of the population are involved in producing our agricultural sustenance the majority of our population are not in control of their supply of food, the basic requirement for survival. This lack of self-reliance in such a critical area is central to an understanding of why the 
interdependence of all sectors within the present economic system is so imperfectly understood.

Further, with less and less people producing more and more goods (this applies to the manufacturing sector as well as the primary sector) there are fewer and fewer consumers able to purchase the goods produced. There is therefore a clear need to provide these people with the financial capacity to purchase these goods. The system has become deceptively inefficient and requires revision. The alternative is not 'business as usual' but total disintegration. This issue will be dealt with in the following chapter. Suffice to say here that the most statistically acceptable comparisons will be between the secondary and tertiary sectors as their response rates are identical. The primary sectors response rates are so much lower and although comparisons will be drawn, the limitations of the comparisons due to the reduced response rates of this particular sector must be noted.

Over a period of approximately one year (from 1993 to 1994), between the collection of the first and second mail surveys, the response rate fell by $10 \%$ from approximately $40 \%$ to $30 \%$. It is possible that this could be due to the differing nature of the survey contents. Equally it could be that over this period environmental issues have become less important to SMEs. It is noticeable, however, that the response rates between sectors has changed with a higher percentage return coming from the secondary sector and a decreased return rate from the tertiary sector. This may suggest that employees in the tertiary sector have an altered perception of the necessity to consider environmental issues.

Tables 7.2, 7.3. and 7.4. illustrate further sample characteristics. These include: business types; business size by number of employees, company age, market (exporters and nonexporters). Table 6.2 portrays a similar distribution to the first mail survey. The majority of respondents $(69.7 \%)$ are from single site businesses, with only $17 \%$ being subsidiaries 
or branches of national or foreign enterprises. Cross tabulation between the surveys would therefore be valid.

Because there are no missing variables i.e. (all respondents answered these two questions) the percentage and valid percentage categories are identical on this occasion. Table 7.3. also displays a similar distribution to the first mail survey, with the only difference being a slightly lower percentage return from the 0-10 employees section in the second mail survey (61.2\% compared with $67.6 \%$ from the first survey).

The second survey provided details on the age composition of the sample. This additional information (Table 6.4) shows that the largest response came from the 11-50 year old companies: in general the skew was towards the older companies. This may reflect time and resource pressures on young start up companies; few have the time available to answer the survey or consider implementation of significant environmental change initiatives.

Figure 7.2. graphically displays the percentage return from exporters and non-exporters. The distribution accords closely with the first mail survey, with approximately one third of respondents being engaged in the export trade.

In general the majority of respondents were from single site businesses with less than 100 employees. Since a significant proportion of the respondents were from the tertiary sector, analysis will be able to focus not only on the medium sized manufacturing companies (the usual focus of environmental management research) but also on the smaller tertiary sector companies. 
The company characteristics discussed correspond closely to the companies in survey one. It is reasonable to assume, therefore, that companies in survey two would answer in a similar way to the companies chosen in survey one. Indeed the level of exporters and non exporters was almost the same. Cross-tabulation between surveys is therefore a valid statistical option.

Figure 7.2. - Percentage Number of Exporters and Non-Exporters

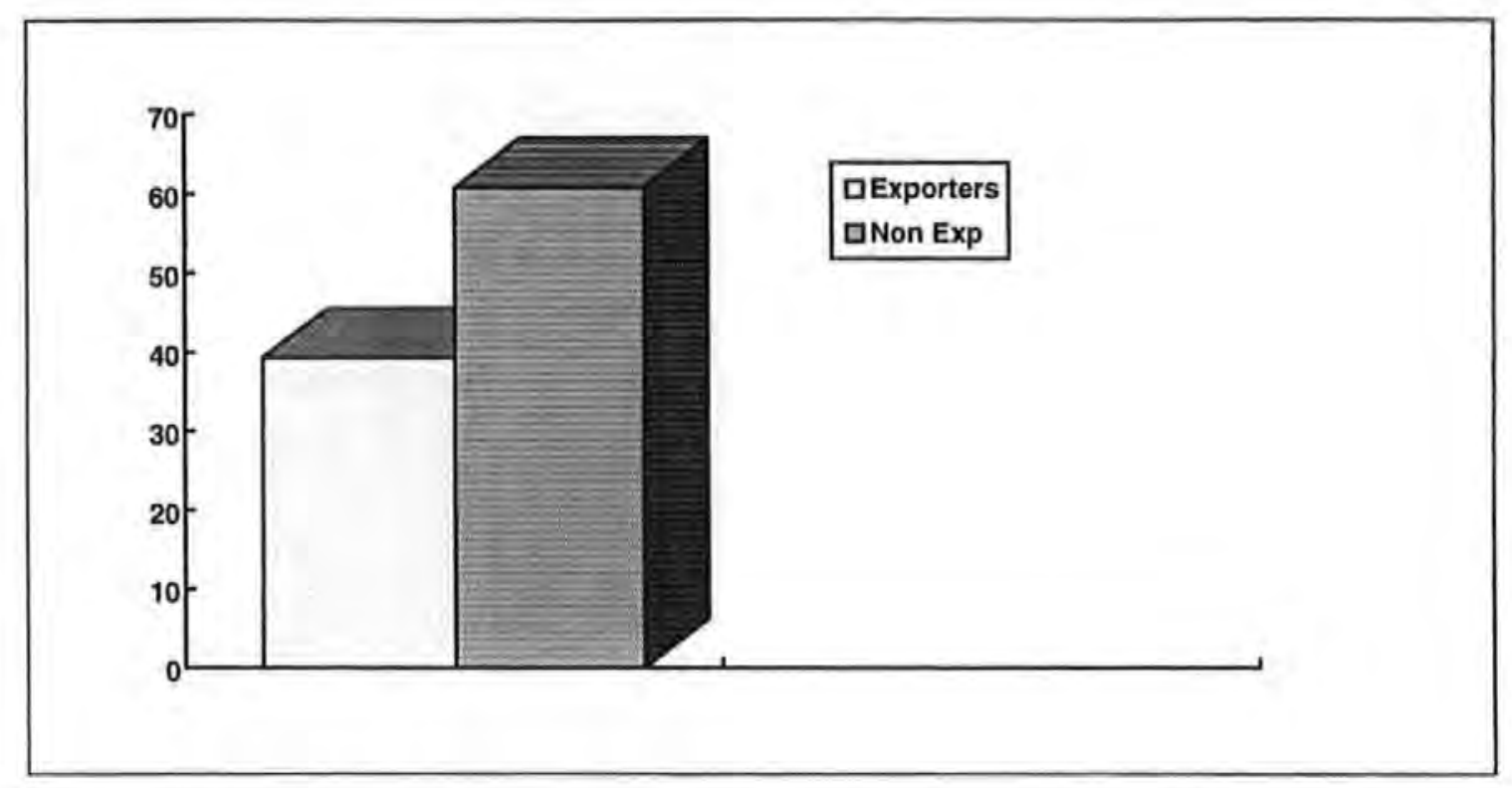

Having descriptively analysed the sample, the following section considers the sample characteristics in rather more depth. It will view the component parts of each significant sample characteristic and highlight any relevant deviations from the sample mean.

\section{Business Types}

Single site businesses had a slightly higher percentage of respondents in the 0-10 employee category $(75 \%)$, fewer companies over 50 years old $(8.9 \%)$ and a smaller 
percentage of exporters (33.9\%) than the sample average (s.a.). There was a marked difference in the amount of employees in the headquarters unit compared with the sample average. Only $37.5 \%$ of them were $0-10$ employees. Most respondents from headquarters unit were in the larger 26-100 and 101-200, category as would be expected. A greater proportion of these were from the tertiary sector $(54.2 \%)$ and were generally slightly younger than the sample average.

Table 7.2. - Business Types

\begin{tabular}{|l|c|c|c|c|c|}
\hline Value Label & Value & Frequency & Percentage & Valid \% & Cum. \% \\
\hline $\begin{array}{l}\text { Single Site } \\
\text { Business }\end{array}$ & 1 & 124 & 69.7 & 69.7 & 69.7 \\
\hline $\begin{array}{l}\text { Head- } \\
\text { quarters }\end{array}$ & 2 & 24 & 13.5 & 13.5 & 83.1 \\
\hline $\begin{array}{l}\text { Subsidiary/ } \\
\text { Branch of } \\
\text { National } \\
\text { Enterprise }\end{array}$ & 3 & 24 & 13.5 & 13.5 & 96.6 \\
\hline $\begin{array}{l}\text { Subsidiary/ } \\
\text { Branch of } \\
\text { Foreign } \\
\text { Enterprise }\end{array}$ & 4 & 6 & 3.4 & 3.4 & 100 \\
\hline
\end{tabular}

There was a far lower percentage of small company respondents in the subsidiary or branch of a national enterprise grouping compared with the sample average. Only $25 \%$ were 0-10 employees. $16.7 \%$ were over 200 employees which compares with a sample average of 3.9\% Primary companies do not exist in this category and there is a higher percentage of tertiary respondents $(54.2 \%)$. There are no companies under 5 years old and there are $37.5 \%$ over 50 years old, which compares with a sample average of $14.6 \%$. As one would expect there is a higher percentage of exporting in this group (58.3\% 
compared with a sample average of $39.3 \%$ ). There are also more respondents from Cornwall $31.8 \%$ compared with $23.4 \%$ s.a.

Response rates generally in the subsidiary or branch of a foreign enterprise group were low and company comparisons are therefore limited. Although accurate comparisons are problematic when cells have so few observations, it is reasonable to conclude that companies in Devon's secondary sector which fall into this category are more likely to be older, larger and more inclined towards exporting than the sample is in general.

\section{Business Sizes}

Of companies with $0-10$ employees, $85.3 \%$ were single site businesses. There were slightly more from the tertiary sector and less exporters in this grouping than the sample average (31.2\%). Companies with $0-10$ employees had a greater percentage of respondents in the subsidiary or branch of a national enterprise section (25\% compared with a sample average of $13.5 \%$ ). They were also more likely to be from the secondary rather than tertiary sector. This grouping also had more respondents towards the older age of the spectrum and also more companies from Devon (80\% of companies with 0-10 employees were from Devon compared with $76.6 \%$ s.a.).

Table 7.3. - Number of Employees

\begin{tabular}{|c|c|c|c|c|c|}
\hline Value Label & Value & Frequency & Percentage & Valid \% & Cum. \% \\
\hline Employees & & & & & \\
\hline $0-10$ & 1 & 109 & 61.2 & $\mathbf{6 1 . 2}$ & 61.2 \\
\hline $11-25$ & 2 & 28 & 15.7 & $\mathbf{1 5 . 7}$ & 76.9 \\
\hline $26-100$ & 3 & 24 & 13.6 & $\mathbf{1 3 . 6}$ & 90.5 \\
\hline $101-200$ & 4 & 10 & 5.6 & $\mathbf{5 . 6}$ & 96 \\
\hline $200+$ & 5 & 7 & 3.9 & $\mathbf{3 . 9}$ & 100 \\
\hline
\end{tabular}


The larger the company the more likely it will be a headquarters unit, a subsidiary, older in age, and an exporter. $30 \%$ of the companies with 101-200 employees were subsidiaries or branches of foreign enterprises and only $20 \%$ single site businesses. $60 \%$ were from the secondary sector and $60 \%$ were over 50 years old. $80 \%$ exported compared with a sample average of $39.3 \%$. $71.4 \%$ of companies with over 200 employees were between 11-50 years which compares with a sample average of $47.8 \%$. $100 \%$ of this section were exporters. The general trend was that the larger the company, the more likely it would be from the secondary sector.

\section{Business Sectors}

It was suggested in the introduction to this chapter that the response rate from the primary sector was low, therefore comparisons may be difficult. However, the general pattern suggested that the primary units were small but older than the average. They are also more likely to export than not to export (60\% export). Further the percentage of primary respondents who were located in Cornwall was significantly higher than the sample average ( $40 \%$ compared with $23.4 \%$ s.a.).

Size, age and type of business in the secondary sector were roughly similar to the sample average, although there are significantly more exporters within the secondary sector (53.6\% compared with $39.3 \%$ s.a.) than non-exporters. Although responses from the tertiary sector were more frequently from smaller, slightly younger companies, they did not differ greatly from the sample average, except for the fact that less respondents from the tertiary sector exported than the sample average $(22.6 \%$ exported compared with $39.3 \%$ from the sample average). 
Company Age

Responses were predictably low from younger SMEs. Lack of time to respond to surveys is a problem for most SMEs but is of particular relevance to companies in start up. The general picture is, however, that the younger the business the smaller it would be and the more likely it would be a single site business.

Responses from companies between the age of 11-50 years were the closest to the sample average because of the larger response rate ( $47.8 \%$ of respondents fell into this group). However, the proportion of secondary respondents were higher than the sample average, 55.3 compared with $47.2 \%$ s.a. The percentage of exporters was also higher than the sample average ( $44.7 \%$ compared with $39.3 \%$ s.a.).

Table 7.4. - Company Age

\begin{tabular}{|c|c|c|c|c|c|}
\hline Value Label & Value & Frequency & Percentage & Valid \% & Cum.\% \\
\hline Age (years) & & & & & \\
\hline Under 1 & 1 & 2 & 1.1 & 1.1 & 1.1 \\
\hline $1-5$ & 2 & 22 & 12.4 & 12.4 & 13.5 \\
\hline $6-10$ & 3 & 43 & 24.2 & 24.2 & 37.6 \\
\hline $11-50$ & 4 & 85 & 47.8 & 47.8 & 85.4 \\
\hline $50+$ & 5 & 26 & 14.6 & 14.6 & 100 \\
\hline
\end{tabular}

As expected the older more established, exporting companies correlated with larger business operations. However, $50 \%$ of respondents in the $50+$ year group were from the 
tertiary sector. There was also a greater percentage of respondents over 50 years that responded from Cornwall (30.4 percent compared with a sample average of $23.4 \%$ ).

Primary Null Hypothesis 4: There is no significant variation in response within the SME sector to indicate why the level of strategic environmental management is so low.

To satisfy this primary, deductive hypothesis, a series of secondary null hypotheses were designed to be tested.

Secondary Null Hypotheses:

1. There is no significant variation in company characteristics between those companies who have a strategic environmental policy and those who do not.

2. There is no significant variation between company characteristics to indicate why they do not have a strategic environmental policy.

3. There is no significant variation between company characteristics to indicate why SMEs would not be able to implement BS 7750.

Secondary Null Hypothesis 1: There is no significant variation in company characteristics between those companies who have a strategic environmental policy and those who do not.

In the survey strategic environmental policy was defined as, a written statement of intent to consider environmental matters as an integral part of long term corporate policy. $16.3 \%$ said that they had a strategic environmental policy in place. This was considerably 
higher than the response in the first survey nearly a year before when only $5 \%$ said that they had a written environmental policy statement. This is encouraging and suggests that SMEs in Devon and Cornwall may be beginning to approach environmental management with rather more long term empathy.

The initial surveys undertaken in this research indicate that more companies were prepared to develop a written policy statement in 1994 than in 1993. The change in practice is most clearly evident within the secondary sector rather than the primary and tertiary sectors. Companies with a written policy statement are more likely to be the larger, older, secondary, subsidiaries of national or foreign companies. They are also more likely to be exporters than non-exporters (see Appendix 3).

There is, therefore, a certain type of company that is more likely to develop strategic environmental management than others. However, because of the nature of the data (in particular the low response rate of the companies with a strategic environmental policy) the difference is not statistically significant at a predetermined confidence level. Both parametric and non-parametric tests (MANOVA and Chi-Squared) were carried out to see if there was any significant difference and they were all negative. It is therefore necessary to accept the null hypothesis, that there is no significant variation in company characteristics between those companies who have a strategic environmental policy and those who do not.

At this stage, the indications are that the trend is towards an increase in the number of companies developing strategic environmental management plans. Although the vast majority of companies (83.7\%) still do not have environmental strategic inclinations. 
Secondary Null Hypothesis 2: There is no significant variation between company characteristics to indicate why they do not have a strategic environmental policy.

For the purpose of this hypothesis, company characteristics refers to company type, size, industrial sector, age and exporting inclinations. Respondents were offered a number of alternative reasons for their failure to develop a strategic environmental policy. Choice was open ended and unlimited. An open qualitative section at the end offered opportunity for further comment regarding additional reasons for failure to develop a strategic environmental management policy.

Questions were asked independently of one another and there was no ranking procedure. However, the results have been ranked for analytical purposes in Table 7.5. Although the vast majority of companies still feel the environment is an important business concern (98.7\% answered that green issues no longer being an important issue was not a reason for their lack of strategic action) $37 \%$ of companies feel that their operational initiatives suffice. A strong core of companies feel that environmental issues have significance for business generally but that they are not applicable to their business operations. This indicates a lack of awareness as all business activity has an environmental impact.

Time and limited financial resources were also seen as major reasons for failure to develop a strategic environmental policy. It is noteworthy that only $3.4 \%$ of respondents considered lack of legislation as a reason for not having a strategic policy on the environment.

Three main reasons for the absence of strategic inclinations towards the environment in SMEs emerged (Table 7.5). $36.9 \%$ considered their existing operational initiatives sufficient. In this instance there may have been some lack of understanding of the terms. 
Any well implemented initiative would require a degree of strategic planning. Hence, if the company was prepared to spend at least this amount of time on environmental issues it is not unreasonable to assume that the formal statement of an environmental policy would not be considered too arduous.

Table 7.5 - Why Companies Do Not Have Environmental Policies

\begin{tabular}{|l|c|}
\hline \multicolumn{1}{|c|}{ REASONS FOR NOT HAVING A } & VALID PERCENTAGE \\
POANKED)
\end{tabular}


The analysis relies on the individual company's impressions of 'policies'. Quite a number of companies suggested in the other reason box that their reason for not having a written policy statement for the environment was due to the inherent bureaucracy of the procedure. There is a certain logic in this approach. An ill considered, quickly drafted policy is often never implemented. Time is limited and the general feeling is that it would be better spent implementing operational changes than drafting policy documents and seeking accreditation for standards that change very little.

Although operational environmental initiatives suffice appears top of the list as the most frequently indicated reason for absence of a formal strategy, this figure incorporates a degree of subjective interpretation. From the figures it is difficult to assess how much the companies are actually doing. However, if one takes survey one as a yardstick it would be reasonable to assume that the majority of the respondents are referring to the fact that they have some sort of recycling procedure in place $(41.8 \%$ had implemented a recycling policy).

The second ranked issue indicates that $32.2 \%$ of respondents regard environmental issues generally as, not relevant to business operations. This would appear to be a low level of understanding of the implications of the environmental debate. This would suggest that small companies perceive having an environmental impact as reserved for large manufacturing companies. Although manufacturing companies usually have a greater impact on the environment, all companies have some impact, individually and cumulatively on the environment. The wasteful energy consumption in light, heating and transport for one firm accumulates across the board to form a devastating effect on the environment. 
$32.2 \%$ of the respondents consider 'the environment' to be peripheral to their business practices. Until ecological concerns are recognised as a central part of the internal environment of all individuals and companies, there will be continued cause for concern. At present, ecological issues can be pigeon-holed as an external threat to most businesses, even to those who recognise the savings that can accrue from frugal waste generation and energy efficiency programmes.

Ecological issues are measured in financial terms and classed as an external business concern. In reality this could be quite different. An alternative view is that industry is in fact peripheral to the environment. The environment encompasses all of industry and every thing industry does has an effect on the environment. For industry to declare that environmental issues are not relevant to their business may indicate a shortage of relevant information and skills. Environmental issues may need to be brought into focus because without an environment there is no market place. Lack of comprehension is not confined to the business community, but is endemic in society as a whole. As the consumer has become further and further detached from the producer the latter has become less and less accountable for their actions. Often the consumer is unfamiliar with the productive processes that go into creating the products they buy. The average good purchased in the UK. in 1993 travelled over one thousand miles to reach the retail shelves. The ecological impact of the production, packaging and transportation involved can be easily overlooked.

In order to assess the quantitative aspects of the statistical analysis in Appendix 3, a Chi Square test was run for each reason for not having a strategic environmental policy. Each company characteristic was considered in turn. Chi Square was selected since the absence of sufficient data cells made employment of the multivariate analysis of variance technique MANOVA inappropriate. The statistical analysis therefore took a more 
descriptive format, considering group means for each possible answer (e.g. for operational initiatives suffice). For example, companies who responded that operational initiatives suffice had a higher percentage response in the single site business category than the sample mean response (Appendix 3).

All of the Chi Square tests run showed that there was no significant variation in the expected values compared to the observed ones. The closest there was to a significant outcome related to financial constraints. Statistically, therefore there are no significant differences between company characteristics and the reasons to indicate why SMEs have failed to adopt an environmental policy.

The descriptive contents of the data was more closely scrutinised in order to analyse some areas that may, with further research, be of interest. $80 \%$ of single site business respondents (compared with a sample mean of $69.7 \%$ ) said that the reason for not having an environmental policy was that their operational initiatives sufficed. Hence single site businesses are more likely to consider that this is a significant reason (than the rest of the sample) for not having a policy. Using the same approach, respondents who suggested that operational environmental initiatives sufficed, also tended to be the smaller, younger, from the tertiary sector. This pattern was replicated with respect to the answer that environmental issues were not relevant to their business operations. Again the respondents in this section were more likely to be the younger, smaller single site businesses from the tertiary sector.

$81 \%$ of respondents who answered that a lack of information was a reason for not having a strategic policy were from the single site businesses section. This compares with a sample mean from all company types of $69.7 \%$. However, unlike the previous two reasons there was more a a bias towards the secondary sector companies here, $(57.1 \%$ 
were from this industrial sector). There was also a difference to the sample means with regard to companies ages. The category, 6-10 years old were more likely to class lack of information as an important issue whereas the older 50+ companies were not. This either suggests that there are diffusional problems with relevant information reaching different companies, or that individual preferences and perceptions of information differ. This does suggest however, that the younger, smaller companies do require more information on environmental best practice, which confirms previous research (Hendry 1993).

A high proportion of respondents indicated that lack of in-house expertise was a relevant issue. $84 \%$ of these respondents were single site businesses compared with a sample average of $69.7 \%$. No company over 100 employees found a lack of in-house expertise to implement the management change an important issue for not having a strategic policy on the environment. Respondents who felt that this was a significant reason were primarily from the secondary sector $(69.2 \%$ compared with a sample average of $47.2 \%)$. They were also more biased towards not exporting (30.8\% compared with $39.3 \%$ ) and more likely to come from Devon. $91.7 \%$ of respondents were from Devon, which compares with an average response of $76.6 \%$ of companies coming from Devon. This may indicate either actual or perceived ability to deal 'in house' with the environment issue, is better in Cornwall than in Devon.

Lack of ability to assess future impact of the environment on performance did not rank high as a reason for not having an environmental policy. However $93.3 \%$ of companies who felt that this was a significant issue were single site businesses. However, rather more of the respondents (30.2\%) found a lack of finance to be a significant reason for not having a strategic policy for the environment. $60 \%$ of these companies came from the secondary industrial sector. The older companies (50+ years) found this to be less of a constraint on their actions. 
Lack of time was a significant reason given by $33.6 \%$ of respondents for not having a strategic environmental policy in place. It was, most noticeable the smaller and younger single site businesses that responded affirmatively to this question. Most respondents did not regard company inertia as a significant reason for not having a policy (only $4.7 \%$ felt this was an issue). It is difficult to assess the extent to which lack of education and information is a contributory factor for the absence of a strategic approach to environmental issues. Older companies, predominantly in Devon, did suggest that this was an issue. These indications are, however, tenuous due to the low response rate.

Over $14 \%$ of the sample were of the opinion that there was a lack of reasons to address environmental concerns. The incidence was highest amongst small companies in the secondary industrial sector. Of the respondents who felt that there were a lack of reasons to address environmental concerns $59.1 \%$ were $11-50$ years old compared with a sample average of (the sample average for companies between the ages of 11-50 years old was 47.8\%). This suggests that the older the company the more likely it would consider this to be a significant reason for not having developed a policy for the environment. Very few respondents from the whole sample felt that a lack of legislation was a significant reason for not having an environmental strategy. $96.6 \%$ of respondents felt that legislation was therefore, by inference, an important reason for having a strategic policy.

The nature of the data indicates no statistically significant difference between companies of differing types and their reasons for not having a strategic policy on the environment. Therefore one has to accept the null hypothesis on this occasion that there is no significant variation between companies characteristics and their reasons for not having a strategic environmental policy. 
What is clear, however, is that strategic planning for the environment is low in general and this is mainly due to the way in which the problem is perceived and a lack of time to focus attention on environmental issues. As one of the interviewees said in the in-depth interviews, one cannot deal with a problem that has not been defined. At present SMEs have no reasons to relate environmental issues to the activities of their company. They are unsure about how any changes in their practices can affect the global environment.

This failure to appreciate cumulative responsibility can be attributed to the value attached to the environment. Under the present economic system value is assessed in financial terms. Goods and services exchanged on the market have no alternative value. However, many environmental resources are not traded. They are social resources and are not measurable synchronously with consumption (Mulberg, 1994). It is for this reason that the use and abuse of the environment can be regarded as a 'free' good. For instance, consumption of non-renewable resources and creation and use of non-biodegradable goods and packaging have long term impacts which are not reflected on a firm's current balance sheets. Like individuals, small businesses fail to appreciate the effect of their activities on the environment and therefore have no motivation to change the status quo.

Although this suggests that self-regulation within the present system is unlikely to achieve environmental sustainability, it is the approach advocated by industry (in particular larger companies, CBI, 1990). The reasons for this are straight forward: selfregulation allows business to determine the pace of change. In the 1980s large businesses opposed controls on the grounds that they would reduce competitive advantage and therefore damage the economic prosperity of the country. Rather than imposing new restrictive environmental legislation, public bodies were invited to track the progress of industrial environmental performance. Hence industry not only sets the pace, but also decides the route. The management systems solution to the environmental issue in the 
form of BS 7750 and the European Unions EMAS, created by industrialists in cooperation with environmentalists are the result.

The 'environment' was/is regarded as an external problem or threat to industrial welfare which required a management solution, just as any other management problem would e.g. quality control or labour relations.

Indeed points of similarity between the management systems BS 5750 (the quality standard) and BS 7750 (the environmental standard) has lead to comparative analysis of the two concepts (Welford, 1992). The two concepts are interlinked: good environmental management is quality management, however the reasons for the existence of the two systems under the present economic paradigm are not synonymous. The pursuit of profit maximisation exclusively at the expense of ethics (an essential prerequisite for environmental sustainability) may inevitably be self-destructive.

To date, however, management systems have been advocated as the solution or panacea to the environmental concerns of UK. businesses. It is to the application and relevance of BS 7750 to SMEs that we know turn.

Secondary Null Hypothesis 3: There is no significant variation between company characteristics and the reasons why SMEs would not be able to implement BS 7750 .

Companies were asked a series of questions that related to the British Environmental Management Standard BS 7750. The intention was to analyse the standard and its implications for SMEs. Although it was already evident that strategic management in the SME sector was low with respect to the environment it was necessary to know why this was the case in order to prescribe any alternative strategy. 
Only $3.4 \%$ of respondents had implemented BS 7750 (Figure 7.3). Most of these companies were larger, older SMEs and were from the secondary industrial sector. Of the companies who had not implemented the standard, $68 \%$ considered that even given the motivation to implement the standard they lacked the capacity to do so (Figure 7.4). The non-exporting, smaller companies in the tertiary sector were inclined towards this response.

Figure 7.3 - Percentage Number of Companies Who Have Implemented BS 7750

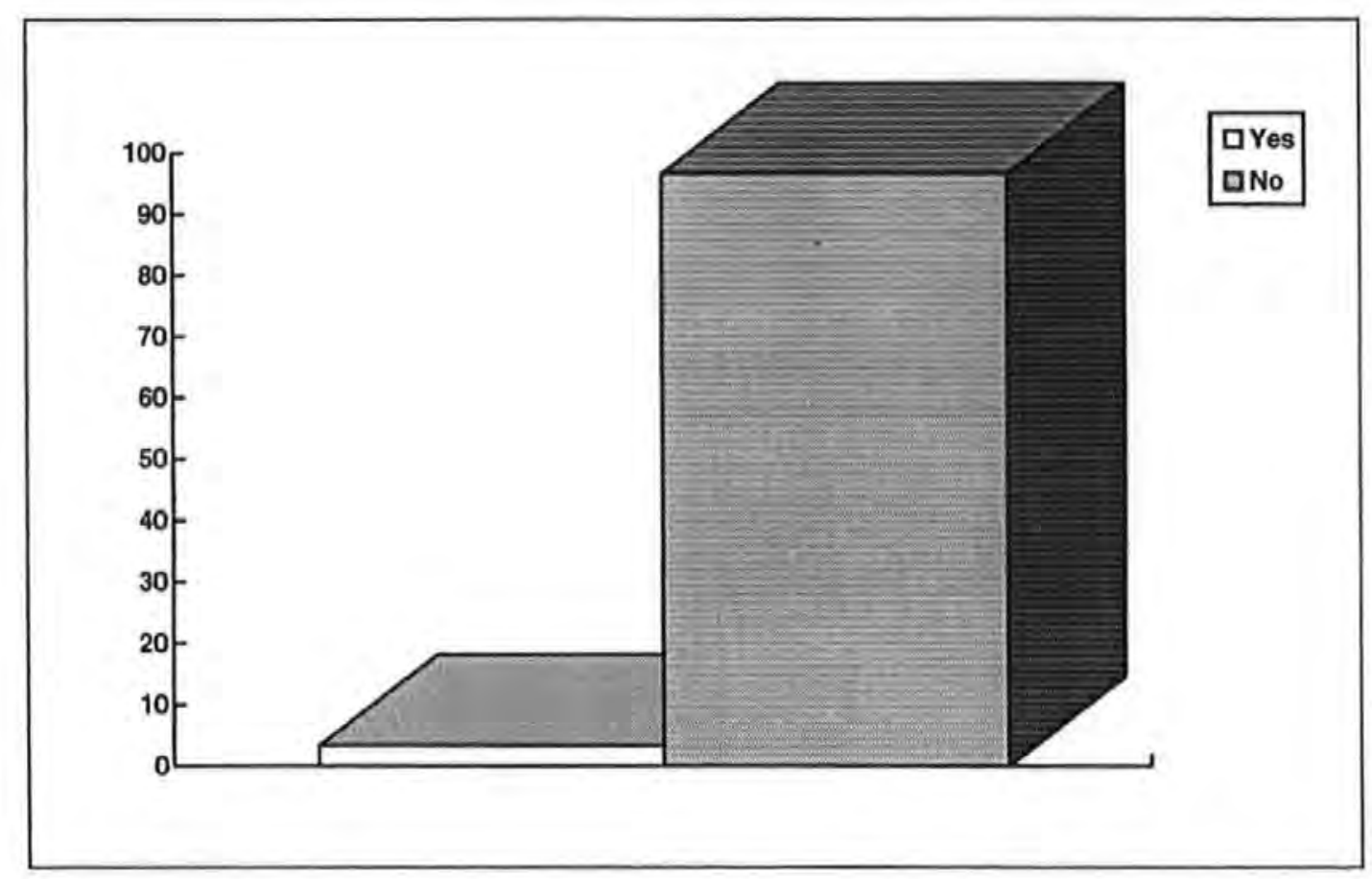

A series of Chi Square tests were run to see if these descriptive variations in response were statistically significant. Table 7.6 shows that there was a significant difference in the expected and observed values with regard to two issues. It was proved that it was more likely that exporters would be able to implement BS 7750 than non-exporters and that companies with a strategic management system already in place would be more likely to be able to implement BS 7750 than companies who did not have a system in place. 
Table 7.6 - Chi Square - Implementation of BS 7750 By Exporting and Strategy

\begin{tabular}{|c|c|c|}
\hline VARIABLE & PEARSON'S CHI & SIGNIFICANCE \\
\hline Exporters/non-exporters & 16.79495 & .00004 \\
\hline Systems predominance & 13.48706 & .00024 \\
\hline
\end{tabular}

It was, however, encouraging that of the $32 \%$ of respondents who did feel that they would be able to implement the standard, $72.7 \%$ said that they would be willing to implement it in the near future. Further analysis of the companies who responded positively to the possibility of implementing the standard showed that they were more likely to be the larger, secondary sector companies between the ages of 11-50 years.

This would suggest that any attempt to improve the environmental performance of SMEs through the implementation of management systems would be best directed towards the larger, older companies from the secondary sector, at least in the initial stages.

However, the vast majority of companies felt that they would not be able to implement BS 7750. Q1 la to Q11h were designed to discover why companies would not be able to implement BS 7750. The possible responses can be seen in ranked format in Table 7.7. Respondents were also given the option of a qualitative response in the from of any other reason for not being able to implement BS 7750. This option was not on the whole exercised, apart from to re-emphasise earlier responses in Q1 la to Q11h. 
Table 7.7 - Why Companies Are Not Able to Implement BS 7750.

\begin{tabular}{|l|c|}
\hline \multicolumn{1}{|c|}{ REASON WHY NOT ABLE TO } & VALID PERCENTAGE \\
\hline IMPLEMENT BS 7750 & 47.9 \\
\hline Limited available staff to implement the & 45.3 \\
change & \\
\hline Inappropriate nature of the standard & 44.4 \\
\hline Lack of time & 38.5 \\
\hline Not cost effective & 22.2 \\
\hline Not company policy & 14.5 \\
\hline Lack of interest & 10.3 \\
\hline Lack of internal commitment within & 6.8 \\
\hline
\end{tabular}

Companies were not asked to rank a preference of response with regard to this particular issue. The percentages in Table 7.7 are therefore statistically independent.

$45.3 \%$ of respondents felt that they did not have the available number of staff required to implement the changes which may suggest that companies feel the standard relates more to larger companies than to small owner managed SMEs. Perceived implementation of BS 7750 was viewed to be difficult because of many of the standard barriers that separate SMEs and strategic management. Lack of time and finance are two obvious reasons why companies feel that it would be difficult to implement a strategic management system. It was noticeable, however, that $44.4 \%$ of respondents that said they would not be able to implement BS 7750 agreed that one reason was because of the nature of the standard. Because of the limited nature of the mail survey procedure it is difficult to expand further 
on this at this stage, suffice to say that a significant proportion of respondents felt that the standard was not appropriate to their company. This area was identified as an important area to research further, in particular to analyse if these companies would be willing to change their practices under different circumstances and using alternative techniques of management.

Clearly, the response of SMEs is split into two general areas on this subject. There are those companies who feel that they are either able or at least willing to implement BS 7750 and there are those companies who feel that they are not able to implement it, for a number of reasons. The first group consists mainly of the larger, secondary companies and the latter group of the smaller tertiary and primary companies. No significant variation in response by the latter suggest why they would not be able to implement the standard.

The secondary null hypothesis 3 that there is no significant variation between company characteristics and the reasons to indicate why SMEs would not be able to implement BS 7750 must therefore be accepted. As all three of the secondary null hypotheses have been accepted the primary null hypothesis stands. There is no significant variation in response within the SME sector to indicate why the level of strategic environmental management is so low.

To appreciate the implications of this finding one has to consider the standard itself and the concept of strategic environmental management with respect to the SME. The above discussion suggests that it is the larger manufacturing companies who are more favourably inclined towards environmental management systems. One route towards sustainable development may therefore be to encourage the growth of small firms and the diversification into the manufacturing process. This argument has predominated in the 
USA in recent years and also within the last round of GATT talks (Lang and Hines, 1993). The feeling is that the larger the company the more likely it will have the capacity to deal with environmental concerns and meet the costs of the environmental clean up its expansion will cause. Clearly this is not a desirable state of affairs. If sustainable development is ever to be achieved the causes of ecological irritation are more satisfactorily dealt with at source rather than at 'end of pipe'.

Small and local businesses can be regulated and measured more easily than the large company with dispersed ownership. Local ownership and management enables companies to be more accessible to the local community and therefore more accountable for their activities. Keeping business small may appear less efficient in a financial sense. This is not however, necessarily the case. A successful local economy may succeed in retaining its capital in the region rather than allowing to filter out to larger multinational corporations, resulting in a general rise in prosperity in the locality. The relinquishing of certain economies of scale allows for greater ecological accountability.

There are, therefore two critical aspects to consider. Firstly there is the applicability of environmental management systems to achieving sustainable development and secondly there is the issue of alternative approaches. Where motivation and resources allow, environmental management systems may reduce environmental impacts of certain secondary companies. The majority of companies, however, remain unconvinced that action is necessary.

The research has demonstrated that the two significant variables in question are management structures and attitudes. A new approach to ecological concerns within management appears necessary. Little has changed in the environmental practices of SMEs since the development of the first environmental management systems nearly 15 
years ago, except perhaps in the secondary sector. At issue is whether the requirement is for a change in management structures or a change in management attitudes. Is it possible through information diffusion and education to persuade small companies to find the time to contemplate environmental concerns? Or could the answer lie in a more structured development of SME practices? To frame the answers to these questions it will be necessary to examine the context within which the SME operates. This will be a primary consideration of the following chapter. First, however, it is necessary to briefly discuss support initiatives in order to clarify attitudes towards future directions of environmental information diffusion and attitudes. The aim was to consider if there were any areas of support or practice that SMEs felt would be particularly helpful with respect to environmental management. In this context the following primary null hypothesis was designed.

Primary Null Hypothesis 2: There are no significant differences in attitudes within the SME sector towards environmental support initiatives.

The main purpose of this hypothesis was to analyse SME perceptions and attitudes towards future support with respect to environmental management. Companies were invited to declare their level of interest in the concept of a Regional Environmental Management System (REMS) and Environmental Performance Contracting (EPC). Definitional explanations were attached to the specific questions (Appendix 3).

A REMS was defined in the survey as a partnership between individuals, businesses, public sector institutions and other agencies designed to systematically improve the environment. Companies were then asked to consider how interested they would be in this concept. There was no distinction made here if this interest would be in theory or in practice. Answers were skewed towards the quite interested end of the scale, although a 
substantial $30.5 \%$ were neither interested nor uninterested in the concept. The distribution of response with respect to EPC (this is where an external consultancy implements environmental changes within a company and then charges on the basis of cost savings to the company) was similar with $30.5 \%$ feeling that they would be quite interested in the concept. It should be stressed, however, that for both concepts the median response was neither interested nor uninterested. This attitude of moderately interested apathy is theory consistent with the previous results. On this occasion there were no significant differences in response to the questions with regard to any company characteristics. This is not theory consistent. One would have expected the larger secondary companies to be more positive in their response towards these concepts.

Table 7.8 - Environmental Support Provision

\begin{tabular}{|l|c|c|c|c|c|}
\hline & \multicolumn{5}{|c|}{ VALID PERCENTAGE INTEREST } \\
\hline SERVICE & $\begin{array}{c}\text { Extremely } \\
\text { interested }\end{array}$ & $\begin{array}{c}\text { Quite } \\
\text { interested }\end{array}$ & $\begin{array}{c}\text { Neither } \\
\text { interested } \\
\text { nor } \\
\text { uninterested }\end{array}$ & $\begin{array}{c}\text { Quite } \\
\text { uninterested }\end{array}$ & $\begin{array}{c}\text { Not at all } \\
\text { interested }\end{array}$ \\
\hline $\begin{array}{l}\text { Environm- } \\
\text { ental } \\
\text { telephone } \\
\text { helpline }\end{array}$ & 6.3 & 21.7 & 32.6 & 5.7 & 33.7 \\
\hline $\begin{array}{l}\text { Up to one } \\
\text { hour's } \\
\text { confidential } \\
\text { advice }\end{array}$ & 6.3 & 20.6 & 35.4 & 8 & 29.7 \\
\hline Newsletter & 4.6 & 33.1 & 27.4 & 8 & 26.9 \\
\hline $\begin{array}{l}\text { Handbook } \\
\text { and up to } \\
\text { date } \\
\text { briefings }\end{array}$ & 5.7 & 28 & 32.6 & 5.7 & 28 \\
\hline $\begin{array}{l}\text { PR for } \\
\text { environment } \\
\text { al success } \\
\text { stories }\end{array}$ & 4 & 19.4 & 38.3 & 5.7 & 32.6 \\
\hline
\end{tabular}


Respondents were then asked a series of questions relating to specific support provision. This was to analyse the potential interest SMEs would have in the support provision. For this purpose the services offered by one of the collaborating establishments (Groundwork Trust's green business club PAYBACK) were used as examples of possible support provision.

Table 7.8 shows the services on offer and the percentage interest of the respondents. Only $2.2 \%$ of respondents from the survey were already members of the club and they felt that the services offered were mostly neither useful nor not useful. Clearly SMEs feel ambivalent towards the services offered as responses are skewed towards the middle response of neither interested nor uninterested.

$33.1 \%$ felt that they would be quite interested in a Newsletter. This is slightly higher than the other responses and suggests that it is one of the more important possibilities to be pursued in respect of SMEs. A series of multivariate tests for variance were run to see if there were any significant differences in response between company characteristics. These all proved to be negative. One has therefore, to accept the null hypothesis that there are no significant differences in attitudes within the SME sector towards environmental support initiatives.

The second mail survey documents the extent of apathy and lack of initiative in the implementation of environment strategy among SMEs. In general, regardless of company size, business sector category or exporter/non-exporter status (except for very minor variations) environmental protection did not rank highly as a priority issue requiring investigation or action. This may be of concern as the cumulative impact of economic activity is leading to depletion and destruction of the common resource base upon which all firms draw in order to conduct the business of production and distribution. 
To date, public awareness of the environment threat has been enhanced through presentation of scientific evidence by the pressure groups and publications of the environmental movement, most notably Friends of the Earth, Greenpeace and "The Ecologist". TV programmes initiated by the groups have alerted the general public, so that it has become in the marketing interests of large companies, e.g. Shell and Macdonalds to be seen to incorporate some environmental protection measures within their strategic plans. Hence the development of strategic systems like BS 7750 and the EU EMA scheme. Closer examination reveals the cosmetic nature of these initiatives (Lang and Hines, 1993 et al). A global market requires mass transportation systems and exploitation of resources on a vast scale in order to provide goods at the cheapest "cost". This cost does not, however, include the cost to the environment. 'Greenwashing' is neither designed nor intended to create sustainable economic development. On the contrary it has been argued that environmental protection and legislation can be manipulated by large companies to erode the market share of SMEs (Clunies-Ross and Hildyard, 1992).

This research argues that genuine environment protection is dependant on the expansion of an environmentally aware SME sector with the resources and will to implement appropriate policies. The predominant obstacle to the implementation of environmental protection policies detected by this survey is the ambivalent attitude towards change.

Appreciation of the need for strategic environmental management is low for a number of differing reasons. Survey 1 showed that operational environmental management is seriously limited in its range and effectiveness. Attitudes are ambivalent and general feeling is that regulation and legislation favours the larger manufacturers (this attitude was particularly prevalent in the in-depth interview stage). There is a dichotomous situation within the SME sector with the larger manufacturing companies perceiving 
green issues as important and seeing sound environmental policies making good business sense. Although this is not exclusively the case, it does seem to be the general trend. The vast majority of SMEs on the other hand, do not consider environmental concerns as cost effective. In this event, however effective management systems may be, radical change will not occur without a fundamental shift in attitude.

A shift on any significant level will only occur through education, awareness and participation programmes. Until SMEs are convinced of the need to consider green issues holistically, little is likely to change. This raises a new question. How can change in attitude be achieved and what are the necessary support structures required? The next chapter approaches this question by considering the external environment in which SMEs operate and the constraints to effective environmental management and sustainable development. 


\section{CHAPTER 8}

\section{TOWARDS A SUSTAINABLE DEVELOPMENT}

\section{STRATEGY FOR THE SME SECTOR}




\subsection{Introduction}

The environmental management literature of the late 1980s onwards has assumed uniform motivation and awareness (from Beale, 1980 to the host of literature associated with BS 7750). The literature has considered strategic (BS 7750, HMSO, 1992) and operational (Bie, Hastam) environmental considerations but has failed to accept that SMEs are endemically different in nature to larger companies. The empirical research has shown that, management applications of theory have, therefore, been misplaced and misguided with respect to the SME. This chapter analyses the implications of the empirical research and satisfies research aims 3 and 4 (see Chapter 4):

3. To utilise the knowledge gained about awareness, attitude and organisational response to assess the relevance of the environmental management systems so far developed and to link this to achieving sustainable development.

4. To draw upon the expertise of owner/managers and appropriate institutions to validate and if appropriate further refine new/and or revised systems as necessary.

To satisfy the above requirements the objectives of the chapter are as follows: first, to explain how the research has found the theory negligent of the needs of the SME sector with respect to the environmental issue; second, to discuss why SMEs are not interested in the main in traditional management response towards the environment; third, to present the requirements for alternative theories based on local economic practice; fourth, to produce a case for a sustainable development model based on local circumstance and fifth, to present case study material to support the development of an alternative model: Rather than concentrating on changing management structures that do not exist or establishing management channels that cannot be established, this chapter argues for a 
more holistic appreciation of the SME sector and how the external business environment may provide the direction required for sustainable change in the form of localised economic trading practices based on a sustainable SME sector.

The following sections summarise the salient points of the empirical research and explains why the existing management theories require revision.

\subsection{Review of Empirical and Qualitative Research}

\subsubsection{Mail Survey 1}

The majority of companies responding to the survey were single-site businesses (67\%), $50 \%$ had less than 10 employees. With only $4 \%$ from the primary sector the survey reflects the attitudes, awareness and practices predominating in the secondary (40\%) and tertiary (56\%) sectors of environmental issues.

\section{a) Attitudes}

In general, interest was greater in specific issues, notable health and safety, water pollution and energy usage. The prevalent view in micro-firms was that environmental considerations, as a whole, were not relevant to the firm's day-to-day business activities. The larger the company, the more likely water pollution, energy usage, effluent waste disposal and solid waste disposal were to be considered important management concerns. The highest degree of interest expressed in relating environmental concerns to their business practices occurred in exporting firms. 


\section{b) Awareness}

The general level of awareness of regulation was low. Over $62 \%$ of respondents were not aware of the 1990 EPA and its implications to their business practices. $87 \%$ had no knowledge of any future European environmental directives. The larger the company, however, the more aware it was likely to be of the implications of the 1990 EPA, the 1989 Water Act and other regulations listed in Table 5.10 Results also show the companies from the secondary sector were more aware of environmental legislation and regulation than their retail or primary counterparts.

\section{c) Practices}

$42 \%$ of respondents had a recycling policy, a quarter had an energy efficiency programme and a quarter had a waste management policy. This evidence suggests that the SME sector is evolving environmentally sound practices. The in-depth interview stage of the research considered SMEs' environmental performance and the results confirmed the findings of the first mail survey.

Levels of strategic environmental management were low compared with previous surveys in the larger firms sector (BIM, 1992). Only 4.3\% had a strategic environmental policy. Companies with strategic inclinations towards the environment tended to be the larger secondary companies. $27 \%$ of respondents felt an environmental audit would be inappropriate and in general the response was one of critical incidence situation management. This reactive approach to the environment was endemic, and there was little evidence of a proactive management response. This type of reactive management approach is highly unlikely to evolve into a pattern of sustainable development. 


\subsubsection{In-Depth Interviews}

Although it is not statistically possible or appropriate to cross-tabulate results, the indepth interviews were consistent with the findings of the first mail survey. Almost 93\% of interviewees admitted to employing reactive critical incident situation management towards environmental problems. The opportunity cost of proactive environmental management was considered too great, creating a general ambivalence towards environmental concerns. $78 \%$ regarded time spent on the perceived logistical bureaucracy of strategic environmental management as capable of being spent more profitably elsewhere.

$86 \%$ of respondents, including secondary sector companies, were cynical about BS 7750 or any EMS. Although legislation was seen as the dominant force of change by $50 \%$ of respondents, only $29 \%$ were aware of the implications of EPA to their business practices. 75\% of these interviewees considered that it had been drawn up without adequate consultation as to the practicalities of implementation. Self-regulation was therefore seen as the preferable instrument for change although the present regulatory mechanisms were viewed as inappropriate to small companies, and there was little evidence of alternative sources of information. Indeed, $71 \%$ felt that information reaching them regarding the environment was poor and inadequate. Companies were in general reluctant to say, however, if any further information provision would induce them to change their practices. On the whole, the micro-firms had not considered the information provision question, regarding the issue as irrelevant to their business practices.

The most common environmental initiatives were recycling (50\%), energy efficiency (36\%) and waste management (43\%). Only $7.1 \%$ had any strategic plan for the environment in their business practices and $100 \%$ of respondents from the tertiary sector 
felt that BS 7750 was totally inappropriate to their operations due to time, financial constraints, and because of the structure of the standard.

$50 \%$ of respondents considered alternative strategies to improve their environmental performance a waste of time. This was due to their perception that their business practices were by their nature environmentally benign. Attitudes towards environmental issues were ambivalent and general awareness and understanding of the holistic interrelationships of economics and the environment were poor.

\subsubsection{Mail Survey 2}

Results of the second mail survey showed that there were no significant variations in response by companys in explanation of the lack of strategic environmental policy. Only $4.6 \%$ had an environmental policy in the first survey. This increased to $16.3 \%$ in the second survey, although the increase was limited in the main to the larger secondary sector companies.

Of the companies who did not have a policy, $37 \%$ considered their operational initiatives sufficient. Lack of time, finance and staff to implement any changes were also seen as important reasons for company inertia with respect to environmental considerations. When asked about BS $7750,68 \%$ felt that they would not be able to implement the standard even if they wanted to. The main reasons for this inability were also lack of financial resources, lack of available staff, the nature of the standard itself and unavailable time.

Proposals for support initiatives, including free consultancy, telephone help-lines or the development of a regional environmental management systems designed to help improve 
environmental performance attracted little positive response. This reaction is a key indicator of the negative aspect of present attitudes to future environmental issues in the SME sector surveyed.

The empirical research has shown, that there is little or no evidence to suggest that actual practices have any basis to support the view that SMEs are exhibiting or are motivated towards employing theoretical management solutions like BS 7750 or indeed the "advice guides" proposed to help companies with environmental management. SMEs are, in general, not interested in employing strategic management or environmental strategic management and find the necessity to change operational practices unnecessary due to their perceived negligible environmental impact.

The literature discussed under Alternative Holistic Solutions in Chapter 3 suggests that sustainable development is not going to be achieved through free trading economics and legislation. Alternative theory dictates the predominance of local economic activity if sustainable development is to be achieved. The next section considers this alternative and the implications for the SME sector.

\subsection{Towards a Sustainable Development Strategy}

The surveys in chapters four and six revealed a failure to develop a strategic environmental policy throughout the SME sector. The most commonly cited reasons by firms for this response were lack of time shortage of finance and failure to detect a direct connection between the activity of the firm and environmental degradation. The latter was in no small part due to the predominance of micro-firms within the survey. Although only $1.3 \%$ of companies registered the belief that the environment was no longer an important issue, complacency ranked high and the belief that operational initiatives 
sufficed was common. This was particularly the case within the micro-grouping where operational initiatives were in the main limited to recycling.

A picture emerged of a lack of understanding of the basic facts and a general unfamiliarity with the issues involved. Firms were unclear as to the aims of legislators and environmentalists. The scale of the problem is beyond the capacity of support organisations like the Groundwork Trust's PAYBACK (Chapter 6). Attempts to increase informational flows and support devices to the SME sector in this way have not been highly successful. The Trust's experiment highlights the irrelevance of 'bolt-on' environmentalism. Advice and education on environmentally sound policies remain unattractive and ineffective in a business environment where economic survival is the predominant preoccupation. Hence there is every indication the environmental management voluntary standardisation directive BS 7750 will be minimal in effect in reducing impacts, particularly in the micro-grouping.

The present information suggests that while environmental protection provision and management systems are evolving in the larger manufacturing companies, there are few signs of change in most other companies, particularly in the micro SME grouping. As things stand this is likely to be the case for the foreseeable future. Were the course of events surrounding the emergence and acceptance of the quality standard BS 5750 to occur with respect to BS 7750 , the effect this would have on achieving the aims of sustainable development would be minimal. Most of the companies interviewed regarded BS 5750 purely as a commercial cosmetic exercise. Rather than companies having to achieve the quality standard, the standard was made to fit the company. Accreditation was being achieved through the establishment of processes rather than changes in practices which had any substance. This research suggests that where the standard was implemented, quality had not increased sufficiently to make the procedure worthwhile. If 
this were to happen with BS 7750 then the reduction in environmental impact would be minimal.

The likelihood is that these environmental management systems could lead to significant reductions in the environmental impact of companies who have clear environmental impacts in the first place. Most other companies, especially micro-firms, however, would find the exercise to be inappropriate and would fail to apply to them. Consequently any significant reduction in overall environmental impact would be unlikely to occur.

As things stand it is unlikely that any of the restraints to environmental self-regulation in the SME sector will cease to be significant. Cost, time and initial lack of commitment will remain as major initial restraints on implementation of effective policies. However, it is equally unlikely that regulatory changes will result in substantial policy changes under the present free trading system. Further, evidence suggests that attempts to impose new environmental legislation on an international or national level are likely to be opposed by GATT as 'barriers' to trade and contrary to the GATT agreements. For example, in 1985 Indonesia banned the export, but not the felling, of logs and rattan from their rain forests. They proposed to process the material themselves, arguing that this would provide an incentive for protection of a natural resource on both environmental and economic grounds. The European Community complained to GATT and won the case on the grounds that such national legislation restricted international competition and free trade (Hines and Lang, p63, 1993).

The 'strengthening' of the GATT agreement through the signing of the Uruguay round on the 15th December 1993 in Geneva further enhanced this position. As national governments lose the power of regulation in this way the potential role of the SME sector in environmental protection will increase. A strong commitment to the environment from 
the SME sector could compensate for the absence of national legislation for environmental protection. The SME retains the option to ostracise environmentally damaging practices and to give high priority to the purchase and supply of socially and environmentally friendly goods and services from known sources. The assumption here of the SME having a strong commitment to the environment is of course a large assumption and is unlikely to occur spontaneously. If, therefore, as appears to be the case, environmental self regulation within the existing trading system is impractical and increased environmental regulation is implausible an ecologically sustainable society may be achievable only within a radically changed framework (Hutchinson and Chaston 1994).

A prerequisite for the implementation of environmentally sustainable policies by the majority of SMEs is an educative approach based on concepts of action learning. Once SMEs appreciate that sound environmental management is good business they may be enabled to perceive that it is in their interests to consider all environmental implications of their business practices. Many SMEs employ minimal workforce and are not much larger than larger households. It is clear from the research findings that these micro-firms are particularly slow to accept responsibility for environmental problems since, like the average household individual, they do not view their own individual lifestyle as earth threatening. This individual centred philosophy creates a mood of complacency and inertia. Facilitating a policy shift away from direct environmental education per se towards alternative forms of priority action that have secondary environmental education effects in-built is therefore a requirement.

Any sustainable system will be dependent upon community understanding for the need to change. This understanding is emerging through conscious raising projects that have significant participatory elements and becomes evident in the re-generation case studies 
detailed in the next section of the research. One of the main problems is that the global trading system as a whole has become too large to regulate. Hence the soundest means to take account of ecological considerations is to decentralise and simplify the decision making process (Dobson. R. 1993). This allows for localised knowledge to enter the decision making process and for social considerations to be taken into account. Education and information, leading to a fuller understanding of the implications of political decision making and the economic ramifications of these new policies are important elements in any system dedicated to achieving sustainable development.

The principles outlined in Agenda 21 provide the basis for the development of regional re-generation strategies. Agenda 21, the global environmental action plan signed in Rio De Janeiro at the 1992 Earth Summit (Keating, 1994), is effectively a guide for business and government policy towards the environment for the next century. Issues covered include poverty, biodiversity, population and sustainability, managing hazardous waste and the financing of sustainable development amongst others. Over two thirds of this action plan requires the commitment and co-operation local government if it is to be implemented and is dependant on local sustainable re-generation. Local government involvement is particularly evident in Chapter 28 of the agenda, known as Local Agenda 21. This deals with localised sustainable development in relation to the following areas: community participation; the greening of the local economy; education and awareness concerns; the transport and planning interface; green purchasing; and sustainability in rural areas. Regional re-generation initiatives could therefore provide one of the most important dissemination outlets for environmental information.

Sustainable economic policies are in the interests not only of the economy as a whole but more specifically of the existing companies within the locality. At present the environmental agenda (including legislative developments) is being determined primarily 
by the larger corporate entities (Clunie-Ross and Hildyard, 1992). Hence such legislation as is permitted under GATT tends to support the interests of the larger companies. This will tend to reduce the market shares of SMEs unless sustainable regional re-generation models are used to increase SMEs competitive advantage. Concepts such as cooperation, networking, LETS involvement and credit unions all act to focus upon opportunities for increased trading at a local level. Reduced energy bills through energy efficiency programmes, waste minimisation procedures and other cost saving initiatives can serve to further increase the competitive advantage of SME business practices.

The secondary policy implication of a regional re-generation model is the education of SMEs in concepts of sustainable development, changing attitudes through action learning. This approach, central to bioregionalist philosophy, promotes the re-inhabitation of the region and the learning aspects of sustainable development. Communities learn how to live 'in place' and reverse dependence upon external economic investment that has little or no local accountability to the environment or to the community. The move enhances local SME good and service provision.

The research has shown that there is a need for a radical change in attitudes and practice of SMEs if sustainable development is to be achieved. It has also shown that this is unlikely to occur through the application of the large business model based on environmental management systems. BS 7750 only serves as a comparative referencing system, it does not and cannot solve the holistic problem of sustainable development. There is therefore a requirement to develop appropriate solutions to move towards a sustainable model for SMEs.

All three stages of empirical research show that the larger secondary companies have a more positive attitude towards the development of environmentally friendly initiatives 
than their smaller counterparts. It might therefore be argued that the solution is to increase the size of SMEs. However, evidence suggests that growth is not the answer. From Schumacher, (1973) to Johannisson, (1983); Conaty, (1993); Morehouse, (1993) and Lang and Hines, (1993) localised, small-scale operational development has been recognised as the optimal route to sustainable development. In fact the larger a company grows the greater its impact on the environment is likely to be as more resources are used, transport distances increase, more energy is employed, more waste generated and consumption in general is increased. Hence it has considerably more scope to seek to reduce its impact on the environment in relative terms. In real terms, however, it will continue to have a greater impact on the environment than the smaller local enterprises.

Larger companies also have an increased motivation to pick up on environmental concerns by virtue of being large. The greater the environmental impact of an organisation the more likely it will be to realise the necessity to be aware of its impact, for legislative or for marketing reasons. Hence, although smaller companies may have a lower level of awareness and fewer strategic policies, this may not necessarily mean that larger firms are preferable in the pursuit of a sustainable development strategy for SMEs. Further, in many cases geographical, personal and/or economic constraints provide additional checks to growth in the SME sector (Johannisson, 1983).

A further case for growth arises over the question of employment provision. It is frequently argued that large firms bring employment to an area and generate economic activity e.g. the Trident contract at Plymouth Devonport. Small scale businesses are often more labour intensive, however, there may be a stronger argument for localised employment provision. The mail surveys and in-depth interviews in Chapters 5,6 and 7, reveal SME perception that information and education on the potential strengths of the sector for present and future development are inadequate. There is therefore a need to 
satisfy this educative void. Alternative localised development strategies based along sustainable lines could provide the necessary information and education through participation, this is an area requiring further consideration.

If, therefore, growth is not the solution, effective legislation is unlikely due to GATT and self-regulation implausible or inappropriate to the SME sector, there is a need for an aiternative model to achieve sustainable development within the SME sector. BS 7750 was not designed to achieve sustainable development. It was designed merely to improve the management of the environment as a strategic issue and is clearly appropriate for the large manufacturing company allowing for more 'efficient' management of the environment. This management does not mean that the environment is going to be sustained however. If the SME sector is unlikely to implement the standard and future provisions of information are greeted with ambivalence, the change of attitude called for by so many writers to achieve sustainable development [Bookchin, (1980); Morehouse, (ed, 1989); Jones, (1993); Lang and Hines, (1993); Plant P. and Plant J. (1993) et al] is unlikely to occur.

Conaty suggests that there needs to be a re-evaluation of priorities for sustainable development to be achieved (Conaty, 1993b). He considers the present system where capital is the determining factor in the productive process, taking precedence over land and labour, as misguided. His vision includes the re-evaluation of financial philosophy so that money supports the needs of people and the earth, and the earth and people cease to support the financial system. He sees the financial system as a tool rather than the master.

The issue is not so much how well the system and business can manage the environment. This is the very philosophy which has created the present predicament. The research 
posed the question of whether sustainable development within the SME sector can be achieved. To satisfy this aim the development of a sustainable system of production and distribution offers a sounder basis for sustainable development than recycling programmes. The present system may be able to provide applicable management systems (or not as the case may be). What is questioned is their ability to induce a sustainable society.

This research has suggested, so far, that there is a requirement for education to achieve sustainable development. Sustainable development is dependant on the expansion of an environmentally aware SME sector conscious of the benefits both economical and environmental, of local trading patterns. Sustainable development implies economic equilibrium and a stable locally oriented economy, which is likely to be beneficial to the SME. The form of action learning educational provision based on participation, which will enhance the development of sustainable philosophies and policies requires research and further analysis.

This section has delineated alternative approaches to sustainable development. It is necessary, therefore, to determine whether such alternative approaches are feasible. The next section presents case study material of actual practice within the area of localised development practice.

\subsection{Socially and Environmentally Accountable Development Strategies - A Series of}

\section{Case Studies}

The case study material details a new generation of projects designed to revitalise economic activity on a regional basis. As the evidence in this chapter indicates, the projects are neither competitive nor mutually exclusive. On the contrary they offer 
indications for a holistic and collective approach to regional revival which has implications both for the viability of the SME sector in the locality and for the creation of a sustainable environment.

The case studies derive from a series of semi-structured in-depth interviews and additional material from the relevant organisations involved. All are local examples of initiatives in different regions across the globe in response to changing economic and environmental pressures. The LETSystems in Devon and Cornwall and Plymouth's Credit Union in Stonehouse are local adaptations based on models developed from the experiences of similar groups. The Keveral Farm Permaculture Design Community in Cornwall is a residential and farming community that is combining long standing local experience with permacultural design features that originated with Bill Mollisons book published in Australia in the 1978 (Mollision and Holmgren, 1978). The Urban Community Regeneration Scheme, Wolseley Community Site Project, Plymouth, Devon, and the Regeneration Unit of Cornwall County Council are seeking to implement Agenda 21 (part of the Earth Summit, 1992 signed in Rio De Janeiro) through collaboration between the local authority, the business community and various other voluntary organisations. Resource Town 2000, Torrington, Cornwall is a further example of formal co-operation between the local authority, local business community and voluntary organisations. 


\subsubsection{Local Exchange Trading Systems (LETS) - Totnes. Devon}

\section{Background Information}

A comparatively recent phenomenon the first LETSystem, devised by Michael Linton, commenced trading in Courtenay, Canada in 1983, (Dauncey, 1988, p53). LETS is a barter system in which the double coincidence of wants is eliminated.

Generally this term refers to Local Exchange Trading Systems, it does however have a number of other alternative descriptions. For example, it has been described as a Local Enterprise Training System which provides low cost, low risk ways of establishing local needs, employing local people. It has been defined as a Local Energy Transfer System, a Local Education Transformation System and a Local Employment Trading System, which would create new work opportunities within a region. For the purpose of this case study, however, the term will relate to the more traditional definition of a Local Exchange Trading System.

The essential characteristics of the LETSystem are as follows:-

1. The agency maintains a system of accounts in a quasi-currency, the unit being related to the prevalent legal tender.

2. All accounts start at zero, no money is deposited or issued.

3. The agency acts only on the authority of an account holder in making a credit transfer from that account to another.

4. There is no obligation to trade.

5. An account holder may know the balance and turnover of another account holder.

6. No interest is charged or paid on balances. 
7. Administrative costs are recovered, in internal currency, from accounts on a cost of service basis.

(LETS Services, 1989)

\section{The Interview}

A LETSystem is a self regulating economic network which allows its account holders to issue and manage their own money supply within a bounded system. This case study concentrates on the LETS scheme in Totnes, Devon and considers the implications of direct SME involvement in the scheme. The case study material is derived from primary source LETS publicity material and a semi-structured interview with LETS organisers. and LETS publicity material.

A LETSystem is founded on the basis of members' commitments to each other and to the community. It is not a barter economy (within the traditional definition of the term). When one person provides a good or service to another the consumer owes the community (rather than the individual who did the work) payment/commitment. This aspect of the LETS concept is seen as a vital aspect of the scheme as it highlights the relationship between the individual and society which traditional money exchange can obscure. For example a consumer who buys vegetables from the supermarket has no knowledge of the processes involved to produce the sustenance they buy. The educational aspect of the consumer being in touch with the producer who lives within the locality is therefore an important feature of the LETSystem. As with a credit union a LETSystem requires considerable trust if it is to function successfully. This suggests an optimum size which is small, local and accountable. The concept of MULTILETS software, computer software that links LETSystems together in space to provide regions with goods they cannot produce, is a recent development within the UK. 
Effectively LETSystems give people and businesses the opportunity to acquire or sell goods and services without traditional cash exchange. This is of particular interest to the SME sector as it offers opportunities for increased market share competition through new market opportunities. For example, a family unable to afford to buy a new dinning table in sterling, may opt to pay their commitment back to the community through the LETSystem. The concept has a number of liberating principles. It allows for the development of dormant skills which the formal economy has made redundant. It allows individuals to attempt new skill development initiatives; Anything from teaching jazz piano to producing local duvet covers or simply mowing lawns can be transformed through a LETSystem into a productive activity.

The implications, therefore, for local economic welfare in general, and the SME sector in particular, appear significant. In Totnes the general consensus is that the LETSystem has provided the community with a significant economic boost. Although formalised economic research has yet to be undertaken in the UK the general feeling is very positive, particularly among small businesses in the area. A number of SMEs are already trading through the LETSystem. These include an accountancy firm, crafts retailers, a child care provision company, a Chinese herbal medicine firm, a traditional carpenter and an organic market garden box scheme (see below). All of these companies accept a combination of sterling and Acorns (the Totnes green pound: every Acorn is worth one pound) as payment for goods and services.

Local employment providing for local needs as far as possible is considered beneficial to the community for a number of reasons. The direct producer/consumer link reduces consumer costs, mainly as a result of the lower transportation costs on products; there is more community involvement; the system has generated a local bond beneficial to community spirit; local production enhances sustainable lifestyles; and generally less 
packaging is used within the LETSystem than in the traditional market as consumers were more ethically aware. LETS is a locally based economy that encourages wealth to stay within and be reinvested in a region. It is seen as beneficial to the economic and social welfare of the community of Totnes and has, according to LETS statistics, significantly improved certain business turnover.

As with the other case studies analysed in this research the secondary effect of sustainable lifestyle education diffusion also applies. The proximity of the producer and consumer makes for mutual accountability. This is particularly relevant in the case of agricultural businesses. The farmer is more accountable for his/her behaviour regarding environmental practices and the consumer is more aware of the expense and complications of effective environmental practice.

In Totnes there is an organic vegetable box system as a part of the LETSystem. The producer sells organically produced goods through a number of distribution points within the community rather than in the local supermarket. Each individual gets a choice of three different sizes of box $£ 3.50, £ 5$ and $£ 7$ containing a selection of seasonal produce as available. Modifications can be made in certain cases to cater for strong preferences, but on the whole consumers get what is on offer. This adds a novel aspect to food shopping within Totnes in that the consumer receives an unexpected selection of vegetables.

Although the economic implications have not been measured in formal terms, the picture is emerging of a system offering opportunities for new markets to SMEs, new training opportunities that could lead to start up programmes and the development of community links within the area that are beneficial for the diffusion of sustainable development ideology. 


\subsubsection{Devon Co-operative Development Agency (CDA)-Credit Union Development}

\section{Project (CUDP)}

\section{Background Information}

About one trillion pounds a day is traded on the London money markets, yet only about $5 \%$ of this turnover has anything to do with world trade (Robertson, 1990). 20 years ago this figure was closer to 30\% (Conaty, 1993 p118). Credit Unions are in essence financial co-operatives run by their members which specialise in consumer lending. Expansion in the UK has been slow even subsequent to the 1979 Credit Union Act. In the USA the expansion has been more marked and lead in part to the American Community Reinvestment Act of 1977. This law stipulates that financial institutions should serve the needs of all of the community and not just the already affluent and requires regular performance appraisal in relation to the policy requirements (Conaty, 1993 p121). Credit Unions offer access to low interest loans, and attainable saving, enhancing (through the training necessary to run a Credit Union) the confidence and skills of the membership. Motivated by the high charges of loan sharks and sharp business practice which may demand exorbitant interest rates [Dauncey, (1988 p175) quotes interest rates of $1163 \%$ p.a. in Birmingham, England and 25\% per day in Calcutta]. As a means to escape debt, credit unions have multiplied significantly on a world scale since the 1980's. In British Columbia by 1988, $\$ 6$ billion were on deposit with credit unions "a figure large enough to allow the province to become a real pioneer in the field of sustainable community economic banking, if local $\mathrm{CU}$ members woke up to the possibilities and started using their democratic rights to bring in the new communitybased lending polices" (ibid, pp177-8). In the UK, however, legal restrictions limit the scope for creative investment decisions the percentage of people belonging to CUs 
remains substantially below the figures for Canada and New Zealand (Dauncey, 1988, p175).

Credit Unions are not charities, although they are motivated by an underlying charitable, self help philosophy. They offer local people the chance to determine their own savings procedures and to be aware of the implications to the locality of their investment decisions. They empower communities to determine the structure of local employment. This ideological approach to the meeting of local needs locally is inherently sustainable, and provides an important medium for the diffusion of education regarding sustainable business practices. UK Credit unions are monitored by the Registrar of Friendly societies. They pay up to $8 \%$ dividend on savings, free Life savings and Loan Protection. One can save up to $£ 5000$ with them and borrow up to $£ 10000$.

Credit Unions are seen as cheap alternatives to other sources of loans and they encourage prudent money management. To comply with the law, (and also to operate effectively) the people who form the membership of a Credit Union must have something in common. They must have a 'common bond'. This common bond can take the form of all the members living in the same area. These are Community Credit Unions sometimes referred to as Residential Unions. A CU may be formed from the members organisation such as a Business Club. These are known as Associational Credit Unions and are occasionally referred to as Occupational Credit Unions.

Community Credit Unions are increasingly being employed as part of anti-poverty strategies in many parts of the country and are growing in the UK at the rate of one a week. They are not, however, a quick fix solution to poverty, unemployment or debt. On the contrary, the CDA perceives credit unions as a highly constructive response to poverty, debt, unemployment and to the principles of sustainable development on a long 
term basis, providing direct access to cheaper credit and encouraging money management and enterprise skills within the community as a whole.

Essentially Credit Unions give loans on the basis of savings records within the Credit Union. Because borrowing is based on savings and trust there is no security required to borrow. CUs are spreading rapidly in the Britain. In 1988 Britain had only 83 CUs with 25,000 members and $£ 5.8 \mathrm{~m}$ in assets (Dauncey, 1988, p176). There are at present an estimated 450 Credit Unions in the UK with about 80,000 members and $£ 16 \mathrm{~m}$ in assets. World wide there are an estimated 110 million Credit Unions with 206,607 million members (Milne, 1994 pxi).

The 1989 Brundtland report cited the elimination of poverty and deprivation as the initial policy requirement for sustainable development (World Commission on Environment and Development, 1987). Her proposal was for world leaders to accept the need for a "new economics" which is both people and earth centred. This new economics requires a system that has alternative ethical considerations attached to the financial requirements of society making credit unions a central aspect of sustainable development. It has been suggested that overindebtedness is as much a pollutant as acid rain and toxic waste (Conaty, $1993 \mathrm{p} 125$ ). The reasoning is that banks fund the projects and commercial enterprises that lead to the environmental degradation in the first place. Regulation and information regarding banking decision making may therefore be a future requirement of sustainable development. If this is the case, the local credit unions offer a structure that can be easily comprehended as well as being more accountable to the local community than a large financial operation. 


\section{The Interviews}

This case study material is derived from interviews with the Devon Co-operative Development Agency (CDA) and their sister organisation the Credit Union Development Project (CUPA). The CUPA has been established to promote, develop and sustain the expansion of credit unions (CU) in Devon and Cornwall. The material relates in particular to an initiative to establish and promote a South Devon Business Club Credit Union.

\section{The Co-operative Development Agency}

The CDA offers the following benefits in support of small businesses facilitating sustainable development through local community action:-

1. Increased members' net disposable income by reducing rates of interest otherwise incurred on loans.

2. Increased investment opportunities for small businesses in co-operation through the recirculation of the Credit Unions funds, via community trusts.

3. Increased organisational, administrative and communication skills of individuals and groups, enhancing a culture of self management and increasing their competitiveness (both as individuals and as traders).

4. Increased 'economic literacy' - eg. money management; debt control; management accounting skills.

5. Increase self confidence of individuals and reduce the blight perceived stigmatisation of debt by building structures of mutual support.

6. Reduction of the psychological and social burden of debt upon individuals.

7. Integration of the work of a wide range of agencies in the fields of economic 
development, employment, enterprise training and services to small businesses.

CUs complement the work of other local agencies and provide vital support for SMEs. They assist in the development of local employment structures and support the principles of Agenda 21 within the area of the Devon CDA.

The South Devon Business Club is an initiative that is attempting to establish an occupational or Associational Credit Union with the common bond of local business involvement. Credit unions, like many regional, community initiatives for sustainable development, require trust as a central ingredient for success. Canadian research has suggested that debts are more likely to be honoured within the confines of a credit union because of the close bond between the borrower and the lender. This trust aspect is central to the community ethos of the credit union and sustainable development (Milne, 1994). The CDA believe that because it is the members who run the union they will be more knowledgeable and sympathetic to the needs of the borrowers. It is stressed, however, that percentage borrowing allowance depends on percentage savings accrued and over time history of repayment. This is seen as a safeguard against debt repayment failure.

The intention behind the South Devon Business Club is that micro-SMEs will be encouraged to start up and that existing SMEs will be encouraged to participate to alleviate the high levels of interest repayments that are seen as such a significant factor by the CDA in the attainment of micro-business sustainability.

The success of the South Devon Business Club is liable to depend on the strengths of relationships within the club. However the principle of community managed capital provision is central to any model of regional self-reliance. Decisions on lending and 
investment can be made by the $\mathrm{CU}$ with the welfare of the communities' employment structures in mind rather than the profits for a centralised banking system located outside of the region as being central variable in the decision making investment and lending process.

\subsubsection{Keveral Farm Permacultural Design Community. Cornwall}

\section{Background Information}

An alternative community has existed on the Keveral Farm site for 22 years. Over that period the character of the project has varied according to its membership and the economic climate. Currently the dominant philosophy among the 11 full time and 9 part time members is based upon permacultural design techniques. Practices couple this philosophy with co-operation with local businesses through a LETSystem. Community self-reliance within the confines of the existing land area is regarded as impractical even in the long term. Regional self-reliance, in which a variety of alternative projects interact with more conventionally based local enterprises is considered a more feasible alternative, creating a vision of an Eco-hamlet. This would form a similar vision to Ken Jones' cornucopian ecotopia (Jones, 1993).

\section{The Interview}

The material from this case study derives from a semi-structured interview with members of the Keveral Farm Community. The interview was designed to explore the following subject areas:-

a) The extent of self-reliance of the community. 
b) The nature and extent of links with local businesses and the potential for SME involvement.

c) The implications of the project lifestyle in furthering the evolution of a sustainable economy.

d) Land tenure and accessibility.

The 30 acre site is leased on six-monthly tenure from a sympathetic local landowner. Hence membership of the community is not dependant upon availability of finance to purchase a share in the land. This is seen as an advantage and, were the site to come on to the market and to be purchased by the community, the policy of open access to membership would continue.

The site comprises woodland, orchards and market gardening areas with stables, animal housing, polytunnels and a series of outbuildings. The latter are used in particular for educational courses designed to increase the diffusion of information about the philosophical and practical elements of the Permacultural Design used on the community land.

Plans are in progress to build a new conservatory in conjunction with the LETSystem to increase energy collection and conservation. The conservatory will extend the growing season for soft fruits and vegetables. Further, the design and construction will involve local firms and will therefore act as an educational exercise in regional empowerment and sustainable development for the firms involved. The perennial garden also has permacultural design features including a pond so placed as to reflect the light on to the wall-clinging plants. 


\section{The Community}

The existing community is as yet little more than an extended household in size. It is envisaged that the residential section (the household co-operative) could grow to the size of a hamlet, offering scope for a broad selection of lifestyles while retaining the informality of personal contacts.

The community owns and runs two businesses. The housing co-operative deals with the housing and financial logistics within the community and the farming co-operative provides the subsistence support structures. Capital is generated by the sub-letting of premises to a local blacksmith. These ventures and involvement with the newly established LETSystem bring the community into contact with the conventional business scene. The links serve to enhance communications between the community and other local enterprises.

The community operates on a combination of pragmatism and idealism. Cars are permitted on the site and, initially, at least, it is recognised that the businesses cannot entirely be self-financing. Social security benefits serve to subsidise the lifestyles, enabling work on the land to be undertaken free of charge. Labour rates are discounted from cash flow projections. In the sense that labour rates are traditionally incorporated into the output of a business in this case, however, they are not included as a direct entry to the books.

The personal empowerment of individuals is central to the community philosophy. Contemporary society is perceived by community members as disempowering and in conflict with principles of self-reliance and ecological sustainability. Work for the farming co-operative is seen as an alternative to involuntary unemployment or 
compulsory workfare schemes. Informal permacultural philosophy and alternative lifestyles is consolidated by the development of the programme of residential and nonresidential courses, including a summer camp for permacultural and bioregional issues. Courses, lead by a number of prominent green writers, have included bioregional practicalities and permacultural workshops. This aspect of educational diffusion is seen as a central aspect of the community's role within the locality.

Propagation of the feasibility and accessibility of alternative lifestyles and the necessity to abandon high consumption and environmentally destructive process of production and consumption underlies all community activity. The community aims to demonstrate that Britain can once again become self-reliant in food supplies, even with the present population/land ratio.

\section{Business Interests}

The community pools its resources to provide housing for its residential and business activities. The farm co-operative sells seasonal market garden produce to the surrounding community including a local monkey sanctuary.

In sharp contrast with the conventional businesses studied in chapters four, five and six, the ecological impact of productive activity is constantly monitored on a day-to-day basis by the community. All aspects of business practice are evaluated from the checking of the polices of suppliers to the minimisation of waste and the re-use of materials.

However, in terms of conventional economics and business practice, the community business practices appear to have little relation to the traditional requirements of commercial participation. The quest for quality of life, minimal ecological impact, 
community welfare, educational authenticity and self provisioning bears little relationship to the philosophical laws of the self financing, financial profitability and economic efficiency as defined by conventional business practice. Where the more conventional SME would in general evaluate its activities by the simple yardstick of financial profit, the Keveral community operates upon fundamentally different principles. Here a distinction is made between full employment and fulfilling employment and between didactic educational methods and alternative educational provision that considers examples of best practice that lead to self-awareness and self determination.

\subsubsection{Urban Community Re-generation Scheme. Wolseley Community Site Project} (WCSP), Plymouth, Devon

\section{The Background}

The Earth Summit in Rio De Janeiro, 1992, included the signing of a global environmental and development action plan called Agenda 21. Chapter 28 of Agenda 21 is an explanation of the requirements of local government towards the concepts within the plan and is called Local Agenda 21. Approximately two thirds of Agenda 21 cannot be properly delivered without local government involvement and co-operation, each local authority has been encouraged to incorporate Local Agenda 21 into its strategies by encouraging local business, community and voluntary participation.

Seven topical areas were highlighted by the UK local authority associations to assist authorities with the implementation of Local Agenda 21;

a) Community participation.

b) North/South linking for sustainable development. 
c) Greening of the local economy.

d) Education and awareness raising.

e) The transport/planning interface.

f) Green purchasing and compulsory competitive tendering.

g) Sustainability in rural areas.

\section{The Interview}

The community project (WCSP) arose in part from the commitment of Plymouth City Council to meet the requirements of Agenda 21. Information in this section is based on a semi-structured in-depth interview with a City Councillor involved in the project.

The main objectives of the case study were:-

1. To decipher the City Council's commitment to Agenda 21 within an urban locality.

2. To consider how SMEs would benefit from the project.

3. How far the project would be community based.

The WCSP was set up to regenerate the local urban economy along sustainable development lines. WCSP aims to satisfy the initial requirements of $a, c, d, e$ and $f$ above. It is an attempt to establish a self-reliant, self-financing community centre training local people for local jobs. Within the parameters of this remit the Centre plans to consider various aspects of sustainable development business practices. The project will therefore raise the consciousness of local people, in the process of training them to establish their own SMEs. 
WCSP will pay for itself through the rent charged to the co-operative enterprises which it generates. These enterprises will be owned by the local community as co-operation is seen to be a central element to the success of the project. The plan is initially to rent five sites mainly to retail co-operative enterprises. It is felt that the retail outlets would succeed as the site is located in a peripheral region of the city where retail provision is not particularly developed. It is also envisaged that the businesses will offer the work to local people who live in the community of Keyham in Plymouth.

Environmental consultants are being employed at the building and design phase of the site. For example the consultants have suggested that any trees with preservation orders on within the site should be conserved and building undertaken around them where ever possible. When completed a community steering group is envisaged to run the site. This community involvement will allow local environmental considerations to be accorded a higher level of importance than if the management and decision makers were not from the locality. The buildings will be developed with environmental specifications in mind with energy efficiency of the buildings being a priority issue at the design stage.

The Community Economic Development Trust (CEDT) which will run the WCSP will include a Forum of local members who will be trained in site management and educated in the principles of sustainable community development. It is envisaged that financial self-sufficiency (ie. existence without local government financial support) could be achieved within a 5 year period.

Through a project of this type, members of a community can be involved in the economic regeneration of their own local area. Further, it provides a valuable opportunity to disseminate concepts of sustainable development through examples of working practice. Theoretical explanation and philosophical arguments are slow means to convince the 
majority of people of the merits of and the necessity for a change of lifestyle. Once a community sees first hand the impact it can have on its own economic destiny and the benefits that accrue from sensible environmental management the merits of an enhanced lifestyle become apparent.

Projects like WCPS therefore have a dualistic purpose. They enhance a community's ability to reduce dependence upon large scale economic structures They simultaneously reduce the environmental impact of business practices and act as an educative awareness/conscious raising exercise. Nothing succeeds like success. Once projects of this type become a familiar part of the business scene the barriers to participation and imitation of those models will largely be overcome.

\subsubsection{Torrington Resource Town 2000, Cornwall}

\section{The Background}

Torrington has a very high level of unemployment. In particular the closure of the Creamery in 1993, the cornerstone of employment provision, lead to a significant reduction of employment in the town. A group of local people decided to take action to find a way forward for the town and on October 25th 1993 a first meeting was held of the Torrington Resource Town 2000 Steering Group. This comprised; the Major of Torrington; Devon County Council's Economic Development Officer and Environmental Officer; Creation Restoration Ltd; Sustainable Futures; the Community Council of Devon; Torridge District Council and a representative of the Tarka Project, an environmental initiative near Torrington. 


\section{The Interview}

The Devon County Council Environment Officer was interviewed and case study material was obtained from this interview to analyse the implications of the initiative to SMEs.

Finance to "pump prime" the project was forthcoming from the County Council's Economy and Europe budget and the Rural Development Commission. A $£ 4000$ budget was secured $(\mathfrak{1 , 0 0 0}$ from the County Council's Economy and Europe budget, $£ 1,000$ from the Rural Development Commission and $£ 1,000$ worth of time each from Sustainable Futures and Creation Restoration Ltd) to fund a three month period in which a number of practical proposals will be developed with the joint aim of promoting community participation and contributing to sustainable development.

\section{Policy Proposals}

The initial aim of the project was to create 150 new jobs in the town of Torrington and the immediate area by the year 2000, using the principles of sustainable development in order to achieve these jobs. The Steering group sought to concentrate on creating local jobs that could be managed in a more ecologically friendly way for local people. It was felt that this economic philosophy would re-empower the locality to supply its own needs and look after the requirements of the area effectively. Attempts to attract larger scale national or foreign subsidiaries into the area were dismissed, since they could decide to leave at any time regardless of the needs of the Torrington area. To this end a number of objectives were established by the winter of 1993 by the Steering Group.

The initial requirement was to promote a self-sufficient local economy that would create secure and rewarding local employment. It was envisaged that this philosophy would 
encourage local production to meet local consumption wherever possible and therefore empower the Torrington community to make more local decisions regarding their economic and environmental future. The Steering group felt in particular that environmental effects of local commerce could be reduced through the reduction of energy and resource usage wherever possible and by having more information available to companies about potential waste and pollution generation.

Central to the local people meeting local needs philosophy was the need to build on and develop local skills and resources. This would enhance community involvement in the project and anchor responsibility for development issues to the community.

Finally the Steering Group felt that the experience of the Torrington project could act as an educative process not only to the community with regard to sustainable development but also to other towns through the development of a model based on the experience in Torrington.

Strategy was concentrated on four main areas: tourism; access and transport; environmental improvement; and business development (all under the auspice of Agenda 21). To this end a number of projects were identified in the initial stages for funding and consideration. The following section considers these projects. They were sectioned by the Steering Group into three categories, large, medium and small scale projects.

\section{Large Scale Project Proposals}

1. The refurbishment of the Pannier Market.

2. A Community Enterprise Centre.

3. The use of the Howe church site as an integrated tourism/heritage facility. 
4. Great Potheridge Farm (Bicton College of Agriculture) as a rural centre.

5. More emphasis on information and interpretation of the town's historical, architectural and other features.

6. Greater links with other bodies, e.g. The North Devon Transport Forum, to improve access to the town especially through public transport and use of the Tarka Train.

7. A 'town scheme' to enhance the town's image coupled with a living over the shop survey.

8. A much greater emphasis on business development particularly with the emerging green business potential, utilising the number of empty industrial units in the area.

\section{Medium-Sized Project Proposals}

1. Investigation and partial movement towards local producer/consumer links.

2. Research into a Community Development Trust.

3. Extension of the Local Exchange Trading System (LETS) which already has $\mathbf{3 0}$ members.

4. Investigation of Credit Union facilities.

5. Holding an exhibition to promote more community involvement

6. Strengthening links with other interested parties e.g. Universities.

7. Increasing the linkages into Hatherleigh and Okehampton which are also implementing Community Development.

8. More research for the development links with companies for joint green development proposals.

9. Continuing progress towards an Energy Advice Centre.

10. A pilot community information point which would use advanced computer technology and video conferencing.

11. More funding to enable the green audit to proceed based on the start already made by 
the group.

12. A skills development programme in conjunction with county Hall officers, Sustainable Futures (a consultancy firm) and other partners.

13. Linking with the Seaford Centre for a 'local distinctiveness' campaign.

14. Proposals for tourism development are likely to form a major element in a strategy for Torrington.

\section{Small-Size Project Proposals}

Small scale ideas are ongoing and increasing in number as the project gains a higher profile. It is envisaged that these schemes will be central to the success of the project because they usually derive directly from community concerns and involvement. The Steering Group rates these proposals highly not only for their intrinsic value but more specifically for their education impact. Proposals include:-

\section{Leaflet production for the Town Council's Craft Fair.}

2. Payments to Sustainable Futures to attend sustainable economic development seminars.

3. Co-operation with Great Portheridge to promote the Open Day.

4. Provision of postage for a survey for information on Community Trusts in the rest of the UK.

Initial feasibility of the above schemes was undertaken throughout 1993 by the commercial consultancies and the Steering Group. As a result, work has commenced on: the development of an energy advice centre; the development of the LETS system; the development of the business unit for community enterprise which is aimed towards empowering the local workforce to provide local needs; and a number of other smaller schemes. 
The Steering Group has been encouraged by the results so far achieved and has consequently designed a development strategy based on the four main areas of concern highlighted at the proposal stage of the project, namely tourism, access and transport, environmental improvement and business development. The following projects were designed in the spring of 1994 to meet each area of concern:

\section{a) Tourism Development}

Tourism is a central source of employment for Torrington. There was a general consensus within the Steering Group that it should be encouraged in a sensitive and appropriate manner based on principles of green tourism. Therefore the following projects were highlighted as potential investment areas.

1. Improving the walking and cycling routes out of town.

2. Creation of more town/local trails.

3. Provision of pioneer local bus services between centres, to the coast and towards Okehampton.

4. Development of Torrington as a walking centre through promotion of accommodation in association with local and long distance paths on Dartmoor and on to North Devon via the Tarka Trail. Cycling links are seen as an integral part of this project.

5. Availability of youth hostel type family accommodation.

6. Market the town as a centre for sustainable green tourism: exploiting in particular the railway.

7. Joint promotion and marketing with local attractions with Hatherleigh and Bideford and other local centres.

8. Improvement of communications regarding accommodation and standards of provision. 
b) Access and Transport

Torrington provides an ideal model for the encouragement and implementation of sustainable transport modes. A survey is planned to identify potential within this area for the town and surrounding areas. It is hoped to link towns with common interests through the project proposals. Potential schemes are therefore as follows:

1. To develop a sustainable transport policy for the region in which public transport is accorded a high priority.

2. To build on existing traffic management measures in the town, in particular traffic calming initiatives.

3. To improve accessibility for disabled people. Carry out a local survey under the remit of a Transport Survey undertaken by or with people with disabilities.

Many local authorities are undertaking similar exercises. What is noteworthy is the holistic nature of the Torrington Resource Town 2000 where every aspect of community life has been analysed with respect to the environment. Therefore, although not all of the above are revolutionary, it should be recognised that they are a part of a larger vision.

c) Environmental Improvement

Whilst there has been a measure of environmental enhancement the Steering Group felt that there was a requirement for an overview of the town and surrounding regions. For this purpose an 'Enhancement Group' has been established to provide an overview of the town and surrounding area. If this group is to make any significant contribution, however, it is recognised that further funding is crucial. The following schemes are proposals delineated by the Enhancement Group. 
1. A 'Town Scheme' to disseminate information and education.

2. Refurbishment of the design of the central areas and improvements to the townscape.

3. Further provision of public open spaces as places for play and recreation and public events.

4. An area wide local distinctiveness campaign.

d) Business Development

The main thrust of the business development element of the Steering Group Strategy focuses on helping new and existing indigenous small, local businesses survive. Companies that place environmental considerations high on their agenda are particularly supported. It is also agreed that there is scope to attract new businesses from outside the area on this basis. The craft sector is seen as having considerable potential.

Help is envisaged for two main areas: ecological auditing and education into more sustainable practices. It is recognised that the primary focus is on the generation of new and financially sustainable employment structures. To this end the Business Unit for Community Enterprise is a focus project. The principles of sustainable development are to be established within the centre by increasing local incentives to provide for local needs locally.

To be effective, the development plans require local involvement at all stages. Wherever possible, therefore, local skills and expertise are being employed for the development and implementation of the proposals by drawing on local consultants, building workers, unemployed trainees and development workers. Local people will be given priority in access to appropriate training to acquire practical skills in, for example, fund-raising and 
building management, which will then be applied to the projects outlined. Potential projects and schemes highlighted as relevant for particular business investment are as follows:-

1. To establish a local vacant business property register.

2. To develop ideas for small workshop units and a craft display area in the town centre.

3. To draw up a register of local crafts people.

4. To encourage a wide range of quality/customer care courses.

5. To continue support for the craft fair and negotiate a permanent venue.

6. To move towards a sustainable development culture to encourage the emerging industries to consider the area as a good business base for investment.

The Steering Group considers education to be a primary consideration. Education and information diffusion will be central to community understanding of the principles of sustainable development and therefore central to the continued success of the Resource Town. To this end the group accords high priority to the provision of a museum or local resource centre, exhibitions and guide maps. A local Community Information Point (using advanced telematics) is also required.

Once the above strategies, and proposals had been delineated the Steering Group propose to facilitate community participation in the schemes. The strategy was to enhance local project groups, to form interagency partnerships and to develop the policy proposals formulated. Community project groups' participation in the formulation of the European $5 \mathrm{~b}$ funding bid formed a vital element in this strategy.

Public meetings, social events and a mini-exhibition were planned as a means to encourage participation. To date these have succeeded in enhancing the image of 
Torrington Resource Town 2000. The lack of the Training and Enterprise Council (TEC) and Rural Development Commission involvement on a day-to-day basis has been pinpointed as an obstacle which requires review. More partners for co-operation are being sought to consolidate the project.

The project is still in its early stages but has achieved substantial local involvement. This initial 'goodwill' interest could deteriorate in the absence of early visible and tangible results. A town centre shop to act as an information point for the community, displaying details of progress, was being given a high priority.

\subsubsection{Comwall County Council (CCC) Planning and Economic Development Committee} - Economic Re-generation Unit. County Hall

\section{The Background}

Following European recognition of the need to boost the economic prosperity of peripheral areas in the mid 1980's, Cornwall gained 5b status, generating the potential for considerable economic re-generation funding. The CCC Re-generation Unit was established to attract this funding and to manage the changes. A total of $f 15-20 \mathrm{~m}$ per year is potentially available over the next 5-6 years, conditional upon matching national financial funding being attained. Finance is also available from the European Single Regeneration Budget, amounting to as much as $£ 1.5 \mathrm{~m}$ over 3 years.

The Re-generation Unit is designed to help local people meet their local needs. In practice this has been achieved by attracting substantial EU capital to pump prime local economies and to educate local communities about the practicalities of re-generation and sustainable development. 
Environmental and economic considerations were at the outlet viewed as theoretically interdependent with economic considerations being accorded priority in practical policy formulation. Predictably, the general philosophy of the Unit held that a healthy local economy was likely to be more environmentally sustainable. What emerged, however, was the realisation that sustainable development should accorded a high priority. This was due in part to the requirements of the European $5 \mathrm{~b}$ funding packages that require a drafted policy for sustainable development. Sustainable development was also accorded a high priority in the re-generation process following the CCC'c commitment to Agenda 21. Although they have not as yet drafted a policy statement to satisfy Chapter 28 (the local government requirements) of Agenda 21, they recognise the need for a proactive stance on the issue. Environmental considerations have traditionally been central to Cornwall's economic policy because of the economic reliance on the farming and tourism both of which are heavily dependant on high land quality.

Effectively the CCC view sustainable development as localised economic re-generation in which significant environmental caveats are applied to all proposed initiatives. Their aims are therefore compatible both with traditional local political philosophies and future possible legal requirements under Agenda 21.

\section{Objectives of the Case Study}

1. To clarify the aims of the Re-generation Unit.

2. To analyse existing re-generation projects in Cornwall with particular regard to sustainable development.

3. To consider the future impact of the re-generation schemes with particular regard to the SME sector and sustainable development. 


\section{The Interview}

The case study material is derived primarily from an interview with the Director of Cornwall County Council's (CCC) Re-generation Unit. Additional material, including aims of specific re-generation projects, was obtained from the unit in report format.

\section{Specific Re-generation Projects}

The first project was established in Looe in 1987. Looe has served as a pilot scheme on the basis of which the Regeneration Unit has devised a strategy for development flexibly applied to new projects. The initial step has been to generate interest within the locality. for the project. Over time, however, this requirement has largely become unnecessary as the success of one project has lead to demands from other communities within the county for similar re-generation programmes.

Established interest groups are drawn together to create a Local Member Steering Group for the project. It is understood that community participation at the initial stage is central to the success of the project as the feeling of community empowerment is seen as one of the greatest mobilising forces behind the success of projects. The Local Member Steering Group generally consists of the local town council, the CCC, an external consultancy, local interest groups and other influential local people.

Stage two of the procedure is to undertake a SWOT (Strengths, Weaknesses, Opportunities and Threats) analysis on the area. In effect the SWOT analysis is a bioregional education process that diffuses information to the community about their bioregion. In the process, the community as a whole is informed about the project and areas of priority action are highlighted. 
As an initial requirement for the re-generation process an external consultancy was paid for by the CCC. Most projects have employed the charitable organisation Civic Trust to undertake the research. Civic Trust is a Charitable trust which operates as a consultancy with a re-generation Unit. Civic Trust rates are competitive and they offer good value, as they do not need to make $20 / 30 \%$ mark up. They also have country wide expertise in regional re-generation. Established a number of years ago to look at the quality of urban life, Civic Trust expanded into wider socio-economic issues. This included the development of local Action Plans which were practical in their approach rather than local authority plans which are often more policy oriented. Once the Civic Trust and County Council (in conjunction with the local authority) has established the options to be considered public meetings are held regularly to maintain the profile and involvement in the process as the Civic Trust draws up an Action Plan and presents the results to the community. The process has typically taken 18 months.

Fifteen Local Member Steering Groups have been established in Cornwall. Located at Looe, Padstow, Camelford, Weighbridge, Bude, St Austell, Callington, Bodmin, Redruth, Newquay, Hayle, St Ives, Penzance, Helston and Bodmin, some are at the pre-draft stage and others more fully established. The Re-generation Unit views the success of Looe as a catalyst for the expansion of the projects.

Minimal direct marketing of the concept has been required. Within the projects themselves, however, marketing is accorded a high priority. The CCC in particular see Cornwall as a quality marketing image to portray. Environmental issues can be marketed easily within this framework on two levels. Firstly environmental concerns are compatible with a healthy tourist environment and are therefore central to the image of the Cornish Tourist industry. Secondly, sourcing locally is seen as good environmentally as unnecessary transport and associated costs are removed. 
At present food is transported out of Cornwall to be packaged and then returned to the supermarket shelves with a $80 \%$ mark up, according to the re-generation unit. This finance is removed from the local economy, and costs to the local community are $80 \%$ more than necessary to provide efficient production and distribution. From this perspective the CCC Re-generation Unit conceives environmental concerns as interdependent with economic re-generation.

With marketing support from the CCC to 'buy local' Cornish SMEs can be encouraged to expand, confident that they have a local market. The support of local SMEs is seen as fundamental to the success of the re-generation projects and to the policy commitment to sustainable development. Catering and retail outlets have traditionally promoted the Cornishness of their food as a marketing strategy. Hence local food producers gain directly from the new marketing strategy and local services generally gain as people associate Cornwall with quality and are therefore attracted to the area. The knock on effects of increased awareness of local issues and environmental concerns are therefore viewed as considerable. Relevant aspects of some of the Action Plans are highlighted below.

\section{Looe}

Since $1987 £ 5 \mathrm{~m}$ has been invested in the first re-generation plan which was located in Looe. Wherever possible local contractors and businesses have been employed to satisfy the aims and priorities of the Action Plan. Some of the initiatives that have been implemented through the Action Plan include:-

1. East Quay wall/market and workspace project. This three phase programme integrated the requirements of the Harbour Commissioners and lead to further investment on a 
traffic management system for the town, due to the changes at the quay. The increase in space allowed the fishermen to ice pack, market and box the fish on site and therefore keep transportation costs down.

2. A new woodwork and metal workshop.

3. A traffic management system which incorporated disabled parking space and tree planting in the town centre. The trees in the car park were planted to mask the impact of the cars. Costs were met by the Harbour Commissioners through reduction in car parking revenue, which was more than balanced out from the increase in revenue the fishermen gained from the new quay/market space.

4. A Discovery Centre. This centre acts as an educative focus for tourists about environmental concerns of the surrounding countryside. It also informs locals and visitors about the regeneration plan.

5. A fishing museum.

6. A town conservation scheme.

7. A Housing Association Scheme. This has been developed from a church site and is designed specifically for homeless and unemployed young people.

Altogether 30-40 initiatives have so far been implemented. Having gone through the process the Local Member Steering Group feel that the plan has been successful. It is however felt that there are no short term answers and that the success of sustainable development will only be able to be measured after a number of years.

\section{Hayle}

Hayle is the latest programme to be established and the following information relates to the pre-draft draft that is required before the initial Action Plan. It was decided in Hayle:- 
that action was required mainly because of the dereliction and neglect of the port. A full strategic economic analysis was therefore required.

The Steering Group for Hayle consisted of the following members:

1. Hayle Town Trust.

2. Hayle Chamber of Commerce.

3. Hayle Town Council.

4. Cornwall County Council.

5. Tehidy Park Officer.

6. Groundwork Trust.

7. Penwith Deputy Planner.

8. CEDO and Penwith Economic Development Officers.

9. Harbour Owner's Representative and Harbour Master.

10. Landscape Architects.

11. Local Secondary School.

12. Highways Department.

13. Gwithian Towans Advisory Group.

14. Cornwall Rescue Archaeology Unit.

15. NSPCC.

The group also included a number of other interested parties in a part-time advisory capacity including English Heritage, English Nature, youth clubs, the police, the Countryside Commission, the DTI, local GPs and the Rural Development Commission. 
The objectives delineated by the Local Member Steering Group were as follows:-

1. To restore and enhance the environmental and historical qualities of the town.

2. To promote action in relation to the economic fabric, infrastructure and potential of the town.

3. To address the social needs of the resident population.

The role of the local SME was recognised as central to any re-generation, in particular with respect to farming and tourism being accorded a high priority. It was decided that any future initiatives to encourage re-generation should give priority to environmentally friendly businesses. Areas of environmental concern ranged from minor schemes of decoration like signposting to reclamation of contaminated land. There was also a decision to establish a Town Scheme based on co-operation between English Heritage, the District and Town Council. This would follow an historic audit of the town. It was felt that the Action Plan should consider the pedestrian and vehicular movement patterns within the locality, eventually leading to an integrated transport control scheme to combine traffic reduction measures with improved public transport and cycling facilities. The provision of affordable housing was viewed as a priority. A skills training programme run through the Devon and Cornwall TEC was endorsed. The primary aim of the skills programme was to train local people for local jobs to enable SMEs to overcome the problem of the wasted resource of human skills and talents which flows from unemployment.

\section{Re-generation Schemes and the SME}

Clearly re-generation schemes can have a significant effect within a region's development programmes. One scheme often leads to further re-generation and increased project 
awareness in a neighbouring area. The process of learning to see the positive qualities and the opportunities available within its locality, enables local communities to realise the potential for re-generation. The railway line between Liskeard and Looe is a prime example. It has broken even this year due to a proactive marketing strategy and now looks set to expand at a time when the national network is considering reduction in the number of branch lines. In 1992 there was an $11 \%$ increase of passengers on the Liskeard-Looe line with a further $7 \%$ the year after. This type of initiative is not only beneficial to the environment as it reduces car traffic: it also benefits local SMEs that are located in the railway towns. At a time when by-passes and congestion in on-street parking is reducing accessibility to local businesses in many areas this is a significant consideration.

With the local bias towards sustainable SME economies, re-generation schemes provide an excellent focus for the diffusion of environmental information to the community. The philosophical aims of sustainable development maybe satisfied in two distinct ways. Firstly, local SMEs are directly encouraged, enabling local people to meet local needs. Secondly the process itself acts as an educative awareness raising exercise, so important in changing individual attitudes towards ecological issues. Local community involvement can be used to further increase the environmental quality of life of an area. For example, in Looe local brownies tend a garden that surrounds a memorial in the town centre. Where previously the memorial was a litter attraction the town is now proud of the area and looks after its welfare enhancing the general ambience.

A major limitation to the re-generation process is shortage of time and resources available to the County Council, and the need to rely on external funding to pump-prime the changes. Ideally this pump-priming could come from within the locality enhancing both motivation, success and efficiency of the projects. This self-sufficiency requires local 
investment that could be managed through the credit unions discussed earlier in this chapter. Community involvement has been highlighted as a central ingredient for the attainment of the aims of local re-generation projects. If the investment came from within the area the initiatives would automatically have community support and consequently have a greater chance of success.

The question was raised of the underlying policy implications of local people meeting local needs with respect to the tourist industry. Tourism requires external interest and capital to survive and there is a direct link between numbers of tourists and environmental damage. The dilemma is illuminated by the example of Newquay's bid to stage the world surfing finals. Sewage produced by the tourist attendance at the event could significantly undermine the event.

In Padstow tourism is critical, and the dichotomy of interests is recognised: on the one hand they want as many tourists as possible to boost local SMEs while on the other they need to conserve the environment for the tourist to enjoy. To some extent the changing structure of the tourist industry in Cornwall, with fewer people coming for shorter periods, has made marketing and maximisation of profits the short term priority. 10 years ago the average length of stay was c.8-9 days, now it is about 5.7. Cornwall has become a second holiday, particularly activity holidays. Hence there has been a shift from quantity to quality which is welcomed by environmental groups. More effective marketing of tourism within Cornwall has therefore become essential. This is an area which may well receive priority attention as environmental pressure groups seek to discourage the practice of holidaying in third world countries and conservation areas. Cornwall may yet regain its place as the provider of the first holiday if current trends of environmental obliteration continue abroad, (Pleumaron, 1994). 
The CCC Re-generation Unit is a practical vehicle for changing peoples circumstances whilst educating communities in the practicalities of effective environmental management. It also provides local authorities with the means to meet the requirements of Agenda 21 and facilitates access to regeneration funding.

\subsection{Conclusion}

The case study material demonstrates the interdependence and knock on effects of any new initiative within a local area. The opening of a Super-Store or Hypermarket in a locality can disrupt trading patterns, causing small local shops to close, generating an increase in private car journeys and removing finance and other policy decisions from the locality to the Headquarters of national corporations. The studies in this chapter demonstrate the potential for reversal of this trend, a reversal which is essential if a sustainable local economy, in both environmental and economic terms, is to be achieved. A common element in the success of these schemes is their relevance to local needs and their educative role. Local management leads to maximum use of knowledge and local skills, facilitating the most efficient use of resources. This could be beneficial both to the SME, in terms of market share, and to the environment.

The model for a locally based environmentally and economically sustainable economy is presented in the following chapter. The model flows from the emerging concepts of best practice as outlined in the case studies. Central to the achievement of sustainable development is an emerging sense of self-awareness (whether of the individual or the firm/organisation) coupled with a heightened awareness of the locality and its needs. A vital element in the process of mutual re-education which occurs as new co-operative business practices are evaluated and implemented, and new approaches to trade, exchange and finance are explored. The case studies break new ground, providing original 
documentation of a changing pattern of re-generative economic activity which has been slow to surface in the formal literature to date. A core element in the case stúdies is the co-operation between different forms of enterprise, both inter-sector and with other bodies, eg local government and voluntary organisations and the community as a whole: 


\section{CHAPTER 9 -}

\section{BIOREGIONAL RE-GENERATION STRATEGIES -}

A MODEL FOR SME SUSTAINABILITY 


\subsection{Model Ideology and Assumptions}

The case study material has shown that there are alternative initiatives that can induce more effective information diffusion to SMEs leading to the adoption of environmentally sustainable regional strategies. Although as yet limited in numbers, these initiatives are conducive to change in perceptions and practices amongst the participants. This section collates these ideologies and formulates a generalised model from the results. The model is split into two parts Figure 9.1 represents the dynamic elements of the model and Figure 9.2 the spatial aspect. The result is a conceptualised ideological representation of a sustainable local economy.

The model fulfils the requirements to satisfy both the economic and environmental aspects of sustainable development in that local trading increases and consolidates the SMEs market share, concurrently allowing ecologically sound business practices to evolve.

Models are necessary...to constitute a bridge

between the observational and theoretical levels;

and are concerned with simplification, reduction, concretization, experimentation, action, extension, globalization, theory formation, and explanation.

$$
\text { (Apostel, 1961, p3) }
$$

One of the main reasons for the development of this particular model is to satisfy what Chorley and Haggett call the "psychological" functional requirement (Chorley and Haggett, 1969 p24). This allows an otherwise complex group of phenomenon to be visualised and comprehended in more simple terms. This cognitive function allows 
complex phenomenon to be understood in diagrammatic format and therefore adds to the explanation and understanding of the subject area.

The model both assumes and generates change in the awareness of needs and wants of local communities through the decentralisation of economic and political decision making. It requires participation in the local economy itself. Orthodox economic theory argues that production is demand lead. In reality, this is not necessarily the case:

\author{
Prioritisation of needs over wants could only be \\ achieved if consumption was demand and not supply \\ lead. This, of course, is what classical economic \\ theory claims happens, but in practice consumption \\ is aggressively supply-led where people... are \\ bombarded with pressures to consume.
}

$$
\text { (Mellor, 1994, p4) }
$$

The model requires an enlightened understanding which would be satisfied through the participation of SMEs within the central circle, Localised Finance and Trading. Therefore operation of the model requires the full participation of SMEs. Existing SMEs and start-ups would not, however, be primarily motivated by considerations of ecological responsibility per se. A strong local economy based on small scale production is centred on the SME sector which increases its market share as larger corporate entities rendered progressively redundant through the barrier of New Protectionism.

In theory SMEs have the potential to be more environmentally conscious in business than large businesses because of their capacity and motivation to respond to environmental concerns at the local level. SMEs have the potential advantage over national chains and 
MNCs to develop sustainable business strategies and increase their market share considerably because of the flexibility and nature of their practices (Hutchinson A., 1994).

Education through participation is central to the model. A further assumption being that demand for locally produced goods substantially increases with awareness of the necessity to consume local goods. This enhances the local SMEs ability to provide the goods and services demanded. Ideally, in the long term, the orientation of production would be shifted towards what Keekok Lee has called Ecologically Sensitive Values (ESVs). These goods and services do not involve per se, more than a modest consumption (Lee, 1989, p197). All activities involve consumption of some ecologically scare resources. Lee suggests that the system should attempt to replace competition for possession and consumption of material things for ESVs (ibid, p211). For example, if one person increases their knowledge of a language this does not stop another person improving their own standard, and enhancing the quality of life for both at the expense of relatively little ecological resource depletion. Through educational awareness exercises SMEs have the potential to relate to the locality they trade in, to be environmentally sensitive to the requirements of the locality and to be flexible enough to alter their practices and subsequently gain from the consequences. 
Figure 9.1

\section{BIOREGIONAL RE-GENERATION}

\section{A Model for SME Sustainability}

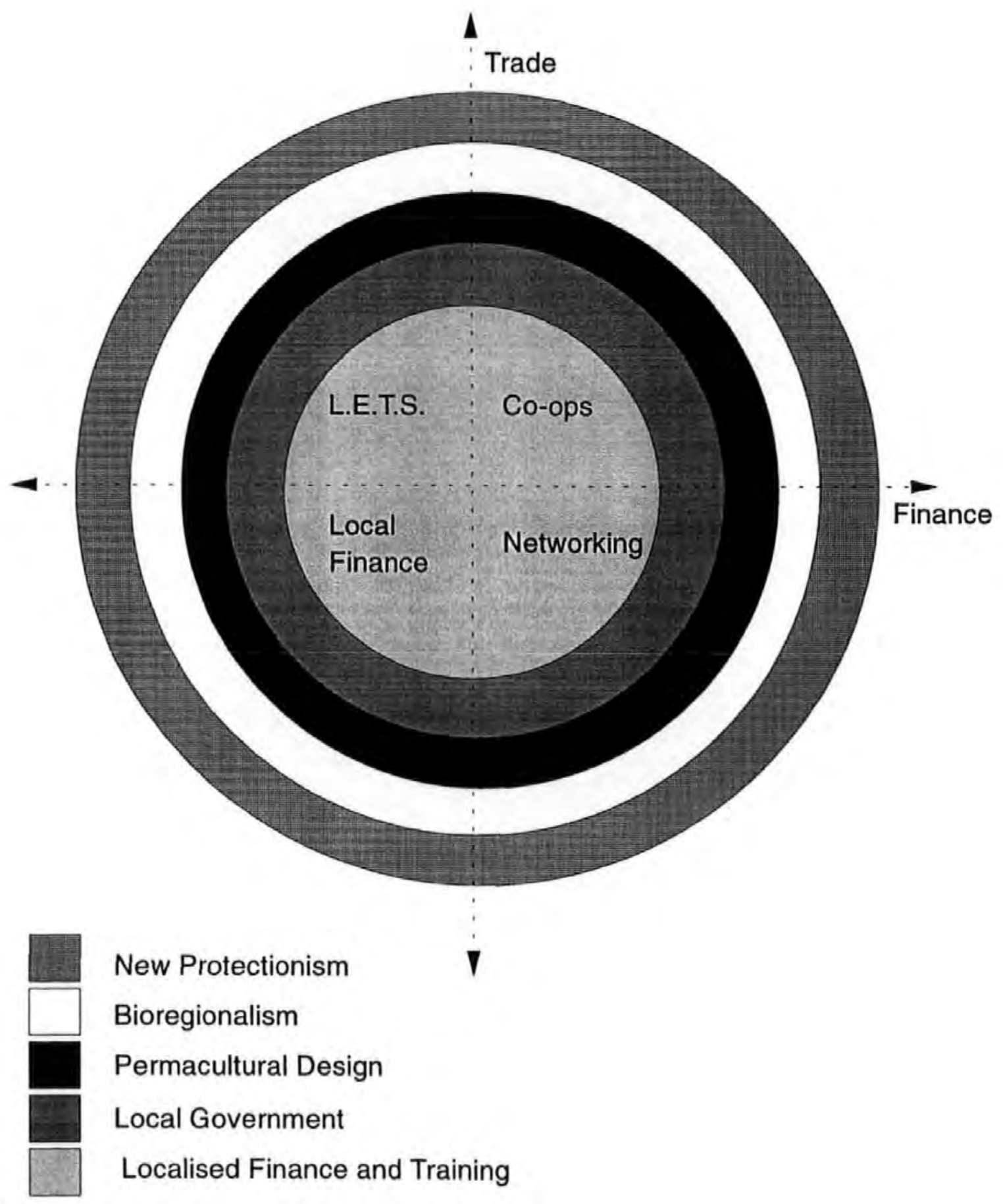


The model (Figure 9.1) assembles the positive elements observed in the research as a whole and combines them with theory to produce a framework for development of sustainable business practices within SMEs. The five parameters of the model are described and analysed in turn.

\section{New Protectionism}

The New Protectionist circle provides the economic and political constraint of the model. It delineates the economic and political changes required for the model to work. This circle defines a new economic emphasis for the region. It stands for reduced external trade and the protection and promotion of local interests. Based on work by Lang and Hines (see Chapter 2 p64) this outer circle acts to counter the chimera of free trade through a re-evaluation of economic priorities. New Protectionism posits that trade is local first, regional second, national third and international as a final resort. Economic policy should be regional rather than international, emphasising co-operation rather than competition, a viable option for SMEs through networking according to Johannisson, (1983 et al) with local producers meeting local needs wherever possible. An immediate environmental benefit of this would be a drastic reduction in greenhouse gases from reduced transport usage. This is an urgent requirement. Already in Europe the average weekly shopping trolley contains goods that have travelled 4,000 miles before they arrive at the place of consumption. Yet total lorry traffic is set to double between 1989 and 2010. Food which could be grown locally is being transported increasing distances, with marked environmental consequences (Griffiths, 1993).

The emphasis here is community based. International trade liberalisation has placed little importance on community welfare and economic security. With changing patterns of 
production and investment it makes economic sense for communities to be self-reliant, enabling consumers to afford the goods that they are producing.

This community orientation tends towards a reduction in resource depletion and encourages activities with low environmental impacts (ESVs). It also includes a level of work sharing. As Lang and Hines suggest:

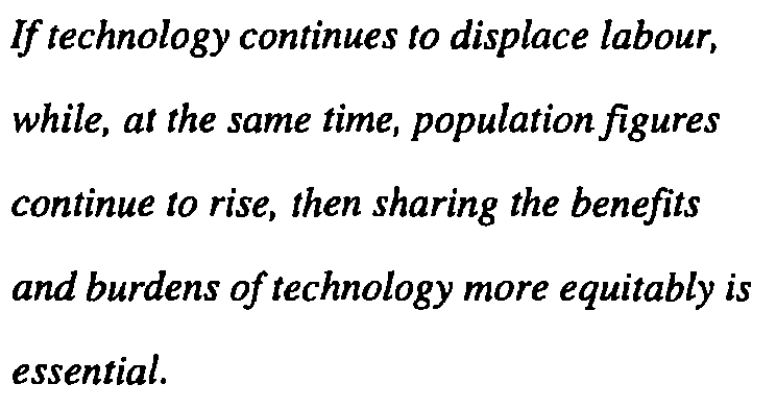

(Lang and Hines, 1993 p99)

It is primarily in the interest of the SME to focus on local trading opportunities. This form of protectionism allows smaller corporate entities to survive the competition of larger companies. Co-operation and networking serve to increase the competitive advantage of the SME within this structure. 
Figure 9.2

\section{BIOREGIONAL RE-GENERAION \\ MODEL - THE SPATIAL DIMENSION}

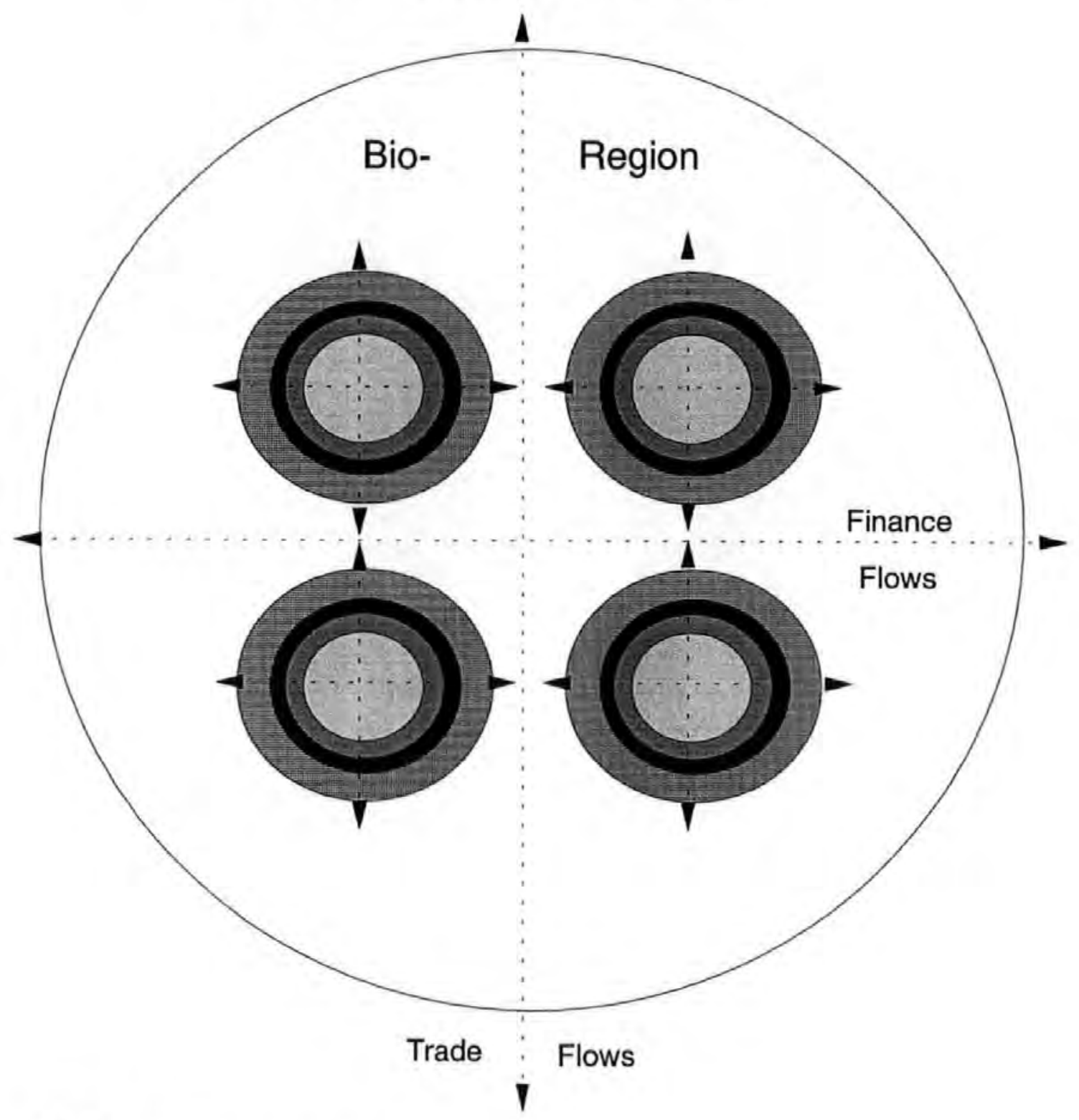

New Protectionism

Bioregionalism

Permacultural Design

Local Government

Localised Trading and

Finance 


\section{Bioregionalism}

The bioregional circle reflects the spatial parameter of the model. It focuses attention on the need to reconsider trade flows in space for the benefit of the local community and provides the philosophical substance behind the concept of localised trading. Here the local community relates to other communities within a regional framework. Figure 9.2 is an extension of Figure 9.1. Each circle in figure 9.2 represents the circle in Figure 9.1, apart from the bioregional circle. Figure 9.2 exists to show that the bioregional parameter of space is not limited to a specific region in the traditional sense. For example the bioregion could be seen as the area between two water sheds however within this region there may be a number of separate, local economies that trade between themselves. Therefore for the purpose of explanation, Figure 9.2 shows that the bioregional parameter in Figure 9.1 is not limited in space.

There are a number of possibilities where local economies overlap within a bioregion and where trade and finance flows in and out of the bioregion. These economic flows are not limited to traditional trade flows in the sense of Sterling movements, the model suggests the possibility (through the MULTILETS concept) of an alternative form of trade flow between regions as well.

Figure 9.2 shows the inter-regional and intra-regional connections of the model. Each concentric circle correlates to a region that is linked to others by trade and finance flows (displayed by the arrows). This cognitively displays that economic and social interrelationships between regions still occurs within the constraints of the model. However, the interactions are less prominent than within the present system where larger companies dominate trade and finance decisions. The finance and trade flows may also take the form of inter-regional MULTILETSystems and/or traditional trade and currency flows. 
Within this "protective/supportive" circle is the overriding philosophy/ideology of the model. Bioregionalism relates to reinhabitation of the locality, learning to live again within our communities and the development of self-reliant lifestyles. The Torrington case study is an example of a bioregional vision where awareness of environmental concerns are being interwoven with economic regeneration. The focus of this regeneration is small scale and local, based on the bioregional philosophy of sustainable development.

Bioregionalism provides the key element in the framework for the model within which all alternatives can be considered. Its function is dualistic in that it forms the philosophical basis for the model but also graphically displays the spatial element of the concept. Bioregionalism facilitates a re-evaluation of all economic, political and sociological components of our lifestyles, a prerequisite of sustainable development.

\section{Permacultural Design}

Where the bioregional circle serves as the spatial parameter for the model the permacultural circle draws together elements of philosophy, practice and idealism to provide the practical parameter. Change is unlikely to occur without this practical reinterpretation of the accepted norm.

This circle emphasises the need for an holistic localised, approach to regional development strategies. Permacultural design (see Chapter 3) considers all aspects of life and aims to achieve sustainable lifestyles. The SME forms a central part of this design system insofar as it stands for localised small scale provision of local needs. 


\begin{abstract}
Permaculture (permanent agriculture or
permanent culture) is a successful approach

to designing sustainable environments. It is

based on the philosophy of co-operating with

nature and caring for the earth and its people.
\end{abstract}

(Permaculture, 1993, p2)

It is essentially a design concept used to create sustainable human habitats anywhere, in cities or towns, or rural areas. When put into practice it empowers the individual to become more self-reliant and conscious of the interdependencies of ecology. It is an holistic system that encompasses economics, societal life and the practicalities of ecological sustainability.

Permaculture provides the practical application (as well as philosophical; each circle is not exclusive in theoretical application) for a bioregionalism vision. It is a low cost, low energy, low consumptive system in which people are enabled to co-operate and to concern themselves with re-inhabiting their region. It requires localised trading predominance and places the attainment of sustainable SME practice at the forefront of the strategy. It seeks to re-educate people in their local, cultural and agricultural heritage. This re-education is integral to the bioregional concept and is part of the re-inhabitation process.

Localised SME trading is a central practical and philosophical requirement of the permacultural system which provides the focus for environmental management training. This aspect of information diffusion is particularly relevant to a system that has close cooperational and networking structures. The Keveral Farm Project demonstrated that 
business links provide a focus for the dissemination of permacultural techniques that are applicable to SME practices. Energy conservation and systematic ecologically sensitive architectural design practices emerged from the case study material as particularly relevant.

Insofar as trade and finance are exported and imported (see Figure 9.2) the model is not a regional autarky. There is, however, a strong bias towards local trade. Part of the concept of New Protectionism is that localised production would be supported and enhanced by the raised consciousness of the community. As far as possible, imports are discouraged and money kept within the locality empowering local businesses to meet local needs (see LETS discussion).

\section{Local Government}

The Local Government circle relates to the political constraint of the model and reflects the legal requirements of the UK Government to implement Agenda 21. Response to these requirements may be through a city Environment Forum (as in the case of Plymouth) where round table discussion leads to proactive response. Government support for the kind of sustainable regional development strategies analysed in the case study material is essential primarily for the initial "pump prime" funding required to establish local community involvement.

Local government support is central to the long term success of sustainable regional development strategies, whether on a regional, city or even parish level. The research findings suggest local government support towards the philosophies of sustainable development is essential. Indeed, both of the urban regeneration programmes in Plymouth and Cornwall owe their existence to initial local government support. 
Commitment to Local Agenda 21 is pivotal to the attainment of regional sustainable development. As far as the evidence in Devon and Cornwall is concerned, this commitment seems to be having positive results. However continued local government support for these initiatives is required to encourage other projects and to act as a focus for research and development funding from Europe.

An example of how government support can significantly boost regional re-generation strategies can be seen in Australia where in 1993 the government invested (through local government) $\$ 3 \mathrm{~m}$ to establish LETSystems. They paid for the marketing and software necessary to establish the system. They also encouraged local churches and other organisations to participate through a strong marketing strategy. Locally unemployed people are sponsored through LETS involvement as local business people buy their LETS commitment from them in return for Australian dollars. It also means that if a MNC wanted to participate, the currency earned and spent would stay within the locality, benefiting the local economy (Knox, 1993 pp 11-12).

\section{Localised Finance and Trading}

The Localised Finance and Trading circle relates to the local economic constraints of the model in which the SME sector is central. Although there are inter-regional and international trading links (the finance and trade arrows), these are seen as declining in significance to localised, small scale trading. Localised trading is dependant upon the establishment of LETS, producer, consumer and worker co-operatives, local banks, credit unions and support organisational networking. These practical variables can be extended as experience requires simply by creating another segment or inner circle to accommodate the future requirements. This section considers the inner core of the model by briefly looking at each aspect in turn. 


\section{L.E.T.S.}

These are non-money exchange mechanisms that operate purely within the locality. LETSystems make use of under-employed and otherwise wasted human resources of the registered and non-registered unemployed (i.e. voluntary workers, artists, housewives and young people on training schemes). They provide an ethical framework for trade that concentrates on needs rather than wants that have been artificially installed in the mind of the consumer through aggressive marketing strategies.

LETSystems also allow SMEs to increase their share of the local markets as the recognition that buying locally strengthens local employment filters through to the consumer. All LETS systems are designed to bolster local employment and are therefore directly linked to the welfare of the SME, through the provision of skills training.

Philosophically the LETS concept considers that localities are best placed to deliver local needs with the least environmental damage. In some cases, however there may be requirements for inter-regional and international trade the MULTLETSystem and traditional currency flows would allow this to occur. The development of the MULTLETS aspect of the model through the inter-regional trading links supports the New Protectionist philosophy that regions should trade locally first, regionally second, nationally third and internationally as a final resort. The concept of comparative cost advantage and least cost provision undermining regional trading structures ceases to apply when the true cost of products are accounted for. When environmental costs, in particular through transportation and ethical/social costs through the regional unemployment that follows on from the globalisation of trade are taken into account, regional self-reliance becomes economically viable. The LETS concept challenges the traditional, classical economic concept that it is cheaper to produce within a Fordist 
paradigm of production which depends entirely upon the variables included within the definition of cost. Orthodox economic theory and reality are not necessarily compatible, (Anderson, 1991).

\section{Local Finance}

The idea behind the Credit Union is to convert national money for local use. First, by removing the burden of debt and by freeing people to make debt-free choices in participating in the economy. Second it is a mechanism for local investment. Present legal constraints within the UK limit CU investment, offering an example of the central government control over local finance.

The LETSystem can co-exist with the pound. It is important for long term bioregional aims to have as many financial decisions made at the local level as possible. Due to strains within the relationships of owner/managers and bank managers, SMEs have found conventional financial support provision inadequate for their investment requirements (Chaston, 1993). One alternative is the credit union provision of capital. Credit Union investment in local businesses could mean that critical financial decisions are made locally by people with a thorough knowledge of local requirements. It might be argued that this could lead to bias within lending procedures, resulting in poor investment decisions. This is unlikely, however, for two reasons. First, the capital is made available only to those who have a savings account with the union: second, the decision makers are the savers themselves, only viable lending ensues.

Local banking and credit unions (small scale ownership and management of finance) are central to the bioregional vision of the model. They empower the locality to make its own decisions for the good of the region rather than on the basis of the monetary profits 
of distant shareholders. Local banking includes all of the region as the stockholder: Since everybody lives in the environment, everybody has a right to a prosperous, clean region.

\section{Co-operatives}

Co-operatives place the control of local resources with the local community. Cooperative ventures were central to most of the case study material as they place alternative emphasis on local management of work and production than more traditional enterprises. The concept of the co-operative provides a structured framework for the grouping of individuals and their education in the benefits of collective production and trade. In association with a well-developed regional networking system linking educationalists, and disseminators of practical information and training, the co-operative system allows SMEs to co-exist in a less competitive, more sustainable way. This forms the basis for a stable regional society in which the SME is the central focus of banking investment along permacultural lines. These SME co-operatives link in with the LETSystem, increasing as far as possible, the local community involvement.

Co-operative SMEs have neither opportunity nor motivation to take advantage of cheaper wage rates overseas because the workers are the owners. Concurrently, co-operatives can guarantee prices for local producers providing a regular market for the SME. This initiative has been successfully implemented by the Seikatsu Club Consumer Cooperative in Japan (Mellor, 1994, p4). The co-operative emphasises the production of goods and services by local people for local people using a locally determined decision making process and local resources. The effect on the environment and social structures is subsequently more visible. As Woodcock comments: 
The positive effects on profits and jobs of employee share-ownership plans are now more widely appreciated by business

(Woodcock, 1994 p10)

Here Woodcock is commenting on the "ESOP Effect". These are Employee ShareOwnership Plans. The first ESOP was established in 1986 and the numbers have increased steadily since. Employee participation is now very much on the management agenda making co-operation a central element to a sustainable re-generation model.

\section{Networking}

The concept of networking allows the SME sector to devise common solutions to common problems through co-operation. This research has suggested that networking provides a diffusive pathway within which the ultimate aims of sustainable development could be realised. Many of the ecological solutions required to achieve sustainable development are common to the SME sector: i.e. increased awareness of ecological impact and the requirement to move away from the global economy towards a more locally based economic trading system. The concept of networking to diffuse these ideas is central, to increase SMEs awareness of the opportunities for the local economic transition and to allow for the pooling of experience within this transitional time.

The ultimate end of effective networking (to increase access to end markets) is also satisfied through a developed local network which is biased towards the philosophy of localised trade and finance. The networking concept provides the main direct educative diffusion point of the model. Although all of the other participatory elements of the model are educative in secondary capacity, the networking concept allows for the direct 
diffusion of the core concepts. This aspect is central for a changing awareness within the region and the SMEs within the trading block.

The networking facet of the model also allows for the continued diffusion of best practice elements of the existing economic system. Companies with expertise in implementing BS 7750 and general environmental management skills would be able to educate others within the trade associational networking structures. Environmental Forums would also be central to this process. The experience of the Plymouth Environmental Forum has shown that round table discussion can induce attitudinal change and facilitate management informational diffusion of best practice.

The model constructed is a conceptualisation based upon observation but has been extended through theoretical analysis of certain possible outcomes. It is not, therefore, a future representation of cornucopian ecotopia per se, rather it forms an amalgamation of theoretical observation constructed from a number of related examples.

The model has five parameters each attached to a circle (Figure 9.1). The external parameter is economic and political. The circle New Protectionism is a new economic analysis reflecting the significance of regional political constraints over encroaching MNC power and influence in local decision-making. The second parameter is spatial in the form of a bioregional circle. This denotes the area or region into which the model fits. Thirdly, the circle relating to permacultural design invokes a practical constraint insofar as the model is limited to the requirements of permacultural philosophy and practice. Fourthly, the local government circle provides the political constraint at local level. Finally, the inner circle represents the community parameter. Without the community will and motivation to change the model would fail. SME involvement within this circle is central to the models existence. The cognitive and spatial dimension of the model is 
displayed in Figure 9.2. This figure shows how the model is dynamic in space whilst: spatially limited in its philosophy. 


\section{CHAPTER 10}

\section{CONCLUSIONS AND RECOMMENDATIONS}




\subsection{Conclusions}

As Chapters 2 and 3 suggest, there is mounting evidence of concern at the environmental degradation resulting from business operations. Further, the documentation indicates an emerging consciousness of a need to enhance awareness of, and support for, measures to empower companies to reduce their detrimental environmental impacts. The research aimed to determine the level of awareness and perception of environmental issues within the SME sector and to assess prevailing attitudes of owner/managers to the importance they attach to managing this aspect of their business operations. The first mail survey empirically tested a sample of 600 companies and found that attitudes and perceptions were more positive towards day-to-day environmental issues that effected company operations, amongst the larger, exporting companies from the secondary sector. Examples of these issues were energy usage, water pollution, and employee health and safety. The smaller, non-exporting companies (in particular the tertiary sector companies) perceived the more macro-scale environmental issues like global warming and acid rain to be of importance. However, the larger and the more environmentally deleterious the company, the more likely it was to understand the necessity of formalising environmental management practice. The first mail survey showed that although companies expressed the view that environmental issues in general were important to their business, the actual practice of these companies (in particular the micro-sized firms) provides little evidence of serious commitment. The smaller, tertiary sector companies in particular, do not perceive their practices as environmentally damaging in the first place. Hence strategic and indeed operational environmental management practices are limited.

Mail survey 2 extended documentation of SME environmental perception and awareness. Results show that the majority of companies consider strategic environmental management irrelevant to their business operations. This perception is confirmed by the 
fact that only $16 \%$ of companies proactively plan to deal with the environment as a strategic issue. The in-depth interviews undertaken in phase 2 (Table 4.1.) of the research suggested that companies were ambivalent towards future initiatives or support programmes. This was confirmed in the second mail survey. Interviewees considered EMS and existing support structures inadequate and were aggrieved at legislative developments which had arisen without prior consultation with their trade organisations. Smaller firms also perceived management systems as primarily cosmetic exercises, applicable only to the larger manufacturing companies. There was, therefore, a dichotomy of response: on the one hand companies felt that environmental issues were important to their business practices, yet on the other they were cynical about the existing solutions and negative in their proactive response to the management challenge. In comparison the larger, secondary sector companies felt positive about the opportunities and confident that they could 'manage' the issue within their present structures.

The second research aim was to gain an understanding of the scale and nature of response to environmental issues across a broad section of SMEs. The first mail survey clarified the perceptions of most SMEs. Although the majority of companies felt that environmental issues were important only $5 \%$ had any strategic plan or policy for the environment (this increased to $16 \%$ a year later in 1993). Nearly half had a recycling programme and a quarter had waste minimisation and energy efficiency programmes. Encouraging as this may seem, the majority of these programmes were in the larger secondary sector companies. An additional question emerged regarding the outcome of the practices. Will consideration of environmental concerns on an ad hoc critical incidence situation management level, as in the introduction of recycling schemes, induce sustainability? This question is covered under the final research aim. 
The in-depth interviews confirmed the results of the first mail survey regarding low levels of strategic management and raised questions about the validity of the management systems solutions and business advice guides offered to companies as tools to minimise environmental impacts. The response was negative and included calls for more accurate information and analysis to be diffused more effectively through trade associations. The second mail survey confirmed the perceived inadequacy of BS 7750. Companies lack the time, finance and staff amongst other things to implement the standard. In general companies also feel that the standard is inappropriate to their business operations. This evidence suggests there is a requirement for an alternative model specific to the SME sector. Because of the generic and diverse nature of the SME sector any such model would have to be holistic in nature and focus upon achieving sustainable development.

Managing the environment in the traditional sense of reducing the 'cost' to the firm is unlikely to induce sustainable development within the SME sector. In view of the requirement to understand the environment and to empower companies to change, the necessity for an enlightened understanding of the financial, economic and environmental benefits of sustainable development becomes evident. However, finding a management system that is applicable to all SMEs appears impractical. What seems to be required is an induction towards a greater understanding of the benefits of sustainable development and indications as to how it might be achieved. These questions of interpretative analysis regarding the need for sustainable development and the subsequent effective environmental management that would ensue are covered by Chapter 8. This chapter satisfies the requirements of the third research aim which was to utilise the knowledge about awareness, attitude and organisational response to assess the relevance of the environmental management systems so far developed and to link this to achieving sustainable development. 
Having established the need to focus on sustainable development to achieve effective environmental management in the SME sector, the fourth aim was to draw upon the expertise of owner/managers and appropriate institutions to validate and if appropriate further refine new/and or revised systems. The knowledge gained from the research process and empirical analysis indicated that the emphasis be shifted away from owner managers (due to their lack of initiatives) towards specific environmental projects, including a consideration of the interface between SMEs and the goal of the particular projects or initiatives. The empirical results and the literature established the requirements of the case studies that were undertaken. These considered examples of best practice and analysed the part SMEs have to play in the attainment of sustainable development.

The dominant theme to emerge from this qualitative research was the requirement for a re-generation initiative that focuses on sustainable development in a practical way. This suggests that the aim of achieving sustainable development is through active community participation in initiatives. Sustainable development may be advanced though participation in a LETSystem or Credit Unions, for example. Concurrently, the SMEs and community gain education and information regarding the qualities and benefits of sustainable lifestyles through these same initiatives. The focus is on localised trading where local firms meet local needs. The re-focusing of priorities in this way is fundamental to sustainable development and requires the active participation of the SME sector. Not only does it benefit the environment through, for example, a reduced value of transportation: it is also of direct benefit to the SMEs themselves through increased localised market share. A number of re-generation initiatives in the sample area provide evidence of this potential. 
The fifth research aim, to assess the possibilities for sustainable development within the SME sector, was satisfied by the development of the conceptualised model and subsequent analysis in chapter 9 on the re-generation process. One reservation regarding the philosophy of the concept of local re-generative sustainable development is the insularity of approach. If the motivation for change is 'self' orientated, the society that could evolve may not accord with the vision of most bioregional writers. Indeed, some forms of bioregionalism could be criticised as being too biocentric, dismissing human requirements as secondary to those of the planets. Equally the concept could be used to argue for a narrow nationalism or regionalism and protectionism to satisfy the requirements of what Harding called his 'Lifeboat Ethic' where the lifeboat cannot take another passenger without drowning everybody (Hardin, 1974). Exclusionary notions of a fascist nature have undoubtedly played some part in the development of bioregional thought and this requires further research. Research could reveal the motivations to become a 'greener' society, wherein the definition of 'green' and notions of co-operation within an international, global framework, would be pivotal.

It could, perhaps, be assumed that the larger the company the more able it would be to deal with environmental considerations, making it more willing to employ stringent selfregulatory mechanisms like BS 7750 . Indeed the empirical research could be argued to support this hypothesis. More detailed consideration shows, however, that growth is not necessarily the solution as it is unlikely to significantly reduce environmental degradation. For example growth may imply an increase in the use of resources and subsequent increase in impact on the environment. Equally the literature suggests that attainment of sustainable development within the SME sector through increased regulation is unlikely to be effective. Macro mechanisms like GATT would oppose any large scale imposition as contrary to free trade (Lang and Hines, 1993). 
Hence, the model evolves from the empirical research which provides a greater understanding of SME motivations and perceptions. The qualitative research in the case studies provided many of the ideas behind the model and the literature. It is argued that this is the most appropriate route for development since there is no evidence that existing initiatives will achieve the requirements necessary to achieve sustainable development.

Overall, the research concludes that SME participation is central if sustainable development is to be achieved. The participation element requires a local bias based on sound economic principles. Concurrently, the literature suggests that decentralisation of economic decision making is an essential requirement of sustainable development (Daly and Cobb, 1989; Dobson, R. 1993; Lang and Hines, 1993; Morehouse, 1993). The SME is a core element in this process, having closer links with the local community, greater accountability for its environmental actions and a better understanding of the needs of the local economy.

A need for greater diffusion of information and education regarding the opportunities and logic of sound localised sustainable economic practice emerged from the study. Any sustainable system requires community understanding of the processes. This does not mean, however, that change has to be delayed until local communities understand the need for change. This would surely lead to inertia. The research and in particular the model argue that this educative change is best managed through participation. The central aspect of the model delineates the local economy. This economy is one that operates in a similar way to our existing economy except that barriers to trade encourage localised production to satisfy local needs. Therefore existing good management practice is retained, with priorities, moved from globalisation towards localisation and local accountability. 
The case study material highlighted common themes for success. The more relevant initiatives are to the local surroundings and the more applicable they are to the community the more likely they will attract local support and be successful. One central element is the emergence from the case study material of an increase in individual selfawareness of participants towards sustainable development ideals. The development of localised economic trading, co-operation, networking and local participation facilitates this process. It is therefore valuable to promote education through re-generation schemes.

Further, a central aspect of the case study material was the requirement for co-operation between different forms of enterprise, local government and the community as a whole. Predominance of local re-generation clearly unites localities with a common cause. This common cause or bond may not initially be concerned with the promotion of sustainable development over time. However, a sustainable economy and local orientation of economic activity could become central for local economic activity. For example the employment to be generated from localised self-reliant economies would outweigh the loss of multinational investment in the region. The literature has shown the validity of localised co-operation and networking in competition with larger companies (Jarillo; 1987; Jakobsen and Mertinussen, 1991). The requirement to compete would itself be reduced by local generated economic activity.

The model links economic and environmental sustainability by altering communities'. expectations and requirements. Present day consumer oriented society assumes that maximum satisfaction means maximum consumption. In practice this may not the case. Alternative aspects of societal life, community welfare and economic sustainability are in reality included in our evaluation of quality of life. The model offers the scope to reflect these alternative aspects in a general sense, for example through encouragement of the 
presently wasted resource of unemployed human labour and preservation of the environment.

The model for re-generative sustainable activity is conceptualised in nature, forming an amalgamation of theoretical observation and practical example. It has five constraints: economic, political, spatial, local political and community. All these aspects are interlinked and logical. They only require a movement away from the idealised position of neo-classical economics with its assumption that there are no limits to growth. This research challenges the legitimacy of this position arguing that it in the interest of the majority and the environment to participate in local re-generation projects. The model developed provides a foundation from which to understand local re-generation and could be further developed in the light of future experience.

\subsection{Recommendations and Limitations}

The evolution of management theory is central to the application of these research findings in particular the bioregional re-generation model. Although management theory has taken several steps towards sustainable development in the form of co-operative and regional networking research (Johanisson, 1983; Jarillo, 1987; Welford and Gouldson, 1993) all aspects of management theory require ecological consideration if sustainable development is to be achieved.

Thurley and Wirdenius [(1989) in Table 3.3.] suggest four main types of management theory, all of which will require differing degrees of revision. However, it is the strategic management section in particular that requires urgent further research within the SME sector. Clearly the environment is by its very nature a strategic issue. Sustainable development is unlikely to be achieved without proactive accounting for the environment. 
However, the research suggests that the increased awareness and education associated with the application of the model could induce the changes required in the SME sector to increase the level of strategic environmental management. Therefore participation and education may precede structural change of management practice. Rather than expecting SMEs to implement strategic programmes for an issue they do not understand, education and awareness raising initiatives like for example the induction of SMEs to LETSystems, or Credit Unions, could facilitate the management attitude required to increase the levels of strategic management within the SME sector. Management theory is constantly evolving to take account of changing global environments. Sustainable development is clearly a central issue facing global industry today, therefore theory needs to reflect this reality. If SME management literature in particular, does not reflect these changing global requirements the whole sustainable development movement could go the way of the early twentieth century co-operative movement, with potentially catastrophic consequences for global survival. The early co-operative movement failed to establish a firm foundation in UK management practice because of the climate of capitalist expansion at the time but also because management theory did not evolve to support the requirements of the movement. Contemporary, management thought will need to evolve with the sustainable development movement to make any application of the bioregional model suggested here feasible. Beatrice Potter suggested that the early co-operatives failed because "they were islands of socialism floating in a sea of capitalism" (in Coates, ed. 1976). The model proposed here would equally fail if it were an island of bioregionalism floating in a sea of global industrialism. The very nature of the model requires self-reliant localised economic trading to be predominant over large scale global trading patterns. If these large scale changes in trading patterns are to evolve, management theory will require revision. For example consideration of entrepreneurship theory which focuses on communities would be necessary. Further research is also required on how localities can build up their capacity to manage their own locality. 
Concurrently, theoretical observation based on competition requires revision if sustainable development is to be achieved. Competition requires winners and losers and sustainable development is necessarily more egalitarian in nature. A limitation of the model is, therefore, the parallel evolution of management theory to support the requirements of the sustainable development movement.

Due to financial and time constraints the research was spatially limited. The empirical research findings should, therefore, be tested over a larger geographical area to ascertain the validity of the results for the UK as a whole. The model also requires further research to determine the validity of the five in-built constraints. Based on literature, empirically tested analysis and qualitative case study material, the model requires practical application. It is recommended that the model is developed through the development of Geographic Information System (GIS) modelling procedures. GIS are computer software that allows a series of maps to be vertically integrated and analysed together providing the ideal system with which to consider a bioregional mapping process on. The maps themselves could provide (as databases) the initial base from which analysis of localised re-generation strategies and action plans for management change process could be developed.

The central element of future research, is therefore, to develop spatially disparate bioregional re-generation models on a GIS system. The models could be made available to local governments to facilitate a greater understanding of their bioregions and to aid the management of change towards a more sustainable society and local economy. Each map layer would have a detailed analysis of the component parts. For example, one layer could constitute existing regional sustainable strategies, another local transportation data, a further layer the topography of the region together with any relevant information and communication links within the areas. These layers are arbitrary and flexible, however, 
and indicate research areas necessary to facilitate the development of a generalised model that could be applicable to a number of disparate areas. A conceptualised model built through research observation could be generalised in nature whilst retaining a degree of flexibility to fit a number of disparate geographical locations.

The development of a Bioregional Re-generation GIS Model would also facilitate further analysis of the interface between local re-generation initiatives, similar to those studied within the case study material, and SMEs. Research is required to consider this interface in more detail and gain a deeper understanding of the part SMEs have to play within a sustainable localised economy. Less generic, more sector specific models could also be developed to aid this process. The research highlighted the need for more accurate information to target the SME sector. This could be achieved through the development of sector specific models based on examples of best practice. It is also conceivable that these models could form a further layer to the Bioregional Re-generation GIS Model, adding depth to the database and providing an informational framework to enable local authorities to implement the requirements of Agenda 21.

This research has clarified SMEs attitudes and practice in relation to their environmental performance and has considered the factors giving rise to policy implementation. It has explored a range of innovative initiatives which offer scope for sustainable development to be achieved within the SME sector. Due to the spatial constraints further research is required to test the results and the model. Further, it is proposed that once the model has been tested and refined it could be practically applied through the development of a GIS application.

In the course of the research a picture emerged of the inadequacy of current management theories as explanations of the problems facing the SME sector, both in general and with 
specific reference to the question of environmental degradation. Recognising the limitations of the research in terms of time and finance, an alternative based on primary source observation and the literature is offered. The research presents a foundation on which research into the UK SME sector and its relevance to sustainable development, could be built. 


\section{Bibliography}

Aberley, D. (1993), The Terrain of Hope. Ecology and Freedom. The Magazine of the Social Ecology Network, No.3. pp 20-22.

Adams, R. Hamil, S. and Carruthers, J. (1991), Changing Corporate Values. Kogan Page. Advisory Committee on Business and the Environment, (1992), Second Progress Report. Department of the Environment.

Advisory Committee on Business and the Environment, (1993a), Third Progress Report. Department of the Environment.

Advisory Committee on Business and the Environment, (1993b), The Environment - A Business Guide. Department of the Environment

Alexander, G.P. (1987), Establishing Shared Values through Management Training. Training and Development Journal Vol 41 No.2.

Alissa, J. (1991), The Case of the Environmental Impasse. Harvard Business Review, May/June.

d'Amboise, G. and Muldowney, M. (1988), Management Theory for Small Businesses: Attempts and Requirements. Academy of Management Review, Vol. 13, No.2 pp 226-240.

Anderson, V. (1991), Alternative Economic Indicators. Routledge.

Andruss, V. and Plant, C. (1990), Home! A Bioregional Reader. New Society Publishers. Ansoff, T.H. (1965), Corporate Strategy. McGraw-Hill: New York.

Apostel, L. (1961), Towards the Formal Study of Models in the Non-Formal Sciences in Freudenthal, H. (ed) The Concept and the Role of the Model in Mathematics and Social Sciences. Dordtrecht, Holland, pp 1-37.

Argyris C. Putman R. and Smith D.M. (1985) Action Science: Concepts, Methods and Skills for Research and Intervention. San Francisco: Jossey-Bass. 
Ashton, D. Easterby-Smith, M. and Irvine, C. (1975), Management Development: Theory and Practice. MCB: Bradford.

Ashton, D. and Easterby-Smith, M. (1979), Management Development in the Organisation. Macmillan.

Bahro, R. (1986), Building the Green Movement. Heretic/GMP.

Ball, S. and Bell, S. (1991), Environmental Law 2nd Ed. Blackstone Press Ltd.

Bamberger, I. (1983), Value Systems, Strategies and the Performance of Small and

Medium-Sized Firms. European Small Business Journal, Vol. 1. No.4, pp 25-39.

Bamberger, I. (1989), Developing Competitive Advantage in Small and Medium Sized

firms. Long Range Planning, Vol. 22. No.5, pp 80-88.

Barde, J. and Pearce, D. (eds), (1991), Valuing the Environment. Earthscan Publications Limited.

Barrow, C. and Burnett, A. (1990), How Green are Small Companies? A Survey by

Cranfield School of Management.

Bartlett, W. (1992), Organisational Change in Italian Workers' Co-operatives. in Welford,

R. (ed), Small Business and Small Business Development - A Practical Approach Vol. 2, pp 83-88, European Research Press.

Bayley, J. and Parnell, E. (eds), (1987), Yearbook of Co-operative Enterprise. Plunkett Foundation.

Beale, J. (1980), The Manager and the Environment. Pergamon Press.

Beckhard, R. (1985), Whither Management Development? Journal of Management Development, Vol. 4. No.2.

Bedeian, A. (1990), Research Notes and Communications Choice and Determinism: A

Comment. Strategic Management Journal, Vol.11. pp 571-573.

Belson, W.A. (1986), Validity in Survey Research. Gower.

Bennett, D. and Wilson, S. (1992), The Entrepreneur in the Driver's Seat - Go Green or

Go Bust? Paper submitted to the 22nd European Business seminar 23rd to 25th 
September, 1992.

Bennett, R.J. McCoshan, A. (1993), A New Strategy for Small Businesses. Financial Times, Tuesday, March 16.

Bennett R.J. (1985) Regional Movements in Britain: A review of aims and status.

Environmental Planning Vol 3 No. 1 pp 75-96.

Bertsch, B. and Williams, R. (1991), Top Management Must Participate. Journal for Quality and Participation, July/August pp 10-14.

Bijapurkar, R. (1990), Building a Competitive Edge for a Brand of Employer. Journal of the Market Research Society, Vol. 32. No. 2. pp 261-279.

Birley, S. and Gibb, A. (1984), Teaching Small Business Management in the U.K. Journal of European Industrial Training, Vol. 8. No.6 pp 17-21.

Bolton Report, (1971), Report of the Committee of Enquiry on Small Firms. Cmnd 4811. Bookchin, M. (1980), Towards an Ecological Society. Black Rose Books.

Boulding, K. (1966), The Economics of the Coming Spaceship Earth. in Daly H. (1973) Toward a Steady State Economy W.H. Freeman and Co: San Francisco.

Bourgeois, L.J. (1980), Strategy and the Environment: A Conceptual Integration. Academy of Management Review, January, pp 25-39.

Brandt, W. (1980), NorthlSouth. Pan.

Bramwell, A. (1989), Ecology in the Twentieth Century. Yale University Press.

British Institute of Management, (1992), Managing the Environment. BIM Foundation. Brown, G. (1994), Fair is Efficient. Fabian Society Pamphlet.

Brytting, T. (1990), Spontaneity and Systematic Planning in Small Firms - a Grounded Theory Approach International Small Business Journal, Vol. 9. No.1 pp 45-63. Buack, E.H. and Mathys, N. (1989), Environmental Scanning Improves Strategic Planning. Personnel Administrator, April, pp 82-87.

Buckley, P. (1993), Foreign Direct Investment by Small and Medium Sized Enterprises: The Theoretical Background In The Internationalisation of the Firm: A Reader. 
Buckley, P. and Ghauri, P. (eds), Academic Press.

Burgess, R. (1978), The Concept of Nature in Geography and Marxism. Antipode 10(2), pp 1-11.

Business in the Community, (1991), Your Business and the Environment. Legal Studies and Services, (publishing).

Cairncross, F. (1991), Costing the Earth. Economist Business Books.

Cairncross, F. (1992), How Europe's Companies. Harvard Business Review, March-April pp 34-45.

Callenbach, E. (1978), Ecotopia. Pluto Press.

Capra, F. (1983), The Turning Point. Flamingo London.

Carson, R. (1962), Silent Spring. Penguin.

Carson, P. and Moulden, J. (1991), Green is Gold. Small Business Reports December. pp 68-71.

Chandler, R. (1988), Understanding the New Age. London Word.

Chaston, I. (1993), Delivering Customer Satisfaction within the SME Client-Banker Relationship. The Service Industries Journal, Vol.13. No.1. pp 98-111.

Child, D. (1990), The Essentials of Factor Analysis. 2nd Ed. Cassell Educational Ltd.

Chorley, R. and Haggett, P. (1969), Socio-Economic Models in Geography. Methuen, London.

Chryssides, G. and Kaler, J. (1993), An Introduction to Business Ethics. Chapman and Hall.

Churchill, N.C. and Lewis, V.L. (1983), The Five Stages of Small Business Growth Harvard Business Review, May-June, pp 31-46.

Classification of Industrial Commodity Groups in the U.K. I-O Table Standard Industrial Classification. (SIC). Central Statistical Office, HMSO.

Club of Rome, (1972), Limits to Growth. Pan Books. 
Clunies-Ross, T. and Hildyard, N. (1992), The Politics of Industrial Agriculture The Ecologist, Vol. 22 No.2, March-April pp 65-71.

Coates, K. (1976), The New Worker Co-operatives. Spokesman Books.

Cockburn, D..(ed)., (1990), How Green was my Audit? C.A. Magazine, November, 1990, pp 52-54.

Collins, D. (1990), Getting Ready for the 1990s Journal of European Industrial Training Vol. 14. No.4.

Commoner, B. (1967), Science and Survival. NY: Compass.

Comte, A. (1853), The Positive Philosophy of Auguste Comte. [translated: H. Martineau] London; Trubner \& Co.

Conaty; P. (1993a), Socially Directed Investment - An Appropriate Use of Excess Credit. Published in the proceedings of Third European Conference on

Overindebtedness, Birmingham, 4th and 5th December, 1992, pp 116-126.

Conaty, P. (1993b), Inverting the Power' of the "Free Market" Pyramid - A New

Economics Approach to Energy Efficiency and the Social Economy. Discussion paper for Joint Seminar of the New Economics Foundation on "Energy Taxation and Fuel Poverty" Regents College, London: November 23rd.

Confederation of British Industry with P.A. Consulting Group, (1990), Survey of British Industrial Attitudes Concerning the Environment. CBI.

Confederation of British Industry, (1989), The Environment Means Business. CBI.

Conservation Trust, (199i1), Business and the Environment-Guide for Managers:

Cook, H. (1981), An Introductory Guide to Questionnaire Design.

Cooper, A:C. (1979), Strategic Management: 'New Ventures and Small Businesses in

Sçhendel; D.E. Hofer C.W. Strategic Management: A New View of Business

Policy and Planning, Little, Brown and Company: Boston.

Cooper, T. (1990), Green Christianity. Spire Books. 
Cope, D. and James, P. (1990), The Enterprise and the Environment - Measuring

Performance U.K. CEED, Bulletin, No. 30. September, pp 6-9.

Cotsgrove, S. and Duff, A. (1980), Environmentalism Middle Class Radicalism.

Sociology Review, Vol.28. pp 335 - 51.

Cowe, R. (1993), Exchange "Could aid Company Clean up" Guardian, 08/02/1993 p10.

Cureton, E. and D'Agostino, R. (1983), Factor Analysis - An Applied Approach,

Lawrence Erlbaum.

Curwen, P. (1990), Principles of Microeconomics. Unwin Hyman: London.

Daly, H. (1973), Towards a Steady State Economy. Pelican.

Daly, H. Cobb, J. (1987), For the Common Good. Green Print.

Darwin, C. (1885), The Origin of Species. London, Murray (6th ed) first published 1859.

Dauncey, G. (1988), After the Crash. Green Print.

David, F.R. (1989), Concepts in Strategic Management Merwill, Columbus.

Davis, J.J. (1991), A Blueprint for Green Marketing. The Journal of Business Strategy July/August, pp 14-17.

Davis, J. (1991), Greening Business. Blackwell.

Department of the Environment, (1991), Waste Management The Duty of Care - A Code of Practice: HMSO.

Devall, B. and Sessions, G. (1985), Deep Ecology. Peregrine Smith Books, Layton, UT.

Dewey J. (1929) The Quest for Certainty. New York Minton Balch.

Dilts, J. Prough, G. (1989), Strategic Options for Environmental Management: A

Comparative Study of Small vs large Enterprises. Journal of Small Business

Management, July pp 43-58.

Dobson, A. (1990), Green Political Thought. Unwin Hyman.

Dobson, R.V.G. (1993), Bringing the Economy Home From the Market. Black Rose Books.

Donaldson, J. (1989), Key Issues in Business Ethics. Academic Press. 
Donaldson, J. (1992), Business Ethics: A European Casebook Academic Press.

Doyle, J. (1992), Hold the Applause: A Study of Corporate Environmentalism. The Ecologist, Vol. 22. No.3 pp 84-90.

Douthwaite, R. (1992), The Growth Illusion, Green Books.

Dundas, K.N.M. and Richardson, P:R. (1980), Corporate Strategy and the Concept of Market Failure, Strategic Management Journal, 1. pp 177-188.

Easterby-Smith, M. (1991), Management Research - An Introduction. Sage Publications. Ecologist Vol.22 No.4. 1992, July/August.

Ehrlich, P. (1968, 1971), The Population Bomb. Sierra Club Ballantine Books.

Ekins, P. and Carcasson, G. (1982), Ecology, Past and Present. Ecology Party.

Ekins, P. (1986), The Living Economy. Routledge and Kegan-Paul, London.

Ekins, P. and Max-Neef, M. (eds), (1992), Real-Life Economics, Understanding Wealth Creation. Routledge

Elkington, J. and Burke, T. (1989), The Green Capitalists. Victor Gollancz.

Elkington, J., Knight, P. and Hailes, J. (1991), The Green Business Guide, Victor Gollancz.

ENDS Report, (1992), No.207 April 1992. Environmental Data Services Ltd.

Environmental Protection Act, (1990), HMSO: London.

Erdos P. (1970), Professional Mail Surveys. McGraw-Hill.

European Observatory for SMEs, (1993), First Annual Report. EIM Small Business and Consultancy.

Fannin, W. and Rodrigues, A. (1986), National or Global? Control V Elexibility. Long Range Planning, Vol. 19.5.

Faulkner, T., Beaver, G., Lewis, J. and Gibb, A. (Ed), (1986), Readings in Small Business Gower.

Foecke, T. (1992), Pollution Prevention: It's not just an Environmental Issue, it's Business Survival Environment Today, (January/February), p14 and pl8. 
Forrester, S (1990), Business and Environmental Groups.

Foster, J. (1992), Starting SPSS/PC+ A Beginner's Guide to Data Analysis. Sigma Press.

Fry, C. (1975), Marxism and Ecology. Ecologist, 6(9) pp 328 - 332.

Gacpar, H. (1993), The ABC of PLC. Environment Today Spring, 1993, pp 10-11.

Galbraith, J. (1958, 1984), The Affluent Society. London: Hamish Hamilton.

Garbutt, J. (1992), Environmental Law - A Practical Handbook. Chancery-Law Publishing.

General, Municipal, Boilermakers and Allied Trades Union, (GMBATU), (1986), Workers' Co-operatives - A GMBATU View. Pergamon Press.

Gibb, A. (1983), The Small Business Challenge. Journal of European Industrial Training Vol. 7. No.5. pp 28-34.

Gibb, A. and Davies, L. (1990), In Pursuit for the Development of Growth Models of the Small Business. International Small Business Journal, Vol. 9. No.1. pp15-31.

Glacken, C. (1967), Traces on the Rhodian Shore. Berkeley University of California Press.

Goldsmith, E. (1971), Can Britain Survive? Lon. T. Stacey.

Goldsmith, E. (ed), (1972), Blueprint for Survival. Ecologist, Vol.2. No.1. pp1-43.

Goldsmith, E. and Hildyard, N. (1986), Green Britain or Industrial Wasteland. Politity.

Goldsmith, E. (1992), The Way - An Ecological World View. Rider Books.

Graham, F. (1970), Since Silent Spring. Pan Books.

Graham, P. (1991), Integrative Management. Blackwell.

Gray, L. (1914), Rent under the Assumption of Exhaustibility. Economics.

Gray, R. (1990), The Greening of Accountancy. ACCA.

Griffiths, J. (1993), A Freer Flow of Goods. Financial Times, March, 12th, 1993.

Gripaios, P. (1989, 1990, 1991), The South West Economy. Annually published report, Plymouth Business School. 
Gruber, E: and Brand, M. (1.991), Promoting Energy Conservation in Small and MediumSized Cómpanies. Energy Policy, Vol.19.pp 279-287.

Hakansson, H. and Johanson, J. (1988), Formal and Informal Co-operation Strategies in International Industrial Networks. In Contractor, F. and Lorange, P. (eds), $\mathrm{Co}-$ operative Strategies in Business. pp 369-79, Lexington Books Massachusetts. Hardin, G. (1974), Living on a Lifeboat. Bioscience.

Hastam,:(199.1), (Authors Anonymous), Environment Audit. Mercury Books.

Hemming, C. (1992), The Proposed Eco-Audit Scheme: AiPilot Exercise European Environment, Vol.2. Pt.3. June.

Hendry, E.M. (1992), A Survey of Environmental Pressures On SMEs' in the Eastern Region. University of Cambridge Programme for:Indụstry. Higgins, J.M. (1991), The Management Challenge. Macmillani New York. Toronto. Hoffman, M. and Moore, J. (1990), Business Ethics. Second Ed! McGraw Hill.

Hooper, T. and Rocca; B. (1991), Environmental Affairs: Now on the Strategic Agenda The Journal of Business Strategy, May/June.

Hotelling, H. (1931), The Economics of Exhaustible Resources: Journal of Politicali Economy.

Houghton; J. R. (1986), The Old Way of Doing Things is Gone: Quality Progress, Vol. 19. No:9.

Huddleston, J. (1937), Industrial Relations in the Distributive Trades - with Special Reference to the.Co-operative Movement. M.A. Thesis Deposited in Leeds University Brotherton Library.

Hughés, D: (1992); Environmental Law. London: Butterworthị.

Hunt, C. and Auster, E. (1990), Proactive Environmental Management: Avoiding the Toxic Trap. Sloan Management Review, Vol. 3i1. No.2. pp 7-18.

Husserl, 'E. (1946), "Phenomenology". in Encyclopaedia Britannica, 14th Ed. Vol. 17 pp $699-7.02$. 
Hutton, W. (1994), Obituary Notice for Old-Style Economics in The Guardian, Monday March, 21st 1994.

Hutchinson, A. and Chaston, I. (1993), Perceptions. Policies and Practices in the SME Sector: A Case Study. Paper presented at the Second Annual Business Strategy and the Environment Conference, Bradford, September, 1993.

Hutchinson, A. and Chaston, I. (1994), Environmental Management in Devon and Cornwall's SME Sector. Business Strategy and the Environment, Vol. 3. pt.1 pp 15-22.

Hutchinson, A. (1994), Environmental Management in the UK SME Sector - Towards a Sustainable Bioregional Re-generation Model. Paper to be presented at the Third International Greening of Industry Conference, November, 13-15, 1994.

Hutchinson, F. (1994), Major Douglas' Proposals for a National Dividend: A Logical Successor to the Wage. International Journal of Social Economics, Vol.21. No.1. pp 19-28.

Irvine, S. (1989), Beyond Green Consumerism. Friends of the Earth, London. Jacobs, M. (1991), The Green Economy. Pluto, London.

Jakobsen, L. and Martinussen, J. (1991), A National Incentive Scheme for Establishing Co-operation Networks Between Small Firms. Paper Prepared for ICSB 36th Annual Conference in Vienna, June 24-26th.

Jarret, H. and Mishan, E. (1969), Economics, the Cost of Economic Growth. Pelican. Jauch, L. and Glueck, W. (1988), Business Policy and Strategic Management 5th ed. McGraw Hill.

Jarillo, J. and Ricart, J. (1987), Sustaining Networks. Interfaces. Vol. 17, No.5. Jarillo, J. (1988), On Strategic Networks, Strategic Management Journal, No.9. pp 31-41. Jevons, W. (1905), The Coal Question. Macmillan. Jobber, D. and Horgan, I. (1987), Market Research Education Perspectives from Practitioners'. Journal of Marketing Management, Vol. 3. pt.1. pp 39-49. 
Johannisson, B. (1983), Swedish Evidence for the Potential of Local Entrepreneurship in

Regional Development Development. European Journal of Entrepreneurship Vol.1. No.2. pp 11-24.

Johnson, G. and Scholes, K. (1989), Exploring Corporate Strategy. Prentice Hall. Journal of Environmental Law, O.U.P.

Jones, K. (1993), Beyond Optimism. New Society Publishers.

Kast, F.E. and Rosenzweig, J.E. (1974), Organisation and Management. McGraw-Hill. Keating, M. (1994), Agenda for Change. The Centre for Our Common Future, 52 rue des Paquis, 1201 Geneva, Switzerland.

Kelly, P. (1984), Fighting for Hope. ChattolWindus.

Kestigan, M. (1991), The Greening of Accountancy. Australian Accountant, September.

Kleiner, A. (1991), What does it mean to be Green? Harvard Business Review, July/August.

Kok, E., Welford, R. and O'Laoire, D. (1993), Environmental Management at the

Regional Level. A Case Study: The Avoca-Avonmore Catchment Conversion

Project. Journal of Environmental Management and Planning Vol 36 No. 3.

Kossoff, G. (1993), Coming Home. Ecology and Freedom, Magazine of the Social Ecology Network.

Kotler, P. (1984), Marketing Management - Analysis. Planning and Control. PrenticeHall.

Kotter, J. (1982), The General Managers. Glencoe Illinois: Free Press.

Knox, P. (1984), The Geography of Western Europe. Beckham: Croom Helm.

Knox, P. (1993), LETS Do It! Green Drum, Issue, 83. Summer, 1993, pp 11-12.

Kropotkin, P. (1955), Mutual Aid, Extending Horizon Books.

Kuhn, T. (1970), The Structure of Scientific Revolutions. University of Chicago Press, Chicago, 66.

Landsman Community Services, (1989), LETS - The Green Pound Eco-Money System. 
Lang, T. and Hines, C. (1993), The New Protectionism, Earthscan.

Leach, R. (1991), British Political Ideologies. Philip Allan.

Lee, K. (1989), Social Philosophy and Ecological Scarcity. Routledge.

LeGuin, U. (1986), Always Coming Home. Bantam.

Leicestershire TEC and Galapagos Management Consultancy, (1993), Survey of

Environmental Practices in Leicestershire Companies - A Summary.

LETS Services, (1989), Eco-Money System. Available from: Liz Sheppard, 61

Woodcock Road, Warminster, Wiltshire, BA12 9DH.

Lewin G. (ed) (1948) Resolving Social Conflicts. New York, Harper and Row.

Lewis, C.S. (1955), Surprised By Joy. Fontana Books.

Lovejoy, A. (1974), The Great Chain of Being. Harvard U.P.

Lovelock, J.E. (1979), Gaia: A New Look at Life on Earth. O.U.P.

Macpherson, E. (1992), The Importance of Being Medium Sized. Observer, 9th August, p26.

Maler, K.G. (1974), Environmental Economics. John Hopkins U.P.

Marx, K. and Engles, F. (1984), The Communist Manifesto. Pelican Books.

Markandya, A. and Richardson, J. (eds), (1992), Environmental Economics. Earthscan Publications Ltd.

Massey, D. (1984) Spatial Division of Labour. London and Basingstoke, Macmillan.

Mately, I. (1966), The Marxist Approach to the Geographical Environment. AAAG 56, pp 97-111.

McKee, B. (1991), The Best Defense Against Pollution Nation's Business, November, pp 53-57.

Mcrobie, G. (1981), Small is Possible. Cape.

Mellor, M. (1992), Breaking the Boundaries - Towards a Feminist Green Socialism Virago Press Ltd. 
Mellor, M. (1994), Envisioning the Future: Women, Environment Sustainability and

Alternative Development. Paper Presented at the World Sociology XIIIth Conference, 1994.

Merchant, C. (1980), The Death of Nature. Harper and Row, New York.

Meredith, S. (1992), Environmentalism and International Business, Who Will Have The Competitive Edge? U.K. AIB Conference Paper, Brighton Polytechnic Business School.

Mills, W. (1982), Metaphorical Vision: Changes in Western Attitudes to the Environment Annals Association of American Geographers, Vol.72. No.2. pp 237-253.

Milne K. (1994), Taking the Credit. The New Statesman Supplement, 17th June, ppxi-xiii.

Mintzberg, H. (1973), The Nature of Managerial Work. London: Harper and Row.

Mishan, E. (1969), The Costs of Economic Growth. Pelican.

Mollison, B. and Holmgren, D. (1978), Permaculture One: A Perennial Agriculture for Human Settlements. Permanent Publications.

Morehouse, W. (ed), (1989), Building Sustainable Communities The Bootstrap Press: New York.

Morgan, G. (1993), Imaginization - The Art of Creative Management. Sage Publications.

Moser, C.A. and Dalton, G. (1971), Survey Methods in Social Investigation. 2nd Ed. London: Heineman.

Mulberg, J. (1992), Economics and the Impossibility of Environmental Evaluation Unpublished paper, University of Bath.

Mumford, A. (1987), Myth and Realities in Developing Directors. Personnel Management, Vol. 19. No.2.

Naess, A. (1973), The Shallow and the Deep, Long Range Ecology Movement: A Summary. Inquiry, No.16. pp 95-99. 
Naess, A. (1990), The Basics of Deep Ecology. In John Button, (ed), The Green Fuse Quartet: London.

Newall, J. (1990), Managing Environmental Responsibility. Business Quarterly, Autumn.

Nielsen, R. (1988), Cooperative Strategy. Strategic Management Journal, Vol.9. pp 475-492.

Nijkamp, P., Van Der Mark, R. and Alsters, T. (1988), Evaluation of Regional Incubator Profiles for Small and Medium Sized Enterprises. Regional Studies, Vol. 22.2 pp 95-105.

Nordhaus, W. (1990a), Global Warming, Slowing the Greenhouse Express. In Aaron H. (ed), Setting National Priorities. Brookings Institution, Washington D.C.

Nordhaus, W. (1990b), Greenhouse Economics: Count Before You Leap. The Economist, 7th July.

O'Connor, J. (1991), Capitalism, Nature and Socialism Vol 2,(2), Issue Seven, June.

O'Neill, P. (1990), For Better or Worse. Chemistry in Britain August, pp 759-760.

Oppenheim, A.N. (1966), Questionnaire Design and Attitude Measurement.

Oppenheim, A.N. (1992), Questionnaire Design. Interviewing and Attitude Measurement New Ed.

Organisation for Economic Co-operation and Development (OECD), The Polluter Pays Principle. (1975), OECD.

O'Riordan, T. (1977), Attitudes. Behavior and Environmental Policy. Human Behavior and the Environment, Vol. 1.

Parson, (1977), Marx and Engels on Ecology.

Patton, D. Elliot, D. and Leneghan, C. (1994), The Environmental Responsibility of Small Firms: An Investigation into Current Awareness and Practice. Paper presented at the Small Business and Enterprise Conference.

P-E International, (1993), Going Green. P-E International Plc. 
Pearce, D., Markandya, A. and Barbier, E. (1989), Blueprint for a Green Economy Earthscan.

Pearce, D. (1989), Tourist Development. Longman, Scientific and Technical.

Pearce, D. (1991a), Blueprint 2: Greening the World Economy. Earthscan.

Pearce, D. (1991b), Towards the Sustainable Economy. Royal Bank of Scotland Review.

Pearce, H. (1993), Putting BS 7750 Under the Microscope. Management Consultancy, September, 1993, pp 49-52.

Pepper, D. (1984), The Roots of Modern Environmentalism. CroomUHelm London.

Peters, T. and Waterman, R. (1982), In Search of Excellence Lessons From America's Best Run Companies. Harper and Row, New York.

Permaculture, (1993), The Editorial. Permaculture Magazine Vol. 1. No.3. Summer p2.

Perry, C. (1986), Growth Strategies for Small Firms: Principles and Case Studies

International Small Business Journal, Vol. 5. No.2. pp 17-25.

Pigou, A. (1932), The Economics of Welfare. Macmillan.

Plant, J. (ed), (1991), Green Business - Hope or Hoax? Green Books.

Plant, P. and Plant, J. (ed), (1993), Putting Power in its Place. New Catalyst Books.

Pleumaron, A. (1994), The Political Economy of Tourism. The Ecologist, Vol. 24. No.4. July-August, pp 142-148.

Polanyi, K. (1978), Personal Knowledge - Towards a Post Critical Philosophy. Routledge and Kegan-Paul London.

Ponting, C. (1991), A Green History of the World Sinclair-Stevenson Ltd.

Porritt, J. (1984), Seeing Green the Politics of Ecology Explained. OxfordlBlackwell.

Porter, M. (1980), Competitive Strategy: Techniques for Analysing Industries and Competitors. New York, The Free Press.

Porter, M. (1985), Competitive Strategy and Competitive Advantage. The Free Press.

Porter, M. (1991), "America's Green Strategy". Scientific American April, 1991.

Prior, M. (1954), Bacon's Man of Science. Journal of the History of Ideas, Vol. 15 
pp $41-54$.

Ralston, K. and Church, C. (1991), Working Greener. Green Print.

Ramstrom, D. (1975, 1986), in Brytting T. (1990), Sponteneity and Syst Rice G. (1983),

Strategic Decision Making in Small Business. Journal of General Management, Vol. 9. No.1 pp 58-65.

Rees J. Hewings G.J. and Stafford H. (eds) (1981) Industrial Location and Regional Systems, J.F. Bergin Publishers Inc.

Rickmann, A. (1992), Developing Environmental Management Strategies. European Environment, Vol. 2. Pt.1.Feb.

Roberts, P. (1992), Business and the Environment: An Initial Review of the Recent

Literature. Business Strategy and the Environment, Vol. 1. Pt.2.

Robertson, J. (1990), Future Wealth. London, Cassell.

Robinson, R.B.Jnr, Pearce, J.A., Vozikis, G.S. and Mescon, T.S. (1984), The

Relationship Between Stage of Development and Small Firm Planning and

Performance. Journal of Small Business Managament, April pp, 45-52.

Rokkan S. and Urwin D. (1983) Economy. Territory, Identity. Politics of Western

European Peripheries. London Sage.

Roome, N. (1992), Developing Environmental Management Strategies. Business Strategy and the Environment Spring, Vol.1 Pt.1.pp 11-24.

Russell, B. (1946), History of Western Philosophy. Unwin.

Sale, K. (1985), Dwellers in the Land. Sierra Club.

Sale, K. (1991) in Dobson, A. (ed), The Green Reader, Deutsch: London.

Sandy, R. (1990), Statistics For Business and Economics. McGraw Hill.

Schmidt, A. (1971), The Concept of Nature in Marx. New Left Books.

Schnaibergs, A. (1980), The Environment from Surplus to Scarcity. N.Y. O.U.P.

Schumacher, E. (1968), Buddhist Economics. Resurgence, Vol.1. No.11. pp 24-38.

Schumacher, E. (1973), Small is Beautiful. Abacus. 
Scott, C. (1961), Research on Mail Surveys. Journal of the Royal Statistical Society, Vol. 124. pt. 2. pp 143-205.

Sexton, D.L. and Van Auken, P.M. (1982), Prevalence of Strategic Planning in Small Business. Journal of Small Business Management, (July 1982), pp 20-26.

Sexton, D.L. (1987), Advancing Small Business Research Utilising Research from Other Areas. American Journal of Small Business, Vol. 11. No. 3. pp 18-25.

Seymour, J. (1987), Blueprint for a Green Planet. Kindersley.

Seymour, J. (1991), Changing Lifestyles, Living as though the World Mattered. Gollancz. Shrivastra, P. (1992), The Greening of Business, in Smith D. (ed), Business and the Environment: Implications of the New Environmentalism, London: Paul Chapman Ltd.

Simms, C. (1990), The Green Business - The Impact of Environmental Issues on Strategic Management. Horton Publishing.

Skolimowski, H. (1993), A Sacred Place to Dwell. Element.

Smith, A. (1776), The Wealth of Nations. New York: Random House.

Smith, D. (1987), Culture and Management Development in Building Societies. Personnel Review, Vol. 15. No.3. pp 2-9.

Smith, D. (1990), Managing for a Better Environment. Chemistry in Britain, August, $1990, \mathrm{p} 758$.

Smith, D. (1992), Strategic Management and the Business Environment: What Lies Beyond the Rhetoric of Greening. Business Strategy and the Environment, Vol.1 Pt.1. pp1-9.

Smith, D. ed. (1992), Business and the Environment. Paul Chapman Publishing.

Smith G. (1985) Nationalism, Regionalism and the State. Environmental Planning Vol 3 No.3 pp3-9.

Spretnak, C. (1985), The Spiritual Dimension of Green Politics. in Spretnak, C. and Capra, F. Green Politics. Paladin, Glasgow. 
Stead; W. and Stead, J. (1992), Management for a Small Planet. Sage Publications Ltd!

Steers; R. Ungson, G. Mowday, R.T.(1985), Managing.Effective Organisations:

Stern, A. (1991), The Case of the Environmental Impasse. Harvard Buisiness Review MayJune.

Storey, D., Keasey, K., Watson, R.and W.ynarczyk, P. (1.987), The Performance of Small Firms. Croom Helm.

Storey, J. (1989), Management Development Part 1. Personnel Review, Vol. 18. No.6. pp 3-19.:

Stretton, H. (1978), Capitalism. Socialism and the Environment. Cambridge University Press.

Sutton, D. (1984), Management.Development in the Small Business. Journal of European Industrial Training, Vol.: 8. No.3. pp 23-28.

Tabachnick, B. and Fidell, L. (1989), Using Multivariate Statistics. 2nd Ed. Harper and Row Publishers.

Tanega, J. (1992), Towards an Environmental Credit Rating Agency - Practical First: Steps in a Conscious Evolutionary Ecological Economics. Paper Delivered at IRNES Conference, September 14th/15th, Leeds.

Thomạs, T. (1993), The Banker as Ethical Businessman. Banking World, March, pp 20-27.

Thurley, K. and Wirdenius, H. (1989), Towards European Management. Pitman; London. Torry, M.(1988), Basic Income for Alli. Bramcote Notts, Grove.

Trist E.L. and Murray H.(eds):(1990) The Social Engagement of Social Science: A Tavistock Anthology. Philadelphia University of Pennsylvania Press.

Trist E.L. (1976): Action Research and Adoptive Planning in Clarke A.W. (ed) Experimenting with Organisational Life, New York Plenum.

Vandermerwe, S. and Oliff, M. (1990), Customers Drive Corporations:Green. Long Range Planning, Vol.23. No,6 pp 10-16. 
Van Hoorn, T. (1979), Strategic Planning in Small and Medium Sized Companies. Long Range Planning, Vol. 12. April pp 84-91.

Wagel, W.H. (1987), Leadership Training for a New Way of Managing. Personnel, Vol. 64. No.12. pp 43-57.

Walker, R. (1985), Applied Qualitative Research. Aldershot, Gower.

Walsh, I. (1993), Separating Fact from Fiction on BS 5750. Management Consultancy, September, 1993, pp 57-59.

Webb, J. (1992), Understanding and Designing Marketing Research. Academic Press.

Welford, R. (1991), The Role of Management in Small Businesses Evidence from Cooperative Enterprises. in Welford R.(ed), Small Business and Small Business Development - A Practical Approach, Vol. 1. pp 43-48, ER Press.

Welford, R. (1992), Linking Quality and the Environment, A Strategy for the Implementation of Environmental Management Systems. Business Strategy and the Environment Spring, Vol.1. Pt.1. pp 25-34.

Welford, R. and Gouldson, A. (1993), Environmental Management and Business Strategy. Pitman Publishing.

Welford R. (1995) Environmental Strategy and Sustainable Development - The Corporate Challenge for the 21st Century, Routledge.

Wheelwright, S.C. (1971), Strategic Planning in Small Business. Business Horizons Vol. 14. No.4 pp 51-58.

Whitaker, B. (1993), Advisory Committee for Business and the Environment (ACBE). The Business Case for the Environment.

White, L. (1967), Historical Roots of Our Ecological Crisis. Science Vol.155 pp 1203-07. Winter, G. (1988), Business and the Environment, McGraw-Hill.

Woodcock C. (1994) "'The ESOP Effect' is no fable where profits are concerned", The Guardian, Monday August 22nd p10. 
World Commission on Environment and Development (1987) "Our Common Future:" OỤ:P.

World Conference on Environmental Management (WICEM). Special Issue. No 5 (1984); United' Nations Environmental Prọramme.

Yates, F.R.S. (1981), Sampling Methods for Censuses and Surveys. Henry Ling Ltd.

Youngman, M.B. (1984), Designing Questionnaires in Bell, J. Bush, T. Fóx, J:Goodey, J.and Goulding, S. (eds)|Conducting Small! Scạle Investigations in Educational Management, London: Harper and Row. 
APPENDIX 1 


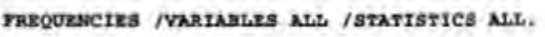

ausriness $\mathrm{Trpz}$

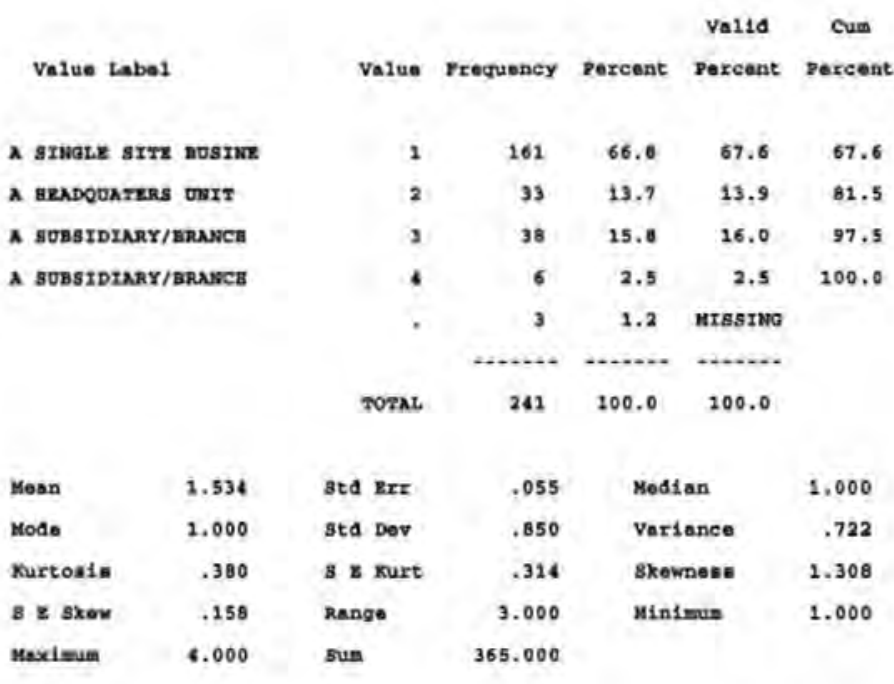

valia Canes 230 Misking Caean 3

Q2 mertores

Valid Cum
Value Label Value Preguency Parcent Percent percent

\begin{tabular}{|c|c|c|c|c|c|c|}
\hline $0-10$ & & 1 & 133 & 55.2 & 55.6 & 55.6 \\
\hline $11-25$ & & 2 & 40 & 19.9 & 20.1 & 75.7 \\
\hline $26-100$ & & 3 & 42 & 17.4 & 17.6 & 93.3 \\
\hline $201-200$ & & 4 & B & 3.3 & 3.3 & 96.7 \\
\hline \multirow[t]{3}{*}{$200+$} & & 5 & E & 3.3 & 3,3 & 200.6 \\
\hline & & . & 2 & .6 & vrssInG & \\
\hline & & rorat. & 242 & 100.0 & 200.0 & \\
\hline Mesn & 1.787 & std Exr & .069 & \multicolumn{2}{|c|}{ Median } & 1.000 \\
\hline Mode & 1.000 & Btd Dev & 1.061 & \multicolumn{2}{|c|}{ Variance } & 1.227 \\
\hline Kurtosl. & 992 & $s$ a Kuxt & .314 & \multicolumn{2}{|c|}{ skevmeas } & 1.286 \\
\hline g z skew & .157 & Range & 4.000 & \multicolumn{2}{|c|}{ xinimia } & 1.000 \\
\hline Maximin & 5.000 & sue & 427.000 & & & \\
\hline
\end{tabular}

Valia casos 239 Miseing casen 2

Q3 Bustess SECTOR

valid Cum
Value Label valus prequency parcent parcent pexcent

\begin{tabular}{|c|c|c|c|c|c|}
\hline AGRI-TORESTRY-7ISIITH & 2 & e & 3,3 & 3,3 & 3.3 \\
\hline ENEROY-NQTER SOPPLTE & 2 & $\mathbf{2}$ & .6 & .8 & 4.2 \\
\hline
\end{tabular}




\begin{tabular}{|c|c|c|c|c|c|}
\hline MTNERAL EXTRACTION-c & 3 & 3 & 1.2 & 1.3 & 5.4 \\
\hline ENGTREERTMG-VEHICLZ & 4 & 22 & 9.1 & 9.2 & 14.6 \\
\hline OTHER WUNOTACTURIMG & 5 & 55 & 22.8 & 23.0 & 37.7 \\
\hline CONSTRDCTION & 6 & 16 & 6.6 & 6.7 & 44.4 \\
\hline DISTRIAUTION-RETAILI & 7 & 13 & 5.4 & 5.4 & 49.8 \\
\hline TRUNSFORTATION-TELEC & 8 & 5 & 2.1 & 2.1 & 51.9 \\
\hline PINONCIAL SERVICES & 9 & 14 & 5.8 & 5.9 & 57.7 \\
\hline \multirow[t]{3}{*}{ OTBER SERVICES } & 10 & 101 & 41.9 & 42.3 & 100.0 \\
\hline & $\cdot$ & 2 & .8 & missing & \\
\hline & TOTAL & 241 & 100.0 & 100.0 & \\
\hline
\end{tabular}

Q3 BUstress szctor

\begin{tabular}{|c|c|c|c|c|c|}
\hline Mean & 7.310 & std $\mathbf{E r r}$ & .176 & Median & 8.000 \\
\hline Mode & 10.000 & Std Dev & 2.725 & Variance & 7.425 \\
\hline Kurtosie & -1.087 & $s$ z kurt & .314 & Skewness & -.424 \\
\hline$s \mathrm{z}$ skew & .157 & Range & 9.000 & Minimum & 1.000 \\
\hline Maximum & 10.000 & sum & 1747.000 & & \\
\hline
\end{tabular}

valla cases $239 \quad$ Misaing cases 2

Q4A Maruxzz - Sw

valid cum

value Label

Value rrequency percent percent percent

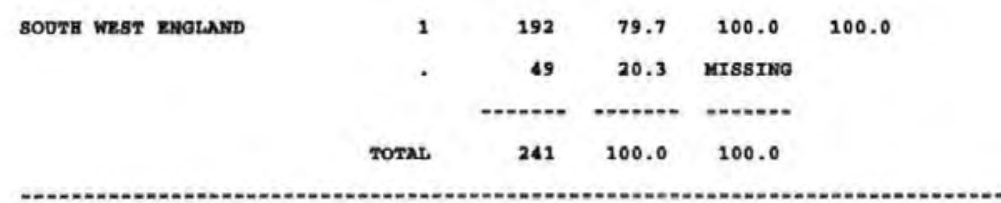

Q48

NURKRTS - ENGLAID

\begin{tabular}{|c|c|c|c|c|c|}
\hline Value Label & Value & Frequency & Percent & $\begin{array}{c}\text { Valid } \\
\text { Percent }\end{array}$ & $\begin{array}{c}\text { cus } \\
\text { percent }\end{array}$ \\
\hline \multirow[t]{4}{*}{ ENGLAND } & 1 & 156 & 64.7 & 100.0 & 100.0 \\
\hline & . & 85 & 35.3 & MISsImo & \\
\hline & & n......... & n........ & - nons. & \\
\hline & TOTAL & 241 & 100.0 & 100.0 & \\
\hline
\end{tabular}

Q4C

Maruxers - EPTX

Valid cum

Value Label Value Frequency percent percent percent

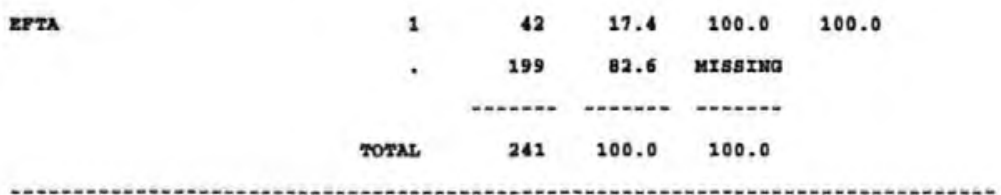




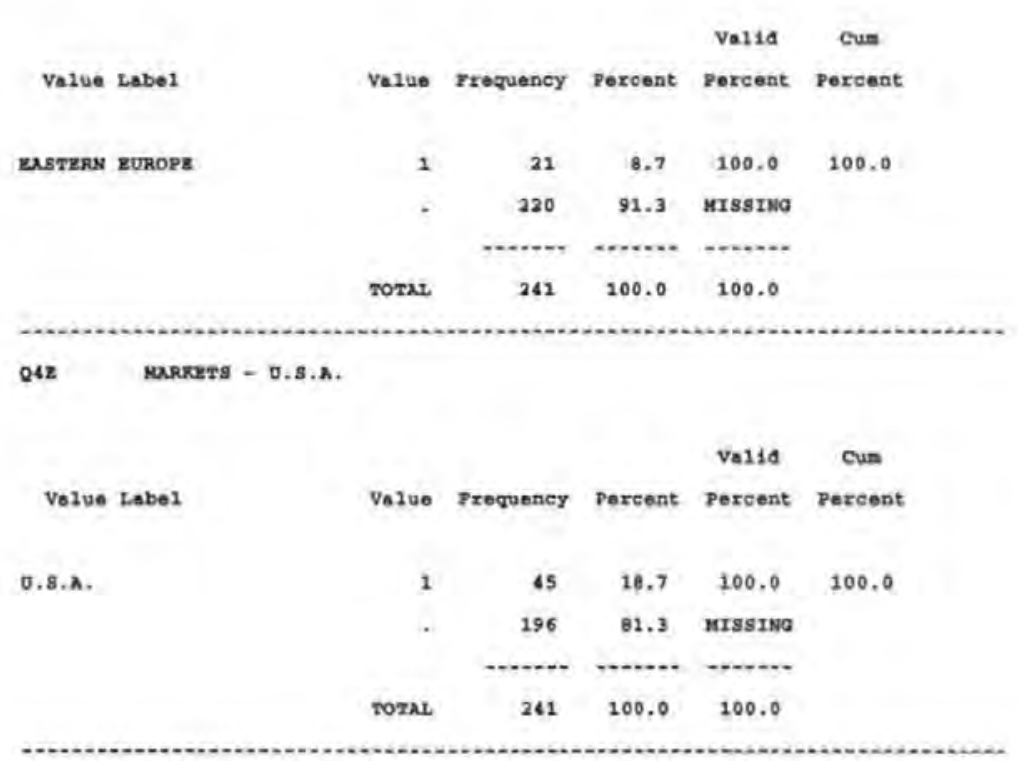

Q47

URRKeTS - THIRD WORLD

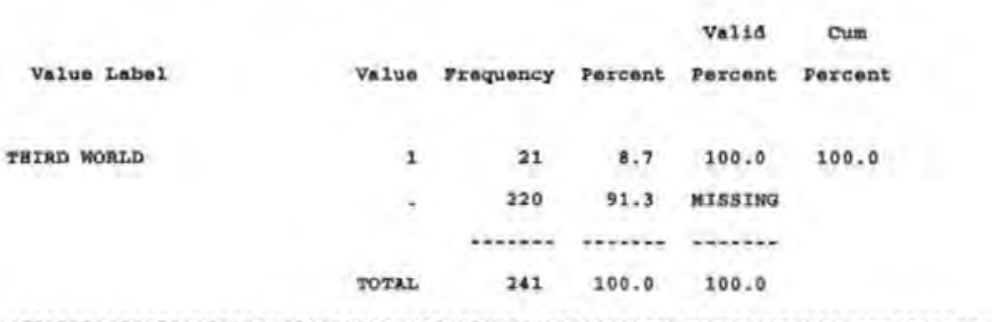

Q6G VORKCTS - TAPNA

valid Cus

Value Label Valve prequency percent percent percent

$\begin{array}{rrrrrr}1 & 22 & 9.1 & 100.0 & 100.9 \\ \text { TATAN } & 229 & 90.9 & \text { MIssrna } & \\ \text { TOTAL } & 261 & 100.0 & 100.0\end{array}$

Q4B MARKETS - ADSTRALIA

\begin{tabular}{|c|c|c|c|c|c|}
\hline Value Label & value & Frogueney & Percent & $\begin{array}{l}\text { Valla } \\
\text { percent }\end{array}$ & $\begin{array}{c}\text { Cul } \\
\text { Percent }\end{array}$ \\
\hline \multirow[t]{3}{*}{ AostruLza } & 1 & 31 & 12,9 & 100.0 & 100.0 \\
\hline & . & 210 & 87.1 & Mrsstug & \\
\hline & sorxe & 241 & 100.0 & 100.0 & \\
\hline
\end{tabular}

Q4I MURKYS - SOUTB AFrIC

Valid cuan

Value Label

Value prequency percent percent percent 


\begin{tabular}{|c|c|c|c|c|c|}
\hline \multirow[t]{4}{*}{ SODTR APRTC } & 1 & 23 & 9.5 & 100.0 & 100.0 \\
\hline & , & 218 & 90.5 & MIssIaG & \\
\hline & & ......... & n........ & ......... & \\
\hline & TOTAL & 241 & 200.0 & 100.0 & \\
\hline
\end{tabular}

Q65 MURKETS - RLSEVEERE

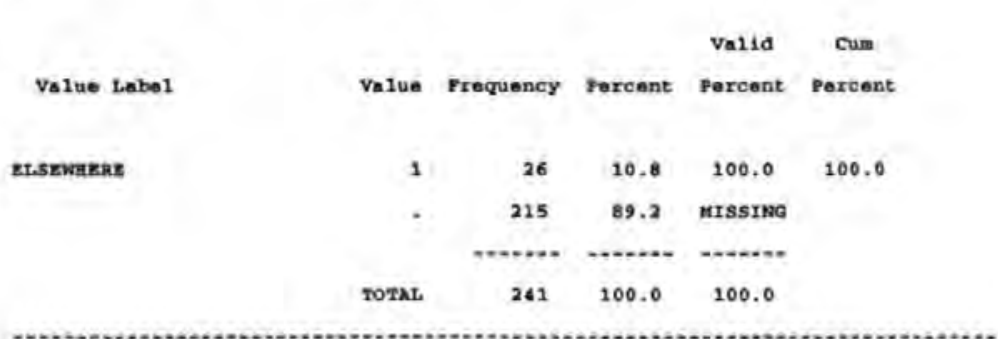

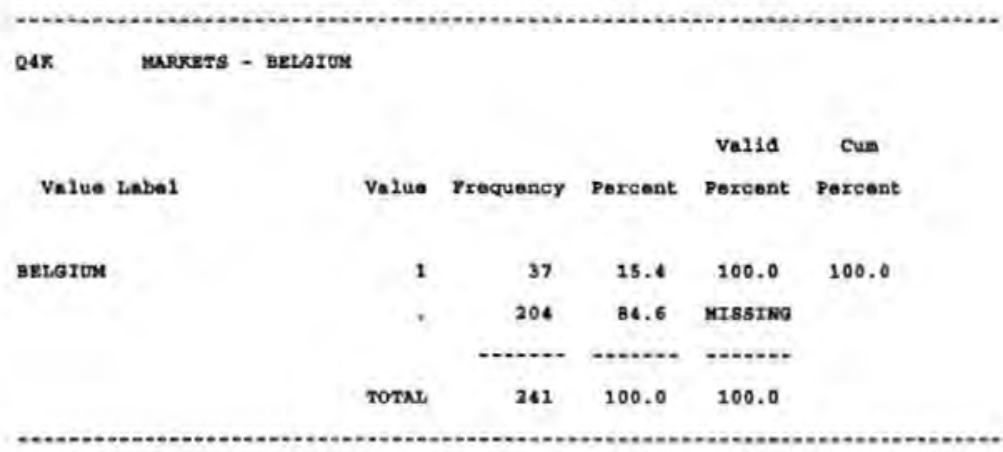

Q4L MUKers - DEwurk

\begin{tabular}{|c|c|c|c|c|c|}
\hline Value Label & value & Frequency & Percent & $\begin{array}{l}\text { Velid } \\
\text { Percent }\end{array}$ & $\begin{array}{c}\text { Cue } \\
\text { Peroent }\end{array}$ \\
\hline \multirow[t]{4}{*}{ DEmovase } & 1 & 33 & 13.7 & 100.0 & 100.0 \\
\hline & , & 208 & 86.3 & missino & \\
\hline & & -..n. & ......... & n......... & \\
\hline & Totat. & 261 & 100.0 & 100.0 & \\
\hline
\end{tabular}

\section{Q4M Markzg - grpangr}

Valid cun

\begin{tabular}{|c|c|c|c|c|c|}
\hline value tabel & Vo1ue & Frequency & Percent & Porcent & Percent \\
\hline \multirow[t]{4}{*}{ IERTCANY } & 1 & 51 & 21.2 & 100.0 & 100.0 \\
\hline & . & 190 & 78.8 & Mrssino & \\
\hline & & (n) & . & ........ & \\
\hline & Totat. & 241 & 100.0 & 100.0 & \\
\hline
\end{tabular}

Q61

maructs - Grezcr

\begin{tabular}{|c|c|c|c|c|c|}
\hline Value tabel & value & Frequency & Parcent & $\begin{array}{l}\text { Valid } \\
\text { Percent }\end{array}$ & $\begin{array}{c}\text { Cus } \\
\text { Varcent }\end{array}$ \\
\hline \multirow[t]{3}{*}{ arrecs } & 1 & 23 & 9.5 & 100.0 & 100.0 \\
\hline & , & 218 & 90.5 & Mussino & \\
\hline & ToTNL & 241 & 100.0 & 100.0 & \\
\hline
\end{tabular}




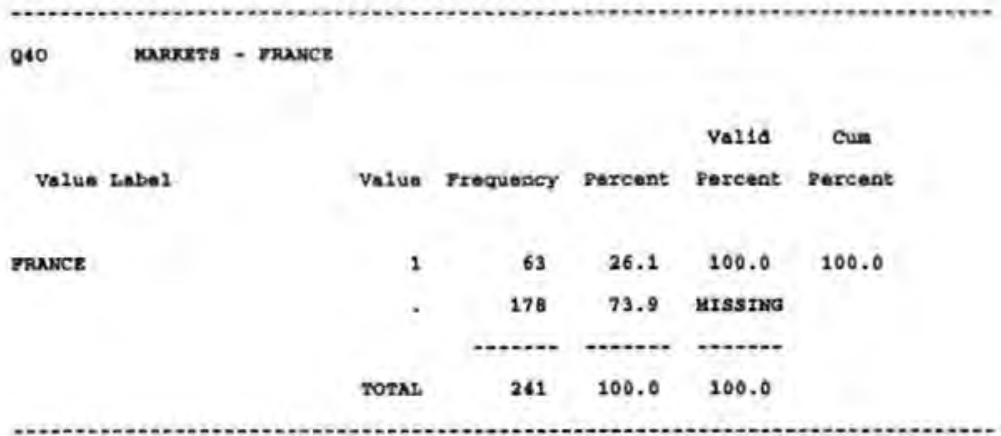

QUP MARETS - IRELAND

\begin{tabular}{|c|c|c|c|c|c|}
\hline Velue Label & Value & Frequency & Percent & $\begin{array}{l}\text { Valid } \\
\text { Percent }\end{array}$ & $\begin{array}{c}\text { Cue } \\
\text { Percent }\end{array}$ \\
\hline \multirow[t]{3}{*}{ IRELARD } & 1 & 57 & 23.7 & 100,0 & 100,0 \\
\hline & - & 104 & 76.3 & nTsstwo & \\
\hline & TOTAL & 261 & 100.0 & 100.0 & \\
\hline
\end{tabular}

040 MARKETS - TTALY

\begin{tabular}{|c|c|c|c|c|c|}
\hline Value Label & Value & Frequency & Percent & $\begin{array}{l}\text { Valid } \\
\text { Percent }\end{array}$ & $\begin{array}{c}\text { Cun } \\
\text { Percent }\end{array}$ \\
\hline \multirow[t]{4}{*}{ IZALY } & 1 & 42 & 17.4 & 100,0 & 100.0 \\
\hline & . & 199 & 82.6 & Mrsstwo & \\
\hline & & (n....... & -....... & nen & \\
\hline & TOTAL & 261 & 100.0 & 100.0 & \\
\hline
\end{tabular}

Q6R MURors - LUKBnBOURa

\begin{tabular}{|c|c|c|c|c|c|}
\hline & & & & Valida & Cua \\
\hline Value Label & value & Frectubney & Percant & Porcent & Percent \\
\hline \multirow[t]{3}{*}{ LUXPMROURG } & 1 & 20 & 8.3 & 100.0 & 100.0 \\
\hline & - & 221 & 91.7 & MISATNO & \\
\hline & Torat. & 241 & 100.0 & 100.0 & \\
\hline
\end{tabular}

Q6S MAKKRTS - NETHERLANDS

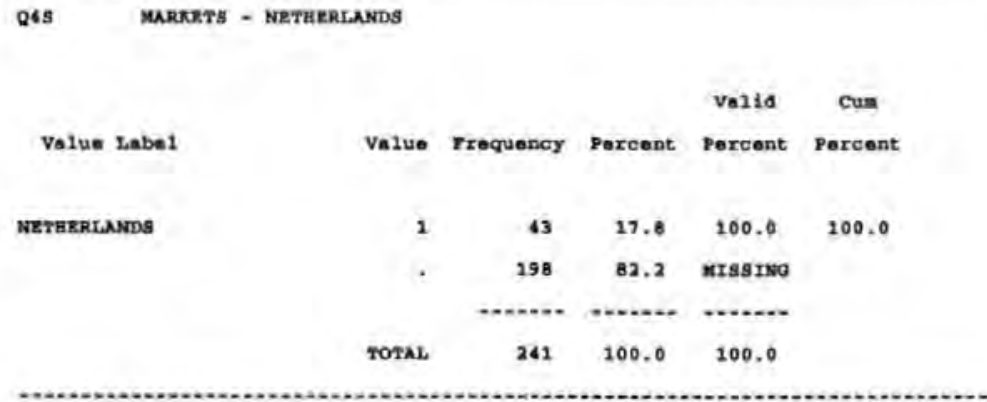

Q67 waRers - PORTUQN 


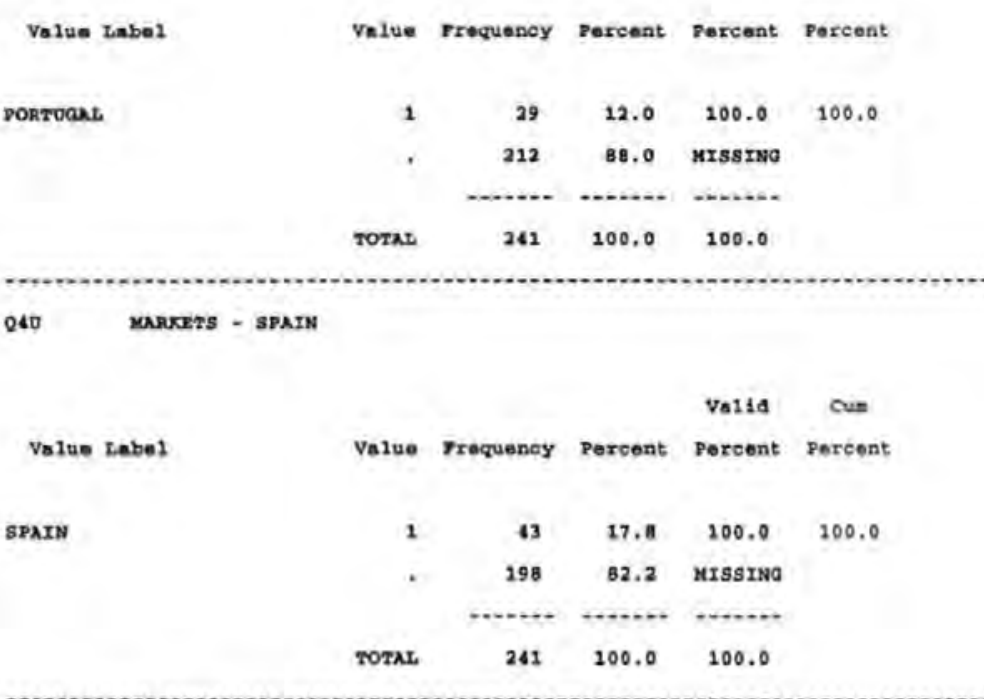

Q4V wacers - o.x.

\begin{tabular}{|c|c|c|c|c|c|}
\hline Value Labol & value & rrequaney & Percent & $\begin{array}{l}\text { Valid } \\
\text { Percant }\end{array}$ & $\begin{array}{c}\text { Cus } \\
\text { Dercent }\end{array}$ \\
\hline \multirow[t]{4}{*}{$\boldsymbol{\nabla}, \boldsymbol{\kappa}}$. & 1 & 97 & 40.2 & 99.0 & 99.0 \\
\hline & 3 & 1 & .4 & 1.0 & 100.0 \\
\hline & . & 143 & 59.3 & kTsstwo & \\
\hline & sotral. & 241 & 200,0 & 100.0 & \\
\hline
\end{tabular}

05x TMP ENV IssUes - COMP

Value Labe1

NO2 AT ALL TMPORTANY QUTTE UATMPORTANY NETTHER URTMPORTAN QUTTR migonTANT EXTREMELY TMPORTANT
Valla cua

Value Proqueney percent percent percent

$\begin{array}{rrrrr}1 & 7 & 2.9 & 2.9 & 2.9 \\ 2 & 1.2 & 5.0 & 5.0 & 7.9 \\ 3 & 63 & 26.2 & 26.4 & 24.3 \\ 4 & 106 & 44.0 & 14.4 & 78.7 \\ 5 & 51 & 21.2 & 21.3 & 100.0 \\ & 2 & .8 & \text { Mrs8rmo } & \\ \text { Totat } & 242 & 100.0 & 100.0 & \end{array}$

\begin{tabular}{|c|c|c|c|c|c|}
\hline Mean & 3.762 & std Etr & .061 & Medinn & 1.000 \\
\hline Mode & 4.000 & sta Dev & .942 & Variance & .688 \\
\hline Kurtoeds & .589 & $S=$ Kurt & .314 & SKovmose & -.721 \\
\hline s I skev & .257 & Range & 4.000 & Minimum & 1.000 \\
\hline Maxi=u & 5.000 & sua & 699.000 & & \\
\hline
\end{tabular}

valid canos 239 Hishing casas 2

Q5B IMP ESV ISB - IND 
Value Label

NOT AT ALL IMPORTANT QUTTE UNIMPORTNGT MEIVEER USTMPORTAKT QUITR IMPORTANT EXTREMELY IMPORTANT

Value Frequency porcent percent Percent

\begin{tabular}{|c|c|c|c|c|}
\hline 1 & 1 & .6 & -4 & .4 \\
\hline 2 & 4 & 1.7 & 1.7 & 2.1 \\
\hline 3 & 22 & 9.1 & 9.2 & 11.3 \\
\hline 4 & 125 & 51.9 & 52.3 & 63.6 \\
\hline 5 & 87 & 36.1 & 36.4 & $100=0$ \\
\hline - & 2 & .8 & KISSING & \\
\hline & 241 & 100.0 & 100.0 & \\
\hline
\end{tabular}

$\begin{array}{lrlrlr}\text { Mean } & 4.226 & \text { Std Brx } & .046 & \text { Medien } & 4.000 \\ \text { Mode } & 4.000 & \text { sta Dev } & .715 & \text { Variance } & .512 \\ \text { Kurtosis } & 1.696 & \text { S z Kurt } & .314 & \text { Skewnens } & -.918 \\ \text { S E Skew } & .157 & \text { Range } & 4.000 & \text { Minimua } & 1.000 \\ \text { Maximum } & 5.000 & \text { Sua } & 1010.000 & & \end{array}$

Valda canes 239 Missing caves 2

Q5X RIV ISS - XCID RAM

value Label

HOT AT ALL TMPORTAST QDTTE UNIMPORTANT QUTTE mPORTAN? EXTREMELY TOCPORTANT RETTHER ONINPORTART

$$
\text { Value Frequency percent percent percent }
$$

$\begin{array}{rrrrr}1 & 33 & 13.7 & 13.9 & 13.9 \\ 2 & 10 & 4.1 & 4.2 & 18.1 \\ 3 & 106 & 44.0 & 44.7 & 62.9 \\ 4 & 52 & 21.6 & 21.9 & 04.8 \\ 5 & 36 & 14.9 & 15.2 & 100.0 \\ . & 4 & 1.7 & 4135140 & \\ \text { Tota2 } & 261 & 100.0 & 100.0 & \end{array}$

\begin{tabular}{|c|c|c|c|c|c|}
\hline Mean & 3.203 & Std Err & .077 & Medion & 3.000 \\
\hline mode & 3.000 & Std Dev & 1.179 & Varlance & 1.391 \\
\hline Kurtoniz & -.355 & $s$ \& Kurt & .315 & Skowmene & -.353 \\
\hline B E skev & $.15 \theta$ & hange & 4.000 & Miniming & 1.000 \\
\hline Maximum & 5.000 & sus & 759.000 & & \\
\hline
\end{tabular}

Valid Casad 237 Mianing Canes 4

068 ENV ISS - CFC's

Value Imbal

not AT aLt IMPORTNAT QUITE UNIDCPRTANT NEITBER ONIMPORTNIT QOITE IMPORTANT EXTHEesLY IMPORTANT valid cum

Value Vrequency percent percent percent

$\begin{array}{rrrrr}1 & 26 & 10.8 & 11.0 & 11.0 \\ 2 & 12 & 5.0 & 5.1 & 16.1 \\ 3 & 90 & 37.3 & 38.1 & 54.2 \\ 4 & 58 & 24.1 & 24.6 & 78.8 \\ 5 & 50 & 20.7 & 21.2 & 100.0 \\ & 5 & 2.1 & \text { MIssing }\end{array}$




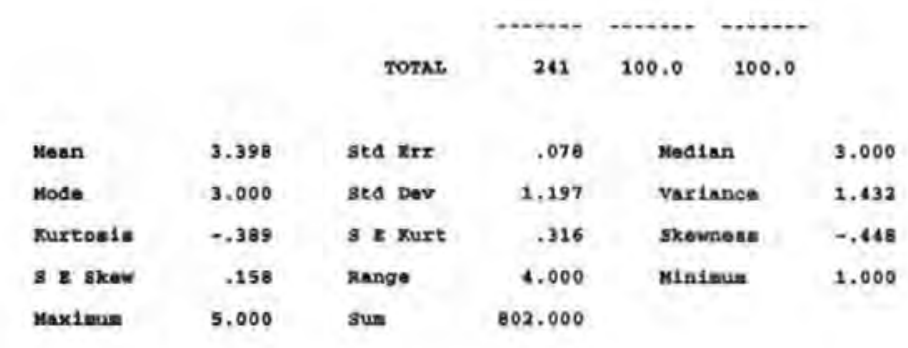

valia casos 236 Minsing Cased I

Q6C anv ISg - GLomk worerrag

value Labes

nOZ AT ALC TMPORTNAT

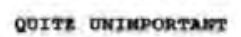
SEITHER UNIMPORTNAT

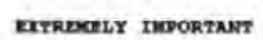
QOTTE INPORTANT

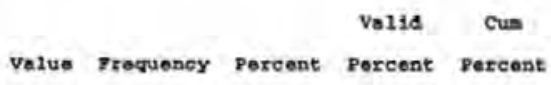

\begin{tabular}{|c|c|c|c|c|}
\hline 1 & 28 & 11.6 & 11.9 & 11.9 \\
\hline 2 & 7 & 2.9 & 3.0 & 14.9 \\
\hline 3 & 96 & 39.8 & 40.9 & 55.7 \\
\hline 4 & 54 & 22.4 & 23.0 & 78.7 \\
\hline 5 & 50 & 20.7 & 21.3 & 200.0 \\
\hline - & 6 & 2.5 & Mrssimg & \\
\hline & 241 & 100.0 & 100.0 & \\
\hline
\end{tabular}

\begin{tabular}{|c|c|c|c|c|c|}
\hline Mean & 3.387 & sed $\mathrm{grr}$ & .078 & Modian & 3.000 \\
\hline Mode & 3.000 & sta Dev & 1.201 & Varlance & 2.643 \\
\hline Rurtosia & -.338 & S E Kurt & .316 & Skemerne & -.455 \\
\hline S $x$ skew & .159 & Range & 4.000 & Miniman & 1.000 \\
\hline $\max 1=$ & 5.000 & sum & 796.000 & & \\
\hline
\end{tabular}

valid coses 235 Miasing camea 6

Q6D EV I9g - MatzR poLLesion

valia cue

Value Label Value Fraguency peroent Percent Percent

NoT AT ALL IMPORTNAT

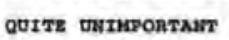

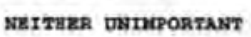
OOTTE TMPORTANE EXTRERELY IMPORTANT

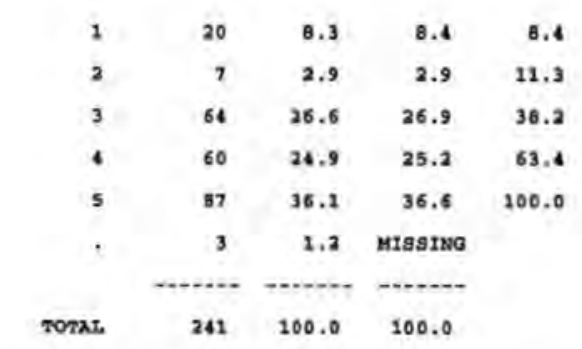

\begin{tabular}{|c|c|c|c|c|c|}
\hline nean & 3.786 & std Erz & .079 & Median & 4.000 \\
\hline Node & 5.000 & Std Der & 1.212 & Variance & 1.469 \\
\hline Kurtosin & -.050 & s E Kurt & .314 & Bkewneass & -.829 \\
\hline 8 \& sken & .258 & range & 4.000 & xinimus & 1.000 \\
\hline Maxisua & 5.000 & sum & 901.000 & & \\
\hline
\end{tabular}


valid cases 238 Misaing cases 3

Q68 ENV TSS - EIRRGY DSAGE

valid cum
value tabel Volue Frequency percent percent percent

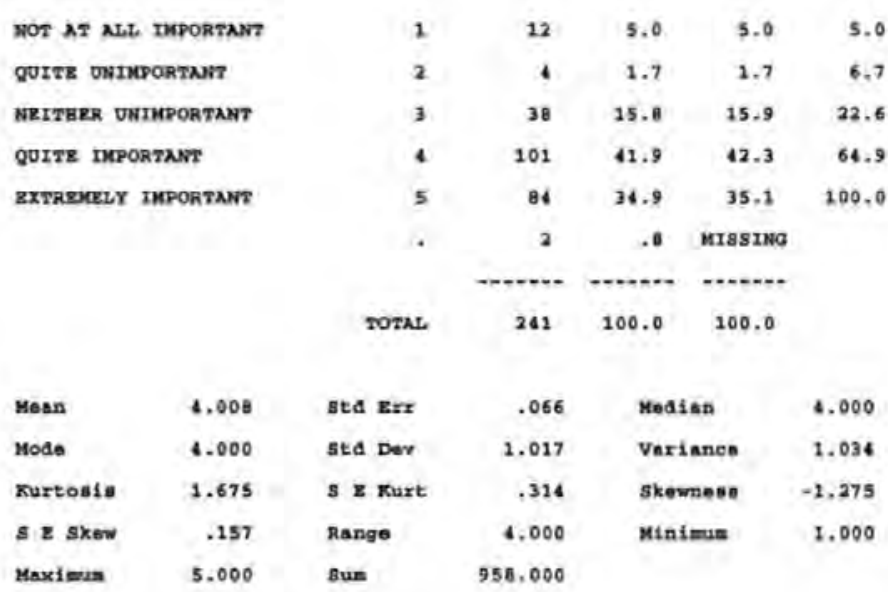

Volid caves 239 Missing cases 2

Q6Y LerV ISS - EYYLUENT waste DIsposal.

\begin{tabular}{|c|c|c|c|c|c|c|}
\hline \multirow{2}{*}{\multicolumn{2}{|c|}{ Value tabel }} & \multirow[b]{2}{*}{ Value } & \multirow[b]{2}{*}{ Frequency } & \multirow[b]{2}{*}{ Percent } & \multirow{2}{*}{$\begin{array}{l}\text { valla } \\
\text { percent }\end{array}$} & \multirow{2}{*}{$\begin{array}{c}\text { Cue } \\
\text { Percent }\end{array}$} \\
\hline & & & & & & \\
\hline \multicolumn{2}{|c|}{ NOT AT ALA IMPORTANT } & 2 & 22 & 9.1 & 9.2 & 9.2 \\
\hline \multicolumn{2}{|c|}{ OUTTE UMINFORTANT } & 2 & 8 & 3.3 & 3.4 & 12.6 \\
\hline \multicolumn{2}{|c|}{ NETTEER ONIMPORTANT } & 3 & 67 & 27.8 & 28.2 & 40.8 \\
\hline \multicolumn{2}{|c|}{ QUITE TamORTAKT } & 4 & 62 & 25.7 & 26.1 & 66.8 \\
\hline \multirow{4}{*}{\multicolumn{2}{|c|}{ EXTREAELY TMPORTXNT }} & 5 & 79 & 32.6 & 33.2 & 100.0 \\
\hline & & s & 3 & 1,2 & missrapo & \\
\hline & & & antos & n.t.2. & $\ldots . . . . .$. & \\
\hline & & rotat. & 241 & 100.0 & 100.0 & \\
\hline Mesn & 3.706 & std $\mathrm{Etr}$ & .079 & \multicolumn{2}{|c|}{ Modian } & 4.000 \\
\hline Modn & 5.000 & sta Dev & 1.225 & \multicolumn{2}{|c|}{ veritehce } & 1.500 \\
\hline Kurtonis & -.179 & s \& Xurt & .314 & \multicolumn{2}{|c|}{ gkevness } &.- .256 \\
\hline S B skow & .158 & Range & c. .000 & \multicolumn{2}{|c|}{ Minimum } & 1.000 \\
\hline Maximus & 5.000 & sum & 882.000 & & & \\
\hline
\end{tabular}

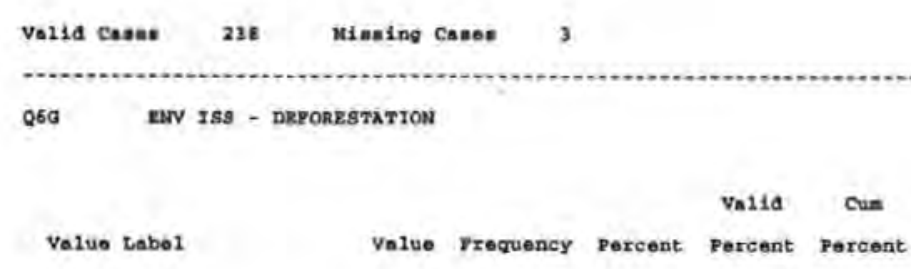




\begin{tabular}{|c|c|c|c|c|c|c|}
\hline WOT AT AL & PORTANT & 1 & 31 & 22.9 & 23.1 & 13.1 \\
\hline QUTrE & TWNT & 2 & 6 & 2.5 & 2.5 & 25.7 \\
\hline IETIEER D & oRTANT & 3 & 93 & 38.6 & 39.4 & 55.2 \\
\hline QUTTE IMP & & 4 & 53 & 22.0 & 22.5 & 37.5 \\
\hline exzRrockLY & ORTuart & 5 & 53 & 22.0 & 22.5 & 100.0 \\
\hline & & . & 5 & 2.1 & mIssino & \\
\hline & & Total & 261 & 100.0 & 100.0 & \\
\hline Menn & 3.386 & sta $\mathbf{x} x \mathbf{x}$ & .082 & Med & & 3.000 \\
\hline Mode & 3.000 & sta Dev & 2.238 & var & ance & 1.532 \\
\hline Kurtosis & -.441 & B a Kurt & .316 & ske & men: & -.468 \\
\hline S R sken & .158 & kenge & 4.000 & Min & & 1.000 \\
\hline onximus & 5.000 & sum & 799.000 & & & \\
\hline
\end{tabular}

valid casen 236 Missing cares 5

Q6a ENY ISS - NOISE POLLUTION

valia cua

value Label

value rroquency porcent porcent percent

\begin{tabular}{|c|c|c|c|c|c|}
\hline NOT AT ALL IMPORTANT & 1 & 13 & 5.4 & 5.5 & 5.5 \\
\hline QDITE UARMPONTAVT & 2 & 5 & 2.1 & 2,1 & 7.6 \\
\hline NEITHER UNTOCPONTANT & 3 & 72 & 29.9 & 30,3 & 37,8 \\
\hline QUITI TMPORTANT & 4 & 87 & 36.1 & 36.6 & 74.4 \\
\hline \multirow[t]{3}{*}{ EXTRERELY IAPORTANT } & 5 & 61 & 25.3 & 25.6 & 100,0 \\
\hline & - & 3 & 2.2 & Mrssing & \\
\hline & & 241 & 100.0 & 100.0 & \\
\hline
\end{tabular}

\begin{tabular}{|c|c|c|c|c|c|}
\hline Meen & 3.740 & sta $\mathbf{z r x}$ & .067 & Median & 4,000 \\
\hline Mode & 4.000 & sed Dev & 1.037 & Variance & 1.075 \\
\hline nurtosis & .556 & s I nure & .314 & Sketmose & -.782 \\
\hline S I skaw & .258 & Range & 4.000 & Minimum & 1.000 \\
\hline Maximum & 5.000 & Sum & 892.000 & & \\
\hline
\end{tabular}

valid cases 238 Miesing casan 3

Q6I ENV ISS - VEHiCLE EMISSIONS

Valid Cum

Value Label

Value Frequency Percent Porcent porcent

nor at ati mportart QUTTE UNTMPORTANT NEITHER UNIMPORTANT gOITE ILPORTANT EXTREDELY TMPORTANT

$\begin{array}{rrrr}24 & 10.0 & 10.1 & 10.1 \\ 6 & 2.5 & 2.5 & 12.7 \\ 79 & 32.8 & 33.3 & 46.0 \\ 78 & 32.4 & 32.9 & 76.9 \\ 50 & 20.7 & 21.1 & 100.0 \\ 4 & 1.7 & \text { missing } & \\ & & & \end{array}$




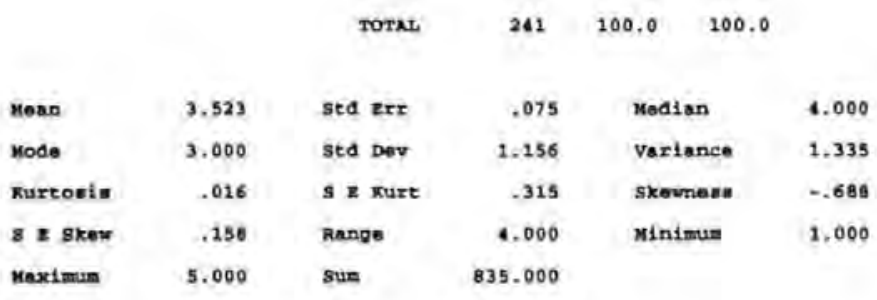

\section{Valia cases 237 Mialng Cases a}

060 RSV ISS - SOLID WASTE DISPOSAL

\begin{tabular}{|c|c|c|c|c|c|c|}
\hline & & & & & valid & Cum \\
\hline Value lab & & Volue & Frequency & Parcent & Percent & Percent \\
\hline NOT AT ALL & PORTANT & 1 & 24 & 10.0 & 10.1 & 10.1 \\
\hline QUITE UNTMP & TANT & J & 3 & 1.2 & 1.3 & 11.3 \\
\hline NEITHER UNI & Dหรมษ & 3 & 67 & 27.6 & 28.2 & 39.5 \\
\hline QUITE IMPOR & & 4 & 77 & 32.0 & 32.4 & 71.8 \\
\hline EXTREMELY I & ORTNAT & 5 & 67 & 27.8 & 28.2 & 100.0 \\
\hline & & . & 3 & 1.2 & Mresta & \\
\hline & & TOTAL, & 241 & 100,0 & 100.0 & \\
\hline Meen & 3.672 & std Erx & .077 & Medi & an & 4.000 \\
\hline Mode & 6.000 & std Dev & 1.191 & Vari & ance & 1.420 \\
\hline Kurtosia & .119 & $s \geq$ Kurt & .314 & Skew & meso & -.837 \\
\hline S \& Skeur & .158 & Range & 4.000 & Mini & תות & 1.000 \\
\hline Maximan & 5.000 & sum & 876.000 & & & \\
\hline
\end{tabular}

valid cases 238 Hissing cases 3

Q6K ENV ISS - RESOURCR DEPLETIOA

value Label

WOT AT ALI IMPONTNAT QUTTE UNDTPORTANT MEITHER ONIMPORTART QUITE IMPORTANT EXTREGLY IMFORTANT

\begin{abstract}
Value rrequency percent percent percent
\end{abstract}

\begin{tabular}{|c|c|c|c|c|}
\hline 1 & 21 & 8,7 & 8.9 & 8.9 \\
\hline 2 & 10 & 6.1 & 4.2 & 13.1 \\
\hline 3 & 79 & 32.8 & 33.5 & 46.6 \\
\hline 4 & 70 & 29.0 & 29.7 & 76.3 \\
\hline 5 & 56 & 23.2 & 23.7 & 100.0 \\
\hline - & 5 & 2.1 & Mrssino & \\
\hline & & n......... & n.ton & \\
\hline & 241 & 100.0 & 100.0 & \\
\hline
\end{tabular}

\begin{tabular}{|c|c|c|c|c|c|}
\hline Maen & 3.551 & Sta Err & .076 & Medion & 4.000 \\
\hline Mods & 3.000 & std Dev & 1.160 & Variance & 2.366 \\
\hline Kurtosiz & -.139 & s z kurt & .316 & Skewnese & .611 \\
\hline s \& skev & .158 & Hange & 4.000 & Minimun & 1.000 \\
\hline Maximum & 5.000 & sum & 838.000 & & \\
\hline
\end{tabular}


valid chose 236 Missing cases 5

Q61.

EWV ISS - miptorex E/s

valid cus
volue Label velue prequency porcent percent percent

\begin{tabular}{|c|c|c|c|c|c|c|}
\hline \multicolumn{2}{|c|}{ WOT AT ALL MUPORTAUT } & 2 & 5 & 2,1 & 2.1 & 2.1 \\
\hline \multicolumn{2}{|c|}{ QOITE UNICPORTNATT } & 2 & 1 & .4 & -4 & 2,5 \\
\hline \multicolumn{2}{|c|}{ 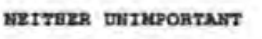 } & 3 & 11 & 4.6 & 4.6 & 7.1 \\
\hline \multicolumn{2}{|c|}{ QUTTE INPORTANT } & 4 & 65 & 27.0 & 27.2 & 34.3 \\
\hline \multirow{4}{*}{\multicolumn{2}{|c|}{ EXTREAELY IMPORTANT }} & 5 & 257 & 65.1 & 65.7 & 100.0 \\
\hline & & . & 2 & .a & krssiva & \\
\hline & & & (t).n. & 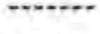 & n.t. & \\
\hline & & TOTAL & 241 & 100.0 & 100.0 & \\
\hline Moan & 4.540 & std exx & .051 & \multicolumn{2}{|c|}{ Modian } & 5.000 \\
\hline Mode & 5.000 & Std Dev & .787 & \multicolumn{2}{|c|}{ Variance } & .619 \\
\hline Kurtonin & 7.087 & S E Kure & +314 & \multicolumn{2}{|c|}{ skevnesu } & -2.376 \\
\hline$S E$ akew & .157 & Range & 4.000 & \multicolumn{2}{|c|}{ Minlsua } & 5,000 \\
\hline Maximus & 5.000 & sua & 1085.000 & & & \\
\hline
\end{tabular}

Velid Cases 239 Miselng Casea 2

Q69 ENV ISS - TINUNCLAL SUPPON2 ENV GROUPS

value tabel

NOZ AZ ALt. IMPORTANT QUITE UNIMPORTANT NEITHER UNIMPORTANT QUTTE IMPORTART

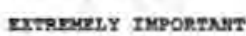

$$
\begin{aligned}
& \text { valid Cue } \\
& \text { Value Prequency Percent Percent Percent }
\end{aligned}
$$

\begin{tabular}{|c|c|c|c|c|}
\hline 1 & 29 & 12.0 & 12.2 & 12.2 \\
\hline 2 & 20 & 8.3 & 8.4 & 20.7 \\
\hline 3 & 113 & 16.9 & 67.7 & 68.4 \\
\hline 4 & 52 & 21.6 & 21.9 & 90.3 \\
\hline 5 & 23 & 9.5 & 9.7 & 100.0 \\
\hline * & 4 & 1.7 & Mrsstno & \\
\hline & 241 & 100.0 & 200.0 & \\
\hline
\end{tabular}

\begin{tabular}{|c|c|c|c|c|c|}
\hline Mean & 3.086 & std $\mathrm{Err}$ & .071 & Modian & 3.000 \\
\hline Mode & 3.000 & gtd Dov & 1.086 & Variance & 1.179 \\
\hline Kurtosis & -.159 & a E Kurt & .315 & Skowness & -.289 \\
\hline$B$ I skow & .158 & Nange & 4.000 & Minimua & 2.000 \\
\hline Maximua & 5.000 & Sun & 731.000 & & \\
\hline
\end{tabular}

Valid canos 237 Minaing Cases

Q7x Nosa - ec sc0-LABELtigo

Valia cie

value tabel

value Prequency percent gercent percent 
res

Do nor Rrow

no

\begin{tabular}{|c|c|c|c|c|}
\hline 1 & 50 & 20.7 & 20.9 & 20.9 \\
\hline 2 & 122 & 46.5 & 46.9 & 67.8 \\
\hline $\mathbf{3}$ & 77 & 32.0 & 32.2 & 100,0 \\
\hline , & 2 & .8 & ursstug & \\
\hline & & ......... & at...... & \\
\hline & 241 & 200.0 & 200.0 & \\
\hline
\end{tabular}

$\begin{array}{lrlrlr}\text { Hean } & 2.113 & \text { Std Err } & .067 & \text { Median } & 2.000 \\ \text { Mode } & 2.000 & \text { std Dev } & .722 & \text { Variance } & .521 \\ \text { Kurtosis } & -1.062 & \text { SE Kurt } & .314 & \text { Skevmens } & -.173 \\ \text { S E skev } & .157 & \text { Range } & 2.000 & \text { Ninimun } & 1.000 \\ \text { Haximum } & 3.000 & \text { Sun } & 505.000 & & \end{array}$

valid cases 339 Missing cases 2

Q7B AKNRE - EC ECO-AUDIT

\section{Value tabel}

Yes

Do No: Kmow

no

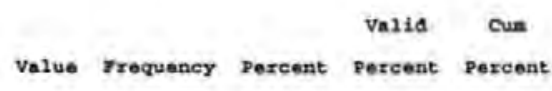

$\begin{array}{rrrrr}1 & 38 & 15.8 & 15.9 & 15.9 \\ 2 & 124 & 51.5 & 51.9 & 67.8 \\ 3 & 77 & 32.0 & 32.2 & 100.0 \\ . & 2 & .8 & \text { Mrsszas } & \\ & \ldots \ldots .7 & \ldots \ldots & \ldots \ldots . . & \\ \text { TOTAL } & 242 & 100.0 & 100.0 & \end{array}$

\begin{tabular}{|c|c|c|c|c|c|}
\hline Mosn & 2.163 & sta Err & .044 & Medion & 2.000 \\
\hline Mode & 2.000 & sta Dov & .676 & Variance & .456 \\
\hline Kurtonia & -.817 & S E Kurt & .314 & skoumeat & -.209 \\
\hline s I skew & .157 & asnge & 2.000 & Minimus & 1.000 \\
\hline Maximus & 3.000 & sum & 517.000 & & \\
\hline
\end{tabular}

Valia Canas 239 Missing Coson 2

Q7C AWNRE - JORTRCOMING EC DIRECrTVes

\section{value Label}

YES

DO sor Roun

no
Value groquency parcent percent Parcent

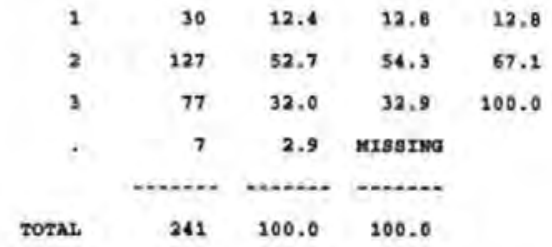

\begin{tabular}{|c|c|c|c|c|c|}
\hline Meen & 2.201 & std Err & .042 & Median & 2.000 \\
\hline Mode & 2.000 & std Dev & .647 & Vartance & 419 \\
\hline Kurtosia & -.678 & s \& Kurt & .317 & Skevmens &. .219 \\
\hline s $\mathrm{z}$ skev & .159 & Range & 2.000 & Minieun & 1.000 \\
\hline Maximas & 3.000 & sum & 515.000 & & \\
\hline
\end{tabular}


Vol1d cases 234 Miasing Cosed

Q7D AYORE - \$S 5750

\section{Value Labol}

res

Do nor kotow

wo

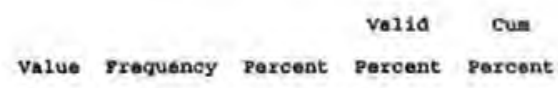

(1)

$\begin{array}{lllll}2 & 32 & 13.3 & 13.6 & 67.7\end{array}$

$\begin{array}{lllll}3 & 29 & 12.0 & 12.3 & 100.0\end{array}$

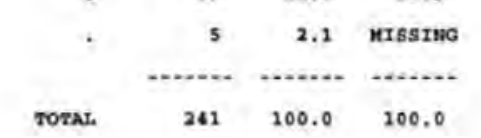

\begin{tabular}{|c|c|c|c|c|c|}
\hline Mean & 1.381 & sta $\mathrm{Exx}$ & .045 & Modian & 1,000 \\
\hline Mode & 1.000 & sta Dov &, 696 & Voriance & .484 \\
\hline Kurtosis & . 332 & s \& Kurt & .316 & Skesmes: & 1.542 \\
\hline$s$ \& skew & .158 & Range & 2.000 & Minimum & 1.000 \\
\hline Maximum & 3.000 & sum & 326,000 & & \\
\hline
\end{tabular}

Valid Caaes $236 \quad$ Mianing Canos 5

Q72 ANare - as 7750

Volid cum
Value Label Vuluo Frequency porcent Porcent Porcont

res

Do not know

No

\begin{tabular}{|c|c|c|c|c|c|c|}
\hline res & & 1 & 63 & 26.1 & 27.4 & 27.4 \\
\hline DO nOT KAC & & 2 & 101 & 41.9 & 43.9 & 71.3 \\
\hline \multirow[t]{4}{*}{ No } & & 3 & 66 & 27.4 & 28.7 & 100.0 \\
\hline & & , & 11 & 4.6 & urssina & \\
\hline & & & .......... & ........ & anc. & \\
\hline & & TOTAL & 241 & 100.0 & 200.0 & \\
\hline Mean & 2.013 & std grr & .069 & \multicolumn{2}{|c|}{ median } & 2,000 \\
\hline node & 2.000 & sta Dev & .750 & \multicolumn{2}{|c|}{ Variance } & .563 \\
\hline Kurtosis & -1.217 & s \& kurt & .320 & \multicolumn{2}{|c|}{ 5kevmesa } & -.021 \\
\hline$s=$ skew & .160 & Range & 2.000 & \multicolumn{2}{|c|}{ Minimun } & 1,000 \\
\hline Meximue & 3.000 & suin & 463.000 & & & \\
\hline
\end{tabular}

valid cases $230 \quad$ Misaing cason 11

Q7F AWNRE - EPA

Value Lebel

value rrequency percent percent percent

res

Do nor RaOH

no 


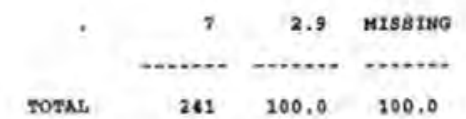

\begin{tabular}{|c|c|c|c|c|c|}
\hline Meen & 1,876 & sto Brr & .051 & Medien & 2.000 \\
\hline Hode & 2.000 & std Der & .779 & Variance & .607 \\
\hline Kurtoed. & $-1,319$ & $s$ \& kurt & .317 & skeiniese & .220 \\
\hline$S$ \& skew & .159 & Range & 2.000 & Mininum & 1.000 \\
\hline Maxitun & 3.000 & sue & 439.000 & & \\
\hline
\end{tabular}

Valid cases 234 Missing Cases 7

Q70 AWRRE - WATER ACT

vadia cu=

Value Label

Value Freguency Percent percent porcent

Yes

Do not Know

NO

$\begin{array}{rrrrr}1 & 73 & 30.3 & 31.2 & 31.2 \\ 2 & 200 & 41.5 & 42.7 & 73.9 \\ 3 & 61 & 25.3 & 26.1 & 100.0 \\ & 7 & 2.9 & \text { 4Issirg } & \\ \text { T0TNL } & 241 & 100.0 & 100.0 & \end{array}$

$\begin{array}{lrlrlr}\text { Mean } & 1.949 & \text { std Err } & .049 & \text { Median } & 2.000 \\ \text { Mode } & 2.000 & \text { std Dev } & .757 & \text { Variance } & .572 \\ \text { Kurtosid } & -1.243 & \text { s z Kurt } & .317 & \text { skewness } & .085 \\ \text { S E Skew } & .159 & \text { Range } & 2.000 & \text { Minimum } & 1.000 \\ \text { Maximus } & 3.000 & \text { sum } & 456,000 & & \end{array}$

volid caser 224 Missing Cowes?

$078 \quad$ NOARE - cosBg

Valla Cua

value tabel

value Frequency percent percent percent

res

Do Nor know

no

$\begin{array}{rrrrr}1 & 133 & 55.2 & 56.6 & \$ 6.6 \\ 2 & 64 & 26.6 & 27.2 & 83.8 \\ 3 & 38 & 25.6 & 16.2 & 100.0 \\ & 6 & 2.5 & \text { M1835NG } & \\ & & & \\ \text { Totrit } & 241 & 100.0 & 100.0 & \end{array}$

\begin{tabular}{|c|c|c|c|c|c|}
\hline Mean & 1.596 & sta zrr & .049 & Median & 1.000 \\
\hline Modn & 1.000 & Std Dev & .753 & Variance & .567 \\
\hline Kurtonfe & -.769 & $s$ \& Kurt & .316 & Skevneas & .822 \\
\hline$s$ \& skew & .159 & Range & 2.000 & Minimun & 1.000 \\
\hline Maximue & 3.000 & sum & 375.000 & & \\
\hline
\end{tabular}

valid casen 235 Mimaing Casen of 


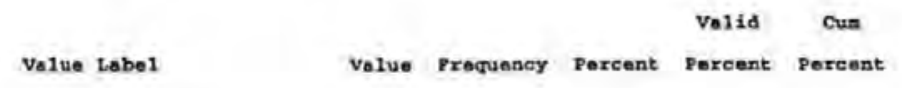

\begin{tabular}{|c|c|c|c|c|c|c|}
\hline \multicolumn{2}{|c|}{ STRONGLY DISMGRER } & 2 & B & 3.3 & 3.3 & 3 . \\
\hline \multicolumn{2}{|l|}{ DISAGRER } & 2 & 19 & 7,9 & 7,9 & 11. \\
\hline \multicolumn{2}{|c|}{ AGRER NOR DISAGREE } & 3 & 34 & 14.2 & 14.2 & \\
\hline \multicolumn{2}{|l|}{ AGREZ } & 4 & 202 & 42.3 & 42.5 & \\
\hline \multirow{3}{*}{\multicolumn{2}{|c|}{ STRONGLY AGREE }} & 5 & 77 & 32.0 & 32.1 & 100 \\
\hline & & . & 1 & .6 & Mrssing & \\
\hline & & rotas & 241 & 100.0 & 100.0 & \\
\hline Yean & 3.921 & std $\mathbf{E x r}$ & .067 & \multicolumn{2}{|c|}{ Median } & 4.000 \\
\hline Mods & 4.000 & std Dev & 1.038 & \multicolumn{2}{|c|}{ Varíance } & 1.077 \\
\hline Kurtoaia & .547 & $s \boldsymbol{z}$ xurt & .313 & \multicolumn{2}{|c|}{ Skewnesa } & -.995 \\
\hline$s$ z skew & .257 & Range & 4.000 & \multicolumn{2}{|c|}{ Minimus } & 1.000 \\
\hline Maximua & 5.000 & sun & 941.000 & & & \\
\hline
\end{tabular}

varia cases 260 Musing cases 1

QBS REV TMPR - COMP SELP REG

volue Label

STRONOLY DISAGREB

Drsagker

AOREE WOR DISAGREX

AGRER

STRONOLY AGREX

Valid cum
Value preguency percent percent percent

\begin{tabular}{|c|c|c|c|c|}
\hline 2 & 9 & 3.7 & 3.6 & 3.8 \\
\hline a & 31 & 12.9 & 13.2 & 17.1 \\
\hline 3 & 32 & 13.3 & 13.7 & 30.6 \\
\hline 4 & 108 & 44. & 46.2 & 76.9 \\
\hline 5 & 54 & 22.4 & 23.1 & 100.0 \\
\hline & 7 & 2.9 & Mrssing & \\
\hline & & n........ & non & \\
\hline & 241 & 100.0 & 100,0 & \\
\hline
\end{tabular}

\begin{tabular}{|c|c|c|c|c|c|}
\hline Moan & 3.714 & Sta Err & .071 & Median & 6.000 \\
\hline Mode & 4.000 & sta bev & 1.080 & Variance & 2.167 \\
\hline Kurtonin & -.087 & $s \mathbf{z}$ kurt & .317 & Skevmosut & -.790 \\
\hline \& g skaw & .259 & Range & 4.000 & Minimus & 2.000 \\
\hline Maximus & 5.000 & sua & 869.000 & & \\
\hline
\end{tabular}

valia Caseas 234 Minaing canes 7 Q9C EAV TRPR - IMDTV DISCTPLIGR

Valuo Labol

STROHGLY DISAGREE Drsagner valla cus

Value Prequency Parcent percent percent

$\begin{array}{rrrrr}1 & 7 & 2.9 & 2.9 & 2.9 \\ 2 & 25 & 10.4 & 10.5 & 13.4\end{array}$


MOREE NOR DISAGRTE AOREE

STROHOLY AGREE

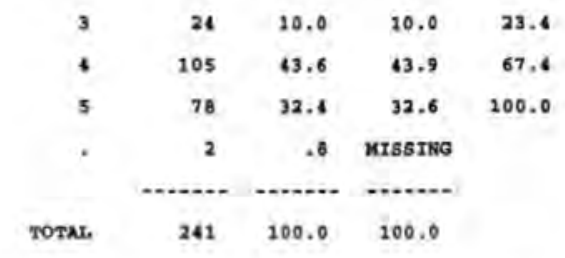

\begin{tabular}{|c|c|c|c|c|c|}
\hline Kean & 3.929 & std $\mathrm{krz}$ & .068 & Medien & 4.000 \\
\hline Mose & 6.000 & sed Dev & 1.053 & Variance & 1.108 \\
\hline Kurconia & .405 & s E Kurt & .314 & Skewnens & -1.012 \\
\hline$g$ \& skaw & .157 & Range & 4.000 & Minimus & 1.000 \\
\hline Maxisum & 5.000 & sum & 939.000 & & \\
\hline
\end{tabular}

valla cases 239 Mineing casen 2

QBD ENV IMPh - MENUKRT PRESSTRE

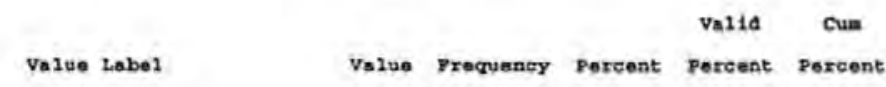

DTsAGRze

AGRER MOR DISAGRER

AGREE

STRONOLY AGRER

\begin{tabular}{|c|c|c|c|c|c|}
\hline Mean & 4.122 & sta $\mathbf{E r z}$ & .052 & Median & 4.000 \\
\hline Mode & 4.000 & sta Dev & .796 & Variance & .633 \\
\hline Xurtosil & -.092 & $g$ \& Rurt & .315 & Skewness & -.630 \\
\hline$s$ s skev & .150 & Range & 3.000 & Miniaum & 2.000 \\
\hline Mnselmun & 5.000 & Suim & 977.000 & & \\
\hline
\end{tabular}

Valla caser 237 Misking Canes it

Q8E EEV IMPR - OTHER

va2ue Label

STAONOLY DTEAGRE

Drsugreg

MOREE WOR DTEMGREE

MAREE

BTRONOLY MOREE

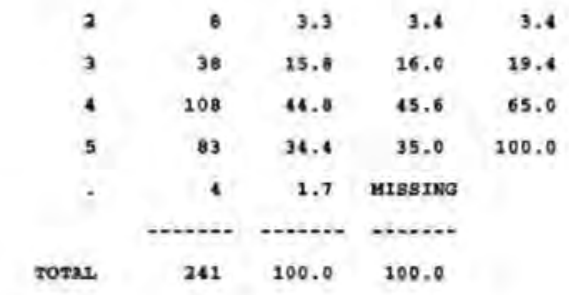




$\begin{array}{lrlrlr}\text { kurtosis } & .779 & \text { S z kurt } & .509 & \text { Skewnens } & .616 \\ \text { g E skew } & .257 & \text { Range } & 6.000 & \text { Minimum } & 1.000 \\ \text { Moximus } & 5,000 & \text { sum } & 291.000 & & \end{array}$

valid cases as Miseing cases 153

Q9A C/PRACTICE - RECYCLIMG

valid Cun

Value Label Valus rrequency Foresnt Percent Vercest

\begin{tabular}{|c|c|c|c|c|c|c|}
\hline \multicolumn{2}{|c|}{ TRRELEVAKT } & 1 & 36 & 15.8 & 15.9 & 15.9 \\
\hline \multicolumn{2}{|c|}{ NOT CONSTDERED } & 2 & 44 & 18.3 & 18,4 & 34,3 \\
\hline \multicolumn{2}{|c|}{ COns rDened } & 3 & 57 & 23.7 & 23.8 & 58.2 \\
\hline \multirow{4}{*}{\multicolumn{2}{|c|}{ THPLEMESTED }} & 4 & 100 & 41.5 & 41.8 & 100.0 \\
\hline & & , & 2 & .6 & urssing & \\
\hline & & & .......... & n....... & n........ & \\
\hline & & Total & 242 & 100.0 & 100.0 & \\
\hline Yesn & 2.916 & std $\mathrm{rrz}$ & .072 & \multicolumn{2}{|c|}{ nodion } & 3.000 \\
\hline Mode & 4.000 & Sta Dev & 1.112 & \multicolumn{2}{|c|}{ Variance } & 1.237 \\
\hline Kurtosis & $-2,118$ & s E Kurt & .324 & \multicolumn{2}{|c|}{ Bkownes: } & -.536 \\
\hline $8 \mathrm{z}$ skew & -157 & Range & 3.000 & \multicolumn{2}{|c|}{ Minimum } & 2.000 \\
\hline Maximue & 4.000 & sum & 697.000 & & & \\
\hline
\end{tabular}

valid Casen $239 \quad$ Kiseing Cases 2

Q9B C/PRACTICE - ENEAGY EFP PROQ

Value Label value prequency percent percent percent

\begin{tabular}{|c|c|c|c|c|c|c|}
\hline \multicolumn{2}{|c|}{ IRUELEvaure } & 1 & 36 & 26.1 & 14.2 & 14.3 \\
\hline \multicolumn{2}{|c|}{ Hor congropued } & 2 & 56 & 23.2 & 23.5 & 37.8 \\
\hline \multicolumn{2}{|c|}{ CONS IDERED } & 3 & 69 & 36.9 & 37.4 & 75.2 \\
\hline \multirow{4}{*}{\multicolumn{2}{|c|}{ TMPLEMENTED }} & 4 & 59 & 24.5 & 24.8 & 100,0 \\
\hline & & - & 3 & 3.2 & Mrssmo & \\
\hline & & & netrer & ment & n....... & \\
\hline & & sosal. & 241 & 100.0 & 100.0 & \\
\hline Mosn & 2.727 & Std Err & .064 & \multicolumn{2}{|c|}{ Medien } & 3.000 \\
\hline Modo & 3.000 & sta Dev & .992 & \multicolumn{2}{|c|}{ variance } & .984 \\
\hline Kurtonia & -.923 & S \& kurt & .314 & \multicolumn{2}{|c|}{ Skewnes: } & -.318 \\
\hline a \& akew & .158 & Range & 3.000 & \multicolumn{2}{|c|}{ Minimum } & 1.000 \\
\hline Maxinum & 4.000 & Bum & 649.000 & & & \\
\hline
\end{tabular}

Valla cases 238 Hianing Cases 3

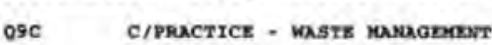


Value label

IRRELEVXYI

NOT CONSIDZRED

CONSTDEakd

MPLECERED

\begin{tabular}{|c|c|c|c|c|c|}
\hline Mean & 2.475 & std $\mathbf{~ z r z}$ & .074 & Median & 2.000 \\
\hline Mode & 1.000 & std Dev & 1.135 & Varlance & 1.289 \\
\hline Kurtosis & -1.397 & $S$ \& Kurt &, 316 & Sxownese & .028 \\
\hline S I skev & .158 & Range & 3.000 & Minimum & 1,000 \\
\hline Maximum & 4.000 & Sum & 584.000 & & \\
\hline
\end{tabular}

volid Cases 236 Mianing Cases 5

Q9D C/PRACZICR - SUPPLIRRS POLICY

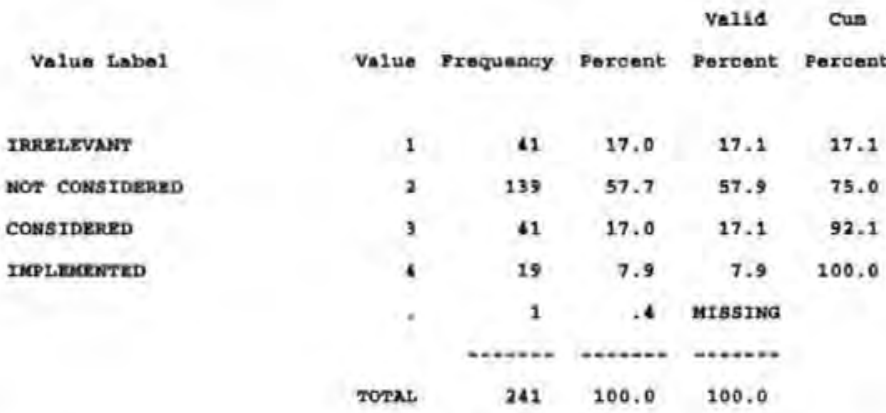

\begin{tabular}{|c|c|c|c|c|c|}
\hline Mosn & 2.156 & std Rrx & .051 & Median & 2.000 \\
\hline node & 2.000 & sta Dev & .797 & variance & .636 \\
\hline surtosie & .283 & S E Rurt & .313 & Skewnese & .656 \\
\hline$s=5 x e v$ & .157 & Rangs & 3.000 & Mini=u= & 1.000 \\
\hline Maximui & 4.000 & sum & $\$ 18.000$ & & \\
\hline
\end{tabular}

Valid cuas: 240 Missing casea i

Q98 C/PRaCtICE - PACKagING

Value Label

IRKELEVAYY

nor Constoerez

constoenzo

TRPLEREATRD valida cum

\begin{tabular}{|c|c|c|c|c|}
\hline Vslue & Frequeney & Porcent & Porcent & Percent \\
\hline 5 & 79 & 32.8 & 32.9 & 32.9 \\
\hline 2 & 59 & 24.5 & 24.6 & 57.5 \\
\hline $\mathbf{3}$ & 69 & 28.6 & 28.8 & 96.3 \\
\hline 4 & 33 & 23.7 & 13.8 & 100,0 \\
\hline . & 1 & -4 & Mrssrao & \\
\hline TOTAL & 241 & 100.0 & 100.0 & \\
\hline
\end{tabular}




\begin{tabular}{|c|c|c|c|c|c|}
\hline Mesn & 2.233 & std err & .068 & Median & 2.000 \\
\hline Modo & 1.000 & std Dav & 1.057 & Variance & 1.117 \\
\hline Kurtosia & -1.221 & s \& Kurt & .313 & skevmoan & .229 \\
\hline S I skew & .257 & renge & 3,000 & Minimus & 1.000 \\
\hline Maximum & c.000 & sue & 536.000 & & \\
\hline
\end{tabular}

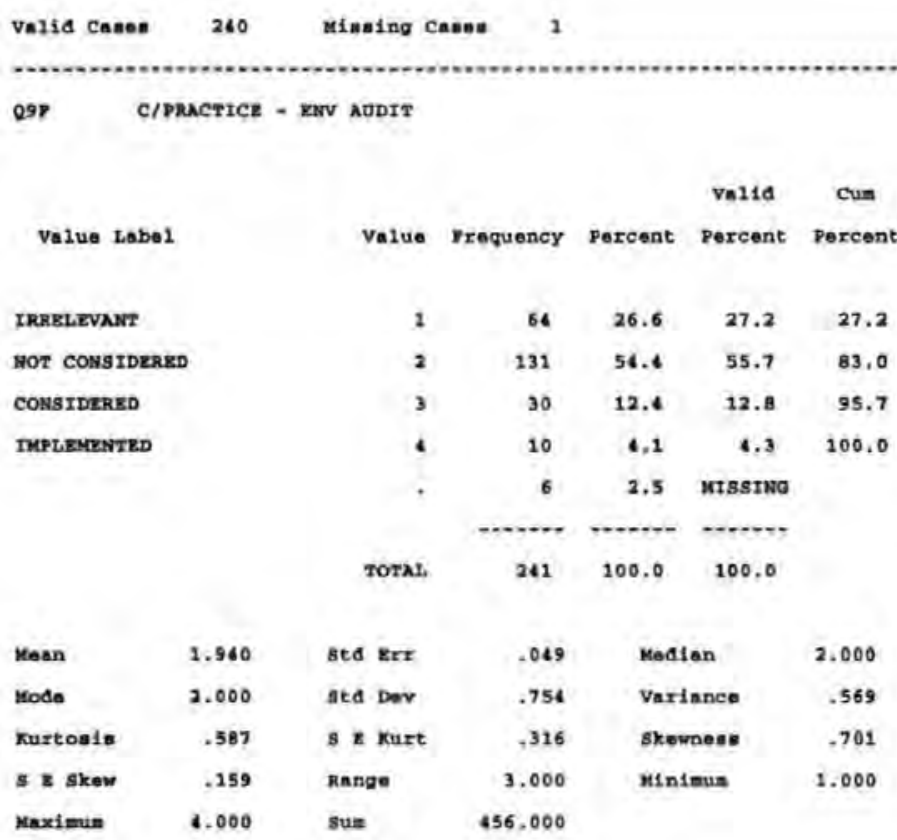

valid cases 235 Hialing caues 6

Q90 C/Practice - POLLUTIOA CONTROL POLICY

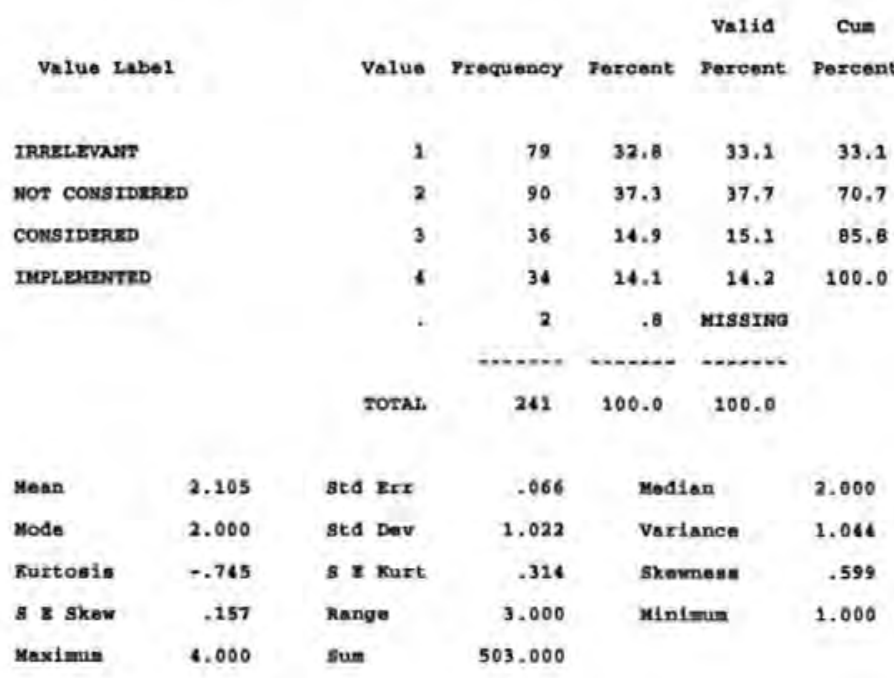

valid canos 239 Misoing canas 2 
Value Label

TRRELEVALT

NOT CONSIDERED

Constakazd

THPLEMENTED

valid cum

value grequency percent percent percent

\begin{tabular}{|c|c|c|c|c|}
\hline 1 & 67 & 27.8 & 28.0 & 28.0 \\
\hline 2 & 124 & 51.5 & 51.9 & 79.9 \\
\hline 3 & 37 & 15.4 & 15.5 & 95.4 \\
\hline 4 & 11 & 4.6 & 4,6 & 100.0 \\
\hline - & 2 & - 8 & Hisstwo & \\
\hline & ......... & ......... & -......... & \\
\hline & 261 & 100.0 & 100.0 & \\
\hline
\end{tabular}

$\begin{array}{lrlrlr}\text { Mean } & 1.967 & \text { ste Erz } & .051 & \text { Median } & 2.000 \\ \text { Hode } & 2.000 & \text { Std Dev } & .780 & \text { Variance } & .621 \\ \text { Kurtosin } & .191 & \text { s X Kurt } & .314 & \text { Skewness } & .631 \\ \text { S E Skew } & .157 & \text { Range } & 3.000 & \text { Minimum } & 1.000 \\ \text { Mnximum } & 4.000 & \text { Sum } & 470.000 & & \end{array}$

valid cases 239 Miseing cases 2

Q9I C/PMACYTCE - TANSPORT POLICY

Valid cien

Value thabel

Value Frequency porcent percent percent

IMRELEVART

NO' CONSIDRRED

CONSIDERED

MTPLERTER

\begin{tabular}{|c|c|c|c|c|}
\hline 1 & 63 & 26.1 & 26,6 & 26.6 \\
\hline 2 & 118 & 49.0 & 69. & 76.4 \\
\hline 3 & 37 & 15.4 & 15.6 & 92.0 \\
\hline 4 & 19 & 7,9 & 8,0 & 100.0 \\
\hline • & 4 & 1.7 & Mrssmo & \\
\hline & & (nensen & n......... & \\
\hline & 241 & 100.0 & 100.0 & \\
\hline
\end{tabular}

\begin{tabular}{|c|c|c|c|c|c|}
\hline Mesn & 2.051 & std Err & .056 & Median & 2.000 \\
\hline Mode & 2.000 & Std Denv & .862 & Vortance & .743 \\
\hline Kurtosia & -.039 & $s$ \& Kurt &, 315 & Skewneas & .663 \\
\hline$s=$ skew & .158 & Range & 3.000 & Minimin & 1.000 \\
\hline Mavimua & 4.000 & sum & 486.000 & & \\
\hline
\end{tabular}

valid conse 237 Misaing cases 4

Q9J C/PRACTICE - EMS

Valid cum

valus Label

velue rrequency percont percent percent

IRREL EVNAY

NOT CONSIDERED

CONSIDERED

IMPLEMEATED

$\begin{array}{rrrr}64 & 26.6 & 27.0 & 27.0 \\ 130 & 53.9 & 54.9 & 91.9 \\ 32 & 13.3 & 13.5 & 95.4 \\ 11 & 4.6 & 4.6 & 100.0 \\ 4 & 1.7 & \text { kTs8Ina } & \end{array}$


TozNe $261 \quad 100.0 \quad 100.0$

\begin{tabular}{|c|c|c|c|c|c|}
\hline nesn & 1.958 & std err & .050 & Medien & 2.000 \\
\hline Node & 2.000 & sta Dev & .769 & variance & .591 \\
\hline Kurtonis & .477 & 8 \& surt & .315 & Skoumesa & .692 \\
\hline S E skow & .158 & Range & 3.000 & Minimun & 1.000 \\
\hline Maxi mus & 4.000 & sue & 664.000 & & \\
\hline
\end{tabular}

valia cases 237 Mineing Cases 4

Q10 HAVE WRITIEN ENV POLICY STATEMERT

value Label

res

so

\begin{tabular}{|c|c|c|c|c|c|}
\hline Yean & 1.942 & sta $\mathrm{grr}$ & .015 & redian & 2.000 \\
\hline Hode & 2.000 & sta Dov & .235 & Variance & .055 \\
\hline Kurtosin & 22,488 & 8 \& kurt & .313 & skemes: & -3.793 \\
\hline S g skev & .157 & Rangs & 1.000 & Minimus & 1.000 \\
\hline Maximan & 2.000 & Bus & $\$ 66.000$ & & \\
\hline
\end{tabular}

Value Frequeney Pereent pereent percent

\begin{tabular}{|c|c|c|c|c|}
\hline 1 & 14 & 5.0 & 5.8 & 5.0 \\
\hline 2 & 226 & 93.8 & 94.2 & 100.0 \\
\hline • & 2 & .4 & orssino & \\
\hline & ......... & -..ent. & .......... & \\
\hline & 241 & 100.0 & 100.0 & \\
\hline
\end{tabular}

Valid chaes 240 Missing cases 1

Q11 TKPLDERTED POLICY

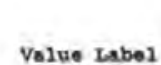

res

no

\begin{tabular}{|c|c|c|c|c|c|}
\hline Menn & 1.231 & std Err & .222 & Median & 1.000 \\
\hline Mode & 1.000 & sta Dev & .439 & Varinnee & .192 \\
\hline Rurtosis & .095 & S \& rurt & 2.191 & Skawnose & 1.451 \\
\hline s $\mathrm{E}$ skem & .616 & Tango & 2.000 & Minimun & 1.000 \\
\hline Maximus & 2.000 & sum & 16.000 & & \\
\hline
\end{tabular}

Volue Labe]

Volue Froguency percent percent percent

$\begin{array}{rrrrr}1 & 10 & 4.1 & 76.9 & 76.9 \\ 2 & 3 & 1.2 & 23.1 & 100.0 \\ . & 228 & 94.6 & \text { 4rssirsa } & \\ \text { rotas } & 261 & 100.0 & 100.0 & \end{array}$

Valia cura

valid casaa 13 Mimaing Casea 228

Q12ג wo Fot - NoT cost errectrve 
Value label

\begin{tabular}{|c|c|c|c|c|c|c|}
\hline STRONGLY D & GARE & 1 & 4 & 1.7 & 2.3 & 2.3 \\
\hline Drsxareg & & 2 & 15 & 6.2 & 0.0 & 11.1 \\
\hline AGREE SOR & AGRER & 3 & 104 & 13.2 & 60. & 71.9 \\
\hline MGREE & & 4 & 40 & 16.6 & 23.4 & 95.3 \\
\hline \multirow[t]{4}{*}{ STRONGLY } & & 5 & n & 3,3 & 4.7 & 100.0 \\
\hline & & . & 70 & 29.0 & Mussing & \\
\hline & & & nen..... & n.t.n. & ........... & \\
\hline & & ToraL & 261 & 100.0 & 100.0 & \\
\hline Mean & 3,193 & std err & $.05 a$ & \multicolumn{2}{|c|}{ Median } & 3.000 \\
\hline Mode & 3.000 & sta Der & .754 & \multicolumn{2}{|c|}{ variance } & .568 \\
\hline Kurtos 1a & 1.196 & g E Rurt & .369 & \multicolumn{2}{|c|}{ Skevmeas } & -.002 \\
\hline s E skew & .186 & Range & 4.000 & \multicolumn{2}{|c|}{ ainimus } & 1.000 \\
\hline Kaximus & 5.000 & sue & 546.000 & & & \\
\hline
\end{tabular}

valid canall 171 Miszing canea 70

Q128 No POL - LACK EXтRRULL PRESSURE

vaisa cus

Va1ue Labes

Yalue Frequency percent percent percent

STRONGLX DISAGRES

DISAGREz

AGRER WOR DISMGERE

AGRzE

STRONGLY MGRER

\begin{tabular}{|c|c|c|c|c|}
\hline 1 & 8 & 3.3 & 4.8 & 4.8 \\
\hline 2 & 17 & 7.1 & 20.2 & 14.9 \\
\hline 3 & 69 & 28.6 & 41.2 & 56.0 \\
\hline 4 & 62 & 25.7 & 36.9 & 92.9 \\
\hline 5 & 22 & 5.0 & 7.1 & 100.0 \\
\hline . & 73 & 30.3 & Mrssram & \\
\hline & -......... & ......... & n....... & \\
\hline rotal. & 241 & 100.0 & 100.0 & \\
\hline
\end{tabular}

\begin{tabular}{|c|c|c|c|c|c|}
\hline Hoan & 3.315 & std Brr & .071 & Medion & 3.000 \\
\hline Mode & 3.000 & sta Dev & .923 & Verience & .952 \\
\hline kurtosis & .296 & s E xurt &, 373 & akewnese & -.485 \\
\hline S \& Skaw & .107 & range & 4.000 & Minimue & 1.000 \\
\hline Maximun & 5.000 & sua & 557.000 & & \\
\hline
\end{tabular}

valid cases 168 Kineing casea 73

$012 \mathrm{C}$

MO POL - LACK OV TIME

Volue Label Value Frequency Parcent percent percent

\begin{tabular}{|c|c|c|c|c|c|}
\hline STRONGLY DISAGRER & 1 & 9 & 3.7 & 5,1 & 5.1 \\
\hline Dtsagrze & 3 & 20 & 8.3 & 11.4 & 15.6 \\
\hline Aaras WON DraAGRE & 3 & 63 & 26.1 & 36.0 & 52.6 \\
\hline Aarzz & 4 & 49 & 20.3 & 28.0 & 80.6 \\
\hline \multirow[t]{2}{*}{ STROUGLY MGREE } & 5 & 34 & 14.1 & 19.6 & 100.0 \\
\hline & - & 66 & 27,4 & MIssING & \\
\hline
\end{tabular}




\begin{tabular}{|c|c|c|c|c|c|}
\hline & & rotat. & 241 & 200.0 & \\
\hline Mean & 3.451 & sta ert & .082 & Modian & 3.000 \\
\hline Hode & 3.000 & sta Der & 1.086 & Variance & 1.180 \\
\hline Kurtonis &,- 420 & S E Kurt & 365 & Skewnea a & -.296 \\
\hline S \& skow & .104 & Bange & 4.000 & Minimum & 1.000 \\
\hline Maximus & 5.000 & Sum & 604.000 & & \\
\hline
\end{tabular}

valia casea 175 Missing Cases 66

Q12D NO POL - INERTIA OP COMFNAY

valid cue

volue Label

Value Frequency percent porcent percent

\begin{tabular}{|c|c|c|c|c|c|c|}
\hline \multicolumn{2}{|c|}{ STRONGLY DISAGREE } & 1 & 15 & 6.2 & 9.2 & 9.2 \\
\hline \multicolumn{2}{|l|}{ DIsAgare } & 2 & 27 & 11.2 & 26.6 & 25.8 \\
\hline \multicolumn{2}{|c|}{ AGREE WOH DTBAGREE } & 3 & 90 & 37.3 & 55.2 & E1.0 \\
\hline \multicolumn{2}{|l|}{ AGRE: } & 4 & 26 & 10.8 & 16.0 & 96.9 \\
\hline \multirow{3}{*}{\multicolumn{2}{|c|}{ STAONGLY AGREE }} & 5 & $s$ & 2.1 & $3 \cdot 1$ & 100.0 \\
\hline & & . & 78 & 32.4 & MISSING & \\
\hline & & Total & 243 & 200.0 & 100.0 & \\
\hline mein & 2.871 & std err & .070 & \multicolumn{2}{|c|}{ Median } & 3.000 \\
\hline node & 3.000 & Std Dev & .097 & \multicolumn{2}{|c|}{ Varlance } & .604 \\
\hline Kurtosia & .354 & $S$ E xurt & .378 & \multicolumn{2}{|c|}{ skewness } & -.262 \\
\hline g E skent & .190 & Range & 4.000 & \multicolumn{2}{|c|}{ Minimua } & 1.000 \\
\hline Mnximun & 5.000 & sum & 468.000 & & & \\
\hline
\end{tabular}

volid cases 263 Miseing cases 78

Q128 WO POL - NOT RELEVNAT TO COLPNHY

valsd cum
value label value Frequency Percent pareent percent

\section{STRONGLY DTSAGRER}

Disiguize

MGRER MOR DISAGRER

AGres

SसRONGLY AGREK value Frequency percent pereent percent

$\begin{array}{rrrrr}1 & 5 & 2.1 & 2.6 & 2.6 \\ 2 & 23 & 9.5 & 12.1 & 14.7 \\ 3 & 58 & 24.2 & 30.5 & 45.3 \\ 4 & 62 & 25.7 & 32.6 & 77.9 \\ 5 & 42 & 17.4 & 22.1 & 100.0 \\ . & 51 & 21.2 & \text { urssing } & \\ & \ldots \ldots & \ldots . . . . & \ldots \ldots .7 & \end{array}$

\begin{tabular}{|c|c|c|c|c|c|}
\hline Mean & 3.595 & Sta erz & .076 & Median & 1. 000 \\
\hline Moda & 4.000 & Sta Dev & 1.043 & Varionce & 1.089 \\
\hline Kurtosis & -.523 & S \& Kurt & .351 & gkeimeas & -.340 \\
\hline s a skev & .176 & Range & 4.000 & Minieua & 1.000 \\
\hline Maxilaus & 5.000 & sum & 683.000 & & \\
\hline
\end{tabular}




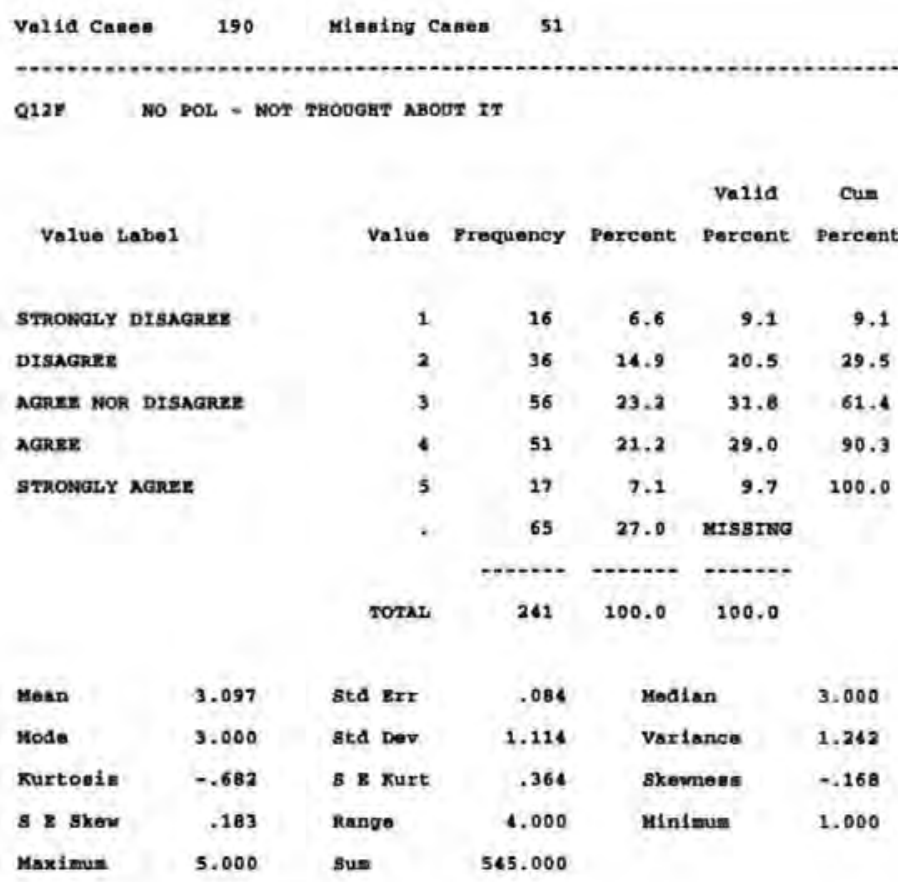

Valid cases 176 Misaing Cased 65

Q126 NO FOL - NLREADY PART OF STRATEGY

value Label

BTHOHGLY DISAGRER

DIAAGREE

AGNXE MOR DIBMGNuE

AGRER

STRONOLY NOREE valid Cun

Value Fraguency Porcent Percent Parcent

Moan

2.857

2.857

atd $\mathrm{zrs}$

sta Dev

1

11

$\begin{array}{lll}4.6 & 6.8 & 6.8\end{array}$

$\begin{array}{lllll}2 & 4 & 17.0 & 25.5 & 32.3\end{array}$

379

$32.8 \quad 69.1 \quad 01.4$

420

$$
\text { 8.3 } 12.4 \quad 93.0
$$

510

$\begin{array}{lll}4.1 & 6.2 \quad 100.0\end{array}$

. $80 \quad 33.2$ urssino

TOTAL. $241 \quad 100.0 \quad 100.0$

Kurtoaia $\quad .235$

3 E skew $\quad .191$

\section{Median}

Varlance

Maximum

5.000

s E kire

.380

skowneus

.886

Bum

6.000

Minimum

$-245$

460.000

valid casea 161 Miasing Cases 80

Q128

so POL - OTHER

Valid Cus

Value Labe1

value proguency percent percent percent 


\begin{tabular}{|c|c|c|c|c|c|c|}
\hline STRONGLY D & Gaxn & 1 & 2 & .6 & 2.9 & 2.9 \\
\hline DISAGRER & & 2 & 2 & .0 & 5.9 & 0.0 \\
\hline Manke nor & AGREE & 3 & 19 & 7.9 & 55.9 & 64.7 \\
\hline verus & & 4 & 2 & .0 & 5.9 & 70. \\
\hline \multirow[t]{4}{*}{ STRONaLX } & & 5 & 10 & 1.1 & 29.4 & 100. \\
\hline & & - & 207 & 85.9 & Mrssing & \\
\hline & & & nt.en & n........ & ......... & \\
\hline & & rotat. & 261 & 100.0 & 100.0 & \\
\hline Mesen & 3.529 & std err & .185 & \multicolumn{2}{|c|}{ Median } & 3.000 \\
\hline Kose & 3.000 & std Dev & 1.000 & \multicolumn{2}{|c|}{ Variance } & 1.166 \\
\hline Kurtosia & -.612 & s a Kurt & .788 & \multicolumn{2}{|c|}{ Skawneas: } & -150 \\
\hline$s=$ skow & .403 & Range & 6.000 & & 1.000 \\
\hline Maximun & 5.000 & sun & 120.000 & & & \\
\hline
\end{tabular}

valid cases 34 Misuing Canas 207

Q13X CATS - LEGISLATION

valia cun

Value Label

Value grequency percent percent percent

Nor at ats moporass

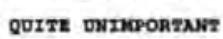
MET wakn UNTMPOATMAT QUTTE IRTORTNR EXThEIELY IRFORTANT

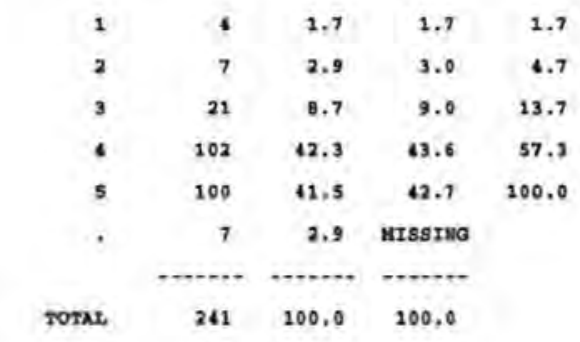

\begin{tabular}{|c|c|c|c|c|c|}
\hline Moen & 4.226 & std $\mathrm{err}$ & .056 & Medion & 4.000 \\
\hline Mode & 4.000 & sta Der & .862 & Veriance & .742 \\
\hline Kurtosin & 2.466 & s 2 Nurt & .317 & skowness & -1.389 \\
\hline$s$ I skev & .159 & renge & 4.000 & Minimim & 1.000 \\
\hline Mnximun & 5.000 & Sun & 989.000 & & \\
\hline
\end{tabular}

Valid Canos 234 Misaing casen 7

Q13B CATS - COSTOMER DRESSURE

valid cun

value Labe1

value Vrequency percent percent percent

NO2 AT ALL TRPORTAM gUITE UAIMPORTNAT NEITEER UATMPORTANT Quits meontart EXTRERELY TMPORTANT

$\begin{array}{rrrrr}1 & 2 & .8 & .9 & .9 \\ 2 & 3 & 1.2 & 1.3 & 2.1 \\ 3 & 20 & 8.3 & 8.5 & 10.7 \\ 4 & 105 & 43.6 & 44.9 & 55.6 \\ 5 & 104 & 43.2 & 14.4 & 100.0 \\ . & 7 & 2.9 & \text { krssina } & \end{array}$




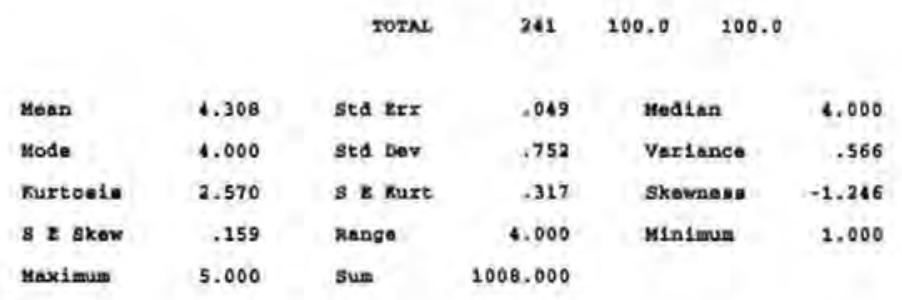

Val1a casea 234 kiasing caves 7

Q13C CATS - MNRKETING IMAGE

Valid Cum
Value Label Value requency percent Porcont Percent

\begin{tabular}{|c|c|c|c|c|c|c|}
\hline \multicolumn{2}{|c|}{ QUTTE ONIMPORTMNT } & 2 & 5 & 2.1 & 2.2 & 2.2 \\
\hline \multicolumn{2}{|c|}{ WETTEER UNINPORTNNT } & 3 & 30 & 12.4 & 12.9 & 15.1 \\
\hline \multicolumn{2}{|c|}{ QUTะE IMPORTANI } & 4 & 128 & 53.1 & 55.2 & 70.3 \\
\hline \multicolumn{2}{|c|}{ EXTRENELY Y IMPORTANT } & 5 & 69 & 28.6 & 29.7 & 100.0 \\
\hline & & - & 9 & 3.7 & Mrssing & \\
\hline & & TOTAL & 241 & 100.0 & 100.0 & \\
\hline Kosn & 4.125 & sed Err & .046 & \multicolumn{2}{|c|}{ Median } & 4.000 \\
\hline Mode & 4.000 & std Der & .707 & \multicolumn{2}{|c|}{ Variance } & -499 \\
\hline Kurtonia & .353 & S I Kurt & .318 & \multicolumn{2}{|c|}{ skewnena } & -.553 \\
\hline S I skew & .160 & Range & 3.000 & \multicolumn{2}{|c|}{ Minimua } & 2.000 \\
\hline Maximua & 5.000 & sum & 957.000 & & & \\
\hline
\end{tabular}

Valid caser 232 Missing Cases 9

Q13D CATS - INVESTOR PRESSURE

value Label

not AT NLL IMPORTANT QUITE UNIMPORTANT NEITHER INIMPORTANT OUITE IMPORTANT EXTRERELY IMPORTANT

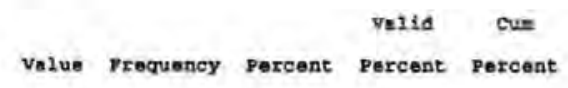

$\begin{array}{rrrrr}1 & 20 & 11.6 & 12.3 & 12.3 \\ 2 & 20 & 8.3 & 8.8 & 21.1 \\ 3 & 70 & 29.0 & 30.7 & 51.8 \\ 4 & 81 & 33.6 & 35.5 & 87.3 \\ 5 & 29 & 12.0 & 12.7 & 100.0 \\ . & 13 & 5.6 & \text { HISSING } & \\ & \ldots \ldots & \ldots \ldots .7 & \ldots \ldots . . . & \end{array}$

\begin{tabular}{|c|c|c|c|c|c|}
\hline Man & 3.276 & std Brx & .078 & Median & 3.000 \\
\hline Hode & 4.000 & std Dov & 1.272 & variance & 1.373 \\
\hline Kurtonis & -.439 & $s$ I Kurt & .321 & Skeimans & -.536 \\
\hline s a skeve & .162 & Range & 4.000 & Minimua & 1.000 \\
\hline ksximun & 5.000 & sua & 747.000 & & \\
\hline
\end{tabular}




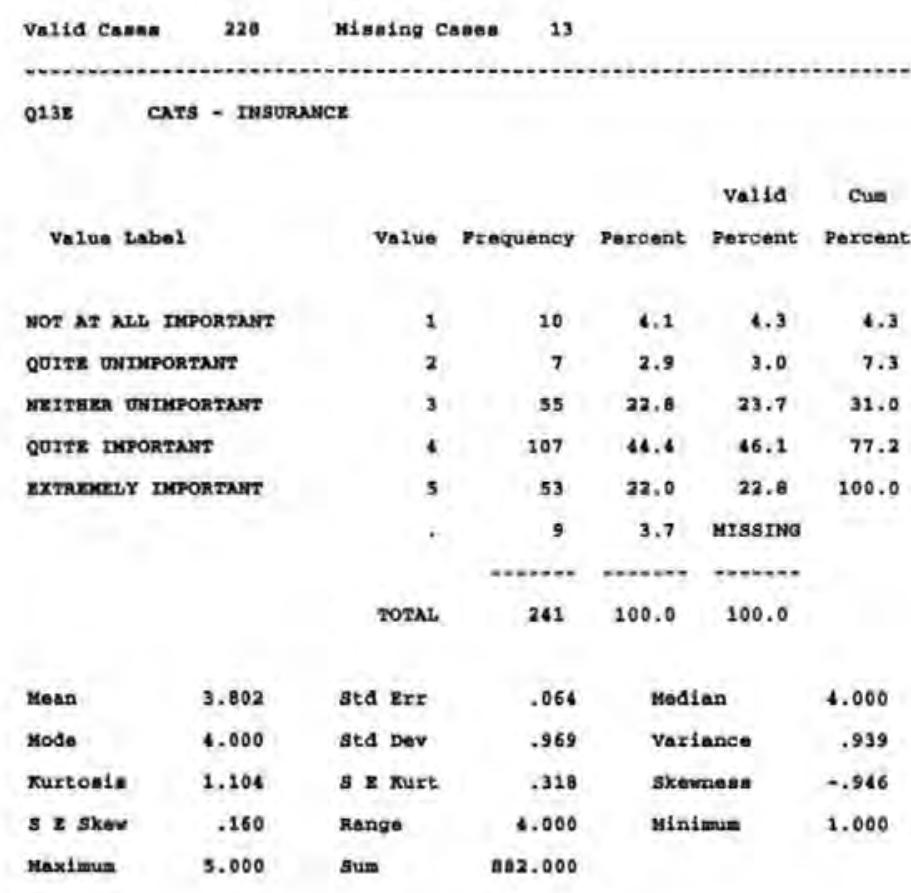

valid cases 232 Miasing cases

Q13P CATS - COMPANY POLICY

\section{Volue Labol}

NOT AT ath rmpontant gOTTE INIMPORTANT NEITHER ORIMPORTNIT QUITE IMPORTANT EXTREReLY IMTORTNI

$\begin{array}{lrlrlr}\text { Mesh } & 3.826 & \text { sta Exr } & .053 & \text { Madina } & 4.000 \\ \text { Mode } & 4.000 & \text { sta Dev } & .807 & \text { Variance } & .651 \\ \text { Kurtonin } & 1.365 & \text { s z Kuxt } & .320 & \text { Skewness } & -.730 \\ \text { S z skev } & .160 & \text { Range } & 4.000 & \text { Minimum } & 1.000 \\ \text { Mnsimus } & 5.000 & \text { sum } & 880.000 & & \end{array}$

$\begin{array}{lllll}1 & 4 & 1.7 & 1.7 & 1.7\end{array}$

$\begin{array}{llllll}2 & 5 & 2.1 & 2.2 & 3.9\end{array}$

$\begin{array}{lllll}3 & 59 & 24.5 & 25.7 & 29.6\end{array}$

$\begin{array}{lllll}4 & 121 \quad 50.2 \quad 52.6 \quad 82.2\end{array}$

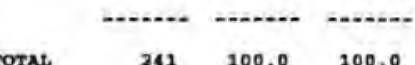

$$
\text { Torat } 241 \quad 100.0 \quad 100.0
$$

Varla cases 230 Milusing casea 11

valid cue

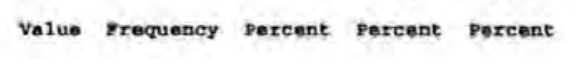

$\begin{array}{lllll}5 & 41 & 11.0 & 17.8 & 100,0\end{array}$

Q130 CATS - RMPLOYRES CONCRRB

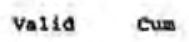

Value Labe1

$$
\text { Value prequency percent parcent percent }
$$

OUTTB ONTMPORTAN

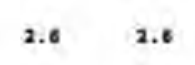




\begin{tabular}{|c|c|c|c|c|c|c|}
\hline \multicolumn{2}{|c|}{ 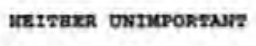 } & 3 & 45 & 18.7 & 19.3 & 21.8 \\
\hline \multicolumn{2}{|c|}{ QUTTE IMPORTAVT } & 4 & 132 & 54.8 & 36.7 & $28: 5$ \\
\hline \multirow{3}{*}{\multicolumn{2}{|c|}{ IXFRERLYX IMPORYANT }} & 5 & 50 & 20.7 & 21.5 & 100.0 \\
\hline & & * & $B$ & 3.3 & MIssino & \\
\hline & & TOTAL & 241 & 100.0 & 100.0 & \\
\hline Mean & 3.970 & std $\mathbf{g r r}$ & .047 & \multicolumn{2}{|c|}{ Median } & 4.000 \\
\hline Hose & 4.000 & sed Dev & .716 & \multicolumn{2}{|c|}{ variance } & .522 \\
\hline Kurtoels & .107 & s E Kurt & .310 & \multicolumn{2}{|c|}{ skewneas } & -.383 \\
\hline s $z$ skew & .259 & Range & 3.000 & \multicolumn{2}{|c|}{ Minlmus } & 2.000 \\
\hline Maximum & 5,000 & sus & 925.000 & & & \\
\hline
\end{tabular}

\section{valid cases 233 Misaing Casea a}

Q138 CATs - presonal conviction

Volue tabel value frequency percent porcent percent

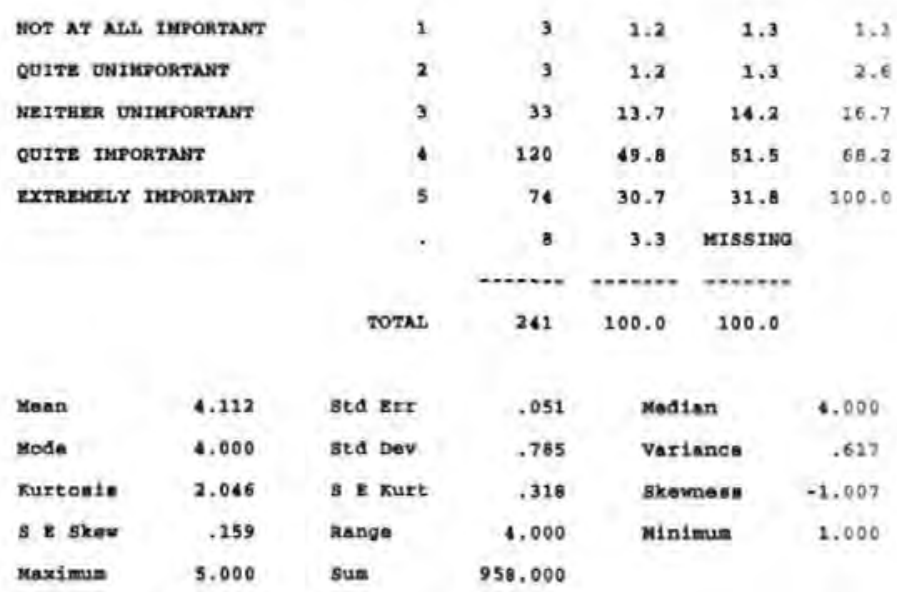

Valid Casas 233 Mianing cones B

Q231 CATs - rC ECO-LANEILInG

value tabe?

NOF AT ALL TMPORTAHT QUTTE ONIMPORTNNT NRTTERR UNIMPORTANT QUITR IMPORTAN EXTRERELY IMPORTANT

Mean

sed $\operatorname{kxx}^{2}$

.067

3.000 


\begin{tabular}{|c|c|c|c|c|c|}
\hline Mode & 3.000 & std Dev & 1.001 & varlance & 2,003 \\
\hline Furtosia & .281 & $s=$ Kurt & .326 & Skewnona & -.466 \\
\hline s I skew & .164 & Range & 4.000 & Minimun & 2.000 \\
\hline Maxitmur & 5.000 & sum & 672.000 & & \\
\hline
\end{tabular}

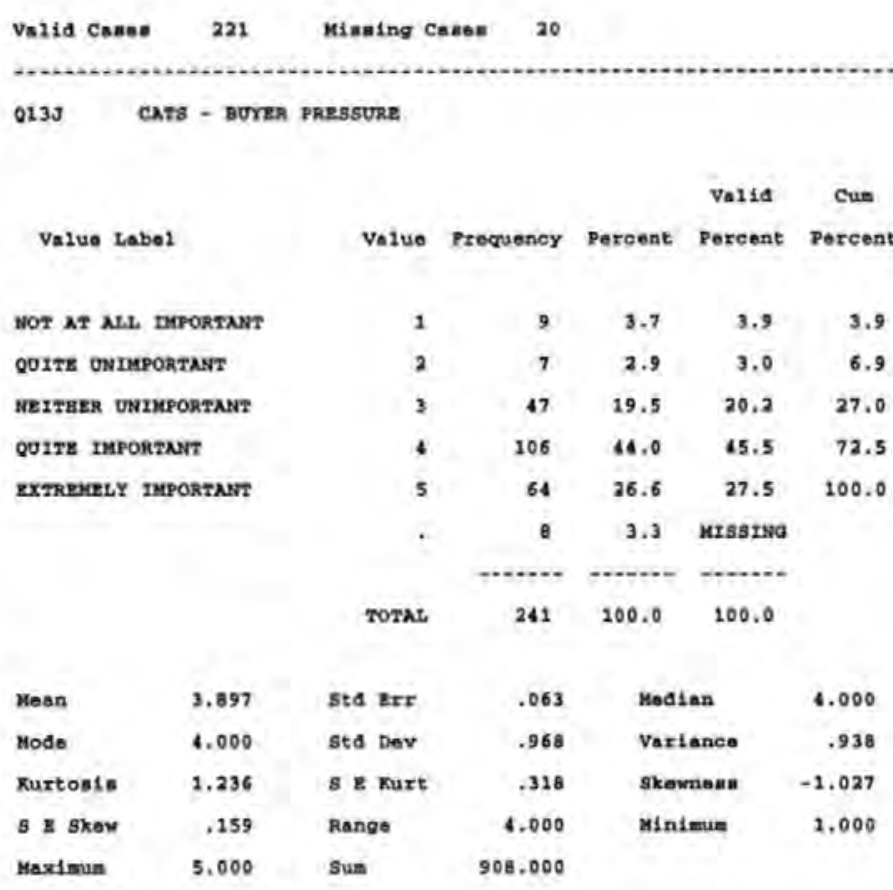

valid cabes 233 Minaing Casen of

$013 \pi$

CATS - SUPPLIERS PRESSURE

value labe 1

NOT AT ALL TMPORTANT QOITE ONTHPORTANT NETTakn ENTOCOATANT QUITE mosetaw? exrnencty montwar

\begin{tabular}{|c|c|c|c|c|c|}
\hline Mean & 3.238 & std $\mathbf{E r r}$ & .073 & Modian & 3.000 \\
\hline Mode & 4.000 & Std Dev & 1.111 & Variance & 1.234 \\
\hline Rurt os in & -.313 & $s$ \& Kurt & .319 & Skeomean & -.521 \\
\hline S I skew & -160 & Hange & 4.000 & Minimun & 1.000 \\
\hline Maximum & 5.000 & sum & 768.000 & & \\
\hline
\end{tabular}




\section{Vazue Label}

NOT AT ALL TMPORTART gOTIE ONIMPOREANT REITEER UNTMPORTNNT ETTREREY TMPORTNVI outre ImPontart

Vnifid cus

Volue prequency percent percent. percent

\begin{tabular}{|c|c|c|c|c|}
\hline 1 & 10 & 4.2 & 6.3 & 4.3 \\
\hline 2 & 7 & 2.9 & 3.0 & 7.3 \\
\hline 3 & 46 & 19,1 & 19.7 & 27.0 \\
\hline 4 & 113 & 46.9 & 48.5 & 75.5 \\
\hline 5 & 57 & 23.7 & 24.5 & 200.0 \\
\hline , & B & 3.3 & Mrssing & \\
\hline & n.t. & -...... & -........ & \\
\hline & 241 & 100,0 & 100.0 & \\
\hline
\end{tabular}

\begin{tabular}{|c|c|c|c|c|c|}
\hline Mean & 3.858 & sta err & .063 & Median & 4.000 \\
\hline node & 4.000 & Std Dev & .966 & Variance & .932 \\
\hline Kurtosis & 1.401 & $s$ \& Kurt & .318 & Skeurness & -1.074 \\
\hline s \& sker & .259 & Pangs & 4.000 & Minimis & 1.000 \\
\hline Maximus & 5.000 & sum & 899.000 & & \\
\hline
\end{tabular}

Q13M CATS - MEDIA VIENS

valia cun

Yalue Label

NOT AT ALL TKPORTAMT QUITE DNIMPORTNWT KETTERR UNTUPOHTANT OUIรE TMPORTANT EXTRERELY TMPORENAT

\section{value proquency percent percent porcent}

\begin{tabular}{|c|c|c|c|c|}
\hline 1 & 14 & $5, \theta$ & 6.0 & 6.0 \\
\hline 2 & 15 & 6.2 & 6.4 & 12.4 \\
\hline 3 & 89 & 36.9 & 38.0 & 50.4 \\
\hline 4 & 89 & 36.9 & 38.0 & 88. 5 \\
\hline 5 & 27 & 12.2 & 11.5 & 100.0 \\
\hline - & 7 & 2.9 & Mtsstuo & \\
\hline & n........ & ...ent. & n....... & \\
\hline & 241 & 200.0 & 200,0 & \\
\hline
\end{tabular}

\begin{tabular}{|c|c|c|c|c|c|}
\hline Moen & 3.427 & std Err & .064 & Madiag & 3.000 \\
\hline Node & 3,000 & std bev & .983 & variance & .967 \\
\hline Kurtonde & .381 & s $\geq$ xurt & .317 & skempen & $-.56 \mathrm{at}$ \\
\hline B z Bkaw & .159 & Range & 4.000 & Kini mux & 1.000 \\
\hline Maxilmum & 5.000 & Sua & D02.000 & & \\
\hline
\end{tabular}

Valia Cases 234 Minsing Cason 7
CATS - gOVERWREN GRANTS

value Label

MOT A? ALL, IMPORTAY QUTRE UNIMPORZNAr

KETTHER UNTMPORTART

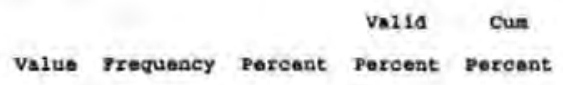

$\begin{array}{lllll}1 & 9 & 3.3 & 3.9 & 3.9\end{array}$

$\begin{array}{lllll}2 & 9 & 3.7 & 3.9 & 7.7\end{array}$

$\begin{array}{lllll}3 & 43 & 17.6 & 18.5 & 26.2\end{array}$




\begin{tabular}{|c|c|c|c|c|c|c|}
\hline \multicolumn{2}{|c|}{ QOTXE IMPORTANT } & 4 & 95. & 39.4 & 80.8 & 67.0 \\
\hline \multirow{4}{*}{\multicolumn{2}{|c|}{ EXTREMRLY THPORTANT }} & 5 & 77 & 32.0 & 33.0 & 100.0 \\
\hline & & $\cdot$ & 8 & 3.3 & MIsstNG & \\
\hline & & & .......... & $\ldots+.$. & n...... & \\
\hline & & rotra & 342 & 100.0 & 100.0 & \\
\hline Maan & 3.953 & std Err & .066 & \multicolumn{2}{|c|}{ Modian } & 6.000 \\
\hline Mode & 1.000 & std Dev & 2.010 & \multicolumn{2}{|c|}{ Variance } & 1.019 \\
\hline Kurtosin & .976 & $s$ E Kurt & .318 & \multicolumn{2}{|c|}{ axemess } & -1.046 \\
\hline s E Skew & .159 & Range & 4,000 & \multicolumn{2}{|c|}{ Hinimum } & 1.000 \\
\hline Maximum & 5.000 & Sum & 921.000 & & & \\
\hline
\end{tabular}

Valid cases 233 Miseing cases 8

Q130 CATS - IEW MARKET OPPORTURITTES

valid Cum

value Label

Value rrequency percent percont percent

Not AT ALL TMPOATNAT QUTTE UNTaPORTANT जETTaER ORTMPORTANY QUTTZ IMPORTANT EXTRERELY TMPORTNAT

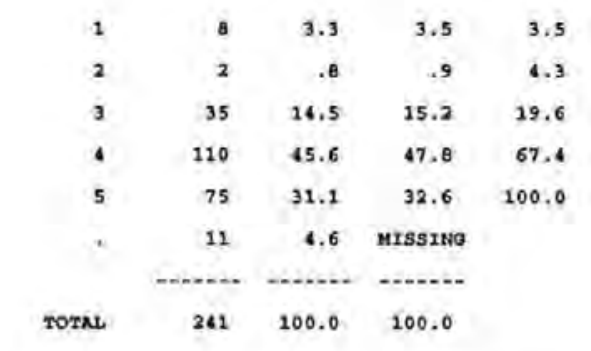

$\begin{array}{lrlrlr}\text { Mean } & 4.052 & \text { std err } & .050 & \text { Median } & 4.000 \\ \text { Mode } & 4.000 & \text { std Dev } & .909 & \text { Variance } & .827 \\ \text { Kurtosis } & 2.422 & \text { s E Kurt } & .320 & \text { skewness } & -1.299 \\ \text { S E skew } & .160 & \text { gange } & 4.000 & \text { Minimum } & 1.000 \\ \text { Maximus } & 5.000 & \text { sum } & 932.000 & & \end{array}$

valia casen 230 Mishing cases 11

Q13P CATB - OTBER

value Label

nOT AT ALL IMPORTANT QOTTE UNTMPORTANT NEITHER MAIMPORTAN? OUITE IMPORTANT EXTREMELY IMPORTANT

Mean 3.345

Mode

3.000

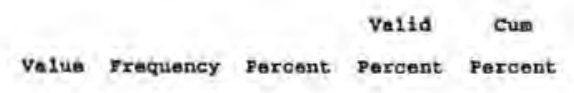

$\begin{array}{rrrrr}1 & 2 & .8 & 6.9 & 6.9 \\ 2 & 1 & .4 & 3.4 & 10.3 \\ 3 & 18 & 7.5 & 62.1 & 72.4 \\ 4 & 1 & .4 & 3.4 & 75.9 \\ 5 & 7 & 2.9 & 24.1 & 100.0 \\ . & 212 & 88.0 & \text { M1885n } & \\ \text { TOTNL } & 241 & 100.0 & 100.0 & \end{array}$

$\begin{array}{lll}\text { sta Err } & 206 \text { Medisn } 3.000\end{array}$

std Dev 1.111 variance 2.234 


\begin{tabular}{|c|c|c|c|c|c|}
\hline Kurtonie & .042 & 8 E kurt & .845 & Skewnesa & .086 \\
\hline S I skeir & .434 & Range & 4.000 & Mindmun & 1,000 \\
\hline Maximu= & 5.000 & sum & 97.000 & & \\
\hline
\end{tabular}

valid cases 29 Missing Cases 212

Q14 exporta/1importa

Value Laber

\section{exporter}

none soporter

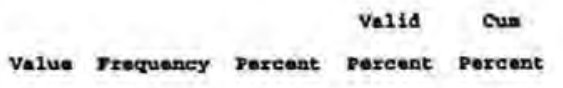

$\begin{array}{rrrrr}1 & 95 & 39.4 & 39.7 & 39.7 \\ 2 & 144 & 59.8 & 60.3 & 100.0 \\ . & 2 & .8 & \text { Mrgsrag } \\ & 241 & 100.0 & 100.0\end{array}$

\begin{tabular}{|c|c|c|c|c|c|}
\hline Hoan & 1.603 & sta Etr & .032 & Medion & 2.000 \\
\hline Mode & 3.000 & Std Dev & .490 & Varianoe & .220 \\
\hline Kurtonis & -1.638 & $S$ E kurt & .324 & skevmess &,- 422 \\
\hline S I gkev & .257 & Range & 1.000 & minimum & 1.000 \\
\hline Maxinue & 2.000 & sum & 383.000 & & \\
\hline
\end{tabular}

PACTOR /VNRTARLes Q6x so Q68.

$$
\text { TAC }
$$

Nnalysil mumber i Listwice deIetion of cases with misalng valuea

Extraction 1 for anslyaid 1, Principal-Componenta Analyaia (PC)

inftisl statiatsea :

\begin{tabular}{|c|c|c|c|c|c|}
\hline Variable & Cormunality & - Pactor & Eigenvalue & Pet of var & Cula Pet \\
\hline Q6x & 2.00000 & $\cdot$ & 7.24266 & 55,7 & 55.7 \\
\hline Q68 & 2.00000 & - & 1.05129 & 0.2 & 63.6 \\
\hline Q6C & 1.00000 & - & .99348 & 7.6 & 71.4 \\
\hline Q6D & 1.00000 & - & .68422 & 5.3 & 76.7 \\
\hline Q65 & 1.00000 & $\cdot$ & .58500 & 4.5 & 82.2 \\
\hline Q6F & 1.00000 & • & .54492 & 4.2 & 85.4 \\
\hline 060 & 1.00000 & $\cdot$ & .44709 & 3.4 & 08.8 \\
\hline Q68 & 1.00000 & $\bullet$ & $.4275 B$ & 3.3 & 92.1 \\
\hline $06 \mathrm{r}$ & 1.00000 & - & .26800 & 2.1 & 94.2 \\
\hline Q65 & 1.00000 & - $\quad 20$ & .24012 & 1.0 & 96.0 \\
\hline Q6K & 1.00000 & 12 & .29713 & 1.5 & 97.6 \\
\hline 06L & 1.00000 & 12 &, 18985 & 1.5 & 99.0 \\
\hline $06 \mathrm{M}$ & 1.00000 & 13 & .12859 & 1.0 & 100.0 \\
\hline
\end{tabular}

PC nutracted 2 sactors, 
Pactor Matris:

nacror 1 mactor 2

\begin{tabular}{|c|c|c|}
\hline Q6X & .03662 & .27880 \\
\hline Q68 & .79106 & .35129 \\
\hline Q6C & .81819 & .30548 \\
\hline Q6D & .60990 & -.17894 \\
\hline Q68 & .71820 & -.35025 \\
\hline $06 \%$ & .78442 & -.18203 \\
\hline Q66 & .84431 & . 11765 \\
\hline $06 \mathrm{~B}$ & .71140 & -.39438 \\
\hline Q6I & .80117 & -.14971 \\
\hline $06 \mathrm{~J}$ & .75758 & -.29675 \\
\hline Q6\% & .76565 & .00752 \\
\hline Q6L & .20010 & .41625 \\
\hline Q6M & .63202 & .34036 \\
\hline
\end{tabular}

Pinal gtatiotice:

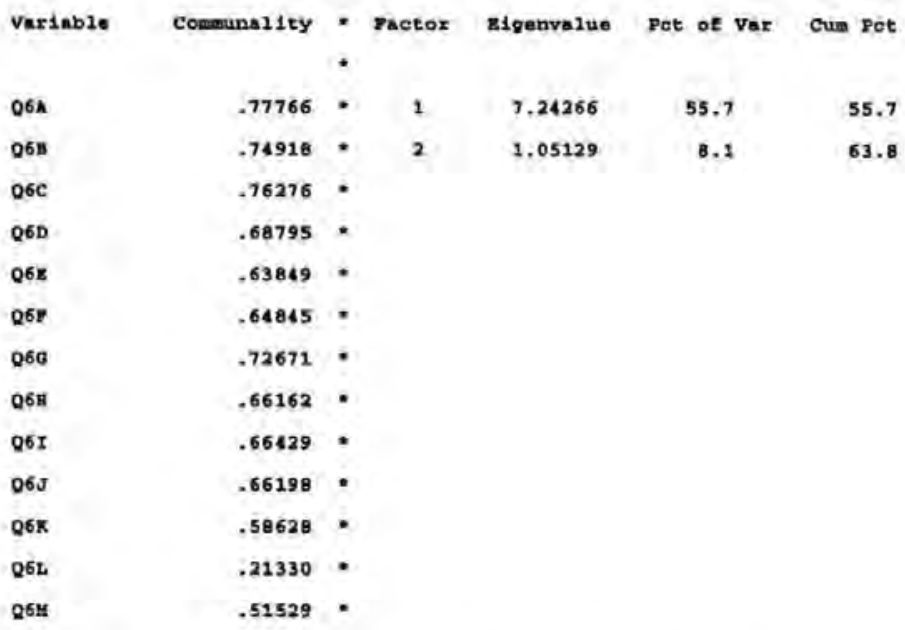

Varimax Rotetion 1, Eatraction 1, Analyais 1 - Kaisor Normalization,

Varimax converged in 3 itaratione.

Rotated Factor Matrixi

FACTOR 1 FACTOR 2

$\begin{array}{lll}\text { Q6A } & .51402 & .71655 \\ \text { Q6B } & .43460 & .74953 \\ \text { Q6C } & .48344 & .72735 \\ \text { Q6D } & .76080 & .33016 \\ \text { Q68 } & .78712 & .13764 \\ \text { Q68 } & .74206 & .31272 \\ \text { Q66 } & .61478 & .59055 \\ \text { 068 } & .80749 & .09791 \\ \text { Q61 } & .73667 & .34871\end{array}$




$\begin{array}{lrr}063 & .78762 & .20406 \\ 06 \mathrm{~K} & .61567 & .65522 \\ 06 \mathrm{~L} & -.08211 & .65469 \\ 06 \mathrm{M} & .31220 & .64639\end{array}$

Pactor Traneforeation Matrix

PACTOR 1 TXCroR 2

ractor $1 \quad .00980 \quad .50660$

FACTOR /VRRTABLES QEA TO QBA.

Analyeis number 1 Listwise delotion of cases with wiseing valuee

Extraotion 1 for Analyale 1, Principal-Componente analyais (FC)

Tnitial statiatios:

variable Comunaity - Yactor eiganvalue pet of var Cun pet

$\begin{array}{lrrrrrr}\text { QEX } & 1.00000 & - & 1 & 1.77835 & 44.5 & 44.5 \\ \text { QOB } & 1.00000 \cdot & 2 & 1.18035 & 29.5 & 74.0 \\ \text { QOC } & 1.00000 \cdot & 3 & .73171 & 18.3 & 92.3 \\ \text { QBD } & 1.00000 \cdot & 4 & .30959 & 7.7 & 100.0\end{array}$

oc sxtracted 2 factora.

Jactor Matrixi

FACTOR 1 FACTOR 2

$\begin{array}{lrr}\text { Q8X } & .29759 & .75554 \\ Q 08 & .89105 & -.02357 \\ \text { Q8C } & .90812 & .04287 \\ \text { QED } & .26671 & .77923\end{array}$

Final statiatice:

\begin{tabular}{|c|c|c|c|c|c|}
\hline Variables & Coemuna $11 t y$ & - Pactor & ESgenvalue & Pet of var & Cun Fet. \\
\hline OQA & .65940 & $\cdot$ & 1.77835 & 46.5 & 44.5 \\
\hline Q8B & .79453 & * & 2.18035 & 29,5 & 78.0 \\
\hline $88 \mathrm{C}$ & .82644 & • & & & \\
\hline QBD & .67833 & $\bullet$ & & & \\
\hline
\end{tabular}

Varimax Rotation 1, Eetraction 1, Nablyais 1- Kainer Normalization.

Vorimax converged in 3 iterationa.

Motated ractor Matrix: 
TACTOR 1 TACTOR 2

$\begin{array}{lrr}\text { Q8A } & -.28798 & .75926 \\ \text { Q8B } & .09068 & -.03488 \\ \text { Q8C } & .90858 & .03034 \\ \text { Q9D } & .27657 & .77578\end{array}$

Pactor Transforeation Matrix:

PACror 1 PACTOR 2

YACrOR $1 \quad .99992 \quad-.01269$

FACTOR $2 \quad .01269 \quad .99992$

FACTOK /VARLARES Q9K TO Q99.

Analyaia Number 1 tintwise delotion of casm with misaing values

Extraction 1 for Analyeis 1, Principel-Componente Analyoil (PC)

Initisi ststiotics;

Variab10 Coemunality * gactor gigenvalue pct of Var cum pct

\begin{tabular}{|c|c|c|c|c|c|}
\hline $09 \lambda$ & 1.00000 & - 1 & 4.22639 & 41.3 & 41.3 \\
\hline Q9B & 1.00000 & 2 & 1.29279 & 22.9 & 54.2 \\
\hline Q9c & 1.00000 & 3 & .07682 & 6.8 & 63.0 \\
\hline 090 & 1.00000 & 4 & .77417 & 7.7 & 70.7 \\
\hline$Q 9 z$ & 1.00000 & 5 & .64803 & 6.5 & 77.3 \\
\hline $09 x$ & 1.00000 & • & .55976 & 5.6 & 12.6 \\
\hline 090 & 1.00000 & 7 & .56568 & 5.5 & 88.2 \\
\hline Q98 & 1.00000 & 8 & .48006 & 4. 8 & 93.0 \\
\hline Q91 & 2.00000 & 9 & .39792 & 4.0 & 97.0 \\
\hline Q90 & 1.00000 & - $\quad 10$ & .29839 & 3.0 & 200.0 \\
\hline
\end{tabular}

PC extracted 2 Esctors.

Factor Matris:

$$
\text { TACTOR } 1 \text { EActon } 2
$$

\begin{tabular}{|c|c|c|}
\hline Q9x & .11658 & .71015 \\
\hline Q9B & .52051 & .50015 \\
\hline Q9C & .70834 & .15583 \\
\hline Q9D & .56428 & .33747 \\
\hline Q9z & .56234 & -13685 \\
\hline Q9P & .70615 & -.22858 \\
\hline 296 & .71327 & -.19982 \\
\hline Q9B & .66572 & -.41026 \\
\hline Q9I & .60486 & -.16415 \\
\hline J9 & .79294 & -.30746 \\
\hline
\end{tabular}


Final statiatica:

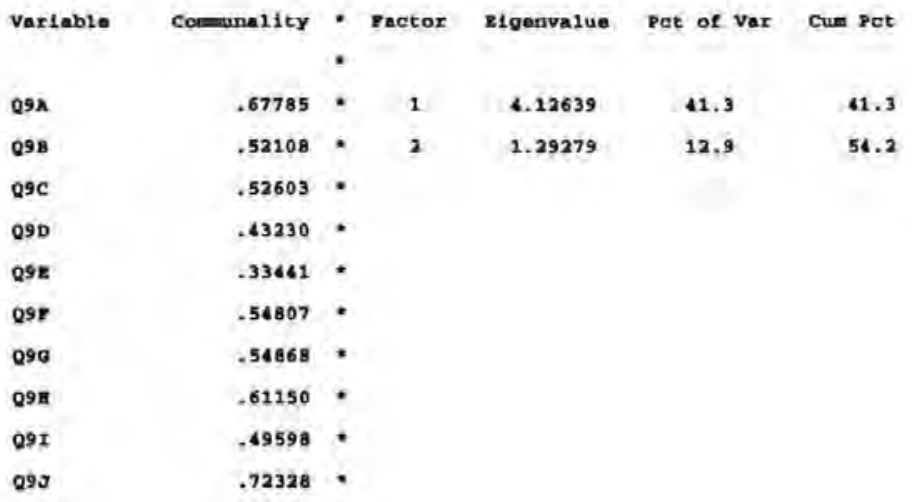

Varimax Rotation 2, Extraction 1, Analyais 1- Kaisor Normalization.

Varimax converged in 3 itnrationa.

Rotated Factor Matrix:

$$
\text { FACTOR } 1 \text { FACTOR } 2
$$

$\begin{array}{lll}Q 91 & -.03818 & .02243 \\ Q 98 & .16347 & .70311 \\ Q 9 C & .50871 & .51696 \\ Q 9 D & .28889 & .59063 \\ Q 97 & .39778 & .41975 \\ Q 97 & .71486 & .19347 \\ Q 96 & .70682 & .22156 \\ Q 91 & .78175 & .01924 \\ Q 97 & .66355 & .23595 \\ Q 95 & .83230 & .17479\end{array}$

Factor Transformation Matrix:

PACror 1 PACTOR 2

$\begin{array}{llrr}\text { FACTOR I } & .03816 & .54543 \\ \text { FACTOR 2 } & -.54543 & .83616\end{array}$

FACTOH /VARTABLES Q2.2A TO Q12g.

Analyaie Number 1 Listwila deletion of canea with misalng values

Extraction 1 for Anslyuis 1, Prineipal-Componente ansiyais (PC)

Initial statiotica:

Variable Comeunality - Factor Eigenvalue pet of Var cum Pet

$\begin{array}{llllll}012 \mathrm{X} & 1.00000 * & 1 & 2.30748 & 33.0 & 33.0 \\ 0128 & 1.00000 \cdot & 2 & 1.48523 & 21.2 & 54.2\end{array}$




\begin{tabular}{|c|c|c|c|c|c|c|}
\hline Q12C & 1.00000 & - & 3 & .80039 & 11.4 & 65.6 \\
\hline 812D & 1.00000 & • & 4 & .70640 & 10.1 & 75.7 \\
\hline Q212 $\mathrm{z}$ & 1.00000 & - & 5 & .64509 & 9.2 & 64.9 \\
\hline Q127 & 1.00000 & - & 6 & .60709 & 6.7 & 93.6 \\
\hline 0120 & 1.00000 & - & 7 & .45031 & 6.4 & 100.0 \\
\hline
\end{tabular}

Factor Matrixt

$$
\text { Factor 2 7actor 2 }
$$

\begin{tabular}{|c|c|c|}
\hline Q12X. & .64626 &, 40035 \\
\hline Q12B & .59683 & -.42247 \\
\hline Q12C & .60706 & -.45626 \\
\hline Q120 & .65996 & -.29190 \\
\hline Q12R & .13860 & .82665 \\
\hline Q127 & .59816 & .26272 \\
\hline 0120 & -.59780 & -.31971 \\
\hline
\end{tabular}

Finsi statiatica:

Variab10 Comanality - Factor zigenvalue Pat of vax cuil Pat

\begin{tabular}{|c|c|c|c|c|c|}
\hline $012 \pi$ & .57792 & - & 1 & 2.30748 & 33.0 \\
\hline Q12H & .53468 & - & 2 & 1.48523 & 22.2 \\
\hline Q12C & .57487 & 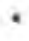 & & & \\
\hline 0120 & .52075 & • & & & \\
\hline Q12R & .70289. & - & & & \\
\hline Q12F & .42202 & $\bullet$ & & & \\
\hline 0220 & .45958 & - & & & \\
\hline
\end{tabular}

Verieax Rotation 1, zxtraction 1, Annlysis 1-Kaiger Normalization.

varimax converged in 3 iterationa.

notated vactor Matrixi

IACTOR 2 RACTOR 2

\begin{tabular}{|c|c|c|}
\hline Q12K & .18462 & .73745 \\
\hline Q12B & .72247 & .11281 \\
\hline Q12C & .75195 & .09713 \\
\hline Q12D & .67677 & .25045 \\
\hline Q22E & -.47669 & .68968 \\
\hline Q12\% & .28313 & 60242 \\
\hline Q12G & -.20604 & -.64585 \\
\hline
\end{tabular}

Vactor Franaformation Matrix:

pactor i pactor a

$\begin{array}{lll}\text { PAcros } 1 & -71731 & .69676\end{array}$

Fuctos $2 \quad-.69676 \quad .72731$ 
TACron /VARIABLEs g13a to 9130.

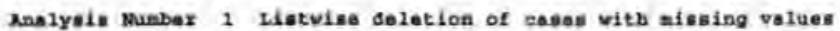

Retraction 1 for analyais 1, Principal-Componenta Analyala (PC)

Indt1aI Statiatieas

Variab1e Comenality , Tactor gigenvalue pet of Vax Cun pet

\begin{tabular}{|c|c|c|c|c|c|c|}
\hline $013 x$ & 1.00000 & • & 1 & 5.22517 & 34.6 & 34.8 \\
\hline Q13B & 1.00000 & • & 2 & 1.73812 & 11.6 & 46.6 \\
\hline $013 c$ & 1.00000 & • & 3 & 1.26127 & 8.3 & 54.7 \\
\hline Q13D & 1.00000 & • & 4 & 1.11426 & 7.4 & 62.1 \\
\hline Q138 & 1.00000 & • & 5 & .89388 & 6.0 & 68.1 \\
\hline Q13F & 1.00000 & • & 6 & .74493 & 5.0 & 73.1 \\
\hline 0130 & 1.00000 & $\cdot$ & 7 & .64907 & 4.3 & 77.4 \\
\hline Q138 & 1.00000 & $\cdot$ & a & .60421 & 4.0 & 81.4 \\
\hline Q13I & 1.00000 & • & 9 & .54536 & 3.6 & 85. 0 \\
\hline $013 \mathrm{~J}$ & 1.00000 & • & 10 & .51461 & 3.4 & 86.5 \\
\hline Q13K & 1.00000 & • & 11 & .66031 & 3.1 & 91.5 \\
\hline Q132 & 1.00000 & • & 12 & .40159 & 2.7 & 94.2 \\
\hline Q13M & 1.00000 & $\cdot$ & 13 & .32696 & 2.2 & 96.4 \\
\hline $013 \mathrm{~N}$ & 1.00000 & $\cdot$ & 14 & .27699 & 1.6 & 98.2 \\
\hline Q130 & 1.00000 & - & 15 & .26538 & 1.8 & 100.0 \\
\hline
\end{tabular}

PC Extractod I Eactors.

Yaotor Matrix:

FAcToR 1 FACTOR 2 FACTON 3 FACTON 4

\begin{tabular}{|c|c|c|c|c|}
\hline $013 x$ & .33099 & -.08940 & .76673 & -.10416 \\
\hline 0138 & .50744 & -.37556 & .27857 & .47259 \\
\hline Q13c & .58591 & -.19597 & .02230 & .47153 \\
\hline Q13D & .64934 & -.15681 & -.06069 & -.39151 \\
\hline Q138 &, 64141 & -.03379 & -.24546 & -.20635 \\
\hline Q13r & .47721 & .54997 & -.00969 & -.21760 \\
\hline 0230 & .41680 & .71591 & .06147 & .22689 \\
\hline Q13E & .41685 & .60606 & .04537 & .39387 \\
\hline Q131 & .62596 & .16703 & .11662 & -.30318 \\
\hline $213 \mathrm{~J}$ & .73148 & -.28935 & -.32264 & .08386 \\
\hline Q213K & .59985 & .11166 & -.40183 &,- 11670 \\
\hline Q13L. & .72777 & -.23205 & -.30066 & .27367 \\
\hline Q13M & .66480 & .06023 & .28041 & -.13919 \\
\hline Q13N & .50859 & -.10569 & .37089 & -.21173 \\
\hline 0130 & .76435 & -.21578 &,- 04331 & .03035 \\
\hline
\end{tabular}

pinal statiatica:

Variable Comanality - Factor gigenvalue pat of vax cua pet 


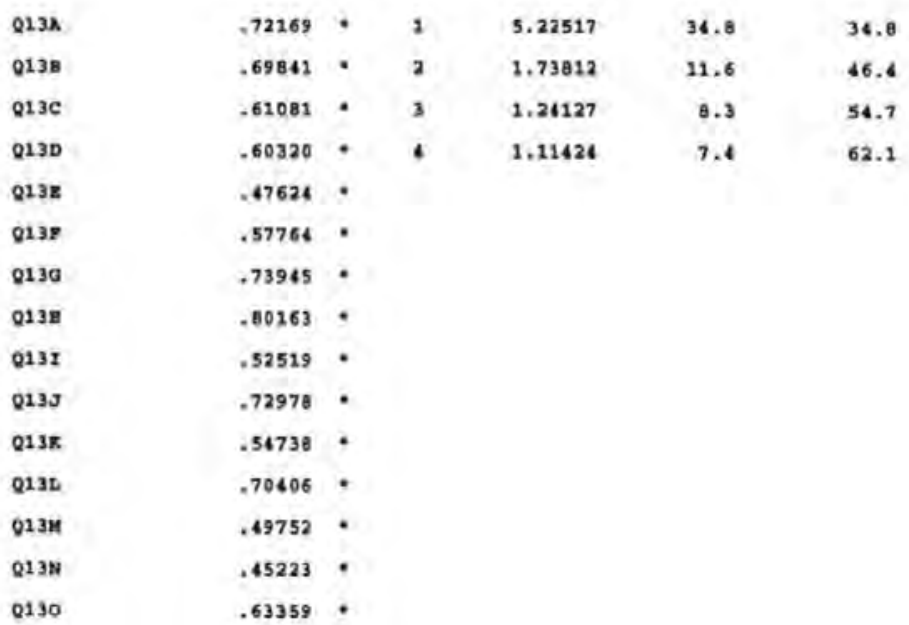

Factor Transtormation Matrix:

FACTOR 2 PACTOR 2 FACTOR 3 YACTOR 4

\begin{tabular}{|c|c|c|c|c|c|}
\hline rucrox & 1 & .74270 & .34509 & .44236 & .36554 \\
\hline racron & 2 & -.13370 & .89517 & -.42022 & -.06491 \\
\hline racion & 3 & -.50534 & .03495 & .21173 & .85677 \\
\hline ғастоп & 4 & -.41050 & .27941 & .78438 & -.36268 \\
\hline
\end{tabular}




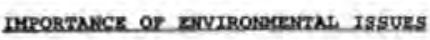

\section{A) BY SECTOR}

vasovn q5a to q5b by q3 $(1,10)$ /print oolinfo.

226 caeer accopted.

o canes rojected because of out-of-renge factor values.

20 esans rejected beckuse of masing date.

10 non-arpty cells,

1 design will be processed.

Ce11 Means and stanasara dovintione

variable .. $05 x$

racrok

cove

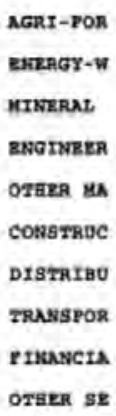

Por ent1re maeple

Variable .. Q5n

rACTOR cone

THP ERV IAS - TND

Mean sta. Dev.

$\begin{array}{lrr}4.225 & .354 & 8 \\ 3.500 & .707 & 2 \\ 3.000 & 2.000 & 3 \\ 4.227 & .813 & 22 \\ 4.313 & .589 & 48 \\ 4.333 & .488 & 15 \\ 3.583 & .900 & 12 \\ 4.400 & .548 & 5 \\ 4.214 & .579 & 14 \\ 4.278 & .703 & 97 \\ 4.217 & .719 & 226\end{array}$

emect .. 93

Multiveriate zeste of significance $(S=2, \mathrm{H}=3, \mathrm{~W}=106 \mathrm{1} / 2$ )

Taat Nawe

VA1U日 Approx, $z$ Eypoth, DF error of B1g, of $z$

$\begin{array}{llllll}\text { Pi11sis } & .20313 & 2.72310 & 18.00 & 432.00 & .000 \\ \text { Botelings } & .23592 & 2.00482 & 18.00 & 428.00 & .000 \\ \text { Wilks } & .00364 & 2.75917 & 18.00 & 430.00 & .000 \\ \text { Roys } & .16113 & & & & \end{array}$


Dnivariate p-tests with $(9,216)$ D. $P$.

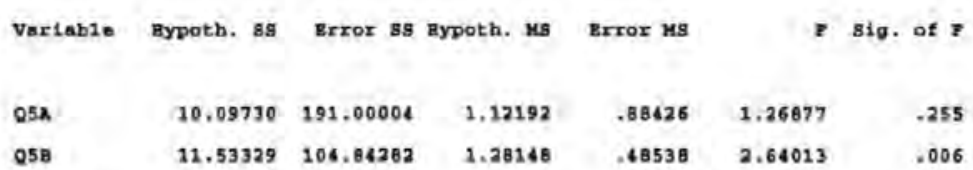

IMPORTAKCE OP PARTICULAR RRVIROTRERTAL ISSUES

\section{A) BY SECTOR}

Musova q6a to $q 6$ a by $43(1,10)$ lprint ceilinfo.

210 cases accepted.

o casse rejected because of out-of-range tactor values.

28 casea refocted becrune of minning dats.

10 non-eapty colla.

1 design will be procenend.

Ce11 Means and standara Devistiona

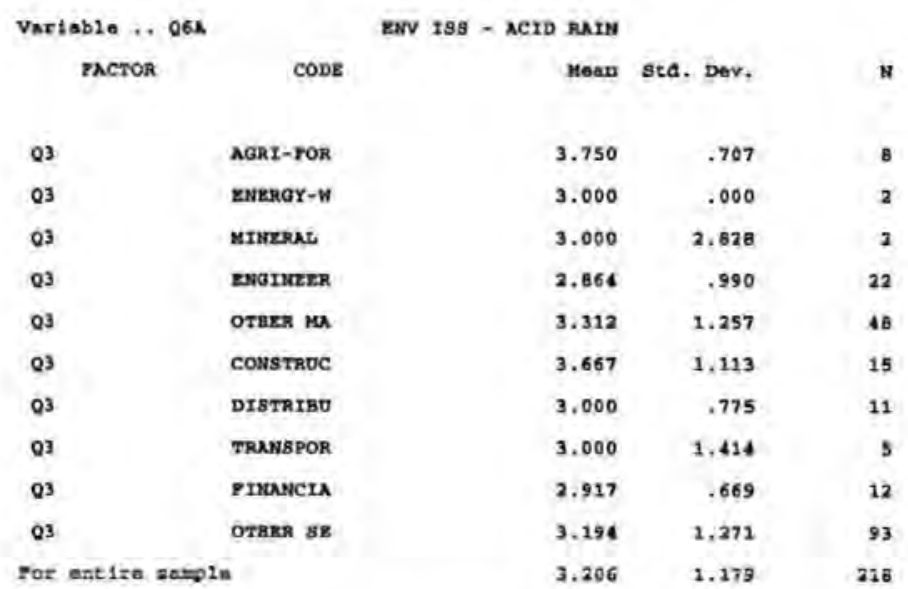

Variable ... Q6B JACTOR

cope

\section{Q3}

Q3

Q3

Q3

03

03

Q3

Q3

03

Q3

por entire sasple

Variable .. Q6C pacror
zST ISS - CPC's

Woun sta. Dev,

$\begin{array}{rrr}3.625 & .764 & 8 \\ 3.000 & .000 & 2 \\ 3.000 & 2.020 & 2 \\ 3.227 & 1.120 & 22 \\ 3.521 & 1.203 & 48 \\ 3.533 & 1.187 & 15 \\ 3.091 & .031 & 11 \\ 3.000 & 1.416 & 5 \\ 3.083 & .900 & 12 \\ 3.652 & 1.281 & 93 \\ 3.399 & 1.288 & 218\end{array}$

ERV ISB - OLOBNL WARMING

Mearl sta. Dev. 


\begin{tabular}{|c|c|}
\hline Q3 & $\operatorname{MaR} 1$ - $P O R$ \\
\hline Q3 & Eatea $0 \gamma-w$ \\
\hline 83 & MTRERE \\
\hline 83 & Evonazs \\
\hline 83 & orazk ma \\
\hline Q3 & construe \\
\hline 23 & DISTRIBD \\
\hline 83 & TRNASPOR \\
\hline Q3 & prouscra \\
\hline 03 & OTERR SE \\
\hline
\end{tabular}

Variable $\ldots$ Q60 PACrOR

\begin{tabular}{|c|c|}
\hline 03 & AGM1-roR \\
\hline 83 & ENERGY-W \\
\hline 03 & minzoul \\
\hline 83 & Evararzen \\
\hline Q3 & orazs $\mathrm{xa}$ \\
\hline 89 & consrape \\
\hline Q3 & Drsmirad \\
\hline Q3 & Trusspon \\
\hline Q3 & rronNicta \\
\hline 03 & OTEER $\mathrm{SB}$ \\
\hline
\end{tabular}

For ontiro anmple

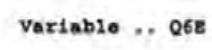

\begin{tabular}{|c|c|}
\hline 03 & XORI-YOF \\
\hline Q3 & EIERGY-w \\
\hline$Q^{3}$ & итNERAL \\
\hline Q3 & zNOHRER \\
\hline 03 & oturen ara \\
\hline Q3 & CONSזRDC \\
\hline 23 & DISTRIBO \\
\hline 03 & TRU⿻上丨龰oR \\
\hline 03 & grnowera \\
\hline Q3 & OTHER $\mathrm{sR}$ \\
\hline
\end{tabular}

For antire sample

Varlable ., asr racron CODs

$\begin{array}{rrr}3.875 & ., 335 & 6 \\ 3.500 & .707 & 2 \\ 3.000 & 1.414 & 2 \\ 3.182 & 1,006 & 22 \\ 3,563 & 1,219 & 48 \\ 3.600 & 1.404 & 15 \\ 3,182 & .751 & 11 \\ 3.000 & 1.414 & 5 \\ 3.083 & .793 & 12 \\ 3,323 & 1.304 & 93 \\ 3.372 & 1.197 & 218\end{array}$

ENV ISS - NATER POLLUTION

Masn sta, Der. N

$\begin{array}{rrr}4.175 & .716 & 0 \\ 5.000 & .000 & 2 \\ 4.500 & .707 & 2 \\ 3.816 & 1.006 & 22 \\ 3.950 & 1.166 & .8 \\ 4.400 & .910 & 15 \\ 3.909 & .944 & 11 \\ 3.400 & 1.673 & 5 \\ 3.000 & .739 & 12 \\ 3.645 & 1.282 & 93 \\ 3.003 & 1.181 & 218\end{array}$

ENV ISS - ENERGY USAGR

Masn std. Dev.

$\begin{array}{llr}3.500 & .535 & 0 \\ 5.000 & .000 & 2 \\ 5.000 & .000 & 2 \\ 4.102 & .733 & 22 \\ 4.063 & .998 & .6 \\ 4.200 & .862 & 15 \\ 4.364 & .674 & 11 \\ 3.800 & .837 & 5 \\ 4.000 & .603 & 12 \\ 3.914 & 1.148 & 93 \\ 4.023 & .990 & 218\end{array}$

ZWV ISS - ETHLENT WOSTR DISPOSAT Menin std. Dev.

$\begin{array}{rrr}3.075 & 1.126 & 8 \\ 5.000 & .000 & 2 \\ 4.000 & 1.414 & 2 \\ 3.618 & 1.097 & 22 \\ 3.813 & 1.261 & 48 \\ 4.133 & 1.060 & 15 \\ 3.727 & .647 & 12 \\ 2.600 & .094 & 5\end{array}$




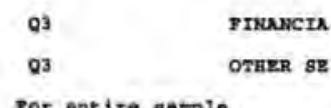

ror antire satole

variable ... Q6a

7ACTOR

\begin{tabular}{|c|c|}
\hline$Q^{3}$ & AGRI-POR \\
\hline 03 & ERERGY - W \\
\hline Q3 & MTHERXI \\
\hline Q3 & EHGIWEER \\
\hline 03 & OTEER MX \\
\hline Q3 & CONSTRUC \\
\hline 03 & DISTMIBU \\
\hline $8^{3}$ & TRUNAPOR \\
\hline Q3 & VINUASCI \\
\hline$Q^{3}$ & OFBEA SE \\
\hline
\end{tabular}

For entire nample

Variab1a . . 06r

rACAOR CODE

03

Q3

03

03

Q3

Q3

Q3

Q3

Q3

Q3

Yot entire anole

Variablo .. $Q 6 I$

$$
\text { racton }
$$

\section{ACRI-POR}

BERRGY-W

MINERTLL.

enotreza

OTBER Ma

constade.

DISTEIBD

zrussspor

prasera

OTHer $\mathrm{sE}$

03

o3

ga

Q3

Q3

Q)

03

Q3

03

Q3

por entire asmola

variabis ... 860

$$
\text { racroa }
$$

TaRI-FOR

EIERGY-W

MrNerat.

ZNGTERER

OTHER MA

consrade

DISTRIBU

RRANSPOR

FINANCIA

OTIER $5 \mathrm{E}$$$
03
$$

03

AGRI-YOR

ENERGY $-w$

$\begin{array}{rrr}3.250 & .965 & 12 \\ 3.677 & 1.287 & 93 \\ 3.729 & 1.178 & 218\end{array}$

nEV ISS - DEPORESTMTION

Moan sta. Dev.

$\begin{array}{lrr}3.350 & .096 & 8 \\ 3.000 & .000 & 2 \\ 3.000 & 2.828 & 2 \\ 3.273 & 1.202 & 22 \\ 3.500 & 1.272 & 48 \\ 3.733 & 1.163 & 15 \\ 3.727 & .796 & 11 \\ 2.600 & .096 & 5 \\ 3.167 & .937 & 12 \\ 3.461 & 1.306 & 93 \\ 3.422 & 1.220 & 216\end{array}$

zar ISS - MOIBE pOLZUTion

Mean std. Dev.

$\begin{array}{lrr}3.250 & .006 & 6 \\ 3.500 & 2.121 & 2 \\ 5.000 & .000 & 2 \\ 3.810 & .560 & 22 \\ 3.646 & 1.000 & 46 \\ 4.267 & .706 & 15 \\ 3.636 & .009 & 11 \\ 3.600 & .540 & 5 \\ 3.583 & .793 & 12 \\ 3.699 & 1.223 & 93 \\ 3.720 & 1.038 & 216\end{array}$

ESV ISS - VEHICLE grrssions

Kean ătã. Dev. Hิ

$\begin{array}{rrr}3.625 & .746 & \text { a } \\ 3.500 & 2.121 & 2 \\ 4.500 & .707 & 2 \\ 3.316 & 1.041 & 22 \\ 3.354 & 1.246 & 48 \\ 3.733 & 1.100 & 15 \\ 3.636 & .674 & 11 \\ 3.000 & 1.225 & 5 \\ 3.500 & .905 & 12 \\ 3.634 & 1.232 & 93 \\ 3.532 & 1.253 & 218\end{array}$

ENV $1 S S$ - SOLID WASTE DISPOSAL

Mesn sta. Dey.

$\begin{array}{rrr}3.625 & .744 & 1 \\ 4.000 & 1.424 & 2\end{array}$




\begin{tabular}{|c|c|}
\hline 03 & MINERAL \\
\hline 03 & ENarmans \\
\hline Q3 & OTEER $\mathrm{MA}$ \\
\hline es & CONSTRUC \\
\hline 23 & DISTRIBO \\
\hline Q3 & TRusspor \\
\hline 03 & PINuncts \\
\hline 23 & orang $\mathrm{sx}$ \\
\hline
\end{tabular}

yor entire saslo

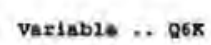

\begin{tabular}{|c|c|}
\hline 23 & AQRI-FOR \\
\hline Q3 & ENEROX-W \\
\hline Q3 & MINERAL \\
\hline Q3 & ENGINEER \\
\hline$Q 3$ & oraes ma \\
\hline 23 & COHSTRUC \\
\hline 93 & DIsTRIAU \\
\hline 23 & TRAMSPOR \\
\hline Q3 & YINANICIA \\
\hline 03 & OTBER $B E$ \\
\hline
\end{tabular}

yox ent1re sample

Variable .. Q64 pactor

\begin{tabular}{|c|c|}
\hline Q3 & MARI-FOR \\
\hline 03 & EREAGY-H \\
\hline 03 & Mricauts \\
\hline Q3 & EnOTNEER \\
\hline 03 & OTBEa $\mathrm{Ma}$ \\
\hline Q3 & CONSTROC \\
\hline Q3 & DIstribo \\
\hline$Q^{3}$ & munston \\
\hline 03 & Frouncra \\
\hline Q3 & OTHza $\mathbf{s e}$ \\
\hline
\end{tabular}

For entirn sampla

Variable .. Q6M cope

$\begin{array}{lrr}3.500 & .707 & 2 \\ 3.591 & 1.182 & 22 \\ 3.813 & 1.161 & 48 \\ 4.200 & .416 & 15 \\ 3.909 & .539 & 11 \\ 2.200 & 1.095 & 5 \\ 3.250 & .452 & 12 \\ 3.602 & 1.336 & 93 \\ 3.656 & 1.166 & 218\end{array}$

ENV ISS - RESOURCE DEPLETIOU

Mean std. Dev.

$\begin{array}{lrr}3.375 & .746 & 8 \\ 3.500 & 2.121 & 2 \\ 5.000 & .000 & 2 \\ 3.609 & 1.102 & 22 \\ 3.812 & 1.045 & 46 \\ 3.600 & 1.146 & 15 \\ 3.364 & .009 & 11 \\ 3.000 & 1.225 & 5 \\ 3.250 & .452 & 12 \\ 3.516 & 1.274 & 93 \\ 3.564 & 1.143 & 218\end{array}$

EWY ISS - DUPLOYRE B/S

Hosn sta. Dev.

$\begin{array}{rrr}6.750 & .707 & 0 \\ 5.000 & .000 & x \\ 5.000 & .000 & 2 \\ 4.545 & .596 & 22 \\ 4.646 & .699 & 48 \\ 4.333 & 1.113 & 15 \\ 4.818 & .405 & 12 \\ 4.400 & .548 & 5 \\ 1.750 & .452 & 12 \\ 4.398 & .922 & 93 \\ 4.528 & .004 & 218\end{array}$

ENV T8S - PTNANCTAL SUPPORT ENV GROUPS Menn std. Dev.

$\begin{array}{rrr}2.075 & .642 & 8 \\ 3.000 & .000 & 2 \\ 4.000 & 1.414 & 2 \\ 2.682 & 1.211 & 22 \\ 3.188 & 1.104 & 48 \\ 3.067 & 1.100 & 15 \\ 3.273 & .647 & 11 \\ 3.000 & .707 & 5 \\ 3.000 & .739 & 12 \\ 3.194 & 1.145 & 93 \\ 3.115 & 1.074 & 218\end{array}$


EPFEC , R R3

Multivariate Teata of significance is $=9$, M $=11 / 2, N=97$,

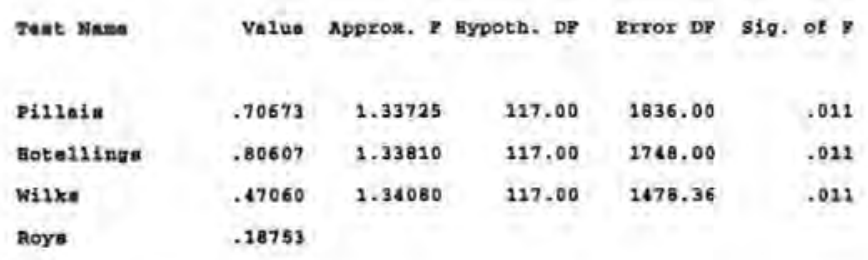

Daiveriato p-teato with $(9,208)$ D. $\boldsymbol{P}$.

Verisble \#ypoth. ss Error ss Hypoth, us trrox us , sig. of 7

\begin{tabular}{|c|c|c|c|c|c|c|}
\hline $06 \lambda$ & 10.58147 & 291.16954 & 1.27127 & 1.39965 & .83671 & .583 \\
\hline 068 & 5.97066 & 300.30915 & .66341 & 1.44379 & -45949 & .900 \\
\hline Q6C & 7.96783 & 302.93584 & .88531 & 1.45642 & .60787 & .790 \\
\hline Q6D & 23.95454 & 278.56381 & 2.66162 & 1.33925 & 1.98739 & .042 \\
\hline Q65 & 9.74282 & 203.14251 & 1.08253 & .97665 & 1.10842 & $.35 \mathrm{a}$ \\
\hline Q67 & 15.88415 & 285.14796 & 1.76491 & 1.37090 & 1.28740 & .245 \\
\hline Q66 & 8.40413 & 914.77019 & .93379. & 1.51332 & .61705 &, 782 \\
\hline Q68 & 10.51395 & 223.41724 & 1.16822 & 1.07412 & 1.08760 & .373 \\
\hline Q6I & 7.59966 & 280.67557 & .84441 & 1.34940 & .62576 & .774 \\
\hline Q6J & 19.55291 & 275.64434 & 2.27255 & 1.32521 & 1.63939 & .106 \\
\hline $06 \pi$ & 12.17397 & 271.42694 & 1.35266 & 1.30494 & 1,03657 & 412 \\
\hline Q62 & 5.70168 & 134.63298 & .63356 & .06727 & .97879 & .459 \\
\hline Q6M & 7.56152 & 262.59151 & .03795 & 1.16631 & .71846 & .692 \\
\hline
\end{tabular}

\section{IMPORTANCE OF ENVIRONMENTAL ISSUES}

BY REDUCED SECTQB

Masovi q5a to $q 5 b$ by $q^{3}(1,3)$ /print de111nfo.

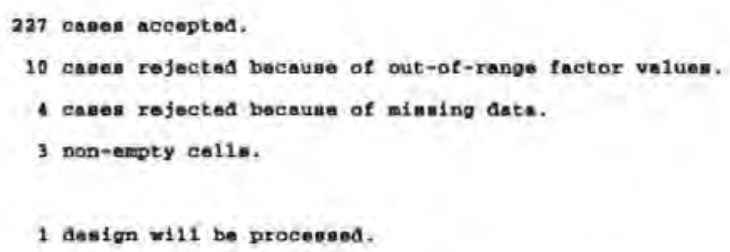




$\begin{array}{llllr}\text { Q3 manufact } & 4.266 & .721 & 94 \\ \text { Q3 } & \text { Eervice } & 4.283 & .688 & 120 \\ \text { Q3 } & \text { retail } & 3.615 & .870 & 13 \\ \text { ror antise measie } & 4.238 & .226 & 227\end{array}$

Erracr ... Q3

Multivariate reste of sigafificance $(S=2, x=-1 / 2, \mathbb{N}=1101 / 2)$

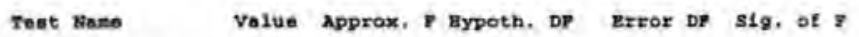

$\begin{array}{llllll}\text { Pi12a18 } & .05216 & 2.99793 & 4.00 & 448.00 & .028 \\ \text { Bota121nge } & .05636 & 3.02703 & 4.00 & 46.00 & .018 \\ \text { Wi1ka } & .94616 & 3.00758 & 4.00 & 466.00 & .028 \\ \text { Roya } & .04560 & & & & \end{array}$

Univariate $\boldsymbol{P}$-teata with $(2,224)$ D. $\boldsymbol{P}$.

Voriable Hypoth, ss Exror ss Bypoth. Ms zrror us $q$ sig. of $p$

$\begin{array}{lllllll}05 \mathrm{~A} & 2.75719 & 202.91682 & 1.37060 & .90588 & 1.52183 & -221 \\ 058 & 5.35953 & 113.79465 & 2.67977 & .50802 & 5.27509 & .006\end{array}$

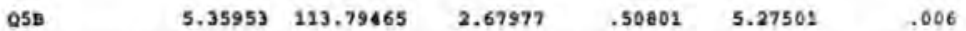

TMPORTANCE OF PARTICULAR ETVIRONMEITAL TSSUZS

\section{BY REDUCED SECTOR}

Mensova q6e to q6a by $q^{3}(1,3)$ /Drint delitnfo.

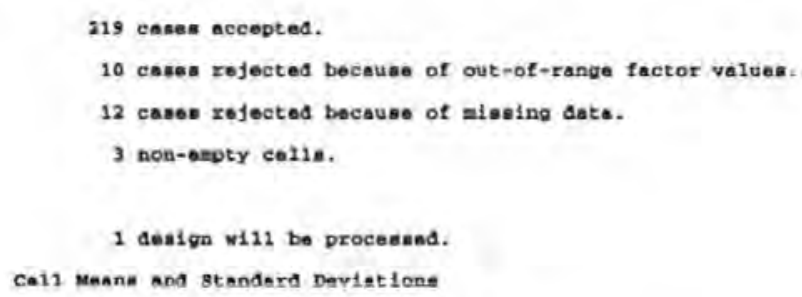

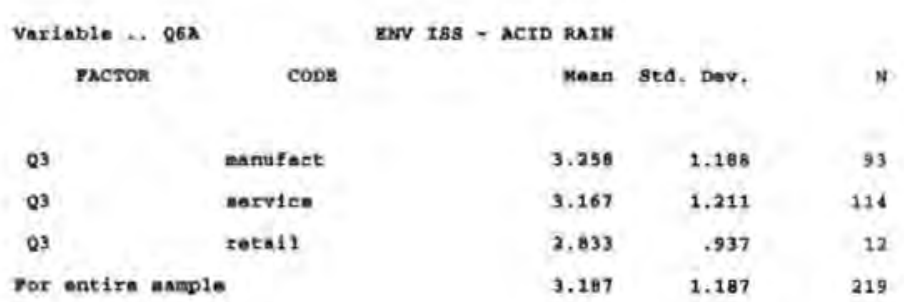

Ce11 Mesne sna stendara Deviatione (CONr.)

\begin{tabular}{|c|c|c|c|c|}
\hline Facton & CODE & Mean & 1. Dev. & x \\
\hline 03 & manufact & 3.673 & 1.105 & 93 \\
\hline 23 & aervicb & 3.395 & 1.238 & 114 \\
\hline 03 & $\operatorname{ratan} 12$ & 2,917 & .996 & 12 \\
\hline \multicolumn{2}{|c|}{ For antixe nanple } & 3.602 & 1.205 & 219 \\
\hline
\end{tabular}




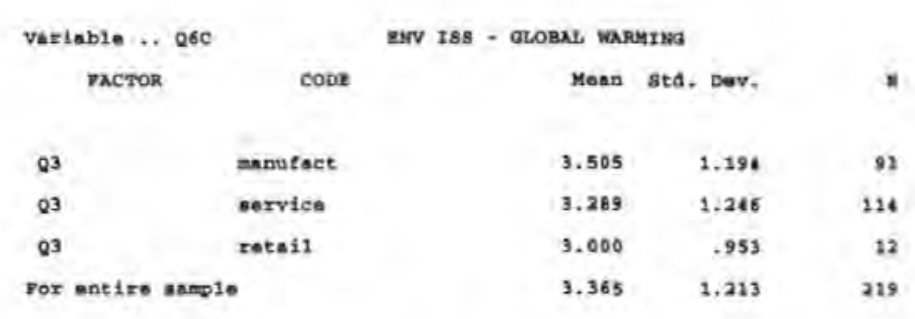

Coll Monna and standard Deviatione (cost.)

variabla.. 960

racros

cove

$\begin{array}{ll}\text { Q3 } & \text { nanufact } \\ 93 & \text { aorice } \\ \text { Q3 } & \text { retail }\end{array}$

For ent lre nample

Verioble .. $96 \mathrm{z}$

pxetor cops

ENV ISS - ERERTY USAGE

Mean sed. Der.

$\begin{array}{ll}\text { Q3 } & \text { manufact } \\ \text { Q3 } & \text { mervica } \\ \text { Q3 } & \text { retail }\end{array}$

por entixe ansple

ENV ISS - WATER TOLLOTION

Mosis ste. Dev.

$\begin{array}{rrr}3.946 & 1.246 & 93 \\ 3.579 & 1.256 & 114 \\ 3.667 & 1.231 & 12 \\ 3.760 & 1.216 & 213\end{array}$

Cell Meane and standerd Deviations (CONr.)

Vsriable... Q67

ractor

$\begin{array}{ll}Q 3 & \text { nemufact } \\ \text { Q3 } & \text { service } \\ \text { Q3 } & \text { retail }\end{array}$

For ent 1re saeplo

Voriable... Q60

racron

Q3

Q3

Q3

ror entire ganple

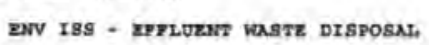

$$
\text { Man gta. Dav. }
$$

$3.817 \quad 1.179 \quad 93$

$3.588 \quad 2.247 \quad 114$

$3.500 \quad 1.000 \quad 12$

$\begin{array}{lll}3.600 & 1.207 & 219\end{array}$

EV IS8 - DEPORESTATOR

Hean sta. Dev. N

$\begin{array}{rrr}3.409 & 1.270 & 93 \\ 3.377 & 1.264 & 226 \\ 3.500 & 1.087 & 12 \\ 3.397 & 1.242 & 219\end{array}$

Cel1 Means and standard Devistions (CONr.)

Variable ... Q6H

ENV ISS - MOISE POLLOTION

FACTOR

CODE

Masn sta. Dev.

n

03

manufact
sorvice
rotant

Q3

retast

Yor antire nampla

Variable .. Q6I

FActor

CODE

$\begin{array}{rrr}3.839 & .876 & 93 \\ 3.693 & 1.153 & 114 \\ 3.417 & 1.086 & 12 \\ 3.740 & 1.041 & 219\end{array}$

zav 1SS - VeHICte Eutssions

Mean sta. Dev. 


\begin{tabular}{|c|c|c|c|c|}
\hline$Q^{3}$ & senufact & 3.419 & 1.164 & 93 \\
\hline Q3 & service & 3.588 & 1.181 & 216 \\
\hline$Q^{3}$ & xetal1 & 3.417 & .996 & 12 \\
\hline \multicolumn{2}{|c|}{$x \operatorname{ent} 1 x$} & 3.507 & 1.163 & 219 \\
\hline
\end{tabular}

Cal1 Meand end standard Deviatione (COMz-)

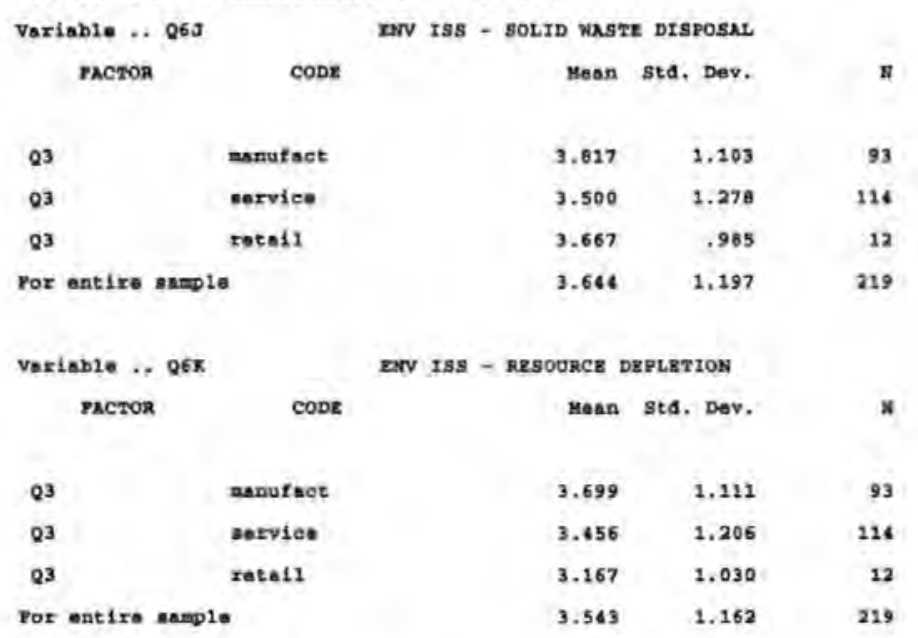

Ce11 uesas and standard Devistions (CONT.)

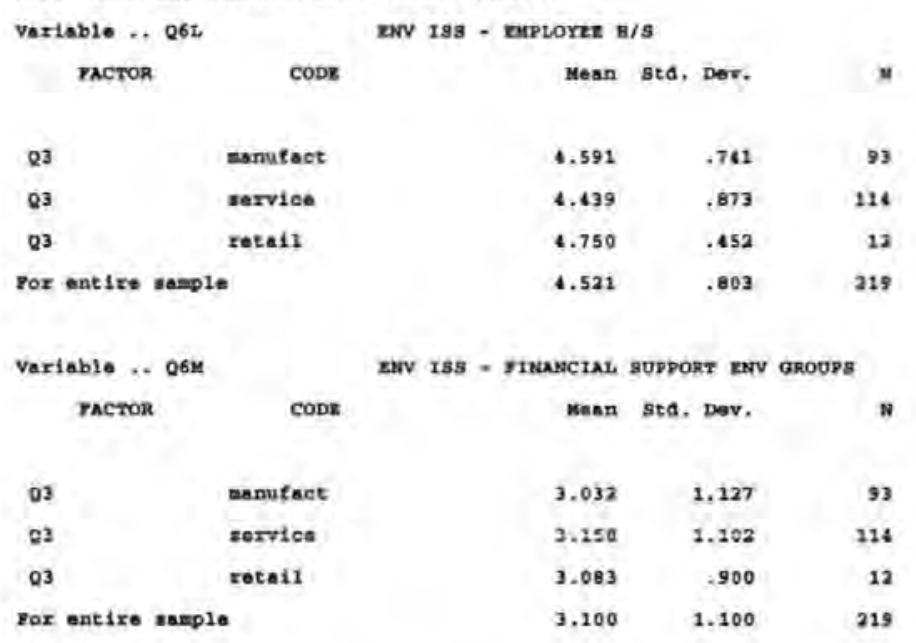

Cell Means and standard Deviations (cosrs.)

erpect ... Q3

Milivariate reats of significance $(B=2, \mathrm{~K}=5, \mathrm{~N}=201$ )

Test wase Value Approx. $z$ Hypoth. DF Error by sig. of $\boldsymbol{Y}$

$\begin{array}{llllll}\text { Pi11nin } & .20698 & 1.82032 & 26.00 & 410.00 & .009 \\ \text { Hotelinga } & .23388 & 1.82607 & 26.00 & 406.00 & .009 \\ \text { Wilka } & .80265 & 1.82325 & 26.00 & 408.00 & .009 \\ \text { Roya } & .13661 & & & & \end{array}$

EPPECT ... Q3 (CONz,)

onfvariate $y$-teste with $\{2,216\}$ D. $y$.

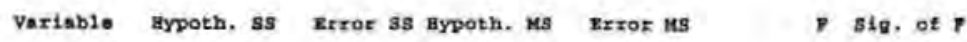




\begin{tabular}{|c|c|c|c|c|c|c|}
\hline Q6x & 2.01775 & 305.30645 & 1.00887 & 1.41346 & .71376 & .651 \\
\hline Q5: & 3.30296 & 313,33630 & 1.65146 & 1.45063 & 1.13846 & .322 \\
\hline Q6C & 4.08158 & 316.69468 & 2.04079 & 1.46618 & 1.39151 & .251 \\
\hline Q6D & 6.97706 & 315.18732 & 3.48653 & 1.45920 & 2.19071 & .094 \\
\hline $06 \mathrm{z}$ & 2.26919 & 223.65775 & 1.13659 & 2.03565 & 1.09575 & .336 \\
\hline 067 & 3.11039 & 314.51528 & 1.55515 & 3.45609 & 1,06803 & .345 \\
\hline 060 & .18454 & 336.25382 & .09227 & 1.55673 & .05927 & .942 \\
\hline 06: & 2.41269 & 233.75170 & 1.20634 & 1.08218 & 1.12473 & .330 \\
\hline Q6r & 1.55509 & 293.18463 & .77755 & 1.35736 & .57285 & .565 \\
\hline Q65 & 5.16004 & 307.05914 & 2.58002 & 1.42157 & 1.81491 & .165 \\
\hline $06 \mathrm{~K}$ & 4.82064 & 289.51726 & 2.41032 & 1.34036 & 2.79827 & .168 \\
\hline$Q 6 \mathrm{~L}$ & 1.86424 & 138.79329 & .93212 & .64256 & 1.45063 & .237 \\
\hline Q6M & .01217 & 262.97779 & .40608 & 1.21749 & .33354 & .717 \\
\hline
\end{tabular}

\section{IMPORTANCE OF ENVIRONMENTAL ISSUES}

\section{C) EXPORTERS AND NONE EXPORTERS}

unsovi q5a to q5b by q14 $(1,2)$ /print collinfo.

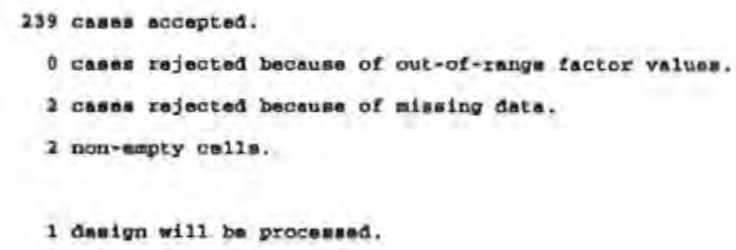


onivariate $\mathrm{p}$-teste with $(1,237)$ D, 8 .

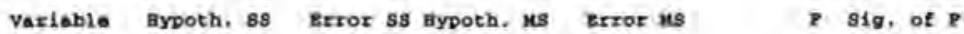

$\begin{array}{lllllll}\text { Q5A } & .77421 & 210,63165 & .77421 & .08874 & .07113 & .352\end{array}$

$\begin{array}{lllllllll}Q 58 & 3.20084 & 118.59832 & 3.20084 & .50041 & 6.39638 & .012\end{array}$

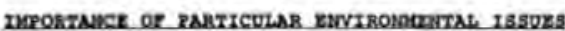

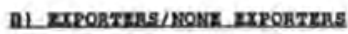

musovi 968 to $26 \mathrm{a}$ by $Q 16(1,2)$ /print celinto.

229 camen acoepted.

O canes rejected because of out-of-rango foctor values.

12 casea rejected becsuse of missing date.

2 non-ompty col1n.

1 design will be processed.

Call moan and standard doviation.

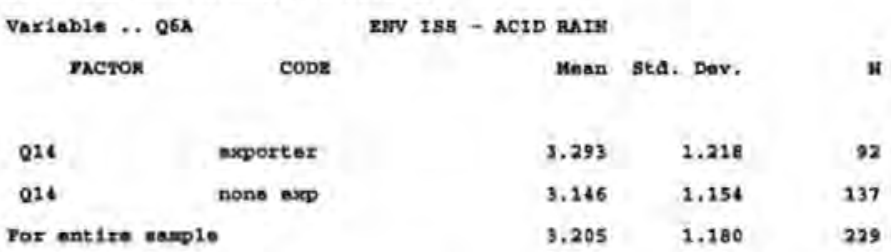

Ce11 Mante and standard Deviations (Covr, )

variable ... 060

2RV 185 - CPC'

FACTOR

CODR

Mean sta. Dev.

Q14

exporter

$3.565 \quad 1.252$

92

Q24

none exp

$3.299 \quad 1.299$

137

Yor ent 1 re nangle

$3.406 \quad 2.202$

229

Variable .. Q6C

ErV ISS - GLOALL wasertwo

racTok

CODE

Hean sta. Dev. B

Q26

exportar

$3.641 \quad 1.201$

92

Q14 none axp

$3.248 \quad 1.168 \quad 137$

For entlre sasple

40

1.194

229

Vartable ., Q6D

nNV ISS - WATER POLLOTIOM

nActor

CODE

Mesn std, Dev.

014

exporter

4.076

1.051

92

014

$3,577 \quad 1.264$

137

Pox entire somite

$3.777 \quad 1.206$

229

Ce11 Mene and stenanrd Deviationa (CONr.)

Variab1n .. Q6E

RNY ISS - ERRRGY USAGE

racror

CODE

Mosn sta. Dev. 


Q14 exporter

yor antire sacole

Variable .. Q6r

ractor

$\begin{array}{rrr}4.130 & .940 & 92 \\ 3.942 & 1.049 & 137 \\ 4.017 & 1.009 & 229\end{array}$

ENV ISS - EYYLUEN VQSTE DISPOSNL.

Mean sta. Dev. N

014 exporter

vor antire easple

Varinble .. 066

yACTOR

cope

ERV ISS - DEPORESTAFION

Q14 exporter

Q14 none axp

ror entire asmple

Mean sta. Dov. n

$\begin{array}{rrr}3.891 & 1.114 & 92 \\ 3.569 & 1.247 & 137 \\ 3.699 & 1.203 & 229\end{array}$

$\begin{array}{lll}3.457 & 1.244 & 92\end{array}$

$\begin{array}{lll}3.343 & 1.239 & 137\end{array}$

$\begin{array}{lll}3.389 & 1.240 & 229\end{array}$

Co11 Means and standard Deviatione (Coms.)

variable .. Q6B

yictor CODB

Q14

014

exporter

none $\exp$

Por entire samplo

Variable ... Q6I

racror

Q14 noporter

For ontire hamplo

Variable .. Q6

zactor

$\begin{array}{ll}014 & \text { exportor } \\ 014 & \text { none exp }\end{array}$

por ant ire mample

Variable ... $06 \pi$

racror

Q14 expartax

For antire asople

Variable .. 06t

racton

Q14

exportax

Q14 none exp

por me1re uanple
ENV ISS - NOISE POLLUTION

Mean stad, Det. n

$\begin{array}{llr}3.772 & 1.017 & 92 \\ 3.715 & 1.057 & 137 \\ 3.738 & 1.039 & 229\end{array}$

ERV ISS - VEHICLE EMTSSIONS Mean std. Dev.

$\begin{array}{rrr}3.457 & 1.226 & 92 \\ 3.555 & 1.106 & 137 \\ 3.515 & 1.153 & 229\end{array}$

EAv ISg - SOLID WASTE DISPOSNL mean std. Dov. I

$\begin{array}{llr}3.641 & 1.254 & 92 \\ 3.620 & 1.151 & 137 \\ 3.629 & 1.191 & 229\end{array}$

ESV ISS - RESOURCZ DEPLETIOH

Mesn sta. Dev. n

$\begin{array}{lll}3.489 & 1.181 & 92\end{array}$

$3.586 \quad 1.242 \quad 237$

$\begin{array}{lll}3.546 & 1.156 \quad 229\end{array}$

YWV ISS - empLorex $\mathrm{a/S}$

Menn std. Dev. y

$4.576 \quad .802 \quad 92$

$4.504 \quad .796 \quad 137$

$\begin{array}{lll}4.533 & .797 \quad 229\end{array}$ 
Variable .. Q6M racros ENV ISS - TINUACLAL SUPPORT ENV GROUPS Maan sta. Dev.

$\begin{array}{lrrrr}014 & 3.043 & 1.257 & 92 \\ 014 & 3.224 & .966 & 137 \\ \text { yor entire Banple } & 3.092 & 1.090 & 229\end{array}$

Ce11 Meana and standard Deviatione (Cowr,)

EFPEC .. Q14

Multivariate reste of significance (s $=1, \mathrm{M}=5$ 1/2, $n=106$ 1/2)

Toet Itnine

Value Approx, $P$ Bypoth, DF Errox DP sig, of $F$

$\begin{array}{llllll}\text { Pillaik } & .12164 & 2.29040 & 13.00 & 215.00 & .007 \\ \text { Botellings } & .13849 & 2.29040 & 13.00 & 215.00 & .007 \\ \text { Wilks } & .87836 & 2.29040 & 13.00 & 215.00 & .007 \\ \text { Hoys } & .12164 & & & & \end{array}$

errect .. 014 (CONT, )

Dnivariate 7 -tenta with $(1,227)$ b. 7 .

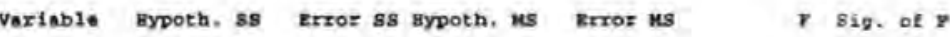

\begin{tabular}{|c|c|c|c|c|c|}
\hline 1.19733 & 316.15638 & 1.29733 & 1.39276 & .83966 & .355 \\
\hline 3.89282 & 325.33862 & 3.69282 & 1.43321 & 2,71615 & .101 \\
\hline 8.50635 & 316.72509 & 6.50635 & 1.39526 & 6.09659 & .024 \\
\hline 13.72927 & 317.91265 & 13.72927 & 1.40050 & 9.00315 & .002 \\
\hline 1.96250 & 229.96763 & 1.96250 & 1.01307 & 2.93718 & .265 \\
\hline 5.70532 & 324.50428 & 5.70532 & 1.42953 & 3.99104 & .047 \\
\hline .70048 & 349.70200 & .70048 & 1.54054 & .45989 & .498 \\
\hline .27514 & 246.10433 & .27514 & 1.08416 & .16155 & .688 \\
\hline .53200 & 302.66550 & .53100 & 1,33333 & .39825 & .529 \\
\hline .02396 & 323.42582 & .02396 & 1.42478 & .01682 & .697 \\
\hline .69476 & 304.27380 & .49476 & 1.34061 & .36911 & .564 \\
\hline .28000 & 144.71557 & .28880 & .63751 & .45301 & .502 \\
\hline .35764 & 270.71660 & .35764 & 1.19253 & .29536 & $.5 \overline{4}$ \\
\hline
\end{tabular}

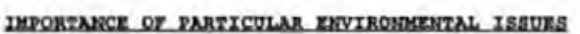

MITIATIVIMO IBLTIATIVE

231 cases sccepted.

o cases rejected because of out-of-range factor values,

10 chese rejected because of winaing asta.

2 non-espty celle.

2 design will be procesaled.

Ca11 Heane and standard Deviationa

variable ... Q6A

pactor

015

Q15

some INI

No INITI

Por entire namplo gsv ras - ACID RAIr

$\begin{array}{lrr}\text { Mean } & \text { Eta. Dev. } \\ 3.152 & 1.112 & 128 \\ 3.010 & 1.233 & 103 \\ 3.199 & 1.177 & 231\end{array}$


Ca11 Mesng and standard Daviations (COMg,

Varinb1e .. Q61

FACTOR

cope

015 sone $\mathrm{mr}$

Q15 Wo TMTTI

For entire sample

Variable .. Q6C

PACTOR

CODE

015

Q15

SOME INI

*ล INITI

For entire nomble

variable .. Q6D

FACTOR

CODE

ENV ISS - WATER POLLUTION

Maan std. Desv.

$\begin{array}{lll}3.906 & 1.111 & 128 \\ 3.621 & 1.299 & 103 \\ 3.779 & 1.205 & 231\end{array}$

a15 SOME INI

Q15 no INITI

por entire asmple

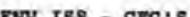

Moen std. Dor. N

$\begin{array}{lll}3.586 & 1.083 & 128 \\ 3.175 & 1.294 & 103 \\ 3.403 & 1.197 & 231\end{array}$

ZNV ISS - GLOBN WAPMINO

Mana std. Dev. n

$\begin{array}{lll}3.578 & 1.098 & 128 \\ 3.165 & 1.284 & 103 \\ 3.398 & 1.200 & 231\end{array}$

Ce11 Heans and standard Devietions (CONz.)

variable .. Q6z

ENV ISS - EARRGY USAGE

phcrok.

CODE

Mean std. Dev, N

015 BONE INI

Q15 No IMrTI

For entire ensople

Variable .. 067

EACroR

ENV ISS - EFPLUENT VASTE DISPOSNL

Mean std, Dov.

$\begin{array}{lrl}4.195 & .905 & 128 \\ 3.786 & 1.081 & 103 \\ 4.013 & 1.006 & 231\end{array}$

Q15 SORE IMI

025 no rerrs?

por entire sanple

$3.013 \quad 1.114 \quad 126$

$3,546 \quad 2.319 \quad 203$

$3.693 \quad 1.314 \quad 231$

Variable .. 066

pACTOR

CODE

ENV ISS - DEFORESTATION

Mean sta. Dev. I

$\begin{array}{lllll}\text { Q15 SOME IMI } & 3.492 & 1.163 & 128 \\ \text { Q15 No ririt } & 3.252 & 1.334 & 103 \\ \text { Por antire saspio } & 3.385 & 1.235 & 231\end{array}$

Ca1I Means and standard Deviations (Conz.)

Voriable ... $06 \mathrm{~B}$

RNV ISS - soIsE pOLLUTIOH

pacror

CODE

Mean std. Dav.

и

015 SONE nir

Q15 No TMITI

Por ontire sample

$\begin{array}{lll}3.836 & -937 \quad 128\end{array}$

$3.592 \quad 1.250 \quad 103$

$3,727 \quad 1,062 \quad 231$

variable... 061

REV ISS - VRBICLE EMISSIONS 


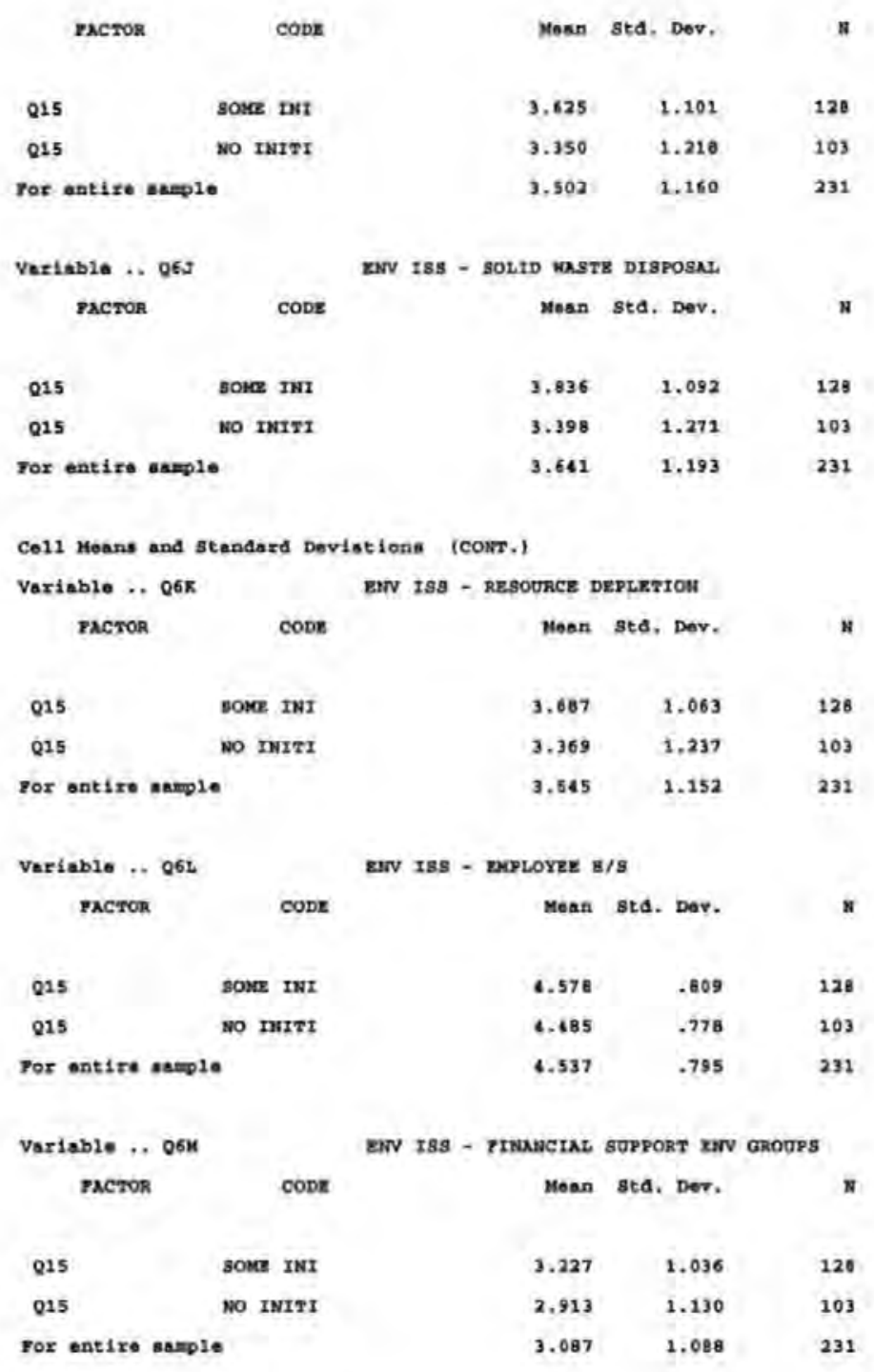

Ca11 Meane and standerd Devistione (COMr,)

EYPzCF .. Q15

Mulfivariate Teate of significance $(s=1, x=51 / 2, x=107$ 1/2)

Tent Nase Value Approx, V Bypoth, DP Exror DE Big. of $P$

$\begin{array}{llllll}\text { Pillais } & .06809 & 1.21957 & 13.00 & 217.00 & .267 \\ \text { Hotolilinga } & .07306 & 1.21957 & 13.00 & 217.00 & .267 \\ \text { Wilks } & .93191 & 1.21957 & 13.00 & 217.00 & .267 \\ \text { Roya } & .06809 & & & & \end{array}$

rezect .. 025 (cowr.)

Dnivariate 7 -teate with $(1,229)$ D. 7 .

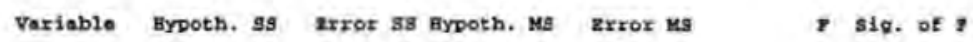

$\begin{array}{lllllll}\text { Q6A } & 6.66985 & 312.16998 & 6.66985 & 1.36319 & 4.89283 & .028 \\ \text { Q6B } & 9.64939 & 319.90906 & 9.64939 & 1.39698 & 6.90730 & .009 \\ \text { Q6C } & 9.73859 & 321.41292 & 9.73059 & 1.40355 & 6.93654 & .009\end{array}$




\begin{tabular}{|c|c|c|c|c|c|c|}
\hline $86 \mathrm{D}$ & 4.63225 & 329.10801 & 4.63225 & 1.43715 & 3.22321 & .076 \\
\hline Q6E & 9.54288 & 223.42816 & 9.56288 & .97563 & 9.78230 & .002 \\
\hline Q67 & 4.12409 & 335.05360 & 6.12609 & 1.46312 & 2.81871 & .095 \\
\hline$Q 60$ & 3.28088 & 347.42908 & 3.20008 & 1.51716 & 2.16252 & .263 \\
\hline Q68 & 3.30971 & 246.42847 & 3.38971 & 1.07611 & 3.14997 & .077 \\
\hline Q6 I & 6.33246 & 305.42748 & 4.33246 & 1.33370 & 3.24769 & .073 \\
\hline Q6J & 20.94319 & 316.23430 & 10.94319 & 1.38094 & 7.92447 & .005 \\
\hline Q6K & 5.79214 & 299.48058 & 5.79214 & 1.30778 & 4.42901 & .036 \\
\hline 06L & .49032 & 146.96691 & .49032 & .63296 & .77666 & .380 \\
\hline Q614 & 5.62512 & 266.64328 & 5.62512 & 1.16436 & 4.83099 & .029 \\
\hline
\end{tabular}

\section{IMPORTANCE OF ENVIRONMENTAL ISSUES}

QY SIZE OP COMPASY

musova qSa to q5b by $q^{2}(1,5)$ /print cellinfo.

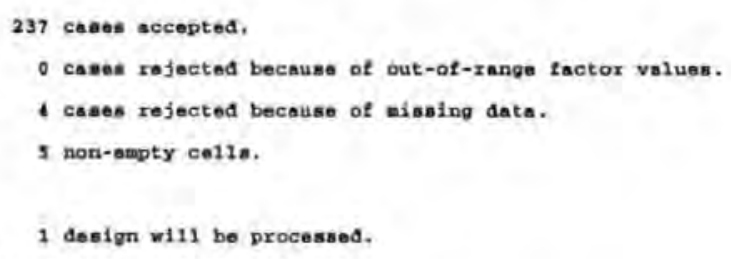

Ce11 Means and stendard Devilat tone

\begin{tabular}{|c|c|c|c|c|}
\hline PACTOR & CODE & Man & std. Dev. & 8 \\
\hline Q2 & $0-10$ & 3.687 & .969 & 131 \\
\hline 22 & $11-25$ & 3.680 & .854 & 48 \\
\hline 22 & $26-100$ & 3.881 & 1.017 & 42 \\
\hline 92 & $101-200$ & 4.125 & .661 & 3 \\
\hline
\end{tabular}

Ce11 woans and staninnd Deviationa (CONT.)

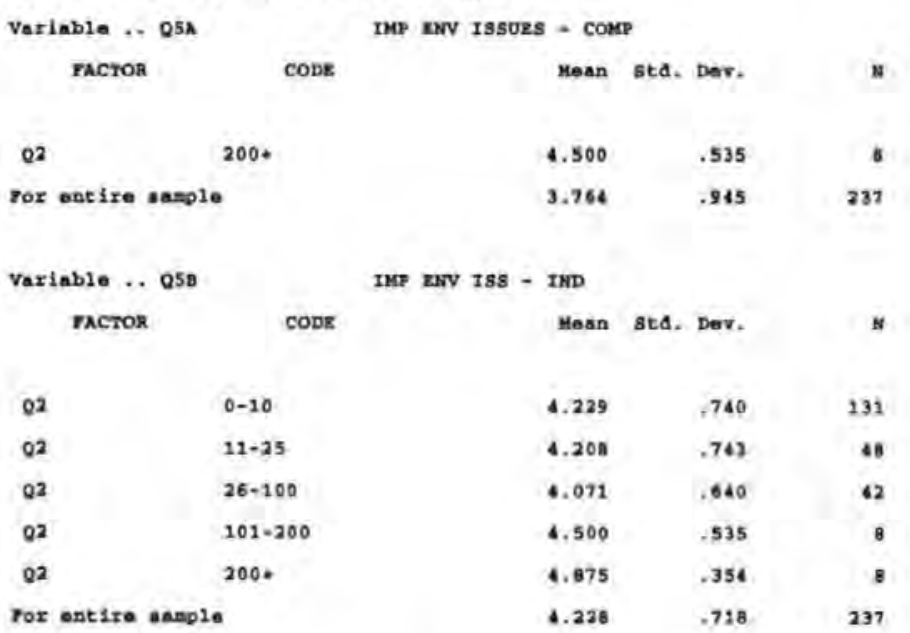

Ca11 Meane and standard Doviatione (CONT.)

zPrect ., Q2

Multivariate Teata of signifieanen $(s=2, M=1 / 2, N=1141 / 2)$

Teat Name Volue Approx, Pypoth. DP error op sig. of $F$ 


$\begin{array}{llllll}\text { Pillald } & .06706 & 2.01237 & 6.00 & 464.00 & .043 \\ \text { Hotelilings } & .06954 & 1.99931 & 8.00 & 460.00 & .045 \\ \text { Wilks } & .93399 & 2.00580 & 0.00 & 162.00 & .044 \\ \text { Roys } & .04182 & & & & \end{array}$

ePrect .. 02 (covrs,)

Onivariate P-teata with $(4,232)$ D. $\mathbf{P}$.

Variable Eypoth. ss Error as Bypoth. us Error us

$\begin{array}{lllllll}\text { Q5A } & 7.00773 & 203.76020 & 1.75193 & .87828 & 1.99874 & .096\end{array}$

$\begin{array}{lllllll}\text { Q5B } & 4.98905 & 116.70715 & 1.24726 & .30305 & 2.47941 & .045\end{array}$

TRPOATANCR OF PARXTCULNR ERVIRONOEENTAL ISSURS

\section{BY SIZE}

Masova a6e to q6e by q2 $^{2}(1,5)$ /print cel1info.

229 cases accepted.

o canes rejected because of out-of-range factor valuak.

12 cases rejected because of nissing dats.

5 non-emty ceila.

1 design will be processed.

Cail Maang and Btandard Deviations

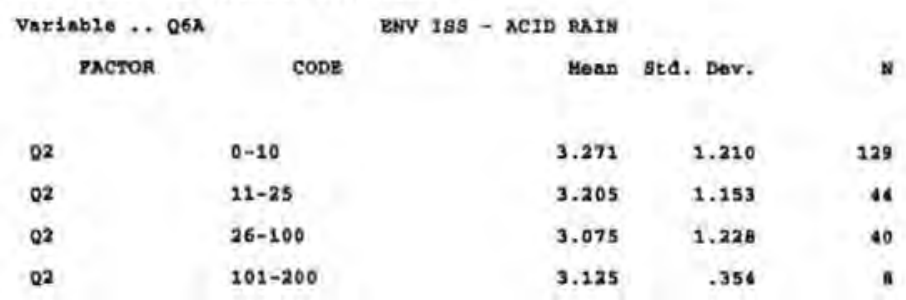

Ca11 Meana and standard Devistiona (COWr.)

Veriab10 .. Q6A ENV ISS - ACID RXIN

pActor CODE

Hean Sta. Dev.

$02 \quad 200+$

Por ant 1re aample

.675

3.205

.991

1.172

229

Variable ... Q68

ENV ISS - $\mathrm{CrC}^{\prime}$

vactor

CODE

Mesa sta. Dev.

\begin{tabular}{|c|c|c|c|c|}
\hline$Q 2$ & $0-10$ & 3.411 & 1,190 & 129 \\
\hline 02 & $11-25$ & 3.250 & 1.104 & 64 \\
\hline$Q 2$ & $26-100$ & 3,400 & 1.257 & 40 \\
\hline Q2 & $101-200$ & 3.375 & 1.061 & 8 \\
\hline Q2 & 2004 & 1.250 & .707 & A \\
\hline Por & & 3.406 & 1.187 & 229 \\
\hline
\end{tabular}

Ce11 Means and Btandard Deviations (CONT.) 


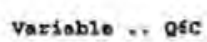

PACTOR

$\begin{array}{ll}02 & 0-10 \\ 02 & 12-25 \\ 02 & 26-100 \\ 02 & 101-300 \\ 02 & 200+\end{array}$

Por ontire masplo

Varieble ... Q6D

PACTOR cone

ENV ISS - WATER POLLUIION

Mean sta. Dev.

$\begin{array}{llrrr}02 & 0-10 & 3.550 & 1.231 & 129 \\ 02 & 11-25 & 3.955 & 1.219 & 14 \\ 02 & 26-100 & 4.000 & 1.086 & 10 \\ 02 & 101-200 & 4.375 & .916 & 8 \\ 02 & 2004 & 4.625 & .746 & 8 \\ \text { ror entire masple } & 3.773 & 1.207 & 229\end{array}$

Ce11 Meane and Stendard Deviations (CONr.)

variable...068

yxcror

02

ror ontire snople

variable .. Q68 Facror

\begin{tabular}{|c|c|c|c|c|}
\hline$Q_{2}$ & $0=10$ & 3.006 & 1.061 & 129 \\
\hline 02 & $11-25$ & 4.227 & 1.008 & 44 \\
\hline 22 & $26-100$ & 4.225 & $=000$ & 40 \\
\hline 02 & $101-200$ & 4.375 & .516 & e \\
\hline 02 & $200+$ & 4.625 & .744 & 8 \\
\hline \multicolumn{2}{|c|}{ Por ontire snople } & 4.009 & 1.009 & 229 \\
\hline
\end{tabular}
zarv ISS - ERERGY DSAGE

ERV ISS - EgFLUENT WASTE DISPOSAL Mean sta. Dev,

$\begin{array}{llrrr}Q 2 & 0-10 & 3.512 & 1.238 & 129 \\ Q 2 & 11-25 & 3.841 & 1.219 & 41 \\ Q 2 & 26-100 & 3.625 & 1.083 & 40 \\ Q 2 & 101-200 & 4.250 & .686 & 8 \\ Q 2 & 200+ & 4.750 & .663 & 0 \\ \text { Por ontire nample } & 3.699 & 1.203 & 229\end{array}$

Cell Moane and standard Doviationa (CONr.)

Variable... 060

ractor

$\begin{array}{ll}Q 2 & 0-10 \\ Q 2 & 11-25 \\ Q 2 & 26-100 \\ Q 2 & 101-200 \\ Q 2 & 2004\end{array}$

For entira samplo

variabl. Q6 Q6 yAcToR
ENV ISS - DEFORESTATION

Mesn sta. Dev.

$\begin{array}{rrr}3.372 & 1.269 & 129 \\ 3.565 & 1.210 & 46 \\ 3.325 & 1.248 & 40 \\ 3.500 & .756 & 0 \\ 3.000 & .926 & 8 \\ 3.389 & 1.225 & 229\end{array}$

saV ISS - NOISE POLLUTION

Mean std. Dev. 


$\begin{array}{llllr}Q 2 & 0-10 & 3.674 & 1.105 & 129 \\ 02 & 11-25 & 3.705 & 1.025 & 46 \\ Q 2 & 26-100 & 3.825 & .956 & 40 \\ Q 2 & 101-200 & 6.000 & .926 & 8 \\ Q 2 & 200+ & 3.750 & .707 & 8 \\ \text { Por entite samplo } & 3.721 & 1.043 & 229\end{array}$

Coll maans and standard peviationa (corr.)

variable .. $06 \mathrm{~T}$

nACroR

ENV ISS - VEHICLE EMISSIONS

$\begin{array}{llrrr}02 & 0-10 & 3.504 & 1.173 & 129 \\ 02 & 11-25 & 3.523 & 1.089 & 41 \\ Q^{2} & 26-100 & 3.575 & 1.230 & 40 \\ Q^{2} & 101-200 & 3.750 & .886 & 8 \\ Q^{2} & 200+ & 3.000 & 1.069 & 8 \\ \text { Por entire anpic } & 3.511 & 1.153 & 229\end{array}$

var1ab10... 065

ractor

$\begin{array}{ll}Q 2 & 0-10 \\ 02 & 11-25 \\ Q 2 & 26-100 \\ 02 & 101-200 \\ Q 2 & 200+\end{array}$

For entire oseple
ENV ISS - SOLID RESTE DISPOSNL Mean ste. Dev.

$\begin{array}{rrr}3.504 & 1.245 & 129 \\ 3.545 & 1.088 & 44 \\ 3.950 & .959 & 40 \\ 4.500 & .756 & 8 \\ 4.125 & 1.458 & 8 \\ 3.646 & 1.182 & 229\end{array}$

Ce11 Meana and standard beviationa (Cokr.)

variable .. $06 \mathrm{~K}$

rACTOR

cope

ENV ISS - RESOURCE DEPLETIOH

Menn std. Dov. *

\begin{tabular}{|c|c|c|c|c|}
\hline Q2 & $0-10$ & 3,550 & 1.205 & 129 \\
\hline 22 & $11-25$ & 3,636 & 1.163 & 44 \\
\hline 02 & $26-100$ & 3.425 & 1.059 & $\leqslant 0$ \\
\hline 82 & $101-200$ & 3.875 & .035 & 8 \\
\hline 02 & $200+$ & 3,000 & .926 & 8 \\
\hline \multicolumn{2}{|c|}{ por entire sempla } & 3.537 & 1.153 & 229 \\
\hline
\end{tabular}

var1ab10 .. 862 ENV ISS - EMPLOYRE $\mathrm{H} / \mathrm{s}$

PACTOR cope Mesn sta. Dav,

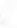
9 


\begin{tabular}{|c|c|c|c|c|}
\hline$Q 2$ & $0-10$ & 3.155 & 1.057 & 229 \\
\hline Q2 & $11-25$ & 3.114 & 1.166 & 44 \\
\hline 02 & $26-100$ & 2.900 & 1.150 & 40 \\
\hline 02 & $101-200$ & 2.875 & .641 & $\theta$ \\
\hline 82 & 2004 & 3.125 & 1.126 & e \\
\hline \multicolumn{2}{|c|}{ Por ont1xo nasplo } & 3.092 & 1,082 & 229 \\
\hline
\end{tabular}

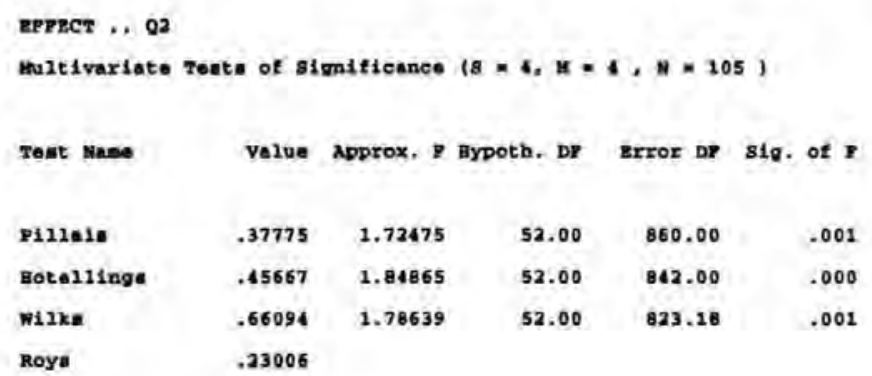




$\begin{array}{llllll}\text { pillale } & .05648 & 2.24737 & 6.00 & 464.00 & .038 \\ \text { Botollinga } & .05899 & 2.26130 & 6.00 & 460.00 & .037 \\ \text { Wi2ks } & .94392 & 2.25441 & 6.00 & 462.00 & .037 \\ \text { loye } & .04820 & & & & \end{array}$

onivariate $\mathbf{r}$-toeti with $(3,232)$ D. P.

variable Bypoth. 85 crror ss Hypoth. Ms trror ms 7 sig. of $z$

$\begin{array}{lllllll}\text { Q5X } & 10.06223 & 200.11998 & 3.35408 & .06259 & 3.68839 & .010\end{array}$

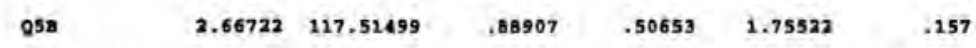

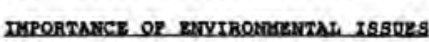

\section{BY COMPANY CHARACTERISTICS}

MAsOVX Q5A TO Q5B BY Q1 $(1,4)$ /Drint callinfo.

236 casen scented.

0 cases rejected beckuse of out-of-range tactor values.

5 camer rejncted because of misuing data.

4 non-ampty cella.

1 design will be procesaed.

cell Mesne and standard Deviatione

variable ... Q5i

ractor

IMP ENV ISSUES - COMP

\begin{tabular}{|c|c|c|c|c|}
\hline 01 & A smorn & 3.679 & .937 & 159 \\
\hline Q2 & A Headou & 3.636 & 1.055 & 33 \\
\hline Q1 & A suasid & 4.132 & .821 & 38 \\
\hline 01 & A sUasto & $\$ .500$ & .548 & 6 \\
\hline \multicolumn{2}{|c|}{ Por ontixe onsolo } & 3.767 & .946 & 236 \\
\hline
\end{tabular}

Co1l Hanz and atandara Devlations (Conr.)

Var1ab10... Q58

racror

IMP ENV ISS - IND

\begin{tabular}{|c|c|c|c|c|}
\hline 01 & A srwoux & 4.195 & .725 & 159 \\
\hline Q1 & a Hexpgo & 4.212 & .740 & 33 \\
\hline Q2 & A sUBsID & 4.316 & .662 & 30 \\
\hline 02 & A SUBSTD & 4.033 & .400 & 6 \\
\hline \multicolumn{2}{|c|}{ ror ent 1 ro ando } & 4.233 & .715 & 236 \\
\hline
\end{tabular}

EPFECT .. Q1

Multivariate reate of significance $(a+2$, U \& O, N $=1141 / 2)$

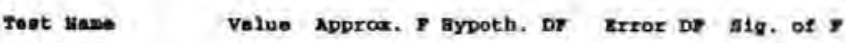

$\begin{array}{llllll}\text { P111aid } & .05646 & 2.24737 & 6.00 & 464.00 & .038 \\ \text { Botel1inge } & .05899 & 2.26130 & 6.00 & 460.00 & .037 \\ \text { wi1ka } & .94392 & 2.25441 & 6.00 & 462.00 & .037 \\ \text { Roya } & .04820 & & & & \end{array}$


Univariate p-teata with $(3,232)$ D. $y$.

Variable Ilypoth. ss zrror ss \#ypoth. MS Error MS F sig. of F

$\begin{array}{lrrrrrr}85 \lambda & 10.06223 & 200.11998 & 3.35408 & .86259 & 3.88839 & .010 \\ Q 58 & 2.66722 & 117.51499 & .88907 & .50653 & 1.75522 & .157\end{array}$

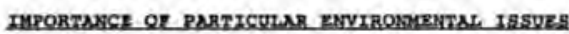

\section{BY COMPANY CHARACTERISTICS}

MNSOVX Q6X TO Q6A BY Q1 $(1,6)$ /Drint co11into.

228 chnall aceepted.

o casas rejected because of out-of-range factor valuea.

13 cases rojected becsura of aissing data,

4 non-enty cella.

1 design will be procosaed.

C611 Mosne and stendard Deviation

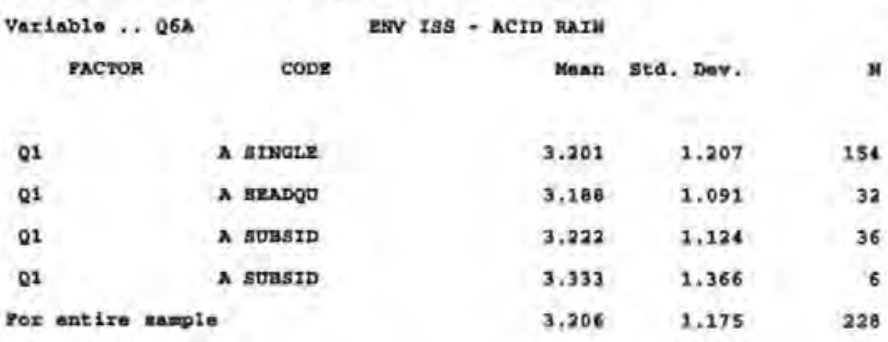

Ca 21 Means and btandard Deviations (CON7.)

Vorinble .. Q68

gactor

EIV IBS - CPC'S

$\begin{array}{rrrrr}01 & \text { A smate } & 3.336 & 1.195 & 154 \\ 01 & \text { A senego } & 3.323 & 2.051 & 32 \\ 01 & \text { A sussid } & 3.667 & 1.265 & 36 \\ 01 & \text { A subsid } & 4.167 & .753 & 6\end{array}$

for ontire sample

$3.400 \quad 1.189 \quad 228$

Variable... QRe

Eav ISS - GLOBAL WARMING

PACTOR cone

Mean gtd. Dev.

$\begin{array}{rrr}3.364 & 1.230 & 154 \\ 3.346 & 1.153 & 32 \\ 3.417 & 1.204 & 36 \\ 4.000 & .632 & 6 \\ 3.386 & 1.202 & 226\end{array}$

por entire sample

A single

A Hzaded

A sUBsid

A susard

$3.386 \quad 1.202$

226

Ce21 Mesna snd stendard Deviatione (CONT.)

variable... Q6D

PACTOR

ENV ISS - WATER POLLUTION

CODE

mean sta. Dev.

$3.662 \quad 1.243$

154 


$\begin{array}{ll}Q 1 & x \text { geadeo } \\ 01 & \text { x subsid } \\ Q 1 & x \text { sugsid }\end{array}$

pox ent1re seaple

variable ... $06 \mathrm{~s}$

pacror

$\begin{array}{rrr}3.012 & 1.176 & 32 \\ 4.026 & 1.055 & 36 \\ 5.000 & .000 & 6 \\ 3.776 & 1.209 & 228\end{array}$

ERV ISS - ERRRGY USAGE

Mesn sta. Der. I

\begin{tabular}{|c|c|c|c|c|}
\hline Q1 & A srwaLE & 3.916 & 1.022 & 156 \\
\hline 21 & A ERADgO & 4.094 & .928 & 32 \\
\hline Q2 & 入 suesto & 4.222 & 2.045 & 36 \\
\hline & A SUBSTE & 4.667 & .516 & 6 \\
\hline & & 4.009 & 2.031 & 228 \\
\hline
\end{tabular}

Cell Beans and standard Deviations (Corr.)

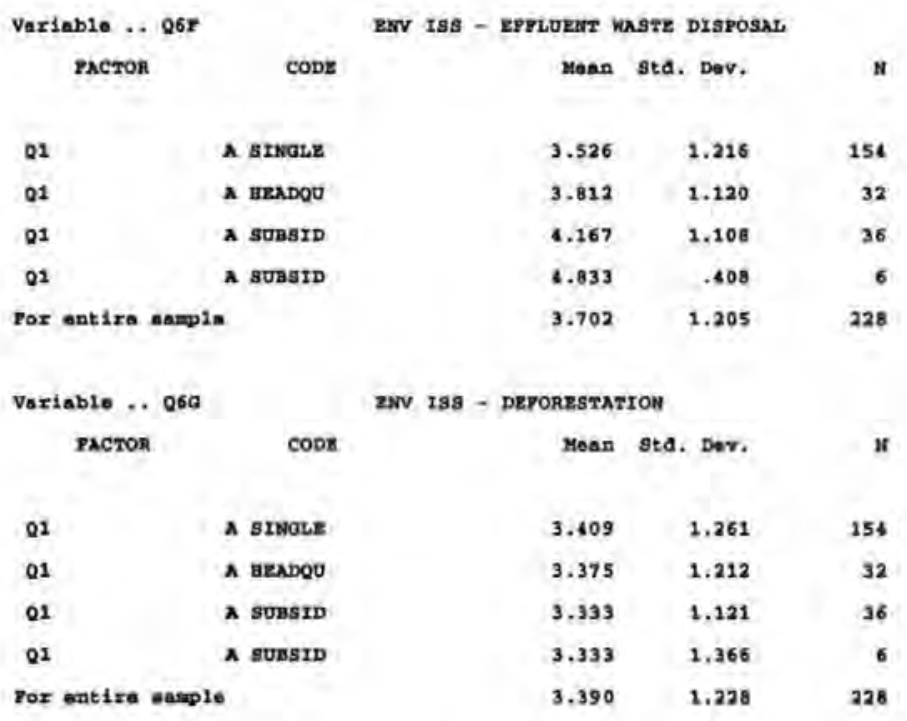

Co 21 Mostil and standard Deviations (CONT.)

variable ... 06B

racron $\cos$

ENV 188 - NOISB POLLUTIOA

Masn std. Dev.

$\begin{array}{rrr}3.656 & 1.025 & 154 \\ 3.613 & 1.120 & 32 \\ 3.861 & 1.099 & 36 \\ 4.167 & .753 & 6 \\ 3.724 & 1.044 & 228\end{array}$

EMV IBB - VEBICLE BISSIONS

varisble .. 061

$$
\begin{aligned}
& \text { A sINGLE } \\
& \text { A BEabev } \\
& \text { A sugsio }
\end{aligned}
$$$$
\text { x sugsid }
$$

7or antire sanple

gACTOR

\begin{tabular}{|c|c|c|c|c|}
\hline 01 & A SINGLR & 3.481 & 1.156 & 154 \\
\hline Q1 & A Hexpgu & 3.531 & 1.218 & 32 \\
\hline Q1 & A SUBSID & 3.639 & 1.073 & 36 \\
\hline 01 & A SUBsid & 3,500 & 1,517 & 6 \\
\hline \multicolumn{2}{|c|}{ Por entira anmole } & 3.513 & 1.155 & 220 \\
\hline
\end{tabular}
cope noen Sta. Dav.

Co11 Menne and standard Deyiatione (CONr.)

variable, 263

ERV ISS - GOLID waste DISPOSAL 


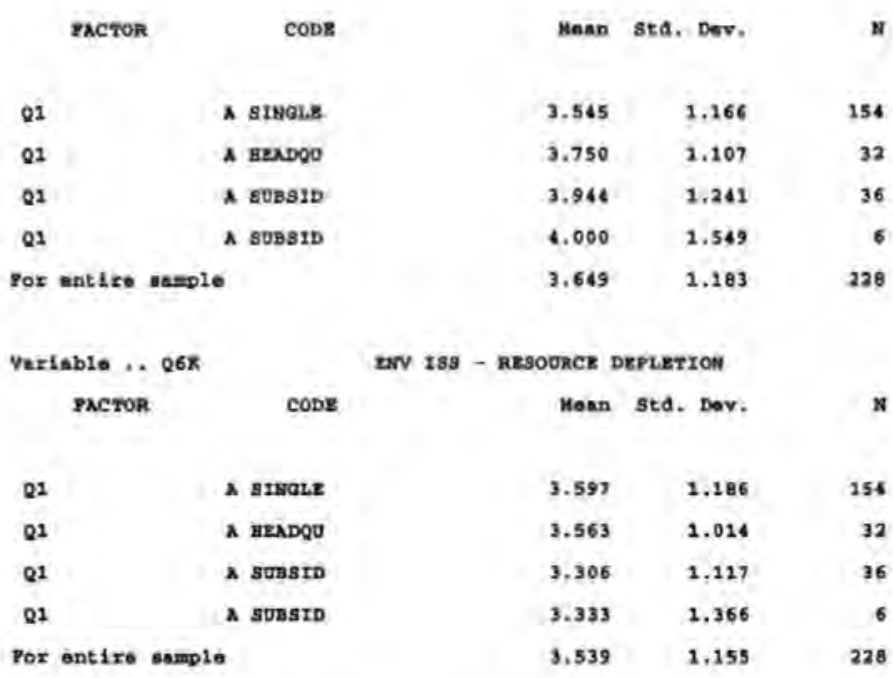

Cell Meane and standard Deviatione (Cokr.)

Variabie .. Q6L

FACTOR

gRV ISS - ERPLOYER B/B

\begin{tabular}{|c|c|c|c|}
\hline Q1 & A sInGLE & 4.508 & .786 \\
\hline Q1 & A Hexpgo & 4.500 & .880 \\
\hline 82 & A. SUBsid & 4.667 & .793 \\
\hline 81 & A SUBSID & 4.833 & .608 \\
\hline \multicolumn{2}{|c|}{ For entire sample } & 4.539 & .793 \\
\hline
\end{tabular}

GTV ISS - YTRANCIAL SUPPORZ gINV GRONPS

$$
\text { Mean sta. Dev, n }
$$

$\begin{array}{rrr}3.104 & 1.115 & 154 \\ 2.075 & .942 & 32 \\ 3.139 & 1.046 & 36 \\ 3.667 & 1.211 & 6 \\ 3.092 & 1.085 & 228\end{array}$

ror entire sarple

$$
\begin{aligned}
& \text { 2. sincle } \\
& \text { A Erengo } \\
& \text { A sugsio } \\
& \text { x sussid }
\end{aligned}
$$

Ce11 Meona and standard Derlationa (CONr.)

errecs .. 22

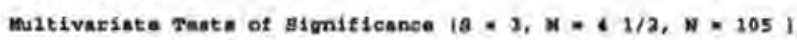

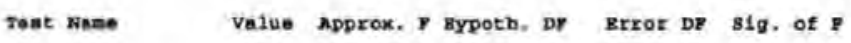

$\begin{array}{llllll}\text { Plilain } & .21168 & 1.24969 & 39.00 & 642.00 & .146 \\ \text { Botolings } & .24562 & 1.32568 & 39.00 & 632.00 & .092 \\ \text { Wi1ke } & .79666 & 1.28737 & 39.00 & 628.53 & .117 \\ \text { Roya } & .16465 & & & & \end{array}$

EFrect, 01 (COAr,)

Dnivariste F-tenta with $(3,226)$ D. $\boldsymbol{r}$.

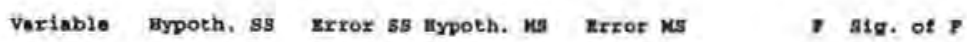

$\begin{array}{llllllll}\text { Q6A } & .12111 & 313.19030 & .04037 & 1.39817 & .02887 & .993\end{array}$

$\begin{array}{lllllll}\text { Q6B } & 6.91590 & 324.14989 & 2.30530 & 1.40245 & 1.64376 & .160\end{array}$ 


\begin{tabular}{|c|c|c|c|c|c|c|}
\hline Q6C & 2.42997 & 325.60512 & 9.80999. & 1.45359 & .55723 & .644 \\
\hline Q6D & 23.30332 & 318.28878 & 0.43466 & 1.42093 & 3.12080 & .027 \\
\hline Q68 & 5.80555 & 226.17690 & 1.93518 & 1.00972 & 1.91656 & .128 \\
\hline Q6F & 20.61486 & 309.10404 & 6.87162 & 1.37993 & 4.97969 & .002 \\
\hline 260 & .19817 & 362.06061 & .06606 & 1.52706 & .04326 & .988 \\
\hline Q6: & 2.81868 & 246.77363 & .93949. & 1.09274 & .85976 & .463 \\
\hline Q61 & .74466 & 302.21586 & .24822 & 1,34918 & .18398 & .907 \\
\hline 265 & 5.85912 & 312.07071 & 1.95306 & 1.39317 & 1.40186 & .243 \\
\hline $06 \mathrm{~K}$ & 2.75855 & 299.88618 & .91952 & 1.33878 & .68683 & .561 \\
\hline & 1.31790 & 141.32684 & .43930 & .63092 & .69628 & .555 \\
\hline & 3.58924 & 263.47655 & 1.19641 & 1.17623 & 1,01715 & .386 \\
\hline
\end{tabular}


GET / FILE 'otlepesiportrec.oye',

The gPSS/PC+ syaten 2110 is roed fros

f110 c: InDEmiportroc, oys

The file was ereated on $4 / 19 / 93$ st 11702:54

and is titled spss/PC+ Syatem File written by bata gatry II

The sPsg/PC+ systea file contains

241 canes, each consinting of

94 variables (inclualng ayaten variablea).

94 variables will be uaed in thla sesalon.

$\begin{array}{lll}\text { Pags } 2 & \text { SPSB } / \mathrm{PC} & 5 / 13 / 93\end{array}$

Thio procedure wan eomplated at $11: 18,36$

$\begin{array}{ll}\text { Page } 3 & \text { spsg/pC+ }\end{array}$

FACTOR /VARIABLES Q6A TO Q6M /anve regression (a11 queens).

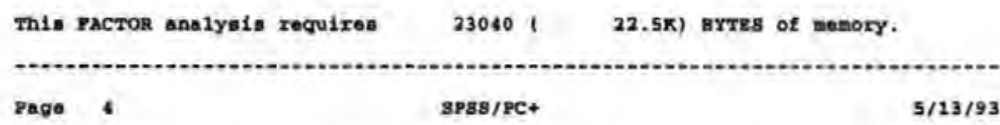

...

Analyail Wuber 1 Lifutwime deletion of cases with minaing valuse

zxtraction 1 for Analysie 1, Principal-Componente Ansiysis (PC)

In1tial statiatics:

\begin{tabular}{|c|c|c|c|c|c|}
\hline variable & Communality & - Factor & gigenvalue & Pot of var & Cun pet \\
\hline Q6x & 1.00000 & $\cdot$ & 7.24266 & 55.7 & 55.7 \\
\hline Q68 & 1.00000 & $\cdot$ & 1.05129 & 8,1 & 63.6 \\
\hline $86 \mathrm{C}$ & 2.00000 & - & $.2934 a$ & 7.6 & 71.6 \\
\hline Q6D & 1.00000 & $\cdot$ & .68422 & 5.3 & 76.7 \\
\hline $06 \mathrm{z}$ & 1.00000 & ? & .58508 & 4.5 & 02.2 \\
\hline 067 & 1,00000 & $\cdot$ & .54492 & 1.2 & e5.4 \\
\hline 060 & 1.00000 & $\cdot$ & .44709 & 3.4 & 88. 8 \\
\hline Q68 & 1.00000 & $\bullet$ & .42758 & 3.3 & 92.1 \\
\hline 261 & 1.00000 & - & .26800 & 2.1 & 94.2 \\
\hline e6s & 1.00000 & 10 & .24012 & 1.8 & 96.0 \\
\hline $06 \pi$ & 1.00000 & 11 & .19713 & 1.5 & 97,6 \\
\hline Q6L & 1.00000 & 12 & .10985 & 1.5 & 99.0 \\
\hline Q69 & 1.00000 & 13 & .12859 & 1.0 & 100.0 \\
\hline
\end{tabular}

$\begin{array}{ll}\text { Page } 5 & \text { SPss/PC+ } \\ \text { 5/13/93 }\end{array}$

PC Eetracted 2 factora.

Fector Matrix: 


\begin{tabular}{|c|c|c|}
\hline Q6x & .03662 & .27880 \\
\hline Q61 & .79106 & .35129 \\
\hline Q6C & 01819 & .30548 \\
\hline Q6D & -80990 & -.17894 \\
\hline Q68 & .71820 & -.35025 \\
\hline Q67 & .78463 & -.18203 \\
\hline Q60 & .86431 & .11765 \\
\hline Q68 & .71140 & $=.39438$ \\
\hline Q61 & 80117 & -.14971 \\
\hline Q65 & .75758 & -.29675 \\
\hline Q6K & .76565 & .00752 \\
\hline 262 & .20010 & .41625 \\
\hline Q6\% & .63202 & .34036 \\
\hline
\end{tabular}

pinal stotistica:

variable Commality - ractor Eigenvalue pet of var Cul pet

\begin{tabular}{|c|c|c|c|c|c|}
\hline $06 \lambda$ & .77766 & - $\quad i$ & 7.24266 & 55.7 & 55.7 \\
\hline Q68 & .74918 & - 2 & 1.05129 & 0.1 & 63.8 \\
\hline $86 \mathrm{C}$ & .76276 & $\bullet$ & & & \\
\hline Q6D & .68795 & $\cdot$ & & & \\
\hline Q68 & .63849 & $\cdot$ & & & \\
\hline Q6r & .64845 & $*$ & & & \\
\hline Q60 & .72672 & • & & & \\
\hline $06 \mathrm{~B}$ & .66162 & * & & & \\
\hline Q6I & .66429 & • & & & \\
\hline Q6a & .66198 & $\cdot$ & & & \\
\hline Q66 & .58628 & - & & & \\
\hline Q62 & .21330 & • & & & \\
\hline Q6u & .51529 & - & & & \\
\hline
\end{tabular}

Verimax Rotation 1, Extraction 1, Ansiysin 1-Kalaer Norma1ization.

Varimax converged in 3 iteration.

Rotated Pactor Matrix:

PACTOR 1 MACTOR 2

Q6x $\quad .51602 \quad .71655$

$\begin{array}{lll}068 & .43460 & .74853\end{array}$ 


$\begin{array}{lll}06 \mathrm{C} & .68364 & .72735 \\ 06 \mathrm{~b} & .76088 & .33016 \\ 06 \mathrm{~B} & .78711 & .13764 \\ 06 \mathrm{Y} & .76206 & .31272 \\ 060 & .61678 & .59055 \\ 06 \mathrm{~B} & .80749 & .09791 \\ 06 \mathrm{I} & .73667 & .34671 \\ 06 \mathrm{~J} & .78762 & .20406 \\ 06 \mathrm{~K} & .61567 & .45522 \\ 06 \mathrm{~L} & -.08211 & .45449 \\ 06 \mathrm{M} & .31220 & .64639\end{array}$

Page a

spss/re.

$5 / 13 / 93$

TAC

Poctor Franuformation Matrix:

PACTOR 1 FACTOR 2

FACTOR $1 \quad .60968 \quad, 58660$

FACTOR $2 \quad-.58660 \quad .80988$

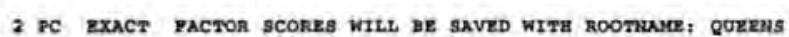

POLLOWTHG PACTOR SCORES WILL, BE ADDED TO THE ACTIVB PTLE,

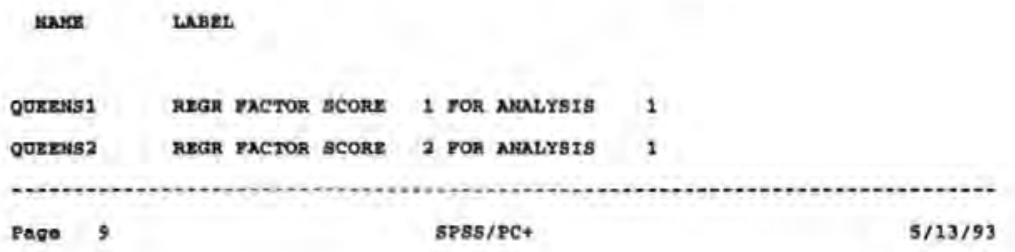

This procedure was conoleted ot $11,21,18$

$\begin{array}{ll}\text { Page } 10 & \text { spsa/pe. } \\ 5 / 13 / 93\end{array}$

T-TEST /PXIQS QUEENS1 QUEENS2.

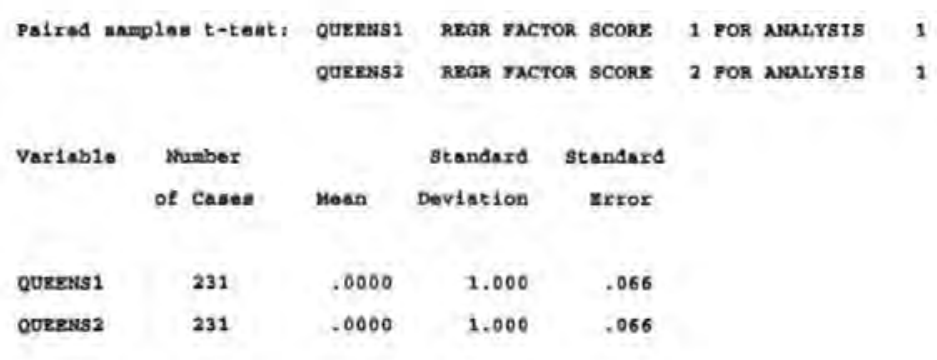




\begin{tabular}{|c|c|c|c|c|c|c|c|}
\hline (Difterence) & standard & Stonderd & 1 & $2-2 \leq 11$ & $1 \quad t$ & Degrees of & $2-\operatorname{Tn} 11$ \\
\hline Moan & Deviation & Erroz & I Corr & Prob. & $\begin{array}{l}\text {, value } \\
\text {, }\end{array}$ & Preedon & Prob. \\
\hline .0000 & 1.416 & .093 & 1.000 & 1.000 & .00 & 230 & 1.000 \\
\hline
\end{tabular}

This procedure was conpleted at $11: 24: 55$

Page $12 \quad$ spss/PC+ $5 / 13 / 91$

phocess Ir (queensel ot 0.5 ).

Phequescres /VARIABLes Q6X To Q6M.

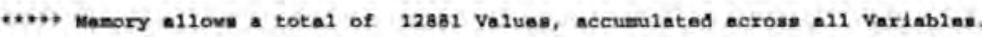
There alwo nay be up to 1610 velue tabele for each variable.

$\begin{array}{rrrrr}1 & 5 & 6.3 & 6.3 & 6.3 \\ 2 & 2 & 2.5 & 2.5 & 8.8 \\ 3 & 28 & 35.0 & 35.0 & 43.8 \\ 4 & 19 & 23.8 & 23.8 & 67.5 \\ 5 & 26 & 32.5 & 32.5 & 100.0 \\ & 10.0 & \end{array}$

valia casea 80 Mialing casea

Fage $16 \quad$ Spss/PC+ $5 / 13 / 93$

Q68 ENV tss - CPC's

valid cun
Value tabel Value prequency porcent percent percent

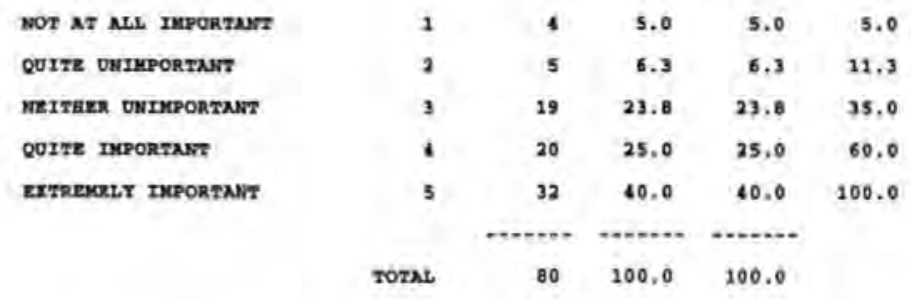

Vasid Cases 80 Mianing Cakes 0 
valia Cum

value Label vilus rraquency fercent fercent parcent

NOT AT ALL IMPORTNIT QUTTE UNIRPORTANT

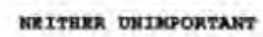
Q0iтg moportun: EXTRECRY LRPORzNAT

$\begin{array}{rrrrr}1 & 5 & 6.3 & 6.3 & 6.3 \\ 2 & 3 & 3.8 & 3.8 & 10.0 \\ 3 & 20 & 25.0 & 25.0 & 35.0 \\ 4 & 22 & 27.5 & 27.5 & 62.5 \\ 5 & 30 & 37.5 & 37.5 & 100.0 \\ & \ldots \ldots & \ldots . .7 .0 & \end{array}$

Valia cases 80 Midesing cases 0

\section{Value Label}

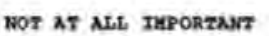
NEITERR ORIMPOREANT QUTTR mpontusr EXTREMELY IMPOREANT

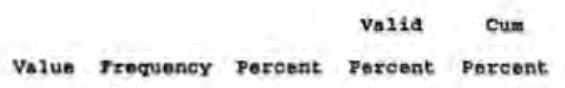

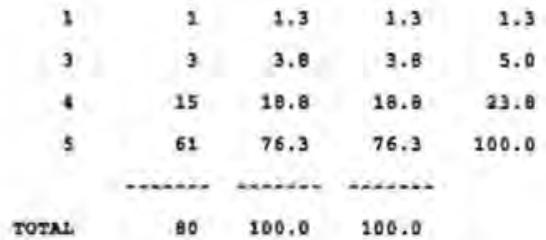

valid cases 00 Missing cases 0

page 17

$06 \mathbf{R}$ ENV ISS - ENERGY USACE

Value Label Neтtake usrmostars: gOITE mePORTNAT EXTREMELY IMPORTANT
Valid cun

valus Prequancy porcent percent percent

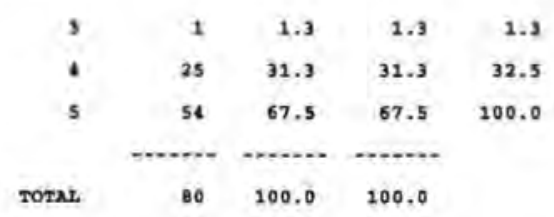

Valid casea 60 Miasing cases 0

$\begin{array}{lll}\text { Page } 18 & \text { SPSS/PC+ } & 5 / 13 / 93\end{array}$

Q67 ENV IBS - EFTLUEAT WA3TE DISFOSAL

valid cum

Value tabel 


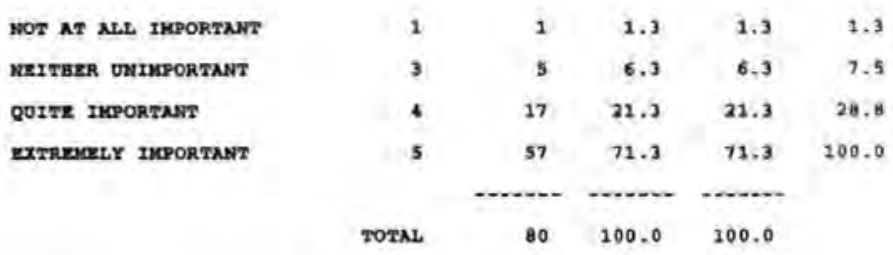

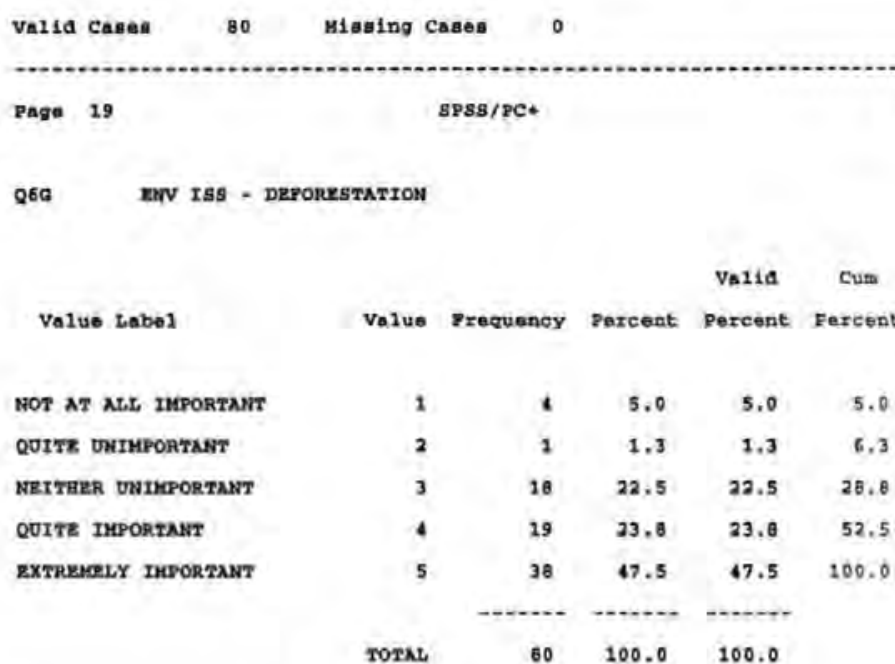

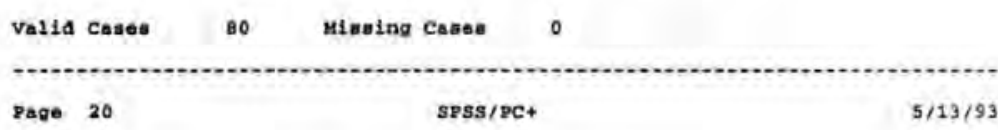

Q68 EAV TSB - NOTSE FOLLLTION

valia cum

Value Label Value grequency percent percent percent

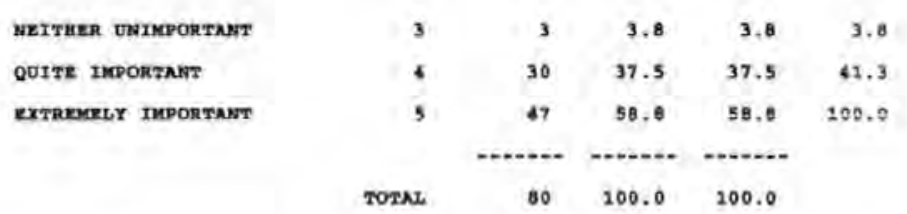

Valia cases go Miasing cases o

21 .

Page 21

SPss/PC+

Q6I ENV ISS - VEBTCLE EMTSSTONS

Val1d cum

Vo1ue tabe1

MOT AT ALL IMPORTANT SEITHER UNTMPORTANT QUITE IMPORTANT exmeMrLY morotart
Volue proquency Percent Percent percent

$\begin{array}{rrrrr}1 & 1 & 1.3 & 1.3 & 1.3 \\ 3 & 8 & 10.0 & 10.0 & 11.3 \\ 4 & 28 & 35.0 & 35.0 & 46.3 \\ 5 & 43 & 53.8 & 53.8 & 100.0 \\ & 100 & 100.0 & 100.0 & \end{array}$




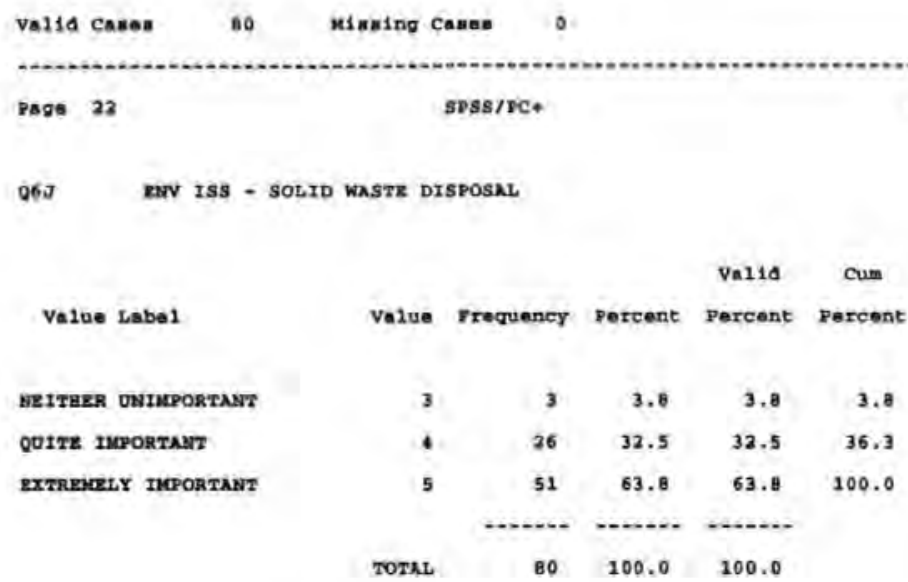

vaild cases 80 Misoing cases o

page 23 SPSS/PC*

$06 \pi$

ENV ISS - RESOURCE DEPLZTION

\begin{tabular}{|c|c|c|c|c|c|}
\hline Volue Labe 1 & value & Frequency & Porcent & $\begin{array}{l}\text { Valid } \\
\text { Percent }\end{array}$ & $\begin{array}{c}\text { Cum } \\
\text { Percent }\end{array}$ \\
\hline MOT AT NLL IMPORTANT & 1 & 2 & 2.5 & 2.5 & 2.5 \\
\hline QUTTE OUIRPORTANT & 2 & 2 & 2.5 & 2.5 & 5.0 \\
\hline NEITEER UNIMPORTAST & 3 & 13 & 16.3 & 16.3 & 21.3 \\
\hline QOITE IMPORTNST & 4 & 23 & 28.8 & 28.8 & 50,0 \\
\hline \multirow[t]{2}{*}{ EXTREIELY MUPORTANT } & 5 & 10 & 50.0 & 50.0 & 100.0 \\
\hline & sorke. & 80 & 100.0 & 100.0 & \\
\hline
\end{tabular}

Volid Cases do Miseing Cames 0

\begin{tabular}{|c|c|c|}
\hline pagn & SPSg/FC+ & $5 / 13 / 93$ \\
\hline
\end{tabular}

Q6L BNV ISS - EMPLOYEE B/S

Valia cua
Value Label Value Frequency percent percent Percent

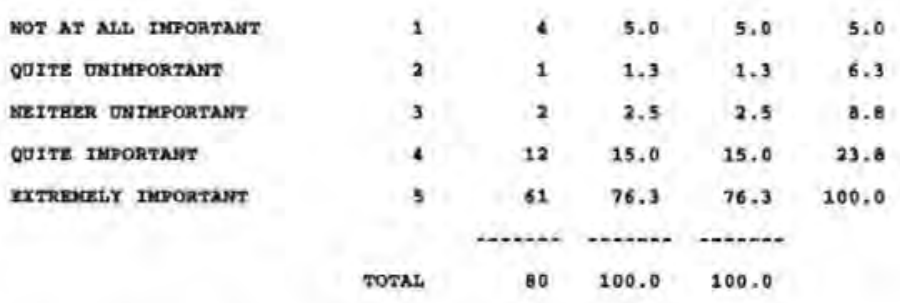

velid canes bo Minging Cason o 


\begin{tabular}{|c|c|c|c|c|c|}
\hline value tabel & value & rrequency & percent & $\begin{array}{l}\text { Valid } \\
\text { percart }\end{array}$ & $\begin{array}{c}\text { Cum } \\
\text { Porcant }\end{array}$ \\
\hline AOT AF NLI TMPORTAN? & 1 & 8 & 10.0 & 10.0 & 10.0 \\
\hline QUTTE URTMPORzAST & 2 & 6 & 7.5 & 7.5 & 17.5 \\
\hline NEITHEX UNTMPORTNT & 3 & 36 & 42.5 & 42.5 & 60.0 \\
\hline gOITE TMPORTANT & 4 & 16 & 20.0 & 20.0 & Bo. 0 \\
\hline EXTUDERY mPONTART & 5 & 16 & 20.0 & 20.0 & 100.0 \\
\hline & TOTAL & 80 & 100.0 & 100.0 & \\
\hline
\end{tabular}

\begin{tabular}{llcl} 
Va11d Cases & $80 \quad$ Mineing Canes 0 & \\
\hline Page 26 & spss/pC. & $5 / 13 / 93$
\end{tabular}

Thin procedure was completed at 11:29:03

Page 27

spss/pct

$5 / 13 / 93$

PROCZss If (queens 1 gt 0.5 ).

Proqunactes /Varialas Q2,

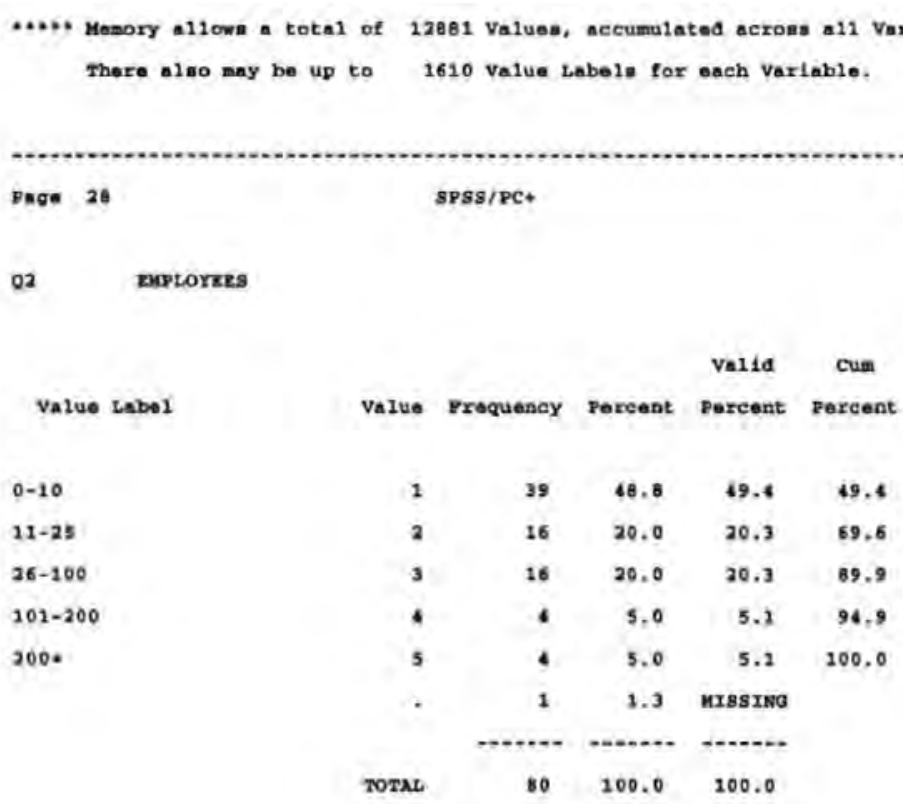

valsa cases 79 Minning Canes 1

\begin{tabular}{|c|c|}
\hline Page & SPSB/FC+ \\
\hline
\end{tabular}

This procedure was completed at 11:29:51 
mocess if (queensi gt 0 ).

Fag QUERCTES IVARTARLES $\mathrm{Q}^{2}$.

A... Memory allows a total of 12881 Values, accunulated across all Variables. There alwo may be up to 1610 value Labels for ench variable.

morioyes

Valid cun

Valua Label

Value rrequancy percent percent percent

$0-20$

$11-25$

$26-100$

$102-200$

2000

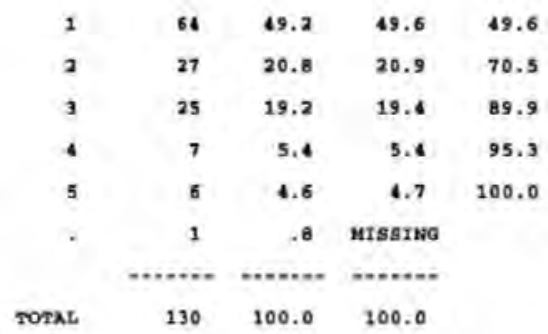

valla cases 129 Miseing Casos 1

Page 32

gPss/PC+

$5 / 13 / 93$

This procedure wal completed at 11:36:27

Page 33

SPSS/PC+

$5 / 13 / 93$

rinisa.

enc of Include $t 120$. 


\section{RRACTICES NTD PROCEDURES - DY BECTOR}

MANOVX q9s to $q 9 \mathrm{f}$ by $q 3 \mathrm{3}(1,10)$ /print cellinfo,

215 cansa accepted.

o cases rejected because of out-of-range factor values.

31 easan rafected because of nisaing data.

10 non-enty cella.

1 design wi11 be procassed.

Ce11 Means and standard Devintiona

Variable .. Q9A

C/PRACTICB - RECYCLING

ractok

CODE

Mean sta. Dev.

\begin{tabular}{|c|c|c|c|}
\hline Q3 & AGRI-FOR & 2.625 & 1.302 \\
\hline Q3 & Earengy-W & 1.500 & .707 \\
\hline $0^{3}$ & urnospat & 3.333 & 577 \\
\hline Q3 & ENGINRER & 2.500 & 1.144 \\
\hline
\end{tabular}

Ca11 mann and standard Daviations (CONT.)

Variable , , $99 \mathrm{~A}$

racror

c/practice - ReCrChing

cons

Makn std. Dev.

Q3

Q3

Q3

Q3

Q3

Q3

por ont 1re nneple

Variab1e ... 998

TACrOR

OTEER WA
CONSTRUC
DTSTRTBU
TRNASTOR
FTRANCIA
OTBER SE

OTHER $\mathrm{SE}$

a)

03

Q3

03

C/practicR - errogr epr pRCQ

$\begin{array}{rrr}3.093 & .996 & 43 \\ 2.100 & 1.082 & 15 \\ 3.091 & 1.044 & 11 \\ 3.000 & 1.414 & 5 \\ 2.917 & 1.165 & 12 \\ 2.968 & 1.140 & 94 \\ 2.916 & 1.112 & 215\end{array}$

Moan ste. Dav.

u

$3.000 \quad .926$

$1.500 \quad .70 ?$

$2.000 \quad 1.000$

$2.818 \quad 1.006$

Coll Meana and standard Daviatione (CONr.)

Variable ... Q 0

C/PRACTICE - ENERGY EYY PHOG

ractor

cops

Mann Sta. Dav.

\begin{tabular}{|c|c|}
\hline 03 & OTHER $\mathrm{Ma}$ \\
\hline 03 & conssruc \\
\hline 03 & DISTRIBU \\
\hline 83 & zRunspor \\
\hline Q3 & rnouicia \\
\hline$Q^{3}$ & OTBER $\mathrm{sE}$ \\
\hline
\end{tabular}

yor ontire asuple

Variablo .. Q9C

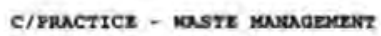

PACTOR

cope

Mesn std. Der.

$\begin{array}{rrr}2.884 & .823 & 43 \\ 2.667 & .976 & 15 \\ 2.909 & .031 & 12 \\ 3.400 & .894 & 5 \\ 2.583 & .996 & 12 \\ 2.670 & 1.072 & 94 \\ 2.744 & .988 & 215\end{array}$

at 


\begin{tabular}{|c|c|c|c|}
\hline Q3 & NGRI-TOR & 2.125 & 192 \\
\hline Q3 & 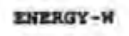 & 3.000 & 1,414 \\
\hline Q3 & MTnEser. & 3.333 & .571 \\
\hline 03 & IsGrareza & 2.545 & 1.101 \\
\hline
\end{tabular}

Coll Means and stendard Deviations (Cowr,)

varlable ... Q9c

ractor

$\cos \mathrm{x}$

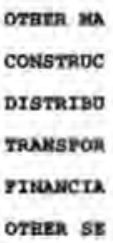

for entsye sapole

Variable .. Q9D

racros

cone

AGRI-TOR

EREara-k

cromerac

ENGTKRER

C/PRACTICE - WASTE MaEDGEREST

Man sta. Dev. N

$\begin{array}{llr}2.660 & 1.037 & 43 \\ 2.933 & 1.100 & 15 \\ 2.455 & 2.128 & 11 \\ 2.000 & 1.225 & 5 \\ 1.833 & 1.115 & 12 \\ 2.223 & 1.109 & 94 \\ 2.437 & 1.121 & 215\end{array}$

C/PRACTICE - sUppLTERS POLICY

Mana sta. Dev.

$\begin{array}{lll}2.000 & .535 & 8 \\ 1.500 & .707 & 2 \\ 1.667 & .577 & 3 \\ 1.909 & .126 & 22\end{array}$

Co11 Means and standerd Devistion. (CONT.)

Variable... Q9D

ractor

cone

Q3 OTazh sa

Q3 Construde

Q) DIstatav

Q3 TRNISPOR

03 FThäeta

Q3 OTHER $\mathrm{sE}$

gor entire asolo

Variable... $09 \mathrm{~g}$

PACTor

cone

Q3) AGRI-7OA

Q3 mareay-m

Q3 MINEAX

Q3 EMTIRER

C/PACYICE - SUPPLIERS POLICY Man std. Dev.

$\begin{array}{llr}2.488 & .827 & 43 \\ 2.067 & .704 & 15 \\ 2.092 & .964 & 11 \\ 2.400 & .894 & 5 \\ 1.833 & .937 & 12 \\ 2.169 & .616 & 94 \\ 2.153 & .727 & 215\end{array}$

C/Practice - pMckagraga

Mens std. Dev.

$\begin{array}{lll}2.375 & .916 & 8 \\ 1.500 & .707 & 2 \\ 2.333 & .577 & 3 \\ 2.318 & .945 & 22\end{array}$

Ca11 Meane and gtandard Devintione (CONT.)

variable .. Q9g

racton
C/PAACTICE - PACRAGTHG

cone

Monn sta. Der.

$\begin{array}{rrr}2.209 & 1.059 & 43 \\ 2.067 & .084 & 15 \\ 2.636 & 1.220 & 11 \\ 2.600 & 1.240 & 5 \\ 1.417 & .793 & 12\end{array}$




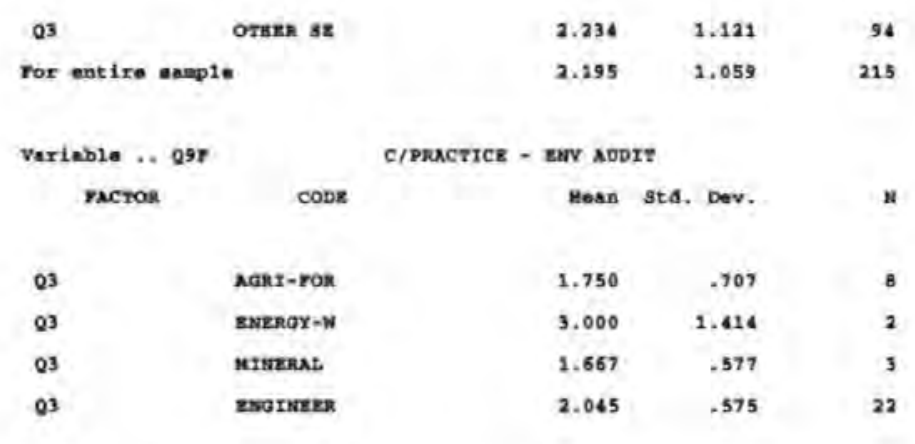

Ceil Meana and standard Doviatione (CONz-)

variable A. Q9r

vacros cons

\begin{tabular}{|c|c|}
\hline Q3 & OTHER Ma \\
\hline 83 & CONSTRUC \\
\hline Q3 & DISTRIBU \\
\hline 93 & TRUAISPOR \\
\hline Q3 & Prouncia \\
\hline 83 & orazi $\mathrm{gE}$ \\
\hline
\end{tabular}

Por entire samplo

variable ... 990

racron CODE

\begin{tabular}{|c|c|}
\hline Q3 & AGRI- $\mathrm{TOA}$ \\
\hline Q3 & EarengY-W \\
\hline Q3 & MTRERAL \\
\hline 03 & ENGTHER \\
\hline
\end{tabular}

c/practice - EIV aUDT?

Mean std. Dev. n

$\begin{array}{rrr}2.140 & .743 & 43 \\ 2.333 & .816 & 25 \\ 1.909 & .701 & 11 \\ 1.400 & .568 & 5 \\ 1.250 & .452 & 22 \\ 1.798 & .682 & 94 \\ 1.902 & .726 & 215\end{array}$

C/PRACTICE - POLLITION CONTROL POLICY

Mean std, Dev.

$\begin{array}{lll}2.125 & 2.226 & \text { 5 } \\ 3.000 & 1.414 & 2 \\ 3.000 & 1.000 & 3 \\ 2.591 & 1.141 & 22\end{array}$

Co11 Meene and standard bevilatione (Coorr.) variable .. Q9e

racton

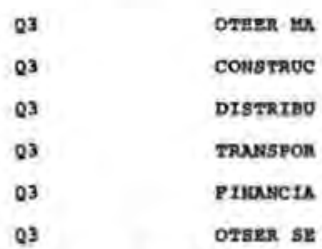

ros entire sasolo

variabie .. Q9n

pxcron
C/PRACTICE - pOLLOTION CONTROL POLICX

Mann std. Dev.

$\begin{array}{rrr}2.395 & .979 & 43 \\ 2.467 & 1.125 & 15 \\ 2.091 & .946 & 11 \\ 2.200 & 1.095 & 5 \\ 1.167 & .389 & 12 \\ 1.766 & .085 & 94 \\ 2.060 & 1.019 & 215\end{array}$

C/PRACTICE - stare matnTno

Mean std, Dev,

$\begin{array}{ll}\text { Q3 } & \text { AGRX-rOR } \\ \text { Q3 } & \text { ENEROY-W } \\ \text { Q3 } & \text { MTERENL } \\ Q_{3} & \text { ENGERER }\end{array}$

$\begin{array}{lll}1.750 & .707 & 9 \\ 2.000 & .000 & 2 \\ 2.000 & .000 & 3 \\ 2.045 & .406 & 22\end{array}$

Co11 Means and standard Devintions (CONT.)

Variable ... Q98

ractor

C/PRACTICE - BEAYP THUTIMG

CoDs

Masn sta. Dev. 


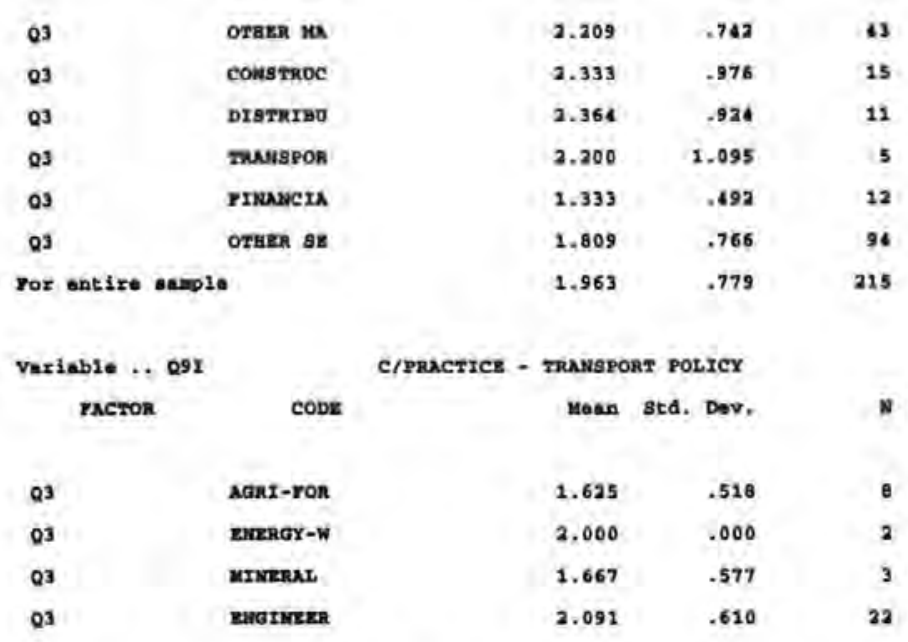

Co11 Moans and standard Doviationa (COWr.)

veriable... $09 \mathrm{~g}$

recros

C/PRACTICE - IRAMSPOKT POLICX

CODE

Mean std. Dev.

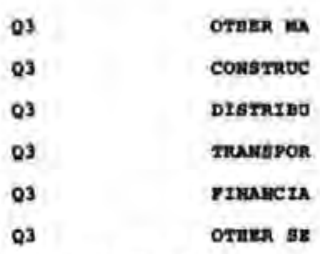

for entire somple

Vaxiable ... Q9J

pacror cone

C/PRACTICE - bes Mean sta, Dev,

\begin{tabular}{|c|c|}
\hline Q3 & AGKI-TOR \\
\hline Q3 & EARRGY-W \\
\hline Q3 & MTMERXI \\
\hline Q3 & 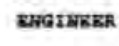 \\
\hline
\end{tabular}

$\begin{array}{rrr}1.625 & .518 & 8 \\ 2.500 & .707 & 2 \\ 2.000 & 1,000 & 3 \\ 2.136 & .640 & 22\end{array}$

Ce11 Moans and standerd Devilations (CONT.)

variable ... Q93

Facror

cope

C/PRACTICE - EMS

\begin{tabular}{|c|c|c|c|c|}
\hline Q3 & oraen ux & 2.093 & .840 & 43 \\
\hline Q3 & consmbc & 2.333 & .816 & 15 \\
\hline Q3 & DIsTreint & 2,091 & .539 & 21 \\
\hline Q3 & TRNASPOR & 2.200 & 1.095 & 5 \\
\hline Q3 & YINANICIA & 1,500 & .674 & 12 \\
\hline Q3 & OTHER 98 & 1.809 & .737 & 94 \\
\hline Fox & & 1.944 & .765 & 215 \\
\hline
\end{tabular}

errect .. 93

mitiveriate teats of significance $(8=9, M=0, w=97)$

Test Nase

Value Approx. F Bypoth. DP Exrox DP sig. of $y$ 


$\begin{array}{llllll}\text { Pi1zata } & .58564 & 1.68494 & 90.00 & 1836.00 & .000 \\ \text { Bote11ings } & .81005 & 1.74810 & 90.00 & 1748.00 & .000 \\ \text { Wilka } & .07525 & 1.72550 & 90.00 & 1339.60 & .000 \\ \text { Roys } & .24225 & & & & \end{array}$

Dnivariate P-teats with $(9,205)$ D. $P$.

\begin{tabular}{|c|c|c|c|c|c|c|}
\hline Variabio & Bypoth. ss & Errox ss & Bypoth. Mg & Error Ms & ? & sig. \\
\hline$Q 9 x$ & 11.19364 & 253.29959 & 1.24372 & 1.23561 & 1.00656 & \\
\hline Q98 & 9.60321 & 199.32702 & 1.06702 & .97233 & 1,09739 & \\
\hline Q9e & 25.10754 & 243.79479 & 2.76973 & 1.18924 & 2.34560 & \\
\hline Q90 & 9.58186 & 226.35302 & 1.06465 & .61636 & 1,72733 & \\
\hline Q98 & 14.41016 & 225.37719 & 1.60202 & 1.09940 & 1.45717 & \\
\hline Q98 & 15.62284 & 97.13600 & 1.75698 & .47383 & 3.70801 & \\
\hline
\end{tabular}

Errect .. QS (Cowr.)

Univariate $\mathrm{y}$-taet with $(9,205)$ D. 7 . (cost.)

variable Hypoth. ss axror ss llypoth. Ms error ies $\quad s i g$. of $F$

$\begin{array}{lllllll}\text { O96 } & 35.78155 & 186.43241 & 3.97573 & .90943 & 4.37169 & .000 \\ \text { Q9B } & 16.23286 & 115.46967 & 1.58143 & .56327 & 2.80761 & .004 \\ \text { Q91 } & 17.17511 & 136.52721 & 1.90835 & .67574 & 2.82407 & .004 \\ \text { Q93 } & 10.14000 & 115.18943 & 1.12676 & .56190 & 1.00526 & .060\end{array}$

RRACTERS AND PROCRDERES - REDUCED 5 RCTOB

Kanova q9a to q9j by q3 $(1,3)$ /print callinfo.

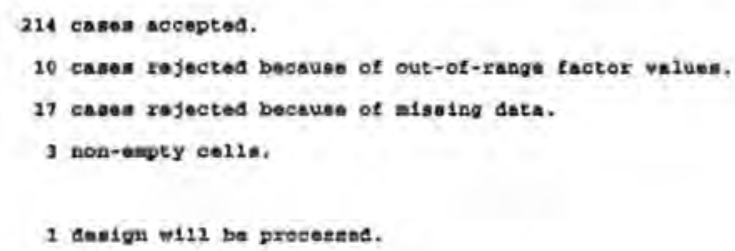

\begin{tabular}{|c|c|c|c|c|}
\hline Q3 & manufact & 2.900 & 1.052 & 87 \\
\hline $0 ?$ & service & 2,965 & 1.147 & 115 \\
\hline 83 & $\operatorname{rot} B 12$ & 3.000 & 1.046 & 12 \\
\hline & & 2.946 & 1.099 & 214 \\
\hline
\end{tabular}

Call Meane and standard Deviationa (Cowz.)

Varisble .. Q9a

ractos

$$
\begin{aligned}
& \text { manufoct } \\
& \text { mervice }
\end{aligned}
$$$$
\text { reta } 11
$$

ror ent1re anople

C/Practice - meraY RPF PROQ

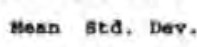

$2.770 \quad .911$

$2.670 \quad 1.057$

2.833 .635

$2.720 \quad .986$

B7

115

12 214 


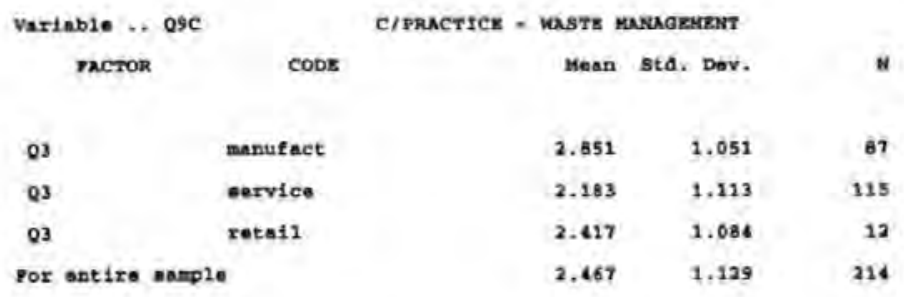

Ce11 Wesns and standard Deviationa (CONT.)

variable ... 090

PAcror

c/practice - sUpptizes policy

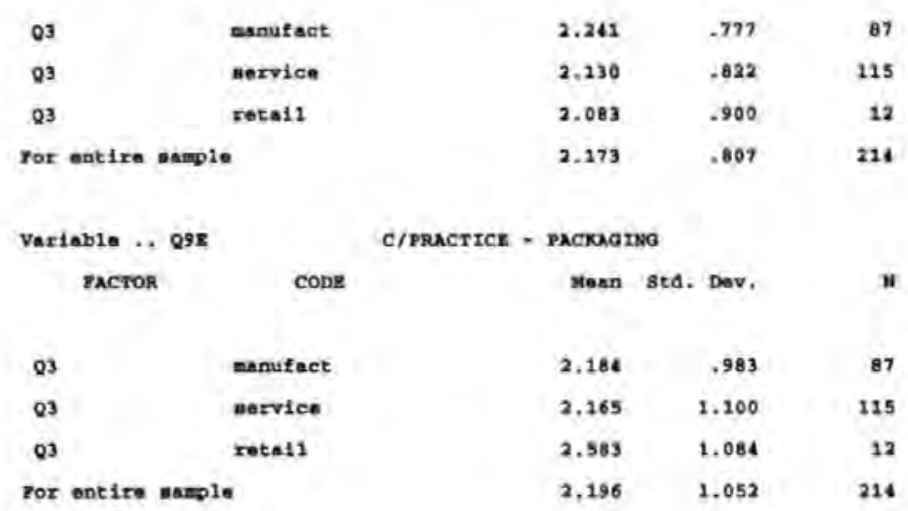

Co11 Meane and gtandsrd Deviatione (CONT.)

Varisble ... Q99

PrCTOR

cone

$\begin{array}{ll}\text { Q3 } & \text { nanufact } \\ \text { Q3 } & \text { sorvice } \\ \text { Q3 } & \text { retoil }\end{array}$

ror entire sarplo

variable .. 090

racros

cons

$\begin{array}{ll}\text { Q3 } & \text { manufect } \\ \text { Q3 } & \text { aorvice } \\ \text { Q3 } & \text { ratal1 }\end{array}$

ror entire sapple
C/PRACTICE - ENV AUDIT

Mean gtd. Dev, n

$\begin{array}{rrr}2.115 & .722 & 87 \\ 1.739 & .677 & 115 \\ 2.000 & .739 & 12 \\ 1.907 & .719 & 214\end{array}$

C/PRACTICE - POLLUTION CONTROL POLICT meen std. Dey.

$\begin{array}{rrr}2.460 & 1.032 & 87 \\ 1.748 & .697 & 115 \\ 2.000 & .953 & 12 \\ 2.051 & 1.008 & 226\end{array}$

Ce11 kesne and stendsird Derlatiens (CONr.)

Varinb10 .. Q9

rACTOR

coos

C/PRACTICE - STAFY TRATATNO

$\begin{array}{ll}\text { Q3 } & \text { manufect } \\ \text { Q3 } & \text { anvice } \\ \text { retail }\end{array}$

Tor ant 1 re asimple

Variable .. $09 \mathrm{r}$

PACTOR
Mean std, Der.

$\begin{array}{llr}2.161 & .713 & 67 \\ 1.791 & .789 & 115 \\ 2.331 & .886 & 12 \\ 1.972 & .787 & 214\end{array}$

C/PRACTICR - TRUISPOKT FOLTCY 


$\begin{array}{llllr}03 & \text { manufact } & 2.149 & .815 & 87 \\ 03 & \text { nervice } & 2.017 & .936 & 115 \\ \text { Q3 } & \text { reta11 } & 2.167 & .577 & 12 \\ \text { Por ent1ro maspid } & 2.079 & .871 & 214\end{array}$

Ce11 Means and standard Deviations (Cotro,)

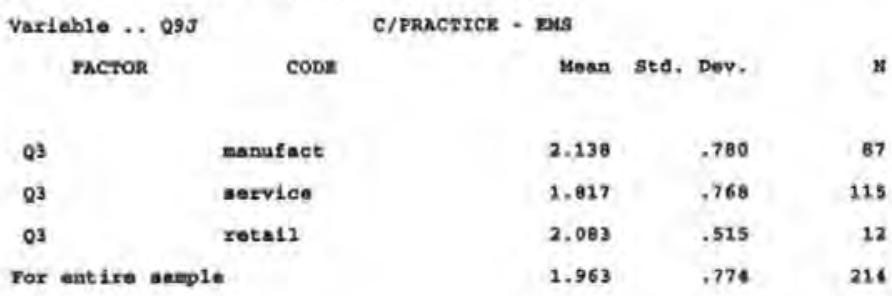

EFrRCT $\ldots Q 3$

Multivaziate reats of Significance $(g=2, M=31 / 2, N=100)$

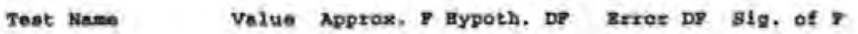

$\begin{array}{llllll}\text { Pillais } & .21854 & 2.49028 & 20.00 & 406.00 & .000 \\ \text { Botelings } & .26264 & 2.63955 & 20.00 & 402.00 & .000 \\ \text { W11kg } & .78734 & 2.56518 & 20.00 & 404.00 & .000 \\ \text { Hoye } & .18714 & & & & \end{array}$

Univariate $\mathrm{F}$-teate with $(2,211) \mathrm{D}, \mathrm{P}$,

Varinble Hypoth. Ss Error ss Hypoth. Ms trror Ms

\begin{tabular}{|c|c|c|c|c|c|c|}
\hline Q9x & .20187 & 257,12524 & .10093 & 1.21860 & .08283 & .922 \\
\hline Q98 & .66513 & 206,51244 & .33256 & .97873 & .33979 & .712 \\
\hline Q9C & 22.13167 & 249.13936 & 11.06584 & 1.18076 & 9.37163 & .000 \\
\hline Q9D & .71162 & 137,89118 & .35581 & .65351 & .54446 & .581 \\
\hline 098 & 1.92300 & 233.83501 & .96100 & 1.10822 & .86715 & .422 \\
\hline$Q 97$ & 7.10635 & 103.02449 & 3.55320 & .68827 & 7.27711 & .001 \\
\hline
\end{tabular}

repret ., Q3 (cons.)

Dnivariate $\mathbf{r}$-teate with $(2,211)$ D. $\boldsymbol{Y}$. (CONY.)

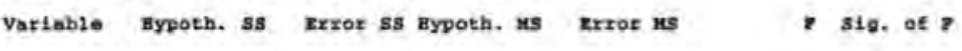

$\begin{array}{lrrrrrr}\text { Q96 } & 25.13843 & 191.29615 & 22.56931 & .90662 & 13.86387 & .000 \\ \text { 098 } & 0.42668 & 123.40510 & 4.31334 & .58686 & 7.20403 & .001 \\ \text { Q91 } & .96018 & 160.68936 & .48009 & .76156 & .63040 & .533 \\ \text { Q9d } & 5.27422 & 132.42671 & 3.63711 & .58022 & . .54501 & .012\end{array}$

PRACTICES AUP PROCRDORES - EXPORTRRS I HOHE EXEORTERS

massova q9a to q9y by q14 $(1,2)$ /print coilinfo,

234 casen accopted.

0 cases rejected because of ouk-of-zango tactor values.

17 casea rejected becaube of malaing data.

2 non-empty ceila. 
A83

1 dasign w11 be procesned.

Co11 Meane and standerd Devilations

variable .. Q9A

C/PRACTICE - RECYCLING

vactor

CODE

Mean Sta. Dev.

n

Q214

sxporter

Q14 none esce

2.930

For antire nample

2.913

2.071

86

138

Co11 Moane and gtabdard Doviatione (CONr.)

Variable .. Q9a C/PRACFICR - EREREY zYY PROO

rActor

CODE

Mean sta. Dav.

N

Q14

014

exporter

Por ontire sasplo

Variable ... Qgc FACTOR none $\operatorname{axp}$

2.886

2.616

2.719

.926
1.013
.987

B6

139

224

Q14 exporter Q14 none exs

ror ent1re sample

varieble .. Q9D FActoR

conz

024

exporter

Q14

none exp

For entire sample

C/PRUCTICE - WASTE MNTACEMRNF

Moan Btd, Dov.

n

$\begin{array}{rrr}2.535 & 1.048 & 86 \\ 2.406 & 1.169 & 138 \\ 2.455 & 1.124 & 224\end{array}$

C/PRACTICE - SUPPLIERS POLICY

Mean std. Dev.

s

2.151

2. 181

2.170

.797

86

138

224

Ca11 Mans and standera Daviatione (Corr.)

variable .. Q98

pactos

cone

C/PRACTICE - PACKAatwa

Q14 axporter
Q14 nons exp
ror antira anmplo

Maan std. Der.

v

variabie .. Q9P pXctor

CODE

Q14

exportex

Q21 none Exp

For ont Ire sample

voriable ... $Q 90$ rAcroR

CODR

014

axporter

Q11 none exp

Por entire sample
2. 407

2.072

2.201

085

1.046

138

224

C/PRACTICE - ENV AODIF

Mean sta. Dev.

2. 035

1.848

1,920

.729

$12 \mathrm{~B}$

224

Moan sta. Dev.

N

$\begin{array}{rrr}2.186 & .980 & 86 \\ 2.000 & 1.025 & 130 \\ 2.071 & 1.013 & 224\end{array}$

Cel1 keana and standard Deviations (CONT.)

variab2e... $Q 9 \mathrm{~B}$

C/PRACTICE - BTAYY TRATRTHG

Factor CODE

Moan Std. Dov.

6

236

n

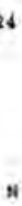




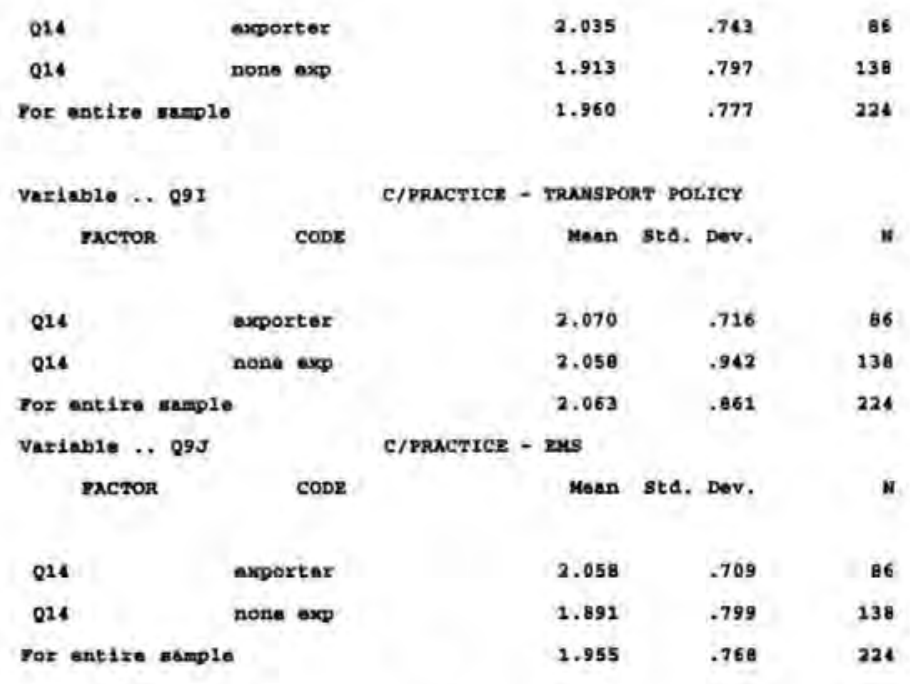

Co11 Moand and standard Daviatione (COsr.)

EPPECT . 014

Muitivariata Teats of significance $(s=3, y=4, *=2052 / 2)$

Teat wame Volue Approx, Y Hypoth, DP Exror DF sig. of

$\begin{array}{llllll}\text { Plilaid } & .06894 & 1.57714 & 10.00 & 213.00 & .115 \\ \text { Botelliage } & .07404 & 1.57714 & 10.00 & 213,00 & .115 \\ \text { W11ka } & .93106 & 1.57714 & 10.00 & 213,00 & .115 \\ \text { Roys } & .06894 & & & & \end{array}$

zerzct ,. Q14 (cowr.)

Dniveriate p-tenta with $(1,222)$ D. $P$.

Variablo Eypoth. Ss trror ss Bypoth, MS Error $\mathrm{kg}$ P Big, of

\begin{tabular}{|c|c|c|c|c|c|c|}
\hline Q9ג & .01565 & 274.53792 & .01565 & 1.23666 & .01266 & .911 \\
\hline 098 & 3.79911 & 213,10214 & 3.79911 & .96163 & 3.95070 & .048 \\
\hline Q9c & .60286 & 280.67071 & .08286 & 1.26428 & .69831 & .404 \\
\hline Q9D & .04767 & 141.50590 & .04767 & .63741 & .07479 & .785 \\
\hline Q98 & 5.92865 & 238,03118 & 5.92865 & 1.07221 & 5.52936 & .020 \\
\hline$Q 9 F$ & 1.65387 & 116.69970 & 1.85387 & .52567 & 3.52666 & .062 \\
\hline Q96 & 1.83389 & 227.02326 & 1.83389 & 1,02263 & 1.79331 & .182 \\
\hline Q98 & .70652 & 233.85187 & .78652 & .60294 & 1,30469 & .255 \\
\hline Q9I & .00737 & 165,11763 & .00737 & .74377 & .00991 & .921 \\
\hline Q9J & 1.67470 & 130.07887 & 1.47470 & .58594 & 2.51681 & .114 \\
\hline
\end{tabular}

PRACTICRS AND RROCEDURES - INITIATXVES OR WO IALTIATIVRS

Mostovi $q 9$ a to q9j by q15 $(1,2)$ /print collinfo.

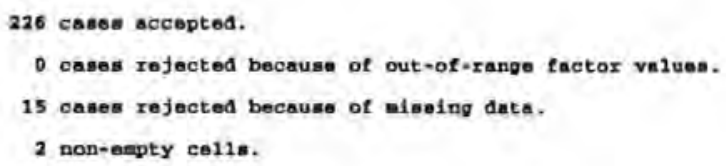


1 deston will be processed,

Co11 Meane and standard peplations

variablo ... Q9A

C/Practice - RecYChING

VACTOR

CODE

Mean sed. Der.

\begin{tabular}{|c|c|c|c|c|}
\hline Q15 & SONE INI & 3.420 & .961 & 132 \\
\hline Q15 & No IKIรI & 2.128 & .793 & 94 \\
\hline For: & & 2.912 & 1.112 & 226 \\
\hline
\end{tabular}

Co11 means and standard poyiations (CONT.)

variable .. Q9B

PACTOR

C/PRACTICE - ENERGY ERT PROO

015 SORE INI

015

no INITI

Por entire vample

Variable ... Q9e

racrok

Q15 SONC INI

Q15 no INITI

Por entire sasple

variabla .. Q90

pacros

C/PRACTICE - SUPPLIERS POLICY

Mean std. Dav. N

Q15

025 no TNTTI

par ontire samplo

Masn std. Dev.

$\begin{array}{rrr}3.015 & 1.034 & 132 \\ 2.277 & .739 & 94 \\ 2.708 & .990 & 226\end{array}$

c/PRACTICE - waste MaNaGEMENT

Mean sta. Dev. n

$\begin{array}{rrr}2.758 & 1.243 & 132 \\ 2.021 & .747 & 94 \\ 2.051 & 1.123 & 226\end{array}$

$1.915 \quad .650 \quad 94$

$2.164 \quad, 797 \quad 226$

Col1 Matan and standard peviations (CONT.)

varinb1. ., 092

rAcTor CODE

Q15

Q15

gor entire aaplo

Variable... Q9F

ractor

Q15 SOME INI

For ontire saepla

Var1sbie .. $89 a$

zActor

covg

c/practick - packagina

Moan sta. Der. II

$\begin{array}{rrr}2.315 & 1.155 & 132 \\ 2.021 & .842 & 94 \\ 2.195 & 1.064 & 226\end{array}$

C/PraCrICE - ENV AODIT

Mean std, Dev. N

$\begin{array}{rrr}2.000 & .791 & 132 \\ 1.798 & .615 & 94 \\ 1.916 & .728 & 226\end{array}$

c/PRACTICE - POLLUTION CONIROL POLICY Mean std. Dev. n

Q2.5 SONE INI

015 No INTTI

gor ontira anopio

$\begin{array}{rrr}2.273 & 1.160 & 132 \\ 1.777 & .658 & 94 \\ 2.066 & 1.011 & 226\end{array}$

Col1 Moane and stsnasra Daviatione (CONT.)

variabla .. Q98

C/PRNCTICE - ETAPY TRATHIMa 


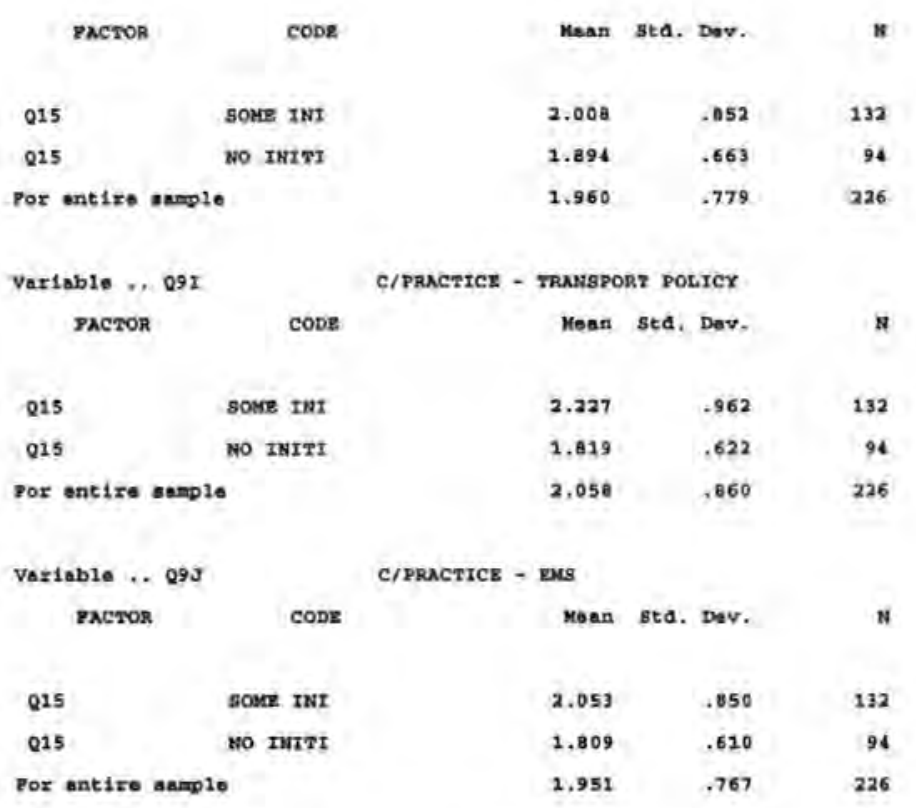

Co11 wanns and stendard Deviations (CONr.)

ervect .. 015

mutivariate feats of signifiennes (s $=1, n=4, N=1061 / 2)$

Teat wame Value Approx. Bypoth, DP Exror DP 8ig. of $F$

$\begin{array}{llllll}\text { P111.10 } & .41951 & 15.53781 & 10.00 & 215.00 & .000 \\ \text { Botelilings } & .72269 & 15.53781 & 10.00 & 215.00 & .000 \\ \text { Wiiks } & .56069 & 15.53781 & 10.00 & 215.00 & .000 \\ \text { Roys } & .41951 & & & & \end{array}$

EFrect ., 215 (CONT,)

Onivariata $\boldsymbol{p}$-tanta with $(1,224)$ D. $\boldsymbol{r}$.

Variable Bypoth, ss zrror ss Hypoth. as Erroz us T 81g. of F

\begin{tabular}{|c|c|c|c|c|c|c|}
\hline Q9a & 98.88322 & 179.34687 & 98.68322 & .80066 & 223.50280 & .000 \\
\hline 098 & 29.94746 & 190.77821 & 29.94746 & -85169 & 35.26246 & .000 \\
\hline Q9e & 29.76473 & 254.19987 & 29.76473 & 1.13682 & 26.22857 & .000 \\
\hline Q9D & 9.96424 & 132.97824 & 9.96424 & .59365 & 16.78462 & .000 \\
\hline Q9E & 4.83982 & 240.59381 & 4. ब3982 & 1.07400 & 4.50601 & .035 \\
\hline Q9y & 2.24308 & 117.15957 & 2,26308 & .52303 & 4.28860 & .000 \\
\hline Q96 & 13.51410 & 216.49033 & 13.51610 & .96547 & 13,98288 & .000 \\
\hline Q98 & -71300 & 135.92859 & .71300 & .60682 & 1.17697 & .280 \\
\hline $09 I$ & 9.24486 & 257.10735 & 9,24486 & .70137 & 13,03853 & .000 \\
\hline Q9J & 3.28262 & 129.16199 & 3.28262 & .57671 & 5,69203 & $.02 \mathrm{E}$ \\
\hline
\end{tabular}

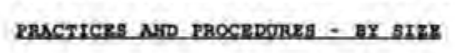

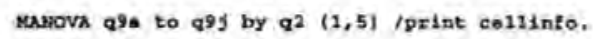

224 ceses accoptad.

- cakas rejected because of out-of-range factor valuea.

17 eness rejected becaues of alasing data. 
5 non-empty celln.

1 denign will be procesaed.

Ce11 Moens and standard Deviations

Variable .. $09 \mathrm{~s}$

C/PRACTICE - RECYCLING

ractor

CODz

Mean sta. Der.

*

$\begin{array}{llrrr}02 & 0-10 & 2.859 & 1.175 & 128 \\ 02 & 11-25 & 2.806 & 1.039 & 14 \\ 02 & 26-100 & 2.973 & 1.093 & 37 \\ 02 & 102-200 & 3.625 & .518 & 8\end{array}$

Ce11 Mesne ond standard Deviations (CONF.)

variable ... 09A

PACTOR

C/PRACTICE - RECYCLTNE

02 Yor antire asmpla

$300+$

Mean sta. Dev.

$\begin{array}{lll}3.143 & -690 & 7\end{array}$

Variable .. Q9a

$2.920 \quad 1.110 \quad 224$

C/PRACTICE - ENERGY RPP PROQ

pactor CODE

Mesn sta. Dav.

$\begin{array}{ll}Q 2 & 0-20 \\ Q 2 & 11-25 \\ Q 2 & 26-100 \\ Q 2 & 101-200 \\ Q 2 & 300+\end{array}$

rox entire angle

Ga12 Meanh and standard Devistion (CONr.)

Variable ., Q9C

FACTOR

CODE

C/PRACTICE - WASTE MANAGEREAT

$\begin{array}{ll}02 & 0-10 \\ Q 2 & 11-25 \\ Q 2 & 26-100 \\ Q 2 & 101-200 \\ Q 2 & 200+\end{array}$

Pox ontire asample

Voriab16 ... Q9D

PAcrok

cops

C/PRACTTCE - SUPPLIERS POLICY

Moan sta. Dev.

$\begin{array}{llllr}02 & 0-10 & 2.109 & .616 & 120 \\ 02 & 11-25 & 2.214 & .655 & 14 \\ 02 & 26-100 & 2.243 & .063 & 37 \\ Q 2 & 101-200 & 2.500 & .756 & 8 \\ 02 & 200+ & 2.571 & .976 & 7 \\ \text { Tor antire sample } & 2.161 & .799 & 224\end{array}$

$\begin{array}{llllr}02 & 0-10 & 2.109 & .616 & 120 \\ 02 & 11-25 & 2.214 & .655 & 14 \\ 02 & 26-100 & 2.243 & .063 & 37 \\ Q 2 & 101-200 & 2.500 & .756 & 8 \\ 02 & 200+ & 2.571 & .976 & 7 \\ \text { Tor antire sample } & 2.161 & .799 & 224\end{array}$

Mean std. Dev.

$\begin{array}{rrr}2.211 & 1.134 & 128 \\ 2.591 & 2.019 & 44 \\ 2.784 & 1.058 & 17 \\ 3.625 & .518 & 8 \\ 3.143 & .900 & 7 \\ 2.460 & 1.124 & 224\end{array}$

224

Co11 Meane and standard Devintions (Cowr.)

Variable ... Q9E

CIPRACTICE - PACKAGINO
RACTOR
CODE 


\begin{tabular}{|c|c|c|c|c|}
\hline 22 & $0-10$ & 2.141 & 1.085 & 128 \\
\hline 22 & $21-25$ & 2.000 & .889 & At \\
\hline 22 & $26-100$ & 2,541 & 1.043 & 37 \\
\hline 02 & $101-200$ & 2,375 & $2.18 \mathrm{~B}$ & a \\
\hline 02 & 2000 & 2.629 & .787 & 7 \\
\hline yox & & 2.196 & 1.045 & 224 \\
\hline
\end{tabular}

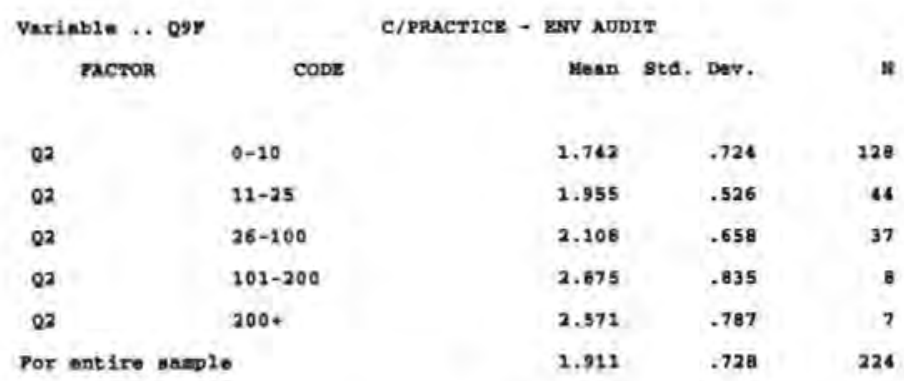

Co11 Meana and standard Deviationa (Corry,)

variable .. Q9a

racron cobe

02

02

02

02

Q2

rot entire sanple

Varlabie ... Q9a

racton

$0-10$
$11-25$
$26-100$
$101-200$
200.

C/PRACTICE - POLLUTION CONRROL POLICY

Mean std. Dev,

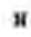

$1.867 \quad 975 \quad 128$

$2.136 \quad .979 \quad 46$

$2.405 \quad 1.066 \quad 37$

$2.500 \quad .926 \quad 8$

$2.057 \quad .900 \quad 7$

$2.063 \quad 1.014 \quad 224$

C/PRACTICE - sTAPY TRATHTNO

Mesn sta. Dev.

$\begin{array}{rrr}1.064 & .818 & 128 \\ 2.000 & .647 & 46 \\ 2.061 & .682 & 37 \\ 2.500 & .756 & 8 \\ 2.714 & .756 & 7 \\ 1.964 & .780 & 224\end{array}$

Cel1 neans and standard Deviationa (Cotrr.)

Vartebla .. $Q 91$

C/PRACTICE - muNispoñ posicy

Fuctor CODE

Mean sta. Dey.

*

$02 \quad 0-10 \quad 2.055 \quad 298$

$0212-25$

Q2 $26-100$

Q2 $101-200$

Q2 $200+$

Por ant 1ra asmola

Variable... 09s

racton Conz

c/practice - me

Mean sta. Dev.

$1.813 \quad .830$

$2.977 \quad-505$

128

$\begin{array}{lllll}02 & 0-10 & 1.813 & .630 & 128 \\ 02 & 13-25 & 2.977 & .505 & 44\end{array}$




$\begin{array}{llllr}Q 2 & 26-100 & 2.081 & .547 & 37 \\ \text { Q2 } & 201-200 & 2.750 & .866 & 8 \\ \text { Q2 } & 200+ & 2.657 & .690 & 7 \\ \text { YOE entiro aesple } & 1.955 & .768 & 224\end{array}$

Coll means and standard Deviations (Covrs,)

RPFECT .. Q2

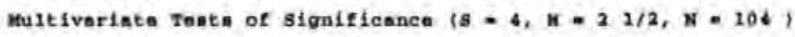

Tant Wame Velue Approx. I lypoth, DP Exror DP sig. de ?

$\begin{array}{llllll}\text { P111n1. } & .33392 & 1.94006 & 40.00 & 852.00 & .001 \\ \text { Hotoli1ings } & .39907 & 2.08018 & 40.00 & 834.00 & .000 \\ \text { W11ka } & .69479 & 2.01128 & 60.00 & 398.15 & .000 \\ \text { Royl } & .21098 & & & & \end{array}$

grrect .. Q2 (cotrr.)

Univariate r-teats with $(4,219)$ D. $\mathbf{r}$.

Varioble Bypoth. 8s zrror 89 Bypoth. Mg zrror Ms $P$ sig, of $p$

\begin{tabular}{|c|c|c|c|c|c|c|}
\hline $09 x$ & 4.94789 & 269.60568 & 1.23697 & 1.23108 & 1.00475 & .406 \\
\hline Q9B & $16: 95457$ & 200.32668 & 4.23864 & .91473 & 4.63374 & .001 \\
\hline Q9c & 26.69493 & 254.94366 & 6.67373 & 1.26413 & 5.73283 & .000 \\
\hline$Q 9 \mathrm{D}$ & 2.78862 & 139.42566 & .69716 & .63665 & 1.09506 & .360 \\
\hline Q9R & 7.10992 & 236.24722 & 1.77760 & 1.07875 & 1.66772 & .163 \\
\hline Q97 & 15.65615 & 102.55813 & 3.91404 & .46830 & 8. 35794 & .000 \\
\hline Q9G & 15.42493 & 213.70007 & 3.85623 & .97580 & 3.95187 & .004 \\
\hline 991 & 0.65396 & 127,06033 & 2.16349 & .58018 & 3.72897 & .006 \\
\hline Q91 & 2.71622 & 162,40878 & .67905 & .74159 & .91567 & .456 \\
\hline Q9J & 13.96240 & 117.59117 & 3.49060 & .53695 & 6.50084 & .000 \\
\hline
\end{tabular}

RRACTICRS AND PROCEDURES - DX COMPAXX CBAHCTERISTICS

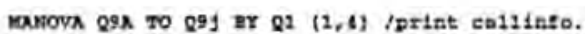

223 cames nocepted.

O cases rejected because of out-of-range factor values.

18 cambe rejected because of aineing dats.

4 non-enpty cells.

1 denign w111 be processed.

Cell Meons and standard Devilations

Variab1, .. Q9a

PACTOR

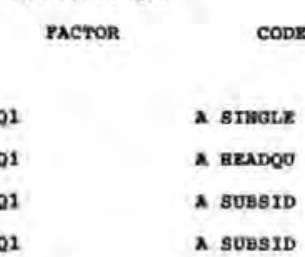

Yoz entire sasple c/practice - azcyching

Mesin sta. Dev. N

$\begin{array}{rrr}2.862 & 1.163 & 152 \\ 2.806 & 1.070 & 31 \\ 3.265 & .864 & 34 \\ 3.333 & .816 & 6 \\ 2.915 & 1.110 & 223\end{array}$

Ca11 Meana and standard Deviationa (CONY.) 


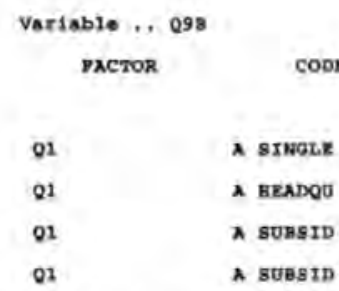

Por ent 1 re momple

variab1e.. $29 \mathrm{C}$

pacror CODE
C/PRACTICE - ERERQY EPY PROG

Mean std. Dev.

$\begin{array}{rrr}2.658 & 1.017 & 152 \\ 2.581 & .958 & 31 \\ 3.029 & .870 & 34 \\ 3.333 & .516 & 6 \\ 2.722 & .988 & 223\end{array}$

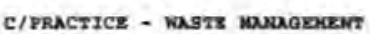

Meen std. Dey.

$\begin{array}{rrr}2.329 & 1.220 & 152 \\ 2.355 & 1.226 & 31 \\ 2.961 & .814 & 34 \\ 3.633 & .408 & 6 \\ 2.466 & 1.122 & 223\end{array}$

For ont1re enmple
A smoLr

a meadou

A suasid

A subsio

Co11 Meano and standard Deviationn (CONr.)

variable .. Q9D

yactor

CODE

$Q 2$

01

Q1

01

yor antire ample

Varinble .. Q9E

racron

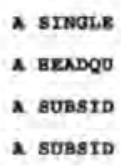

C/PRACTICE - SUPPLIRRS POLICX Mesn sta. Dev.

$\begin{array}{rrr}2.079 & .793 & 152 \\ 2.161 & .688 & 31 \\ 2.412 & .021 & 34 \\ 2.633 & .983 & 6 \\ 2.161 & .000 & 223\end{array}$

c/practick - packagrag

Mean std. Dev.

$\begin{array}{rrr}2.145 & 1.076 & 252 \\ 2.000 & .056 & 31 \\ 2.500 & 1.052 & 34 \\ 2.667 & .616 & 6 \\ 2.193 & 1.046 & 223\end{array}$

Ca11 masnu and standard Devtationa (CONr-)

variable .. QSr

racton

cops

a sUBSID

yor ent1ro a ample

Variable ... 096

pactor cope

Q2

Q1

A sxale

A meapgo

01

Q2

a subsro

A sUBsio

C/MRACTICE - arV AUDIT

Mean std. Dert. N

$\begin{array}{rrr}1.757 & .630 & 152 \\ 2.000 & .735 & 32 \\ 2.353 & .812 & 34 \\ 2.633 & .753 & 6 \\ 1.910 & .730 & 223\end{array}$

C/PRACTICE - POLLOTION CONTROL POLICY Mean sta. Dey.

$\begin{array}{rrr}1.974 & .983 & 152 \\ 1.935 & .929 & 31 \\ 2.412 & 1.106 & 34 \\ 3.167 & .753 & 6\end{array}$


Cel1 Means and standard Deviationa (Cowr.)

variabla .. $\mathrm{QgH}$

racron

C/PRACTICE - STAYY truTwING

$\begin{array}{ll}\text { Q1 } & \text { A amalz } \\ 01 & \text { A meabgo } \\ 01 & \text { a suasid } \\ 01 & \text { a sunsin }\end{array}$

Por ontire anaple

Variab1e.., Q9T

racrom cope

C/PRACTICE - TRAUSPORT POLTCY

Q2

01

Q1

ot

yor eatire asuple

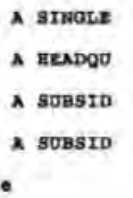

A smane

suesro

$\begin{array}{rrr}1.336 & .723 & 152 \\ 2.129 & .846 & 31 \\ 2.235 & .819 & 34 \\ 2.633 & .753 & 5 \\ 1.964 & .782 & 223\end{array}$

copz

$1.993 \quad .600 \quad 152$

$2.065 \quad 016 \quad 31$

$2.265 \quad .790 \quad 34$

$2.333 \quad .516 \quad 6$

$\begin{array}{lll}2.056 & .853 \quad 223\end{array}$

Cel1 Meane and standard Devistione (CONz.)

variable .. Q9

c/pructrer - mas

zactor

CODz

Mann std, pay. $\quad x$

$\begin{array}{ll}01 & \times \text { BINGLE } \\ 01 & \text { A BZADQ0 } \\ 01 & \text { त SUBSID } \\ 01 & \times \text { SUBSID }\end{array}$

ror ontire nample

SUBSID

EPrec: ... Q1

multigariace tente of significaned is $=3, \mathrm{M}=3, \mathrm{u}=104$ )

\begin{tabular}{|c|c|c|c|c|c|}
\hline Test Hases & velus & Approx. $Y$ & Hypoth. Dr & Exrox DY & sig. of $₹$ \\
\hline p111ata & .21757 & 1.65775 & 30.00 & 636.00 & .016 \\
\hline Hotel1ings" & .25295 & 1.75939 & 30.00 & 626.00 & .000 \\
\hline wilke & .79119 & 1,70854 & 30,00 & 627.07 & .012 \\
\hline Roy: & .16816 & & & & \\
\hline
\end{tabular}

Univariate 8 -toets with $(3,219)$ D. 7 .

Variable gypoth. Ss Erroz 58 Bypoth, MS Etror MS P sid. of P

$\begin{array}{lrlllll}\text { Q9X } & 6.38095 & 267.00022 & 2.12698 & 1.21918 & 1.74460 & .159 \\ \text { Q98 } & 6.69950 & 210.06203 & 2.23317 & .95919 & 2.32818 & .075 \\ \text { Q9C } & 22.13267 & 257.36509 & 7.37756 & 1.17518 & 6.27779 & .000 \\ 09 D & 5.87353 & 136.31481 & 1.95784 & .62244 & 3.14542 & .026 \\ 092 & 6.05940 & 236.64912 & 2.01980 & 1.08059 & 1.86916 & .136 \\ 097 & 15.61462 & 102.59146 & 5.20494 & .66845 & 11.21084 & .000\end{array}$

ErPeCX ., Q1 (CONr.)

Univariate p-teats with $(3,219)$ D, F. (CONT.) 
Variable Bypoth. $8 s$ Error ss Bypoth. Ms Error ms

Q99

Q98

Q9 I

ดو

$\begin{array}{rrrrrr}13.15670 & 214.83433 & 4.38557 & .98098 & 4.47060 & .005 \\ 10.39000 & 125.32301 & 3.46333 & .57225 & 6.05212 & .001 \\ 2.53889 & 158.81537 & .84630 & .72518 & 1.16701 & .323 \\ 8.38636 & 123.16521 & 2.79545 & .56240 & 4.97059 & .002\end{array}$


Page

grgs/PC+

$5 / 16 / 94$

Recode $q 1 \quad(1=1) \quad(2=2) \quad(3-3) \quad(4=3)$.

Page 6

spss/PC+

$5 / 16 / 94$

Crosstabs / TABteseq7a by q2 /option. 14 /statiotics 1 ,

The raw data or tronsforation pess in procesding

241 cases are written to the compressed active ille.

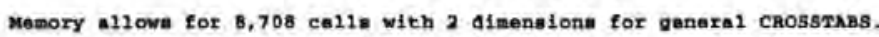

Page,$\quad$ SPSS/PC+ $\quad 5 / 16 / 94$

Q7A AWARE - EC ECO-LARELLING bY Q1 BUSTNESS TKPE

Q1 Page 1 of 1

BoS VAI,

3A sImGLE A BEAdo a sUBsid

1 aITE BO ATERS UH LRY/BRA RON

27ג

12,3, Total

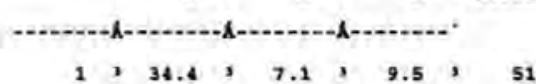

YRs
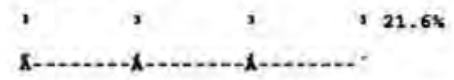

$2,74.1,25.4,20.5,110$

Do NOT KNOW
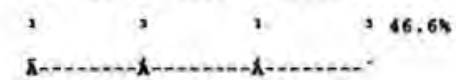

$3=50.5=10.5>14.0=75$

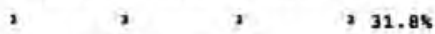

no

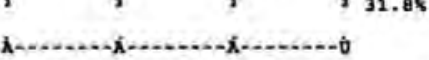

$\begin{array}{lllll}\text { colusn } & 159 & 33 & 44 & 236\end{array}$

Totn2 67.45 14.0\% $18.6 \% 100.0 \%$

\begin{tabular}{|c|c|c|c|}
\hline Page $B$ & BPBg/PC+ & & $5 / 16 / 94$ \\
\hline Chi-Squaro & Value & DF & Bignificance \\
\hline 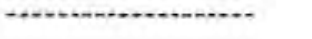 & 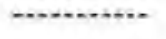 & $\cdots$ & ............... \\
\hline Pourson & 31.98445 & 4 & .00000 \\
\hline Itkelihood ratio & 28.68268 & 4 & .00001 \\
\hline Montel-ghenszel tost for & 23.16163 & 1 & .00000 \\
\hline
\end{tabular}

Hinlmula Expeted rrequency - $\quad 7.131$

Number of Miseing Obaervations: $s$

$\begin{array}{lll}\text { Page } 9 & \text { SPgs/PC+ }\end{array}$


This procedure was conpleted at 15:00:27

Pagge 20

spss/pC+

$5 / 16 / 94$

RECODE Q1 $(2-1) \quad(2-2) \quad(3-3) \quad(6-3)$.

Crosstxas /2xatesantb by al loptiona 14 latatiatics 1.

The raw data or traneformation pase is procosding

241 canes sre written to the compreuned active file.

Memory allown for 8,708 cella with a dimonsions for general crosstabs.

Page 1

BPSB/PC+

$5 / 16 / 94$

Q78 ANANE - EC ECO-AUDIT by Q2 HUBTIEgS TYPE

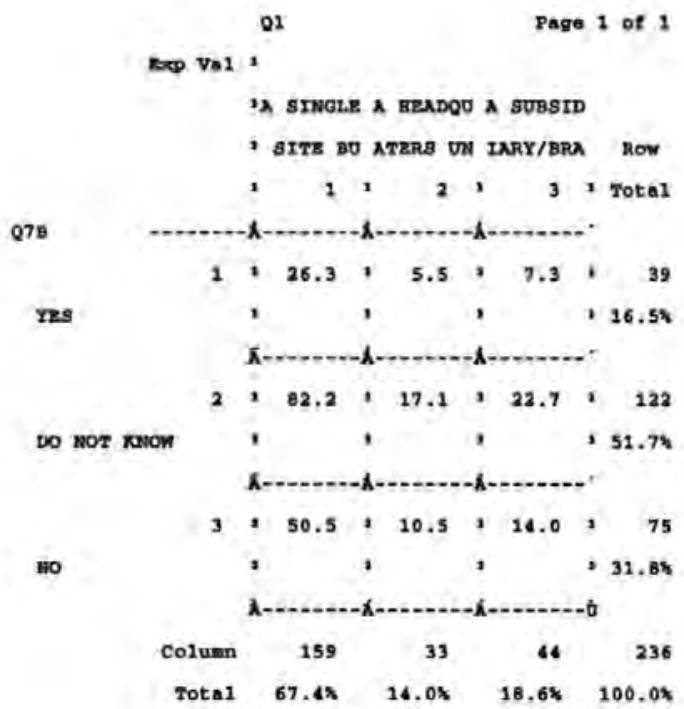

Page 12

chi-square

Pearion

Likelihood Ratio

Mante1-Heansae 1 teat for

inesx association

$\begin{array}{llr}\begin{array}{c}\text { Spss/PC+ } \\ \text { Value }\end{array} & \text { DE } & \begin{array}{r}5 / 16 / 96 \\ \text { significance }\end{array} \\ 24.54011 & 4 & .00006 \\ 23.01561 & . & .00013 \\ 19.58738 & 1 & .00001\end{array}$

Minimua zxpected rrequency - 5.453

Thuber of Misuing observations: 5

Page 13

SPSB/PC+

$5 / 16 / 94$

This procedure was eoepleted at 15,00141 
RxCODE \& $(1=1) \quad(2=2) \quad(3=3) \quad(4-3)$.

CRosstaBs /TABLES-g7e by Q1 loptione 16 /Atatiatiea 1.

The raw data or transformation pase is proceeding

241 canal are written to the compressed active file.

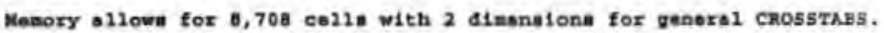

Page $15 \quad$ SPSg/PC+ $5 / 16 / 94$

Q7C AVARE - FORTBCOMTNG EC DIRECTIVES bY Q1 AUSIRESS TYPE

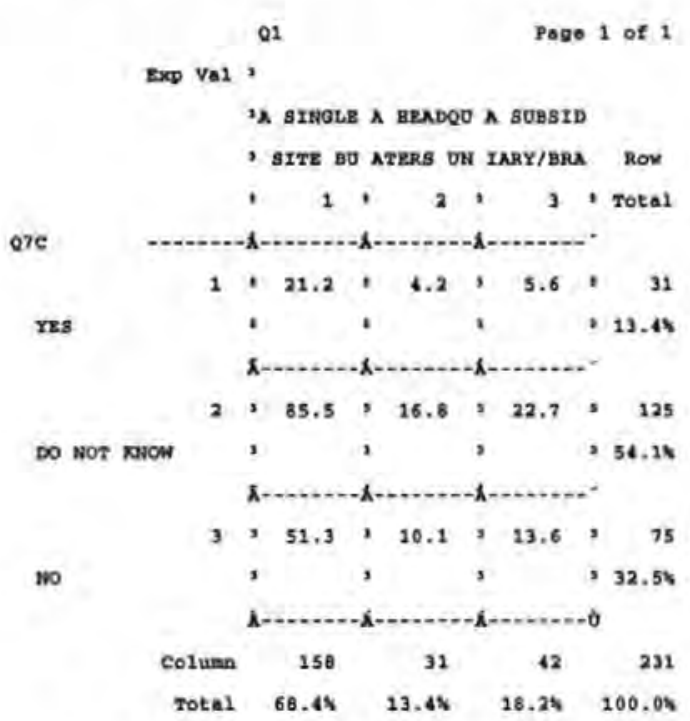

\section{Page 16 \\ Ch1-Square}

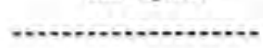

\section{Pearnon}

Like1ihood Ratio

Mantel-Basenazel teat for

lineax ansociation

Minimim Expected rrequency - 4.160

Cella with expected rrequency $<5-\quad 1$ or 9 (11.14)
$5 / 16 / 94$

significance

$\begin{array}{ccc}\text { Va1ue } & \text { DP } & \text { significance } \\ 12.90064 & - & .01177 \\ 11.66594 & 4 & .02002 \\ 10.30952 & 1 & .00132\end{array}$

Mumber of Minaing Observations: 10

Page $17 \quad$ spss/pC+ $5 / 16 / 94$

Th1 procedure was completed ot 15:01:00 
AECODE Q1 (2-1) $(2-2)(3-3)(4-3)$.

CROsstaBs /TABLEs-g7d by q1 foptiona 14 /atatiatica 1.

The raw dats or transformation pase is proceeding

as1 cakes are witten to the compreased active file.

Mamory allowe for 8,708 cells with 2 dimenaion. for ganeral CrOssTABs.

$\begin{array}{lll}\text { Page } 19 & \text { SPss/PC+ } & 5 / 16 / 94\end{array}$

Q7D AWRAE - 995750 by Q1 BUSIMRSS TYPE

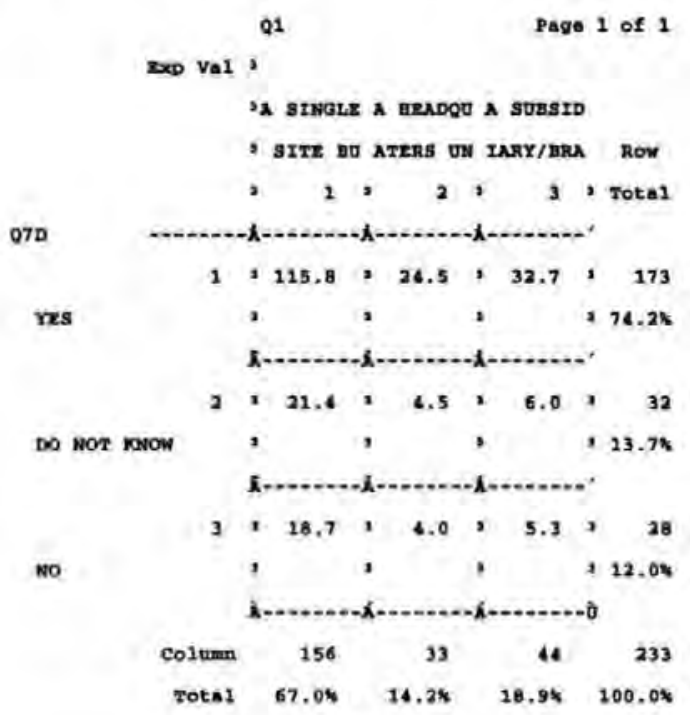

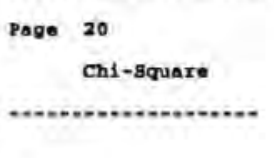

Pearson

Likelihood ratio

Mante1-Haensel toet for

11neax abociation

Minimue Eopected Froguency - $\quad 3.966$

Ce11. with Expected praquency $<5 . \quad 2$ op $\quad 9(22.25)$
$5 / 16 / 94$

signifieance

DF

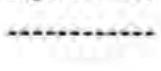

.02692

.01393

.00209

Thubber of uiseing Obeervations: o

Th1. procedure was completed at $15: 01: 15$ 
RECODB $q^{1}(1.1)(2-2)(3-3)(4=3)$.

CAOsstaBs /rabieseg7e by $q 1$ loptions 14 /statiatica 1.

The rav dath or transformation pana in prochnding

241 cases are witten to the conpresusd active file.

Mesory allows for 8,708 celle with 2 dimensions for general crosstXBs.

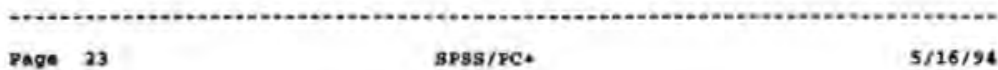

Q7E ANORE - as 7750 by Q1 nUSINEgS TYPE

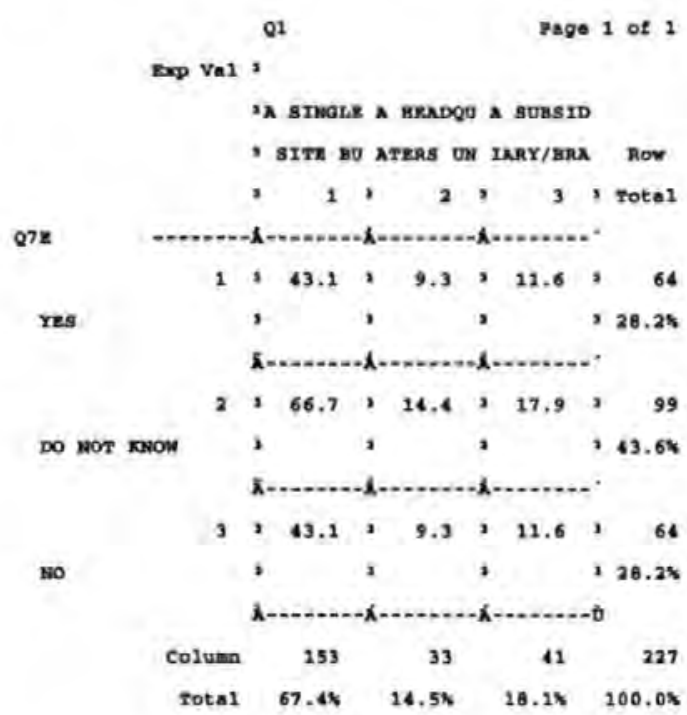

Dage 24

SPSS/PC+

Ch1-square

value

(................

19.37284

\section{Pearaon}

Like11hood Rat io

Mante1-Baenere1 toat for

11near asmociation

18.80341

13.85876

1* $100.0 x$

Minimum Expected rreguency - 9.304

$5 / 16 / 94$

signitioance

DF

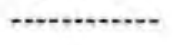

.00066

.00086

.00020

Mumber of miasing obervations: 14

Page 25

gPss/FC+

$5 / 26 / 94$

Thls procedure was completed at 15:01:29

ReCODE \&1 $(1=1) \quad(2=2) \quad(3=3) \quad(4-3)$. 
Crosstass /TABLEseq7e by q1 loptions 14 /etatietica 1.

The raw date or traniforation pass id proceeding

261 casen are written to the coepressed active flle.

Menory allowa for 8,708 colls with 2 aimbnatona for genaral crosstabs.

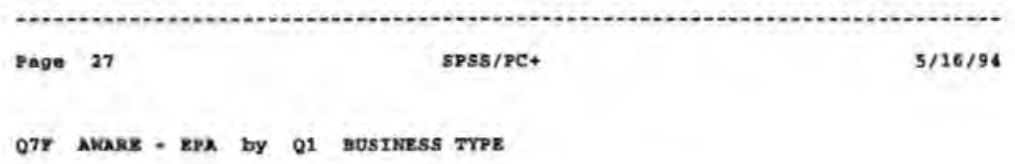

Q1 Page 1 of 1

Exp $v a 1$,

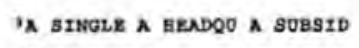

3 STTE BU ATERS UR LARY/BRA ROW

Q78

, $1,2,3$, Tote 1

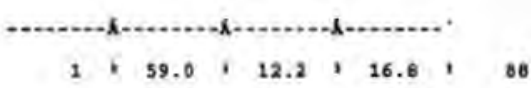

res

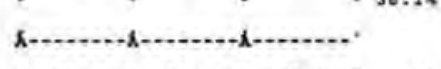

$2,58.4+12.1+16.6=67$

Do nor know

37.74

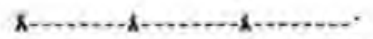

$3,37.6,7.6$ i $10.7,56$

no
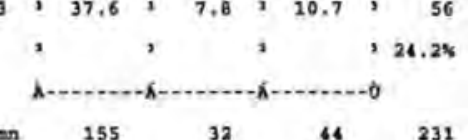

$\begin{array}{lllll}\text { Colume } & 155 \quad 32 & 64 & 231\end{array}$

sotal $67.1 \mathrm{~h} 13.95 \quad 19.0 \% 100.0 \%$

\begin{tabular}{|c|c|c|c|c|}
\hline \multirow[t]{2}{*}{ Page } & 28 & \multicolumn{2}{|l|}{ SPSS/FC+ } & \multirow{2}{*}{$\begin{array}{r}5 / 16 / 9 \\
\text { significanc }\end{array}$} \\
\hline & Chi-square & Value & DP & \\
\hline$\cdots+4$ & 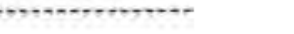 & 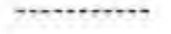 & $\cdots$ & conenten \\
\hline \multicolumn{2}{|c|}{ Pearaon } & 20.63949 & 4 & .00037 \\
\hline \multicolumn{2}{|c|}{ tikelinood ratio } & 20.73141 & 4 & .00036 \\
\hline Mante & 1-Habnezel toat for & 18.44120 & 4 & .00002 \\
\hline & I1near ansoolation & & & \\
\hline
\end{tabular}

Minimue Expected riequency - $\quad \mathbf{7 . 7 5 8}$

Sumber of Miseing obeervatione: 10

rage $29 \quad$ spss/PCt $5 / 16 / 94$

This procedure was coeplated at 15,01144

Page 30

SPSSIPC.

$5 / 16 / 94$

RECODE Q1 $(1-1) \quad(2-2) \quad(3-3) \quad(4-3)$.

CROSSTABS /TABLES-q79 by Q1 loptions 14 /statiation 1.

The rav aste or tranaformation pass is proceading 
241 onses are written to the compressed sctive tile.

Manory allowe for 0,700 colla with 2 dimanalons for generel crosstass.

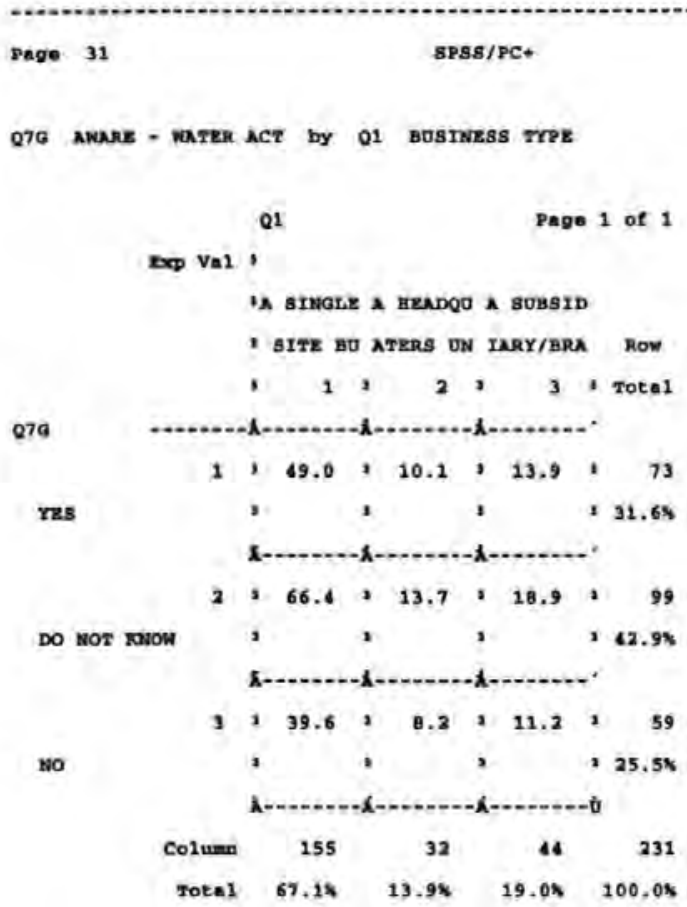

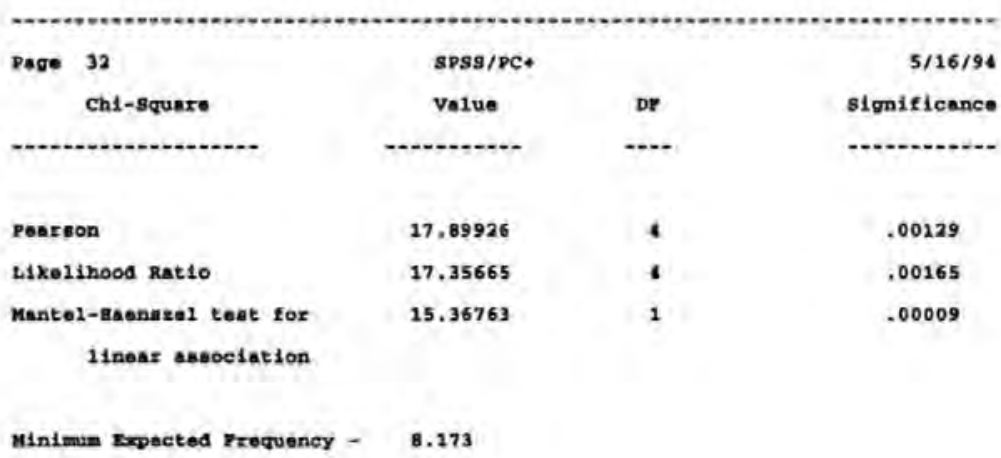

Number of Misaing Obaervations: 10

Page $33 \quad$ SYss/PC+ $5 / 16 / 94$

This procedure was completed at $15,01,59$

Page 34

SPSS/PC*

$5 / 16 / 94$

RECODE Q1 $(1-1)(2-2)(3-3) \quad(4-3)$.

CRosstaBs / TABtes=c7b by $\mathrm{Q1}$ /Options 14 /atatistice 1.

The raw date or trensformation pase if proceeding

241 cases exe written to the compresued active file. 
Memory allowe tor 8,708 celle with 2 dimansions for general crosszass.

\begin{tabular}{|c|c|}
\hline Page 35 & SPBS/PC+ \\
\hline
\end{tabular}

Q7日 ANAYE - COSER by 01 G0szkess TYPE
01
Page 1 of 1

Exp val,

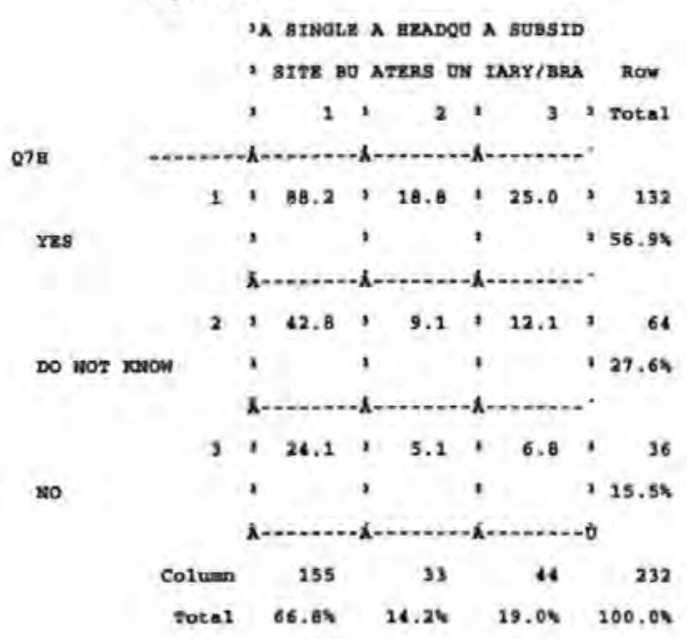

\begin{tabular}{|c|c|c|c|c|}
\hline \multirow[t]{2}{*}{ Page } & 36 & \multicolumn{2}{|l|}{ SPss/FC+ } & \multirow[b]{2}{*}{ sigrificance } \\
\hline & chi-sguare & value & DE & \\
\hline$\cdots$ & 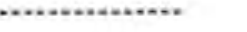 & changentents & $\cdots$ & $-200-2000$ \\
\hline Pears & & 22.31162 & 4 & .00027 \\
\hline Like1 & Ihood ratio & 24.59519 & 4 & .00006 \\
\hline Monte & $\begin{array}{l}\text { 2-Haenizel teat tor } \\
\text { 11nesr asnociation }\end{array}$ & 18.70797 & 2 & .00002 \\
\hline
\end{tabular}

Number of Missing observations: 9

\begin{tabular}{|c|c|}
\hline Page & SPBS/PC4 \\
\hline
\end{tabular}

Thla procedure was completed at $15: 02: 14$

\begin{tabular}{|c|c|}
\hline page & SPBS/FC. \\
\hline
\end{tabular}

RECODE Q2 (101) $(2=1)(3=3) \quad(4=4) \quad(5=6)$.

CROsgrass /TAatrgeg7a by q2 loptions 14 latatistica 1.

rhe sew dats or transtorastion psus is procheaing

241 casen are vritten to the compreased active :ile.

Measey allows for 8,700 celle with 2 dimensions for general Crosstabs. 
Q7A NONRX - EC ECO-LABELLING by Q2 ECPLOYERS

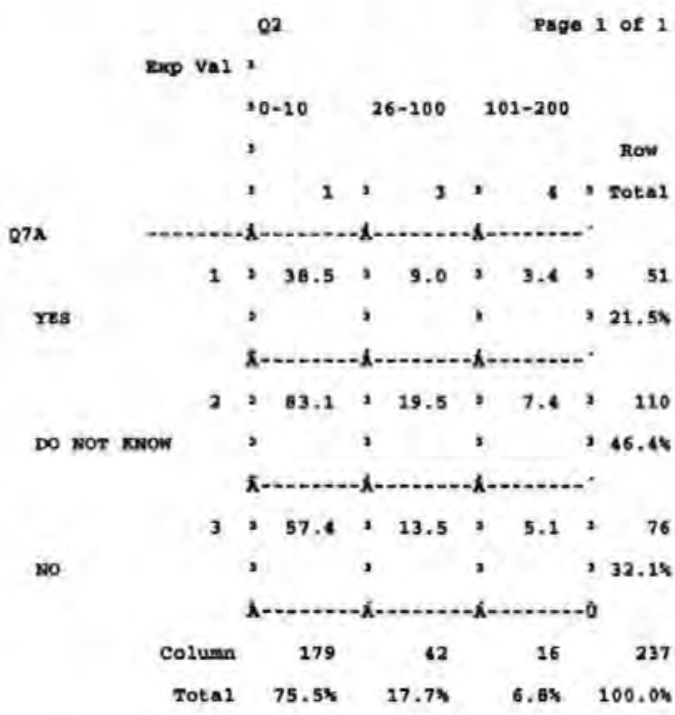

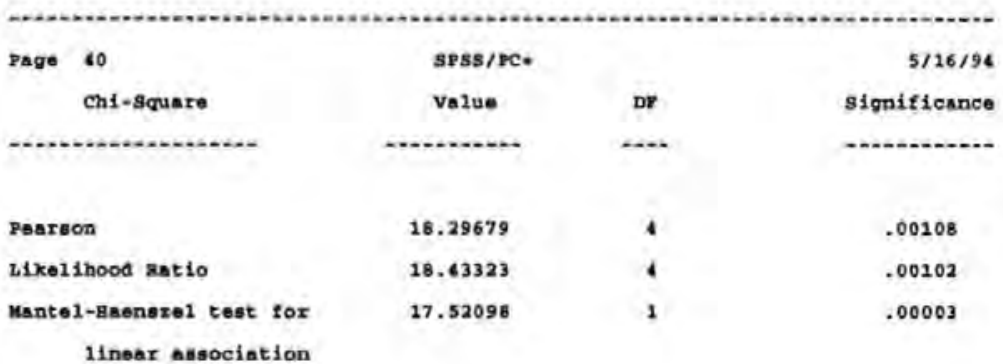

Minimum sepected Frequency - 3.443

Cells with Expected rreguancy \& $5-\quad 1$ or 9 (21.2v)

Mumber of wissing observations!

$\begin{array}{ll}\text { Page } 41 & \text { apss/PC+ }\end{array}$

This procedure was completed at 15:04:08

$\begin{array}{lll}\text { Page } 12 & 8 P S S / P C+ & 5 / 16 / 94\end{array}$

RECODE q3 (1-1) $(2-1)(3-3) \quad(1-4) \quad(5-4)$.

CROSBTABS /TABLES=q7b by qa loptione 14 /statistica 2.

The raw dats of transformation paga is proceeding

241 cases are written to the comprassed aotive file.

Mamory sllow for 8.706 cells with 2 dimengione for general crosszass. 
Q78 ANORE - zC zCO-AUDIT by Q2 zMPLOYZES

Q2

Page 1 of 1

$\operatorname{Lxp} \mathrm{val}_{a 1}$

$$
10-10 \quad 26-100 \quad 101-200
$$

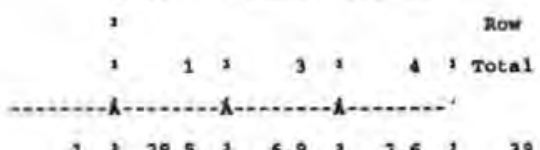

Q78

$1+29.5+6.9=2.6,39$

res
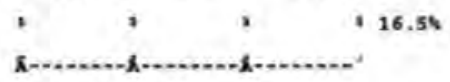

$2,92.1321 .6,8.2,122$

Do NOS KNOW, , , 51,5X

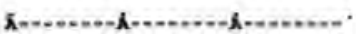

$3,57.4,13.5,5.1,76$

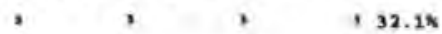

no

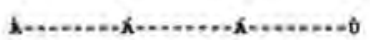

$\begin{array}{lllll}\text { Coluan } & 279 & 42 & 16 & 237\end{array}$

Total $75.54 \quad 17.74 \quad 6.84 \quad 100.04$

\begin{tabular}{|c|c|c|c|c|}
\hline \multirow[t]{2}{*}{ PAge } & 86 & \multicolumn{2}{|l|}{ SPSS/PC+ } & \multirow{2}{*}{$\begin{array}{r}5 / 16 / 94 \\
\text { slgnificance }\end{array}$} \\
\hline & Ch1-squero & velue & $\mathrm{DP}$ & \\
\hline & . & 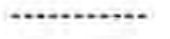 & $\cdots$ & (n............... \\
\hline \multicolumn{2}{|c|}{ Fearaon } & 15.97179 & 4 & .00306 \\
\hline Like & lihood ratio & 16.58795 & 4 & .00232 \\
\hline Mant & 1 - Inenesel teat for & 15.68508 & t & .00008 \\
\hline
\end{tabular}

Kinimen Expected Proguency - 2.633

Ce11s with Exwected Froquency \& $5-\quad 1$ or $\quad 9(12.1 \mathrm{w})$

Number of Mlasing obeervationst a

Page 45

spss/PC+

$5 / 16 / 98$

This procedure wan conpleted at 15:04:26

Page 46

SPSB/PC.

$5 / 16 / 94$

RECODE \& $(1-1) \quad(2-1)(3-3) \quad(4-4) \quad(5-4)$.

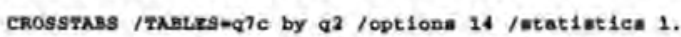

The raw data or tranaforeation pann in procending

241 cases are written to the compreaned active tilo.

Memory allowe for 6,708 cells with 2 aimensions for general crosstups. 
Q7C AKARE - FORTACOMTNG EC DIRECTIVES bY Q2 EUPLYKES

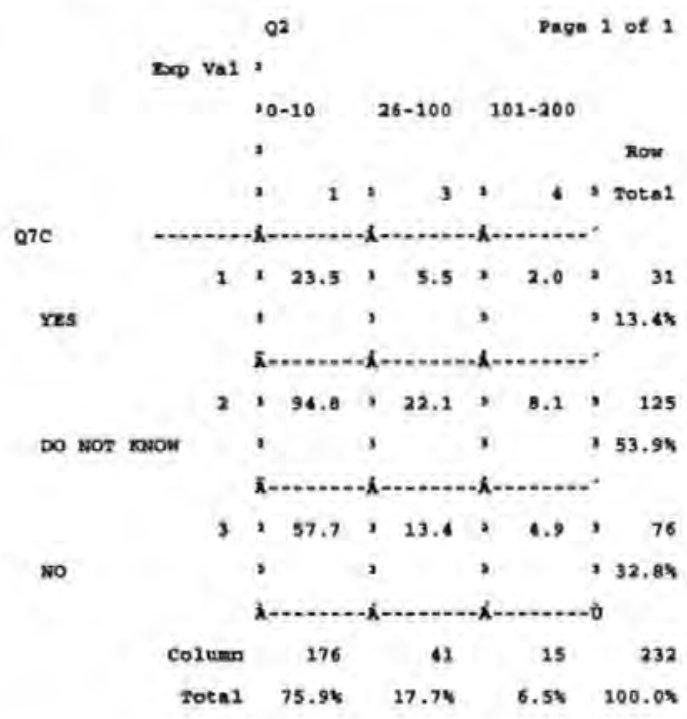

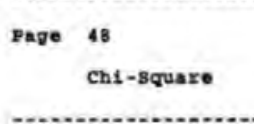

\section{Pesraon}

Iike1 ihood Rat fo

Mantel-Baenserel toat for

linear aboociation

Minimum Expected Froguency - 2.004

Ce11s with Expected Prequency \& $5-\quad 2$ or $9(22.2 k)$
$5 / 16 / 94$

significance

DF

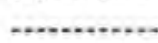

.00000

.00003

.00000

Number of Miasing observations: 9

Pege 49 SPSS/PC+ $5 / 16 / 94$

Thla procedure was oocoloted at $15: 04: 42$

RECODE Q2 (2-1) $(2-1)(3-3)(4-6)(5-6)$,

CROSSTABS /TABLES-g7d by q2 /Optiona 14 /atatiatics 1.

The rax date or trenstornation pase is proceeding

241 csses sre witten to the compressed active elle,

Mesory allow for 8,708 cells with 2 dimenaions for general crosstals.

$\begin{array}{lll}\text { Page } 51 & \text { SPSS/PC+ } & 5 / 26 / 94\end{array}$

Q7D ANQRE - AS 5750 by Q2 EMPLOYEZS 


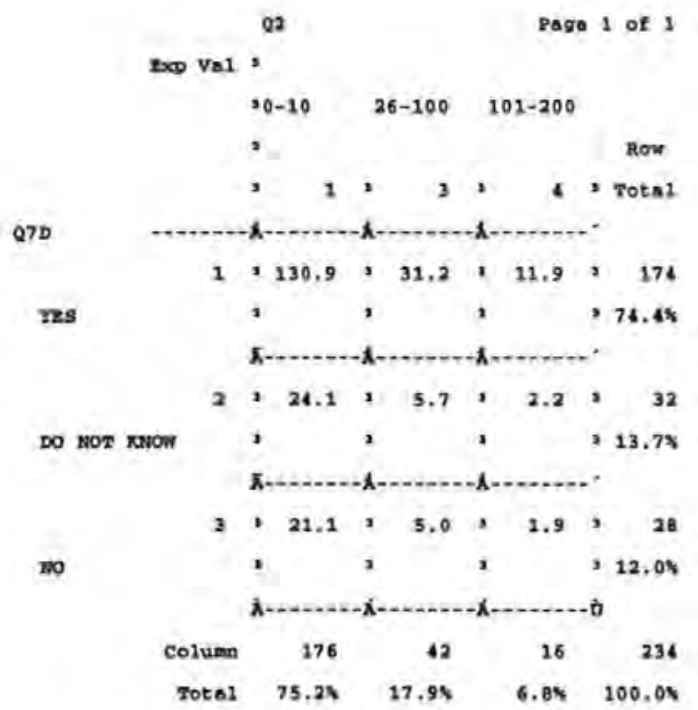

\begin{tabular}{|c|c|c|c|c|}
\hline \multirow[t]{2}{*}{ Page } & 52 & \multicolumn{2}{|l|}{ sPss/PC+ } & \multirow{2}{*}{$\begin{array}{r}5 / 16 / 94 \\
\text { signifieance }\end{array}$} \\
\hline & Chl-squere & value & Ds & \\
\hline$\cdots$ & and & n.t.n.t. & $\cdots$ & n.t.n. \\
\hline Peare & son & 14.55518 & 4 & .00572 \\
\hline Likel & lihood natio & 18.89381 & 4 & .00082 \\
\hline uante & $\begin{array}{l}\text { e1-Basenesel teat for } \\
\text { 1inase ansociation }\end{array}$ & 11.23485 & 1 & .00080 \\
\hline
\end{tabular}

sumber of alssing obeervations; ?

$\begin{array}{lll}\text { Pags } 53 & \text { SPSS/FC+ } & 5 / 16 / 94\end{array}$

This procedure was comploted of $15,06,58$

Page 54

gPSS/PC+

$5 / 26 / 94$

RECODE Q2 (1-1) $(2-1)(3-3)$ (4-4) $(5-4)$.

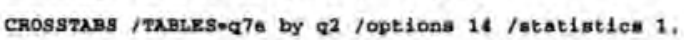

The raw data or tranaformation pana is procending

281 easse are written to the compresabd active filo.

Mesory allows for 8,706 cells with 2 aimonsions for general crosstxis.

Page $55 \quad$ SPss/PC+ $5 / 16 / 94$

Q7Z AMNRE - ES 7750 by Q2 EMLOYYES 


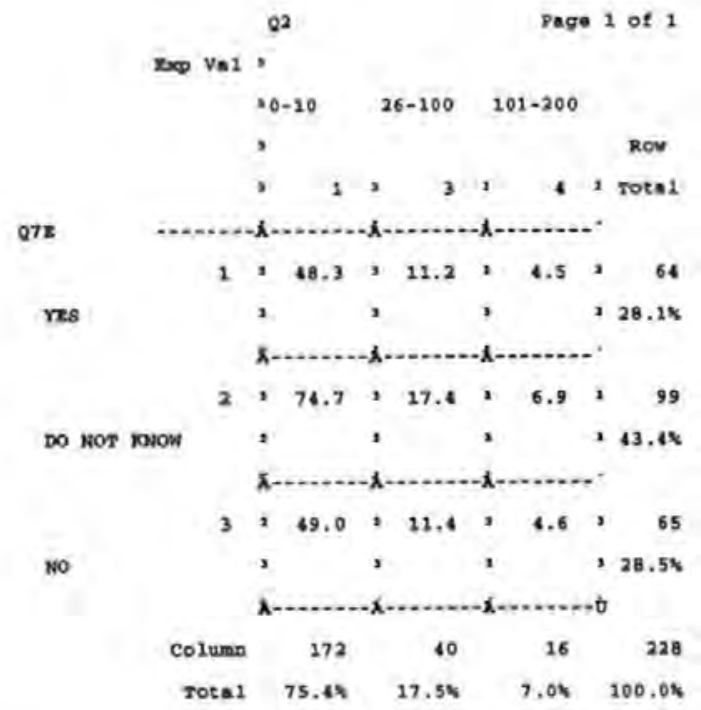

\begin{tabular}{|c|c|c|c|c|}
\hline \multirow[t]{2}{*}{ Page } & 56 & \multicolumn{2}{|l|}{ SPSE/PC+ } & \multirow{2}{*}{$\begin{array}{r}5 / 16 / 94 \\
\text { significance }\end{array}$} \\
\hline & Chi-square & Value & DP & \\
\hline$\cdots$ & - & ...2. & $\ldots$ & coten \\
\hline Pesrac & & 23.92479 & 4 & .00008 \\
\hline tikel & inood rat io & 23.54796 & 4 & .00010 \\
\hline Mante & $\begin{array}{l}\text { 2-Heonazol test for } \\
\text { I1noar ansociation }\end{array}$ & 20.94277 & 1 & .00000 \\
\hline
\end{tabular}

Mumber of Miseing Obaervationat 13

Page $57 \quad$ grag/rC, $5 / 16 / 34$

This procedure wan completed at 15:05:12

Page 58

BPss/PC.

$5 / 16 / 94$

REcope Q2 $(1-1) \quad(2-1) \quad(3-3) \quad(4-4) \quad(5-4)$,

CROSSTABS /TABLeseq7t by Q2 /Options 14 /etatiatice 1.

The raw dats or transformation pas if proceeding

241 cagen are written to the compessed active file.

Meary allows for 8,708 celle with 2 diansiona for general chosstiks,

Page $59 \quad$ SPS5/PC. $5 / 16 / 94$


QT?

$\operatorname{mep} V=1$

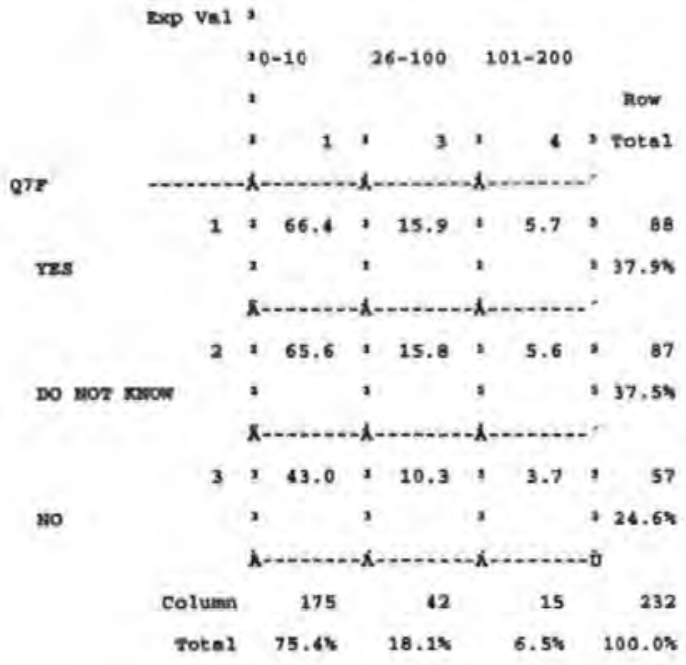

Page 60

SPSs/PC.

$5 / 16 / 94$

Chi-square

value

by

signifieance

Pearson

Likalihood natio

Mente1-Baensas 1 teat for

ingear aagociation

24.82143

.00005

26,38434

.00003

22.04957

.00000

Minimum zxpected Frequency - 3.685

Cel1. with zxpected Freguency \& $5-1$ or 9 (11.14)

Muaber of Miseing obaervations: 9

Thie procedure was coupleted at $15: 05: 26$

Paga 62

RECODE Q2 (1-1) $(2-1)(3-3) \quad(4-4) \quad(5-4)$.

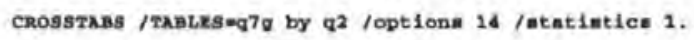

The rav dats or trangforation pess is proceeding

241 cases are written to the compresasd active file.

Menory allow tor 8,708 celle with 2 dimensions for genersi CRosstass.

Page $63 \quad$ SPSB/PC. $5 / 16 / 94$

Q79 ANORE - WaTES ACY by 92 enpLotees 


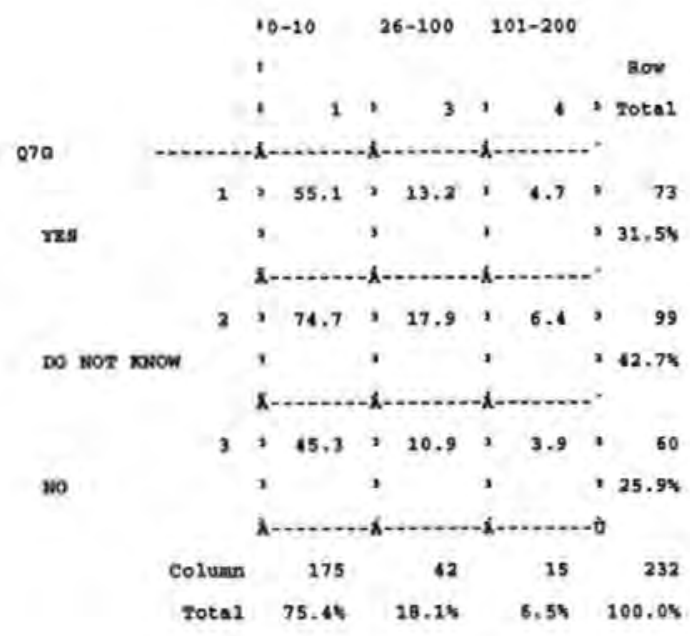

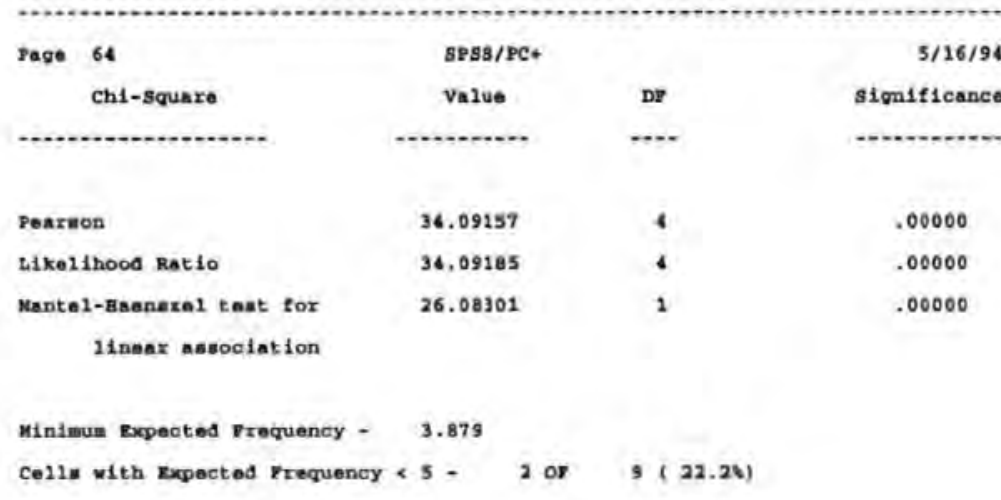

Thuber of Mianing obaervationas 9

Page $65 \quad$ SPsg/RC+ $5 / 16 / 94$

This procedure ves completed at 25,05143

Jage $66 \quad$ SPSIPC+ $5 / 16 / 94$

RECODH Q2 (2-1) (2-1) (3=3) (4-1) (5-4).

crosstabs /TABueseg7b by q2 /Optiona 14 /atatiatics 1.

The raw dats or transforeation pase is procesding

241 enmes sre written to the compressed sctive $\$ 110$.

Memory allow for 6,708 cella with 2 dimenalons for ganeral CRosstils,

Page 67

BPS/PC+

$5 / 16 / 94$

Q71 NWARE - COBHB bY Q2 EMPLOYEES

Q2

Page 1 of 1

aco VaI .

$\quad 30-10 \quad 26-100 \quad 101-200$ 


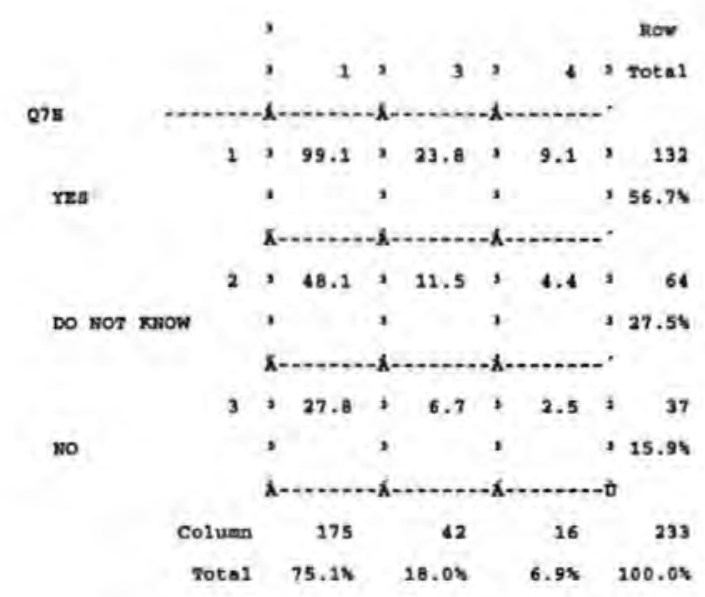

\begin{tabular}{|c|c|c|c|}
\hline Page 68 & SPBS/PC+ & & $5 / 16 / 94$ \\
\hline Ch1-Square & value & DF & Significance \\
\hline 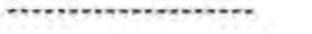 & - & $+\cdots$ & (c) \\
\hline Pearaon & 21.11315 & 4 & .00030 \\
\hline Likelihood Ratio & 26.19195 & 4 & .00003 \\
\hline Mantend-Haonazel teat fox & 17.42792 & 1 & .00003 \\
\hline
\end{tabular}

uin1mun Eacpected rrequency - 3.541

Ce11. with Expected rrequency \& 5,2 of $9(22.2 \times)$

Nuber of Misoing Observations: o

Page 69

spss/PC+

$5 / 16 / 94$

Thin procedure wal complated at $15,05: 57$

Page 70

sPss/PC+

$5 / 16 / 94$

rIMrge.

the of Inelude 2110 . 
APPENDIX 2 
In-depth Interviews

$\underline{7 / 1993}$

\section{Company 1 - Heavy Manufacturer}

COST - Most important criteria.

Background - Manufacture component parts for the aircraft industry. Grind dust and metals (cobalt is a sensitive issue).

Process all coolants. USA owned. Rationalisation process on how they deal with waste. Problems with waste disposal middle men, not up to date with the new Duty of Care requirements.

General feeling of anti 1990 EPA and legislation as a regulator. But the interviewee said that legislation could be effective to encourage self-regulation. Recycling, energy efficiency and waste minimisation programmes in place.

Shared responsibility for environmental issues. Essential to have shop floor interest and understanding. Environmental information diffusion is the main requirement for managers and workers to improve their environmental performance. One stop shop would be useful if only to supply newsletters.

Changing the individuals perceptions and increasing their understanding of their responsibilities through environmental training courses. Half day seminars were suggested to direct in house training methods. Plus proper layout of reports to senior managers regarding environmental issues.

Essential to have standards like the BS 7750 and policing through these rather than through legislation. Has implemented BS 5750 costly, time consuming and difficult. Would consider BS 7750 from the image point of view.

CPF, (Continuing Educational Forum run by PMG, Plymouth Manufacturers Group). Seminars, one on energy efficiency. Trade journals and associations were held in high regard and could be the best route to make people aware of their responsibilities.

"If there's profit in it then there is interest, if there is no profit then interest wains"

\section{Company 2 - Packaging Company}

Polystyrene packaging company dealing with Toshiba, Panasonic, Hitatchi. Two satellites but Torpoint is the HQ. Est. 1965, therefore fairly old and market is still increasing.

No strategic written down approach to the environment. The interviewee sees environmental issues as transitory and unpredictable. "How can you define the solution when the problem is undefined?". But had operational initiatives such as a recycling programme, waste minimisation, and pollution control policies and considers packaging output.

But have plans to implement BS 7750 as well as BS 5750 . BS 5750 was seen as a cosmetic exercise as you can obtain the standard by satisfying quality procedures and still 
selling rubbish. BS 7750 is seen in a more positive light as clear targets and requirements are laid out.

No direct pressure from customers to become more environmentally friendly. But pressure to use cardboard or re-cycled polystyrene. Especially from West Germany. (through Toshiba).

Therefore legislative pressure filtering back down the supply chain from West Germany (Herr Kopfler the environmental Minister). Didn't want polystyrene. Fundamental problem with Polystyrene is the lack of alternatives. The pulp packaging is more environmentally unfriendly and the $30,50,80 \%, 100 \%$ recycled Polystyrene is $50 \%$ more expensive. i.e. $£ 1000$ per tonne becomes $£ 1500$ per tonne. Pulp still goes back to trees.

Answer is a integrated, unified and structured approach to the solution, i.e. for legislators to speak firstly to trade associations, like the British Plastics Federation and to individual leaders in the industries. Then to develop considered, legislation's. These could then be policed by the Health and Safety inspectorate as well as being self regulated by companies.

Solution is from intelligent discussion, research and identification of credible solutions in a sensible time series. Plus means by which to do the recommendations.

18 months two years ago, there was an inkling of discussions by the Government with BPF, now fissled out. Consumer goods manufacturer has very important views on environmental issues. They seem to be determining policy as much as $\mathrm{HQ}$.

Suggesting that the supply side of his equation, i.e. Panasonic and Toshiba, should be forcing the legislators arm but are not at this moment. Market pressure seen as uninformed comment. i.e. no idea about alternatives to polystyrene. The tail can't wag the dog. Global companies are in the driving seat and should be forcing sympathetic legislation's that are credible.

The company has reacted to market pressure by investing in equipment which enables them to recycle on site. Plus produce alternatives, but people don't want it.

Recycling has been $100 \%$ successful. Waste recycling has saved them a lot. Reduced costs. As with energy efficiency programme. Cost saving is the best motivator. Vague topic and undefined problem. Extremely negative about the solutions, i.e. the new packaging directive requires transport back to source which means increased transport.

Heavy investment in the environment. But sceptical and cynical. Can recycle any waste used on site and any materials brought in from outside. i.e. tubes brought in. Potential for end consumer to send back Polystyrene. No specific transport policy. Not aware of the eco-labelling scheme. Plus possibility that many others were not as he said yes in the survey.

The British do not like "sticks". Especially if they are European sticks. But exporters realise that they have to keep up with European regulations or risk reduction of market share. Legislation does increase awareness well. Especially at the industrial level. Mustn't have blanket legislation's.

Very concerned about the ACBE proposal to pressure companies to become more environmentally clean through loans. As it would become a personal issue and subjective and would not necessarily respect the judgement of the environmentalist at the bank etc. 
Research is taking place into looking into alternatives and the Plastic Federation is trying to encourage people that polystyrene is not that bad and therefore to release the pressure.

\section{Company 3 - Small Office}

Business Background - Single office/site business. Environmental issues, office based. Rapidly expanding and in the stage of considering expansion by taking on more help. Deals with individuals as well as companies. Regular travelling by car, salesman technique. 8 years $\mathrm{p} / \mathrm{t}, 3$ years full time.

Main issue was that the company was interested in environmental issues for personal ethical issues more than for short term financial response.

Although environmental issues are the raison d'etre of the company. Runs the business as an extension of the household. He recycles waste and tries to keep energy usage to a minimum.

Does not have a strategic plan to accommodate the environment, but does feel that a company should be able to strategically plan however small they are. They should be flexible and always aware of future problems. Has a recycling programme, an energy efficiency procedure, a waste policy and considers the environmental implications of transport. Does 40000 miles a year mostly in the car. But tries to arrange jobs close to each other for convenience sake rather than anything else.

Takes household and business waste up to chelsom meadows. Was asked to pay when he had c. $\$ 500$ of paper work to scrap. Tries not to make any more copies of material than he needs. Turns off machines at the wall when he goes away. No low energy light bulbs in the office.

Essentially the business is an educational diffusion agency in itself and provides companies with plans to change and improve their internal business environment if not their external one as well. (reference to paper and tobacco coming from trees). Also, he never gets regulations through, i.e. he had to go looking for the new Health and Safety at work regulations, from January 1993, that require some sort of environmental awareness on smoking. Information diffusion problem.

Interested in environmental issues mainly because he has worked in medicine and in an environmental health department for the NHS. Educated about the environment. Does not see environmental compliance as a cost saving exercise, more as an ethical issue. Sees the solution to be self imposed rather than being made to comply by legislation. Also feels that this would be more effective as then companies would comply fully without reservation if they believed in the change.

Therefore he believes in some sort of legislation but mostly in self regulation for efficiency purposes. Legislation could lead to developing a policy just for the sake of it. Minimum legislation for those who are not convinced. Convinced, may do more. If the customer does not demand changes then must look at the supply side, i.e. to create the demand through supply. But therefore requires legislation.

Most have not thought about sustainable growth. Increase public consciousness and educational programmes. Health and Safety or fire reasons lead to Stop Smoking, but USA suing for passive smoking is another reason to call him in on a corporate level. 
Used to be a member of Plymouth Rotary Club, but not in touch with support organisations. Interested in Groundwork or a one stop advice shop from a commercial point of view, i.e. acquiring work through seminars. Not concerned about financial incentives to become more environmentally friendly. But unaware of the requirements.

Highlighted the confusion with 'eco' labels from a consumers point of view. Highlights day to day survival rather than strategic planning ahead. But "any business that is going to survive has to look ahead". Lack of strategic planning has lead to many small businesses going bust over the last few years. Aware that there are environmental issues that he is not aware of with respect to the business. Would like to be informed of what the requirements or possibilities are for environmental improvement.

Legislation means that companies will wait until they are made to undertake the requirements and then they will only do the minimum requirement. Therefore it is better to educate and encourage companies of the virtues of environmental improvement rather than imposing unwanted requirements on companies that they will not understand.

Workforce support is absolutely essential,

\section{Company 4 - Manufacturer}

Part of a PLC. 18 branches, Plymouth is one of the smallest branches. Safety equipment for ships plus fishing equipment. HQ is in Grimsby.

There is a central policy on the environment, but it has not filtered down yet to Plymouth. Reason is customer pressure from larger buyers. No manufacturing processes in the division. Health and safety manger is most involved with the environmental issues.

All they want is a piece of paper to show that they have an environmental policy. The fact that it has not and probably will not ever be implemented is neither here nor there. It is a charade. The larger firms do not even need assurance, just a piece of paper.

The interviewee had not heard of BS 7750 and suggested it was nothing new. BS 5750 had been implemented and the interviewee suggested it make them more efficient and was worth doing as it is a requirement to allow them to compete. Doubts that the environment assurance will be as conclusive but if it was they would consider its implementation. Could implement it.

Branch is more or less autonomous, each branch has a branch manager, who reports to an area manager. Far more pressing things than environmental issues. 5 years ago there were big pools of resources therefore time to discuss these "peripheral" issues. Now when they get together to discuss policy and direction keeping above water is the most important thing.

Not really thought about it very much and customer pressure and legislation would be the only real concerns that would lead them to consider environmental issues on a large scale. Seen as a very low priority due to time and financial restraints.

Very sceptical about the use of economic instruments in the environmental field, but the interviewee did not really understand the implications or concepts discussed. Although the company did have a recycling initiative.

\section{Company 5 - Guest House}


Deals with yearly tourist trade on the level of a small hotel. Does not feel environmental issues are at all important to the business practices.

Has no buying ethics aside the cheapest available commodities. Does not feel any real consumer pressure to change. Used to but environmentally friendly household goods, washing powders and detergents. No longer does as they were not as good.

Has not heard of the British Tourist Boards Green Initiatives or feels they will be relevant. BS 7750 seen as totally inappropriate and a waste of time.

Generally felt that environmental issues are still important but are the problem of large scale manufacturing companies and not guest houses. Some interest in the issue that a clean environment would benefit the South West's Tourist trade, but does not feel that they could induce any change.

Only pressure to change would be through the customers, many of whom are regulars.

Company 6 - Small antiques distributor

Buys and sells antiquities in the South West and abroad where possible. Believes in entrepreneurial spirit and free will. Therefore does not appreciate any form of regulation or legislation.

No specific environmental policies as lack of time and motivation. Although he did consider the environmental implications of his transportation mode. Transport is essential and therefore not an issue. But does have an unleaded car as the petrol is cheaper. General feeling that the environment is irrelevant and that waste is an unfortunate necessity. i.e. packaging.

General feeling that economic instruments like these are good. If costs are reduced then interest increases. But never consider energy efficiency as an option. Although did recognise this as a possibility, if only to reduce bills by turning off the light.

Sole trader therefore no other employee to educate which made BS 7750 irrelevant. Did not have any sort of management system or strategic management structure in place aside to maximise profit and survive the recession.

Only incentive to change would be from customers unless legislation forced him to. This was seen as unlikely in his business as it would be impractical. Therefore economic instruments and customer pressure would be the most effective ways of improving his environmental performance.

Company 7 - Shop/Retail outlet.

Selling office stationary. 
Unaware of any environmental pressures. Do not feel they are particularly environmentally unfriendly. But feel that an environmental newsletter distributed through retail trade associations would be useful.

No staff training or pressure from staff to consider environmental issues. Only source of environmental impact they felt they had was through the company transport policy. As most vans were running on lead free petrol this was seen as adequate.

Packaging was not an issue they had considered and they had no formal environmental policy although they agreed that this could be a possibility. Operation initiatives, did, however include recycling.

\section{Company 8 - Management consultancy}

Did not feel it had particularly large impact on the environment but was interested from a commercial point of view. Felt its environmental impact would come from internal operations within the office.

No audit had been undertaken, but they encourage the reduction of office paper, recycling and the use of energy saving measures, i.e. turning off lights when not required. No further analysis of energy usage had been undertaken.

The use of trade journals were felt primary sources of information diffusion. They also said that trade journals were the most frequently referred to source of information for many of their clients. Suggesting that this would be the best avenue to walk down if changes were to occur. They were unaware of the implications of the 1990 EPA but considered legislation a necessity in the long term.

BS 7750 was being considered but only as a commercial exercise,

Company 9 - Small engineering

Specialisation was small batch injection moulding mainly in engineering polymers. Assembly and fabrication.

Employee and investor pressures had lead to the formulation of an environmental policy. Trade journal is seen as very useful but the chamber of commerce is not. Groundwork Trust has been approached for help and were helpful.

Feeling that free consultancy and increased information flows would be helpful. Concurrently, more half day seminars would be useful. When the interviewer pointed out that there was an environmental forum (Plymouth Environment Forum) for the exchange of views the interviewee was very interested.

Waste disposal, employee health and safety, energy efficiency and the control of emission were seen as the most important issues. BS 7750 was seen as appropriate but the interviewee did not envisage employing it in the near future. Was currently seeking BS 5750 accreditation and felt this was enough for the meantime. Although it was suggested that BS 7750 may be considered at a later date if customer pressure increased.

Company 10 - Manufacture -

Manufacture of joinery and other specialist requirements of the construction industry. 
The use of solvents requires the company to be subject to the COSHH requirements and this has lead to an interest in the environment generally. The pressure to address the issue has come through a feeling of legislative compliance rather than customer pressure.

Does not consider itself a prime polluter but accepts that it has some detrimental effect on the environment. Feels information is hard to get hold of and requires further assistance on the legislative level.

Being a small local manufacturer, the impact on the local community is of concern. Although the company has not as yet been subject to local criticism, the standing of the company in the locality is an important issue.

The interviewee felt that legislation development would "level the playing field" and could therefore be beneficial. Personal conviction is seen as of secondary importance to legislative pressures as a catalyst for change. Feels that BS 7750 could be applicable to the company but recognises that it would have to reconsider its own management channels first. Being a small company the interviewee also feels there should be some financial subsidy to encourage environmental best practice.

Economic instruments were viewed in a very negative light as the market was seen as uninformed. Case study material from firms with similar constraints would be useful.

Company 11 - Manufacturer engineering.

Light engineering company producing sheet metal and light fabrication work.

Legislation is the prime cause for concern. Is as yet unaware of its legislative requirements but is taking steps to redress this balance. They did, however feel the necessity for legislation if only to level the playing field.

The interviewee felt that a one stop advice shop would be useful as a starting point and that a data base would also be of use. BS 7750 was viewed as a waste of time and money and would never be considered. It was also described as "jobs for the boys" for his experience of BS 5750 .

Time and money were seen as the most important reasons for the company's lack of environmental initiatives. The interviewee also felt that although they would have to keep up with the developments of legislation, "Green" was no longer such an important issue.

They had no formal environmental policy. The use of economic instruments as a way of cleaning up the environment was seen as extremely dangerous although some reevaluation of the tax system could be beneficial for small firms.

Company 12 - Design, marketing and communications company

As an office based company the interviewee felt the company's environmental impact was very low and therefore a low priority. Waste paper was recycled but apart from this there were no environmental initiatives in place.

This was due to the perceived lack of environmental impact and to the lack of external pressure to change. BS 7750 was viewed as a complete waste of time and also totally inappropriate. They had no formal environmental policy. 
The company would not be interested in any external consultancy even if it were subsidised as time would still be wasted.

Company 13 - Large tourist attraction

Environmental issues were taken very seriously here due to customer pressure and personal conviction. An environmental audit had been undertaken and an holistic approach was being taken throughout the company with respect to environmental issues. A written environmental policy was also produced and available to the general public. This was a substantial document that went into detail about current practices and was not simply cosmetic.

Energy efficiency measures were in place, low energy light bulbs and increases in insulation were being considered. The company also felt the requirement to divulge what it was doing to its customers and felt that there were marketing opportunities available in this respect.

BS 7750 was seen as a possibility but the interviewee felt that the company had environmental issues well in hand. It was agreed that BS 7750 was a possibility if only for commercial exploitation.

Trade journals had been very useful but further best practices would be interesting to compare and improve. Legislation was also seen as a requirement to level the playing field and they were aware of the implications of the 1990 EPA to their business practices.

Company 14 - Solicitors practice

Environmental issues were viewed here as a commercial opportunity and nothing more.

The interviewee felt that his company had no environmental impact over and above that of a normal household. They did however feel that more co-ordination of environmental information and best practices would be useful. They also felt that further legislation could be useful to reduce SMEs environmental impacts but could not see how it would be policed.

In general they felt that information on how to improve practices was limited and required attention. BS 7750 was seen as inappropriate and unnecessary. 


\section{APPENDIX 3}




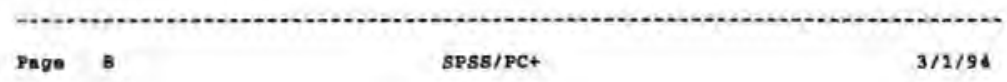

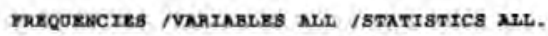

W... Hesory allown a total of 12881 values, accumulated acroes all variables. thare siwo may be up to 1610 Value Labels for each variable,

Paga 9

sPss/PC+

$3 / 1 / 96$

Q1 bustneas type

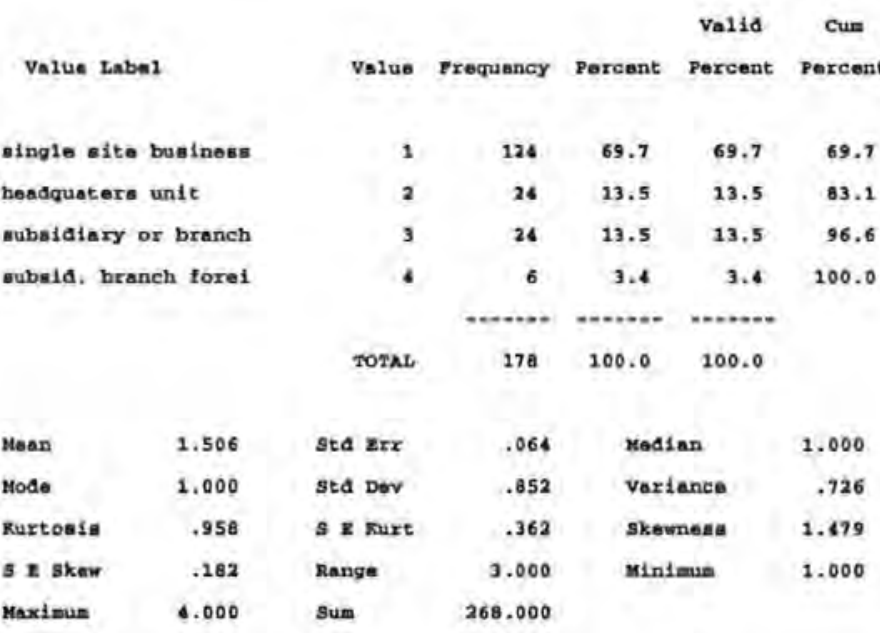

Vel1d Cases $178 \quad$ Miasing Cseos 0

Page 10

BPss/PC.

$3 / 1 / 94$

02 andoyen

value Iabei

$0-10$

11-25

26-100

101-200

$200 *$

\begin{tabular}{|c|c|c|c|c|c|}
\hline Mean & 1.753 & std Err & .025 & Median & 1.000 \\
\hline Mode & 1.000 & Btd Dev & 1.128 & Variance & 1.272 \\
\hline Kurtaein & 1.018 & s \& Kure & .962 & Skewnene & 1.409 \\
\hline$B$ E sken & -182 & Range & 4.000 & Minimue & 1.000 \\
\hline Maximan & 5.000 & stum & 312.000 & & \\
\hline
\end{tabular}




\begin{tabular}{lcc} 
val1d Canes $178 \quad$ Missing Caned 0 \\
\hline page 11 & BPg8/PC+ & $3 / 1 / 94$
\end{tabular}

Q3 businees soctor

value rabel

\begin{tabular}{|c|c|c|c|c|c|}
\hline prlary & 1 & 10 & 5.6 & 5.6 & 5.6 \\
\hline secondary & a & 64 & 47.2 & 47.2 & 52.8 \\
\hline \multirow[t]{3}{*}{ tertiary } & 3 & 63 & $\$ 6.6$ & 16.6 & 99.4 \\
\hline & 10 & 1 & .6 & .6 & 100.0 \\
\hline & rotal. & $17 \theta$ & 100.0 & 100.0 & \\
\hline
\end{tabular}

\begin{tabular}{|c|c|c|c|c|c|}
\hline Moan & 2.453 & ata Brr & .062 & redian & 2.000 \\
\hline rods & 2.000 & Gtd Dev & .824 & Variance & .679 \\
\hline Nurtosio & 38.765 & $g=$ mart & .362 & gkemeag & 1.130 \\
\hline A I Bkow & .182 & Range & 9.000 & Mindane & 1.000 \\
\hline Maximan & 20.000 & sum & 437.000 & & \\
\hline
\end{tabular}

valia casos 278 Mleoing cases 0

Pege $12 \quad$ BP8g/PC+ $\quad 3 / 1 / 94$

at comongy age

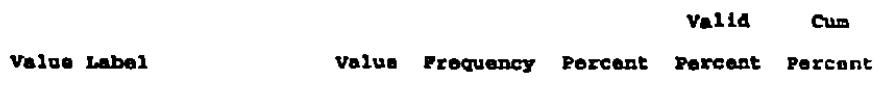

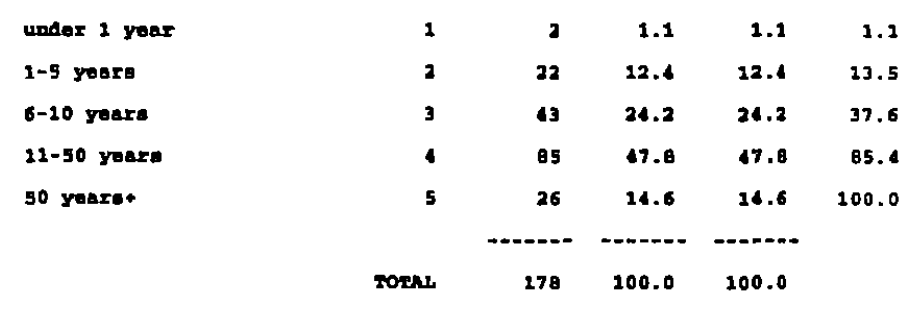

\begin{tabular}{|c|c|c|c|c|c|}
\hline Hoan & 3.624 & Bta Bry & .069 & Hodian & 4.000 \\
\hline Hode & 1.000 & sta Dav & .920 & Vaxiance & .046 \\
\hline ructonde & -.202 & $a$ a murt & .362 & gkemases & -.502 \\
\hline g I Skew & .282 & Range & 1.000 & mintarin & 1.000 \\
\hline Marsman & 5.000 & Sum & 645.000 & & \\
\hline
\end{tabular}

\begin{tabular}{lcc} 
val1d caver $170 \quad$ miesing Camer 0 & \\
\hline Page 13 & SPas/PC+ & $3 / 1 / 94$
\end{tabular}

Q5 export/non exportere 
volue Label

yes

no

valsa cum

Volue Froguency percent percent percent

$\begin{array}{rrrrr}1 & 70 & 39.3 & 39.3 & 39.3 \\ 2 & 108 & 60.7 & 60.7 & 100.0 \\ \text { TOTNL } & 178 & 100.0 & 100.0 & \end{array}$

\begin{tabular}{|c|c|c|c|c|c|}
\hline Mesn & 1.607 & std Erx & .037 & Median & 2.000 \\
\hline Mode & 2.000 & Sta Dev & .490 & Variance & .260 \\
\hline Rurtoain & -1.826 & S E ruxt & .362 & Skewnes: &. .441 \\
\hline 5 z skew & .182 & range & 2.000 & Mininua & 1.000 \\
\hline Maximus & 2.000 & Sum & 286.000 & & \\
\hline
\end{tabular}

Valid Caven 178 Maning Cases a

page 14

spssipct

$3 / 2 / 94$

06 atrotegic ann policy

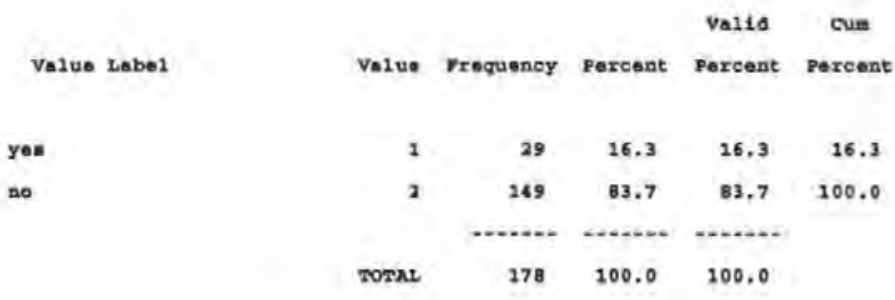

\begin{tabular}{|c|c|c|c|c|c|}
\hline Moen & 1.837 & sta $\mathrm{Brx}$ & .028 & Median & 2.000 \\
\hline Mods & 2.000 & sta Dor & .370 & Variance & .137 \\
\hline Kurtosis & 1.405 & $s \boldsymbol{x}$ kurt & .362 & Skcerneasa & -1.841 \\
\hline S E Skew &, 102 & Range & 1.000 & Minieua & 1.000 \\
\hline Moximua & 2.000 & Sum & 327.000 & & \\
\hline
\end{tabular}

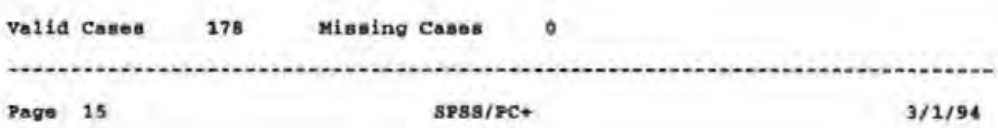

Q7x no atrat policy

Volue Label

operations 1 env Init no opinion

Mean

node
1.632

2.000
SPss/FC+

$9 / 1 / 94$ vaisd cua

value rreguency percent percent pereent

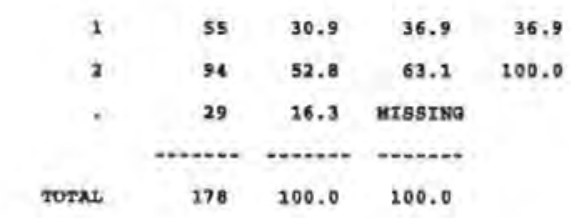

Sta err

.040 Median

2.000

sta Dev .484 variance .234 


\begin{tabular}{|c|c|c|c|c|c|}
\hline Kurtosill & -2.723 & s E Kuxt & .395 & skamases & -.548 \\
\hline S I sker & .199 & Hange. & 1.000 & Miniman & 1.000 \\
\hline Maximun & 2.000 & sum & 263.000 & & \\
\hline
\end{tabular}

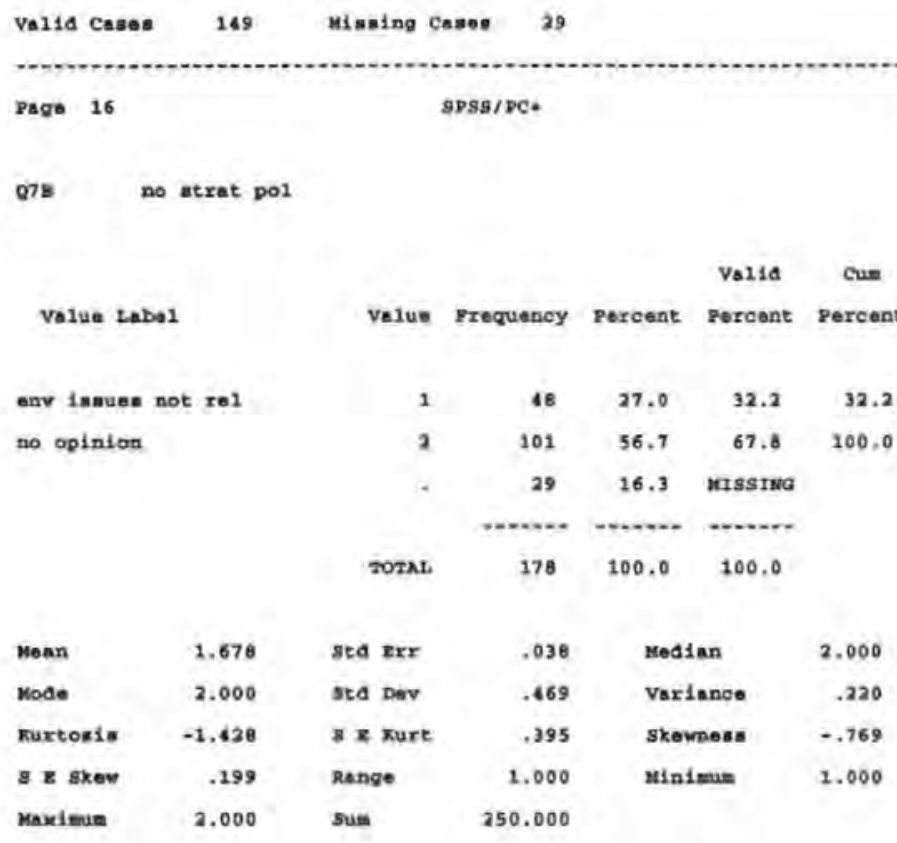

Valta casen 149 Miseing casea 29

page 17

spss/pC.

97e no atrat pol

value tabel

lack of info

no opinton

\begin{tabular}{|c|c|c|c|c|c|}
\hline meso & 1.859 & sed $\mathrm{rrx}$ & .029 & Median & 2.000 \\
\hline Mode & 2.000 & sta Dev & .349 & Var1enes & .122 \\
\hline Kurtonia & 2.378 & s x Kurt & .395 & Skewmeaso & -2.085 \\
\hline S E skow & .199 & nange & 1,000 & Minieun & 1.000 \\
\hline Maxi $1=10$ & 2.000 & Sum & 277.000 & & \\
\hline
\end{tabular}


valid cur

value tabol

Volue Fregueney percent parcent parcent

1sck of in houns oxp no opinion

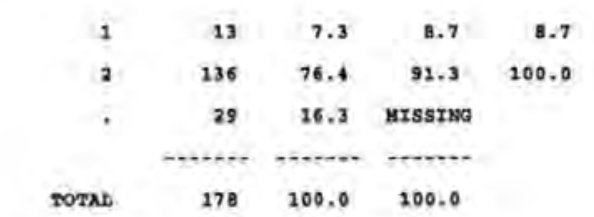

\begin{tabular}{|c|c|c|c|c|c|}
\hline Maan & 1.913 & Std Err & .023 & Median & 2.000 \\
\hline Mode & 2.000 & sta Der & .283 & Varience & .080 \\
\hline Kurtonile & 6.824 & S E kurt & .395 & Skewneas & -2.955 \\
\hline$s$ z skev & 199 & range & 1.000 & Minimus & 1.000 \\
\hline Moximun & 2.000 & sua & 285.000 & & \\
\hline
\end{tabular}

valla cases 149 Miasing cases 29

Page $19 \quad$ BPSB/FC+ $3 / 1 / 94$

Q78 no atrat pol

valus tabe1

1ack of ablitty to a no opinion

$$
\begin{gathered}
\text { Val1a cum } \\
\text { Value Frequency percent parcent percent }
\end{gathered}
$$

\begin{tabular}{|c|c|c|c|c|c|}
\hline Mesn & 1.699 & sta $\mathbf{z r x}$ & .025 & Median & 2.000 \\
\hline Mode & 2.000 & sta Dev & .302 & Variance & .091 \\
\hline Rurtosia & 5.260 & s g kurt & .395 & skevmess & -2.681 \\
\hline a z Skew & .199 & Nange & 1.000 & Minimu= & 1.000 \\
\hline Maritmun & 2.000 & sum & 283.000 & & \\
\hline
\end{tabular}

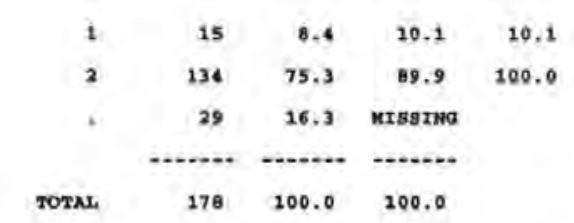

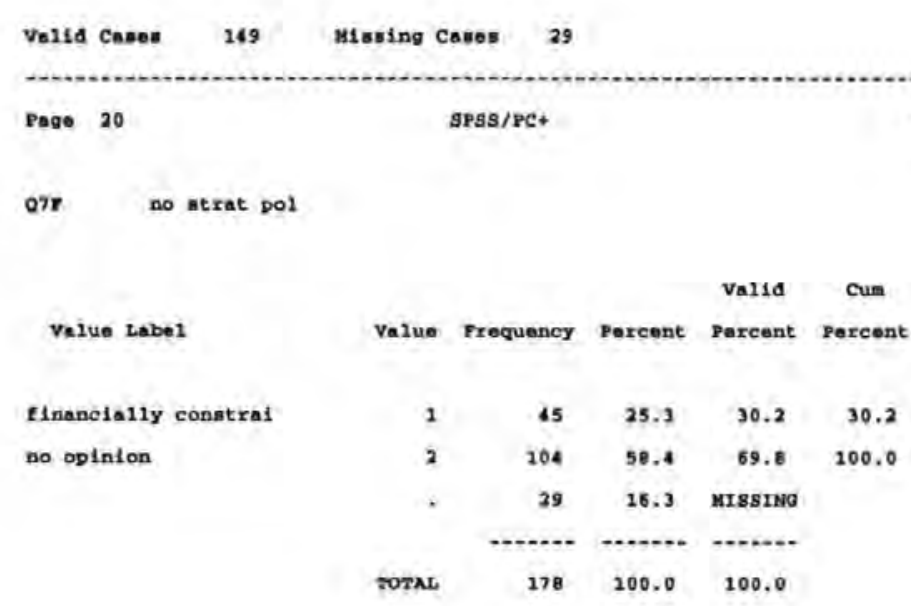




\begin{tabular}{|c|c|c|c|c|c|}
\hline Mean & 1,698 & std Erx & .038 & Modian & 2.000 \\
\hline Mode. & 2,000 & sta Dev & .461 & Varlance & .212 \\
\hline Kurtoeis & -1.258 & s 2 Kurt & .395 & Skownanas & -.871 \\
\hline s E skev & .199 & Range & 1.000 & Hinimua & 1.000 \\
\hline Maxileum & 2.000 & Bu= & 253.000 & & \\
\hline
\end{tabular}

Valid cases 149 Missing Cakes 29

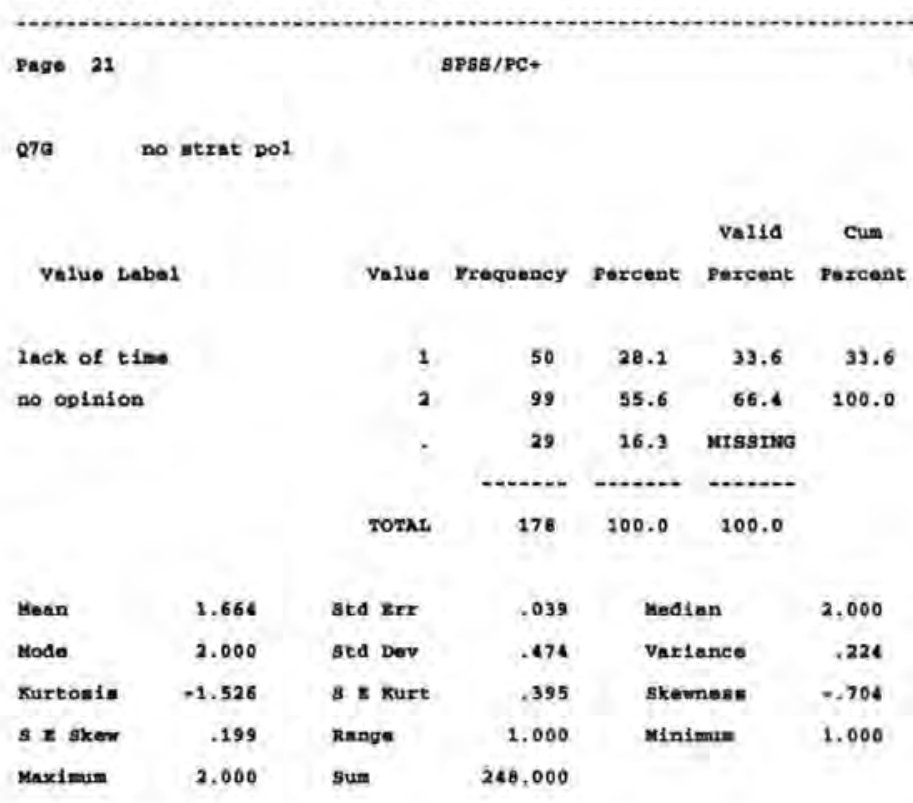

valid cases $149 \quad$ misuing cosed 29

Page 22

spss/PC+

$3 / 1 / 94$

Q7a no atrat pol

Vnlue Label

company inertit

no opinion

\begin{tabular}{|c|c|c|c|c|c|}
\hline Mean & 1.953 & sta $\mathbf{z r r}$ & .027 & Median & 2.000 \\
\hline node & 2.000 & sta Dev &, 212 & Variance & .045 \\
\hline Kurtes ie & 26.938 & $s$ E kurt & .395 & skevaese & -4.326 \\
\hline S I Skow & .299 & 8ango & 1.000 & Minimun & 1.000 \\
\hline Maximum & 2.000 & Bun & 291.000 & & \\
\hline
\end{tabular}


Val14 Cuta

value zabel

Velue grequancy percent percent parcent

1hek of ressons to a $122 \quad 22.4 \quad 14.4 \quad 14.8$

no opinion

$\begin{array}{lllll}2 & 127 \quad 71.3 & 85.2 & 100.0\end{array}$

$29 \quad 16.3$ หrgsina

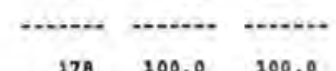

Totul $\quad 278 \quad 100.0 \quad 100.0$

\begin{tabular}{|c|c|c|c|c|c|}
\hline Moan & 1.852 & std err & .029 & Medion & 2.000 \\
\hline Mode & 2.000 & std Dev & .356 & Voriance & .127 \\
\hline Kurtoeid & 2.054 & $s$ \& Kuxt & 395 & Skevabas & -2.007 \\
\hline S E skew & .299 & Range & 1.000 & Minimin & 1.000 \\
\hline Maximu= & 2.000 & sue & 276.000 & & \\
\hline
\end{tabular}

Valid cases 249 Missing cease 29

Page $24 \quad$ SPSB/PC+ $\quad 3 / 1 / 94$

075 no atrat do?

Velid cue

value Label

value rrequency percent percent percent

\section{1nck of leginlative}

no opinton

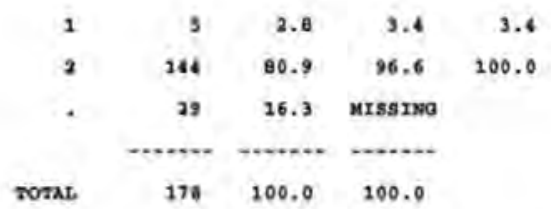

\begin{tabular}{|c|c|c|c|c|c|}
\hline Mean & 1.966 & std Erx & .015 & Median & 2.000 \\
\hline Mode & 2.000 & gtd Dev & .281 & Varlance & .033 \\
\hline Kurtoala & 25.730 & s \& kure & .395 & 3kevaese & -5.233 \\
\hline s z skew & .199 & Range & 2.000 & Minimus & 1.000 \\
\hline Maximum & 2.000 & sun & 293.000 & & \\
\hline
\end{tabular}

Va11d Canes 149 Missing Cskes 29

Page 25

BPss/PC+

$3 / 2 / 94$

Q7K no atrat pol

Valld Cum
Value Label Value Frequency Percent Percent parcent

1aok of Incentives t

$\begin{array}{rrrrr}1 & 14 & 7.9 & 9.4 & 9.4 \\ 2 & 135 & 75.6 & 90.6 & 100.0 \\ . & 29 & 16.3 & \text { MIssimo } & \end{array}$




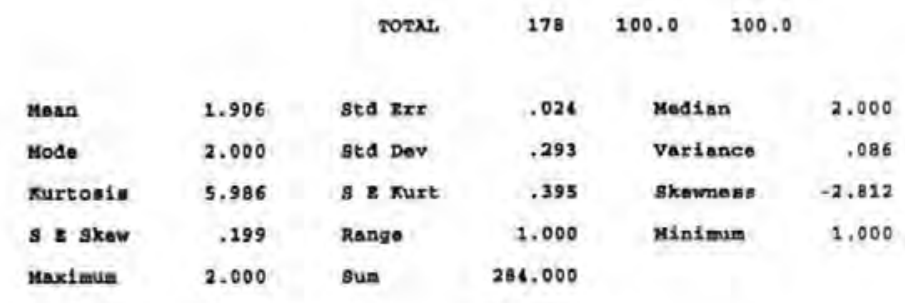

valid cases 149 Misting Caser 29

$\begin{array}{lll}\text { Page } 26 & \text { SPSS/PC+ } & 3 / 1 / 94\end{array}$

Q71 no strat pol

Value Labal Value proquency porcent parcent percent

\begin{tabular}{|c|c|c|c|c|c|c|}
\hline no longer an & inporta & 1 & 2 & 1.1 & 1.3 & 1.3 \\
\hline \multirow[t]{4}{*}{ no opinton } & & 2 & 147 & 82.6 & 98.7 & 100.0 \\
\hline & & . & 29 & 16,3 & Mrssing & \\
\hline & & & (n.t.n. & (t) & now & \\
\hline & & TOTAL & 138 & 100.0 & $160=0$ & \\
\hline Mean & 1.987 & std $\mathrm{kxT}$ & .009 & \multicolumn{2}{|c|}{ Medion } & 2.000 \\
\hline Mode & 2.000 & sta Dev & .115 & \multicolumn{2}{|c|}{ Varlance } & .013 \\
\hline Rurtosin & 71.945 & S I Kurt & .395 & \multicolumn{2}{|c|}{ skevnesin } & -8.543 \\
\hline$s$ \& skow & .199 & Range & 3.000 & \multicolumn{2}{|c|}{ Mini=um } & 1.000 \\
\hline Meximum & 2.000 & suo & 296.000 & & & \\
\hline
\end{tabular}

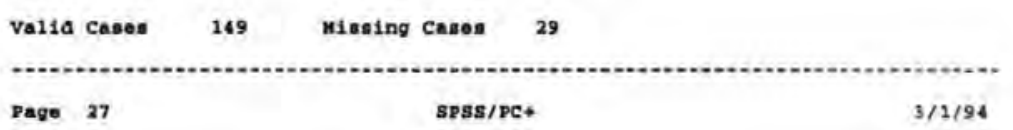

Q i Implemented the standerd

Va1id cum

Value Label

value Froquency Percent Percent Percent

yes

no

\begin{tabular}{|c|c|c|c|c|c|}
\hline Masn & 1.966 & Sta Err & .016 & Madian & 2.000 \\
\hline Mode & 2,000 & std Dev & .181 & Varianea & .033 \\
\hline Kurtonsa & 25.464 & s a kurt & .362 & Bkewnes: & -5.211 \\
\hline$g$ z Bkew & .182 & Range & 1.000 & Minimum & 1.000 \\
\hline Maximun & 2.000 & Sun & 350.000 & & \\
\hline
\end{tabular}




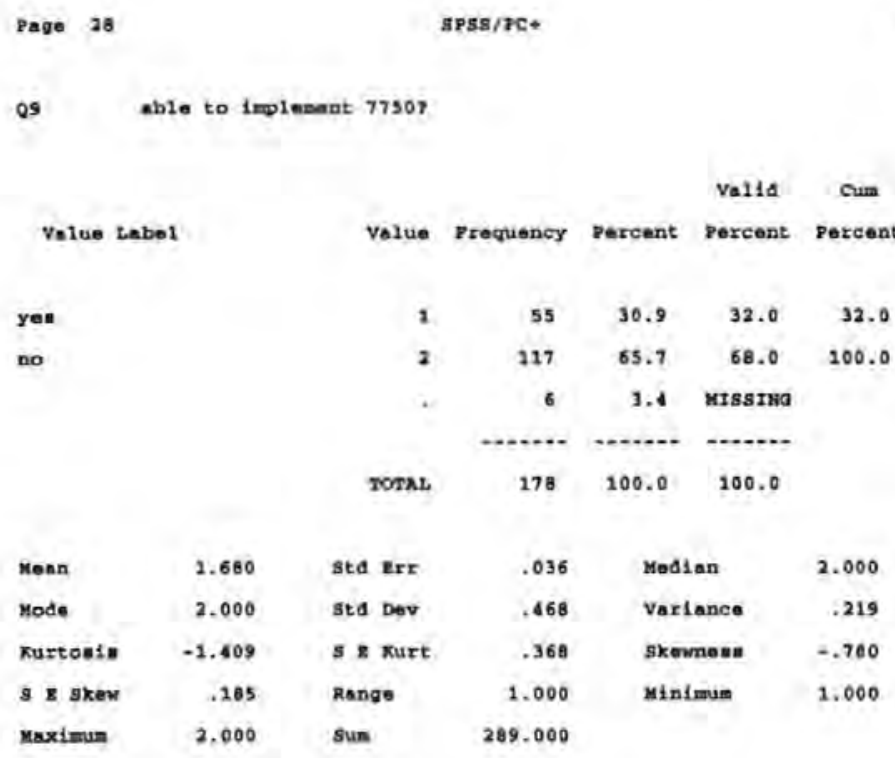

\begin{tabular}{llcl} 
valid cases $272 \quad$ Missing Cases 6 & \\
\hline rage 29 & SPss/pC+ & $3 / 2 / 94$
\end{tabular}

Q10 wiling to implement 7750?

\begin{tabular}{|c|c|c|c|c|c|c|}
\hline \multicolumn{2}{|c|}{ value Labe 1} & value & Vraquency & Porcent & $\begin{array}{l}\text { Val1d } \\
\text { Darcent }\end{array}$ & $\begin{array}{c}\text { Cum } \\
\text { Pereent }\end{array}$ \\
\hline ros & & 1 & 40 & 22.5 & 72.7 & 72.7 \\
\hline bo & & 2 & 15 & 8.4 & 27.3 & 100.0 \\
\hline & & • & 123 & 69,1 & MTBSTNO & \\
\hline & & Totat & 178 & 100.0 & 100.0 & \\
\hline Mesn & 1.273 & sta grx & .061 & Mad & $\operatorname{lon}$ & 2.000 \\
\hline Mode & 1.000 & Std Dev & .449 & Vax & iance & .202 \\
\hline Kurtoala & -.934 & $s \times$ Kurt & .634 & Sken & mens: & 1.069 \\
\hline 8 I 5kev & .322 & Range & 1.000 & Min & Iman & 1.000 \\
\hline Kaximum & 2.000 & Sum & 70.000 & & & \\
\hline
\end{tabular}

Varia Casen 55 Minnsing Casas 123

baga $30 \quad$ spsg/pC. $3 / 1 / 94$

Q11X why not sbie to implement

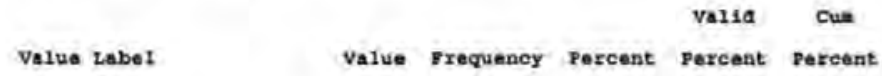

$\begin{array}{llrrrr}\text { lack of interest } & 1 & 12 & 6.7 & 20.3 & 10.3 \\ \text { no opinion } & 2 & 104 & 58.4 & \text { 19.7 } & 100.0 \\ & & 62 & 34.8 & \text { MIssmis } & \end{array}$




\begin{tabular}{|c|c|c|c|c|c|}
\hline & & Forxi. & 278 & 100.0 & \\
\hline Mesn & 1.897 & std $\mathrm{zxx}$ & .028 & Modian & 2.000 \\
\hline Mode & 2.000 & std Dev & .306 & Veriance & .094 \\
\hline Kurtonia & 5.040 & $s$ x Kurt & .446 & skowness & -2.638 \\
\hline$s$ \& skev & .225 & Range & 1.000 & Minimum & 1.000 \\
\hline Maximum & 2.000 & sum & 220.000 & & \\
\hline
\end{tabular}

Valid casas $\quad 116 \quad$ Misuing cases 62

Page 31

sPss/PC+

$3 / 1 / 94$

Q118 why not ab1e to inglesent

Valia cuin

Value Labol Value prequency percent porcent percent

$\begin{array}{lrrrrr}\text { lack of timo } & 1 & 45 & 25.3 & 38.5 & 38.5 \\ \text { no opinion } & 2 & 72 & 40.4 & 61.5 & 100.0 \\ & 61 & 34.3 & \text { Missing } & \\ & & -178 & 100.0 & 100.0 & \end{array}$

\begin{tabular}{|c|c|c|c|c|c|}
\hline Mean & 1.615 & sta $\mathbf{z r x}$ & .045 & Median & 2.000 \\
\hline Mode & 2.000 & sta Dev & .489 & variance & .239 \\
\hline Kurtosis & -1.800 & $s$ z Kurt & .444 & Skevmeas & -.481 \\
\hline g E skev & .224 & Range & 1.000 & Minima & 2.000 \\
\hline Maximua & 2.000 & Sun & 189.000 & & \\
\hline
\end{tabular}

valia cagea $117 \quad$ Minaing cased 61
Page 32
Q11C Wss/pC+
Whot able to Implement

value Label Value Freguency Porcent Percent percent

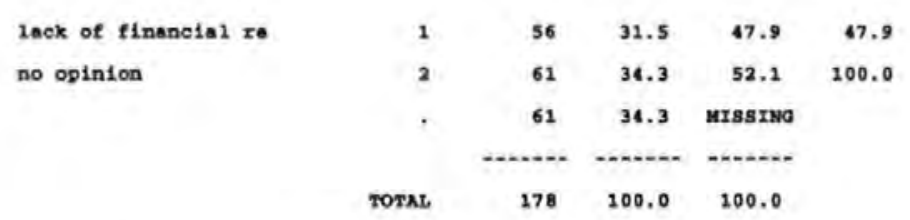

\begin{tabular}{|c|c|c|c|c|c|}
\hline Moan & 1.521 & sta Rrx & .046 & Median & 2.000 \\
\hline Mode & 2.000 & std Dev & .502 & Variance & .252 \\
\hline Kuxtosie & -2.027 & S E Kuxt & .444 & Skewneas & -.087 \\
\hline s g skew & .224 & range & 1.000 & Minieum & 1.000 \\
\hline Maximum & 2.000 & suen & 178,000 & & \\
\hline
\end{tabular}




Page $33 \quad$ Spss/PC+ $3 / 1 / 94$

Q11D vtry not able to itolement

volue Label

1ack of internal com no opinion

\section{Value prequancy Dercant percent porcent}

\begin{tabular}{|c|c|c|c|c|}
\hline 1 & $A$ & 4.5 & 6.0 & 6.8 \\
\hline $\mathbf{2}$ & 109 & 61,2 & 93.2 & 100,0 \\
\hline a & 61 & 34.3 & NISBING & \\
\hline & 278 & 100.0 & 100.0 & \\
\hline
\end{tabular}

\begin{tabular}{|c|c|c|c|c|c|}
\hline Meen & 2.932 & sta $\mathrm{Err}$ & .023 & Medion & 2.000 \\
\hline Hode & 2.000 & sta Dav & .253 & Veriance & .064 \\
\hline Kurtenin & 10,179 & s I Kurt & .444 & Skovrsean & -3.465 \\
\hline S z skew & .224 & Range & 1.000 & Minimus & 1.000 \\
\hline Maximus & 2.000 & sus & 226.000 & & \\
\hline
\end{tabular}

\section{Valdd Cases $\quad 127 \quad$ Minsing Casea 63}

Page 34

sPSs/PC+

Q112 Why not oble to imploment

Value Labal

Inapproprinte nature

no opinion

\begin{tabular}{|c|c|c|c|c|c|}
\hline Mean & 1.556 & sed Err & .046 & Modian & 2.000 \\
\hline Mode & 2.000 & std Dev & .699 & Variance & .249 \\
\hline Nurtosia & -1.983 & S \& Kurt & .444 & skemeat & -.227 \\
\hline$s \mathrm{z}$ skew & .224 & Range & 1.000 & Minimum & 1.000 \\
\hline Maxidmum & 2.000 & sua & 182.000 & & \\
\hline
\end{tabular}

valió Cares $\quad 117 \quad$ Minesing Canos 61

Page 35

sgss/pC.

Q11\% why not able to implement

valia cue

Value Labe 1

not cont of zoctive value grequency percent percent percent.

$\begin{array}{lllll}1 & 26 & 24.6 & 22,2 & 22,2\end{array}$




\begin{tabular}{|c|c|c|c|c|c|c|}
\hline \multirow[t]{4}{*}{ no opinton } & & 2 & 91 & $\$ 1.1$ & 72.6 & 100.0 \\
\hline & & , & 61 & 34.3 & MISSING & \\
\hline & & & n........ & n......... & neneses & \\
\hline & & TOEAL & 178 & 100.0 & 100.0 & \\
\hline Mean & 1.778 & std err & .039 & Medi & & 2.000 \\
\hline Hode & 2.000 & sta Dev & .416 & vari & ance & .274 \\
\hline Kurtosis & -.171 & $s$ \& Kurt & .444 & Skew & nose & -1.354 \\
\hline$s$ z skev & .224 & Range & 1.000 & kind & mum & 1.000 \\
\hline maximum & 2.000 & sun & 208.000 & & & \\
\hline
\end{tabular}

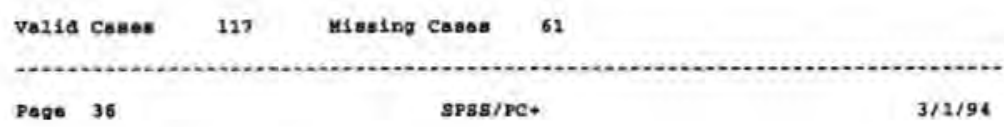

0210 why not able to implesent

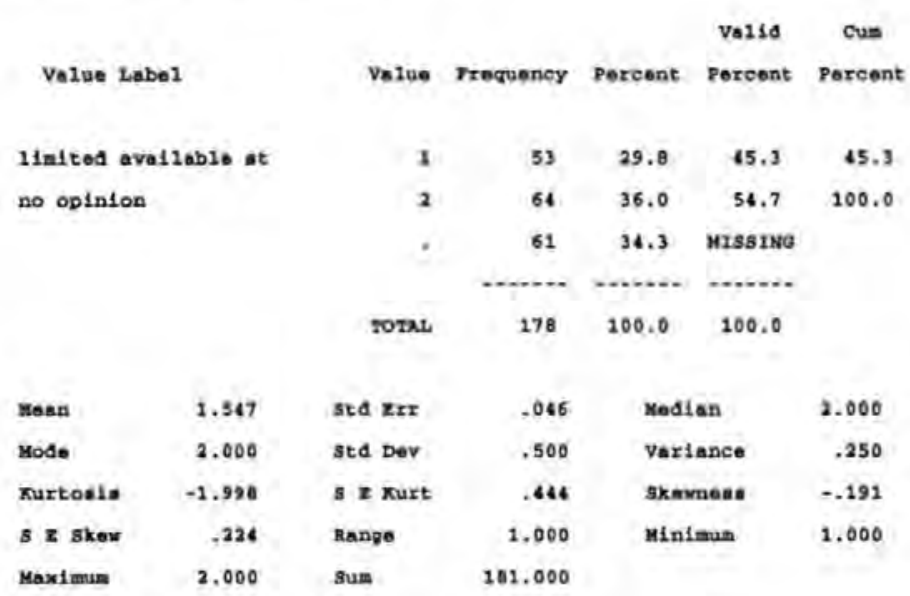

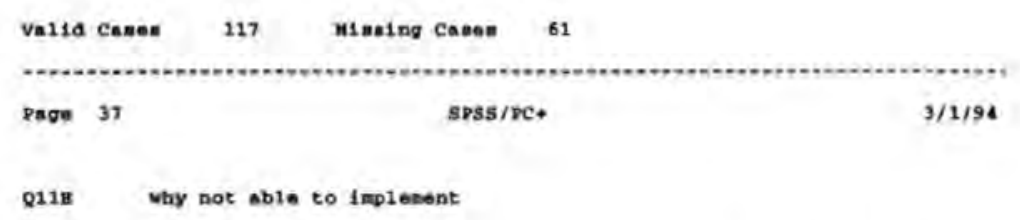

\begin{tabular}{|c|c|c|c|c|c|c|}
\hline \multicolumn{2}{|c|}{ Value Label } & value & Frequency & percent & $\begin{array}{c}\text { Volld } \\
\text { Percent }\end{array}$ & cun \\
\hline not company & 011 cy & 1 & 27 & 9.6 & 14.5 & 14.5 \\
\hline \multirow[t]{3}{*}{ no opinion } & & 2 & 100 & 56.2 & 85.5 & 100.0 \\
\hline & & . & 61 & 36,3 & Mrsstng & \\
\hline & & SOTAL & 170 & 100.0 & 100,0 & \\
\hline Mean & 1.055 & std $\mathrm{xer}$ & .093 & \multicolumn{2}{|c|}{ Median } & 2.000 \\
\hline mode & 2.000 & sta Der & .354 & \multicolumn{2}{|c|}{ Voriance } & .125 \\
\hline Kurtosis & 2.196 & s $\mathbf{x}$ Kurt & .446 & \multicolumn{2}{|c|}{ Skewnease } & -2.039 \\
\hline S 2 skaw & .224 & Range & 1.000 & \multicolumn{2}{|c|}{ Minimua } & 1.000 \\
\hline Maximun & 2.000 & sue & 217.000 & & & \\
\hline
\end{tabular}




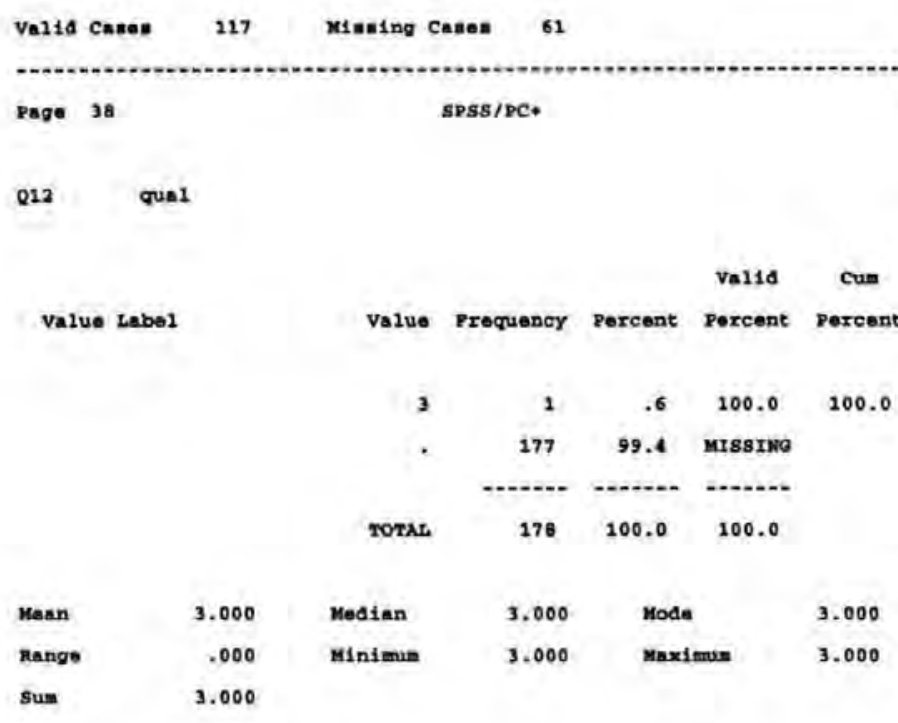

volid cases 1 Misoing Cases 177

\begin{tabular}{|c|c|c|c|c|c|c|}
\hline Page 39 & & & SPSS/PC. & & & \\
\hline \multicolumn{7}{|c|}{ Q13 reas } \\
\hline \multirow{2}{*}{\multicolumn{2}{|c|}{ Valiue Label }} & & & & Valid & cus \\
\hline & & value & Fxequency & Percent & Percent & Percent \\
\hline \multicolumn{2}{|c|}{ not at all intereate } & 1 & 29 & 16.3 & 16.4 & 16.4 \\
\hline \multicolumn{2}{|c|}{ guite uninterested } & 2 & 15 & 8.4 & 8.5 & 24.9 \\
\hline \multicolumn{2}{|c|}{ neither interested a } & 3 & 54 & 30.3 & 30.5 & 55.4 \\
\hline \multicolumn{2}{|c|}{ guite interented } & 4 & 62 & 34.6 & 35.0 & 90.4 \\
\hline \multirow{3}{*}{\multicolumn{2}{|c|}{ axtreno1y intereated }} & 5 & 17 & 9.6 & 9.6 & 100.0 \\
\hline & & $\cdot$ & 1 & .6 & uIssino & \\
\hline & & Torke. & 278 & 100.0 & 100.0 & \\
\hline Mean & 3.130 & sta Err & .091 & \multicolumn{2}{|c|}{ Modian } & 3.000 \\
\hline Moden & 4.000 & std Dev & 1.211 & \multicolumn{2}{|c|}{ Variance } & 1.466 \\
\hline Kurtosis & -.686 & S E Kuxt & .363 & \multicolumn{2}{|c|}{ Bkowness } & -.406 \\
\hline s z skow &, 183 & Range & 4.000 & \multicolumn{2}{|c|}{ Minimus } & 1.000 \\
\hline Maximum & 5.000 & Sum & 554.000 & & & \\
\hline
\end{tabular}

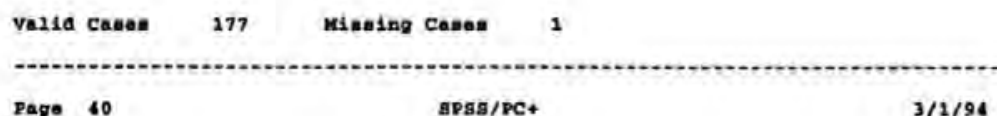

Q24 ODC

Value Label value prequency percent percent percent




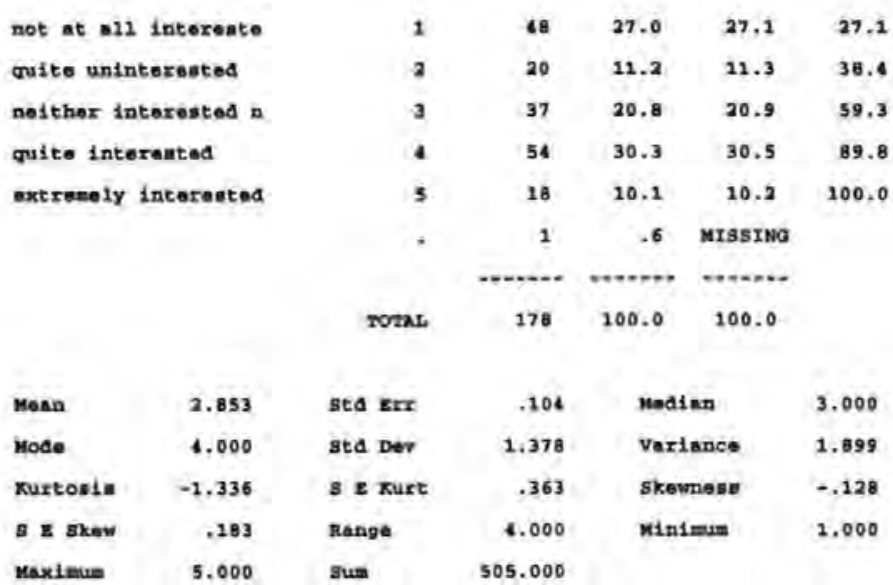

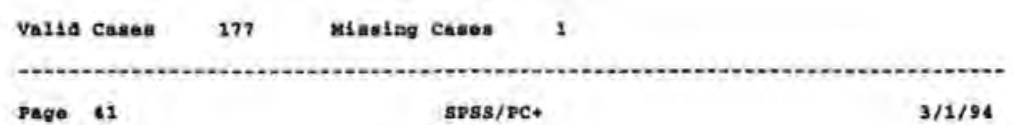

015 Daybeck nomber?

Value tabe1 Value prequency percent percont pias

yen

no

\begin{tabular}{|c|c|c|c|c|c|}
\hline Mean & 1.983 & sta $\mathbf{z x x}$ & .013 & Median & 2.000 \\
\hline Hode & 2.000 & sta Der & .167 & Varionce & .028 \\
\hline Kurtosia & 32.073 & g $\mathbf{E}$ Kurt & .362 & gkovmeas & -3.359 \\
\hline a $\mathbf{E}$ skew & .182 & Range & 2.000 & Minimur & 1.000 \\
\hline $\operatorname{cox} 1 \operatorname{mu}$ & 3.000 & sum & 353.000 & & \\
\hline
\end{tabular}

Valid Caseg $178 \quad$ Mlesing cases 0

\begin{tabular}{|c|c|c|c|c|c|}
\hline Page 42 & & SPss/zC4 & & & \\
\hline \multicolumn{6}{|l|}{ ot $6 x$ env halpitine } \\
\hline value Label & Value & rrequency & Porcent & $\begin{array}{l}\text { Val1d } \\
\text { varcent }\end{array}$ & $\begin{array}{c}\text { Cum } \\
\text { Percent }\end{array}$ \\
\hline not at a11 intereste & 1 & 59 & 33.1 & 33.7 & 33.7 \\
\hline guite uninterented & 2 & 10 & 5.6 & 5.7 & 39.4 \\
\hline nofther intereuted $\mathrm{n}$ & 1 & 57 & 32.0 & 32.6 & 72.0 \\
\hline guite interested & 4 & 38 & 21.3 & 21.7 & 93.7 \\
\hline \multirow[t]{2}{*}{ extrenely intereated } & s & 11 & 6.2 & 6.3 & 100.0 \\
\hline & . & 3 & 1.7 & mssrad & \\
\hline
\end{tabular}




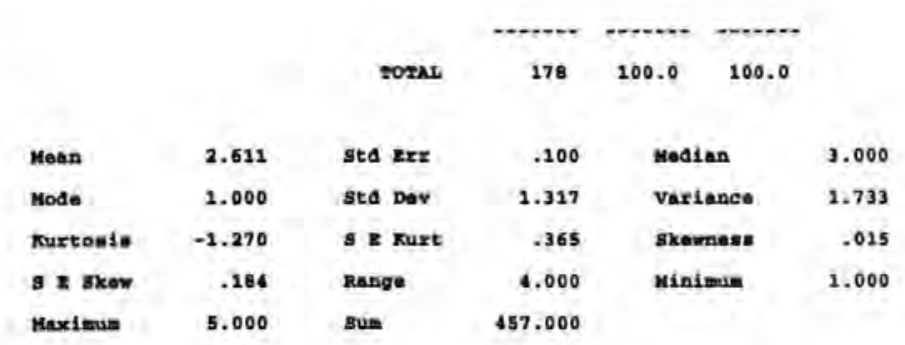

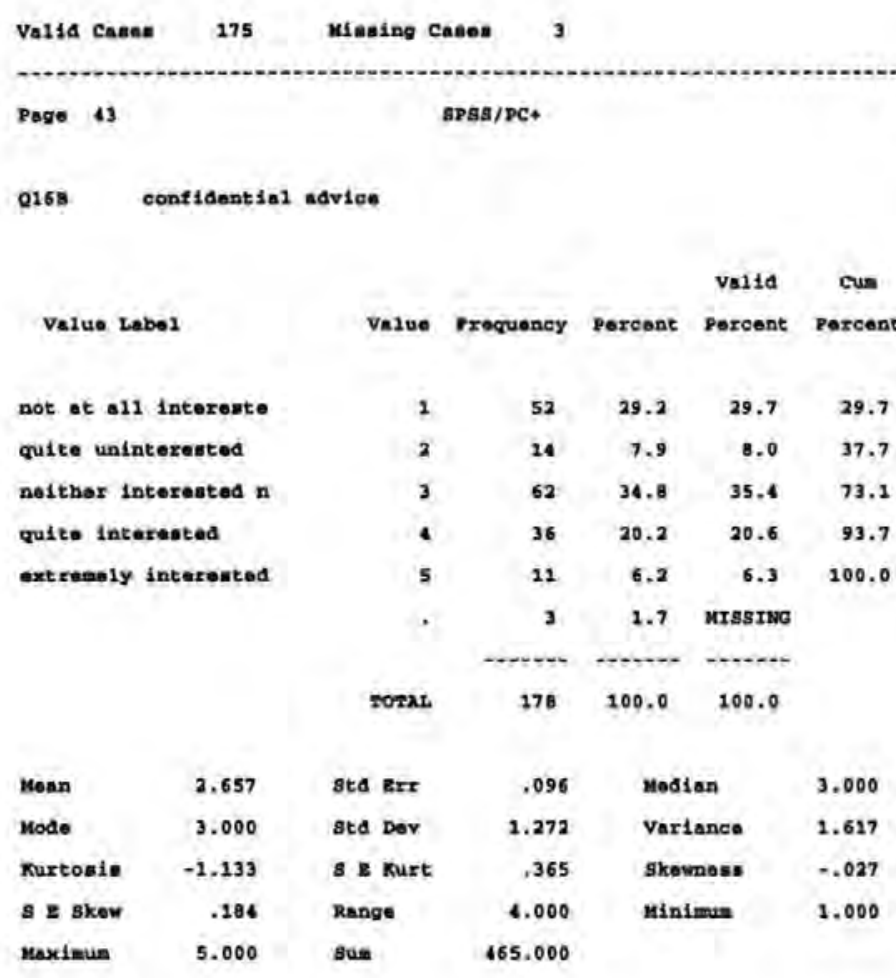

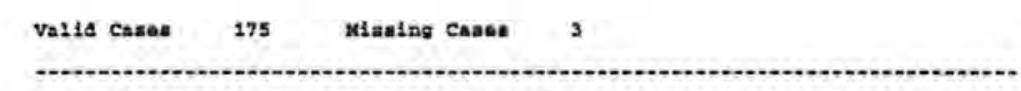

Page 44

spss/PC+

$3 / 1 / 94$

Q16C newslottar

Value Label

not at all intorente culte uninterosted neither interested $\mathrm{n}$ guite Interested extremely interasted

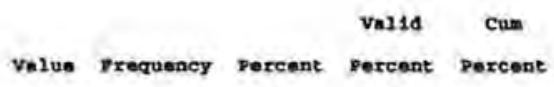

\begin{tabular}{|c|c|c|c|c|}
\hline 1 & 47 & 26.4 & 26.9 & 26.9 \\
\hline 2 & 14 & 7.9 & 8.0 & 34.9 \\
\hline 3 & 48 & 27.0 & 27.4 & 62.3 \\
\hline 4 & 58 & 32.6 & 33.1 & 95.4 \\
\hline 5 & - & 4.5 & 4.6 & 300.0 \\
\hline - & 3 & 1.7 & MIsstiva & \\
\hline & & n........ & n....... & \\
\hline & 178 & 100.0 & 100.0 & \\
\hline
\end{tabular}




\begin{tabular}{|c|c|c|c|c|c|}
\hline Mode & 4.000 & sta Dev & 1.281 & Varianca & 1.660 \\
\hline rurtosis & -1.263 & s s kurt & .365 & Skemesnas & -.278 \\
\hline S I skew & .284 & Range & 4.000 & Minimus & 1.000 \\
\hline Maximu & 5.000 & sum & 491.000 & & \\
\hline
\end{tabular}

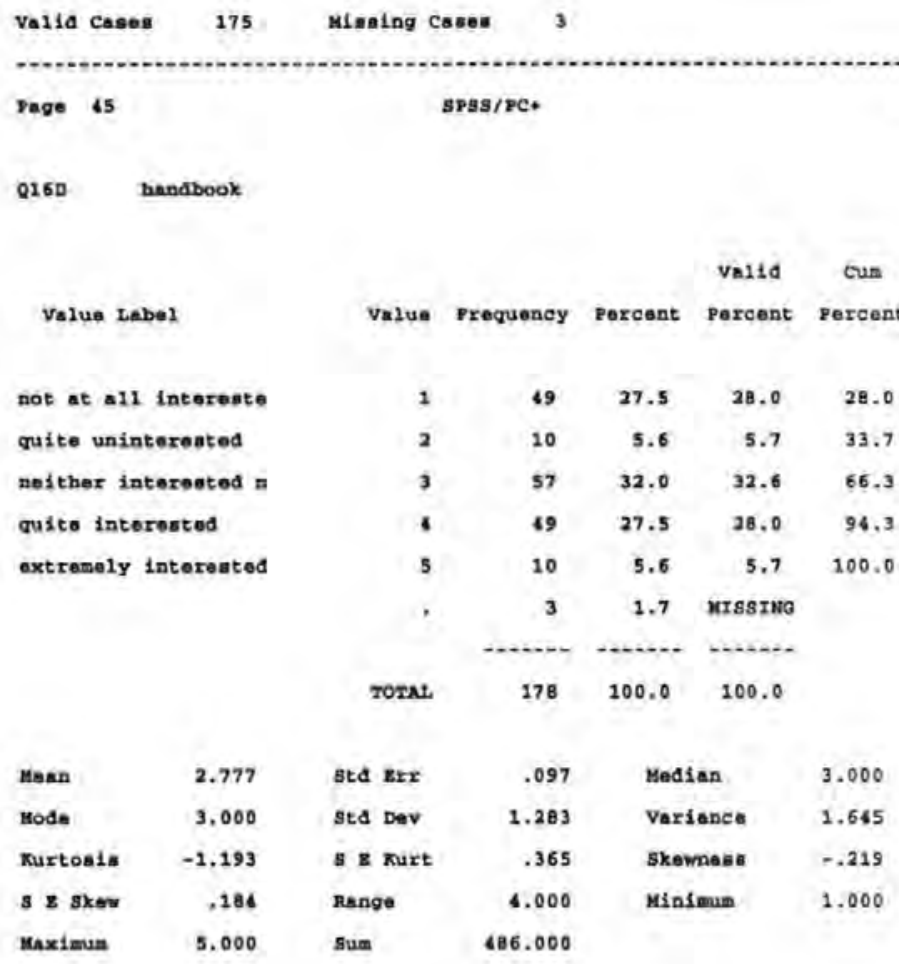

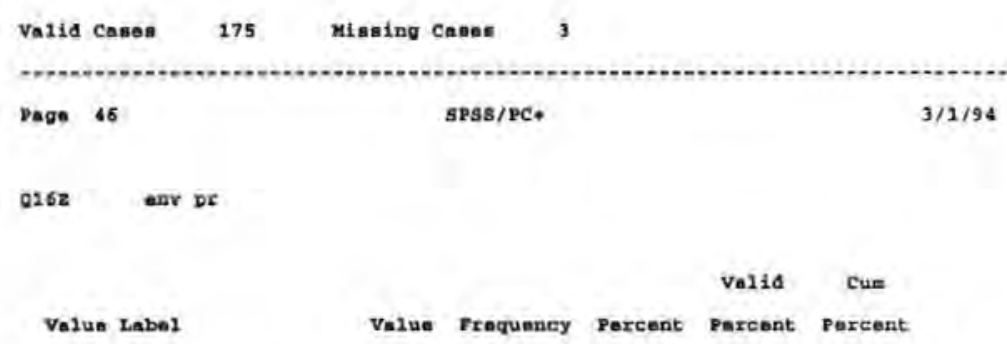

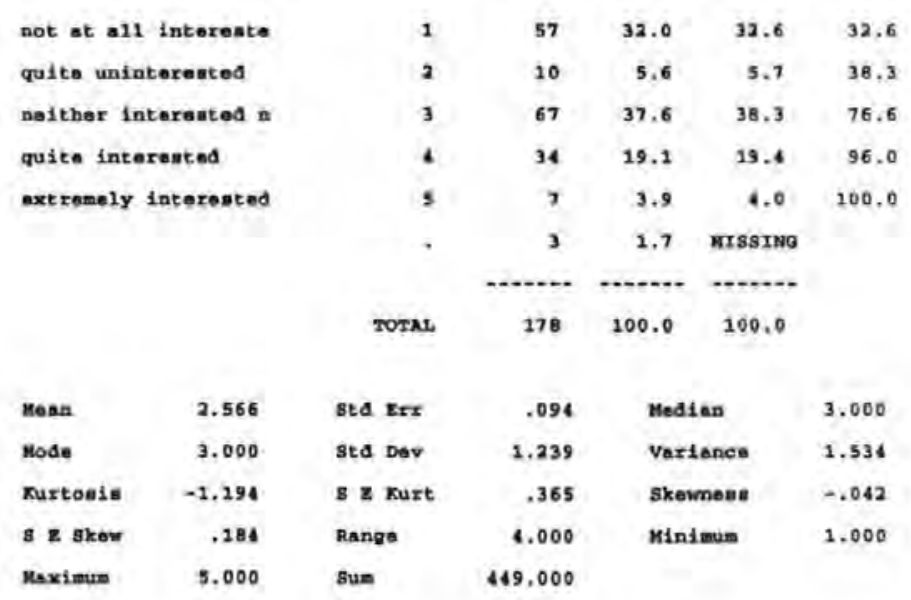




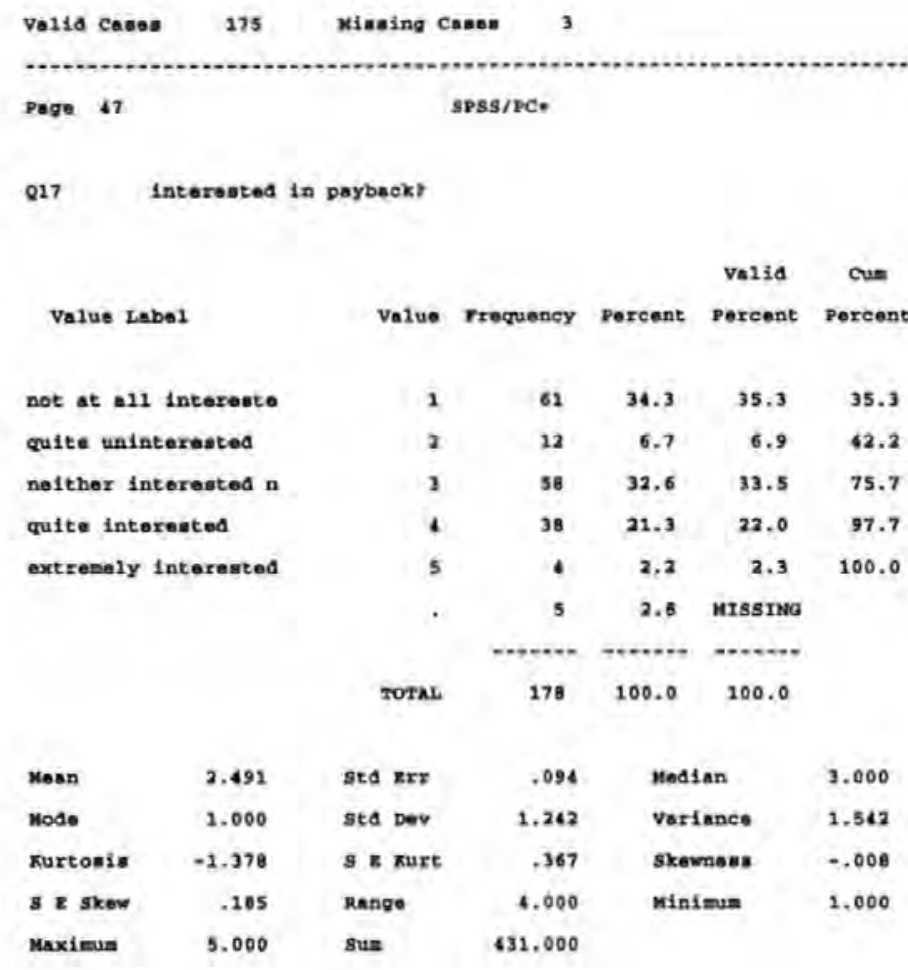

Vel1A Cames $173 \quad$ Mianing Cases 5

Page 48

Q18 Tua12

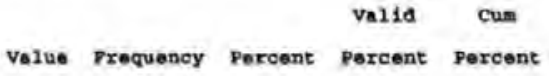

$\begin{array}{cccc}. & 178 & 100.0 & \text { krssing } \\ & 170 & 100.0 & 100.0\end{array}$

val14 Cason Mioning Came 178

Page is spss/pet $3 / 1 / 94$

Q19A env holpitina

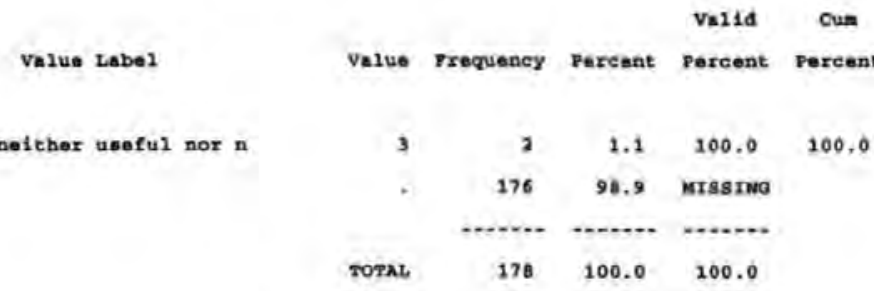




\begin{tabular}{|c|c|c|c|c|c|}
\hline Manan & 3.000 & sta $\mathbf{E r r}$ & .000 & Median & 3.000 \\
\hline Mode & 3.000 & std Dez & .000 & Variance & .000 \\
\hline renge & .900 & minlmum & 3.000 & Maximua & 3.000 \\
\hline Sue & 6.000 & & & & \\
\hline
\end{tabular}

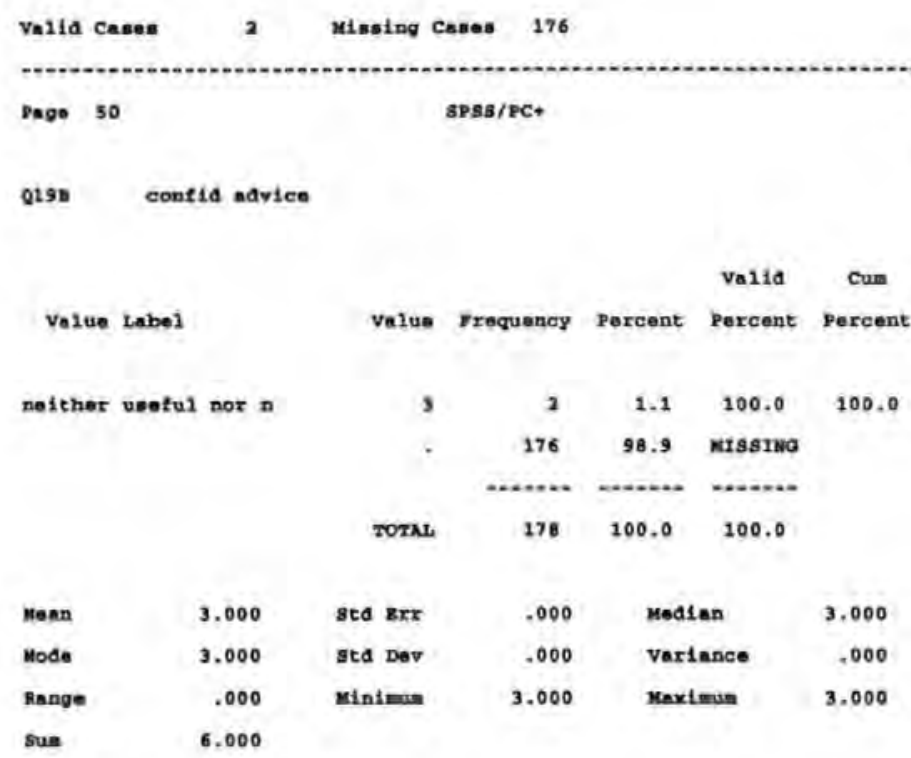

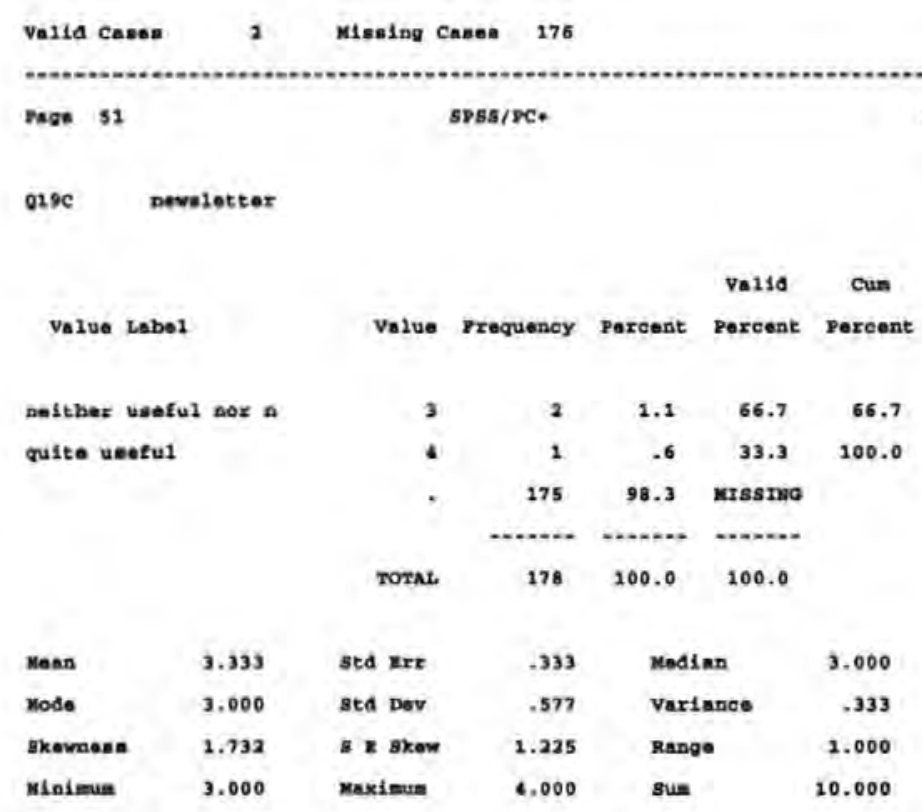

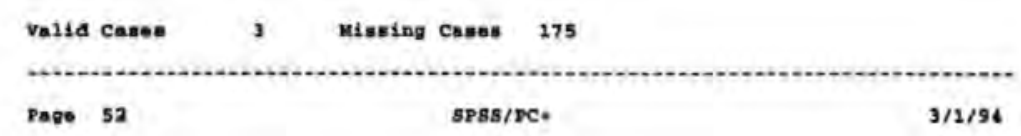

Q19D hancbook 


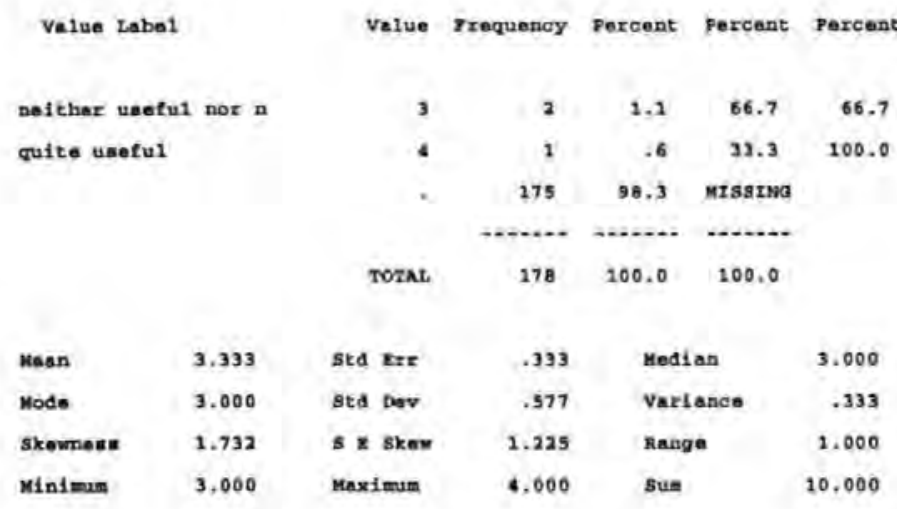

valid canes Minaing casas 175

Page 53

spss/PC+

0198 De

Value Label

natehor ugetul nor a guits useful

\begin{tabular}{|c|c|c|c|c|c|}
\hline mean & 3.333 & std Brr & .333 & Modian & 3.000 \\
\hline Mode & 3,000 & std Dav & .577 & Variance & .333 \\
\hline Skermeas & 1.732 & A \& Bkew & 1.225 & Range & 1.000 \\
\hline Minimum & 3,000 & Maximula & 4.000 & Bum & 10.000 \\
\hline
\end{tabular}

$\begin{array}{rrrrr}3 & 2 & 1.1 & 66.7 & 66.7 \\ 6 & 1 & .6 & 33.3 & 100.0 \\ & 175 & 98,3 & \text { 4rssing } & \\ & 178 & 100.0 & 100.0 & \end{array}$

Valla cages 3 Mieaing Cages 275

Page 54

sPss/FC+

$3 / 1 / 94$

Q19p consultancy service

volue tabe?

Doitber uaeful nor $\mathrm{D}$

$\begin{array}{lr}\text { Mean } & 3.000 \\ \text { Hode } & 3.000 \\ \text { Range } & .000\end{array}$

Sum $\quad 9.000$

$$
\text { value rrequency percent percent percent }
$$




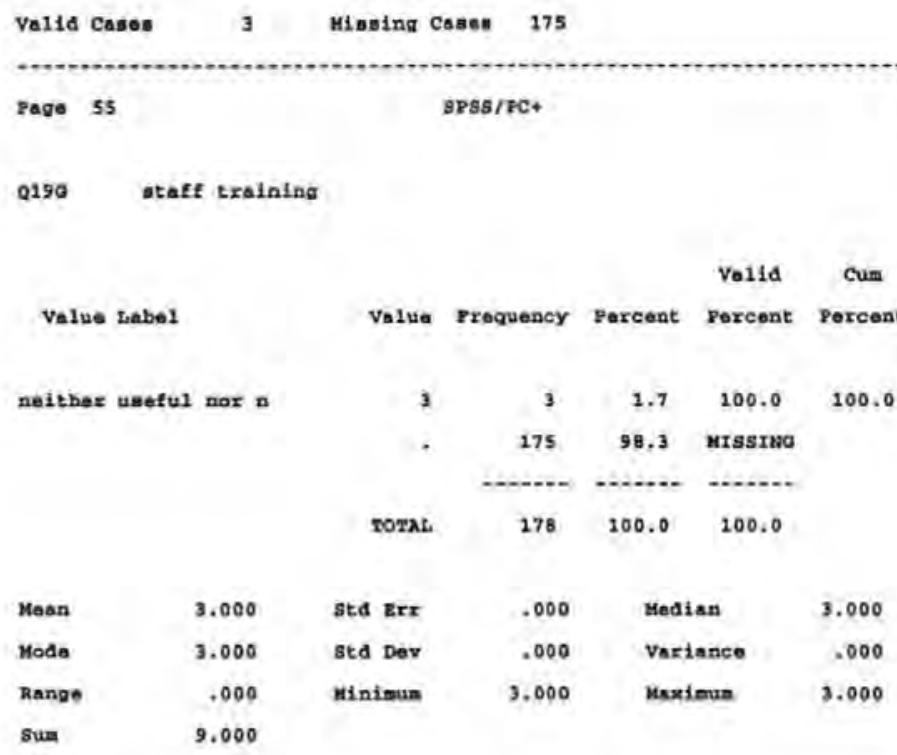

valla caser 3 misning canen 175

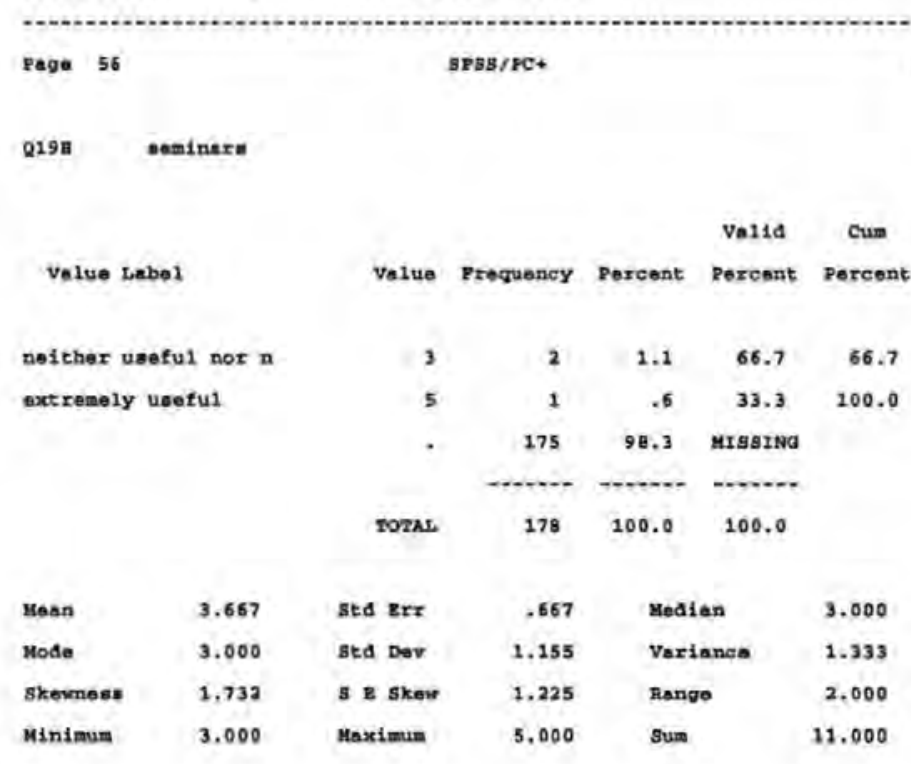

valia cases Miang Casos 175

rage 57

spss/re+

Q20 devon/cormesi1

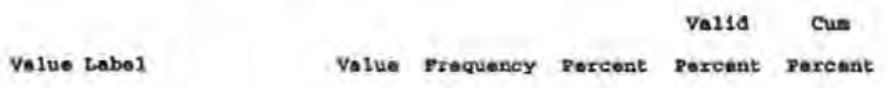

$\begin{array}{lrrrrrr}\text { devon } & 2 & 121 & 68.0 & 76.6 & 76.6 \\ \text { cormuati } & 2 & 37 & 20.8 & 23.4 & 200.0 \\ & - & 20 & 11.2 & \text { Mrgstro } & \end{array}$




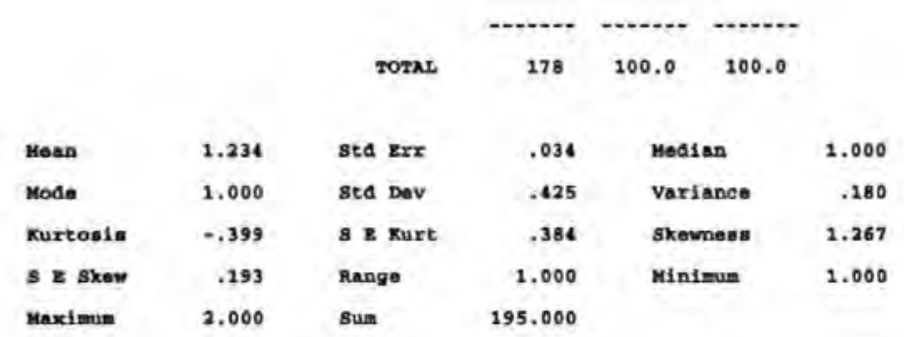

Valid cases 158 Misaing Cases 20

Page 50

SPSS/PC.

$3 / 1 / 94$

This procedure whe complated at 11:17:41 


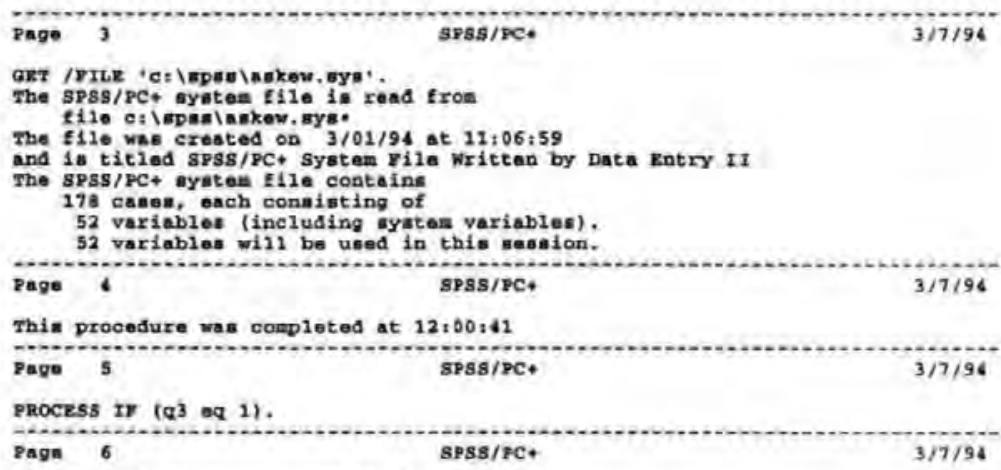

FRepuenctes Q1 Q2 Q3 Q4 Q5 Q6 Q6 Q20.

+.t.. vamory allows a total of 12881 values, accunulated acrosn all variables. There also noy be up to 1610 value Labela for each Varloble.

\begin{tabular}{|c|c|c|c|c|c|}
\hline businexn eype & & & & & \\
\hline Value Label & value & Prequency & Percent & $\begin{array}{c}\text { Valida } \\
\text { Porcent }\end{array}$ & $\underset{\text { rercent }}{\text { Cum }}$ \\
\hline $\begin{array}{l}\text { Aing1e aite bueineas } \\
\text { heodquaters unit } \\
\text { mubsia. branch forei }\end{array}$ & $\begin{array}{l}1 \\
2 \\
4\end{array}$ & $\begin{array}{l}7 \\
2 \\
1\end{array}$ & $\begin{array}{l}70.0 \\
20.0 \\
10.0\end{array}$ & $\begin{array}{l}70.0 \\
20.0 \\
20.0\end{array}$ & $\begin{array}{r}70.0 \\
90.0 \\
100.0\end{array}$ \\
\hline & TOTAX & 10 & 100.0 & 100.0 & \\
\hline
\end{tabular}

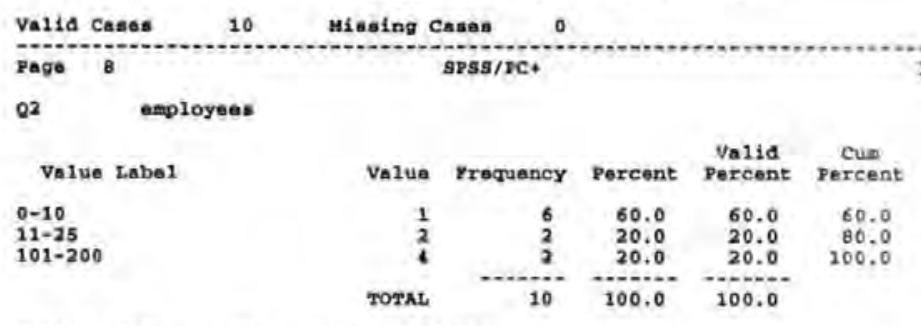

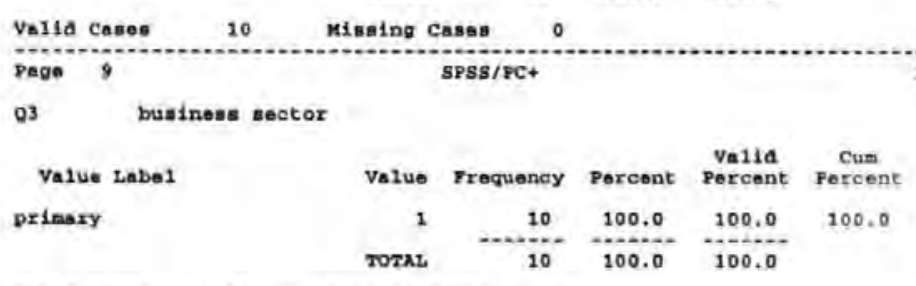

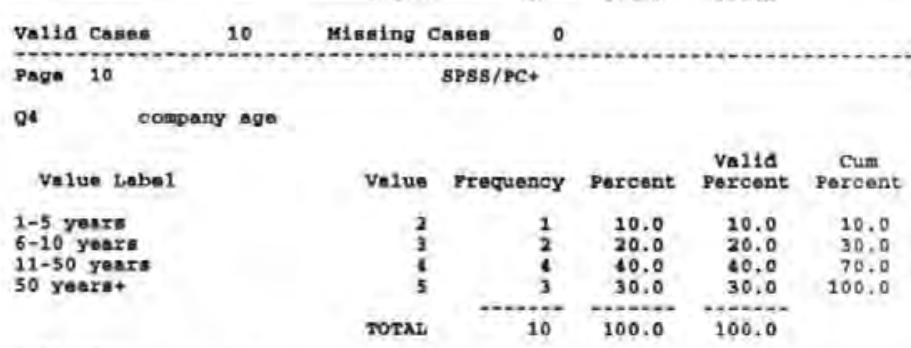

\begin{tabular}{|c|c|c|c|c|c|c|}
\hline Valia $\mathrm{c}$ & 10 & Missing $C$ & Casea & & & \\
\hline Page 1 & & & \multicolumn{4}{|l|}{ SPSs/FC. } \\
\hline 05 & \multicolumn{6}{|c|}{ export/non exportera } \\
\hline Ve2us & Label 2 & Value & Frequency & Parcent & $\begin{array}{l}\text { Valida } \\
\text { Percent }\end{array}$ & $\begin{array}{c}\text { Cum } \\
\text { percent }\end{array}$ \\
\hline $\begin{array}{l}\text { You } \\
\text { no }\end{array}$ & & $\frac{1}{2}$ & $\begin{array}{l}6 \\
4\end{array}$ & $\begin{array}{l}60.0 \\
10.0\end{array}$ & $\begin{array}{l}60.0 \\
40.0\end{array}$ & $\begin{array}{r}60.0 \\
100.0\end{array}$ \\
\hline & & TOTAL & 10 & 100.0 & 100.0 & \\
\hline
\end{tabular}

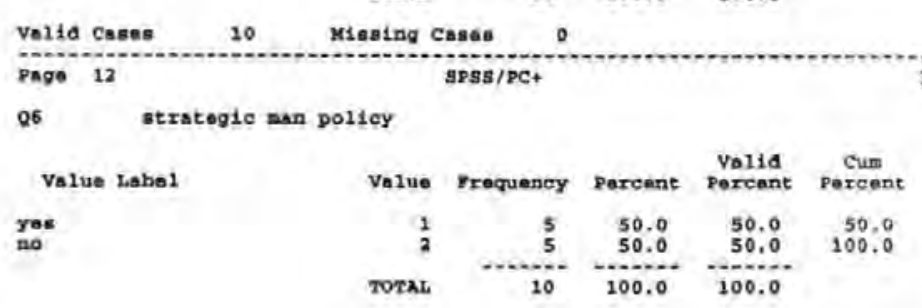




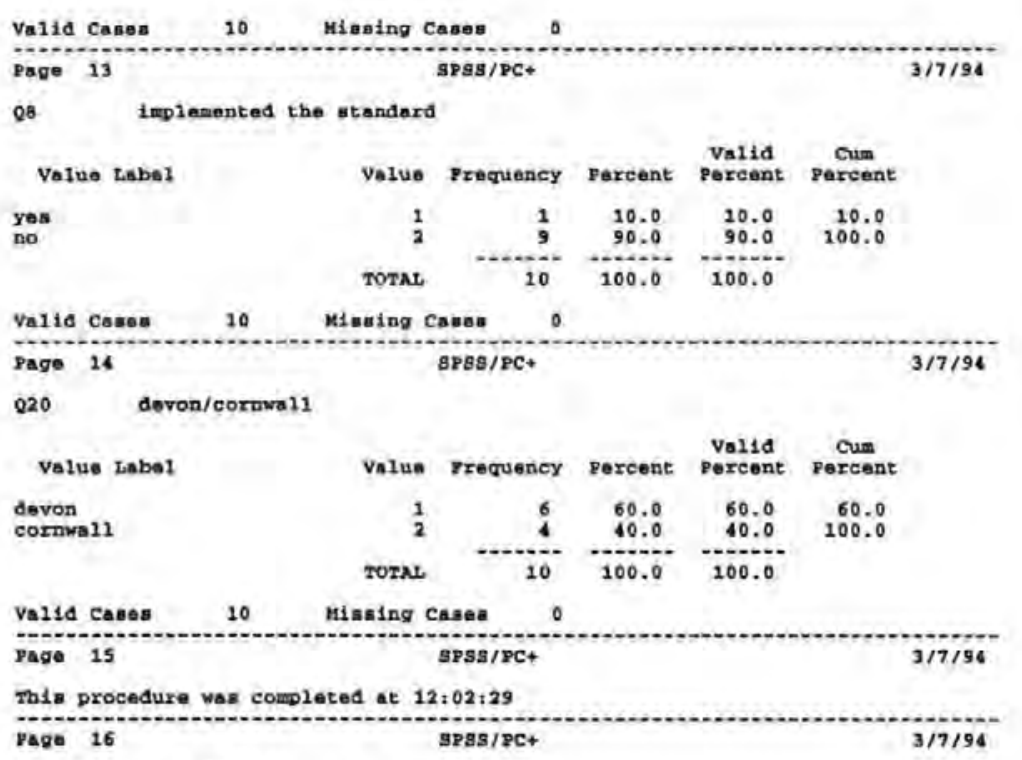

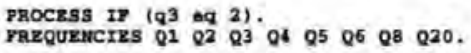

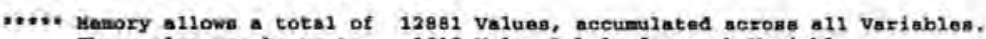

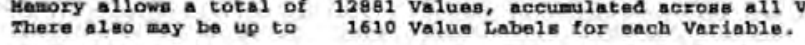

\begin{tabular}{|c|c|c|c|c|c|c|}
\hline Page 17 & & BPSS/PC+ & & & & $3 / 7 / 94$ \\
\hline bulinean type & & & & & & \\
\hline value Label & va1ue & Prequency & Percent & $\begin{array}{c}\text { Valid } \\
\text { Percent }\end{array}$ & $\begin{array}{c}\text { Cum } \\
\text { Percent }\end{array}$ & \\
\hline $\begin{array}{l}\text { alngle eite business } \\
\text { headqusters unit } \\
\text { subsidisy or branch } \\
\text { mubsid. branch forai }\end{array}$ & $\begin{array}{l}1 \\
2 \\
3 \\
4\end{array}$ & $\begin{array}{r}60 \\
9 \\
11 \\
4\end{array}$ & $\begin{array}{r}71.4 \\
10.7 \\
13.1 \\
4.8\end{array}$ & $\begin{array}{l}71.4 \\
10.7 \\
13.1 \\
1.8\end{array}$ & $\begin{array}{r}71.4 \\
82.1 \\
95.2 \\
100.0\end{array}$ & \\
\hline & TOTAL & 86 & 100.0 & 100.0 & & \\
\hline valia canes & Missing $c$ & Canase & & & & \\
\hline Page 18 & & spssipC+ & & & & $3 / 7 / 94$ \\
\hline employeen & & & & & & \\
\hline value tabel & value & Frequency & Percent & $\begin{array}{c}\text { Valia } \\
\text { parcent }\end{array}$ & $\underset{\text { Purcent }}{\text { Cum }}$ & \\
\hline $\begin{array}{l}0-10 \\
11-25 \\
26-100 \\
101-200 \\
300+\end{array}$ & $\begin{array}{l}1 \\
2 \\
3 \\
4 \\
5\end{array}$ & $\begin{array}{r}46 \\
16 \\
10 \\
6 \\
6\end{array}$ & $\begin{array}{r}54.8 \\
19.0 \\
11.9 \\
7.1 \\
7.1\end{array}$ & $\begin{array}{r}54.8 \\
19.0 \\
11: 9 \\
7.1 \\
7.1\end{array}$ & $\begin{array}{r}54.6 \\
73.8 \\
85.7 \\
93.9 \\
100.0\end{array}$ & \\
\hline & Totat & 84 & 100.0 & 100.0 & & \\
\hline
\end{tabular}

valid Casos o4 Misoing Caser o

Page 19

Q3 busineas sector

\begin{tabular}{|c|c|c|c|c|c|}
\hline Volue tabel & volue & Prequancy & Percent & $\begin{array}{l}\text { valia } \\
\text { Parcant }\end{array}$ & Percont \\
\hline \multirow[t]{2}{*}{ Becondary } & 2 & of & 100.0 & 100.0 & 100.0 \\
\hline & TorגA & 84 & 100.0 & 100,0 & \\
\hline
\end{tabular}

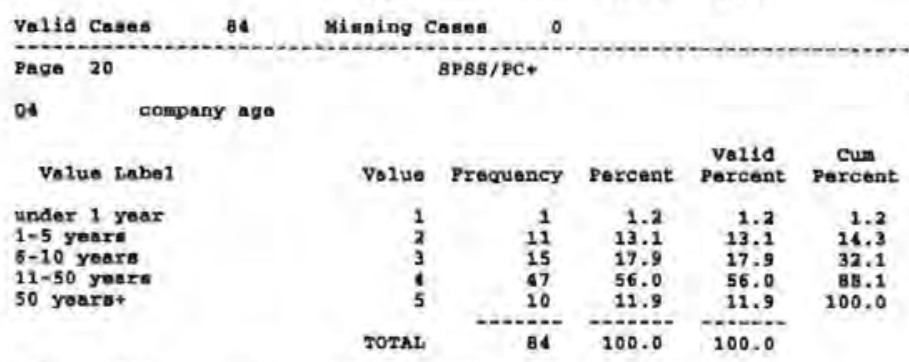

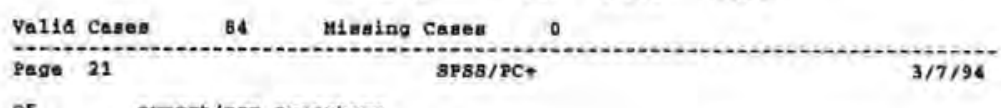

Q5 export/non exporters

Valus Labe1 value progrency percent percent parcent

yes

$\begin{array}{llrrr}1 & 45 & 53.6 & 53.6 & 53.6 \\ 2 & 39 & 46.4 & 56.4 & 100.0\end{array}$ 


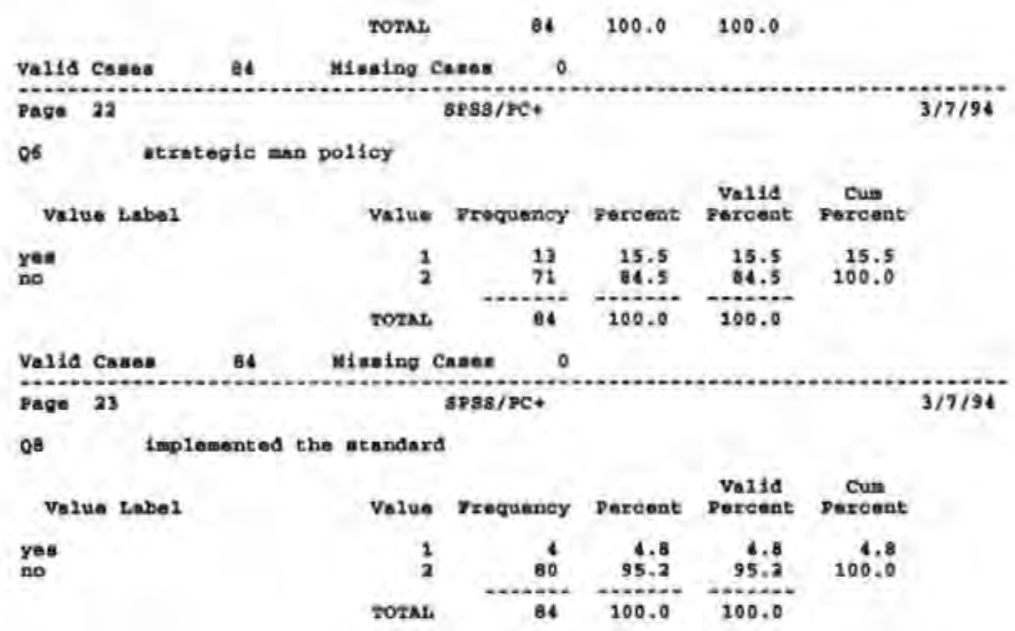

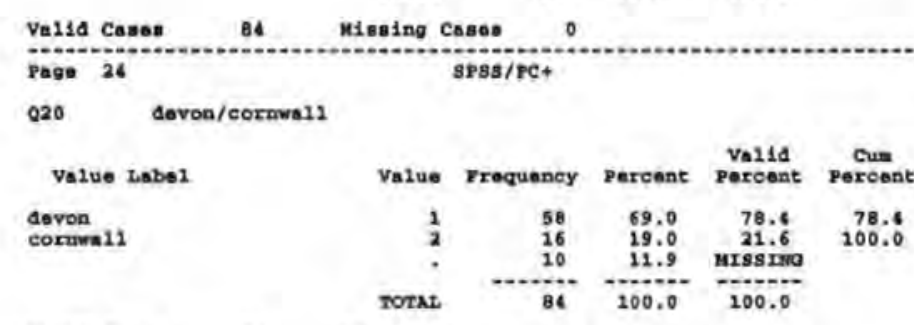

Valid cased
Fage 25
mis procedure wal completed ot $12: 03: 00$

Page 26 SPSB/YC+ $3 / 7 / 94$

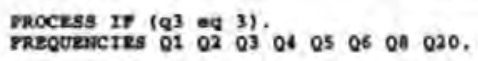

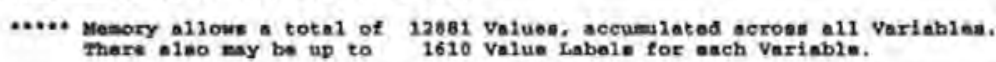

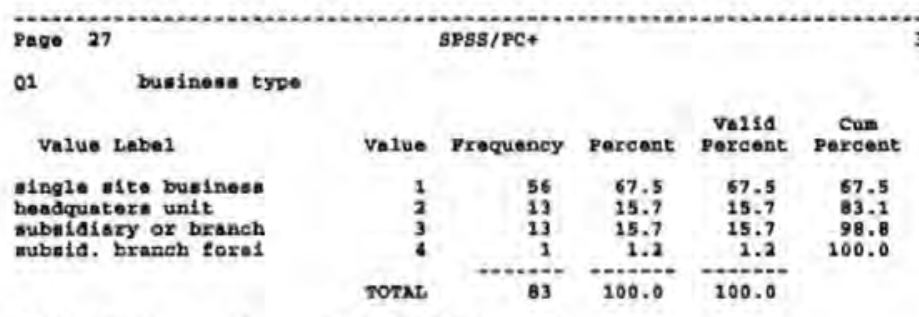

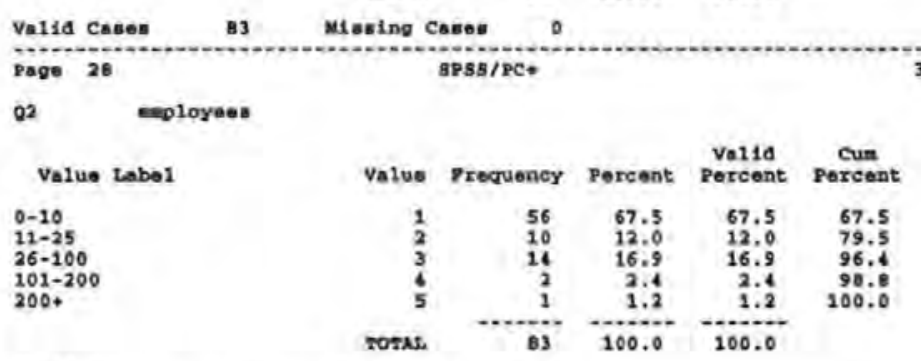

Valia cases 83 Misaing cases 0

Pags 290 SPSS/PC+ $3 / 7 / 96$

Q3 businmas sector

\begin{tabular}{|c|c|c|c|c|c|}
\hline Value Label & value & rreguency & Percent & $\begin{array}{l}\text { Val14d } \\
\text { Percent }\end{array}$ & $\begin{array}{c}\text { Cun } \\
\text { percent }\end{array}$ \\
\hline \multirow[t]{2}{*}{ tertiary } & 3 & 83 & 100.0 & 100.0 & 100.0 \\
\hline & TOTAL & 83 & 100.0 & 100.0 & \\
\hline
\end{tabular}

Valid cases 83 Misoing Casea 0

Paga 30 BPSB/PC+ $3 / 7 / 94$

Q6 cospany age

Value tabel

under 1 your

$1-5$ years

$\begin{array}{ccccc}\text { Value Praquency } & \text { Parcent } & \begin{array}{c}\text { Valid } \\ \text { Parcent }\end{array} & \begin{array}{c}\text { Cum } \\ \text { Parcent }\end{array} \\ 1 & 1 & 1.2 & 1.2 & 1.2 \\ 2 & 10 & 12.0 & 12.0 & 13.3\end{array}$ 


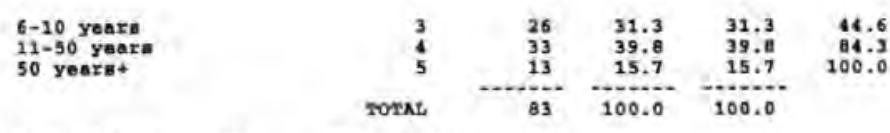

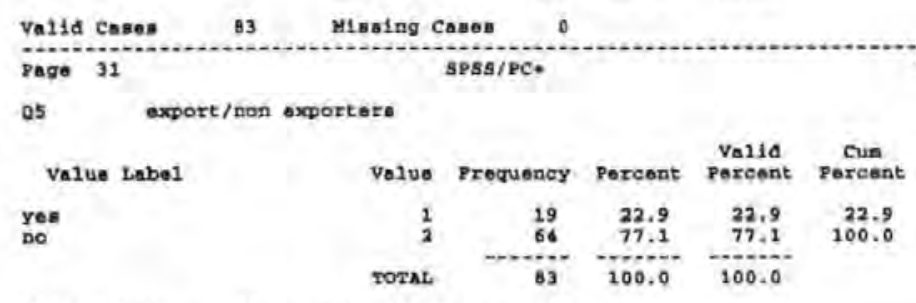

\begin{tabular}{|c|c|c|c|c|c|c|}
\hline volid c & ases & wisuing & coses: & & & \\
\hline Page 3 & & & SPSS/PC+ & & & \\
\hline \multirow[t]{2}{*}{06} & atrategio & policy & & & \multirow[b]{2}{*}{$\underset{\text { Parcent }}{\text { Pald }}$} & \multirow[b]{2}{*}{$\begin{array}{l}\text { Cun } \\
\text { Percont }\end{array}$} \\
\hline & Label & value & Frequency & Percent: & & \\
\hline \multirow[t]{2}{*}{$\begin{array}{l}\text { yea } \\
\text { no }\end{array}$} & & $\frac{1}{2}$ & $\begin{array}{l}12 \\
72\end{array}$ & $\begin{array}{l}13.3 \\
86.7\end{array}$ & $\begin{array}{l}13.3 \\
66.7\end{array}$ & $\begin{array}{r}13.3 \\
100.0\end{array}$ \\
\hline & & TOTAL & 83 & 100.0 & 100.0 & \\
\hline
\end{tabular}

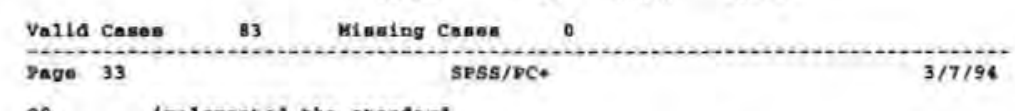

Q8 implemented the standard

\begin{tabular}{|c|c|c|c|c|c|}
\hline Value Labol & Value & Prequency & Porcent & $\begin{array}{l}\text { Valid } \\
\text { Percent }\end{array}$ & $\begin{array}{l}\text { Cum } \\
\text { Parcant }\end{array}$ \\
\hline res & $\begin{array}{l}1 \\
2\end{array}$ & 12 & $\begin{array}{l}1.2 \\
98.8\end{array}$ & $\begin{array}{r}1.2 \\
98.8\end{array}$ & $\begin{array}{r}1.2 \\
100.0\end{array}$ \\
\hline & TOTAL & 03 & 100.0 & 100,0 & \\
\hline
\end{tabular}

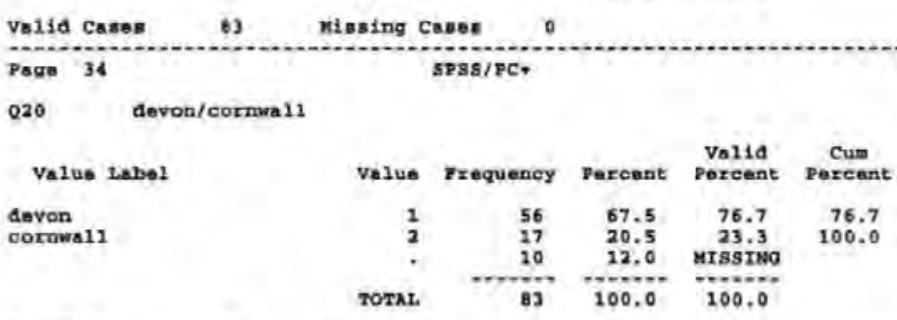

Valid cases 73 Kineing Cases 20

Page 35 SPSB/PC+

Thia procedure wall completed at $12: 03: 36$

Page $36 \quad$ SPgs/PC+ $3 / 7 / 94$

PROCESB IF $\lg 4$ og 1$).$

rraquancirs Q1 Q2 Q3 Q6 Q5 Q6 Q8 Q20.

..... Meseory allows a total of 12881 valubs, sccumulated acrase all Variables. There also eay be up to 1610 value Labala tor each Variable.

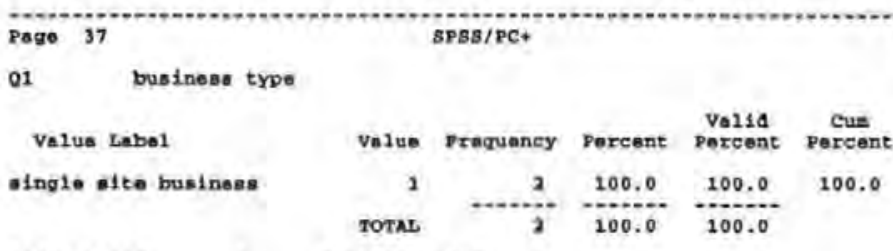

\begin{tabular}{|c|c|c|c|c|c|c|}
\hline valia c & Canos: & Hiseing & SEOE & & & \\
\hline Page & 38 & & SPSS/PC+ & & & \\
\hline 22 & eaployesen & & & & & \\
\hline Value & - tabol & value & Frequency & Fercent & $\begin{array}{l}\text { Val1d } \\
\text { Fercent. }\end{array}$ & $\begin{array}{c}\text { Cua } \\
\text { Percent }\end{array}$ \\
\hline \multirow[t]{2}{*}{$0-10$} & & 1 & 2 & 100.0 & 100.0 & 100.0 \\
\hline & & TOTAL. & 2 & 100,0 & 100.0 & \\
\hline
\end{tabular}

Yarid Cases 2 Miasing casea 0

page 39

03 businese sector

Value Label

$\begin{array}{rrrrr}\text { Value Frequency } & \text { Percent } & \begin{array}{c}\text { Valid } \\ \text { Percent }\end{array} & \begin{array}{c}\text { Cum } \\ \text { Percent }\end{array} \\ 2 & 1 & 50.0 & 50.0 & 50.0 \\ 3 & 1 & 50.0 & 50.0 & 100.0 \\ \text { TOTAL } & 2 & 100.0 & 100.0 & \end{array}$




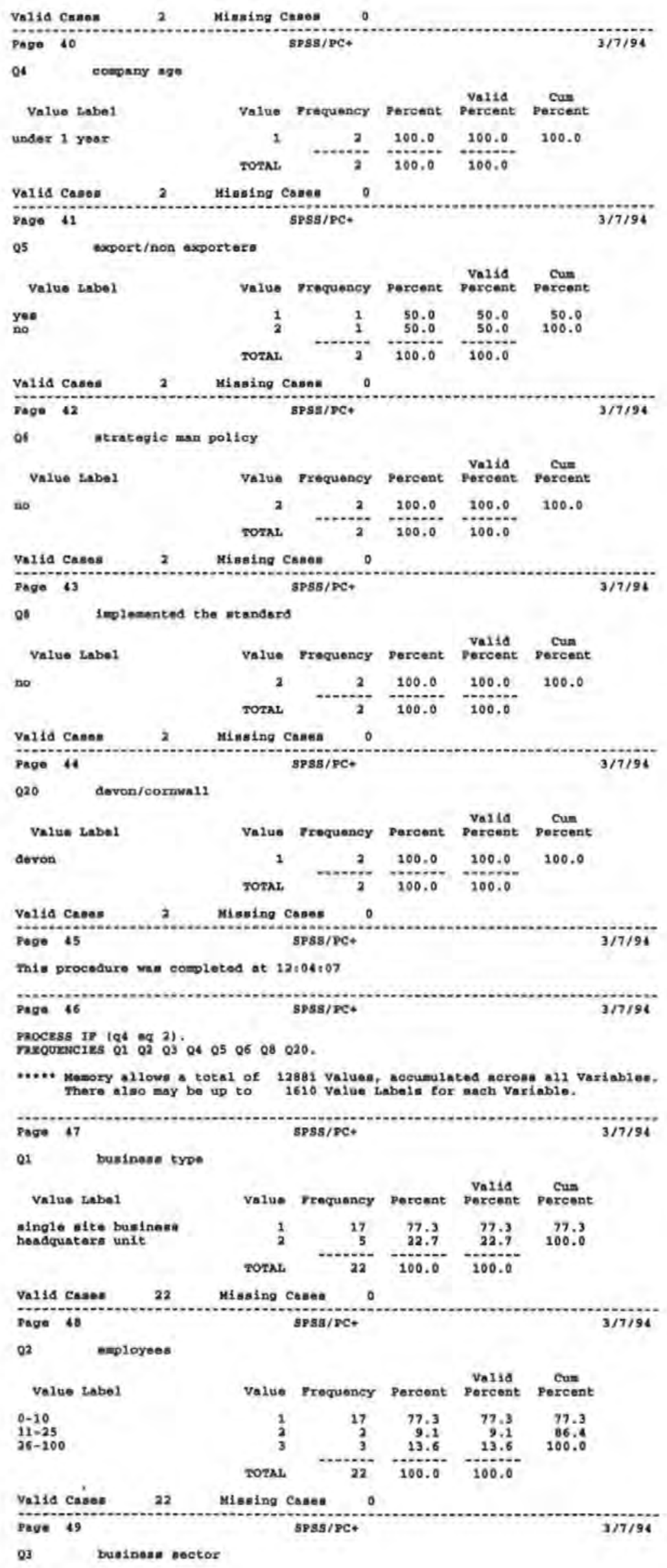




\begin{tabular}{|c|c|c|c|c|c|}
\hline Value Label & velue & Prequency & Percent & $\begin{array}{l}\text { Valida } \\
\text { Porceent }\end{array}$ & $\underset{\text { Percent }}{\text { Cus }}$ \\
\hline $\begin{array}{l}\text { primary } \\
\text { uacondary } \\
\text { tertiazy }\end{array}$ & $\begin{array}{l}1 \\
2 \\
3\end{array}$ & $\begin{array}{l}11 \\
10 \\
10\end{array}$ & $\begin{array}{l}4.5 \\
50.0 \\
45.5\end{array}$ & $\begin{array}{l}50.5 \\
45.5\end{array}$ & $\begin{array}{r}5.5 \\
58.5 \\
100.0\end{array}$ \\
\hline & Tozat. & 22 & 100.0 & 100.0 & \\
\hline
\end{tabular}

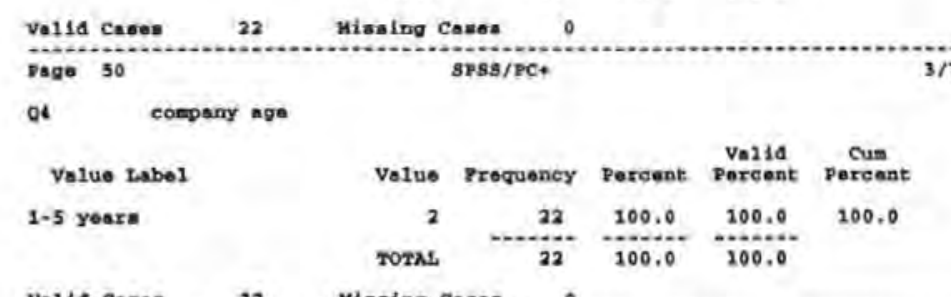

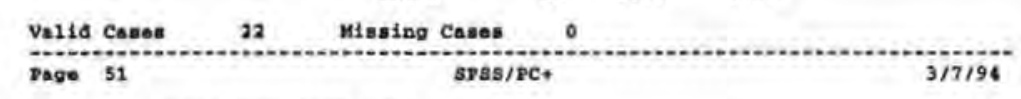

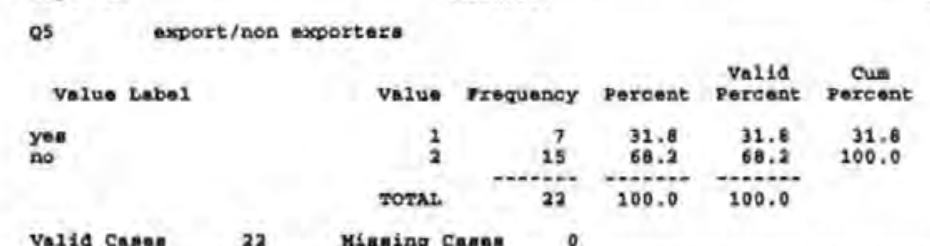

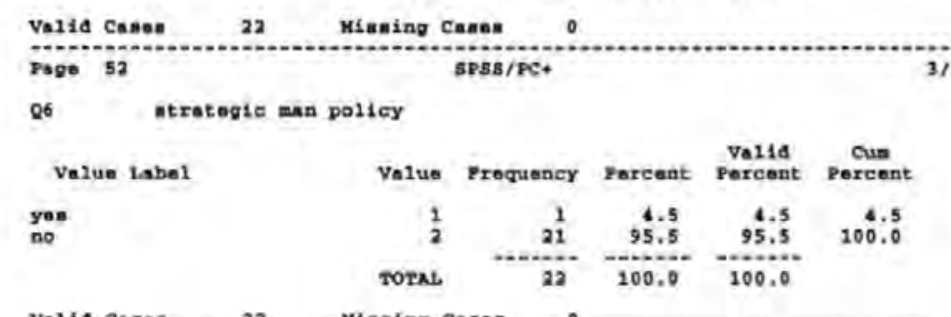

\begin{tabular}{l} 
Yalia cames $22 \quad$ Minaing Cases 0 \\
\hline Page 53 \\
Q
\end{tabular}

\begin{tabular}{|c|c|c|c|c|c|}
\hline Value Label & value & Frequency & Percent & $\begin{array}{l}\text { Val1d } \\
\text { percent }\end{array}$ & $\begin{array}{c}\text { Cuin } \\
\text { percent }\end{array}$ \\
\hline $\begin{array}{l}\text { yee } \\
\text { no }\end{array}$ & $\begin{array}{l}1 \\
2\end{array}$ & 21 & $\begin{array}{r}4.5 \\
95.5\end{array}$ & $\begin{array}{r}4.5 \\
95.5\end{array}$ & $\begin{array}{r}4.5 \\
100.0\end{array}$ \\
\hline & TOTN: & 22 & 100.0 & 200.0 & \\
\hline
\end{tabular}

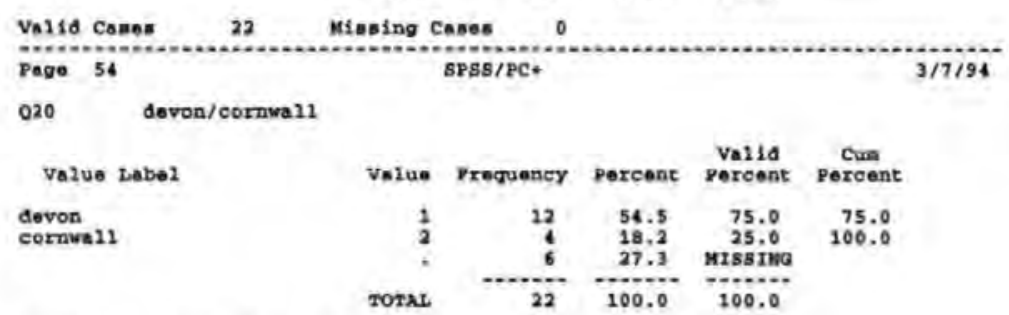




\begin{tabular}{|c|c|c|c|c|c|}
\hline value Label & value & Frogrency & Porcent & Parcent & Fercent \\
\hline $\begin{array}{l}0-10 \\
11-25 \\
26-100 \\
101-200\end{array}$ & $\begin{array}{l}1 \\
2 \\
3 \\
4\end{array}$ & $\begin{array}{l}34 \\
\vdots \\
1\end{array}$ & $\begin{array}{r}79.1 \\
9.3 \\
9.3 \\
2.3\end{array}$ & $\begin{array}{r}79.1 \\
9.3 \\
9.3 \\
2.3\end{array}$ & $\begin{array}{r}79.1 \\
58.4 \\
97.7 \\
100.0\end{array}$ \\
\hline & 2072Rב. & 43 & 100.0 & 100.0 & \\
\hline
\end{tabular}

\begin{tabular}{ll} 
Valid Casea $43 \quad$ Missing cases 0 \\
\hline Page 59
\end{tabular}

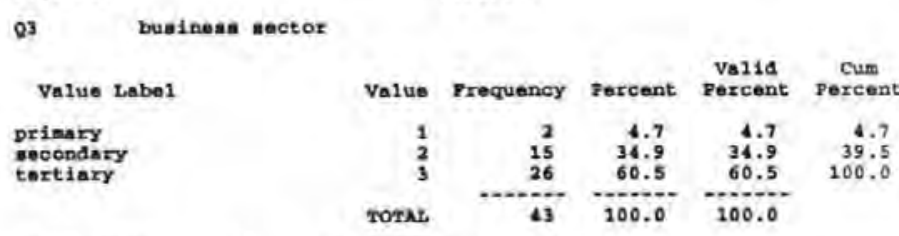

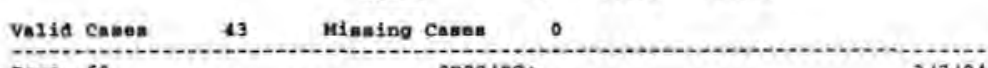

\begin{tabular}{|c|c|c|c|c|c|}
\hline Page 60 & & BPSS/PC+ & & & \\
\hline company age & & & & & \\
\hline Value Labol & value & Prequency & Percent & $\begin{array}{l}\text { Validd } \\
\text { Percent. }\end{array}$ & $\underset{\text { Cum }}{\text { Percent }}$ \\
\hline \multirow[t]{2}{*}{$6-10$ yeer" } & 3 & 43 & 100.0 & 100.0 & 100,0 \\
\hline & TOTAL & 43 & 100.0 & 100.0 & \\
\hline
\end{tabular}

Valia casea 43 Miseing caes 0

Page $61 \quad$ SPss/PC+ $3 / 7 / 94$

Q5 export/non exportera

$$
\begin{aligned}
& \text { value Label Value Froquency percent porcent percent } \\
& \text { yos } \\
& \text { Value Froguency Percent percent porcent } \\
& \begin{array}{rrrrr}
1 & 12 & 27.9 & 27.9 & 27.9 \\
2 & 31 & 72.1 & 72.1 & 100.0 \\
\text { Toraxt } & 43 & 100.0 & 100.0 &
\end{array}
\end{aligned}
$$

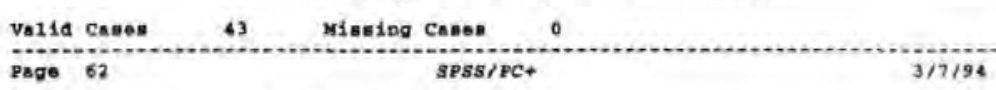

Q6 Strategie man policy

$$
\begin{aligned}
& \text { value Label Value proquency percent porcent percerst } \\
& \begin{array}{llllll}
\text { yea } & 1 & 6 & 14.0 & 14.0 & 14.0 \\
\text { no } & 2 & 37 & 86.0 & 86.0 & 100.0
\end{array} \\
& \begin{array}{rrrrr}
2 & 37 & 86.0 & 86.0 & 100.0
\end{array}
\end{aligned}
$$

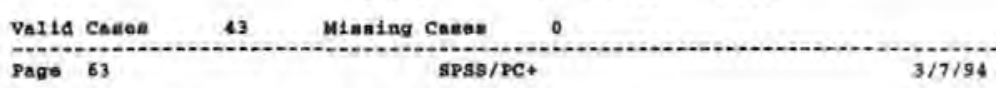

Q8. 1mplemented the standard

value Labe1 Value rrequency percent porcent percent $\begin{array}{llllll}\text { no } & 2 & 13 & 100.0 & 100.0 & 100.0\end{array}$

$$
\begin{array}{ccccc}
2 & 13 & 100.0 & 100.0 & 100.0 \\
\operatorname{rotax} & 13 & \frac{100.0}{100.0} &
\end{array}
$$

Valid caser 43 Miening Cases 0

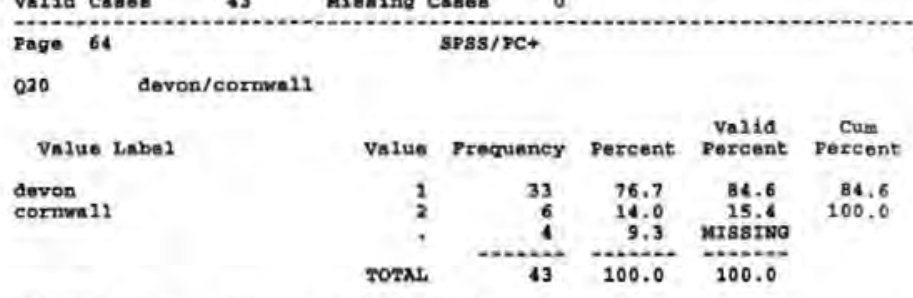

valid caser 39 Misesing cases t

Page 65 SPss/PC+ $3 / 7 / 94$

Thill procedure wall congleted at 12:05:00

Page 66 BPS/PC.

$3 / 7 / 94$

PROCEss IF (gi eq 6).

PREQUENCTES Q1 Q2 Q3 0405 Q6 Q8 020.

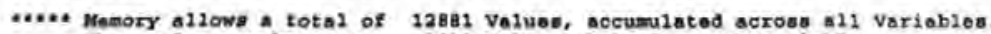

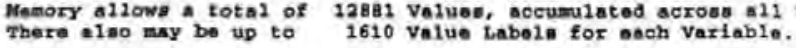

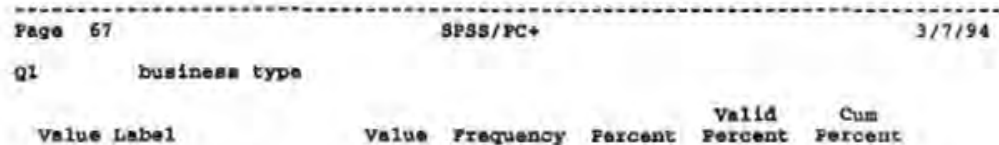




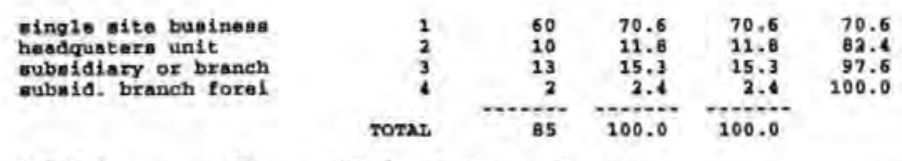

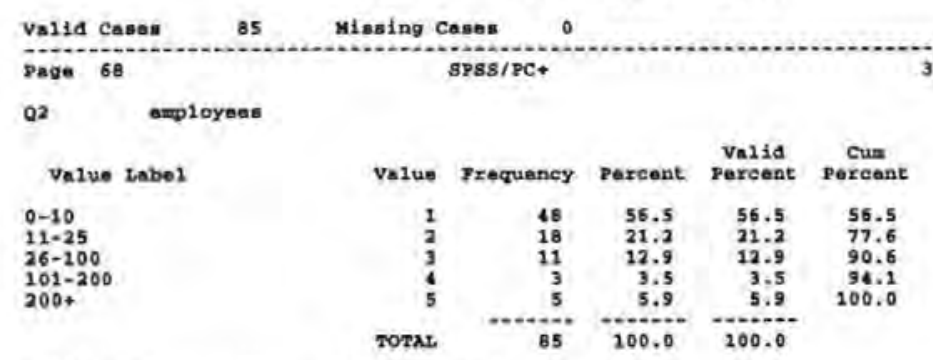

Valla cases B 5 Missing casea o

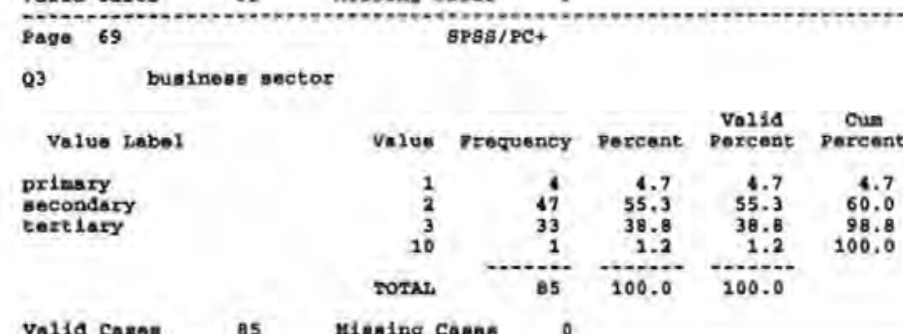

Volia cazen as Miesing cames 0

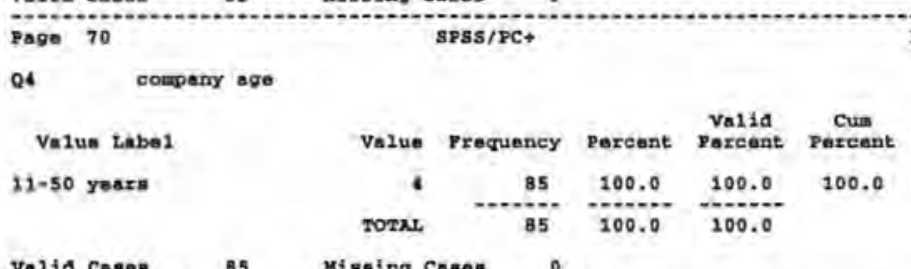

Valid Casea Biseing casea 0

Page 71 SPSB/PC+ $3 / 7 / 94$

Q5 export/non exporters

$$
\begin{aligned}
& \text { Value tabel value rreguency porcent percent percent } \\
& \begin{array}{lrrrrr}
\text { yen } & 1 & 38 & 46.7 & 44.7 & 44.7 \\
\text { ho } & 2 & \$ 7 & 55.3 & 55.3 & 100.0
\end{array}
\end{aligned}
$$

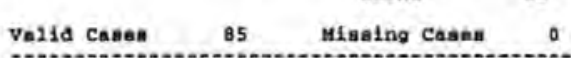

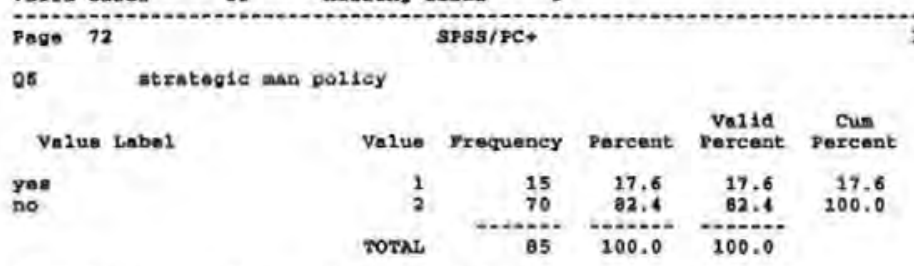

Valia cases 85 Miesing cason 0

Pago 73 SPs 13 PC.

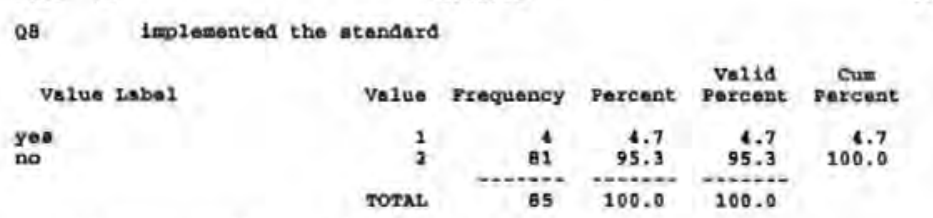

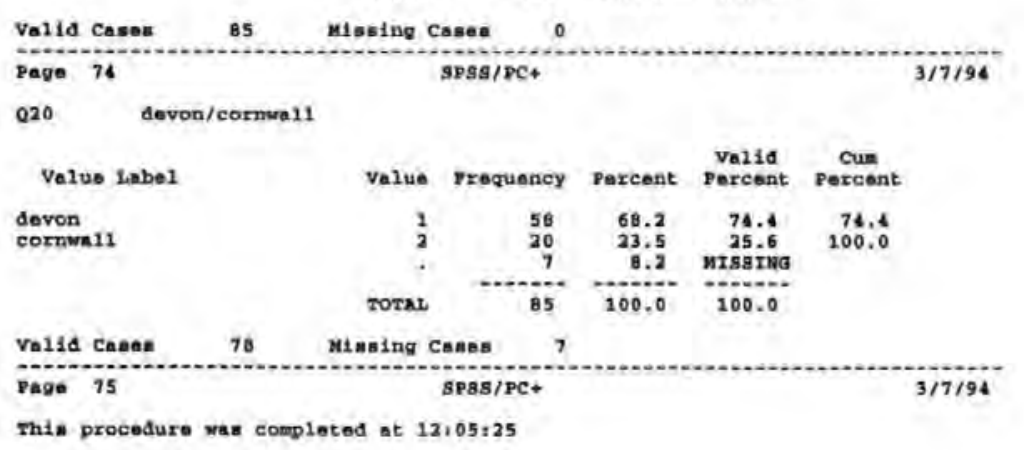




Fage 76 spss/PC+

PRocess If (g4 og 5 ).

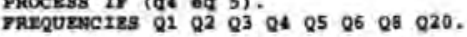

*E. Mesory allows a total of 12881 values, scoumulated acrosa all variables. There also may be up to 1610 value Labela for each variable.

\begin{tabular}{|c|c|c|c|c|c|}
\hline \multirow{2}{*}{$\begin{array}{l}\text { Page } 77 \\
\text { Q1 }\end{array}$} & \multicolumn{3}{|c|}{ SPSS/PC+ } & \multirow[b]{3}{*}{$\begin{array}{l}\text { Volida } \\
\text { Porcent }\end{array}$} & \multirow[b]{3}{*}{$\begin{array}{c}\text { Cus } \\
\text { Pexcent }\end{array}$} \\
\hline & & & & & \\
\hline Value Lebel & value & Frocuency & Percent: & & \\
\hline $\begin{array}{l}\text { aingle ste business } \\
\text { hesdquaters unit } \\
\text { mubsidiary or branch } \\
\text { eubold. brsneh forei }\end{array}$ & $\begin{array}{l}1 \\
2 \\
3 \\
4\end{array}$ & $\begin{array}{r}11 \\
3 \\
9 \\
3\end{array}$ & $\begin{array}{l}12.3 \\
11.5 \\
34.6 \\
11.5\end{array}$ & $\begin{array}{l}12.3 \\
12.5 \\
34.6 \\
11.5\end{array}$ & $\begin{array}{r}12.3 \\
53.8 \\
88.5 \\
100.0\end{array}$ \\
\hline & TOTAL & 26 & 100,0 & 100.0 & \\
\hline
\end{tabular}

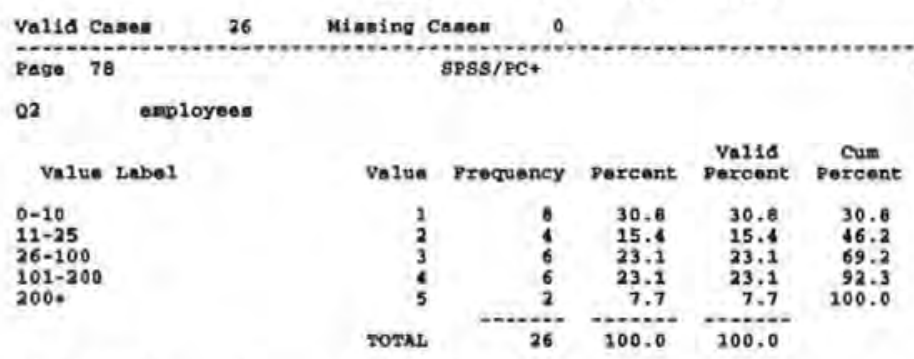

Valia casea $26 \quad$ Miesing caser 0

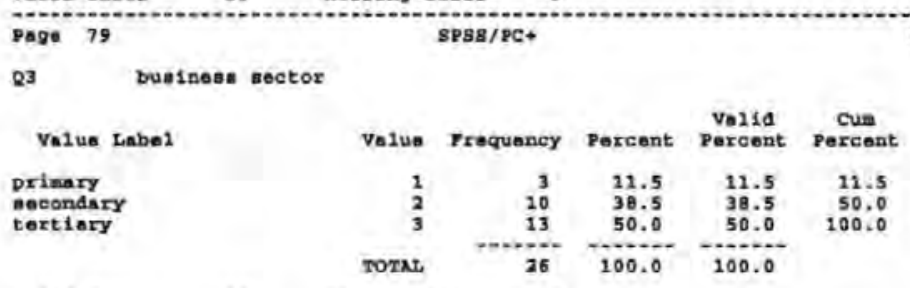

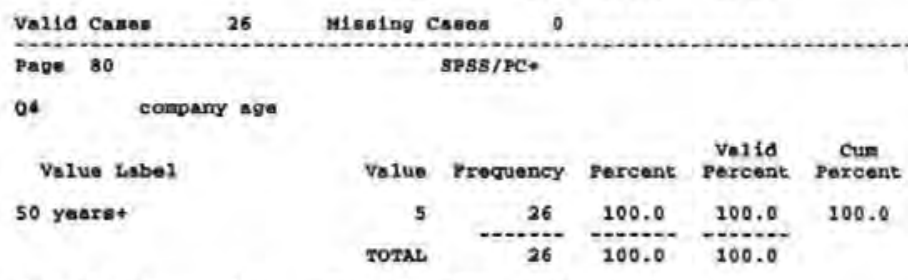

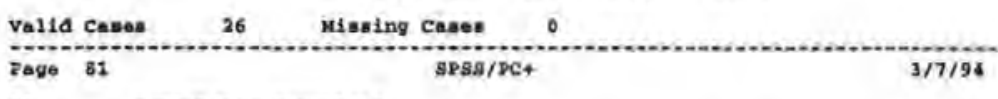

Q5 export/non exportere

$$
\begin{aligned}
& \text { Velue tabel value yrequency porcant percent percent } \\
& \begin{array}{llllll}
\text { yea } & 1 & 12 & 46.2 & 46.2 & 46.2 \\
\text { no } & 2 & 14 & 53.8 & 53.8 & 100.0
\end{array} \\
& \text { rotAl } \quad \begin{array}{ccc}
26 & -100.0 & -100.0
\end{array}
\end{aligned}
$$

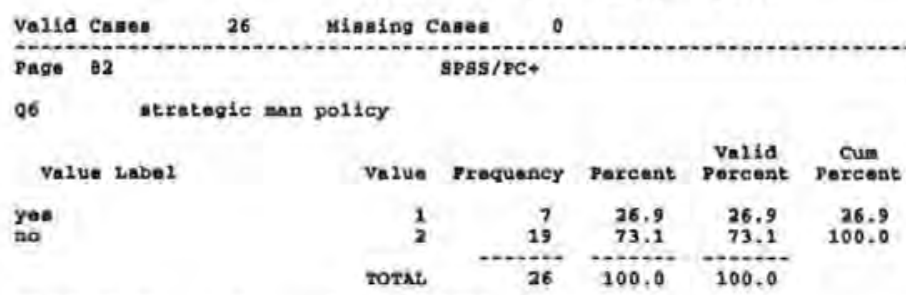




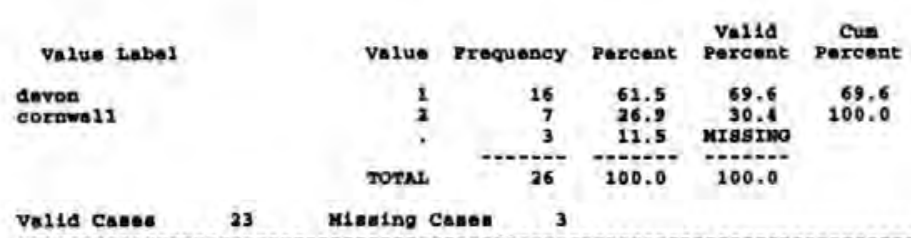

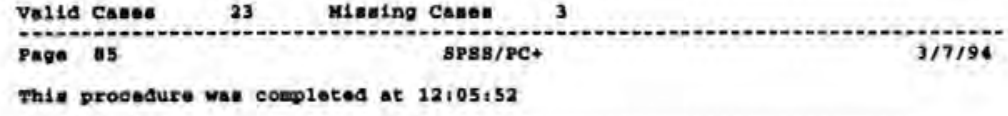

Page 86 SPSg/PC+ $3 / 7 / 94$

phocess If $\left(g^{5} \circ 1\right)$.

varouracteg Q1 Q2 Q3 Q4 Q5 Q6 Q8 Q20.

...., wesory allow - total of 13881 values, sccumulated acrosi al1 variables. There allo may bo up to 1610 Value Labolo for ach Variable.

\begin{tabular}{|c|c|c|c|c|c|}
\hline businese typo & & & & & \\
\hline Velue tabel & value & Froquency & Percent & $\begin{array}{l}\text { Ve11d } \\
\text { percent }\end{array}$ & Percent \\
\hline \multirow[t]{2}{*}{ 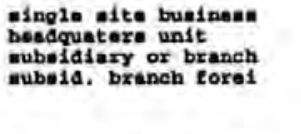 } & $\begin{array}{l}1 \\
2 \\
3 \\
4\end{array}$ & $\begin{array}{r}42 \\
14 \\
6\end{array}$ & $\begin{array}{r}60.0 \\
11.4 \\
20.0 \\
8.6\end{array}$ & $\begin{array}{r}60.0 \\
11.4 \\
20.0 \\
8.6\end{array}$ & $\begin{array}{r}60.0 \\
71.4 \\
91.4 \\
100.0\end{array}$ \\
\hline & TOTAL & 70 & 100.0 & 100.0 & \\
\hline
\end{tabular}

valia canes 70 Miesing cases

\begin{tabular}{|c|c|c|c|c|c|}
\hline Fage 88 & & SPBS/PC+ & & & \\
\hline \multicolumn{6}{|l|}{ mployesn } \\
\hline Value label & Valuo & Proqueney & Porcent & $\begin{array}{l}\text { Valld } \\
\text { Porceont }\end{array}$ & Puresent \\
\hline $\begin{array}{l}0-10 \\
11-25 \\
26-100 \\
101-200 \\
200+\end{array}$ & $\begin{array}{l}1 \\
2 \\
3 \\
4 \\
5\end{array}$ & $\begin{array}{r}34 \\
10 \\
11 \\
8 \\
7\end{array}$ & $\begin{array}{l}10.6 \\
14.3 \\
15.7 \\
11.4 \\
10.0\end{array}$ & $\begin{array}{l}48.6 \\
14.3 \\
15.7 \\
11.4 \\
10.0\end{array}$ & $\begin{array}{r}10.6 \\
62.9 \\
70.6 \\
90.0 \\
100.0\end{array}$ \\
\hline & TORNL & 70 & 100.0 & 100.0 & \\
\hline
\end{tabular}

valia casea 70 Minaing Casas 0

page 69 sps/PC+

Q3 businase sector

Velue Label value rrequeney Percent Pareent Percent

Deimary

mocondary

tortiary

$\begin{array}{rrrrr}1 & 65 & 8.6 & 8.6 & 8.6 \\ 2 & 45 & 54.3 & 64.3 & 72.9 \\ 3 & 19 & 27.1 & 27.1 & 100.0 \\ \text { rorat, } & 70 & 100.0 & 100.0 & \end{array}$

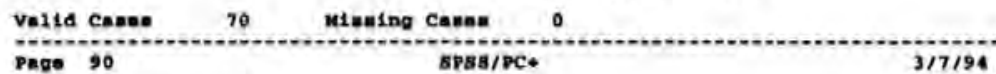

04 company age

value Label

value rreguency percent percent percent

undex 2 yea:

$1-5$ yeara

$11-50$ years.

50 yearset

$\begin{array}{lllll}1 & 1 & 1.4 & 1.4 & 1.4\end{array}$

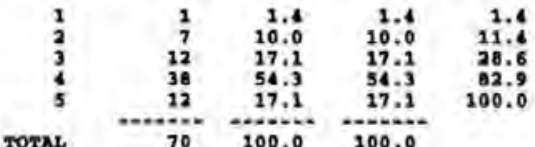

valid cases 70 minaing canen 0

Yago 91 3pss/PC+

Q3 export/non exportera

\begin{tabular}{|c|c|c|c|c|c|}
\hline Vhlue thabel & value & rrequency & Percent & $\begin{array}{l}\text { Val1d } \\
\text { Parcent }\end{array}$ & $\begin{array}{l}\text { Cul } \\
\text { Parcent }\end{array}$ \\
\hline & 1 & 70 & 100,0 & 100.0 & 100,0 \\
\hline & TOTAL & 70 & 100.0 & 100.0 & \\
\hline
\end{tabular}

Valla casses 70 misoing casos 0

Yaga 92 spss/pct $3 / 7 / 94$

06 atretegie man policy

value tabel

Yes

\begin{tabular}{|c|c|c|c|c|}
\hline Value & Prequency & Percant & $\begin{array}{l}\text { Vollia } \\
\text { percent }\end{array}$ & $\begin{array}{l}\text { Cun } \\
\text { Parcont }\end{array}$ \\
\hline$\frac{1}{2}$ & $\begin{array}{l}15 \\
55\end{array}$ & $\begin{array}{l}21.4 \\
78.6\end{array}$ & $\begin{array}{l}22.4 \\
78.6\end{array}$ & $\begin{array}{r}21.4 \\
100.0\end{array}$ \\
\hline & 70 & 100.0 & 100.0 & \\
\hline
\end{tabular}




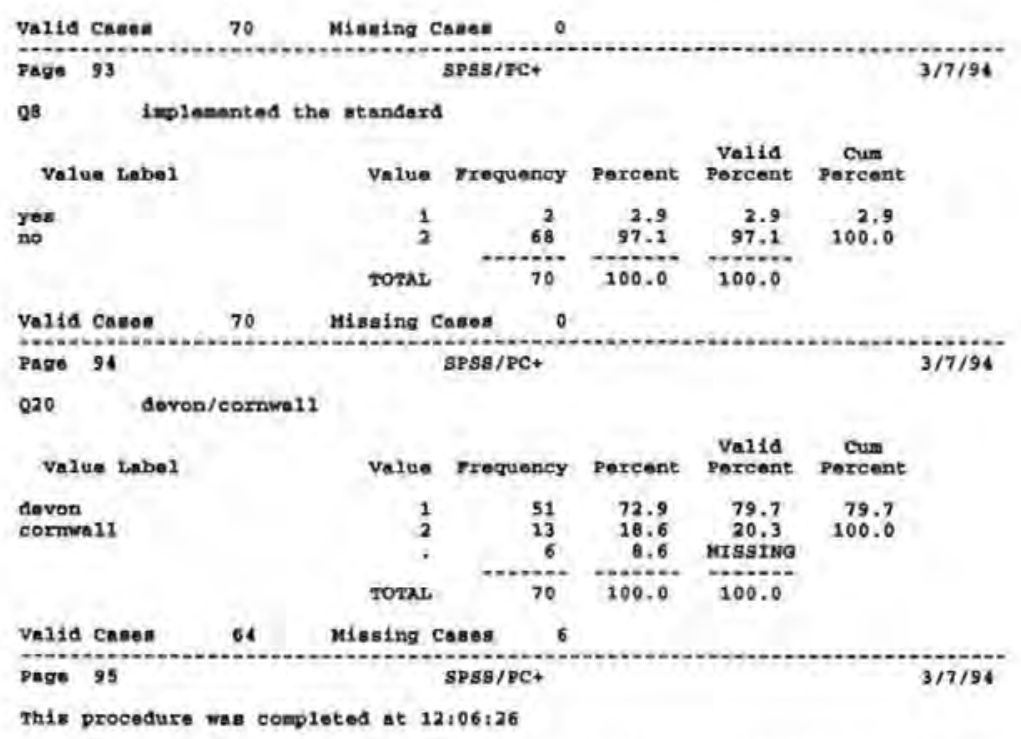

Pago 96 spss/PC+

PROCESS IP (Q5 eq 2$)$.

FREQUEMCIES Q1 Q2 Q3 $Q 4$ Q5 Q6 QB Q20.

\#Fe sesory allows a total of 12881 values, accumulated across all variables.

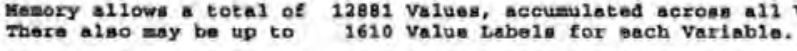

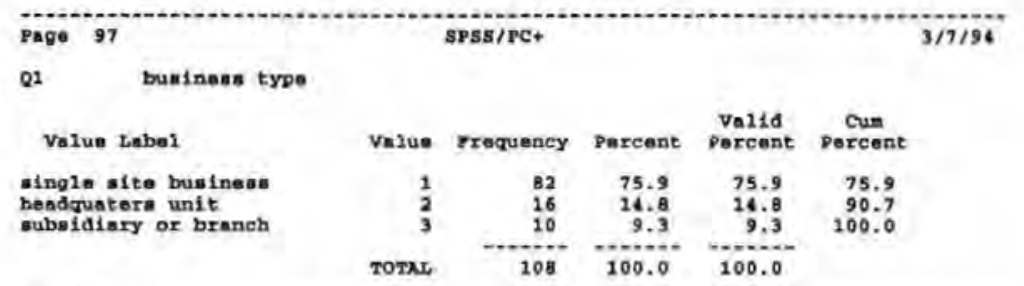

\begin{tabular}{|c|c|c|c|c|c|}
\hline valia Canen & Mialog $c$ & canea & & & \\
\hline Page 98 & & spss/PC+ & & & \\
\hline anployee: & & & & & \\
\hline Value tabel & value & yrequency & Percent & $\begin{array}{l}\text { Valid } \\
\text { Percent }\end{array}$ & $\begin{array}{c}\text { Cum } \\
\text { Percent }\end{array}$ \\
\hline \multirow[t]{2}{*}{$\begin{array}{l}0-10 \\
11-25 \\
26-100 \\
101-200\end{array}$} & $\begin{array}{l}1 \\
2 \\
3 \\
4\end{array}$ & $\begin{array}{r}75 \\
18 \\
13 \\
2\end{array}$ & $\begin{array}{r}69.4 \\
16,7 \\
12.0 \\
1,9\end{array}$ & $\begin{array}{r}69.4 \\
16.7 \\
12.0 \\
1.9\end{array}$ & $\begin{array}{r}69.4 \\
86.1 \\
96.1 \\
100.0\end{array}$ \\
\hline & "sotat: & 108 & 100.0 & 100.0 & \\
\hline
\end{tabular}

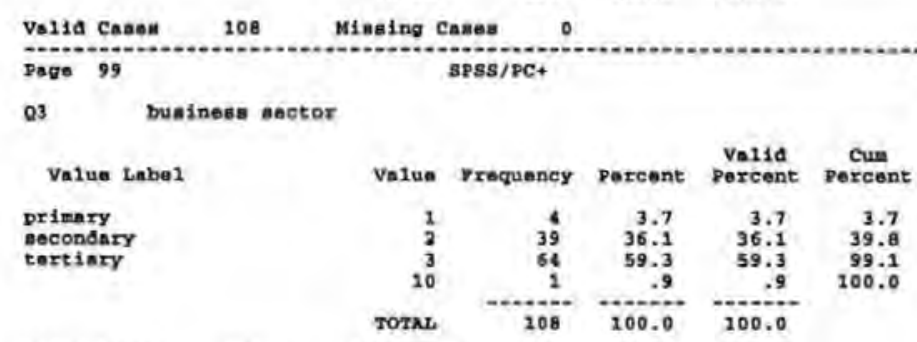

\begin{tabular}{|c|c|c|}
\hline Valid Canaa & Minsing Canea & 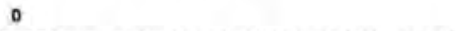 \\
\hline Page 100 & SPAs/PC+ & $3 / 7 / 94$ \\
\hline
\end{tabular}

Q4 company sge

valus tabel

Volue Frequency percent parcent porcent

under 1 year

$1=5$ yanra

$6-10$ yoar
$11=50$ years

$11-50$ yesir
50 yourst

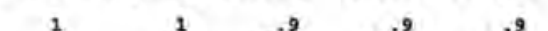

volld cases $100 \quad$ Missing Casen 0

PQge 101 SPSg/PC+

Q5 export/non exportara

Value Label value Frequency percent parcant porcent 


\begin{tabular}{|c|c|c|c|c|c|}
\hline \multicolumn{6}{|c|}{ Page 102} \\
\hline & \multicolumn{5}{|c|}{ strategle ann pollcy } \\
\hline Value zabel & value & Prequency & percent & $\begin{array}{l}\text { Valid } \\
\text { Parcent }\end{array}$ & Cus \\
\hline $\begin{array}{l}\text { Yos } \\
\text { no }\end{array}$ & $\frac{1}{2}$ & 94 & $\begin{array}{l}13.0 \\
87.0\end{array}$ & $\begin{array}{l}13.0 \\
07.0\end{array}$ & $\begin{array}{r}13.0 \\
100.0\end{array}$ \\
\hline & rorax & 108 & 100.0 & 100.0 & \\
\hline
\end{tabular}

velld cages 108 wiesing caser 0

Pago 103 aPss/PC+ 3/7/94

Q日 Inolamanted tho atandard

\begin{tabular}{|c|c|c|c|c|c|}
\hline Value Zabal & value & Prequency & Parcent & $\begin{array}{l}\text { Volid } \\
\text { Percant }\end{array}$ & $\begin{array}{c}\text { Cum } \\
\text { percent }\end{array}$ \\
\hline $\begin{array}{l}\text { yed } \\
\text { no }\end{array}$ & $\frac{1}{2}$ & 104 & $\begin{array}{r}3.7 \\
96.3\end{array}$ & $\begin{array}{r}3.7 \\
96.3\end{array}$ & $\begin{array}{r}3.7 \\
200.0\end{array}$ \\
\hline & TOTAS & 108 & 100.0 & 100.0 & \\
\hline
\end{tabular}

valid cases 108 Higring cases 0

Page 104 BPsG/8C+

Q20 Gevon/cormall

\begin{tabular}{|c|c|c|c|c|c|}
\hline value Labol & value & Prequency & Porcent & $\begin{array}{l}\text { Valld } \\
\text { Porcent }\end{array}$ & Purem \\
\hline $\begin{array}{l}\text { devan } \\
\text { cormma11 }\end{array}$ & $\begin{array}{l}1 \\
2 \\
.\end{array}$ & $\begin{array}{l}70 \\
24 \\
14\end{array}$ & $\begin{array}{l}64.0 \\
22.2 \\
13.0\end{array}$ & $\begin{array}{c}74.5 \\
25.5 \\
\text { urgsino }\end{array}$ & $\begin{array}{r}74.5 \\
100.0\end{array}$ \\
\hline & $2002 x$ & 108 & 100.0 & 100.0 & \\
\hline
\end{tabular}

Valid Camas $94 \quad$ Mlasing cased 14

Pago 105 spsg/Pet $3 / 7 / 94$

This procedure wen completed at 12:06:51

Page 106 BPs8/8C. 3/7/94

PROCEgS IP $\log \propto 1)$.

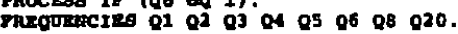

"..." remory allowg a total of 12881 Values, accumplated acxogy all Variables. there 1100 may be up to 1610 value tabele for oach Vaxiable.

Page 107

BPBg/PC+

$3 / 7 / 94$

Q2

buelnoes type

value zabel

value Frequency percent percent percent

Ingle alte buelinoss

aubgidiary or branch

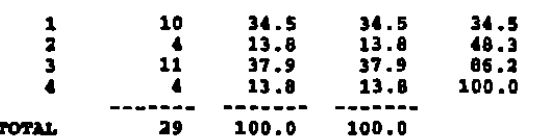

Valla cases 29

Page 108 Higedng Cabon

Q2 exployeas

Valuo rabel

$0-10$

$11-25$
$26-100$

$26-100$

$200+$

opss/PC+

$3 / 7 / 94$

valla canes 29 morne Hasing cases 0

Page 109
SPSB/PC.

$3 / 7 / 94$

03 buelnese abctor

\begin{tabular}{|c|c|c|c|c|c|}
\hline Value Inabel & value & Prequancy & Pexcent & $\begin{array}{l}\text { Valid } \\
\text { Percent }\end{array}$ & $\begin{array}{c}\text { Cum } \\
\text { Porcent }\end{array}$ \\
\hline $\begin{array}{l}\operatorname{lmaxy} \\
\text { scomdary } \\
\operatorname{srt} \operatorname{lary}\end{array}$ & $\begin{array}{l}1 \\
2 \\
3\end{array}$ & $\begin{array}{r}5 \\
13 \\
11\end{array}$ & $\begin{array}{l}17.2 \\
44.0 \\
37.9\end{array}$ & $\begin{array}{l}17.2 \\
14.0 \\
37.9\end{array}$ & $\begin{array}{r}17.2 \\
62.1 \\
100.0\end{array}$ \\
\hline & Toral & 29 & 100.0 & 100.0 & \\
\hline
\end{tabular}

Valtd canes 29 Higaing canes

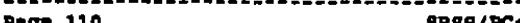

Q4 company age 


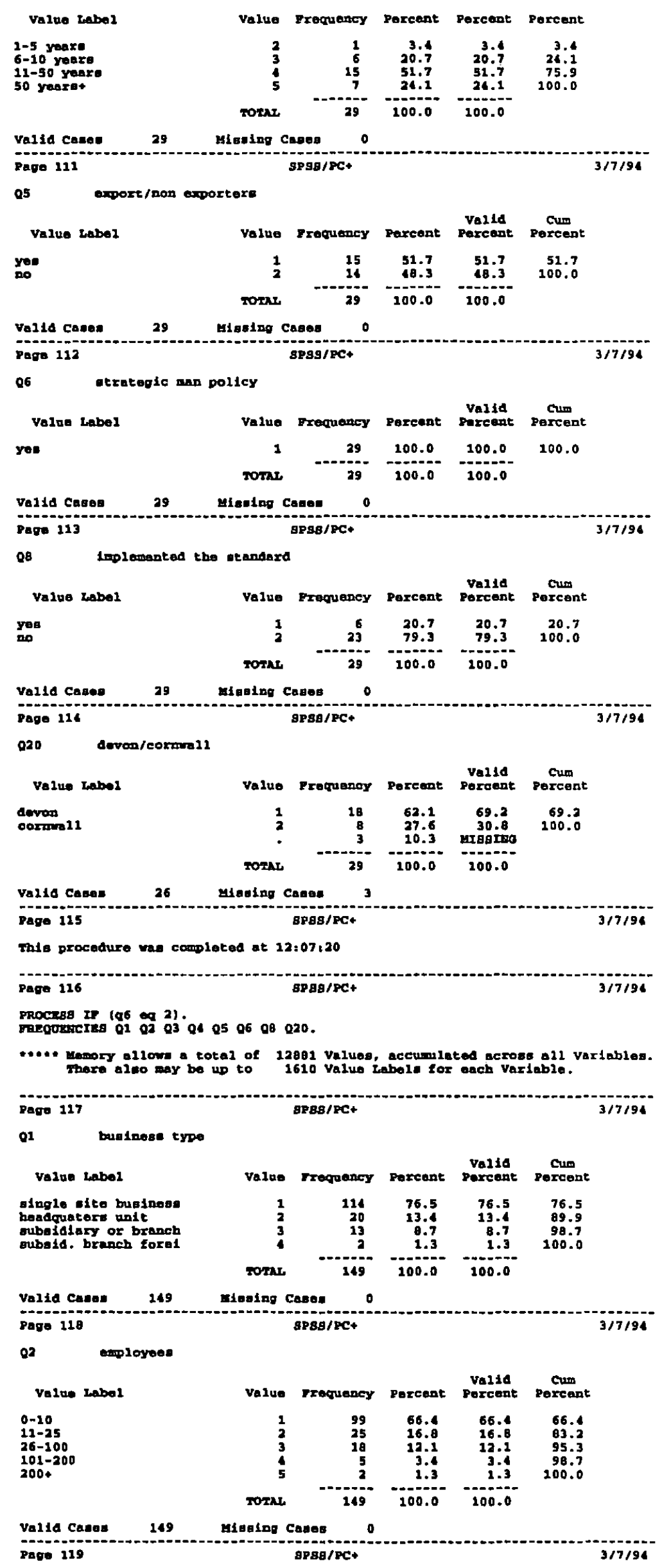




\begin{tabular}{|c|c|c|c|c|c|}
\hline value Iabel & value & Frequency & Percent & $\begin{array}{l}\text { Valid } \\
\text { Percent }\end{array}$ & $\begin{array}{c}\text { Cun } \\
\text { Parcent }\end{array}$ \\
\hline $\begin{array}{l}\text { Drdmany } \\
\text { tecomalary } \\
\text { tertlary }\end{array}$ & $\begin{array}{r}1 \\
2 \\
3 \\
10\end{array}$ & $\begin{array}{r}5 \\
71 \\
72 \\
1\end{array}$ & $\begin{array}{r}3.4 \\
47.7 \\
48.3 \\
.7\end{array}$ & $\begin{array}{r}3.4 \\
47.7 \\
48.3 \\
.7\end{array}$ & $\begin{array}{r}3.4 \\
51.0 \\
99.3 \\
100.0\end{array}$ \\
\hline & Torax & 149 & 100.0 & 100.0 & \\
\hline
\end{tabular}

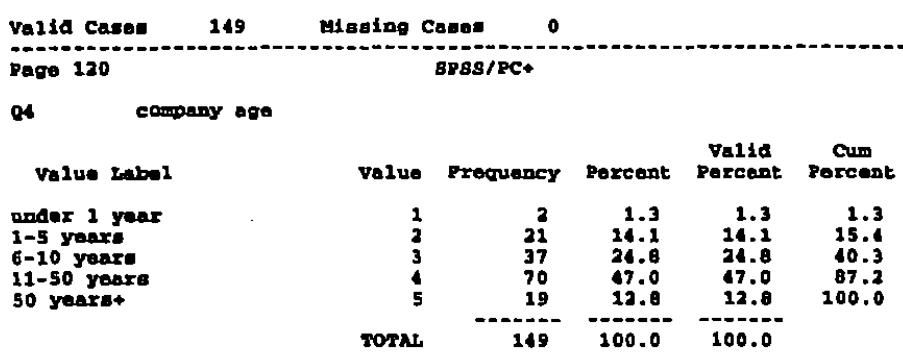

$$
\begin{aligned}
& \text { valid Canes } 149 \quad \text { Hisaing Caber } 0
\end{aligned}
$$

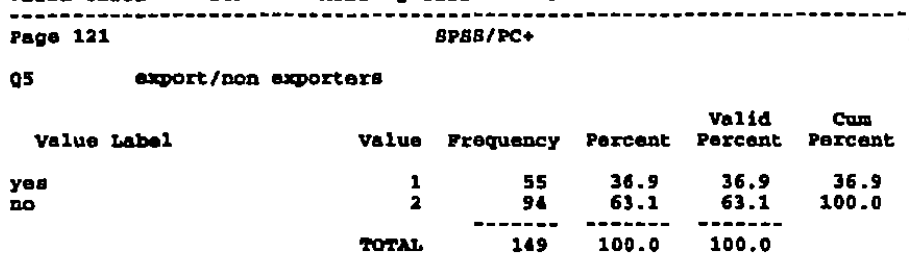

$$
\begin{aligned}
& \begin{array}{l}
\text { val1d cases } 149 \quad \text { Mlasing Cases } 0 \\
\hline \text { pago } 122
\end{array}
\end{aligned}
$$

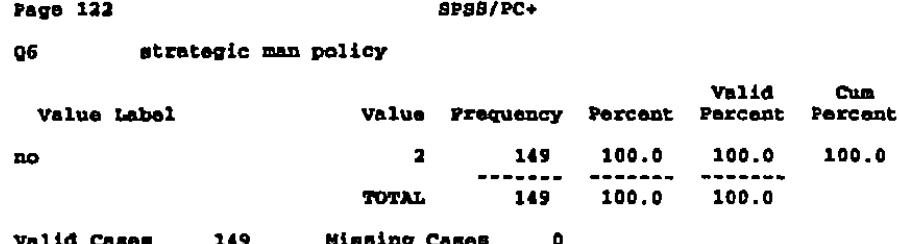

\begin{tabular}{l} 
valid Cased 249 Minsing Cases 0 \\
\hline Page 123
\end{tabular}

Q8 Inlemented the at andard

$$
\begin{aligned}
& \text { value sabel value Frequency pexcent parcent percent } \\
& \begin{array}{llllll}
\text { no } 2 & 149 & 100.0 & 100.0 & 100.0
\end{array} \\
& \begin{array}{ccccc}
2 & 149 & 100.0 & 100.0 & 100.0 \\
\hline \text { rorar } & 149 & 100.0 & 100.0 &
\end{array}
\end{aligned}
$$

Pago 126 BP8B/PC+

\begin{tabular}{|c|c|c|c|c|c|}
\hline \multirow{2}{*}{$\begin{array}{l}\text { Page } 127 \\
02 \quad \text { businass type }\end{array}$} & \multicolumn{2}{|r|}{ APSO/PC+ } & & \multirow[b]{3}{*}{$\begin{array}{l}\text { Velid } \\
\text { Percent }\end{array}$} & \multirow[b]{3}{*}{$\begin{array}{l}\text { Cum } \\
\text { Pexcent }\end{array}$} \\
\hline & & & & & \\
\hline 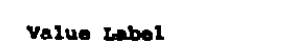 & Value & Trequency & Percent & & \\
\hline \multirow[t]{2}{*}{ 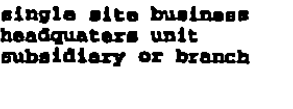 } & $\begin{array}{l}1 \\
2 \\
3\end{array}$ & $\begin{array}{l}1 \\
1 \\
4\end{array}$ & $\begin{array}{l}26.7 \\
16.7 \\
66.7\end{array}$ & $\begin{array}{l}16.7 \\
16.7 \\
66.7\end{array}$ & $\begin{array}{r}16.7 \\
33.3 \\
100.0\end{array}$ \\
\hline & TOTAL & 6 & 100.0 & 100.0 & \\
\hline
\end{tabular}

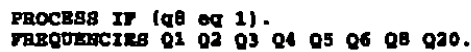

\#... yemory allow a total of $128 \theta 1$ valuen, accumulated scross all variablos.

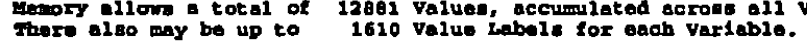

Val1d Canag 6 migsing Canos 0

Page 120


$92 \quad 0$ -

\begin{tabular}{|c|c|c|c|c|c|}
\hline Value Labol & Value & Prequency & Percent & $\begin{array}{c}\text { Valida } \\
\text { Parceont }\end{array}$ & $\begin{array}{c}\text { Cum } \\
\text { Percent }\end{array}$ \\
\hline $\begin{array}{l}-10 \\
1-25 \\
b-100 \\
00+\end{array}$ & $\begin{array}{l}2 \\
2 \\
3 \\
5\end{array}$ & $\begin{array}{l}2 \\
2 \\
1 \\
1\end{array}$ & $\begin{array}{l}33.3 \\
33.3 \\
16.7 \\
16.7\end{array}$ & $\begin{array}{l}33.3 \\
33.3 \\
16.7 \\
16.7\end{array}$ & $\begin{array}{r}33.3 \\
66.7 \\
83.3 \\
100.0\end{array}$ \\
\hline & $\operatorname{rom} t$ & 6 & 100.0 & 200.0 & \\
\hline
\end{tabular}

velid canes:

ahaning cages 0

Pago 129 BP8g/PC.

$3 / 7 / 94$

Q3

bunlnaes sector

\begin{tabular}{|c|c|c|c|c|c|}
\hline Value label & value & Prequoncy & Percent & $\begin{array}{c}\text { val1d } \\
\text { porcent }\end{array}$ & Cun \\
\hline $\begin{array}{l}\text { primary } \\
\text { eocondingy } \\
\text { tert } 1 \text { ary }\end{array}$ & $\begin{array}{l}1 \\
2 \\
3\end{array}$ & $\begin{array}{l}1 \\
1\end{array}$ & $\begin{array}{l}16.7 \\
66.7 \\
16.7\end{array}$ & $\begin{array}{l}16.7 \\
66.7 \\
16.7\end{array}$ & $\begin{array}{r}16.7 \\
83.3 \\
100.0\end{array}$ \\
\hline
\end{tabular}

valid cased 6 biesing cases 0

\begin{tabular}{|c|c|c|c|c|c|}
\hline conpany age & & & & & \\
\hline Value labol & value & Prequeney & Percent & $\begin{array}{l}\text { Velid } \\
\text { Porcent }\end{array}$ & $\begin{array}{c}\text { Cum } \\
\text { Porcent }\end{array}$ \\
\hline $\begin{array}{l}1-5 \text { yeare } \\
11-50 \text { yesra } \\
50 \text { yourgt }\end{array}$ & $\begin{array}{l}2 \\
4 \\
5\end{array}$ & $\begin{array}{l}1 \\
1\end{array}$ & $\begin{array}{l}16.7 \\
66.7 \\
16.7\end{array}$ & $\begin{array}{l}16.7 \\
66.7 \\
16.7\end{array}$ & $\begin{array}{r}16.7 \\
83.3 \\
100.0\end{array}$ \\
\hline & Totrat & 6 & 100.0 & 100.0 & \\
\hline
\end{tabular}

valid canes 6 Misalng ceser 0

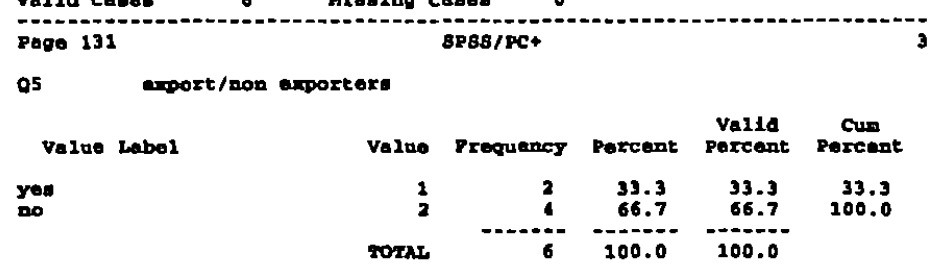

valid caster 6 Mineing cases 0

Paga 132 BPBg/PC+ $3 / 7 / 94$

o6 etrategic man polley

\begin{tabular}{|c|c|c|c|c|c|}
\hline Value tabel & value & rrequency & Porcent & $\begin{array}{l}\text { Val1d } \\
\text { percent }\end{array}$ & $\begin{array}{c}\text { Cun } \\
\text { Percent }\end{array}$ \\
\hline yos & 1 & 6 & 100.0 & 100.0 & $100: 0$ \\
\hline
\end{tabular}

valua cases 6 ulesing cases 0

Page 133 Bs8s/PC+

OP Loplenanted tho atandird

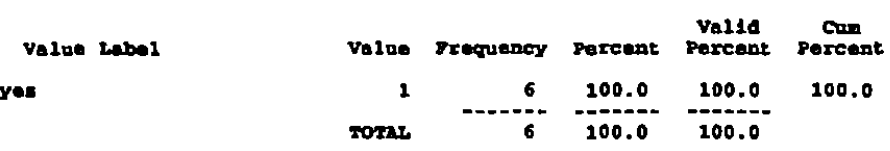

valid canos 6 uloulog cases 0

Page 134 BPsi/PC+

020 dovon/cormall

Value Label

covon 11

value Frequency porcent parcent porcent

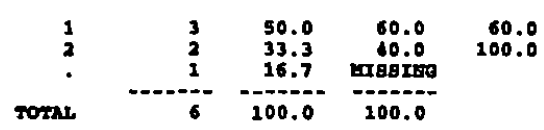

valia cased 5 Hesing cesos 1

Page 235

Thid procedure wa conoteted at 12,0814

Pape 136 SPBg/PC+

procteas If $\left(Q^{\circ} \propto 2\right)$.

mRousterso 0102 Q3 0405 os 00020.

..... manosy allore a cotal of 12881 values, sceumlated acroas all varieblos. thare siso ady be up to 1610 value inable for ench variable.

Pago 137 8988/Pe+ 
01 businese tyou

valov Lebel value Frequenoy percent porcent poxcent alng2e site buplneas hoedquatere unit oublidiaxy or branch mbida. branch gorel

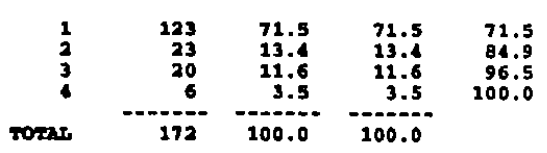

val1d canses

lesing cames

0

\begin{tabular}{|c|c|c|c|c|c|}
\hline aloyeas & & & & & \\
\hline Valoe Labol & valuo & Prequency & Percent & $\begin{array}{l}\text { Vol1d } \\
\text { Porcent }\end{array}$ & $\begin{array}{c}\text { Cus } \\
\text { Porcent }\end{array}$ \\
\hline $\begin{array}{l}0-10 \\
11-25 \\
26-100 \\
101-200 \\
200+\end{array}$ & $\begin{array}{l}1 \\
2 \\
3 \\
1 \\
5\end{array}$ & $\begin{array}{r}107 \\
26 \\
23 \\
10 \\
6\end{array}$ & $\begin{array}{r}62.2 \\
15.1 \\
13.4 \\
5.6 \\
3.5\end{array}$ & $\begin{array}{r}62.2 \\
15.1 \\
13.4 \\
5.8 \\
3.5\end{array}$ & $\begin{array}{r}62.2 \\
77.3 \\
90.7 \\
96.5 \\
100.0\end{array}$ \\
\hline & Total & 172 & 100.0 & 100.0 & \\
\hline
\end{tabular}

valla cases 172 Hiseing cases 0

Page 139

Q3 bueinone sector

\begin{tabular}{|c|c|c|c|c|c|}
\hline Value Labol & Value & Fropuency & Parcent & $\begin{array}{l}\text { Valld } \\
\text { percent }\end{array}$ & $\begin{array}{c}\text { Cun } \\
\text { Porcent }\end{array}$ \\
\hline $\begin{array}{l}\text { prinary } \\
\text { gecondary } \\
\text { tert lary }\end{array}$ & $\begin{array}{r}1 \\
2 \\
3 \\
10\end{array}$ & $\begin{array}{r}99 \\
00 \\
02 \\
1\end{array}$ & $\begin{array}{r}9.2 \\
16.5 \\
17.7 \\
.6\end{array}$ & $\begin{array}{r}3.2 \\
18.5 \\
67.7 \\
.6\end{array}$ & $\begin{array}{r}5.2 \\
51.7 \\
99.4 \\
100.0\end{array}$ \\
\hline & soral & 172 & 100.0 & 100.0 & \\
\hline
\end{tabular}

vella cases $172 \quad$ Higning Caces

Page 160 8P88/PC+

Q4 comong age

Value Label value Frequency percent percent percent

under 1 year

1-5 yeara

$6-10$ yente

11-50 rasa:

50 yearat

valid canes

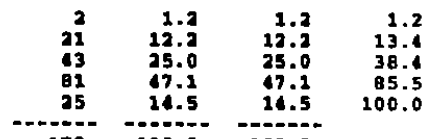

272 Mlesing caser 0

QS aport/non exporter:

value tabel

value jrequenoy percent porcent percent

you

$\begin{array}{rrrrr}1 & 68 & 39.5 & 39.5 & 39.5 \\ 2 & 106 & 60.5 & 60.5 & 100.0\end{array}$

roms $\quad 172 \quad 100.0 \quad 100.0$

valid cases 272 maling cases 0

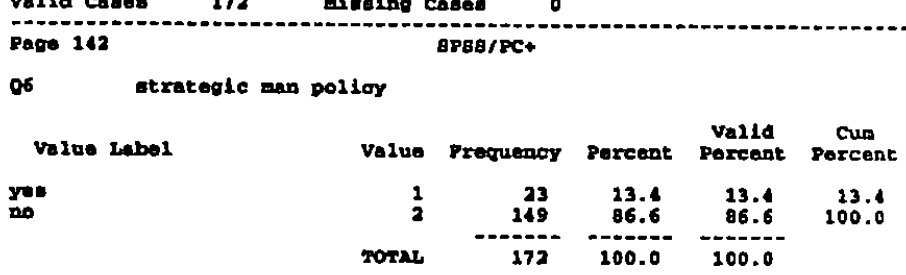

valia cenes

miesing camos

Poge 143 8PBs/pct

Q0 Imolemeded the itandard

\begin{tabular}{|c|c|c|c|c|c|}
\hline Value Label & Value & Frequener & Percent & $\begin{array}{l}\text { Val1d } \\
\text { pareost }\end{array}$ & $\begin{array}{c}\text { Cun } \\
\text { Porcant }\end{array}$ \\
\hline & -2 & 172 & 100.0 & 100.0 & 100.0 \\
\hline & rotax & 172 & 100.0 & 100.0 & \\
\hline
\end{tabular}

Valsd Cares

uisoing caces:

Page 144
BPBg/PC+

020

Lovon/cormal1

value rabel

Value Frequency porcent porcent percent

devon

cormall

$3 / 7 / 94$

$3 / 7 / 94$ 


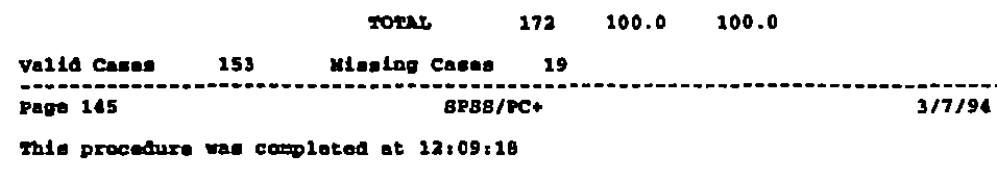

Page 146 BPBg/PC+

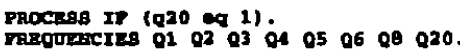

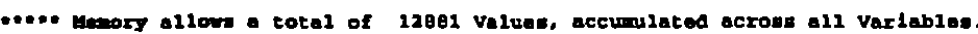

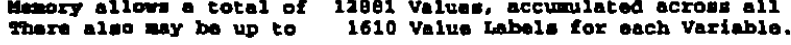

\begin{tabular}{|c|c|c|c|c|c|}
\hline buelnete type & & & & & \\
\hline Value Label & value & Proguency & Parcent & $\begin{array}{l}\text { Val1a } \\
\text { percent }\end{array}$ & $\begin{array}{c}\text { Cus } \\
\text { Parcen }\end{array}$ \\
\hline 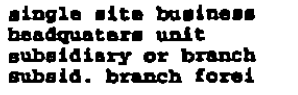 & $\begin{array}{l}1 \\
2 \\
3 \\
4\end{array}$ & $\begin{array}{r}89 \\
13 \\
15 \\
4\end{array}$ & $\begin{array}{r}73.6 \\
10.7 \\
12.1 \\
3.3\end{array}$ & $\begin{array}{r}73.6 \\
10.7 \\
12.4 \\
3.3\end{array}$ & $\begin{array}{r}73.6 \\
94.3 \\
96.7 \\
100.0\end{array}$ \\
\hline & rotax & 121 & 100.0 & 100.0 & \\
\hline
\end{tabular}

\begin{tabular}{|c|c|c|c|c|c|}
\hline Page 148 & & 8P8g/PC+ & & & \\
\hline onogen & & & & & \\
\hline Valuo tenbel & value & Frequency & Percent & $\begin{array}{c}\text { Val1d } \\
\text { Percent }\end{array}$ & $\begin{array}{l}\text { Cum } \\
\text { Percent }\end{array}$ \\
\hline \multirow[t]{2}{*}{$\begin{array}{l}0-10 \\
11-25 \\
26-100 \\
201-200 \\
200+\end{array}$} & $\begin{array}{l}1 \\
2 \\
3 \\
1 \\
5\end{array}$ & $\begin{array}{r}75 \\
20 \\
15 \\
6 \\
5\end{array}$ & $\begin{array}{r}62.0 \\
16.5 \\
12.4 \\
5.0 \\
4.1\end{array}$ & $\begin{array}{r}62.0 \\
16.5 \\
12.4 \\
5.0 \\
4.1\end{array}$ & $\begin{array}{r}62.0 \\
76.5 \\
90.9 \\
95.9 \\
100.0\end{array}$ \\
\hline & rorax & 221 & 100.0 & 100.0 & \\
\hline
\end{tabular}

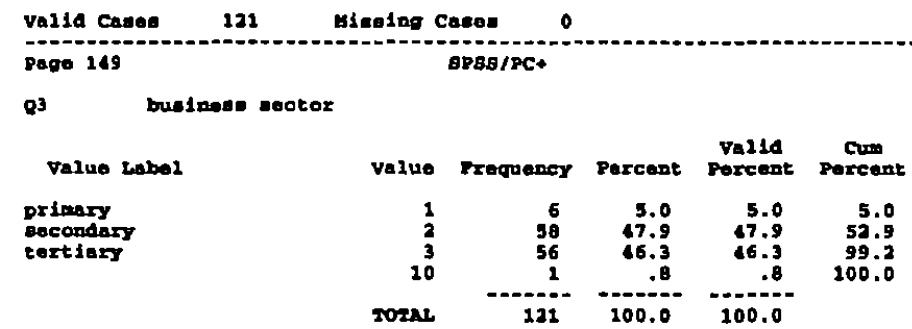

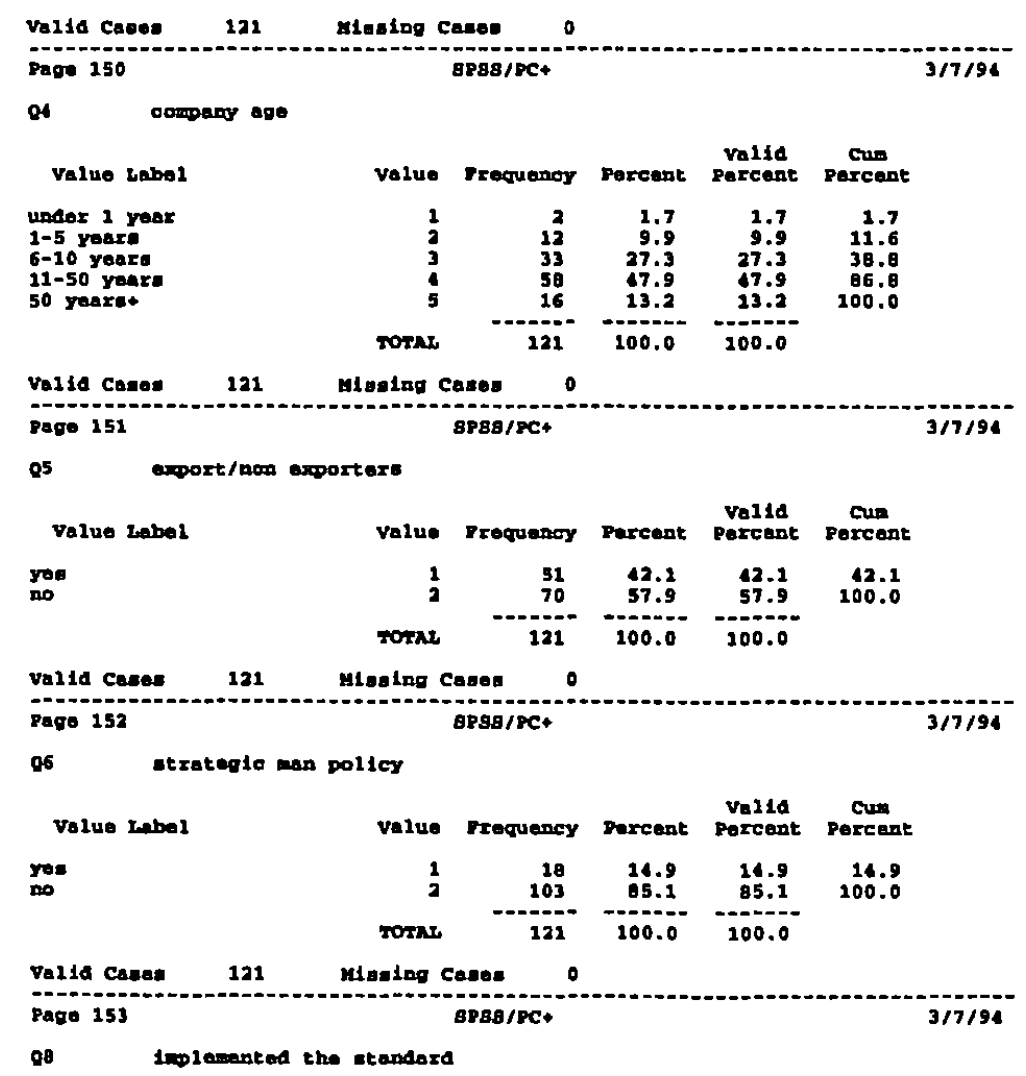




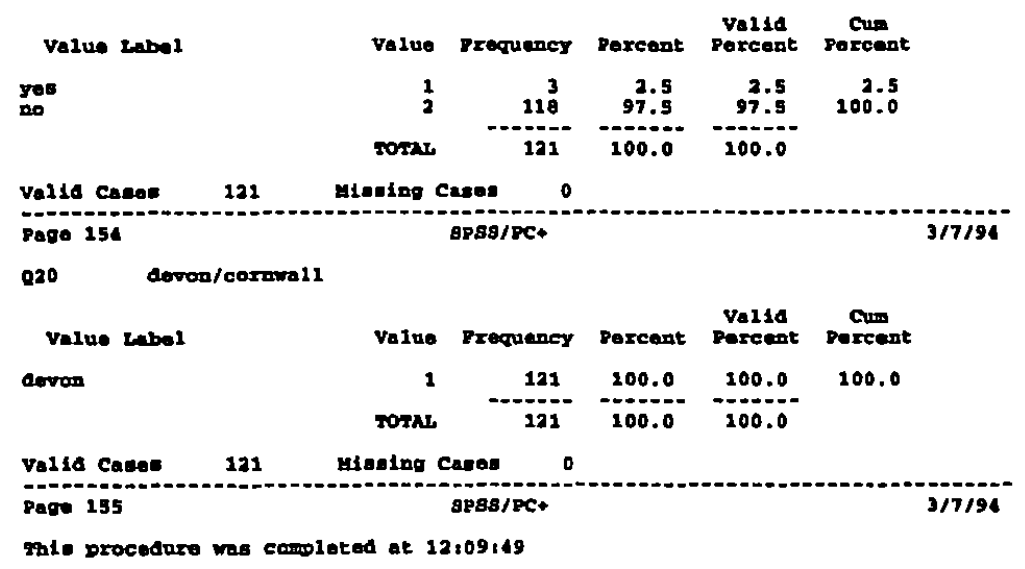

Page 156 SPB8/PC+

Process If (420 as 2$)$.

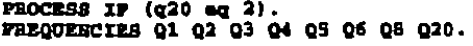

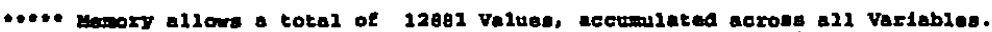

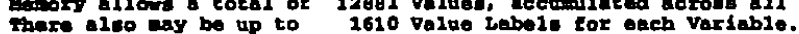

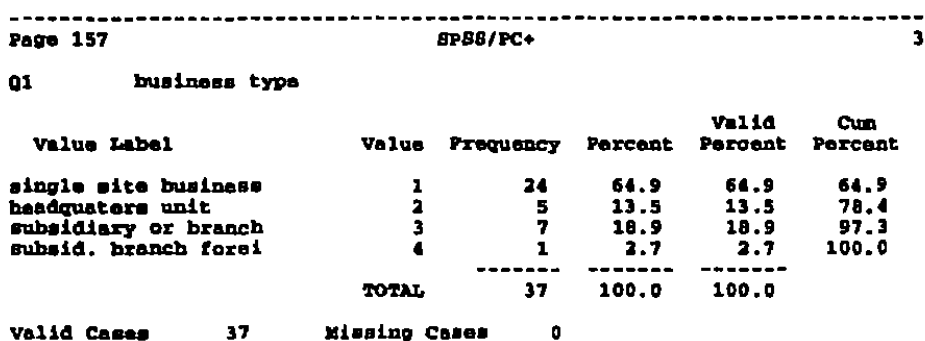

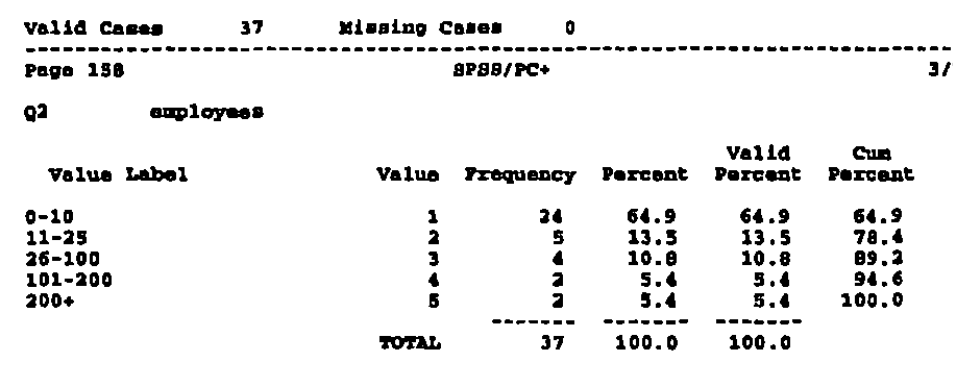

valid Cases 37 Migeing cases 0

\begin{tabular}{|c|c|c|c|c|c|}
\hline bueinose mector & & & & & \\
\hline value Iabel & Value & Proquenoy & Paroent & $\begin{array}{l}\text { val1a } \\
\text { Porcont }\end{array}$ & Percent \\
\hline $\begin{array}{l}\text { primary } \\
\text { gocondary } \\
\text { tort1ary }\end{array}$ & $\begin{array}{l}1 \\
2 \\
3\end{array}$ & $\begin{array}{l}16 \\
17\end{array}$ & $\begin{array}{l}10.8 \\
43.2 \\
45.9\end{array}$ & $\begin{array}{l}10.0 \\
43.2 \\
45.9\end{array}$ & $\begin{array}{r}10.8 \\
54.1 \\
200.0\end{array}$ \\
\hline & rorend, & 37 & 100.0 & 100.0 & \\
\hline
\end{tabular}

valid caces $37 \quad$ Hesing Cases 0

\begin{tabular}{|c|c|c|c|c|c|}
\hline company age & & & & & \\
\hline Value Labol & Value & Frecpuency & Parcent & $\begin{array}{l}\text { Valld } \\
\text { Percent }\end{array}$ & $\underset{\text { Pancent }}{c \text { Cun }}$ \\
\hline $\begin{array}{l}\text { 1-5 yenre } \\
5-10 \text { yeare } \\
11-50 \text { yeare } \\
50 \text { yearst }\end{array}$ & $\begin{array}{l}2 \\
3 \\
1 \\
5\end{array}$ & $\begin{array}{r}6 \\
20 \\
7\end{array}$ & $\begin{array}{l}10.0 \\
16.2 \\
51.1 \\
18.9\end{array}$ & $\begin{array}{l}10.0 \\
16.2 \\
56.1 \\
20.9\end{array}$ & $\begin{array}{r}10.0 \\
27.0 \\
91.1 \\
100.0\end{array}$ \\
\hline & 202ar & 37 & 100.0 & 100.0 & \\
\hline
\end{tabular}

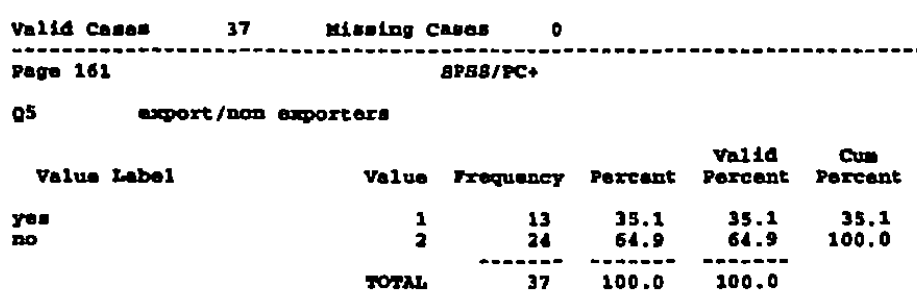

valid caser 37 uimolno cases 0

Page 162 
as etrategle mas policy

\begin{tabular}{|c|c|c|c|c|c|}
\hline Value label & Value & Froculaney & Percent & $\begin{array}{l}\text { Val1d } \\
\text { Pexeont }\end{array}$ & $\begin{array}{c}\text { Cum } \\
\text { percent }\end{array}$ \\
\hline you & $\frac{1}{2}$ & $\begin{array}{r}0 \\
29\end{array}$ & $\begin{array}{l}21.6 \\
78.6\end{array}$ & $\begin{array}{l}21.6 \\
78.4\end{array}$ & $\begin{array}{r}21.6 \\
100.0\end{array}$ \\
\hline & 202al & 37 & 100.0 & 100.0 & \\
\hline
\end{tabular}

valla cases $37 \quad 41801 \mathrm{ng}$ cases 0

Page 163 gPs8/PC+ $3 / 7 / 94$

ga

issolemented the atandare

\begin{tabular}{|c|c|c|c|c|c|}
\hline Value zabel & value & Frequency & Percant & $\begin{array}{c}\text { Vel1d } \\
\text { percent }\end{array}$ & $\begin{array}{c}\text { Cum } \\
\text { percent }\end{array}$ \\
\hline & 2 & $\begin{array}{r}2 \\
35\end{array}$ & $\begin{array}{r}5.4 \\
94.6\end{array}$ & $\begin{array}{r}3.4 \\
94.6\end{array}$ & 100.0 \\
\hline & TOTAX & 37 & 100.0 & 100.0 & \\
\hline
\end{tabular}

valia cases $37 \quad$ Hiselng Casen 0

Page 164 SPgs/PC+ $3 / 7 / 94$

920

devon/cormall

Value Iabel

value Frequency percent percent percent

cormall

$\begin{array}{rcccc}2 & 37 & 100.0 & 100.0 & 100.0 \\ \text { rotax } & -37 & 100.0 & 100.0 & \end{array}$

Valld cason 37 Hiasing cases 0

Pago 165 SPBS/PC.

$3 / 7 / 94$

Thls procedore was conpleted at 12:10:13

Page 166

spgs/pe+

$3 / 7 / 94$

PIAs8a.

end of inolude 2110. 


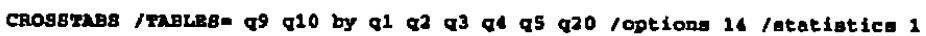

Yemory allows for 7,849 cells with 2 dinenglong for genoral CROSBTABs.

Page $6 \quad$ BPBg/PC+ $6 / 21 / 94$

Q9 able to 1mplement 7750\% by 01 busineas type

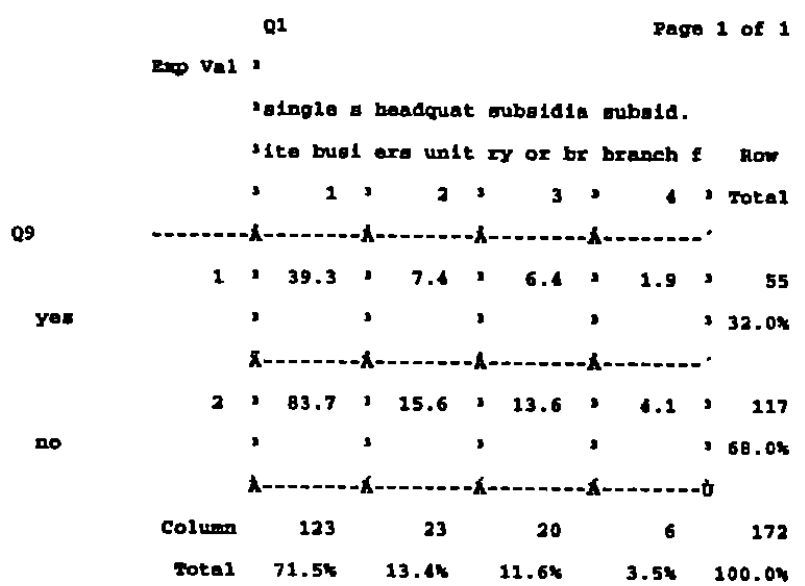

\begin{tabular}{|c|c|c|c|}
\hline Page 7 & BPBg/PC+ & & $6 / 21 / 9$ \\
\hline Cht-square & value & DP & Biondficanc \\
\hline - & 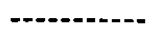 & --- & 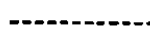 \\
\hline Pearaon & 14.74557 & 3 & .00205 \\
\hline Likel lhood Ratio & 16.14719 & 3 & .00271 \\
\hline Hantel-Heenazel teat for & 12.59683 & 1 & .00039 \\
\hline
\end{tabular}

sintmus enpectod rropuency - 1.919

Cella wh Expeoted Frequency < 5 - 2 or 8 (25.0\%)

thuber of Misaing Observatione, 6

Q9 ablo to ituplament 7750 p by 02 amoloyous

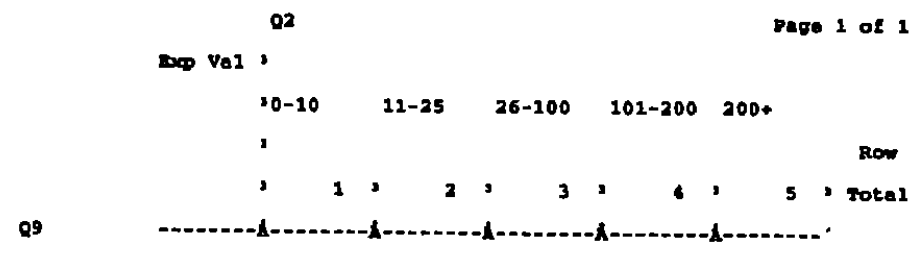




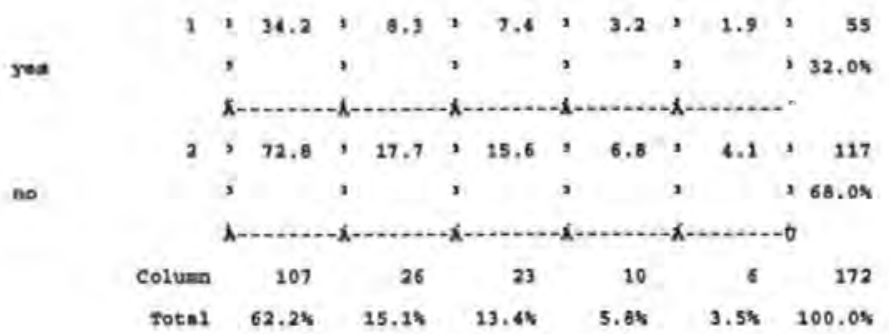

\section{Pags 9 \\ chi-square}

Panareon

Like1 thood ratio

Mante1-Rsensazel teat for Ilnear anmociation

$\begin{array}{lcr}\begin{array}{l}\text { Spss/PCt } \\ \text { Volue }\end{array} & \text { DF } & \begin{array}{r}6 / 21 / 94 \\ \text { significance }\end{array} \\ 21.79774 & 4 & .00022 \\ 20.96260 & 4 & .00032 \\ 15.40228 & 1 & .00009\end{array}$

Minimua Expected Frequency - 1.919

Cells with Expected prequency $<5-3$ of 10 (30.0x)

Mumber of winsing observations: 6

$\begin{array}{lll}\text { Page } 10 & \text { SPgS/PC+ } & 6 / 21 / 94\end{array}$

Q9 able to 1 mplesent 77507 by Q3 buniness sector

Q3 Page 1 of 1

Lxp val,

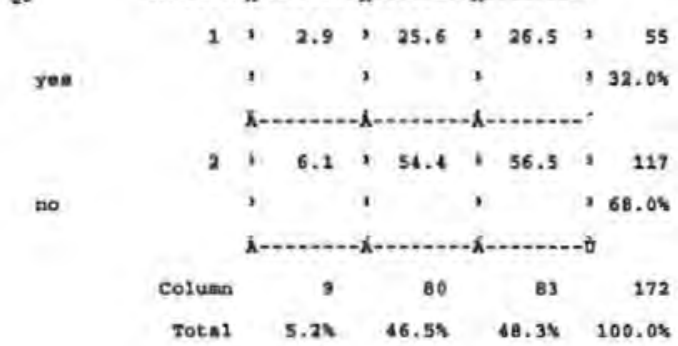

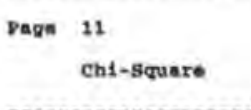

Pearson

Likel thood ratio

Mantel-Hasuzel teat for

inese asociation

iprinary socondar tertiary

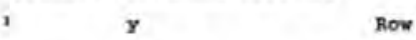

$12=3$ T Total

.04

172

$\begin{array}{lllll}\text { Total } 5.2 \mathrm{~N} & \mathbf{4 6 . 5 4} \quad 48.3 \mathrm{~N} & 100.0 \mathrm{x}\end{array}$


Minitu= Bepected Frequency - 2.678

Ce110 with expected Prequency \& S 1 or $6(16.7 \mathrm{~V})$

Number of Miseing Obeervationat 6

Page 12

sPss/PC+

$6 / 21 / 94$

Q9 able to itaplement 77502 by of company age

06

Page 1 of 2

$\operatorname{Exp}$ vel 3

sunder 1 1-5 year 6-10 yea 11-50 ye 50 years

syear a th ara bou

09

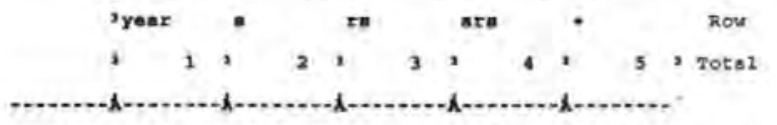

yes

$1, .6,6.7,13.8,25.9,8.0,55$

2 I 2 , 32.04

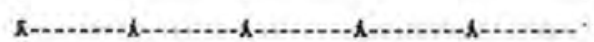

$2+1.4,14.3,29.3,55.1,17.0,117$

no
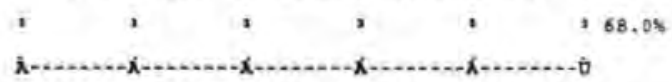

$\begin{array}{lllllll}\text { Columen } & 2 & 21 & 43 & \text { 81 } & 25 & 172\end{array}$

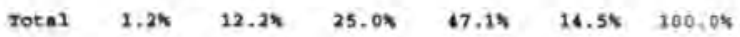

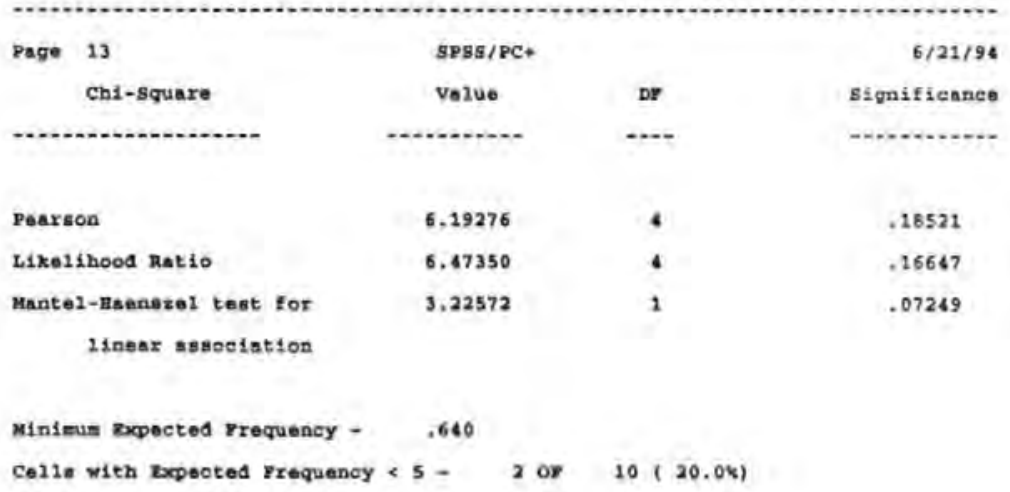

Number of Misaing Obeervations: 6

Page 14

SPSs/PC+

$6 / 21 / 94$

Q9 able to implement 7750 ? by Q5 export/non exportare

Q5 Page 1 of 1

Exp $V_{A 1}$,

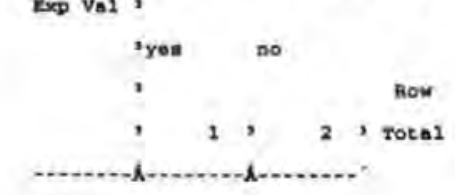




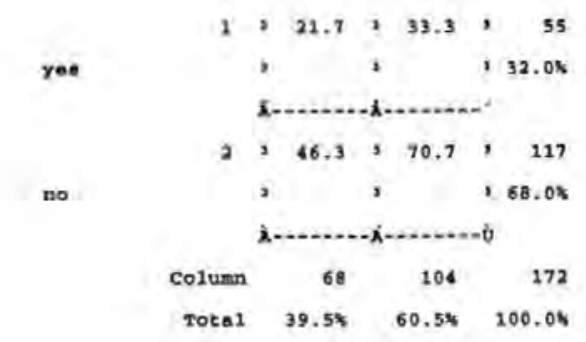

\section{Page 15 \\ Ch1-8quare}

\section{Pearson}

Continuity Correction

Like1ihood rat 10

Mantel-Haenszel tent for

Iinear ammoetation

\begin{tabular}{ccc}
$\begin{array}{c}\text { SPSS/PC+ } \\
\text { Value }\end{array}$ & $\mathrm{DE}$ & $\begin{array}{r}6 / 21 / 96 \\
\text { Significanon }\end{array}$ \\
\hline 16.79495 & 1 & .00004 \\
15.65254 & 1 & .00008 \\
16.67890 & 1 & .00004 \\
16.69731 & 1 & .00004
\end{tabular}

Minimum Expected Procriency - 21.744

Number of Misaing Obaervationst 6

$\begin{array}{lll}\text { Page } 16 & \text { SPSS/PC. } & 6 / 21 / 94\end{array}$

Q9 ab1e to implemant 7750 ? by $Q 20$ devon/cornwall

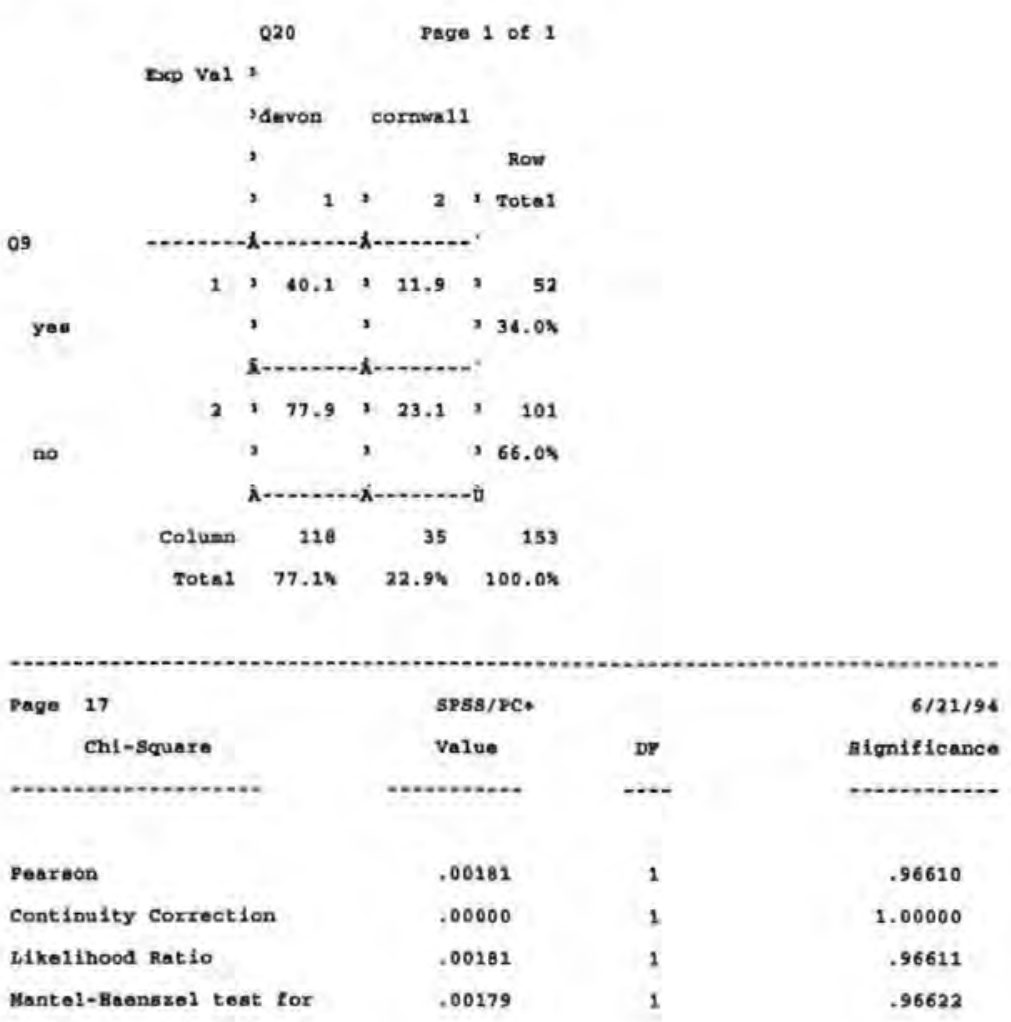




\section{2inear aseocistion}

Minimue Expected Frequency - 11.095

Mumber of Miseing obaervations: 25

Page 18

SPSS/PC+

$6 / 21 / 94$

Q10 willing to impleant $7750 ?$ by Q1 business typo

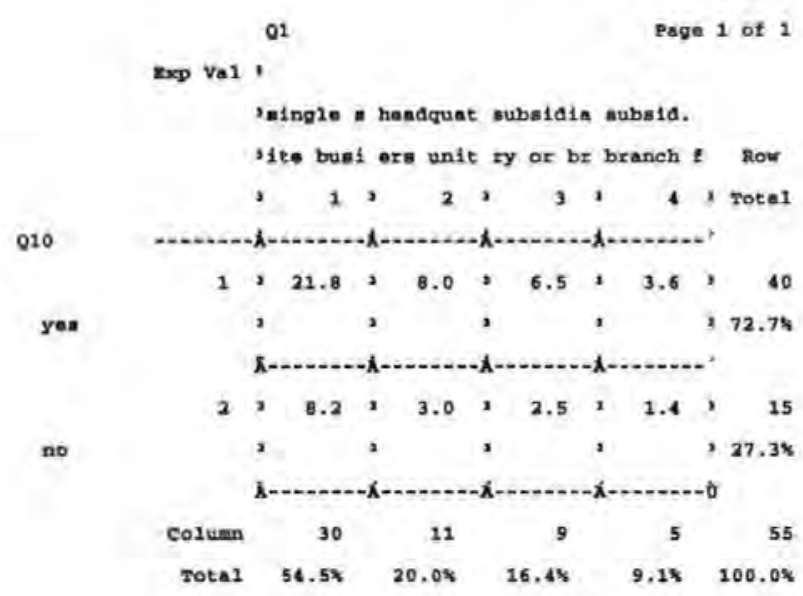

Page 19

SPgS/PC+

Value

Ch1-Sguaxe

\section{Pearson}

Like11hood RAt10

Mantel-Haonasel teat for

Ifnear aasociation

Minimua Expected Frequency - 1,364

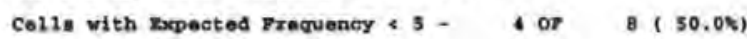

Nuabex of Miasing obaervations: 123

Page 20

SPSS/PC+

$6 / 22 / 94$

Q10 willing to implement 7750? by Q2 smployees

Q2

Page 1 of 1

Exp Val,

10-10 11-25 26-100 101-200 200 .

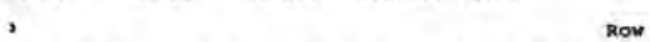

010

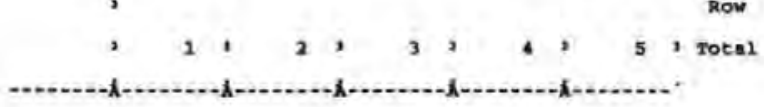




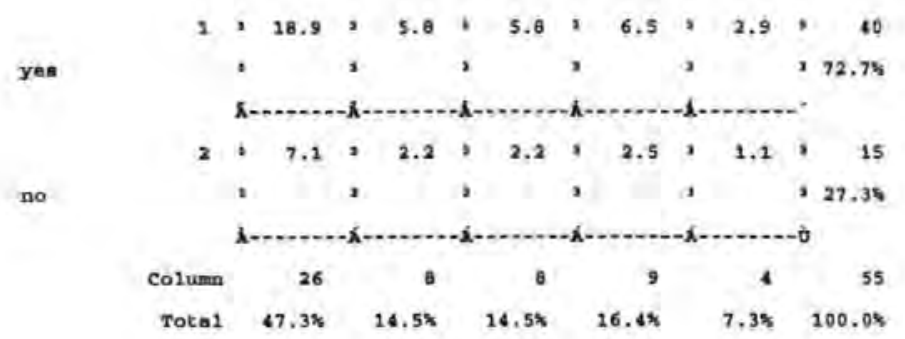

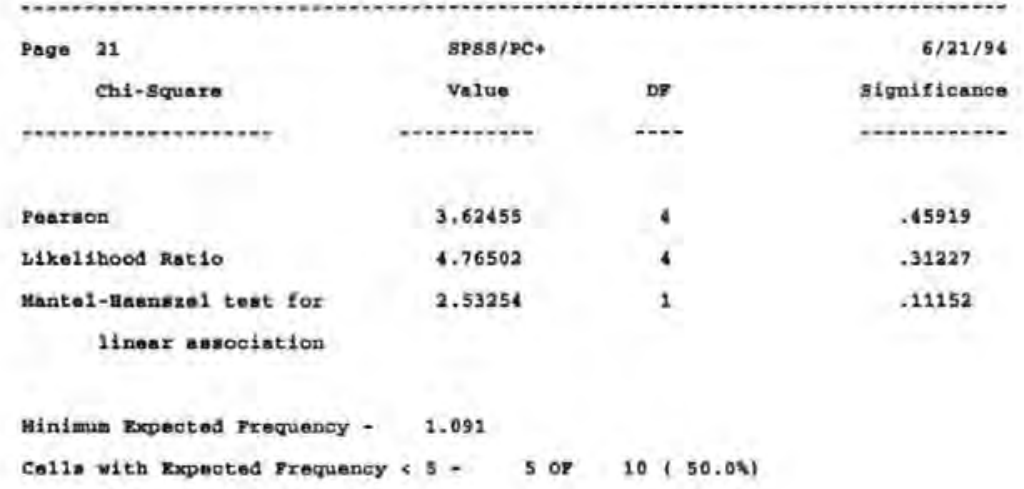

Number of viesing obeervations 123

Page $22 \quad$ SPSS/PC+ $6 / 21 / 94$

Q10 wiling to Implement 7750 by 03 business sector

Q3 Page 1 of 1

EOQ Val 2

'primary ecconasax tertsary

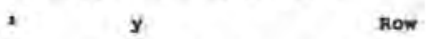

210
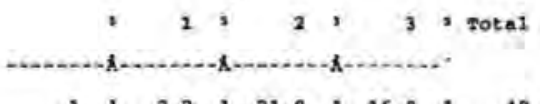

$1,2.2=21.8,26.0,40$
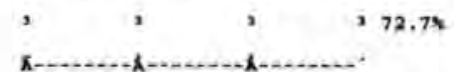

$3 \times, 8 \times 6,2,6,0,15$
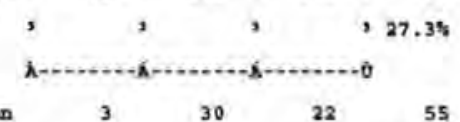

$\begin{array}{lllll}\text { Column } & 3 & 30 & 22 & 55\end{array}$

Total 5.5\% 54.5\% 40.0\% $100.0 \mathrm{~V}$

\begin{tabular}{|c|c|c|c|c|}
\hline \multirow[t]{2}{*}{ Page } & 23 & \multicolumn{2}{|l|}{ SPSS/PC+ } & $6 / 21 / 94$ \\
\hline & Chi-square & value & $\mathrm{DF}$ & signifleance \\
\hline 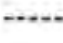 & (n) & 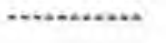 & $\cdots$ & 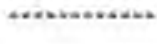 \\
\hline \multicolumn{2}{|c|}{ Poarson } & 2.58194 & 2 & .27500 \\
\hline \multicolumn{2}{|c|}{ Likelihood ratio } & 2.25856 & 2 & .32327 \\
\hline Mante & 1-Baenszel teat for & 1.27811 & 1 & .25825 \\
\hline
\end{tabular}

linesx associntion 
Minimua zxpected rrequency - .818

Cells with bxpected rrequency \& s, 2 or $6(33.34)$

number of Missing Oblervations: 123

$\begin{array}{lll}\text { Page } 24 & \text { SDSs/aC+ } & 6 / 21 / 94\end{array}$

010 wiling to implement 77508 by Q4 compeny age

Page 1 of 1

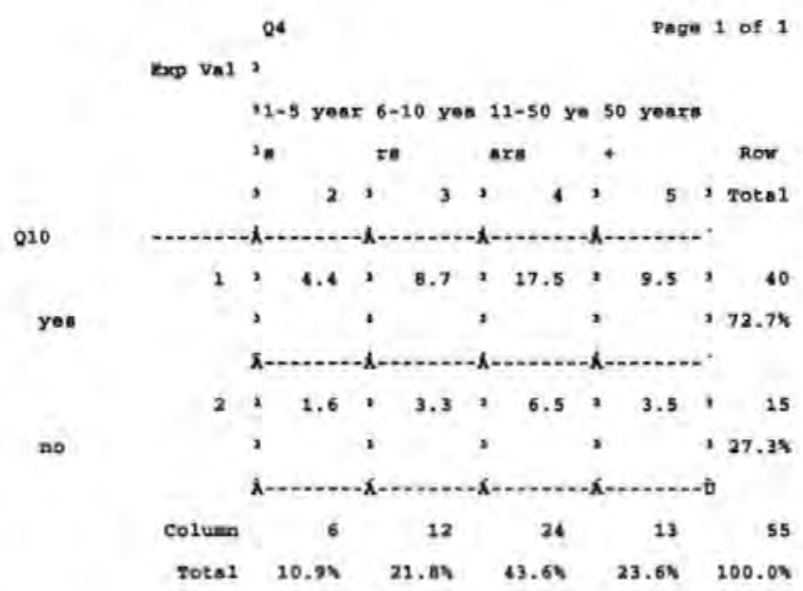

Page 25

SP95/PC.

$6 / 21 / 94$

Chi-square

Volue

DF

significance

Chi-square

Whe

\section{Pearaon}

Lika1ibood Ratio

Mantel-Haenmzel test for

$\begin{array}{rl}4.87420 & 3 \\ 6.43907 & 3 \\ .00000 & 1\end{array}$

Minimun Expected Frequency - 1.636

Ce110 with Expoctod Froguency \& 5 , or 8 (50.0 $)$

Mumber of Miasing Observations: 123

Page $26 \quad$ SPss/PC+ $6 / 21 / 94$

Q10 willing to teplaesent 7750 r by Q5 export/non expottera

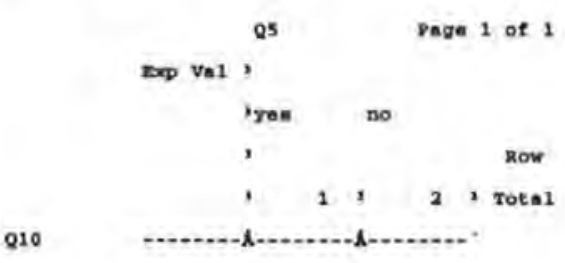




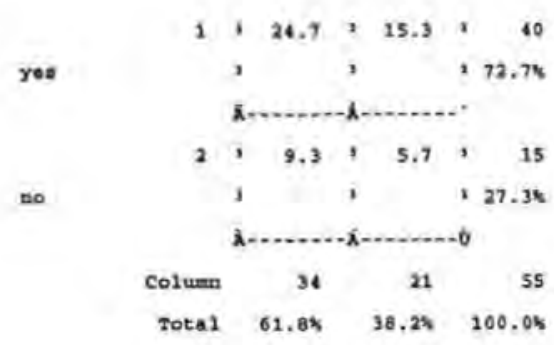

\begin{tabular}{|c|c|c|c|}
\hline Dage 27 & spss/PC+ & & $6 / 22 / 94$ \\
\hline Chi-square & value & $D F$ & significance \\
\hline cascon & 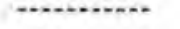 & $\cdots$ & - \\
\hline Penraon & .02889 & 1 & .86504 \\
\hline Continuity Correction & .00000 & 1 & 1.00000 \\
\hline Liko2 ihood Ratio & .02879 & 1 & .06527 \\
\hline $\begin{array}{r}\text { Kante1-Baenszel teat for } \\
\text { linear asmociation }\end{array}$ & .02836 & 1 & .86626 \\
\hline
\end{tabular}

Humber of Minking Observations: 123

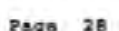

spss/FC+

$6 / 21 / 94$

Q10 wising to inplement 77507 by Q20 devon/cormali

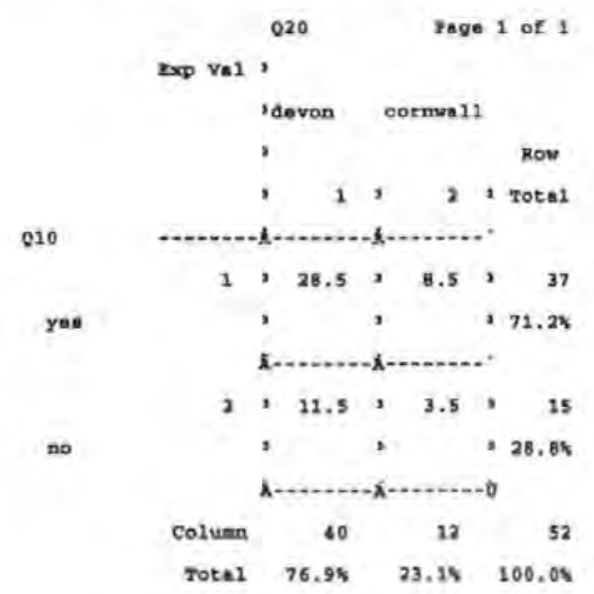

Page 29

SPSS/PC+

$8 / 21 / 94$

chl-square

Value

signiesicance

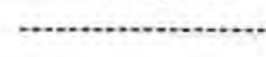

pearson

Continuity Correction

Likelihood ratio

1.12745 
Iingar manociation

pisher's exact rest:

One-Tail -24836

Tro-zail $\quad .47038$

Minlaum sepected rrequency - 3.462

Cell. with Expected Frequency \& $5-1$ OP 4 (25.05)

page $30 \quad$ spsg/pet

Mumber of Missing obaervations: 226

$\begin{array}{lll}\text { Page } 31 & \text { sps3/8Ct } & 6 / 21 / 96\end{array}$

This procedure was completed at $22,58,22$

Page 32

SPSB/PC+

$6 / 21 / 94$

PROCESS IF $(Q 1$ \& 1$)$.

FREQUENCTES Q1 Q2 q3 Q4 q5 q6 q8 q20,

Mamory allows a total of 11474 Values, accumulated across a.11 varinblea.

There also any be up to 1434 Volue Labela for each Varisbie.

busineas type

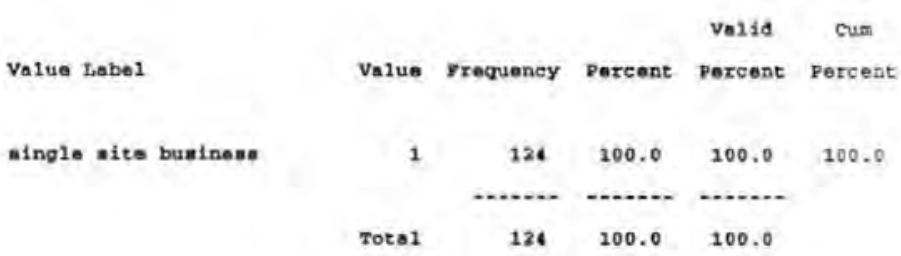

val1d coses 124 Miasing caser 0

Page ${ }_{33} \quad$ spssirct $\quad 6 / 21 / 96$

Q2 onployen.

\begin{tabular}{|c|c|c|c|c|c|}
\hline Value Label & velue & Frequency & Percent & $\begin{array}{l}\text { Valid } \\
\text { Percent }\end{array}$ & $\begin{array}{l}\text { Cum } \\
\text { Percent }\end{array}$ \\
\hline $0-10$ & 1 & 93 & 75.0 & 75,0 & 75.0 \\
\hline $22-25$ & 2 & 17 & 13.7 & 13.7 & 86.7 \\
\hline $26-100$ & 3 & 11 & 8.9 & 0.9 & 97.6 \\
\hline $101-200$ & 4 & 2 & 1.6 & 1.6 & 99.2 \\
\hline 2009 & 5 & 1 & .8 & .0 & 100.0 \\
\hline
\end{tabular}


Total $\quad 124 \quad 100.0 \quad 100.0$

Valta casas 124 Missing easas 0

rage 34

spss/PC+

$5 / 21 / 94$

03 buaines" mector

Valia cum

Volue Labe1

value prequency percent percent percent

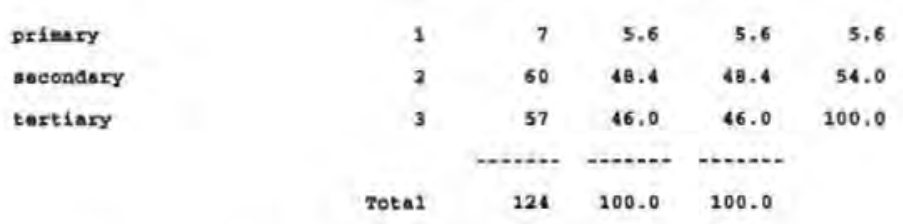

Valia easen 124 Missing eases 0

Page $15 \quad$ SPSS/PC. $6 / 21 / 94$

Q4 company age

\begin{tabular}{|c|c|c|c|c|c|}
\hline value Labet & value & Frequency & Porcent & $\begin{array}{l}\text { Valia } \\
\text { Percent }\end{array}$ & $\begin{array}{c}\text { Cum } \\
\text { Percent }\end{array}$ \\
\hline under 1 year & 1 & 2 & 1.6 & 1.6 & 1.6 \\
\hline 1-5 years & 2 & 17 & 13.7 & 13.7 & 15,3 \\
\hline $6-10$ yeare & 3 & 34 & 27.4 & 27.4 & 42.7 \\
\hline $11-50$ yeare & 4 & 60 & 48,4 & 48,4 & 91,1 \\
\hline \multirow[t]{3}{*}{50 yearat } & 5 & 11 & 8.9 & 0.9 & 100.0 \\
\hline & & atr... & nent & n....... & \\
\hline & Totel & 124 & 100.0 & 100.0 & \\
\hline
\end{tabular}

Valia eases $124 \quad$ Misming coses 0

Fage $36 \quad$ SPSB/PC.

$6 / 21 / 94$

05 export/non exportars

value Label

yea

no

Volid casen 124 Miseing cases 0 


\begin{tabular}{|c|c|c|c|c|c|}
\hline volue Label & value & Frequency & & $\begin{array}{l}\text { Valia } \\
\text { Percent }\end{array}$ & $\begin{array}{l}\text { Cun } \\
\text { Percent }\end{array}$ \\
\hline yose & 1 & 10 & 8.1 & 6.2 & 8.1 \\
\hline \multirow[t]{3}{*}{ no } & 2 & 114 & 91.9 & 91.9 & 100.0 \\
\hline & & ......... & (n...ent. & morte & \\
\hline & Tota 1 & 124 & 100.0 & 100.0 & \\
\hline
\end{tabular}

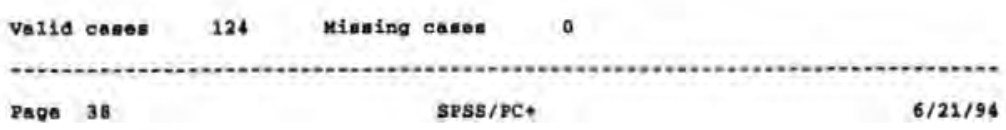

Q8 inplesented the atandard

\begin{tabular}{|c|c|c|c|c|c|}
\hline Volus Label & value & Frequency & Percent & $\begin{array}{l}\text { Velid } \\
\text { Percent }\end{array}$ & $\begin{array}{c}\text { Cum } \\
\text { Porcent }\end{array}$ \\
\hline yes & 1 & 1 & 6 & 8 & .8 \\
\hline \multirow[t]{3}{*}{ no } & 2 & 123 & 99.2 & 99.2 & 100.0 \\
\hline & & n......... & n........ & ......... & \\
\hline & Total & 124 & 200.0 & 100.0 & \\
\hline
\end{tabular}

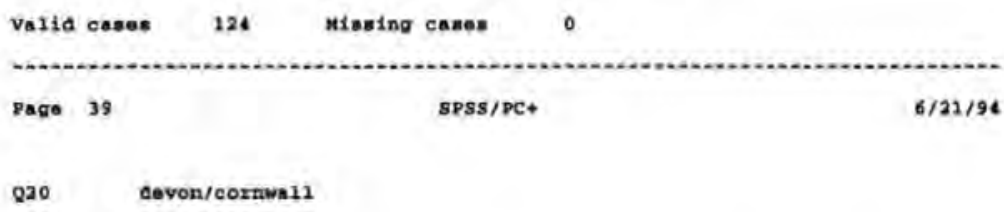

\begin{tabular}{|c|c|c|c|c|c|}
\hline Yalue Label & volue & Preguancy & Dercant & $\begin{array}{c}\text { Valid } \\
\text { parcent }\end{array}$ & $\begin{array}{c}\text { Cu= } \\
\text { parcent }\end{array}$ \\
\hline devon & 1 & 89 & 71.6 & 78.6 & 78,8 \\
\hline \multirow[t]{3}{*}{ eormmali } & 2 & 24 & 19.4 & 21.2 & 100.0 \\
\hline & $\rightarrow$ & 11 & 6,9 & Mineing & \\
\hline & Total 1 & 126 & 100.0 & 100.0 & \\
\hline
\end{tabular}

valla casas $113 \quad$ Miasing cabse 11

Page 40

SPss/PC+

$6 / 21 / 94$

This procedure was coepleted at 13:00:03

Page 41

spss/pC.

$6 / 21 / 94$

process IF (q1 Qq 2).

Farouracies q1 q2 q3 q4 q5 q6 q8 q20. 
.... Menory s1lows a total of 12474 valuev, eccumulated across all variables. There also eay be up to 2434 value tabele tor ench variable.

Q1 bunineas type

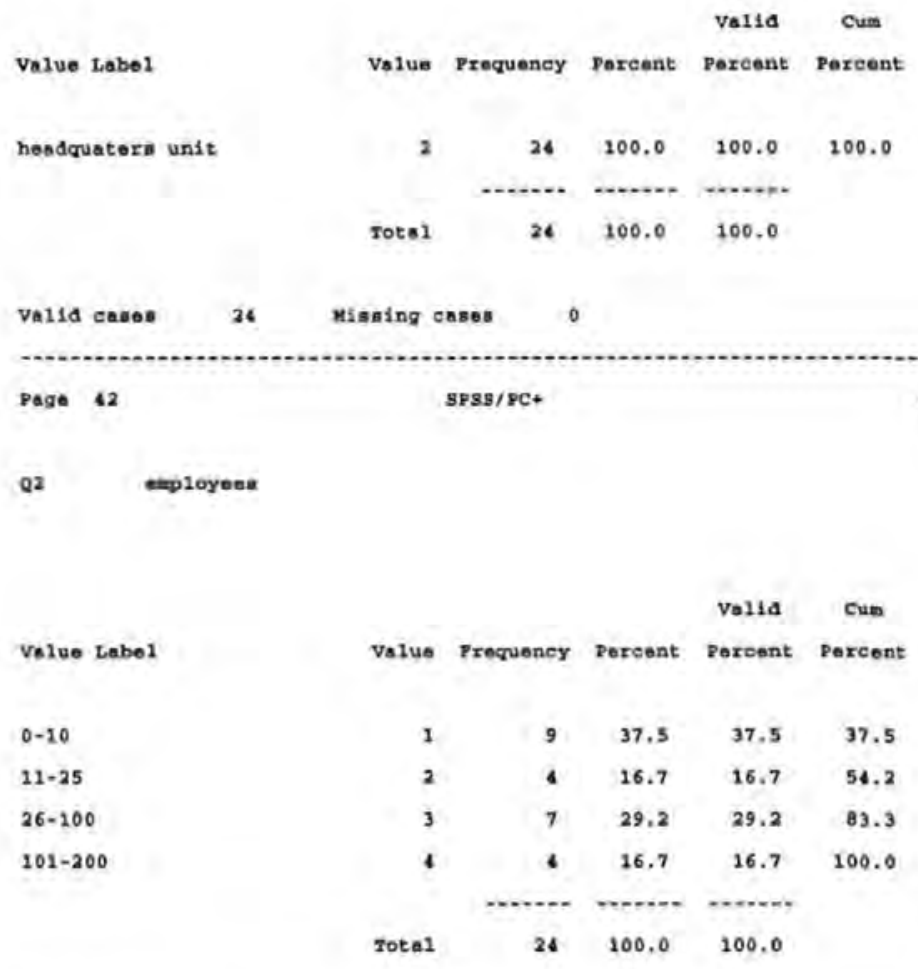

valia cabes 24 Missing cased 0

Page $43 \quad$ SPBS/PC. $6 / 21194$

Q3 butinans sector

\begin{tabular}{|c|c|c|c|c|c|}
\hline \multirow[b]{2}{*}{ Value Label } & \multirow[b]{2}{*}{ velue } & \multirow[b]{2}{*}{ rrequency } & \multirow[b]{2}{*}{ Dercent } & \multirow{2}{*}{$\begin{array}{l}\text { Valid } \\
\text { Porcent }\end{array}$} & \multirow{2}{*}{$\begin{array}{c}\text { Cum } \\
\text { Percent }\end{array}$} \\
\hline & & & & & \\
\hline primary & 1 & 2 & B.3 & 8.3 & 8.3 \\
\hline ascondary & 2 & 9 & 37,5 & 37.5 & 45.8 \\
\hline tertiary & 3 & 13 & 54.2 & 54.2 & 100.0 \\
\hline & Tota 1 & 24 & 100.0 & 100.0 & \\
\hline
\end{tabular}

Volid cases 24 Misking cases 0

Page 44
SPSE/PC*

$6 / 21 / 94$ 


\begin{tabular}{|c|c|c|c|c|c|}
\hline Vnlue tobse & Value & Frequency & Percent & $\begin{array}{c}\text { Valid } \\
\text { Percent }\end{array}$ & $\begin{array}{c}\text { Cum } \\
\text { Percent }\end{array}$ \\
\hline 1-5 yeara & 2 & 5 & 20.8 & 20.8 & 20.8 \\
\hline $6-10$ yekrs & 3 & 6 & 25.0 & 25.0 & 45.8 \\
\hline $11-50$ yeare & 4 & 10 & 41.7 & 41.7 & 87.5 \\
\hline 50 yesret & 5 & 3 & 12,5 & 12.5 & 100,0 \\
\hline
\end{tabular}

Valid canas 24 Misaing cassa 0

Pago $45 \quad$ SPss/PC+ $6 / 21 / 94$

Q5 export/non nxporters

\begin{tabular}{|c|c|c|c|c|c|}
\hline falue tabel & value & Yraquency & Porcant & $\begin{array}{l}\text { Valid } \\
\text { Percent }\end{array}$ & $\begin{array}{c}\text { Cum } \\
\text { Percent }\end{array}$ \\
\hline & 1 & 8 & 33.3 & 33.3 & 33.3 \\
\hline & 2 & 16 & 66.7 & 66.7 & 100.0 \\
\hline & Total & 24 & 100.0 & 100.0 & \\
\hline
\end{tabular}

Valid casea 24 Missing cases 0

Page 46

spss/PC+

$6 / 22 / 94$

Q6 otrategic man policy

Value Label

yos

no velia cus

valun prequency percent percent percent

$\begin{array}{rrrrr}1 & 4 & 16.7 & 16.7 & 16.7 \\ 2 & 20 & 83.3 & 83.3 & 100.0 \\ & \ldots \ldots & \ldots . .2 & \ldots . .1 . . & \\ \text { Total } & 26 & 100.0 & 100.0 & \end{array}$

valid caser 24 Missing caser 0

page 47

spss/PC+

$6 / 21 / 94$

08 inplanented the atanased

valid cus

value Labe 1

Volue rregiency percent percent porcent

yos

$\begin{array}{llll}4.2 & 4.2 & 4.2\end{array}$ 


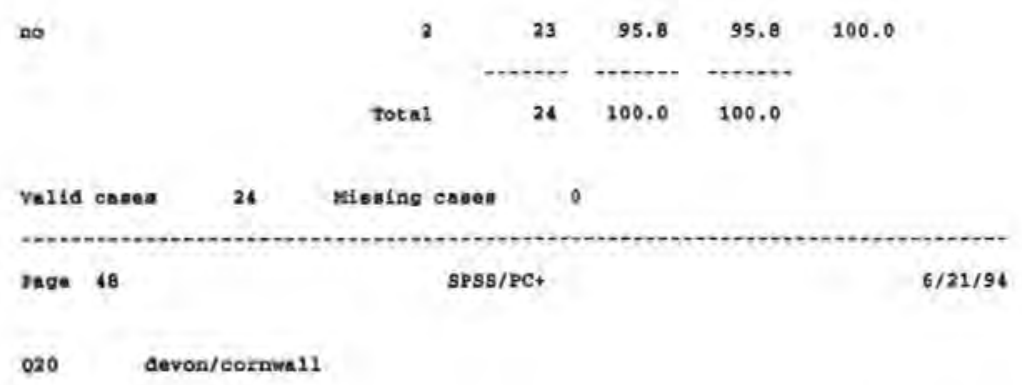

\begin{tabular}{|c|c|c|c|c|c|}
\hline Volue Label & Value & Frequancy & Dercent & $\begin{array}{c}\text { Valid } \\
\text { Parcent }\end{array}$ & $\begin{array}{c}\text { Cum } \\
\text { Percent }\end{array}$ \\
\hline devon & 1 & 13 & 54.2 & 72.2 & 72.2 \\
\hline \multirow[t]{3}{*}{ cornual1 } & 2 & 5 & 20.8 & 27.8 & 100.0 \\
\hline & , & 6 & 25.0 & Misosing & \\
\hline & Total & 24 & 100,0 & 100.0 & \\
\hline
\end{tabular}

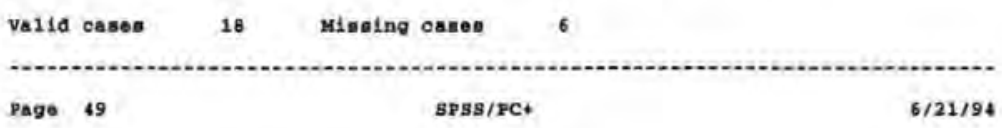

This procedure was completed at 13:00:17

Poge 50

BPSS/FC+

$6 / 21 / 94$

PRocrss If (q2 oq 1$)$.

Fergugactes q2 q2 q3 q4 q5 q6 q6 q20,

..... Mesory allows a totol of 11474 valuen, accumuleted acrosa all variables. There also may be up to 1434 value labele for each variable.

Pnge 51

spss/PC+

$6 / 21 / 94$

a businesa type

velue Labe?

single site büineas nesdquatere unit mubalainxy or branch subsid, brench foroi

Valla casea $\quad 109$ Misaing cases $\quad$ valld cus

value rxequency Fureent parcent pareent

$\begin{array}{rrrrr}1 & 93 & 85.3 & 85.3 & 85.3 \\ 2 & 9 & 8.3 & 8.3 & 93.6 \\ 3 & 6 & 5.5 & 5.5 & 99.1 \\ 6 & 1 & .9 & .9 & 100.0 \\ & \ldots .7 & & \\ \text { Total } & 109 & 100.0 & 100.0 & \end{array}$




\begin{tabular}{|c|c|c|c|c|c|}
\hline \multirow[b]{2}{*}{ Value tabel } & \multirow[b]{2}{*}{ Value } & \multirow[b]{2}{*}{ Frequency } & \multirow[b]{2}{*}{ Percent } & \multirow{2}{*}{$\begin{array}{l}\text { Val1d } \\
\text { Percent }\end{array}$} & \multirow{2}{*}{$\begin{array}{l}\text { Cum } \\
\text { forcent }\end{array}$} \\
\hline & & & & & \\
\hline $0-10$ & 1 & 109 & 100.0 & 100.0 & 100.0 \\
\hline & Tote 1 & 109 & 100.0 & 100.0 & \\
\hline
\end{tabular}

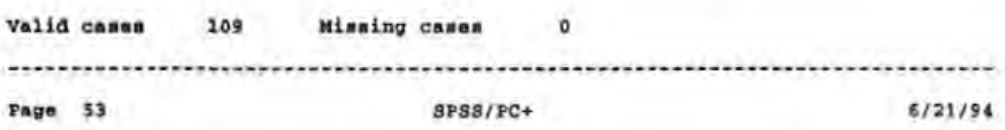

Q3 business nector

\begin{tabular}{|c|c|c|c|c|c|}
\hline \multirow[b]{2}{*}{ Volue Labal } & \multirow[b]{2}{*}{ value } & \multirow[b]{2}{*}{ rrequency } & \multirow[b]{2}{*}{ Percent } & Va114 & \multirow{2}{*}{$\begin{array}{c}\text { Cum } \\
\text { Percent }\end{array}$} \\
\hline & & & & Percent & \\
\hline priascy & 1 & 6 & 5.5 & 5.5 & 5.5 \\
\hline secondary & 2 & 46 & 42.2 & 42.2 & 47.7 \\
\hline tertiory & 1 & 57 & 52.3 & 52.3 & 100.0 \\
\hline & Total & 109 & 100.0 & 100.0 & \\
\hline
\end{tabular}

valid caken $109 \quad$ Miseing osses 0

Page $54 \quad$ SPss/PC+ $6 / 21 / 94$

Qt comany age

value tabel

valid curs

under 1 year

1-5 yeare

$5 \rightarrow 10$ yenra

$11-50$ years

50 years+

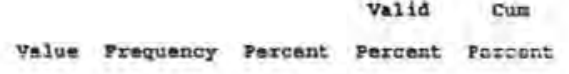

$\begin{array}{rrrrr}1 & 2 & 1, \theta & 1,6 & 1.8 \\ 2 & 17 & 15,6 & 15.6 & 17.4 \\ 3 & 34 & 31.2 & 31.2 & 48.6 \\ 4 & 46 & 44.0 & 44.0 & 92.7 \\ 5 & 6 & 7.3 & 7.3 & 100.0 \\ & \ldots \ldots y & & \end{array}$

Valid casen 109 Missing cases

$\begin{array}{lll}\text { Page } 55 & \text { SPSB/PC+ } & 6 / 21 / 94\end{array}$

Q5 export/non exporters 


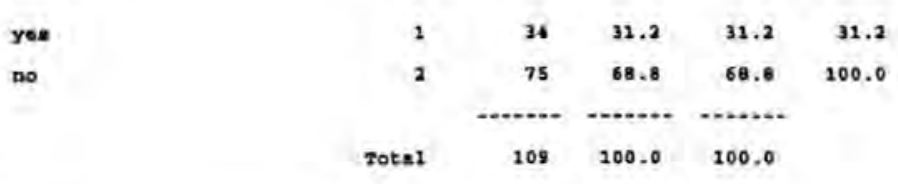

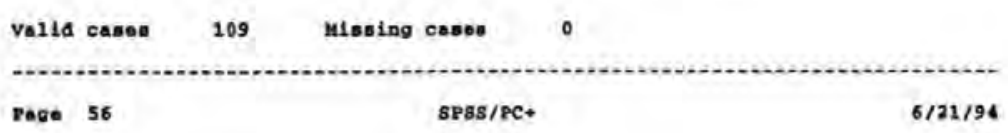

Q6 atrategic wan policy

\begin{tabular}{|c|c|c|c|c|c|}
\hline \multirow[b]{2}{*}{ Value Label } & \multirow[b]{2}{*}{ value } & \multirow[b]{2}{*}{ Yroguency } & \multirow[b]{2}{*}{ Percent } & \multirow{2}{*}{$\begin{array}{l}\text { Valia } \\
\text { Parcent }\end{array}$} & \multirow{2}{*}{$\begin{array}{c}\text { cum } \\
\text { Percent }\end{array}$} \\
\hline & & & & & \\
\hline yax & 2 & 10 & 9.2 & 9.2 & 9.2 \\
\hline no & 2 & 99 & 90,8 & 90.8 & 100,0 \\
\hline & Total & 109 & 100.0 & 100.0 & \\
\hline
\end{tabular}

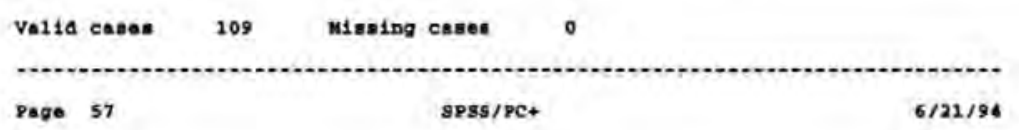

Q8 Iaplemented the etandsra

\begin{tabular}{|c|c|c|c|c|c|c|c|}
\hline Value & 2abel & & Valua & Procqueney & Perebnt & $\begin{array}{c}\text { Valid } \\
\text { Percent }\end{array}$ & $\begin{array}{c}\text { Cum } \\
\text { Percent }\end{array}$ \\
\hline yes & & & 1 & 2 & 1.0 & 1,6 & 1.0 \\
\hline \multirow[t]{3}{*}{ no } & & & a & 107 & 98.2 & 98.2 & 100.0 \\
\hline & & & & n........ & - n...... & .......... & \\
\hline & & & Total & 109 & 100.0 & 100.0 & \\
\hline valla & casere & 209 & Miseing & ceres & & & \\
\hline page & so & & & GPSS/PC+ & & & \\
\hline 820 & do & /corr & & & & & \\
\hline
\end{tabular}

\begin{tabular}{|c|c|c|c|c|c|}
\hline Volue Iabel & value & prequency & Percent & $\begin{array}{l}\text { Volld } \\
\text { Percent }\end{array}$ & $\begin{array}{c}\text { Cum } \\
\text { Pereont }\end{array}$ \\
\hline abven & 1 & 75 & 58.8 & 75.1 & 75.8 \\
\hline \multirow[t]{4}{*}{ cormwa11 } & 2 & 24 & 22.0 & 24,2 & 200.0 \\
\hline & • & 10 & 9.2 & Miosing & \\
\hline & & nenter & - & nenter & \\
\hline & Total & 109 & 100.0 & 100.0 & \\
\hline
\end{tabular}

vaj1d casea 99 Migsing casas 10 
Thie procedure wan conpleted at 13:00:46

process IF (ca oq 2).

mrounacizs q1 d2 a3 q4 q5 q6 q8 d20.

.... Menory allowa a total of 11474 values, accumulated scrose all variables. There also may be up to 1434 Value Labele for oach variablo.

$\begin{array}{lll}\text { Page } 61 & \text { SPSS/PC+ } & 6 / 21 / 94\end{array}$

Q1 buineas tyoe

\begin{tabular}{|c|c|c|c|c|c|}
\hline Value Labe1 & Value & Prequancy & Percent & $\begin{array}{l}\text { valid } \\
\text { Percent }\end{array}$ & $\begin{array}{c}\text { Cun } \\
\text { Percent }\end{array}$ \\
\hline single site buninese & 1 & 17 & 60.7 & 60.7 & 60.7 \\
\hline headquaterm unit & 2 & 4 & 24.3 & 24.3 & 75,0 \\
\hline aubldiary or branch & 3 & 7 & 25.0 & 25.0 & 100.0 \\
\hline & Total & 28 & 100.0 & 100.0 & \\
\hline
\end{tabular}

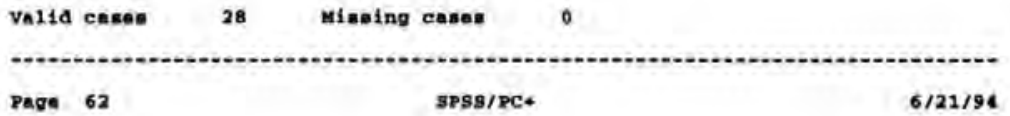

Q2 ployes:

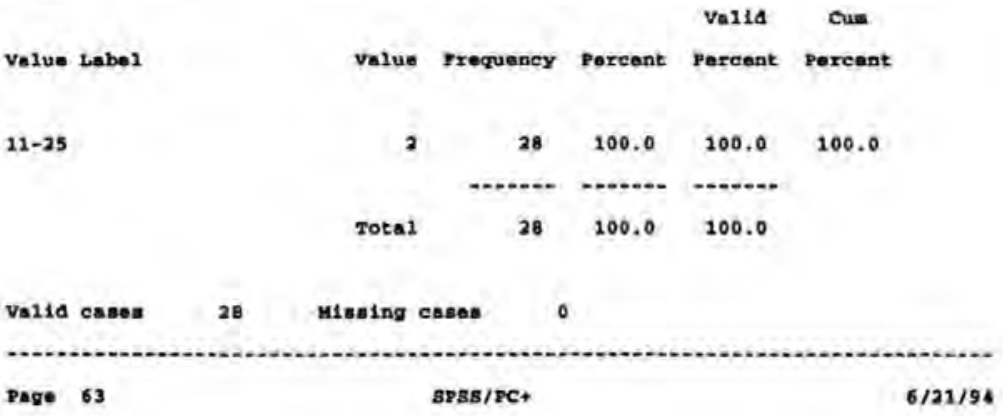

Q3 business sector

Value Label

primary

ancondary
Vaild Cum

value rrequency percent percent porcent

$\begin{array}{rrrrr}1 & 2 & 7.1 & 7.1 & 7.1 \\ 2 & 16 & 57.1 & 57.1 & 64.3\end{array}$




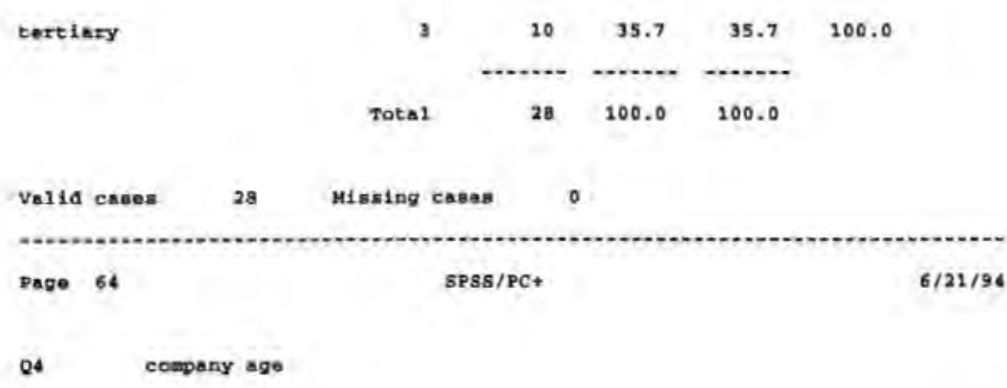

\begin{tabular}{|c|c|c|c|c|c|}
\hline Value Label & value & Prequency & Percent & $\begin{array}{l}\text { Varid } \\
\text { Porcent }\end{array}$ & $\begin{array}{c}\text { Cum } \\
\text { Percent }\end{array}$ \\
\hline $1-5$ years & 2 & 2 & 7.1 & 7.1 & 7.1 \\
\hline $6-10$ yoars & 3 & 4 & 14.3 & 14,3 & 21.4 \\
\hline 11-50 renr: & 4 & 18 & 64.3 & 64.3 & 65.7 \\
\hline 50 yesrest & 5 & 4 & 14.3 & 24,3 & 100.0 \\
\hline & Total & 28 & 100,0 & 100.0 & \\
\hline
\end{tabular}

Valia enses $28 \quad$ Misaing casea $\quad 0$

$\begin{array}{lll}\text { Page } 65 & \text { SPsS/PC+ } & 6 / 21 / 94\end{array}$

Q5 export/non exportera

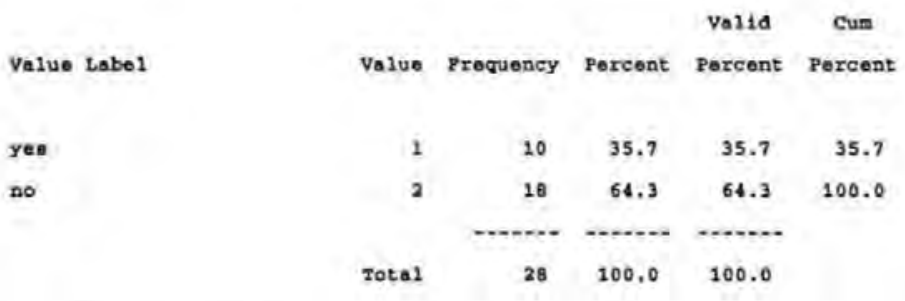

Valld casas $26 \quad$ Missing canes 0

(2.

Page 66

$6 / 21 / 94$

Q6 atrategic man po11ey

volue Labe1

yea

no
Valid cum

Value frequency percent percent percent

\begin{tabular}{|c|c|c|c|c|}
\hline 1 & 3 & 10.7 & 10.7 & 10.7 \\
\hline 2 & 25 & 89,3 & 89,3 & 100.0 \\
\hline & 28 & 100.0 & 100.0 & \\
\hline
\end{tabular}

valid cames 28 Misming casea 0 


\begin{tabular}{|c|c|c|c|c|c|}
\hline value Label & volue & Preguency & Percent & $\begin{array}{l}\text { Valid } \\
\text { porcent }\end{array}$ & $\begin{array}{c}\text { Cum } \\
\text { Percent }\end{array}$ \\
\hline yea & 1 & 2 & 7.1 & 7,1 & 7.1 \\
\hline no & 2 & 26 & 92.9 & 92.9 & 100.0 \\
\hline & Tota1 & 28 & 100.0 & 100.0 & \\
\hline
\end{tabular}

\begin{tabular}{llcl} 
valid canes & $28 \quad$ Misoing caser 0 & \\
\hline Page 68 & SPSs/PC+ & $6 / 21 / 94$
\end{tabular}

Q20 devon/cornwall

\begin{tabular}{|c|c|c|c|c|c|}
\hline \multirow[b]{2}{*}{ Value Label } & \multirow[b]{2}{*}{ Value } & \multirow[b]{2}{*}{ Frequency } & \multicolumn{2}{|r|}{ valid } & Cum \\
\hline & & & Percent & Percent & Percent \\
\hline devon & 1 & 20 & 71.4 & 80.0 & 80.0 \\
\hline \multirow[t]{3}{*}{ cornvell } & 2 & 5 & 17.9 & 20.0 & 100.0 \\
\hline & . & 3 & 10.7 & Missing & \\
\hline & Tote1 & 28 & 100.0 & 200.0 & \\
\hline
\end{tabular}

\begin{tabular}{l|ccc} 
Valid cases & 25 & Missing casos 3 & \\
\hline Page 69 & SPsB/PC+ & $6 / 21 / 96$
\end{tabular}

Thia procedure was conpleted at 13:01:03

\begin{tabular}{|c|c|c|}
\hline Paga 70 & arsa/pet & $6 / 22 / 94$ \\
\hline
\end{tabular}

End of Include tile. 
musova $q 13$ by $q^{3}(1,3)$ /print cellinfo-

nore 22167

The lant subeomend 1 n not a design specification-- $\mathrm{f}$ full factoriol bodel

is generated for this problem.

176 cases scoptod.

o cans rejected because of out-of-range factor values:

1 cases rejocted becsuse of mineing dace.

3 non-empty ce11s.

1 denign wili be processed.

Cell Heann and standard Devintions

variabla ... 813

PACTOR CODE Man std. Dey, N

$\begin{array}{lllll}\text { Q3 } & \text { primary } & 3.100 & 1.449 & 10 \\ 93 & \text { secondar } & 3.143 & 1.184 & 84 \\ \text { Q3 } & \text { tertiory } & 3.122 & 1.231 & 82 \\ \text { Yor entiro atogle } & 3.131 & 1.214 & 176\end{array}$

Page 19

SPSB/PC+

$2 / 27 / 94$

- andiysts of variance -- destan 1 .

Ce11 Meane and standnrd Deviationa (Cowr.)

Teste of significance for Q13 uging ontQde gums of Bquares

Source of variation

ss

py Ms

$F$ sid of $p$

WITAIM CELLS

$257.97 \quad 173 \quad 1.49$

COASTANT

Q3

$\begin{array}{rrrrr}706.69 & 1 & 706.69 & 473.93 & .000 \\ .03 & 2 & .01 & .01 & .991\end{array}$

3592 gYYRS OF WORKSPACE MEEDED FOR MAROVA EXECDTION.

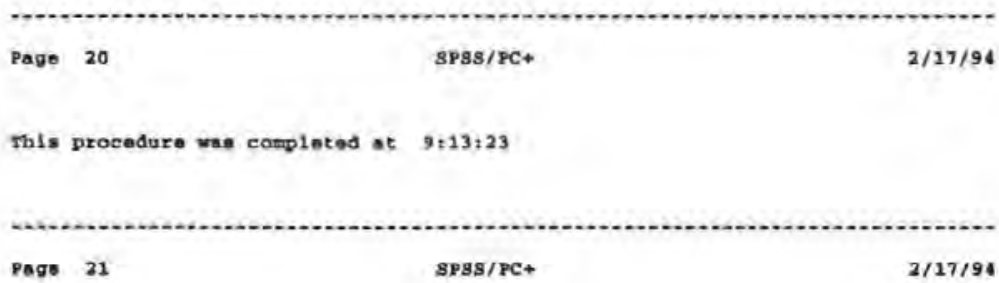

movova q1e by q3 $(1,3)$ lprint cellinfo.

morr $\quad 12167$

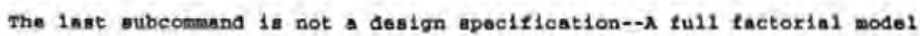

fo generated for thin probles. 
176 essor accopted.

0 cages rejected because of out-of-range foctor valuen.

1 casen rejected because of miesing data.

3 non-enpty cells.

1 Aosign w111 be procenasd.

Ea11 Meana and Btendara Deviatione

variable .. 014

epe

rucion

cons

Mosn sta, Dev.

$\begin{array}{lllll}\text { Q3 } & \text { primary } & 2.300 & 1.410 & 10 \\ \text { Q3 } & \text { secondax } & 3.131 & 1.351 & 84 \\ \text { Q3 } & \text { tertisry } & 2.634 & 1.365 & 82 \\ \text { For entire sanple } & 2.852 & 1.362 & 176\end{array}$

Vage 22

spgs/pC.

$2 / 17 / 94$

- anulysis of variance -. DEgian 1 .

Dell Means and standara Deviationa (cowr.)

Tasta of Bignifleance for Q14 using usrque sues oz hquares

Gource of variation

ss

DP

ns

7 sig of $y$

wTrkts crits

$320.68 \quad 173 \quad 1.89$

constuse

Q3

$\begin{array}{rrrrr}524.14 & 1 & 524.14 & 282.76 & .000 \\ 13.48 & 2 & 6.74 & 3.63 & .020\end{array}$

$\ldots \ldots$

3592 aYTzS OE WORKSPACE NEEUED FOR MANOVA EXECOTION.

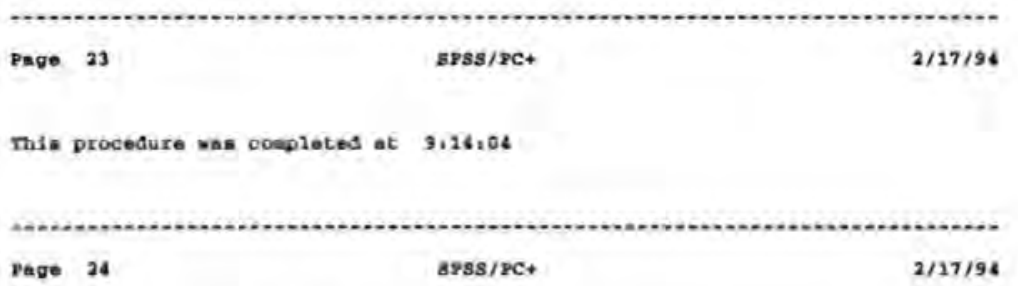

Masova $q 16 \mathrm{se}$ to $q 160$ by $q 3(1,3)$ /print colitinfo,

nOTE 22167

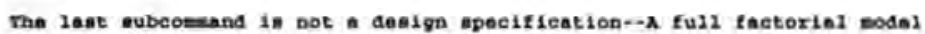

is generated for thie problea.

274 csuss scepted.

o caser rejected becauge of out-of-range tactor valuee,

3 canes rejected because of mianing anta.

3 non-espty colle. 
1 design w122 be proceasud.

Coll Meana and standard Deviationa

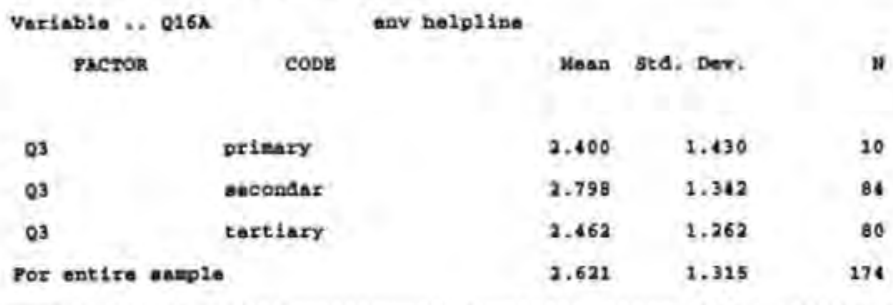

page 25

SPsS/PC+

$2 / 17 / 94$

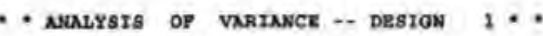

Cell means and standerd Deviations (Cowr,)

Variab10... Q16B

contidential advice

FACTOA

CODE

Mean std, Dev,

N

Q3 priasty $2.300 \quad 1.160 \quad 10$

Q3 wocondax $2.865 \quad 1.294$ 84

Q3 tertiety $2.525 \quad 1.242 \quad 00$

$\begin{array}{llll}\text { ror entire sanple } & 2.667 & 1.269 & 174\end{array}$

$\ldots . . . . .$.

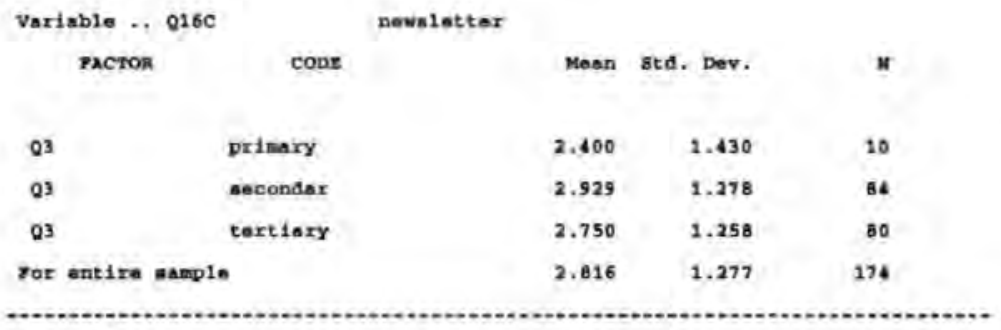

Page 26

SPSS/PC+

$2 / 27 / 94$

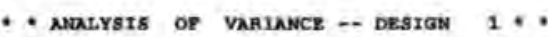

Co11 Meann and standard Deviations (CONT.)

Variable .. Q16b

handbook

pacros

cobe

Mean sta, Dev,

n

Q3 prienry

Q3) necondar

Q3 tertinry

ror ent1ro ansple

$2.300 \quad 1.337 \quad 10$

$2.093 \quad 1.317 \quad 64$

$2.738 \quad 1.230 \quad 50$

$\begin{array}{lll}2.787 & 1.279 & 174\end{array}$

Variable .. Q16E

vacror cops

env pr

Mean std. Dev,

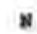

\begin{tabular}{|c|c|c|c|c|}
\hline 03 & pelasy & 2.400 & 1.506 & 10 \\
\hline Q3 & socondar & 2.583 & 1.234 & 84 \\
\hline 23 & tortiscy & 2.588 & 1.219 & 80 \\
\hline & & 2.575 & 1.237 & 174 \\
\hline
\end{tabular}


- analysis of variance -. DEstga 1 .

Cell Means and standerd Deviations (CONr.)

errect .. Q $Q^{3}$

Multivariate rasta of significance $(s=2, H=1, k=821 / 2)$

Test wame Velue Approx. 7 Hypoth. DP Errot DP sig. of $z$

$\begin{array}{llllll}\text { Pillail } & .05956 & 1.03132 & 10.00 & 336.00 & .616 \\ \text { Botallinge } & .06193 & 1.02796 & 10.00 & 332.00 & .419 \\ \text { Wilks } & .98108 & 1.02966 & 10.00 & 334.00 & .418 \\ \text { Roya } & .04564 & & & & \end{array}$

$\ldots \ldots$

Page 38

SPBS/PC+

$2 / 17 / 94$

- analysis or variahcz a- desian 1 -

errect .. 03 (CONT.)

Dnivariate $\mathbf{r}$-tests with $(2,171)$ D. $\boldsymbol{r}$.

Veriable Bypoth. SB Error 9s Bypoth, MS Brror Ms

\begin{tabular}{|c|c|c|c|c|c|}
\hline Q16 & 5.11869 & 293.86702 & $2.5592 \mathrm{~S}$ & 1.71840 & 1.48932 \\
\hline Q16s & 5.62857 & 273.03810 & 2.81429 & 1,59671 & 1.76255 \\
\hline Q16C & 3.14351 & 278.97143 & 1.57276 & 1.63141 &, 96343 \\
\hline Q16D & 3.50897 & 279.62321 & 1.75448 & 1.63522 & 1.07293 \\
\hline $016 \mathrm{z}$ & .32457 & 264.20417 & -16228 & 1.56505 & .10503 \\
\hline
\end{tabular}

$\ldots . . .$.

Page 29

spss/PC

$2 / 17 / 94$

- antalysts of vartance - Destge 1 .

EFTECT , CONSTANT

multivariate Testa of significance $(8-1, \mathrm{~K}=11 / 2, \mathrm{~N}=821 / 2$ )

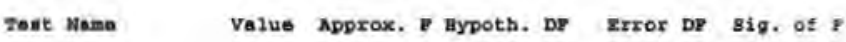

$\begin{array}{lrllll}\text { Pillals } & .68567 & 72.85903 & 5.00 & 167.00 & .000 \\ \text { Botellingh } & 2.18161 & 72.85903 & 5.00 & 167.00 & .000 \\ \text { Wilke } & .31433 & 72.85903 & 5.00 & 167.00 & .000 \\ \text { Royn } & .68567 & & & & \end{array}$

$\cdots+\cdots+\cdots$

Onivariate $\mathbf{p}$-tests with $(1,171)$ D, $\boldsymbol{F}$.

Varsable Bypoth, gs error ss Hypoth, hs zrror as 7 sig. of $p$

$\begin{array}{lllllll}\text { Q16ג } & 471.66542 & 293.84702 & 471.66542 & 1.71860 & 274.47883 & .000\end{array}$ 


\begin{tabular}{|c|c|c|c|c|c|c|}
\hline Q16B & 472.91238 & 273.03810 & 472,91238 & 1.59671 & 296,17851 & .000 \\
\hline Q16C & 524.60465 & 278.97143 & 524.60465 & 1.63141 & 321.56481 & .000 \\
\hline Q16D & 505.53181 & 279.62321 & 505.53101 & 1.63522 & 309.15151 & .000 \\
\hline Q16z & 460.73411 & 264.20417 & 460.73611 & 1.54505 & 298.19943 & .000 \\
\hline
\end{tabular}

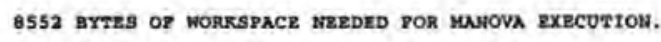

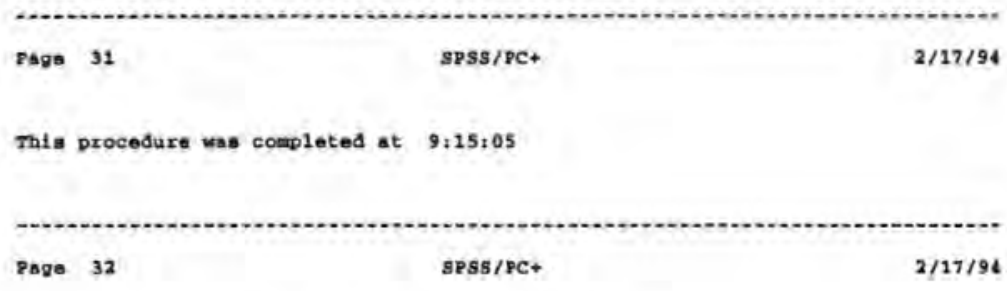

Crosstaks /TABLEs q 6 by 43 /options 14 /statiatica 1 .

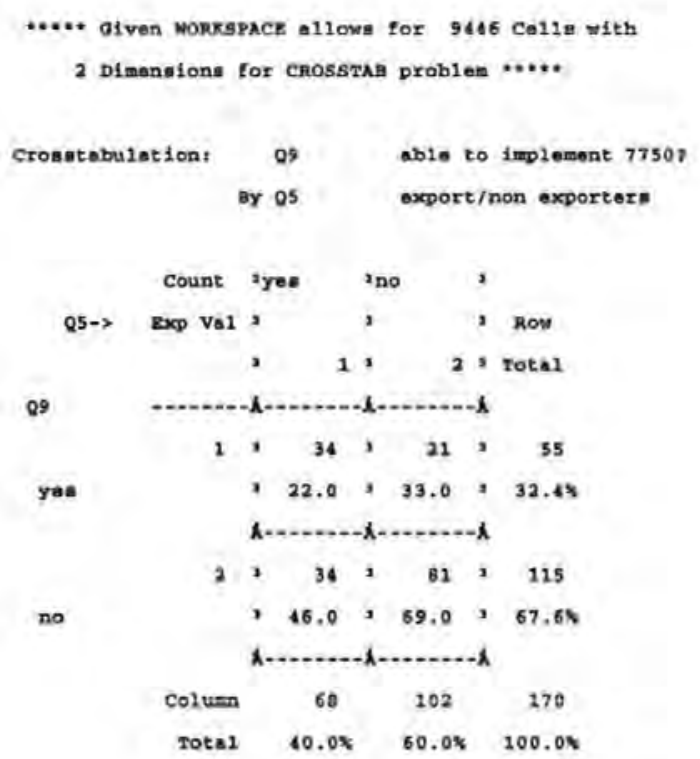

2 Dlmensions for Crosstal probles ......

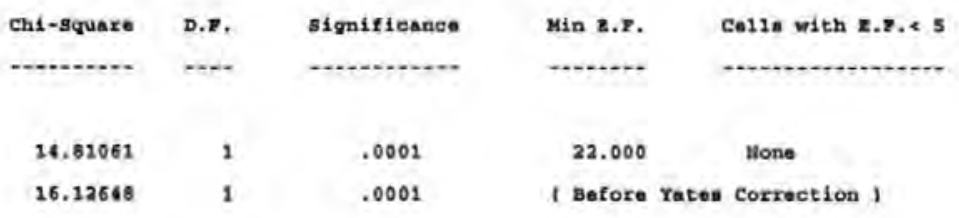

shimber of Miening observations = ?

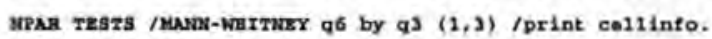

ERRON 11610, Text: PRINT

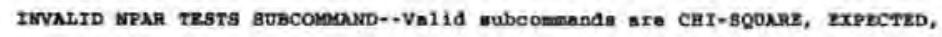

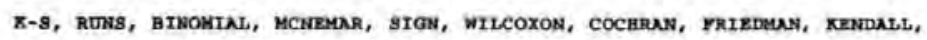
MEDIAs, $M-W, W-W$, woses, and $K-W$.

This conmand not exscuted. 
WDAR TESTS /MONN-WRTTNEY q6 by $q^{3}(1,3)$,

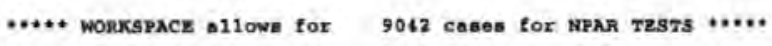

$\begin{array}{lll}\text { Page } 142 & \text { BPssfret } & 2 / 17 / 94\end{array}$

... Mann-Whitney $\mathrm{v}$ - Wileoxon Rank Sum $w$ Test

$\begin{array}{ll}\text { Q6 } & \text { atrategic man policy } \\ \text { by } 93 & \text { bueineas actor }\end{array}$

Mean rank cosea
$31.75 \quad 10 \quad Q^{3}=1$ primary
46.86 $83 \quad Q^{3}=3$ tertiary
$\cdots$
93 Total

\begin{tabular}{ccccc} 
& & \multicolumn{2}{c}{ Corrected for F1en } \\
0 & $W$ & $z$ & $2-$ tailed $P$ \\
262.5 & 317.5 & $-2,8930$ & .0038
\end{tabular}

Page 143

SPSS/PC+

$2 / 17 / 96$

Th1s procedure was completed at $10: 13: 4$ ?

Page 144

SP3B/PC+

$2127 / 94$

NPNR TESTS /MANA-WBITWEY g6 by q3 $(2,3)$,

..... WORRSPACR allowa fOr 9042 caser FOT NPAR TESTB .....

Page 145

SPSS/FC+

$2 / 17 / 94$

... Mann-Whitney 0 - wilcoxon gank sum $w$ Test

Q6 itrategic man poifey

by Q3 busineas sactor

Menn Rank Cases
83.08
84 Q3 $=2$ seconary
04.93

g3 $\mathrm{Q}^{3}=3$ tertiary 
-.

167 Total

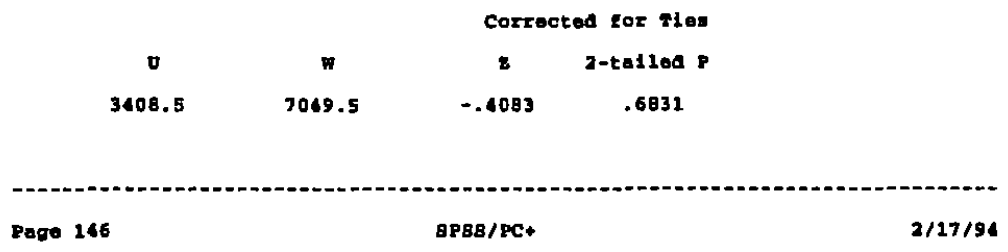

Thle procedure was cospleted at 10:15:07

Page 147

8P89/PC+

$2 / 17 / 94$

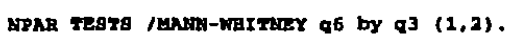

..... workspace allowe for 9042 casoe gox IPAR gegtr .....

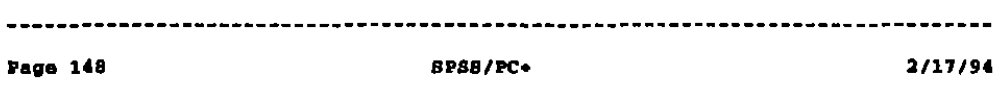

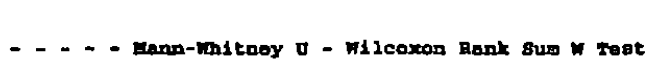

06 atrategle man pollcy

by $Q^{3}$ business sactor

Wan Rank Cases
$33.00 \quad 10 \quad 03 \cdot 1$ primary
19.23 $8403=2$ eecondery
---
$94 \operatorname{rot} 82$

\begin{tabular}{|c|c|c|c|}
\hline \multirow[b]{2}{*}{ ర } & \multicolumn{3}{|c|}{ corrocted for lies } \\
\hline & $m$ & 8 & $2-\operatorname{tallod} p$ \\
\hline 275.0 & 330.0 & -2.6089 & .0091 \\
\hline
\end{tabular}

This procedure we couplated at 10:25:27

Page 130

spse/pe.

$2 / 27 / 94$

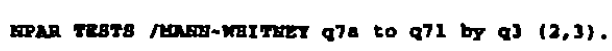

.... worrepace allowe tor 3988 casos tor GPAR 28978 .... 


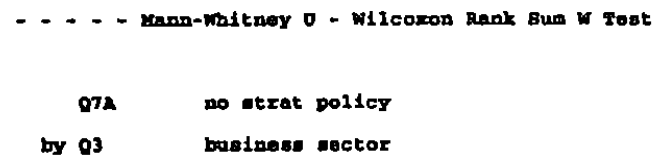

Ban Ranx Carsg

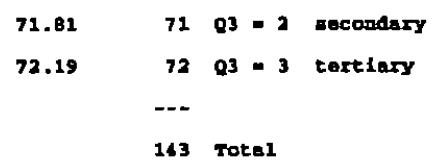




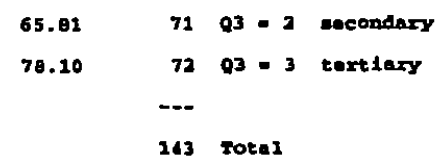

\begin{tabular}{|c|c|c|c|}
\hline \multicolumn{4}{|c|}{ Corrected for Iled } \\
\hline 0 & $n$ & $\mathbf{z}$ & 2-talled $P$ \\
\hline 2116.5 & 1672.5 & -2.2493 & .0245 \\
\hline
\end{tabular}

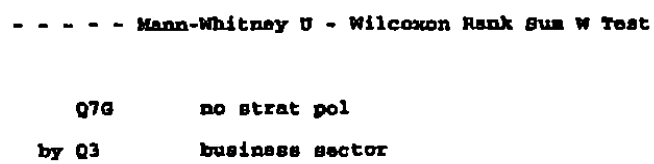

Hean Rank Cagns

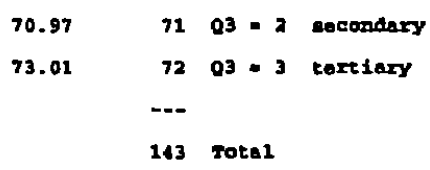

\begin{tabular}{cccc} 
& & \multicolumn{2}{c}{ Corrected for Ties } \\
0 & $w$ & $z$ & $2-t a 110 d$ P \\
2483.0 & 5039.0 & -.6487 & .3960
\end{tabular}




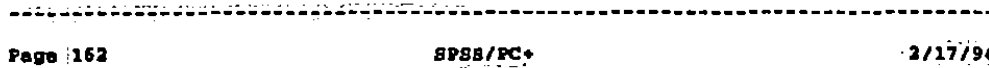

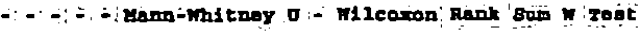

$\begin{array}{ll}072 & \text { no: otrat pol } \\ \text { by 03: } & \text { budinesg ioctor }\end{array}$

Hoon Rank: Cageg

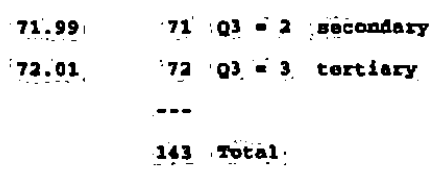

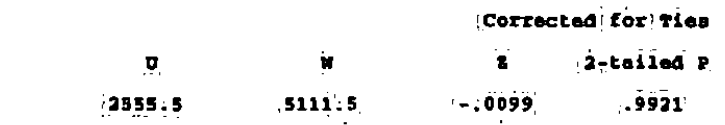

Pogo 163

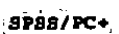

$2 / 17 / 94$

Thli procedure ras comploted at 11240,40

Page: 164

GPAB/PC+:

$2 / 27 / 94$

pirigi.

End of Include file: 


\section{Contents}

\begin{tabular}{|c|c|c|}
\hline \multicolumn{2}{|c|}{$\begin{array}{l}\text { Committees responsible } \\
\text { Foreword }\end{array}$} & $\begin{array}{r}\text { Page } \\
\text { Inside front cover }\end{array}$ \\
\hline \multicolumn{3}{|c|}{ Specification } \\
\hline \multicolumn{3}{|c|}{ Introduction } \\
\hline 1 & Scope & \\
\hline 2 & Informative references & \\
\hline 3 & Definitions & \\
\hline 4 & Environmental management system requirements & \\
\hline 4.1 & Environmental management system & \\
\hline 4.2 & Environmental policy & \\
\hline 4.3 & Organization and personnel & \\
\hline & Environmental effects & \\
\hline 4.5 & Environmental objectives and targets & \\
\hline 4.6 & Environmental management programme & \\
\hline 4.7 & Environmental management manual and documentation & \\
\hline 4.8 & Operational control & \\
\hline 4.9 & Environmental management records & \\
\hline 4.10 & Environmental management audits & \\
\hline 4.11 & Environmental management reviews & \\
\hline
\end{tabular}

A Guide to environmental management system requirements 9

A.1 Environmental management system 9

$\begin{array}{ll}\text { A.2 Environmental policy } & 10\end{array}$

A.3 Organization and personnel 10

A.4 Environmental effects 11

A.5 Environmental objectives and targets 12

A.6 Environmental management programme 12

A.7 Environmental management manual and documentation 12

$\begin{array}{ll}\text { A.8 Operational control } & 13\end{array}$

$\begin{array}{ll}\text { A.9 Environmental management records } & 14\end{array}$

A.10Environmental management audits $\quad 14$

$\begin{array}{ll}\text { A.11 Environmental management reviews } & 14\end{array}$

B Links to BS 5750 'Quality systems' 15

C Links to the draft European Community Eco-Audit Regulation
(Version 3, December 1991)

D Bibliography of glossaries and other sources of general information on environmental matters 20

Tables

B.1 Links to BS 5750 : Part 1: 1987

C.2 Links to the draft European Community Eco-Audit Regulation (Version 3, December 1991)

\section{Figure}

1 Schematic diagram of the stages in the implementation of an environmental management system 


\section{Foreword}

This British Standard has been prepared under the direction of the Environment. and Pollution Standards Policy Committee in response to increasing concerns about environmental protection and environmental performance. It contains a specification for an environmental management system for ensuring and demonstrating compliance with stated environmental policies and objectives. It also provides guidance on the specification and its implementation within the overall management system of an organization.

The standard is designed to enable any organization to establish an effective management system, as a foundation for both sound environmental performance and participation in 'environmental auditing' schemes.

This standard shares common management system principles with BS 5750 (EN 29000, ISO 9000), the European and internationally recognized quality systems standard, and organizations may elect to use an existing management system developed in conformity with BS 5750 as a basis for environmental management. To achieve equivalence with the requirements of this standard by such means could require the application of a suitable sector application guide. Established procedures for the assessment of compliance with BS 5750 should also be capable of extension to deal with the assessment of compliance with this standard, provided that the common assessment team encompasses the appropriate level of environmental expertise and detailed knowledge of this standard.

Guidance on acceptable levels of environmental management performance for particular sectors may be given in complementary documents, e.g. sector application guides. These would be produced to explain and amplify the requirements in certain situations. They may be issued as British Standard codes of practice after they have been established and used. It is recognized that in certain industry sectors use of this standard may be delayed until agreed sector applieation guides are available. Such sector application guides will be particularly relevant to industrial sectors having:

- complex environmental effects

- large numbers of constituent companies

- widely differing, but loosely related, operations and disciplines

- temporary and/or off-site activities

- substantial use of subcontracting

Compliance with a British Standard does not of itself confer immunity from legal obligations.

This British Standard is issued subject to review by the technical committee responsible for drafting no later than 1 September 1993 to facilitate pilot application. At the time of the review, changes will be made where required in the light of the experience gained or to reflect changes to the draft European Community Eco-Audit Regulation (Version 3, December 1991) in the intervening time from publication of this standard. 


\section{Specification}

\section{Introduction}

Organizations of all kinds are increasingly concerned to achieve and demonstrate sound environmental performance. They do so in the context of increasingly stringent legislation, the development of economic and other measures to foster environmental protection, and a general growth of concern about environmental matters.

Many organizations have undertaken environmental 'reviews' or 'audits' to assess their environmental performance. On their own, however, reviews and audits cannot provide an organization with the assurance that its performance not only meets, but will continue to meet, legislative and policy requirements. To be effective, they need to be conducted within a structured management system, integrated with overall management activity and addressing all aspects of desired environmental performance.

This British Standard specifies the elements of such an environmental management system, intended to apply to all types and sizes of organization. The basis of the approach is shown in flow chart form in figure 1. (It should be noted that any of the stages may be revisited at any time.) A system of this kind enables an organization to establish procedures to set an environmental policy and objectives, achieve compliance with them, and demonstrate such compliance to others. The standard is also intended to support certification schemes.

In addition to specifying the requirements for an environmental management system, the standard also provides guidance, in annex $\mathrm{A}$, to implementation and assessment. For ease of use, the principal subclauses of the specification and guide have related numbers; thus, for example, 4.5 and A.5 both deal with environmental objectives and targets, and 4.10 and A.10 both deal with environmental management audits.

NOTE. The initial review is included in the guide, but is not part of the specification, because it is not an assessable element of an established system.

Environmental management audits and environmental management reviews are inherent, but separate, parts of the system. Audits assess both the effectiveness of the environmental management system and the achievement of the environmental objectives. Reviews check the continuing relevance of the environmental policy, update the evaluation of environmental effects, and check the efficacy of audits and follow-up actions.

This British Standard complements BS 5750, as they take parallel approaches to achieving and demonstrating compliance with specified requirements. Annex B explains the links between them. It is expected that organizations operating to BS 5750 will readily be able to extend their management systems in accordance with this standard, but operation to BS 5750 is not a prerequisite for operation to this standard.

This British Standard also complements the draft European Community Eco-Audit Regulation (Version 3, December 1991). The draft Regulation establishes a voluntary scheme, membership of which requires participating companies to have an internal environmental protection system. The standard specifies the elements of such a system. Additionally, the environmental management audits and environmental management reviews together cover the activities of 'environmental auditing' as described by the International Chamber of Commerce, and in the draft Regulation.

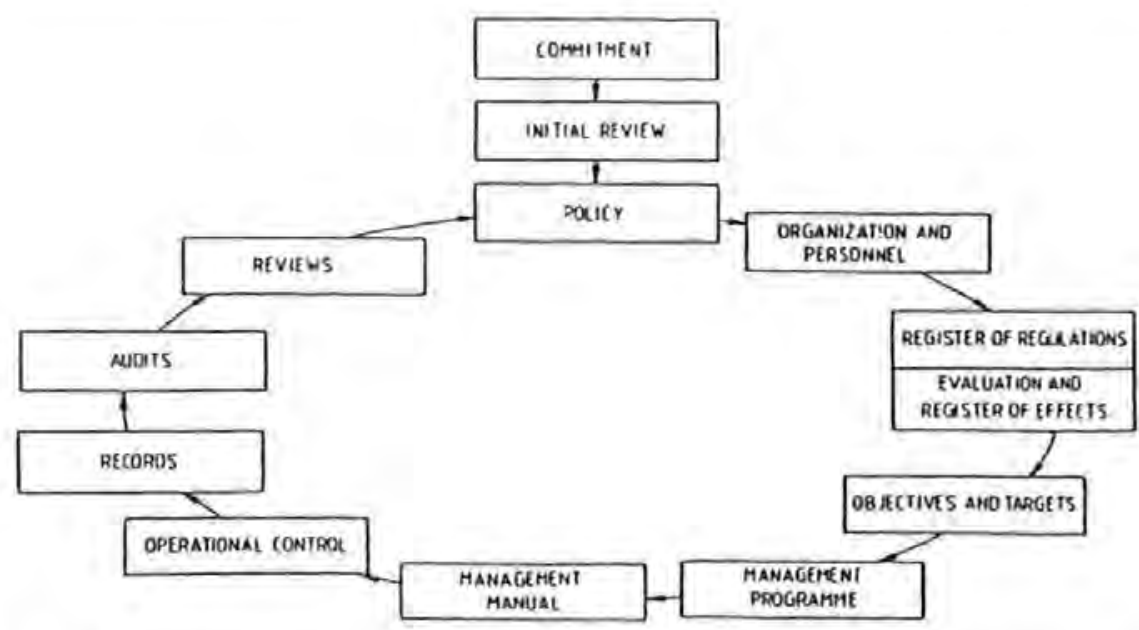

Figure 1. Schematic diagram of the stages in the implementation of an environmental management system 


\section{Scope}

This British Standard specifies requirements for the development, implementation and maintenance of environmental management systems aimed at ensuring compliance with stated environmental policy and objectives. The standard does not itself lay down specific environmental performance criteria.

The standard is applicable to any organization which wishes to:

a) assure itself of compliance with a stated environmental policy, and

b) demonstrate such compliance to others.

All the elements specified in the standard are intended to be incorporated into any

environmental management system, but the extent of the application of any one element will depend on such factors as the environmental policy of the organization, the nature of its activities and the conditions in which it operates.

\section{Informative references}

This British Standard refers to other publications that provide information or guidance. Editions of these publications current at the time of issue of this standard are listed on the inside back cover, but reference should be maile to the latest editions.

\section{Definitions}

For the purposes of this British Standard the following definitions apply.

\section{1 environment}

The surroundings and conditions in which an organization operates, including living systems (human and other) therein. As the environmental effects (see 3.2 ) of the organization may reach all parts of the world, the environment in this context extends from within the workplace to the global system.

\section{2 environmental effect}

Any direct or indirect impingement of the activities, products and services of the organization upon the environment, whether adverse or beneficial.

\section{3 environmental effects evaluation}

A documented evaluation of the environmental significance of the effects of the organization's activities, products and services (existing and planned) upon the environment.

\section{3,4 environmental effects register}

A list of the significant environmental effects, known or suspected, of the activities, products and services of the organization upon the environment.

\section{5 environmental mituagement}

Those aspects of the overall management function (including planning) that determine and implement the environmental policy.
3.6 environmental management audit

A systematic evaluation to determine whether or not the environmental management system and environmental performance comply with planned arrangements, and whether or not the system is implemented effectively, and is suitable to fulfil the organization's environmental policy.

\section{7 environmental management manual}

The documentation describing the procedures for implementing the organization's environmental programme.

3.8 environmental management programme

A description of the means of achieving environmental objectives and targets.

\section{9 environmental management review}

The formal evaluation by management of the status and adequacy of systems and procedures in relation to environmental issues, policy and regulations as well as new objectives resulting from changing circumstances.

\subsection{0 environmental management system}

The organizational structure, responsibilities, practices, procedures, processes and resources for implementing environmental management.

\subsection{1 environmental objectives}

The goals, in terms of environmental performance, which an organization sets itself to achieve and which should be quantified wherever practicable.

\subsection{2 environmental policy}

A public statement of the intentions and principles of action of the organization regarding its environmental effects, giving rise to its objectives and targets.

\subsection{3 environmental targets}

Detailed performance requirements, quantified wherever practicable, applicable to the organization or parts thereof, which arise from the environmental objectives and which need to be met in order to achieve those objectives.

\subsection{4 interested parties}

Those with an interest in the environmental effects of an organization's activities, products and services. These include those exercising statutory environmental control over the organization, local residents, the organization's investors, insurers and workforce, customers and consumers, environmental interest groups and the general public.

\subsection{5 organization}

Any organized body or establishment, for example, a business, company, government department, charity or society. For bodies or establishments with more than one site, a single site may be defined as an organization.

\subsection{6 verfication activities}

All inspection, test and monitoring work related to environmental management. 


\section{Environmental management system requirements}

\subsection{Environmental management system}

The organization shall establish and maintain an environmental management system as a means of ensuring that the effects of the activities of the organization conform to its environmental policy and associated objectives and targets. This shall include:

a) the preparation of documented system procedures and instructions in accordance with the requirements of this standard;

b) the effective implementation of the system procedures and instructions.

In implementing the environmental management system, the organization shall take account of any pertinent code of practice $t o$ which it subscribes.

\subsection{Environmental policy}

The organization's management shall define and document its environmental policy. The management shall ensure that this policy:

a) is relevant to its activities, products and services, and their environmental effects;

b) is understood, implemented and maintained at all levels in the organization;

c) is publicly available;

d) includes a commitment to continual improvement of environmental performance;

e) provides for the setting and publication of environmental objectives.

\subsection{Organization and personnel}

\subsubsection{Responsibility, authority and resources}

The organization shall define and document the responsibility, authority and interrelations of key personnel who manage, perform and verify work affecting the environment, including those who need the organizational freedom and authority to:

a) provide sufficient resources and personnel for implementation;

b) initiate action to ensure compliance with environmental policy;

c) identify and rccord any environmental problems:

(1) initiate, recommend or provide solutions to those problems through designated channels;

c) verify the implementation of such solutions;

f) control further activities until any environmental deficiency or unsatisfactory condition has been corrected;

g) act in emergency situations.

\subsubsection{Verification resources and personnel}

The organization shall identify in-house verification requirements and procedures, provide adequate resources and assign trained personnel for verification activities (see also 4.3.4).

\subsubsection{Management representative}

The organization shall appoint a management representative who, irrespective of other responsibilities, shall have defined authority and responsibility for ensuring that the requirements of this standard are implemented and maintained.

\subsubsection{Personnel, communication and training}

The organization shall establish and maintain procedures to ensure that its employees or members, at all levels, are aware of:

a) the importance of compliance with the environmental policy and objectives, and with the requirements of this standard;

b) the potential environmental effects of their work activities and the environmental benefits of improved performance;

c) their roles and responsibilities in achieving compliance with the environmental policy and objectives, and with the requirements of this standard;

d) the potential consequences of departure from agreed operating procedures.

The organization shall establish and maintain procedures for identifying training needs, and for providing appropriate training for all personnel whose work may have a significant effect upon the environment. Appropriate records of training shall be maintained (see also 4.9).

Personnel performing specific assigned tasks shall be qualified on the basis of appropriate education. training and/or experience, as required.

\subsection{Environmental effects}

\subsubsection{Register of legislative, regulatory and other policy requirements}

The organization shall establish and maintain procedures to record all legislative, regulatory and other policy requirements pertaining to the environmental aspects of its activities, products and services.

\subsubsection{Communications}

The organization shall establish and maintain procedures for receiving, documenting and responding to communications (internal and external) from relevant interested parties concerning its environmental effects and management (see also 4.9). 


\subsection{Environmental effects evaluation and gister}

The organization shall establish and maintain rocedures for examining and assessing the nvironmental effects, both direct and indirect, of Is activities, products and services, and for compiling a register of those identified as ignificant. The procedures shall include, where ppropriate, consideration of:

a) controlled and uncontrolled emissions to atmosphere;

b) controlled and uncontrolled discharges to water;

c) solid and other wastes;

d) contamination of land;

e) use of land, water, fuels and energy, and other natural resources;

f) noise, odour, dust, vibration and visual impact; g) effects on specific parts of the environment and ecosystems.

The procedures shall include effects arising, or ikely to arise, as consequences of:

1) normal operating conditions;

2) abnormal operating conditions;

3) incidents, accidents and potential emergency situations;

4) past activities, current activities and planned activities.

\subsection{Environmental objectives and targets}

The organization shall establish and maintain rocedures to specify its environmental objectives, and consequent targets at all relevant levels within the organization.

In addition to compliance with all legislative and regulatory requirements, other objectives and targets shall be identified after consideration of the environmental effects register and the financial, operational and business requirements of the organization, in conjunction with the views of interested parties.

The objectives and targets shall be consistent with the environmental policy, and shall quantify wherever practicable the commitment to continual improvement in environmental performance over defined time-scales.

\subsection{Environmental management programme}

The organization shall establish and maintain a programme for achieving the objectives and targets. It shall include:

a) designation of responsibility for targets at each function and level of the organization;

b) the means by which they are to be achieved.
Separate programmes shall be established in respect of the environmental management of projects relating to new developments, or to new or modified products, services or processes, to define:

1) the environmental objectives to be attained;

2) the mechanisms for their achievement;

3) the procedures for dealing with changes and modifications as projects proceed;

4) the corrective mechanisms which shall be employed should the need arise, how they shall be activated and how their adequacy shall be measured in any particular situation in which they are applied.

NOTE. The phrase 'environmental assessment' is widely used to mean a study required by planning authorities for certain types of development.

\subsection{Environmental management manual and documentation}

\subsubsection{Manual}

The organization shall establish and maintain a manual or manuals to:

a) collate the environmental policy, objectives and targets, and programme;

b) document the key roies and responsibilities;

c) describe the interactions of system elements;

d) provide direction to related documentation and describe other aspects of the management system, where appropriate.

In addition to dealing with the normal activities of the organization, the manual (or related documentation) shall cover abnormal operating conditions, and incidents, accidents and potential emergency situations. Emergency plans shall, where appropriate, contain relevant environmental information and instructions.

\subsubsection{Documentation}

The organization shall establish and maintain procedures for controlling all documents required by this standard to ensure that:

a) they can be identified with the appropriate organization, division, function or activity;

b) they are periodically reviewed, revised as necessary and approved for adequacy by authorized personnel prior to issue;

c) the current versions of relevant documents are available at all locations where operations essential to the effective functioning of the system are performed;

d) obsolete documents are promptly removed from all points of issue and points of use. 


\subsection{Operational control}

\subsubsection{General}

Management responsibilities shall be defined to ensure that control, verification, measurement and testing within individual parts of the organization are adequately coordinated and effectively performed.

\subsubsection{Control}

The organization shall identify functions, activities and processes which affect, or have the potential to affect, the environment, and are relevant to its policy, objectives and targets. The organization shall plan such functions and activities to ensure that they are carried out under controlled conditions. Particular attention shall be paid to the following:

a) documented work instructions (consistent with, or forming a part of, the organization's environmental manual) defining the manner of conducting the activity, whether by the organization's own employees or by others acting on its behalf. Such procedures shall be prepared for situations in which the absence of such instructions could result in infringement of the environmental policy;

b) procedures dealing with procurement and contracted activities, to ensure that suppliers and those acting on the organization's behalf comply with policy requirements that relate to them; c) monitoring and control of relevant process characteristics (e.g. effluent streams and waste disposal);

d) approval of planned processes and equipment;

e) criteria for performance, which shall be stipulated in written standards.

\subsubsection{Verification, measurement and testing}

The organization shall establish and maintain procedures for verification of compliance with specified requirements (c.g. in the programme, targets, manual and work instructions) and for establishing and maintaining records of the results.

For each relevant activity or area, the organization shall:

a) identify and document the verification information to be obtained;

b) specify and document the verification procedures to be used;

c) establish and document acceptance criteria and the action to be taken when results are unsatisfactory;

d) assess and document the validity of previous verification information when verification systems are found to be malfunctioning.

\subsubsection{Non-compliance and corrective action}

The responsibility and authority for initiating investigation and corrective action in the event of non-compliance with specified requirements shall be defined.

The organization shall establish and maintain procedures for such investigation and corrective action, by which the management of the individual function or activity concerned, in consultation with the management representative (or a nominated deputy), shall:

a) determine the cause;

b) draw up a plan of action;

c) initiate preventive actions, to a level corresponding to the risks encountered;

d) apply controls to ensure that any preventive actions taken are effective;

e) record any changes in procedures resulting from corrective action.

\subsection{Environmental management records}

The organization shall establish and maintain a system of records in order to demonstrate compliance with the requirements of the environmental management system, and to record the extent to which planned environmental objectives and targets have been met.

The organization shall establish and maintain procedures for the identification, collection, indexing, filing, storage, maintenance and disposition of environmental management records. Pertinent contractor and procurement records, and the results of audits and reviews (see 4.10 and 4.11) and training records (see 4.3.4) shall form an element of these records.

All environmental records shall be legible and identifiable to the activity, product or service involved. Environmental records shall be stored and maintained in such a way that they are readily retrievable and protected against damage, deterioration or loss, and their retention times shall be established and recorded.

Policies shall be established and implemented regarding the availability of records, both within the organization and to interested parties.

\subsection{Environmental management audits}

\subsubsection{General}

The organization shall establish and maintain procedures for audits to be carried out, in order to determine:

a) whether or not environmental management activities conform to the environmental management programme, and are implemented effectively;

b) the effectiveness of the environmental management system in fulfilling the organization's environmental policy.

For this purpose, the organization shall establish and maintain an audit plan. 


\subsection{Audit plan}

the audit plan shall deal with the following points.

a) The specific activities and areas to be audited, which include;

1) organizational structures;

2) administrative and operational procedures;

3) work areas, operations and processes;

4) documentation, reports and records;

5) environmental performance.

b) The frequency of auditing of each activity/area, audits being scheduled on the basis of the nature and environmental importance of the activity concerned, and the results of previous audits.

c) The responsibility for auditing each activity/area.

d) The personnel requirements, and specifically that those carrying out the audits:

1) are independent, so far as is possible, of the specific activities or areas being audited;

2) have expertise in relevant disciplines;

3) have support, where necessary, from a wider range of specialists, who may be internal or external to the organization.

e) The protocol for conducting the audits, which may involve the use of questionnaires, checklists, interviews, measurements and direct observations, depending on the nature of the function being audited. f) The procedures for reporting audit findings to those responsible for the activity/area audited, who shall take timely action on reported deficiencies. Reporting shall address:

1) conformity or nonconformity of the environmental management system elements with specified requirements;

2) the effectiveness of the implemented environmental management system in meeting objectives and targets;

3) implementation and effectiveness of any corrective actions recommended in previous audits;

4) conclusions and recommendations.

g) The procedures for publishing audit findings, if the organization has such a commitment.

\subsection{Environmental management reviews}

The organization's management shall, at appropriate intervals, review the environmental management system adopted to satisfy the requirements of this standard, to ensure its continuing suitability and effectiveness. The results of such reviews shall be published if the organization has a commitment to do so.

Management reviews shall include assessment of the results of environmental management audits (see 4.10). 


\section{Annexes}

\section{Annex A (informative) \\ Guide to environmental management system requirements}

\section{A.1 Environmental management system}

\section{A.1.1 The system}

All organizational activities, products and services interact with, and have some effect upon, the environment, and an effective environmental management system needs to be capable of dealing with this complexity. Therefore, the environmental management system components will be inextricably interwoven with most, if not all, of the organization's overall management system.

Existing components of the overall system may be common to, for example, operational management, occupational health and safety management, quality management and environmental management. In such cases, documentation and records may be shared between the systems to avoid duplication, but the inter-relationships should be explained and cross-referenced.

Effective integration and coordination of the overall system components is essential to ensure consistent decision making, for example, in relation to environmental matters and occupational health and safety. However, this standard is not intended specifically to address occupational health and safety management.

The organization's management should give timely consideration to identifying, acquiring and/or developing any skills, plant equipment, controls, processes, monitoring systems and other resources needed to achieve the required environmental performance.

The environmental inanagement system should be designed so that emphasis is placed on the prevention of adverse environmental effects, rather than on detection and amelioration after occurrence. It should:

a) identify and assess the environmental effects arising from the organization's existing or proposed activities, products or services;

b) identify and assess the environmental effects arising from incidents, accidents and potential emergency situations;

c) identify the relevant regulatory requirements;

d) enable priorities to be identified and pertinent environmental objectives and targets to be sc $t$;

c) facilitate planning, control, monitoring, auditing and review activities to ensure both that the policy is complied with, and that it remains relevant;

f) be capable of evolution to suit changing circumstances.

\section{A.1.2 Preparatory environmental review}

An organization with no existing formal environmental management system should, as a first step, establish its current position with regard to the environment by means of a preparatory review. The aim should be to consider all aspects of the organization, to identify strengths, weaknesses, risks and opportunities as a basis for establishing the environmental management system.

The preparatory review should cover four key areas:

a) legislative and regulatory requirements;

b) an evaluation and registration of significant environmental effects;

c) an examination of all existing environmental management practices and procedures;

d) an assessment of feedback from the investigation of previous incidents and non-compliance.

In all cases, consideration should be given to normal and abnormal operation of the onganization, and to possible emergency conditions howsoever caused.

A suitable approach to the preparatory review would be to employ a combination of questionnaires, checklists, interviews and other forms of consultation, and direct inspection and measurement, depending on the nature of the activities.

The following list gives examples of areas which might be appropriate for many organizations to consider in the preparatory review. The list is not intended to be exhaustive, and the development of a specific list for the organization under review is itself an important and valuable early step in the review process: (Further information on environmental issues and terminology is given in the references listed in annex D.)

- areas where environmental performance could be improved

- views of relevant interested parties

- environmental objectives and targets beyond regulatory requirements

- expected changes in regulations and legislation

- adequacy of resources and environmental information

- environmental records

- environmental cost/benefit analysis and accounting methods

- internal and external communications on environmental issues

- environmental training plans

- environmental aspects of products and services 
- incorporation of environmental considerations in design and marketing

- resource consumption (energy, fuels, materials)

- waste minimization/recycling initiatives

- use of hazardous prociesses

- use and disposal of hazardous materials and products

- transport policy

- nature conservation

- complaints and their recording and follow-up

- visual impact, noise and odours

- environmental probity of suppliers

- environmental hazard and risk assessment of potential emergency situations

- environmental aspects of emergency planning

- envirommental effects of investment policies

The resulting report should highlight:

1) the nature and extent of problems and deficiencies; and the priorities to be accorded to rectifying them;

2) an improvement programme designed to ensure that the personnel and material resources required are identified and made available.

\section{A.2 Environmental policy}

The policy should:

a) be initiated, developed and actively supported by management at the highest level;

b) be consistent with the occupational health and safety policy and other organizational policies (such as the quality policy);

c) not only commit the organization to meet all relevant regulatory and legislative requirements, but also define how it will seek to meet, exceed or develop the requirements of some, or all, of the other interested parties and secure continual improvement in environmental performance (see A.5);

d) be made available, in a readily understood format, to interested parties, for example, by use of the organization's annual report, booklet or display.
The policy will frequently address very broad aspects of an organization's activities. For example, a company may wish to ensure that investment of reserves is undertaken in an environmentally responsible manner, which will require examination of the investment policy and practice.

The issues addressed in the policy will depend on the nature of the organization. Where the organization is lange or complex, supporting information, in a readily understood format, may be given in the environmental objectives and programme. However, the policy may, for example, state commitments to:

- reduce waste and the consumption of resources (materials, fuel and energy);

- reduce or eliminate the production of polluting releases to the environment;

- design products in such a way as to minimize their environmental effects in production, use and disposal;

- control the environmental effects of raw material sourcing (e.g. on habitats, on species diversity and on natural beauty);

- minimize the environmental effects of new developments through strategic planning.

Appropriate levels of management should, where necessary, define specialized and/or more detailed environmental targets, consistent with the organization's policy, in addition to the overall objectives.

\section{A.3 Organization and personnel}

The management representative should have sufficient knowledge of the activities of the organization, and of environmental issues, to undertake his or her role effectively. Whilst he or she should maintain overall responsibility for implementing this standard, and for coordinating environmental management activities across all functions and groups, there may be circumstances where nominated deputies will act on his or her behalf. If the representative has other functions to perform, there should be no conflict of interest. 
The responsibility of the management representative for implementing this standard does not absolve line management from their responsibilities for detailed implementation (in consultation with the representative). The allocation of such responsibilities will depend upon the nature and structure of the individual organization; some examples might be:

a) Senior management. Assume responsibility for developing, resourcing, reviewing and complying with the environmental policy.

b) Management representative. In addition to having overall responsibility for ensuring compliance with this standard, the management representative should ensure that developments in environmental legislation and regulation, and in environmental issues, concerns and understanding relevant to the organization, are monitored.

c) Finance. Develop and maintain accounting procedures which enable identification of costs and benefits relating to environmental management.

d) Personnel. Develop and maintain (in consultation with all employees) appropriate effective two-way communication and training programmes on environmental matters.

e) All individual function, activity and process managers (e.g. Safety, Planning, Research and Developmient, Product and Process Design, Marketing, Sales, Purchasing, Packaging, Distribution, Operalions, Production, Finance, Site Services, Facilities, Personnel). Develop and implement the environmental management system as it pertains to their areas of responsibility (see A.8).

In addition to allocating responsibilities, management should determine the level of competence, experience, formal qualification and training necessary to ensure the capability of personnel, especially those carrying out certain specialized environmental management functions. Where appropriate, activities and roles which affect the environmental performance of the organization should be included in job deseriptions and performance appraisals.

Training may need to be provided for:

1) executive and management personnel, to ensure that they understand the environmental management system, have the necessary knowledge to play their part in it, and understand the criteria by which its effectiveness will be judged;

2) other personnel, to ensure that they can make an appropriate contribution to the environmental management system;

3) new recruits, and staff assigned to new tasks, equipment and procedures.
All employees should be motivated towards a proper regard for environmental concerns by, for example:

i) introductory and refresher programmes;

ii) effective two-way communication;

iii) recognition of performance when environmental objectives and targets are achieved;

iv) encouragement of employees' suggestions that lead to improved environmental performance;

v) participation in environmental initiatives.

\section{A.4 Environmental effects}

Legislative and regulatory requirements may include planning conditions, discharge consents, process authorizations, and improvement notices; other policy requirements may include, for example, commitments to reducing waste production and energy use.

In evaluating effects and developing objectives and targets (see 4.5 and A.5), consideration needs to be given to any codes of practice to which the organization subscribes. These may commit the organization to achieve certain levels of control over adverse effects, specify numerical targets for such matters as pollutant load reduction or waste reduction, and/or require the installation and use of certain types of technology. The views of interested parties, and the frequency and nature of complaints about environmental performance, may also assist in identifying and evaluating environmental effects.

The environmental probity of suppliers should also be considered, with regard to their products and activities. Whilst in many instances it will not be possible to compile detailed registers of supplying organizations, it will often be possible to at least compare alternative suppliers in respect of their most important environmental effects.

Consideration should be given to the consequences of past activities of the organization (e.g. liability for former products), the consequences of activities of other organizations which are transferred (e.g. through acquisitions), and future consequences which may arise from present activities (e.g. responsibilities for continued monitoring and management of a landfill site).

In assessing effects, attention should be paid to both the normal and abnormal operating conditions of the organization, and to emergency situations (e.g. fire, traffic accident, explosion, flood, malicious damage, as appropriate). In dealing with the latter, both the risks of such a situation arising and the severity of potential environmental effects need to be considered as a basis for establishing objectives, controlling risks and developing an environmental component of the emergency plan. 
ie degree of detail of the evaluation of divironmental effects should depend upon such factors as:

a) the nature and scope of the environmental policy;

b) the likely environmental significance of the effect in question, in relation both to other effects of the organization, and to effects from other sources upon the environmental medium or target organism/ecosystem in question;

c) any regulatory requirements relating to the effect in question;

d) the extent of concern of other interested parties about effects of the type in question;

e) existing knowledge, in the organization or elsewhere, of the type of effect.

- isk assessment and other techniques may be used order to compare the effects identified. When a Tegulatory assessment has been made, the organization may, depending on its environmental olicy, accept the assessment implied by the egulatory conditions.

With regard to a manufacturing organization, the valuation of effects should address all phases from roduct conception, through research and uevelopment, design, marketing, raw material sourcing, purchasing, production, waste lanagement, packaging, storage, distribution, sales nd use, to ultimate disposal. This is particularly important for identifying targets and objectives relating to product design functions.

Vith regard to a service organization, the valuation should similarly address all aspects, stages, practices and procedures of service evelopment and provision.

$n$ both kinds of organization, the evaluation should address effects arising from support functions, such ss planning, finance, personnel, and

dministration/services. Both direct and indirect ffects should be considered. Examples of direct effects are: disposal/release of solid, liquid and gaseous wastes arising in a production process; isage of fuels, energy and materials in all functions of the organization; effects of transport; land management practices. Examples of indirect effects ure: extraction of raw materials supplied by inother organization; effects of other businesses in which the organization's reserves are invested; and ffrects of the use, possible misuse, and disposal of the organization's products.

The organization should identify environmental issues relevant to new developments, products, processes, services, technologies and other flements of its activities, to ensure that environmental aspects of their introduction are considered at the earliest stages of planning.

\section{A.5 Environmental objectives and targets}

The objectives should include a commitment to continual, year-on-year improvement in overall environmental performance, but not necessarily in all areas of activity.

Areas targeted for improvement should include those where improvements are most necessary to reduce risks (to environment and organization) and liabilities, and should be identified by cost-benefit analysis where practicable.

Objectives and targets should be set within the context of the environmental effects evaluation, quantified wherever practicable. Targets derived from the objectives should be quantitative and achievable, albeit demanding; when agreed, they should form components of personal accountability and performance appraisal.

\section{A.6 Environmental management programme}

Following an environmental programme is the key to compliance with the organization's environmental policy. The implementation of the programme should involve a clear and unequivocal commitment from all personnel, and in particular from management at the most senior levels.

A designated senior of ficer of the organization (who may or may not be the management representative) should be responsible for ensuring that suitable organizational systems are in place to ensure that appropriate operational procedures are prepared and executed.

The programme should, if appropriate, include actions to deal with the environmental consequences of the organization's past activities Programmes relating to the development of new products or services should address the environmental effects arising at all stages of the life cycle, to ensure that adverse environmental effects are controlled by effective planning and design. For the same reason, programmes relating to new installations or modifications to processes and plant should cover all stages of the development, from feasibility studies, through planning and design, to construction, commissioning operation, and eventual decommissioning.

\section{A.7 Environmental management manual and} documentation

The primary purpose of environmental management documentation is to provide an adequate description of the environmental management system, whilst the manual serves as a permanent reference to the implementation and maintenance of that system. Where other pre-existing parts of the overall management system (e.g. occupational health and safety. emergency plans) form parts of the environmental management system, their documentation need not be duplicated, but should be referenced in the environmental manual. 
The documentation relating to the environmental management system may take various forms, but should include some or all of the following:

a) a manual covering the whole organization:

b) divisional manuals;

c) specialized manuals covering individual functions (e.g. design, marketing, finance, investment) and activities (e.g. individual process lines).

These should be consistent in approach and content, and should be subject to similar rules regarding control, review and amendment.

The site emergency plan and occupational health and safety manual should also incorporate relevant environmental information and associated instructions.

The manual should be sufficiently detailed to be used by the system auditor to verify that:

1) the system exists;

2) it is fit for its purpose, given the nature of the environmental effects involved.

All written procedures should be stated simply, unambiguously and understandably and should indicate methods to be used and criteria to be satisfied.

All documentation should be legible, dated (with dates of revision and future revísions), readily identifiable, maintained in an orderly manner and retained for a specified period. Clear policies and responsibilities should be established conceming the modification of the various types of document, and their availability within the organization and to interested parties.

\section{A.8 Operational control \\ Control and weification}

Appropriate control and verification procedures should cover all functions, activities and processes which have, or could have if uncontrolled, a significant effect (direct or indirect) on the environment, relevant to the environmental policy. Thus, such procedures may need to deal with functions, activities and processes which:

a) relate directly to the principal business, products or services, e.g. research and development, design, production, distribution;

b) relate indirectly to the principal business, products or services, e.g. raw material sourcing, purchasing, and product use;

c) provide support to the principal business, e.g. finance, personnel, and administration.

The type and scope of control and verification mechanisms should be appropriate to the nature, complexity and environmental importance of the function, activity or process which they address.
For example, control and verification within an investment department will be very different in detail from control and verification of effluent streams. In all cases, however, the objectives should be to control the activity in question in accordance with specified requirements (e.g. in the programme, manual and/or work instructions), and to verify the outcome.

In the case of indirect effects, control and verification procedures should address those functions, activities and processes by which the organization can exert influence. Thus, for example, if a company's policy commits it to providing customers with information about the environmentally-responsible use of its products, procedures should be implemented to control and verify the provision of such information. If an organization's policy commits it to purchasing materials from companies whose environmental performance meets specified standards, procedures should be implemented to obtain the necessary information from suppliers.

With regard to procurement activities, suppliers may not always be able or willing to provide all the information necessary for control purposes.

However, in circumstances where information can reasonably be obtained (e.g. if the organization and suppliers are part of the same group of companies) the organization should be able to demonstrate that its suppliers observe the policy requirements of the organization.

In the case of verification involving measurement, the organization should:

1) identify and document the measurements to be made and specify the accuracy required of results;

2) specify and document the locations and times of measurement;

3) establish, document and maintain measurement quality control procedures, including quality control charts, and maintain records thereof:

4) establish and document acceptance criteria and the action to be taken when measurements are unsatisfactory;

5) maintain calibration records for measuring and testing equipment;

6) assess and document the validity of previous measurement and test results when measurement systems are found to be out of control or equipment is found to be out of calibration;

7) safeguard measurement and test facilities, including hardware, software and the laboratory environment, from adjustments, damage or tampering which would invalidate the measurements or tests. 


\section{n-compliance and comective action.}

idents of non-compliance with specified quirements may be sudden and accidental, or y may last for a period of time. They may result. $m$ deficiencies or failures in plant/equipment, om human error or from deficiencies within the anagement system.

the investigation of non-compliance the Jisative mechanism should be fully established ad reported, including the predetermining (or asposing) factors within the management tem.

uch investigation will enable the planning of vrective action, which should include measures

- restoring compliance as quickly as practicable;

preventing recurrence;

- assessing and mitigating any adverse environmental effects:

- ensuring satisfactory interaction with other components of the management system such as occupational health and safety, and quality;

- assessing the effectiveness of the above measures.

ne implementation of the corrective action should ot be deemed to have been completed until the

iectiveness of all the alreve has been

monstrated and the appropriate changes made in ie procedures, documentation and records.

Fere corrective action may involve the initiation a project over a significant time scale this should rm part of the management programme.

\section{Environmental management records}

cords are the evidence of the ongoing operation the environmental management system. Care ould be taken to limit records to the extent rtinent to the application, but they should be pt in order and designed to demonstrate mpliance with environmental policy and the tent to which environmental objectives and rgets are achieved. Relevant records compiled ider other parts of the overall management stem need not be duplicated, but means of access them should be specified. In addition to the ister of legislative and regulatory requirements, 3 register of environmental effects, and the orts of audits and reviews, records should lude:

) details of any failures to comply with policy, nd of corrective actions taken;

) details of any ineidents and follow-up actions sken; c) details of any complaints and follow-up actions taken;

d) appropriate supplier and contractor

information;

e) inspection and maintenance reports;

f) product identification and composition data;

g) monitoring data.

\section{A.10 Environmental management audits}

Audits may be ínternal (carried out by personnel from within the organization, but wherever possible independent of the part being audited) or external, but in either case the persons conducting the audit should be properly trained to carry out the task objectively and effectively. Independent, external verification of audits may be required by certain agencies; the organization should identify any such requirements it is committed to meet.

Auditors may need expertise in certain disciplines, depending on the nature and activities of the organization, or part of the organization, being audited, but they will certainly require broad knowledge of environmental processes and effects. Whilst the primary function of audits is to assess the extent of compliance and non-compliance, and assess the effectiveness of previous corrective actions, they may suggest remedial measures to overcome problems, or they may simply note the nature of the problems and require the management of the audited function to devise and implement an appropriate solution.

The audit report should be submitted to the management representative, the local line management, and that level of senior management appropriate to the organization or function being audited.

In addition to establishing an independent audit procedure, organizations may find it beneficial to establish self-assessment procedures carried out by the responsible line management to assess audit readiness.

An existing British Standard, BS 7229, deals with quality system auditing, and its broad principles are relevant to auditing of environmental management systems.

\section{A.11 Environmental management reviews}

The scope of the review should include the entire organization and all its activities, products and services; it should not be confined to those relevant to existing environmental policy, objectives and targets.

For example, a review of the environmental management system applied to a product design department would examine the extent to which the system was implemented, and its effectiveness in ensuring that products were designed according to the organization's objectives, and whether the objectives should be modified. 
Such reviews should be carried out by appropriate members of, or competent independent personnel appointed by, the organization's management.

Issues to be addressed as part of the review process should include:

a) any recommendations which have been made in environmental management audit reports, and how these should be implemented;

b) the continuing suitability of environmental policy, and whether it should be revised in the light of, for example:

1) emerging/growing environmental concerns

in specific areas;

2) developing understanding of environmental issues;

3) potential regulatory developments;

4) concerns amongst interested parties;

5) market pressures;

6) changing activities of the organization;

7) changes in sensitivity of the environment;

c) the continuing suitability of environmental targets and objectives, and revisions to the environmental management programme, manual and other documentation to reflect changes in these.

Reports of reviews should make clear the reasons for their conduct (e.g. routine procedure, organizational changes, developments in understanding of environmental effects, changes in environmental sensitivity, reported deficiencies in envîronmental management system).

Findings, conclusions and recommendations reached as a result of review and evaluation should be submitted in documentary form for necessary action by the organization's management.

\section{Annex B (informative)}

\section{Links to BS 5750 'Quality systems'}

To assist organizations operating to BS 5750 and wishing to extend their management systems in accordance with this standard, table B.1 links the specification of requirements in this standard to the specification of requirements in BS 5750 : Part 1: 1987.

The reasoning behind the linkages is outlined below, where the subclauses of this standard are given as headings.

NOTE. All references to BS 5750 in this annex should be read as references to DS 5750 : Part 1: 1987.

\section{a) 4.1 Environmental management system}

The requirements that appropriate system procedures and instructions are prepared and implemented are counterparts to those in 4.2 of BS 5750. As effective implementation of any management system is dependent upon the commitment of the organization's management, there are also similarities with 4.1 of BS 5750 .

\section{b) 4.2 Envirommental policy}

The requirement for an environmental policy is analogous to that for a quality policy, as required by 4.1 of BS 5750 , but with additional requirements; namely that the policy should be supported by environmental objectives, quantified where practicable, and that both the policy and objectives should be publicly available.

\section{c) 4.3 Organization and personnel}

The requirements of this subclause are counterparts to those of $\mathbf{4 . 1}$ of BS 5750 (with some additional emphasis on internal communications), and those of 4.18 of BS 5750 , which addresses training.

\section{d) 4.4 Environmental effects}

No direct parallels to this subclause exist in BS 5750; it is in the area of environmental effects and their evaluation that the two standards are at their most dissimilar. However, in broad terms, the requirements pertaining to the evaluation of the environmental effects of an organization's activities may be considered as analogous to discussions with a customer prior to drawing up a specification, and applicable legislation and regulations may be considered as analogous to part of a specification.

As evaluation of environmental effects should include (amongst others) those arising from:

1) purchased products and services: 4.6 and 4.7 of BS 5750 ;

2) packaging and delivery: $\mathbf{4 . 1 5}$ of BS 5750 ;

3) products during use: 4.19 of BS 5750 ;

the systems developed for compliance with the above subclauses of BS 5750 could be extended to address environmental management.

e) 4.5 Environmental objectives and targets The organization's objectives and targets, whether identified by regulatory bodies or self-imposed, serve a similar purpose to that of contractual requirements addressed in 4.3 of BS 5750, in that they define the level of performance to be achieved by implementation of the system. However, under environmental management the implications for the organization are necessarily more wide-ranging, as can be seen from the definition of "interested parties" (3.14 of this standard), i.e. those with an interest in the environmental effects of the organization's activities.

\section{f) 4.6 Environmental management programme}

This subclause is concerned with the means of achieving the organization's objectives and targets. In a similar way, 4.3 of BS 5750 is concerned with ensuring that the organization can meet contractual requirements, and 4.4 of BS 5750 is concerned with the means by which these are met by the control of design activities. 
wever, the management programme required rler an environmental management system suld need to be broad and related to all jectives and targets, and not confined to these No aspects.

1 4.7 Environmental management manual and cumentation

re documentation of design activities is idressed by 4.4 of BS 5750 and control of all cuments within the management system is dressed by 4.5 . The requirements for ,cument control are essentially the same in "th standards, with the difference that the untents of the environmental management ystem manual are specified in the nvironmental management standard (though scy may be "signposted" rather than included ( full). The reference to a quality manual occurs the note to 4.2 of BS 5750 .

\subsection{Operational control}

is subclause requires that all activities which :e relevant to compliance with the rganization's environmental policy, objectives nd targets are carried out under controlled onditions. The origins of BS 5750 are evident re as it does not have a single corresponding ticlause, but a number of subclauses relating to ifferent stages of the production process. These re:

\subsection{Design control}

\subsection{Purchasing}

4.9 Process control

4.10 Inspection and testing

4.11 Inspection, measuring and test equipment

4.12 Inspection and test status

1.13 Control of nonconforming product

4.14 Corrective action

4.15 Handling, storage, packaging and delivery

4.19 Servicing

4.20 Statistical techniques

\section{i) 4.9 Environmental managernent records}

The requirement that records be kept to demonstrate compliance with the environmental management system is a counterpart to that of 4.16 of BS 5750 , which requires demonstration or achievement of the required quality and the effective operation of the quality system. 4.8 of BS 5750 is also concerned with records, in this case relating to products.

\section{j) 4.10 Environmental management audits}

The auditing requirement of this standard is a counterpart to that of $\mathbf{4 . 1 7}$ of BS 5750 . Whilst auditing of an environmental management system could be conducted as part of a broader audit, the auditors would need to be suitably qualified in terms of environmental knowledge. k) 4.11 Environmental manuyement reviews The requirement for management reviews of the system is a counterpart to that stated in 4.1 of BS 5750. Important additional requirements are the review of environmental policy, objectives and targets. 
疍 


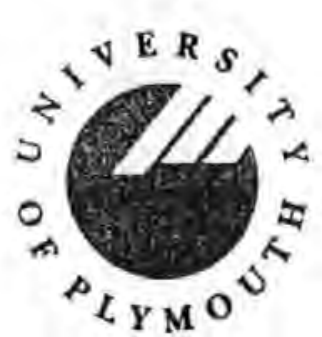

Plymouth Business School

University of Plymouth

Drake Circus

Plymouth

Devon PL4 8AA

United Kingdom

Telephone: 0752232800

Fax: 0752232853

Mr D T King, BSc (Econ), MSc, FBIM

Dean

\section{ANDREW HUTCHINSON}

EXT.255882

\section{Dear Sir/Madam}

This questionnaire will take you 5 minutes to fill in but will provide you with invaluable information in the rapidly evolving field of Business and the Environment.

Plymouth Business School, in association with Plymouth Area Groundwork Trust and Plymouth Chamber of Commerce, has committed research funds to investigate Corporate Environmental Performance in Devon and Cornwall. For this purpose I need your co-operation.

This survey will cover a large sample of the Small and Medium Enterprise sector of Devon and Cornwall and will be totally confidential. However if you take part in the survey the results can be made available to your company on request.

For the purpose of this survey, Environmental Issues are any issues that have an impact on nature, see Question 6 for examples of these issues.

Could I take this opportunity to thank you in advance for your participation. Please fill in the survey and return it in the Freepost envolope provided. If you experience any difficulties with the questionnaire or have any queries please do not hesitate to contact me on (0752) 255882 or Fax (0752) 232853).

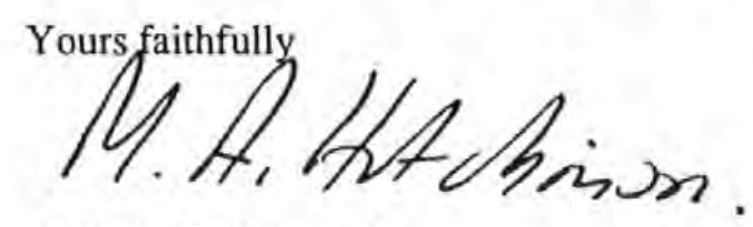

\section{M.A.HUTCHINSON}




\section{SOUTH WEST "GREEN" BUSINESS SURVEY FOR THE SMALL AND MEDIUM SIZED ENTERPRISE SECTOR}

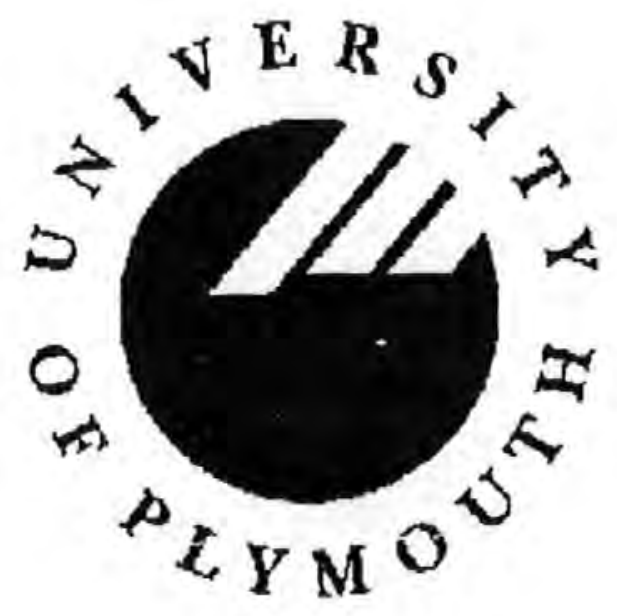

\section{BY: ANDREW HUTCHINSON M.A.}

In association with:

\section{Plymouth Area Groundwork Trust}

\section{Plymouth Chamber of Commerce}




\section{"Green" Business Survey}

1) Is your business at the address overleaf (Please tick one box)

A single site business

A headquarters unit

A subsidiary or branch of a national enterprise

A subsidiary or branch of a foreign enterprise

2) How many employees are currently at your establishment?

(Please tick one box)

$0-10$

$11-25$

26-100

$101-200$

$200+$ (specify)

3) Which is the main business sector your company operates in? (Please tick one box only)

Agriculture, forestry \& fishing

Energy and water supplies

Mineral extraction, mineral \& chemical manufacture

Engineering or vehicle manufacturing

Other manufacturing

Construction

Distribution, retailing, hotel \& catering

Transportation and telecommunications

Financial services

Other services

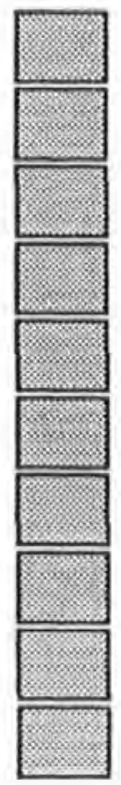


4) Please indicate the location of all of your markets.

(Please tick as many as necessary)

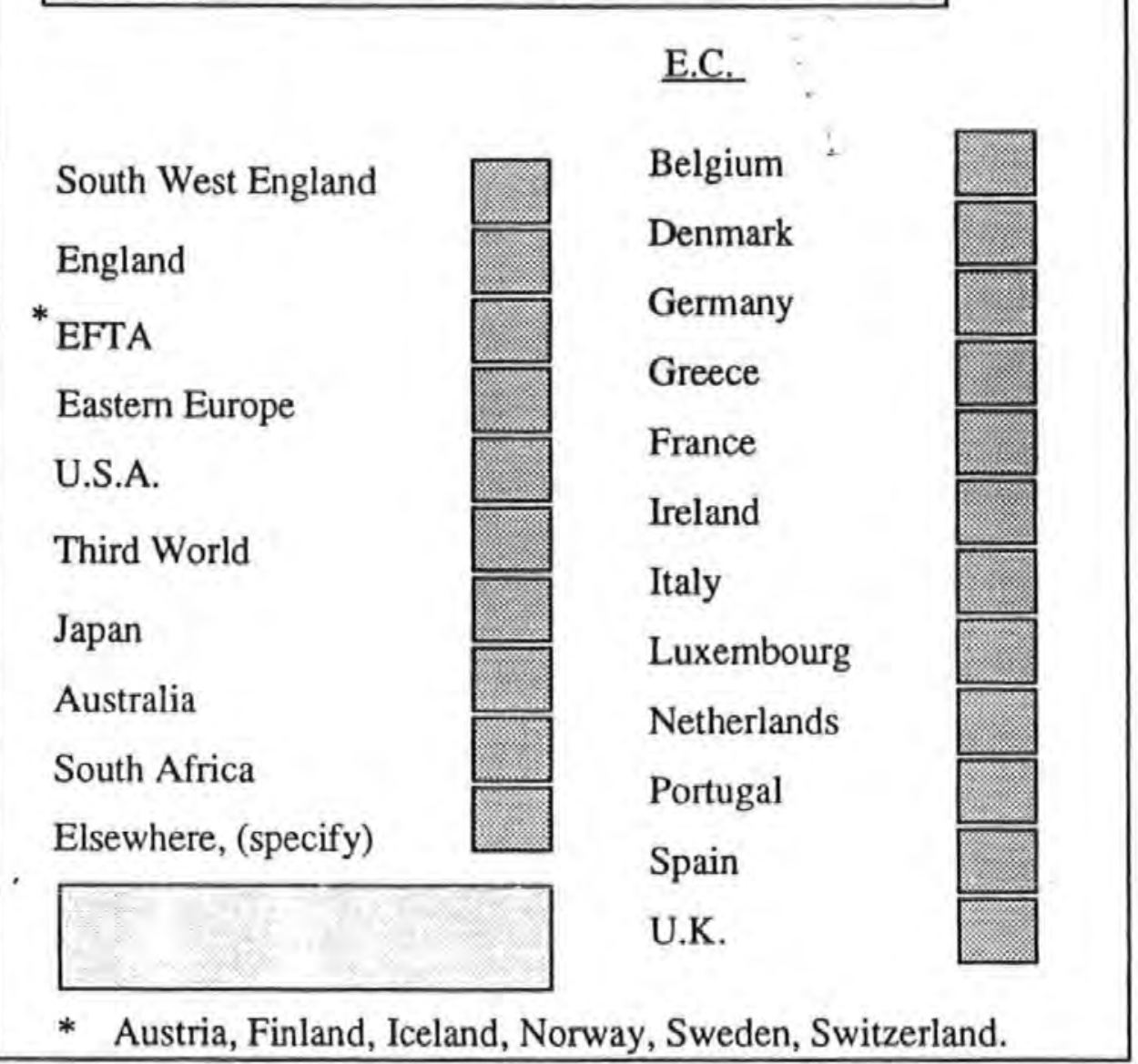

\begin{tabular}{|l|l|l|}
\hline \multicolumn{3}{|c|}{ 5) How important are environmental issues to, } \\
(Tick one box per line)
\end{tabular}


6) How important are the following environmental issues to your company? (Please tick one box per line)

\begin{tabular}{|c|c|c|c|c|c|}
\hline & $\begin{array}{l}\text { Extremely } \\
\text { important }\end{array}$ & $\begin{array}{l}\text { Quite } \\
\text { Important }\end{array}$ & $\begin{array}{l}\text { Neither } \\
\text { unimportant or } \\
\text { important }\end{array}$ & $\begin{array}{l}=\text { Quile } \\
\text { unimportant }\end{array}$ & $\begin{array}{l}\text { Not at all } \\
\text { important }\end{array}$ \\
\hline Acid rain & & & & & \\
\hline $\begin{array}{l}\text { CFC' slozone } \\
\text { layer depletion }\end{array}$ & & & & & \\
\hline Global warming & & & & & \\
\hline Water pollution & & & & & \\
\hline Energy usage & & & & & \\
\hline Effluenț waste disposal & & & & & \\
\hline Deforestation & & & & & \\
\hline Noise pollution & & & & & \\
\hline Vehical emissions & & & & & \\
\hline Solid waste disposal & & & & & \\
\hline Resource depletion & & & & & \\
\hline $\begin{array}{l}\text { Employee health } \\
\text { and safely }\end{array}$ & & & & & \\
\hline $\begin{array}{l}\text { Financial support for } \\
\text { environmental groups }\end{array}$ & & & & & \\
\hline
\end{tabular}




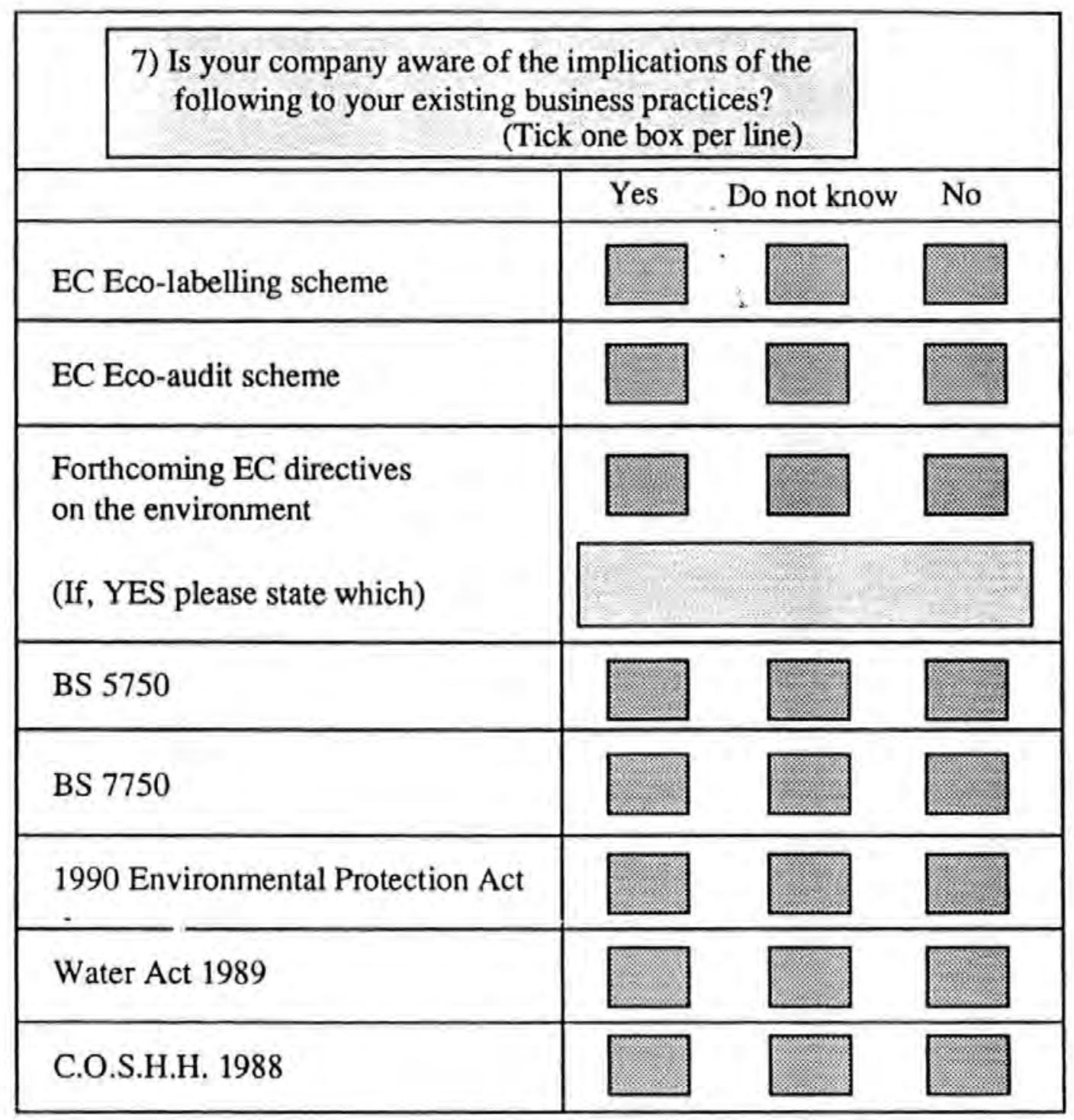

\begin{tabular}{|c|c|c|c|c|c|}
\hline \multicolumn{6}{|c|}{$\begin{array}{l}\text { 8) What are the most effective ways of improving } \\
\text { Environmental business practices? (Tick one box per line) }\end{array}$} \\
\hline & $\begin{array}{l}\text { Strongly } \\
\text { agree }\end{array}$ & Agree & $\begin{array}{l}\text { Agree } \\
\text { nor } \\
\text { Disagree }\end{array}$ & Disagree & $\begin{array}{l}\text { Strongly } \\
\text { disagree }\end{array}$ \\
\hline \multicolumn{6}{|l|}{ Legislation } \\
\hline \multicolumn{6}{|l|}{ Company self regulation } \\
\hline Individual discipline & & 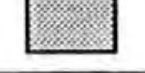 & 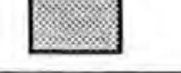 & L & L \\
\hline Market pressure & & 1 & 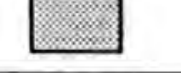 & 2 & 2 \\
\hline Other & 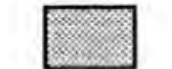 & $\square$ & $\square$ & 10 & 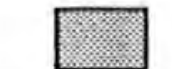 \\
\hline
\end{tabular}


9) Has your company considered or implemented any of the following?

(Tick one box per line)

\begin{tabular}{|c|c|c|c|c|}
\hline & Implemented & Considered & Not considered & Itrelevant \\
\hline \multicolumn{5}{|l|}{ Recycling policy } \\
\hline \multicolumn{5}{|l|}{ Energy efficiency programme } \\
\hline \multicolumn{5}{|l|}{ Waste management programme } \\
\hline \multicolumn{5}{|l|}{$\begin{array}{l}\text { Checking your suppliers } \\
\text { environmental policy }\end{array}$} \\
\hline \multicolumn{5}{|l|}{ Reduction of packaging } \\
\hline \multicolumn{5}{|l|}{ Environmental audit } \\
\hline \multicolumn{5}{|l|}{ Pollution control policy } \\
\hline \multicolumn{5}{|l|}{$\begin{array}{l}\text { Environmental staff training } \\
\text { programme }\end{array}$} \\
\hline \multicolumn{5}{|l|}{$\begin{array}{l}\text { Environmental transport } \\
\text { policy }\end{array}$} \\
\hline $\begin{array}{l}\text { Environmental management } \\
\text { system }\end{array}$ & & & & \\
\hline
\end{tabular}

10) Does your company have a written environmental policy statement? (Please tick one box)

Yes, (Go to Question 11)

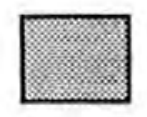

No, (Go to Question 12)

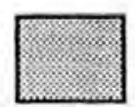


11) Have you implemented the written environmental policy yet?

(Please tick one box)

Yes, (Go to question 13)

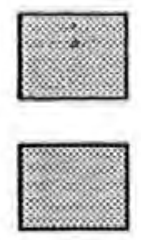

No, (Go to question 13)

12) Why does your company not have a written environmental policy?

(Tick one box per line)

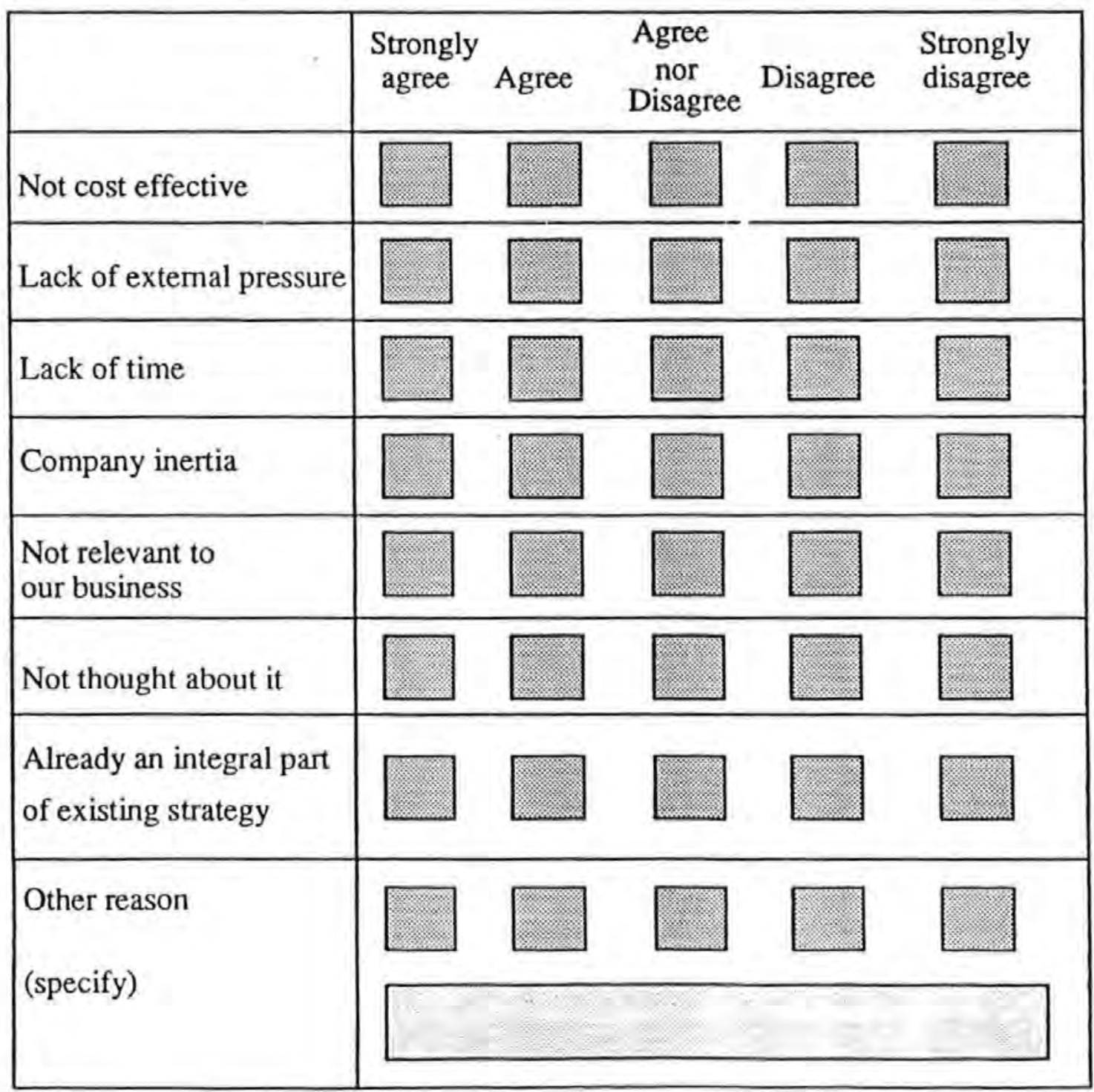


13) How important are the following issues as catalysts to make business practices more environmentally friendly?

(Please tick one box per line)

\begin{tabular}{|c|c|c|c|c|c|}
\hline & $\begin{array}{l}\text { Extremely } \\
\text { important }\end{array}$ & $\begin{array}{l}\text { Quile } \\
\text { important }\end{array}$ & $\begin{array}{l}\text { Neither important } \\
\text { or unimportant }\end{array}$ & $\begin{array}{l}\text { Quite } \\
\text { unimporant }\end{array}$ & $\begin{array}{l}\text { Not at all } \\
\text { important }\end{array}$ \\
\hline Legislation & & & & & \\
\hline Customer pressure & & & & & \\
\hline Marketing image & & & & & \\
\hline Investor pressure & & & & & \\
\hline Insurance reasons & & & & & \\
\hline Company policy & & & & & \\
\hline Employees concerms & & & & & \\
\hline Personal conviction & & & & & \\
\hline EC Eco-labelling & & & & & \\
\hline Pressure from buyers & & & & & \\
\hline Pressure from suppliers & & & & & \\
\hline Competitor behaviour & & & & & \\
\hline Media views & & & & & \\
\hline Government grants & & & & & \\
\hline $\begin{array}{l}\text { New market } \\
\text { opportunities }\end{array}$ & & & & & \\
\hline Other & & & & 1 & \\
\hline (specify) & & & & & \\
\hline
\end{tabular}


* Please fill in company details

Name of company:

Address:

Telephone:

Fax:

Name of Respondent:

Position in Company:.

* All information will be treated in the strictest of confidence and no data will be published that could be identified with a specific company.

\section{Thank you for your co-operation!}

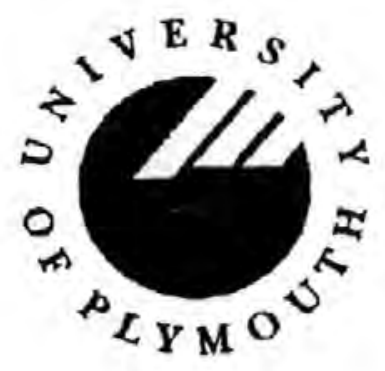




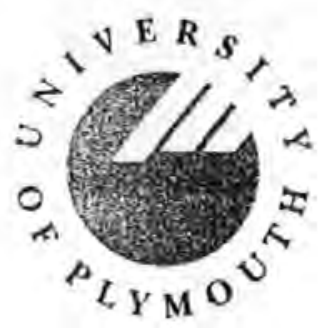

Plymouth Business School

Uniscrsity of Plsmouth Drake Circas

Plvmouth

DeVOM P'A SAA

United Kingdom

Telephone: 0752232800

Fix: 0752232853

Mr DT King, BSC (Econ), MSc, FBM Deall

Andrew Hutchinson

Ext. 2850

\section{Dear Sir/Madam}

The enclosed questionnaire will take you approximately 5 minutes to complete and will provide you with invaluable information on the increasingly important subject area of business and the environment. Enclosed in the survey are details of the new British Standard for the environment BS7750.

With over 350 pieces of environmental legislation now published in the EC, the environment is now of central concern to your company. It is for this reason that Plymouth Business School, in association with the Groundwork Trust and the Chamber of Commerce, have allocated research funds to investigate Corporate Environmental Performance in Devon and Cornwall.

By completing and returning this survey in the Freepost envelope provided (by 31st January 1994) you could take an important step forward in understanding some of the environmental issues that face your company today.

All of the information in the survey will be treated in the strictest confidence and no information will be published that could be associated with any particular company. A copy of the report will be available on request.

Could I take this opportunity in thanking you in advance for your participation. Please do not hesitate to contact me should you have any questions.

Yours sincerely

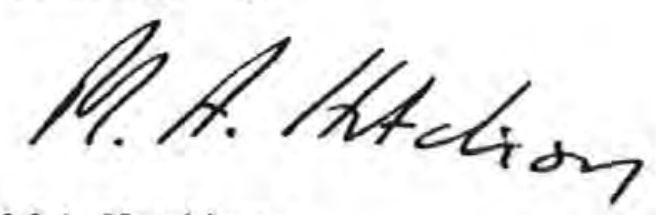

M.A. Hutchinson 


\section{A SURVEY OF DEVON AND CORNWALL'S ENVIRONMENTAL PERFORMANCE IN THE SMALL AND MEDIUM SIZED ENTERPRISE SECTOR (SME)}

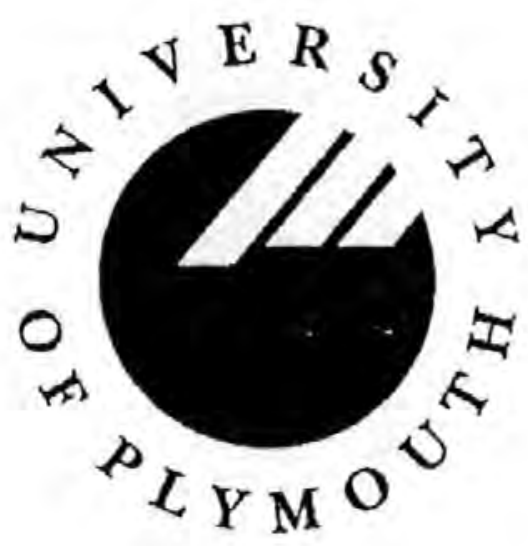

Compiled by Andrew Hutchinson M.A.

The Business School, University of Plymouth, Drake Circus, Devon, PL4 8AA. Tel: 0752 232850; Fax 0752232853

In Association with: Plymouth Area Groundwork Trust PAYBACK and Chamber of Commerce 


\section{BUSINESS ENVIRONMENT SURVEY}

1) Is your business at the address overleaf

(Please tick one box)

A single site business

A headquarters unit

A subsidiary or branch of a national enterprise

A subsidiary or branch of a foreign enterprise

2) How many employees are currently at your establishment? (Please tick one box)

$0-10$

$11-25$

26-100

101-200

$200+($ specify $)$

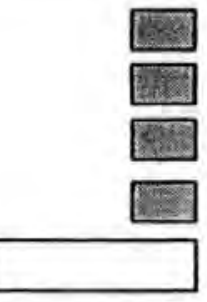

3) Which is the main business sector your company operates in? (Please tick one box only)

Agriculture, forestry \& fishing

Energy and water supplies

Mineral extraction, mineral \& chemical manufacture

Engineering or vehicle manufacturing

Other manufacturing

Construction

Distribution, retailing, hotel \& catering

Transportation and telecommunications

Financial services

Other services

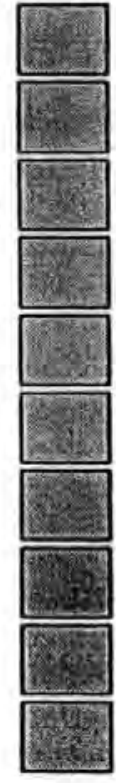


4) How old is your company?

(please tick one box only)

Under 1 year

1-5 years

6-10 years

11-50 years

$50+$ years (specify)

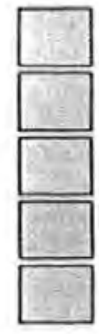

5) Does your company export?

(please tick one box only)

Yes

No
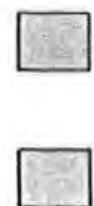

6) Does your company have a strategic environmental policy? *

(please tick one box only)

Yes (if yes, go to Q8)

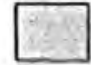

No

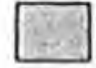

* A strategic environmental policy is a written statement of intent to consider environmental matters as an integral part of long term company policy. 
7) Why does your company not have a strategic environmental policy? (Please tick as many boxes as required)

Operational environmental initiatives suffice

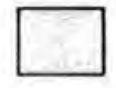

Environmental issues are not relevant to our business operations

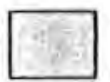

Lack of relevant information/educational programmes

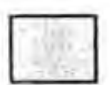

Lack of in-house expertise to motivate change

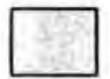

Lack of ability to assess future impact of

the environment on performance

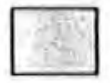

Constrained by financial resources

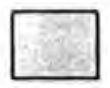

Lack of time

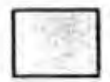

Company inertia and reluctance to change

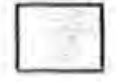

Lack of reasons or pressure to confront the issues

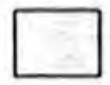

Lack of legislative requirements to conform to standards

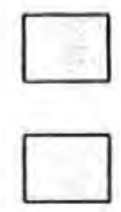

Lack of incentives to change

The environment is no longer an important business issue

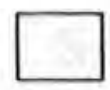

Any other reason (please specify below) 
Please view the diagram below and answer the following questions

\section{ENVIRONMENTAL MANAGEMENT SYSTEMS - (BS7750)}

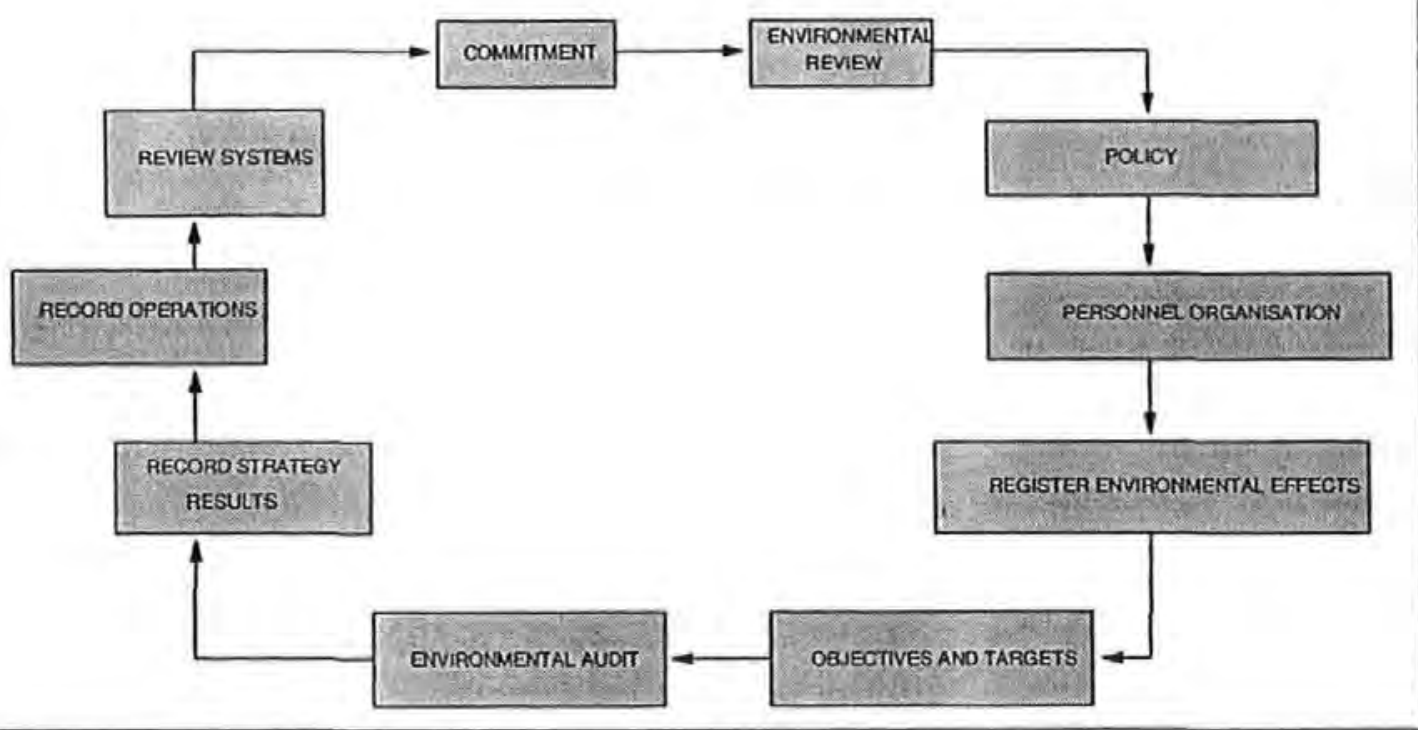

8) Has your company implemented this standard?

(please tick one box only)

Yes (if yes, go to Q13)

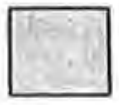

No (if no go to Q9)

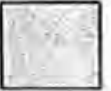

9) Would your company be able to implement this standard?

(please tick one box only)

$$
\begin{aligned}
& \text { Yes (if yes, go to Q10) } \\
& \text { No (if no, go to Q11) }
\end{aligned}
$$
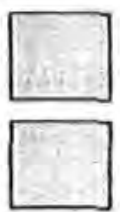

10) Would your company be willing to implement this standard in the near future? (please tick one box only)

Yes (if yes, go to Q13)

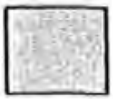

No (if no, go to Q12) 
11) Why would your company not be able to implement the British Standard 7750 ?

(please tick as many boxes as required)

Lack of interest

Lack of time

Lack of financial resources

Lack of committment within the company

Inappropriate nature of the standard

Not cost effective

Limited available staff to implement the change

Not company policy

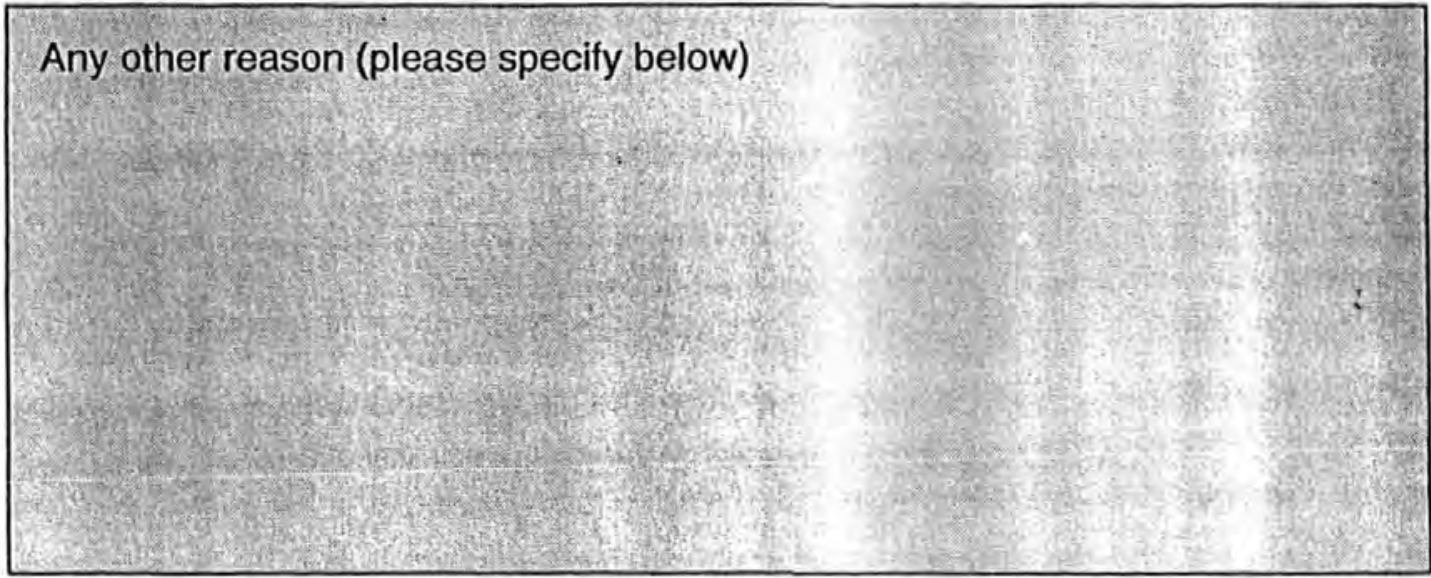

12) Why would your company not be willing to implement the British Standard? 
13) A Regional Environmental Management System (REMS) is a partnership between individuals, businesses, public sector institutions and other agencies, designed to systematically improve the local environment.

How interested would your company be in this concept?

(please tick one box only)

Extremely interested

Quite interested

Neither interested nor uninterested

Quite uninterested
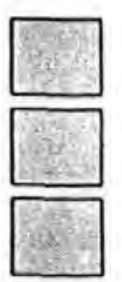

Not at all interested

14) Energy Performance Contracting (EPC) is where an external consultancy implements and pays for energy efficiency improvements in your company, charging for the service only from the cost savings that would accrue.

How interested would your company be in this concept? (please tick one box only)

Extremely interested

Quite interested

Neither interested nor uninterested

Quite uninterested

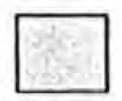

(please tick one box only)

Not at all interested

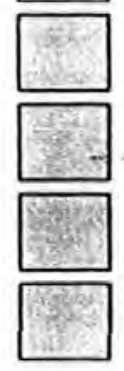


The following questions relate to a "Green" Business Club based in the Plymouth Area called PAYBACK. PAYBACK operates under the auspice of the Groundwork Trust and costs one pound per employee to join. (minimum subscription of fifty pounds)

15) Is your company a member of PAYBACK? (please tick one box only)
Yes
No
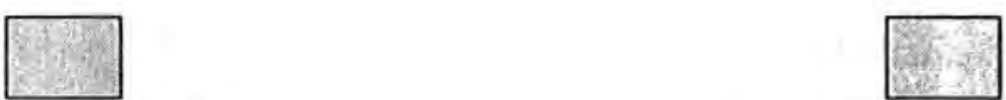
(if no go to Q16)

(if yes, go to Q19)

16) The following services are offered fee to all members.

How interested would your company be in the following services?

(please tick one box per line)

\begin{tabular}{|l|c|c|c|c|c|}
\hline & $\begin{array}{l}\text { Extremely } \\
\text { interested }\end{array}$ & $\begin{array}{c}\text { Quite } \\
\text { interested }\end{array}$ & $\begin{array}{c}\text { Neither interested } \\
\text { nor uninterested }\end{array}$ & $\begin{array}{c}\text { Quite } \\
\text { uninterested }\end{array}$ & $\begin{array}{l}\text { Not at all } \\
\text { interested }\end{array}$ \\
\hline $\begin{array}{l}\text { Environmental } \\
\text { telephone helpline }\end{array}$ & $\square$ & $\square$ & $\square$ & $\square$ & $\square$ \\
\hline $\begin{array}{l}\text { Up to one hour's } \\
\text { confidential advice }\end{array}$ & $\square$ & $\square$ & $\square$ & $\square$ & $\square$ \\
\hline Newsletter & $\square$ & $\square$ & $\square$ & $\square$ & $\square$ \\
\hline $\begin{array}{l}\text { Handbook and up to } \\
\text { date briefings }\end{array}$ & $\square$ & $\square$ & $\square$ & $\square$ & $\square$ \\
\hline $\begin{array}{l}\text { PR for environmental } \\
\text { success stories }\end{array}$ & $\square$ & $\square$ & $\square$ & $\square$ & $\square$ \\
\hline
\end{tabular}


PAYBACK membership also offers a $10 \%$ discount on Groundwork's commercial services like consultancy, environmental reviews and landscaping services. Training in environmental management; seminars, conferences and environmental Forums for formal and informal exchange of information, amongst other services, are also available.

17) How interested would your company be in a concept like PAYBACK? (please tick one box only)

Extremely Quite Neither interested Quite Not at al!
Interested Interested nor interested Uninterested Interested
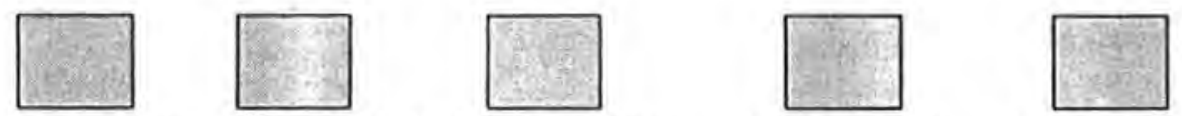

(go to end of questionnaire) (go to Q17) (go to Q17) (go to Q17)

18) If your company is neither interested nor uninterested, quite uninterested or not at all interested; please state below why this is the case. 


\section{ONLY ANSWER Q19 IF YOUR COMPANY IS A MEMBER OF PAYBACK}

19) How useful have the following PAYBACK services been to your company? (please tick one box per line)

\begin{tabular}{|l|l|c|c|c|c|}
\hline & $\begin{array}{l}\text { Extremely } \\
\text { useful }\end{array}$ & $\begin{array}{c}\text { Quite } \\
\text { useful }\end{array}$ & $\begin{array}{c}\text { Neither useful } \\
\text { nor not useful }\end{array}$ & Not useful & $\begin{array}{c}\text { Not at all } \\
\text { useful }\end{array}$ \\
\hline $\begin{array}{l}\text { Environmental } \\
\text { telephone helpline }\end{array}$ & $\square$ & $\square$ & $\square$ & $\square$ & $\square$ \\
\hline $\begin{array}{l}\text { Up to one hour's } \\
\text { confidential advice }\end{array}$ & $\square$ & $\square$ & $\square$ & $\square$ & $\square$ \\
\hline Newsletter & $\square$ & $\square$ & $\square$ & $\square$ & $\square$ \\
\hline $\begin{array}{l}\text { Handbook and up to } \\
\text { date briefings }\end{array}$ & $\square$ & $\square$ & $\square$ & $\square$ & $\square$ \\
\hline $\begin{array}{l}\text { PR for environmental } \\
\text { success stories }\end{array}$ & $\square$ & $\square$ & $\square$ & $\square$ & $\square$ \\
\hline $\begin{array}{l}\text { consultancy } \\
\text { service }\end{array}$ & $\square$ & $\square$ & $\square$ & $\square$ & $\square$ \\
\hline staff training & $\square$ & $\square$ & $\square$ & $\square$ & $\square$ \\
\hline $\begin{array}{l}\text { seminars } \\
\text { and conferences }\end{array}$ & $\square$ & $\square$ & $\square$ & $\square$ & $\square$ \\
\hline
\end{tabular}

* Please fill in company details.

\begin{tabular}{|l|}
\hline Name of Company: \\
\hline Address: \\
\hline \\
\hline Telephone: \\
\hline Name of Respondent: \\
\hline Position in Company: \\
\hline
\end{tabular}

* All information will be treated in the strictest of confidence and no data will be published that could be identified with a specific company.

\section{Thank you for your co-operation!}




\section{AUTHOR'S DECLARATION}

At no time during the registration for the degree of Doctor of Philosophy has the author been registered for any other University award.

This study was financed with the aid of a studentship from the Plymouth Business School, University of Plymouth.

Relevant MBA lectures, seminars and conferences were regularly attended at which work was often presented. External institutions were consulted in the preparation of this thesis and a number of papers have been prepared relating to the research.

Publications: Hutchinson, A. and Chaston, I. (1993), Perceptions. Policies and

Practices in the SME Sector: A Case Study. Proceedings of the

Second Annual Business Strategy and the Environment Conference,

Bradford, September, 23-24th, 1993.

Hutchinson, A. and Chaston, I. (1994), Environmental Management in

Devon and Cornwall's SME Sector. Business Strategy and the

Environment, Vol. 3. pt.1. pp 15-22.

Hutchinson, A. (1994), Environmental Management in the UK SME

Sector - Towards a Sustainable Bioregional Re-generation Model.

Proceedings of the Third International Greening of Industry

Conference, November, 13-15th, 1994.

External Contacts: Douglas Peedle (Confederation of British Industry - Economic and Development); Adrian Watts (Plymouth Chamber of Commerce); Peter Seldon (Groundwork Trust); Kate Evans (Plymouth City Council - Recycling Officer); Chris Trevan (Cornwall County Council - Economic and Development Unit); Ian Hutchcroft (Devon County Council - Education Officer); Chris Redding (Training and Enterprise Council).

Signed:

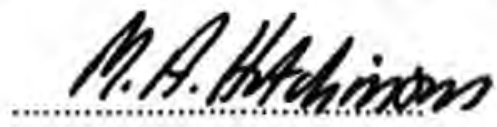

Date:

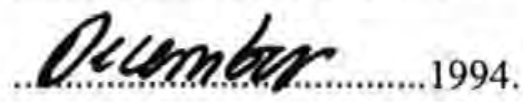


To my Mother and Father for my education 


\section{COPYRIGHT STATEMENT}

This copy of the thesis has been supplied on condition that anyone who consults it is understood to recognise that its copyright rests with its author and that no quotation from the thesis and no information derived from it may be published without the author's written consent.

Signed:

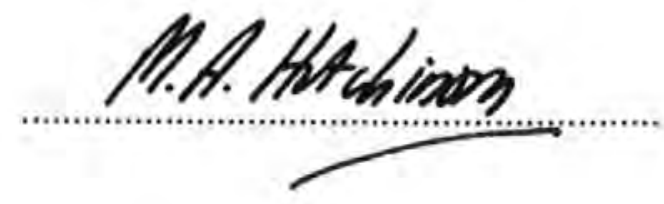

Date: 1994. 